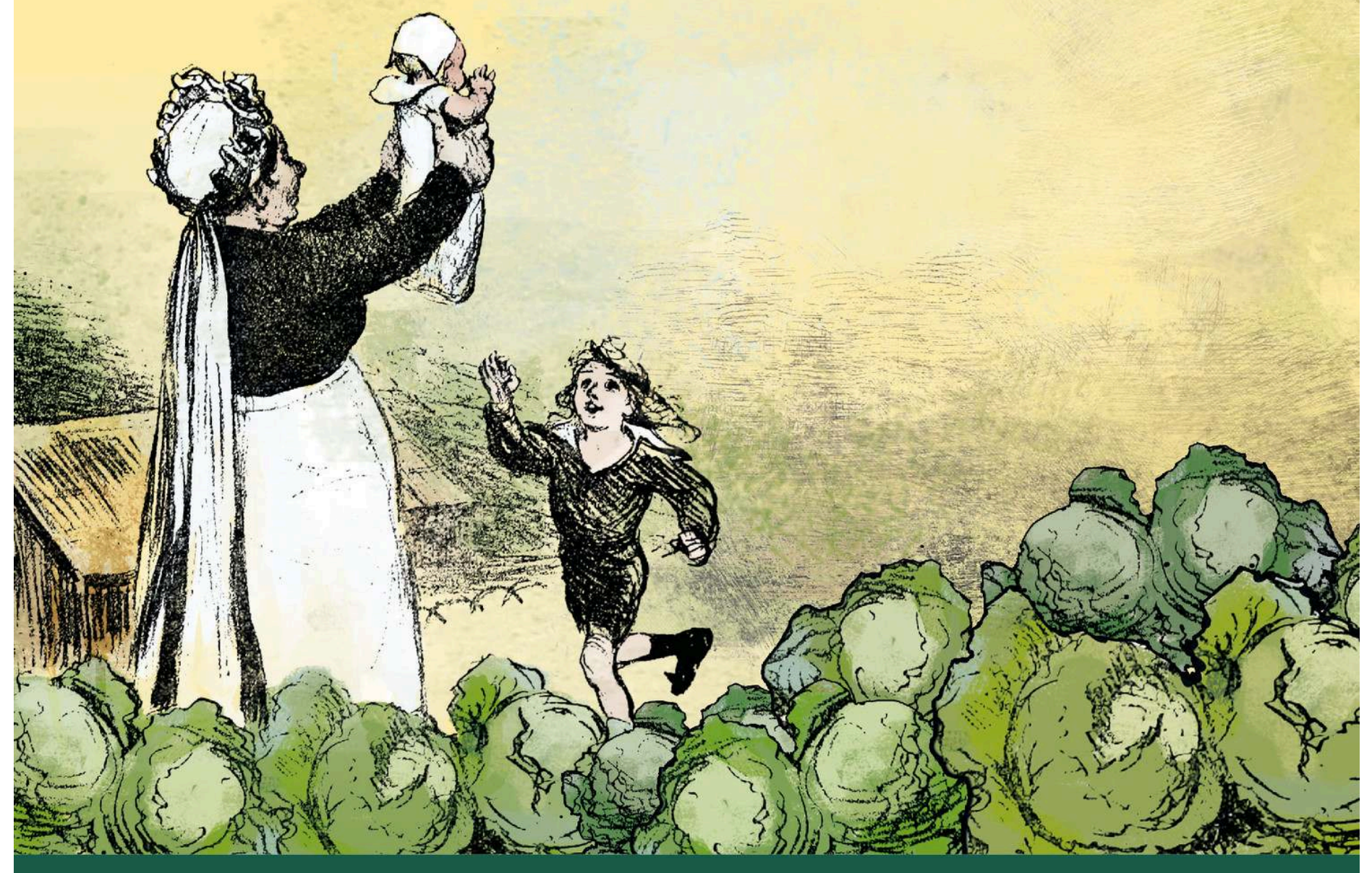

Nathalie Sage Pranchère

\title{
L'école des sages-femmes
}

Naissance d'un corps professionnel 1786-1917

Préface Jean-Pierre Bardet 


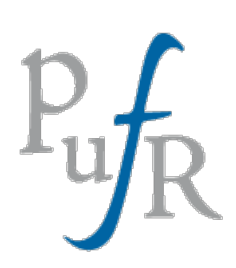

Presses universitaires François-Rabelais

\section{L'école des sages-femmes}

Naissance d'un corps professionnel, 1786-1917

\section{Nathalie Sage Pranchère}

DOI : 10.4000/books.pufr.13172

Éditeur : Presses universitaires François-Rabelais

Lieu d'édition : Tours

Année d'édition : 2017

Date de mise en ligne : 17 octobre 2018

Collection : Perspectives Historiques

EAN électronique : 9782869066113

\section{OpenEdition}

\section{Books}

https://books.openedition.org

\section{Édition imprimée}

EAN (Édition imprimée) : 9782869064225

Nombre de pages : 453-[14]

Référence électronique

SAGE PRANCHĖRE, Nathalie. L'école des sages-femmes : Naissance d'un corps professionnel, 1786-1917. Nouvelle édition [en ligne]. Tours : Presses universitaires François-Rabelais, 2017 (généré le 28 janvier 2022). Disponible sur Internet : <http://books.openedition.org/pufr/13172>. ISBN : 9782869066113. DOI : https://doi.org/10.4000/books. pufr.13172. 


\section{RÉSUMÉS}

Protéger l'homme " au moment où il arrive au port de la vie ", telle est la mission que les gouvernements français, de l'Ancien Régime à la III ${ }^{\mathrm{e}}$ République, assignent aux sages-femmes. Accompagnatrices des mères et désormais membres du corps médical, les sages-femmes se sont constituées au cours du XIX siècle en profession scientifique, détentrice d'un savoir riche et varié. Partout en France, leur formation a occupé administrateurs et médecins, faisant naître des dizaines d'écoles départementales, dont le dynamisme n'a souvent eu que peu à envier à l'école de l'Hospice de la Maternité de Paris.

Du cours hospitalier à la véritable école-maternité, les institutions de formation ont accueilli en un siècle des dizaines de milliers de jeunes femmes qui, leur diplôme en main, se sont faites dans les campagnes les « institutrices du système de santé » français.

Lettrées, compétentes et respectées, les sages-femmes ont ainsi fait bénéficier leurs patientes d'une qualité de soins acquise aux meilleures sources du savoir obstétrical. Légitimées par leur formation et le monopole que l'État leur accorde face aux matrones, elles ont mis au monde l'essentiel de la population française, ont vacciné des générations de nouveau-nés et se sont faites les chantres de l'hygiène pasteurienne dès ses débuts. L'histoire de l'émergence de ce corps professionnel, né d'une volonté politique et du consentement des accoucheuses, est riche d'enseignements pour les enjeux contemporains de la naissance et de ses acteurs.

\section{NATHALIE SAGE PRANCHÈRE}

Nathalie Sage Pranchère, archiviste-paléographe et historienne, Université ParisSorbonne, Centre Roland-Mousnier (UMR 8596). 
Cet ouvrage est diffusé en accès ouvert dans le cadre du projet OpenEdition Books Select.

Ce programme de financement participatif, coordonné par OpenEdition en partenariat avec Knowledge Unlatched et le consortium Couperin, permet aux bibliothèques de contribuer à la libération de contenus provenant d'éditeurs majeurs dans le domaine des sciences humaines et sociales.

La liste des bibliothèques ayant contribué financièrement à la libération de cet ouvrage se trouve ici :

https://www.openedition.org/22515.

This book is published open access as part of the OpenEdition Books Select project.

This crowdfunding program is coordinated by OpenEdition in partnership with Knowledge Unlatched and the French library consortium Couperin. Thanks to the initiative, libraries can contribute to unlatch content from key publishers in the Humanities and Social Sciences.

Discover all the libraries that helped to make this book available open access: https://www.openedition.org/22515?lang=en.

\section{IAI Sopenedition coupernoren}




\section{L'école des \\ sages-femmes \\ Naissance \\ d'un corps professionnel \\ 1786-1917}



Nathalie Sage Pranchère

\section{L'école des \\ sages-femmes \\ Naissance \\ d'un corps professionnel 1786-1917}

Collection «Perspectives historiques»

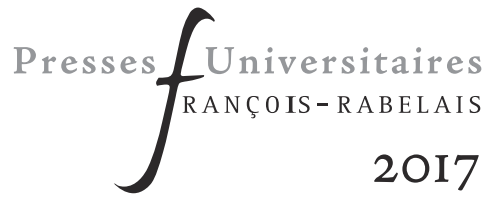


Maquette et conception graphique Mickaël Robert - PUFR

Mise en page

Christine Martin - PUFR

(C) Presses Universitaires François-Rabelais de Tours, 2017 60, rue du Plat d'Étain - BP 12050

37020 Tours cedex I, France

http://pufr-editions.fr/

ISSN $: 1764-4305$

ISBN : 978-2-86906-422-5

Dépôt légal : I semestre 2017 


\section{Remerciements}

À l'origine de ce livre, il y eut une thèse, et le ig septembre 20II, j'écrivais : «À l'issue de ce travail, toute ma gratitude va à Olivier Faron qui a su être présent à toutes les étapes essentielles de sa réalisation.

Ma profonde reconnaissance va à Jean-Pierre Bardet qui a suivi cette recherche depuis le début et m'a toujours accompagnée de ses bienveillants conseils et ses judicieuses suggestions.

Que les directrices et directeurs d'archives départementales et municipales que j’ai parcourues et leurs équipes trouvent ici l'expression de ma gratitude. Cette thèse est le fruit de leur parfait travail de conservation. Parmi eux, un merci tout particulier à Gaël Chenard, François Giustiniani, Marie-Adélaïde Zeyer, Stéphanie Roussel, Bruno Isbled, et Hugues Moreau.

Pour leur aide précieuse au cours de ces années de recherche, pour leur écoute toujours attentive, pour l'intérêt qu'ils ont porté à ce sujet, mes remerciements vont à Christine Nougaret, François-Joseph Ruggiu, Nicolas LyonCaen, Catherine Rollet, Claire Fredj, Marie-France Morel, Françoise Vielliard, Jean-Loup Lemaître.

Pour tout cela et pour leurs patientes relectures, je remercie Fabrice Boudjaaba, Vincent Gourdon et Annliese Nef.

Pour son aide cartographique, merci à Timothée Le Moing.

Pour avoir vécu jusqu'au bout cette thèse aussi intensément que moi et pour $\mathrm{y}$ avoir leur immense part, merci à mes parents. Merci à ma famille et à mes ami-e-s pour leur présence et leur soutien sans faille.

Pour avoir partagé cette écriture depuis le premier jour, merci à Philippe Büttgen. »

Les années ont passé, quelques patients relecteurs se sont ajoutés : merci à Jean-David Richaud, Isabelle Robin et Romain Telliez.

Merci à la Société de l'École des Chartes et au Conseil national de l'Ordre des sages-femmes pour leur aide généreuse à la publication de cet ouvrage.

Merci enfin aux Presses universitaires François-Rabelais d'accueillir ce travail dans leurs collections. 



\section{Abréviations}

ADH Annales de démographie bistorique

Annales. ÉSC Annales. Économies. Sociétés. Civilisations

AHRF Annales bistoriques de la Révolution française

AD Archives départementales

AM Archives municipales

AN Archives nationales

$A P$

ARSS

Archives parlementaires de 1787 à 1860

BAM

Actes de la recherche en sciences sociales

BSFHM

Bibliothèque de l'Académie nationale de Médecine

CDIHÉRF Collection des documents inédits pour l'histoire économique

Bulletin de la Société française d'bistoire de la médecine de la Révolution française

EDRES Enquêtes et documents relatifs à l'enseignement supérieur

HES Histoire, économie et société

RHMC

Revue d'bistoire moderne et contemporaine

RLRES

Recueil des lois et règlements sur l'enseignement supérieur

RD CG

Rapports du préfet et procès-verbaux des délibérations

du conseil général

SRM

Société Royale de Médecine 



\title{
Préface
}

\author{
- Jean-Pierre Bardet \\ Professeur émérite à l'université Paris-Sorbonne
}

Voilà un ouvrage important qui permet de saisir une entreprise vitale au cœur d'un changement historique qui bouleverse les structures antérieures à la Révolution. Cette histoire poursuit en même temps un effort entamé sous l'Ancien Régime. Le même esprit éclairé inspire les coordonnateurs de l'assistance publique de la Monarchie et des temps révolutionnaires.

La publication du livre de Nathalie Sage Pranchère apporte une information importante, à vrai dire centrale, sur un personnel médical redéfini au $\mathrm{XIX}^{\mathrm{e}}$ siècle, ce corps national des sages-femmes dont la constitution poursuit, institutionnalise et accroît les initiatives d'Ancien Régime si bien étudiées par Jacques Gélis qui a établi que, bien avant la Révolution, des médecins, des chirurgiens et des sages-femmes, encouragés par des administrateurs éclairés, se sont souciés de réduire les lourds risques de la naissance pour la mère et pour l'enfant. Ainsi ont été proposés en divers lieux des cours d'accouchement plus théoriques que pratiques car la plupart des femmes accouchaient alors à leur domicile. Ces enseignements avaient au moins le mérite d'informer les futures accoucheuses sur les gestes opportuns de la mise au monde, sur ceux à éviter, sur les rythmes à suivre et sur les accidents à prévoir. Ces formations souvent itinérantes ont mobilisé d'assez nombreuses volontaires soucieuses d'aider les parturientes. Sur le terrain, les résultats tels qu'on peut les mesurer ont été limités car les risques infectieux (dont je reparlerai plus loin) étaient ignorés. Malgré tout, ces enseignements ont contribué à améliorer notablement les conditions de la mise au monde et les gestes qui doivent l'accompagner.

Assez curieusement, la poursuite de leurs efforts après 1789 n'a pas été systématiquement étudiée même si la bibliographie comporte des titres suggestifs et utiles, mais souvent monographiques. L'objectif de Nathalie Sage Pranchère n'était pas de revenir sur les accidents tragiques de la naissance bien connus 
12 - L'ÉCOLE DES SAGES-FEMMES. NAISSANCE D'UN CORPS PROFESSIONNEL

désormais par les travaux de démographie historique mais d'étudier la mise en place à l'échelle nationale d'un corps médical féminin consacré à l'accouchement. Point de départ de cette vaste enquête, sa belle thèse d'École des Chartes consacrée aux sages-femmes et aux accouchées du département de la Corrèze avait permis à l'auteure de vérifier la pertinence de ce thème de recherche, de bien cerner les pistes documentaires et de mettre au point une grille de lecture pour des sources immenses et dispersées.

L'objectif est clair. Il s'agit de comprendre comment l'aide apportée aux femmes en couches, rarement professionnelle dans la société traditionnelle et en fait assez diversifiée, se transforme entre le milieu du XVIII ${ }^{\mathrm{e}}$ siècle et le début du $\mathrm{xx}^{\mathrm{e}}$, grâce à un effort coordonné, en une profession médicale, contribuant au développement de la médecine, reconnue et somme toute efficace. Comment est-on passé de la matrone à l'agent médical ? Cette recherche sur la construction progressive d'une formation professionnelle comporte neuf chapitres, distribués de manière habile et rendant compte des difficultés et des discontinuités de la documentation sans trahir la diversité des situations locales et des rythmes de modernisation. Ces différences interdisaient à la fois le plan chronologique qui aurait brisé les continuités et la description géographique plate qui aurait abouti à un fastidieux inventaire hors du temps. L'habile combinaison des composants s'avère bien plus efficace car elle permet de mettre en valeur l'évolution des institutions et des discours tout en cernant l'ampleur des projets et des réalisations. L'analyse menée par l'auteure révèle les qualités acquises dans sa double formation d'archiviste paléographe et d'agrégée d'histoire et aussi un grand talent d'imagination, une véritable érudition et une extraordinaire intuition pour détecter les sources et les mettre en perspective.

De la chronologie retenons deux dimensions : la relative rapidité de la décision qui conduit à la constitution d'une profession médicale reconnue et la plus lente mise en place du réseau de ces nouveaux agents de santé qui exigeait des moyens, des formateurs et des candidates capables de s'adapter aux exigences de la formation.

La loi du I9 ventôse an XI (Io mars I803) sur l'exercice de la médecine complétée par l'arrêté du 20 prairial ( 9 juin 1803 ), textes fondateurs pour tout l'ordre médical, réforment les corps existants et créent de toutes pièces un métier nouveau ou presque. Les sages-femmes étaient déjà présentes dans certains hôpitaux où elles étaient formées sous la houlette des maitresses sages-femmes et de chirurgiens mais en nombre limité, la plupart des naissances se déroulant à domicile avec l'aide de «matrones » plus ou moins habiles, rarement sous la conduite d'un médecin ou d'un chirurgien. Il s'agissait en fait de bannir les actions dangereuses liées à l'ignorance de certaines intervenantes déjà dénoncées au XVIII ${ }^{e}$ siècle. 
La nouveauté résulte de la définition d'une nouvelle profession à l'échelle de toute la France, bel exemple de l'action de l'État unificateur issu de la Révolution. La définition du contenu des enseignements à prodiguer aux futures accoucheuses et des lieux de formation donna lieu à bien des discussions.

Ces débats illustrent l'esprit centralisateur des réformateurs : Paris est un instant envisagé comme unique lieu de formation comme disposant des meilleurs spécialistes et de l'énorme maternité de Port-Royal qui accueillait 2000 accouchées chaque année et offrait évidemment un beau terrain d'apprentissage. Mais devant les réticences des autres départements, on finit par concéder le principe d'une formation locale dans les départements disposant de formateurs (chirurgiens et sages-femmes) et de maternités assez importantes pour offrir la possibilité d'un apprentissage pratique. Tous ne furent pas dotés d'école et, surtout, les centralisateurs imposèrent la reconnaissance de deux classes de sages-femmes - la première, la plus noble, nécessitant un séjour de formation à Paris, au départ tout au moins car, par la suite, les institutions habilitées à attribuer la première classe furent multipliées. L'enjeu avait un réel intérêt pour les bénéficiaires : seules les sages-femmes de première classe pouvaient exercer dans un autre département que celui de leur formation, mais la distinction fut maintenue avec ses obligations de mobilité, de prestige et aussi d'honoraires pendant tout le XIX ${ }^{\mathrm{e}}$ siècle et jusqu'en 1916.

La mise en place de la nouvelle formation fut à la fois rapide et assez uniforme dans son contenu. Autre preuve de la capacité unificatrice du nouveau régime.

Au-delà de l'aspect institutionnel révélateur aussi de la volonté de l'État d'encadrer et d'unifier la formation des soignantes, il est intéressant de découvrir comment les programmes d'enseignement des sages-femmes ont évolué en lien avec les découvertes médicales (voir par exemple l'adoption immédiate des principes pastoriens et des méthodes antiseptiques destinées à éviter les infections souvent fatales) ce qui confirme que la greffe sur le corps médical avait parfaitement réussi, une greffe particulière qui créait un échelon intermédiaire plus accessible mais compétent entre le médecin et l'accouchée, ce qui ne se passa pas de la même façon dans tous les pays. Ainsi se met en place une auxiliaire médicale qui se substitue aux matrones et autres accoucheuses traditionnelles. L'efficacité de leur savoir acquis dans des cours délivrés par des praticiens bien formés et des spécialistes de l'accouchement n'aboutit pas d'abord à des progrès très palpables, mais tout de même perceptibles, pendant les premières décennies du $\mathrm{XIX}^{\mathrm{e}}$ siècle avant les découvertes pastoriennes, car la plupart des décès maternels étaient provoqués non par « choc » obstétrical mais par des infections dont la pire était la fièvre puerpérale qui ravageait périodiquement les maternités. Faute d'information et de précaution, les 
14- L'ÉCOLE DES SAGES-FEMMES. NAISSANCE D'UN CORPS PROFESSIONNEL

sages-femmes contribuaient parfois à la diffuser involontairement. Longtemps l'accouchement à domicile fut moins dangereux qu'à hôpital car partiellement à l'abri de ces intrusions microbiennes. À partir de Pasteur, la situation se retourna évidemment.

La croissance progressive des effectifs d'accoucheuses diplômées aboutit à mettre à la disposition des futures mères une sage-femme pour moins de 3 ooo habitants, contribuant ainsi à la médicalisation des naissances villageoises. Cela ne veut pas dire que les auxiliaires traditionnelles des mères aient toutes disparu, il en subsistait assurément malgré les menaces assez théoriques de poursuites pour exercice illégal du métier, mais la présence des accoucheuses professionnelles était rassurante, contribuait à la diffusion des gestes efficaces quand elles n'opéraient pas elles-mêmes, ce qui s'est assez vite généralisé.

Ainsi émerge peu à peu un agent médical nouveau à côté des médecins et des officiers de santé dont le profil est bien tracé dans ce livre. Par ses origines souvent modestes, ses attaches locales, la sage-femme est une soignante présente et appréciée et une intermédiaire précieuse avec les médecins. Son rôle ne s'arrête pas à l'accouchement, elle est consultée en cours de grossesse et conseille les mères et les femmes enceintes.

Ces quelques réflexions préalables sont destinées à inciter à la lecture de ce livre qui me paraît constituer un modèle pour l'histoire sociale.

J'ai évoqué les qualités érudites de son auteure, je voudrais aussi souligner la richesse de sa documentation : bibliographie exemplaire, évocation passionnante des sources qui décrit une lecture minutieuse des textes réglementaires et plus impressionnante encore une plongée abyssale dans les sources départementales pour la collecte des documents de la série « $\mathrm{M}$ » et une exploration des archives communales. Dans le cadre d'une enquête nationale, il est facile d'imaginer l'inlassable patience qu'exige une telle investigation. On ne sait ce qu'il faut le plus admirer : l'immensité de cet effort documentaire ou la capacité du chercheur à le doser. Ce qui est clair - et c'est important - c'est que cette érudition n'est pas pesante, simplement convaincante.

Parmi les pièces justificatives, le lecteur appréciera le tableau départemental des formations obstétricales qui permet de suivre pas à pas la mise en place des écoles de sages-femmes. Il découvrira aussi avec intérêt la bibliographie des publications des sages-femmes qui contribue à nous convaincre du sérieux de la formation de ces obstétriciennes.

Le cheminement adopté par Nathalie Sage Pranchère est très habile. Il accorde beaucoup de place aux débats qui ont surgi avant et pendant la mise en place de ce corps national des sages-femmes : ils sont révélateurs des idées, parfois antagonistes, que se font administrateurs et médecins sur l'importance 
et les risques de la naissance, sur le rôle des femmes dans la médecine, sur l'organisation et le contenu des enseignements destinés à des intermédiaires médicales, sur leur rapport aux initiatives d'Ancien Régime entre admiration et critique, sur l'esprit nouveau qui conduit à cette vaste construction marquée par les Lumières, empreinte d'un souci démographique et freinée par la nécessité de ménager les finances de l'État. Tous les acteurs en jeu sont décrits avec finesse et le souci de cerner les antagonismes, les enjeux de pouvoir des uns et des autres.

Ce livre est ainsi une invitation à mieux connaitre les parcours des professeurs et des élèves même si l'approche sociale est nécessairement générale. En réalité un tel ouvrage ouvre des pistes en apportant une synthèse solide qui permet de poursuivre l'approche anthropologique des groupes et des individus, au cœur des interrogations des historiens. 



\section{Introduction}

En novembre 2013, les sages-femmes françaises descendaient massivement dans la rue. S'ouvrait alors une année de grèves et de manifestations pour être reconnues comme le «praticien de premier recours » dans le suivi gynécologique et obstétrical des femmes. La légitimité de ce rôle d'accompagnement, dont les sages-femmes déploraient et déplorent encore l'insuffisante reconnaissance, a pourtant été affirmée il y a plus de deux siècles, lorsqu'elles sont devenues les agents « à la française » d'une politique d'encadrement de la naissance et de réduction des mortalités maternelle et infantile.

La sage-femme s'invente au tournant des XVIII et ${ }^{e}{ }^{e} x^{e}$ siècles. Avec ses devancières, elle a en commun la fonction de «lever les enfants» mais à la différence de l'immense majorité d'entre elles, pour exercer cette fonction, elle doit désormais s'instruire aux sources d'un savoir médical sur la naissance. La formation obstétricale est devenue en un quart de siècle le seul point d'entrée possible et admis dans ce métier.

Dès la fin du Xvir ${ }^{\mathrm{e}}$ siècle, l'accouchement est pris dans un vaste mouvement de scientifisation et de médicalisation. Cette « nouvelle conception de la vie » (Jacques Gélis) découle de l'entrée sur la scène obstétricale du corps chirurgical qui fait de cette pratique le fer de lance de sa reconnaissance scientifique et sociale. Sur fond de dépopulation fantasmée, les accoucheuses y perdent en réputation, érigées en bouc-émissaire de la mortalité maternelle et infantile. Mais c'est paradoxalement de cette redéfinition de la naissance et de cette redistribution des pouvoirs biomédicaux que surgissent les sages-femmes. Car la prise en mains de l'accouchement par les chirurgiens n'a été que partielle pour des motifs financiers et de prestige social, et, à ce titre, incapable de répondre 
à la recherche politique d'un « agent de transformation » de la population ${ }^{1}$ au service des objectifs populationnistes de l'État. Seule la sage-femme a alors paru capable à l'orée du XIX ${ }^{e}$ siècle d'être cet agent, de tenir le rôle d'« intermédiaire culturel » entre une conception nouvelle de la naissance et la population ${ }^{2}$.

\section{Des sages-femmes à la sage-femme}

La sage-femme n'est toutefois pas que le réceptacle passif d'évolutions extérieures à elle, pour la simple raison qu'il existe, à la fin du xvini ${ }^{e}$ siècle, plusieurs sages-femmes dont certaines (accoucheuses au service des princes, des villes, hospitalières) sont aux premières loges du profond changement qui s'opère ${ }^{3}$. Elles sont au contact quotidien de la science obstétricale en voie de formalisation et n'hésitent pas à s'en saisir à leur profit : Louise Bourgeois à la cour de France, Justina Siegemund à la cour de Brandebourg, Marguerite de la Marche à l'Hôtel-Dieu de Paris, sont toutes trois auteures de traités ou de manuels de l'art des accouchements ${ }^{4}$. Ces femmes sont parmi les premières à avancer la nécessité de former leurs consœurs pour protéger l'ensemble des praticiennes des attaques réitérées du corps médico-chirurgical, à l'instar de Sarah Stone qui publie en 1737 sa Complete Practice of Midwifery à l'intention de ses «Sister Professors in the Art of Midwifery ${ }^{5} »$.

I. Foucault M., Sécurité, territoire, population. Cours au Collège de France, 1977-1978, Paris, Gallimard, Seuil, 2004, p. 73 .

2. Gélis J., « L'accoucheuse rurale au Xviri ${ }^{\mathrm{e}}$ siècle : transformation du rôle d'un intermédiaire entre culture rurale et culture urbaine », dans Les Intermédiaires culturels. Actes du colloque du centre méridional d'Histoire sociale, des mentalités et des cultures, 1978, Aix-en-Provence, Publications de l'Université de Provence, I98I, p. I27-I37.

3. Gélis J., La Sage-femme ou le médecin. Une nouvelle conception de la vie, Paris, Fayard, I988, p. 23-39.

4. Bourgeois L., Observations diverses sur la stérilité, perte de fruit, fécondité, accouchements et maladies des femmes et enfants nouveaux nés amplement traitées et heureusement pratiquées par L. Bourgeois, sage-femme de la reine, Paris, A. Saugrain, 1609, voir Gélis J., «Louise Bourgeois (1563-1636) : une sage-femme entre deux mondes », dans Histoire des sciences médicales, 2009, vol. 43, no I, p. 27-38 ; Siegemund J., Die Chur-Brandenburgische Hoff-Wehe-Mutter, Berlin, Ulrich Liebperten, I690, voir Pulz W., «Aux origines de l'obstétrique moderne en Allemagne (XVI ${ }^{\mathrm{e}}$-XVIII ${ }^{\mathrm{e}}$ siècles) : accoucheurs contre matrones ? », dans RHMC, 1996, 43-4, p. 599 ; Marche M. (de la), Instruction familière et utile aux sages-femmes, pour bien pratiquer les accouchemens, faite par demandes et réponses [1677], Paris, L. d'Houry, I710.

5. Donnison J., Midwives and Medical Men. A History of the Struggle for the Control of Childbirth, London, Heinemann Educational, 1977, p. 35-36 ; Gelbart N. R., The King's Midwife. A History and Mystery of Madame du Coudray, Berkeley, University of California Press, 1998. 
En France, l'action pionnière d'Angélique du Coudray à partir de 1759 lie irréversiblement, et pour des milliers d'accoucheuses, savoir scientifique, enseignement et pratique du métier. Moins d'un demi-siècle plus tard, la loi du I9 ventôse an XI (IO mars I803) conditionne officiellement l'exercice professionnel à l'obtention d'un diplôme. La formation est donc ce qui permet, dès les années I800, de parler de la sage-femme, au sens d'un unique corps professionnel réglementé.

\section{Aux sources de l'identité : la formation}

La formation des sages-femmes est d'abord conçue pour répondre à une inquiétude démographique transformée en besoin social. Au-delà, elle pose après 1803 la question de la genèse d'une profession. La succession des projets règlementaires de la Révolution au Consulat détermine uniquement les exigences d'instruction et de contrôle du savoir, sans jamais prendre en compte la pratique quotidienne, manière de fonder l'officialisation de la profession sur l'obligation nouvelle d'apprentissage. Par cette obligation, la législation découple l'exercice professionnel de l'expérience personnelle de la parturition. L'aide aux femmes en couches ne procède donc plus de la maternité vécue mais d'un savoir revendiqué comme universel et généralisable. Le modèle dans la formation et la pratique est celui de la médecine.

L'originalité de ce processus, c'est qu'il marche vite tant dans ses réalisations scolaires (la plupart des écoles d'accouchement sont fondées avant I840) que dans sa rapide intériorisation par les praticiennes, que ces dernières soient clandestines $^{6}$ (matrones) ou légales. Les matrones perdent avec la loi de ventôse an xi la partie de la pratique publique et officielle de l'obstétrique. Non sans heurts, elles se maintiennent par la fidélité des populations et la bienveillance de certaines autorités locales mais cèdent progressivement la place aux sages-femmes dans l'accompagnement des mères à partir des années I860$1880^{7}$. La pacification relative du territoire de l'accouchement n'empêche pas à la fin des années 1890 de grandes campagnes du syndicat national des sagesfemmes contre l'exercice illégal de l'art des accouchements ; mais elle produit aussi la «femme-qui-aide » étudiée par Yvonne Verdier, celle qui, au tournant

6. Léonard J., "Les guérisseurs en France au xix ${ }^{\mathrm{e}}$ siècle », RHMC, I980, p. 50I-5I6 ; Faure O., Les Français et leur médecine au XIX siècle, Paris, Belin, 1993, p. 29-40.

7. Sage Pranchère N., «Bébés sans diplôme. Les matrones, le droit et les légitimités locales en France, 1780-1900 », dans Barbulescu C., Ciupala A. (eds), Medicine, Hygienism and Society in XVIIIth-XXth centuries, Cluj-Napoca, Editura Mega, 20I2, p. 25-54. 
des $\mathrm{XIX}^{\mathrm{e}}$ et $\mathrm{XX}^{\mathrm{e}}$ siècles, «fait les bébés », mais ne touche pas la mère, qui n'a aucun diplôme mais connaît les vertus de la désinfection et de la propretée ${ }^{8}$.

Du côté des sages-femmes officielles, le consentement à l'obligation de formation est quasi immédiat. Il témoigne du changement irréversible qui s'est produit dans l'approche de l'accouchement. Si les sages-femmes sont partie prenante de ce changement, c'est qu'elles en ont éprouvé l'intérêt sanitaire et qu'elles y trouvent un intérêt personnel. Les accoucheuses n'expriment aucune nostalgie d'un âge d'or que le processus de scolarisation aurait mis à mal. Le diplôme consacre la continuité d'un encadrement féminin de la naissance tout en le dissociant de la marginalisation sociale qui est le lot de la plupart des sages-femmes rurales jusqu'à la fin du XVIII ${ }^{e}$ siècle. Le diplôme reconnaît l'acte de l'accoucheuse comme un travail et ouvre le droit à la reconnaissance matérielle et sociale de ce travail.

Ce consentement à la formation se lit à deux niveaux. Les sages-femmes instruites lors des cours du dernier quart $\mathrm{du} \mathrm{XvIII}^{\mathrm{e}}$ siècle dirigent naturellement leurs filles vers les écoles qui s'ouvrent au début du siècle suivant. Elles choisissent ainsi d'ignorer la petite latitude que la loi de ventôse laisse en théorie à l'apprentissage de l'art des accouchements auprès d'un médecin ou d'une autre accoucheuse, renonçant à perpétuer un mode interpersonnel de transmission.

\section{Sages-femmes professionnelles}

La sage-femme a donc très vite accepté de mettre sa formation entre les mains de tiers. Cette décision ne vaut pourtant pas renoncement à toute maitrise des accoucheuses sur elles-mêmes. Les sages-femmes se professionnalisent, selon une évolution qui sera avec un bon demi-siècle de décalage celle des institutrices ; leur formation est au cœur de cette dynamique de professionnalisation.

Désignées comme l'une des seules corporations féminines d'Ancien Régime, les sages-femmes n'ont cependant jamais fait l'expérience du fonctionnement en métier pleinement constitué. Placées dans la dépendance des chirurgiens, les accoucheuses urbaines jurées trouvent à ce regroupement plus de limitations qu'elles n'y gagnent de reconnaissance ${ }^{9}$. Lorsque la loi de ventôse an xi établit un personnel médical régi nationalement et très largement uniformisé par rapport au foisonnement d'Ancien Régime, elle offre aux sages-femmes les conditions nécessaires à l'émergence d'une conscience professionnelle, même si elle réserve à l'État le soin de règlementer l'exercice du métier. Les scolarités font le reste.

8. Verdier Y., Façons de faire, façons de dire, Paris, Gallimard, 1979, p. 95-96 et 155.

9. Gélis J., La Sage-femme ou le médecin..., op. cit., p. 40-45. 
Après la délimitation d'un corpus spécifique de savoir au Xviri ${ }^{\mathrm{e}}$ siècle, le $\mathrm{XIX}^{\mathrm{e}}$ siècle complète le processus de professionnalisation. Il ouvre le temps de la normalisation de la formation et correspond à la transformation de la pratique des accouchements en principale source de revenus pour les sages-femmes désormais diplômées ${ }^{10}$. Le contrôle sur la transmission du savoir, autre facette essentielle de l'autonomisation professionnelle, est réduit sans être perdu. Le modèle de la maîtresse sage-femme enseignante de l'Office des Accouchées de l'Hôtel-Dieu de Paris perdure à l'Hospice de la Maternité et se diffuse dans les écoles départementales ${ }^{11}$. Les professeurs masculins d'accouchements, héritiers des chirurgiens démonstrateurs sous l'Ancien Régime, n'occupent qu'une partie du terrain ${ }^{12}$ car les sages-femmes continuent de former les sagesfemmes, et elles le font sans doute plus au XIX ${ }^{e}$ siècle qu'elles ne l'ont jamais fait auparavant. Elles participent aussi aux progrès de leur art grâce à l'œuvre de praticiennes (Marie-Louise Lachapelle, Marie-Anne Boivin) exceptionnelles mais révélatrices du niveau de scientificité que peut atteindre la profession.

Un des enjeux de ce travail est ainsi de comprendre l'intrication qui s'opère tout au long du siècle entre le pouvoir de prescription de quelques grandes figures (féminines et masculines), de quelques institutions de la science obstétricale et le travail en apparence anonyme et universel de la législation.

\section{Chronologie : les sages-femmes et la médicalisation de la société française}

L'histoire de la formation des sages-femmes au XIX ${ }^{e}$ siècle est une histoire aux bornes chronologiques précises qui déjouent pourtant la grande respiration du siècle. Elle s'ouvre en 1786 avec la première enquête nationale sur les sagesfemmes et sur leur instruction ${ }^{13}$. Elle se clôt en 1916 et I9I7 sur l'unification définitive des sages-femmes en un seul corps professionnel, à la formation identique, par la loi du 5 août et la réforme des études en janvier suivant. Dans tous les cas, elle dépasse, en amont et en aval, le cadre dessiné par les bouleversements politiques que sont la Révolution et la Grande Guerre, signe de la continuité et de l'autonomie d'une politique de la population.

Io. Borst C. G., Catching Babies. The Professionalization of Childbirth, 1870-1920, Cambridge (Massachussetts)/London, Harvard University Press, 1995, p. 2.

II. Beauvalet-Boutouyrie S., Naître à l'hôpital au XIX siècle, Paris, Belin, 1999, p. 25-27 ; IO8-IO9.

I2. Gélis J., La Sage-femme ou le médecin..., op. cit., p. I23-129.

I3. Gélis J., «L'enquête de 1786 sur les sages-femmes du royaume », ADH, I980, p. 299-343. 
Dans ce $\mathrm{XIX}^{\mathrm{e}}$ siècle élargi, vient s'insérer une seconde chronologie structurante. La loi du I9 ventôse an XI (Io mars I803) sur l'exercice de la médecine est l'aboutissement de la volonté manifestée par l'enquête de i786. Elle confirme l'appartenance des sages-femmes au personnel médical et l'impératif de leur formation. La loi du 30 novembre I892 sur l'exercice de la médecine et le décret du 25 juillet 1893 sur les études des aspirantes sages-femmes réforment les exigences de la loi de 1803 en préparant le rapprochement des deux catégories de sages-femmes, et donc la loi de igi6.

Ces grandes dates, à l'exception de la dernière, ne sont pas propres aux accoucheuses. Elles rythment plus largement l'histoire du personnel médical entre la fin du XVIII ${ }^{e}$ siècle et la fin du siècle suivant. Elles offrent la confirmation administrative et règlementaire d'une révolution politique et sociale : l'émergence de la notion de santé publique ${ }^{14}$. La redéfinition des acteurs médicaux en est la conséquence autant que l'instrument, réponse toujours incomplète à la demande croissante de soins ${ }^{15}$. La dynamique de formation des sages-femmes est donc à replacer dans le cadre plus vaste de la multiplication des personnels de santé qui fait du XIX ${ }^{e}$ siècle le temps de l'irruption du soignant dans la société. Aux côtés des sages-femmes, et selon une même chronologie, médecins, chirurgiens, officiers de santé forment ainsi, de l'Ancien Régime à la Troisième République, les différentes figures d'une profession en complète mutation ${ }^{16}$. Plus tard dans le siècle, ce sont les gardes-malades ${ }^{17}$, puis, filles de la révolution pastorienne, les infirmières qui s'affirment en nouvelles professions du $\operatorname{soin}^{18}$.

14. Teysseire D., «Aux origines de la médecine sociale et de la politique de la santé publique : l'Avis au peuple sur sa santé de Tissot », Mots, I991, nº 26, p. 47-64 ; Jorland G., Une société à soigner. Hygiène et salubrité publiques en France au XIX $x^{e}$ siècle, Paris, Gallimard, 2010. 15. Faure O., Les Français et leur médecine au XIX $x^{e}$ siècle, Paris, Belin, I993, p. 6.

I6. Léonard J., Les Médecins de l'Ouest au XIX siècle, Lille/Paris, Atelier de reproduction des thèses, université de Lille 3, Diffusion Honoré Champion, 1978, reproduction de la thèse présentée en 1976 .

17. Le métier de garde-malade a fait l'objet de plusieurs études pour la Suisse du XIX ${ }^{\mathrm{e}}$ siècle : Francillon D., "Construction et évolution du rôle de la garde-malade (XviII ${ }^{e}$-XIX ${ }^{e}$ siècles). De l'émergence d'un nouveau rôle aux structures d'apprentissage », dans Head-König A.-L., Mottu-Weber L. (dir.), Les Femmes dans la société européenne. $8^{e}$ congrès des Historiennes suisses, Genève, Société d'histoire et d'archéologie de Genève, 2000, p. I06-I2I et dans le même volume, Pilloud S., «Le Journal de l'école d'infirmière La Source, une étude du discours porté sur le rôle de la garde-malade entre I890 et I945 », p. I23-I38. Pour la France au début du Xx $x^{\mathrm{e}}$ siècle, voir Diebolt É., « Les gardes-malades hospitalières. Personnel secondaire des hôpitaux et révolution pasteurienne. Un exemple en France », Culture technique, 1985, n ${ }^{\circ}$ 15, p. 303-3II.

I8. Knibiehler Y., Leroux-Hugon V., Dupont-Hess O., Tastayre Y., Cornettes et blouses blanches. Les infirmières dans la société française, 1880-1980, Paris, Hachette, 1984 ; Leroux- 


\section{Les sages-femmes au cour d'une floraison historiographique}

Histoire du soin, histoire des soignants, tels sont en effet les pôles entre lesquels balance une histoire de la santé au $\mathrm{XIX}^{\mathrm{e}}$ siècle qui délaisse partiellement l'histoire traditionnelle des institutions pour placer au cœur de ses préoccupations les acteurs et les pratiques ${ }^{19}$. Sans être expressément désignée, l'histoire de la formation médicale constitue un des ensembles principaux de cette production historienne. C'est d'ailleurs sous cet angle que l'institution, en l'espèce le champ hospitalier, retrouve une place dans l'espace historiographique ${ }^{20}$.

À la croisée de ces chemins, les études sur les sages-femmes ont retrouvé une actualité à partir des années 1990. L'ouvrage de Jacques Gélis, La sage-femme ou le médecin, publié en 1988, avait constitué une première somme des études menées depuis le milieu des années 1970 sur l'histoire de la naissance et de ses acteurs. Marqués par la double généalogie de la démographie historique et de l'histoire des mentalités ${ }^{21}$, les travaux de Mireille Laget, Jacques Gélis et Marie-France Morel restituent dans toute sa complexité une « ancienne manière d'être au monde $»-$ et de mettre au monde, pourrait-on dire aussi ${ }^{22}$. S'y ajoute pour la période contemporaine la thèse de Françoise Thébaud sur l'accouchement hospitalier dans l'entre-deux-guerres ${ }^{23}$. L'objet de ces études

Hugon V., Des saintes lä̈ques. Les infirmières à l'aube de la Troisième République, Paris, Sciences en situation, 1992 ; Chevandier C., Infirmières parisiennes, 1900-1950. Émergence d'une profession, Paris, Publications de la Sorbonne, 20II.

19. Faure O., «La recherche en histoire de la santé. Axe de recherche santé et assistance. Centre Pierre Léon d'histoire économique et sociale UMR 5599 du CNRS », Cabiers d'bistoire, 1998, 43-I [en ligne] ; P. Bourdelais, O. Faure (dir.), Les Nouvelles Pratiques de santé, objets, acteurs, pratiques sociales, Paris, Belin, 2005.

20. Bueltzingsloewen I. (von), Machines à instruire, machines à guérir. Les hôpitaux universitaires et la médicalisation de la société allemande, Lyon, Presses universitaires de Lyon, 1997 ; C. Bonah, Instruire, guérir, servir. Formation, recherche et pratique médicales en France et en Allemagne pendant la deuxième moitié du XIX siècle, Strasbourg, Presses Universitaires de Strasbourg, 2000.

21. Ariès P., Histoire des populations françaises et de leurs attitudes devant la vie depuis le XVIII ${ }^{e}$ siècle [1948], Paris, Éditions du Seuil, I97I.

22. Gélis J., La Sage-femme ou le médecin..., op. cit., p. 489 ; Gélis J., Laget M., Morel M.-F., Entrer dans la vie. Naissances et enfances dans la France traditionnelle, Gallimard, Julliard, Paris 1978 ; Laget M., Naissances. L'accouchement avant l'âge de la clinique, Paris, Éditions du Seuil, 1982 ; Gélis J., L'arbre et le fruit, Paris, Fayard, 1984.

23. Thébaud F., Quand nos grands-mères donnaient la vie. La maternité en France dans l'entredeux-guerres, Lyon, Presses universitaires de Lyon, 1986. 
déborde néanmoins très largement l'histoire des auxiliaires de la naissance par leur approche globale des événements que sont la grossesse et l'accouchement. Elles ne dépassent cependant que rarement la fin du XVIII ${ }^{e}$ siècle, vue comme un temps d'effacement de la sage-femme au profit de l'accoucheur en France comme dans d'autres pays occidentaux (Angleterre et Amérique ${ }^{24}$ ). L'incursion dans le $\mathrm{XIX}^{\mathrm{e}}$ siècle reste isolée (Claudia Pancino sur l'Italie ${ }^{25}$ ) et n'a, pour la France, d'équivalent que la thèse de Danielle Tucat soutenue en 1983 sur les sages-femmes parisiennes entre 1870 et I9I4 et celle en I988 de Michelle Zancarini-Fournel et Mathilde Dubesset qui consacrent une partie de leur recherche aux sages-femmes stéphanoises entre 1880 et $1950^{26}$.

L'intérêt des historien-ne-s pour cette profession rebondit au milieu des années 1990 sous l'impulsion de travaux américains, anglais, allemands ou suisses et se porte désormais, en amont des recherches précédentes, sur la première modernité ${ }^{27}$, ou, en aval, sur la période contemporaine ( xIX $^{e}$ et $\mathrm{XX}^{\mathrm{e}}$ siècles $)^{28}$. En 1995, Olivier Faure déplore en introduction d'un numéro du Bulletin du Centre Pierre-Léon consacré aux femmes soignantes les « lacunes [de l'histoire des sages-femmes] entre la Révolution et Pasteur ${ }^{29}{ }$. Il revient en 2004 sur le sujet dans un article programmatique paru dans un ouvrage collectif sur Les nouvelles pratiques de sante ${ }^{30}$. Entre temps, l'étude de Scarlett

24. Donnison J., Midwives and medical men..., op. cit. ; J. B. Litoff, American Midwives, 1860 to the Present, Westport, Conn., Greenwood Press, 1978.

25. Pancino C., Il bambino e l'acqua sporca. Storia dell'assistenza al parto dalle mammane alle ostetriche (secoli XVI-XIX), Milano, Franco Angeli, «Storia », I984.

26. Tucat D., Les Sages-femmes parisiennes, 1871-1914, thèse de troisième cycle soutenue à l'université Paris VII, sous la direction de Michelle Perrot ; Zancarini-Fournel Z., Dubesset M., Parcours de femmes. Réalités et représentations, Saint-Étienne, 1880-1950, thèse pour le doctorat d'histoire, université Lyon II, I988, sous la direction d'Yves Lequin, publiée sous le même titre en 1993, aux Presses Universitaires de Lyon.

27. Marland H. (dir.), The Art of Midwifery. Early Modern Midwives in Europe, London/ New York, Routledge, 1993 ; Labouvie E., Beistand in Kindsnöten. Hebammen und weibliche Kultur auf dem Land, 1550-1910, Frankfurt/New York, Campus Verl., 1999.

28. Borst C. G., Catching Babies..., op. cit. sur les sages-femmes du Wisconsin ; VouillozBurnier M.-F., L'Accouchement entre tradition et modernité, naître au XIX ${ }^{e}$ siècle, Sierre, Monographic, 1995, sur les sages-femmes du Valais suisse ; Marland H., Rafferty A. M. (dir.), Midwives, Society and Childbirth. Debates and Controversies in the Modern Period, London/New York, Routledge, 1997.

29. Faure O., «Introduction », Bulletin du Centre Pierre-Léon d'bistoire économique et sociale, I995, $\mathrm{n}^{\circ}$ 2-3, «Les femmes soignantes », p. 4.

30. Faure O., «Les sages-femmes en France au XIX ${ }^{\mathrm{e}}$ siècle : médiatrices de la nouveauté », dans Bourdelais P., Faure O. (dir.), Les Nouvelles Pratiques de santé..., op. cit., p. 157-174. 
Beauvalet sur l'Hospice de la Maternité de Paris en 1999 a cependant rouvert le chantier de la formation de ces praticiennes ${ }^{31}$.

Les années 2000 confirment le renouveau historiographique pour les époques moderne et contemporaine : le XVIII ${ }^{e}$ siècle fait l'objet en Angleterre d'une vaste entreprise d'édition de sources ${ }^{32}$, tandis que les $\mathrm{XVI}^{\mathrm{e}}$ et $\mathrm{XVII}^{\mathrm{e}}$ siècles suscitent de nouveaux travaux sur le rôle social des sages-femmes et leurs premières tentatives de cantonnement par le corps médical ${ }^{33}$. À l'autre bout de la période, les sages-femmes du $\mathrm{xx}^{\mathrm{e}}$ siècle sont utilisées comme un prisme de compréhension des politiques natalistes autoritaires voire eugénistes (Italie fasciste, Allemagne nazie $\left.{ }^{34}\right)$. En France, la dernière décennie correspond à l'émergence des recherches sur les sages-femmes en contexte colonial avec les travaux d'Anne Hugon (Ghana), Pascale Barthélémy (AOF) et Claire Fredj (Algérie) ${ }^{35}$. Enfin, se dessine une histoire du temps présent des sages-femmes, nourrie aux apports de l'histoire orale et de l'enquête sociologique, qui interroge leur place entre parturiente et médecin et dans une ritualisation contemporaine de la naissance ${ }^{36}$.

3I. Beauvalet-Boutouyrie S., Naître à l'hôpital..., op. cit.

32. Eighteenth-Century British Midwifery, London, Pickering and Chatto, 2007-2009, I2 vol.

33. Evenden D., The Midwives of Seventeenth-Century London, Cambridge, Cambridge University Press, 2000 ; Bicks C., Midwiving Subjects in Shakespeare's England, Aldershot, Ashgate, 2003 ; McTavish L., Childbirth and the Display of Authority in Early Modern France, Aldershot, Ashgate, 2005 .

34. Gissi A., Le segrete manovre delle donne. Levatrici in Italia dall'unità al fascismo, Roma, Biblink, 2006 ; Benedict S., Shields L. (ed.), Nurses and Midwives in Nazi Germany. The "Euthanasia Programs", London, Routledge, 2014.

35. Hugon A., «Les sages-femmes africaines en contexte colonial : auxiliaires de l'accouchement ou agents de la médicalisation ? Le cas du Ghana, des années 1930 aux années 1950 », dans Bourdelais P., Faure O. (dir.), Les Nouvelles Pratiques de santé., , op. cit., p. 175-193 ; ead., "L'internat de l'école de sages-femmes d'Accra à l'époque coloniale : lieu de sociabilité et formation d'une identité professionnelle (années 1930-1950) », dans Fourchard L., Goerg O., Gomez-Perez M. (dir.), Lieux de sociabilité urbaine en Afrique, Paris, L'Harmattan, 2009, p. 135I50 ; ead., "Mémoire de (sages)-femmes à l'époque coloniale (Ghana, I920-1960) : sources orales, émergence d'un nouveau groupe socio-professionnel et histoire de la maternité », dans Thébaud F., Dermenjian G. (dir.), Quand les femmes témoignent. Histoire orale, Histoire des femmes, Mémoire des femmes, Paris, Publisud, 2009 ; Barthélémy P., Africaines et diplômées à l'époque coloniale (1918-1957), Rennes, PUR, 2010 ; Fredj C., " Encadrer la naissance dans l'Algérie coloniale. Personnels de santé et assistance à la mère et à l'enfant « indigènes 》 ( $\mathrm{XIX}^{\mathrm{e}}$ début du xx ${ }^{e}$ siècle », $A D H, 2011-2$, p. 169-203.

36. Knibiehler Y., Accoucher. Femmes, sages-femmes et médecins depuis le milieu du XXe siècle, Rennes, Éditions de l'École Nationale de la Santé Publique, 2007, édition revue et augmentée en 2016 ; Charrier P., Clavandier G., Sociologie de la naissance, Paris, Armand Colin, 2013. 


\section{Aux confins de l'histoire du travail}

Ce rapide tour d'horizon des publications consacrées aux sages-femmes pendant les quarante dernières années montre le passage progressif des recherches du champ de la naissance et des agents et pratiques qui s'y rattachent à celui d'un corps professionnel spécifique. L'évolution souligne la part croissante occupée par cette dimension professionnelle dans l'étude des sages-femmes, dimension qui les rattache naturellement à une histoire du travail des femmes dont elles ont longtemps été absentes.

La tentative d'équilibrer ce que Michelle Perrot désigne comme une «valorisation, abusive mais signifiante, du travail "productif" au XIX ${ }^{e}$ siècle » qui érige en « seules travailleuses les salariées ${ }^{37}$ » ne permet toutefois pas aux sages-femmes de quitter les oubliées de l'histoire du travail féminin. Peu nombreuses en comparaison des trois figures majoritaires que sont la domestique, la couturière et l'ouvrière, les sages-femmes comme travailleuses restent continûment hors $\mathrm{du}$ champ historiographique. En 1987, un numéro du Mouvement social consacré aux « métiers de femmes » les évoque en passant, avec une formule ambiguë :

Restent, comme seuls vrais métiers féminins admis et socialement reconnus, les métiers de sages-femmes et d'institutrices. Mais ne renvoient-ils pas fondamentalement au rôle traditionnel de la femme : donner la vie et éduquer ? ? $^{38}$

Trop féminin pour être vrai... La formule est révélatrice de tout ce qui pèse sur le métier de sage-femme : trop lié à la fonction génésique, trop traditionnel pour être perçu comme porteur d'une quelconque modernité. Prises entre la mise en lumière historico-anthropologique des mutations de leur fonction auprès des femmes en couches et leur appartenance progressivement affirmée au personnel médical, les sages-femmes du XIX ${ }^{e}$ siècle sont niées par l'historiographie du travail dans la dimension éminemment professionnelle de leur activité.

La conscience d'exercer un métier et la revendication de pouvoir vivre de ce métier sont pourtant au cœur des préoccupations des sages-femmes dès le début du Xix ${ }^{e}$ siècle. Actrices d'un événement majeur de la vie familiale, les sages-femmes sont des femmes qui sortent, délaissant leur propre foyer pour celui des autres, contre tous les principes bourgeois de confinement féminin. Loin d'être synonyme de repli sur la sphère privée, leur activité est une

37. Perrot M., « De la nourrice à l'employée... Travaux de femmes dans la France du $\mathrm{xIx}^{\mathrm{e}}$ siècle », Le Mouvement social, $1978, \mathrm{n}^{\circ}$ I05, p. 3.

38. Burdy J.-P., Dubesset M., Zancarini-Fournel M., « Rôles, travaux et métiers de femmes dans une ville industrielle : Saint-Étienne, 1900-1950 », Le Mouvement social, 1987, nº I40, p. 54. 
composante essentielle de l'ouverture des familles aux nouvelles pratiques de santé. À tous ces titres, les sages-femmes sont des travailleuses et sont reconnues comme telles par leur clientèle.

Le statut de profession médicale creuse plus encore le fossé entre les sagesfemmes et les autres femmes au travail et ce dès le $\mathrm{XIX}^{\mathrm{e}}$ siècle. Cela n'annule toutefois pas les effets de la frontière de genre qui traverse le personnel médical et qui place les sages-femmes dans une position potentiellement vulnérable. Car si l'histoire des sages-femmes françaises est aux antipodes de la disparition orchestrée des sages-femmes américaines au profit des obstétriciens à l'aube du $\mathrm{xx}^{\mathrm{e}}$ siècle ${ }^{39}$, elle n'en reste pas moins marquée, dans ses relations avec le personnel médical masculin, par une représentation binaire des rôles et capacités du masculin et du féminin ${ }^{40}$. Le choix politique de conserver et d'officialiser les accoucheuses est en partie fondé sur leur appartenance au genre féminin et sur l'affinité censée en découler avec l'objet de leurs soins. Le choix tout aussi politique de placer des professeurs hommes à la tête des cours d'accouchements participe pour sa part de plusieurs monopoles masculins : sur l'exercice de la médecine et sur la capacité d'enseignement théorique, déniée aux femmes ${ }^{41}$. La sage-femme construit son identité professionnelle dans un contexte contraint par la coexistence et le coexercice forcés avec les médecins mais aussi sur la base d'une formation spécifique.

\section{Du savoir à l'école : un modèle français}

L'histoire de la formation des sages-femmes au $\mathrm{xIX}^{\mathrm{e}}$ siècle est l'histoire de la formation d'une étrange élite du savoir, dissociée de l'élite sociale. Elle se situe à l'intersection de deux champs historiographiques au développement d'ordinaire strictement parallèle : l'histoire de l'enseignement médical et l'histoire de l'éducation des femmes. Le premier champ a longtemps constitué la chasse gardée des médecins, historiens de leur propre science, et n'a été investi par la science historique qu'à partir des années 1970 avec l'ouvrage fondateur de

39. Borst C. G., Catching Babies..., op. cit. ; McGregor D. K., From midwives to medicine. The Birth of American Gynecology, New Brunswick/New Jersey/London, Rutgers University Press, 1998.

40. Knibiehler Y., «Les médecins et la "nature féminine" au temps du Code civil », Annales. ÉSC, 1976, p. 824-845 ; Arnaud-Duc N., « Les contradictions du droit », dans Fraisse G., Perrot M. (dir.), Histoire des femmes en Occident..., op. cit., p. IOI-I25.

4I. Rogers R., «Le professeur a-t-il un sexe ? Les débats autour de la présence d'hommes dans l'enseignement secondaire féminin, I840-1880 », Clio. Histoire, femmes et sociétés, 1996-4, p. 22I-238. 
Jacques Léonard ${ }^{42}$. L'histoire de l'éducation des femmes émerge au début des années 1970 avec le renouveau de l'histoire sociale et l'essor de l'histoire des femmes. Les travaux de Françoise Mayeur sur l'enseignement secondaire des filles en $1977^{43}$ inaugurent une production historiographique abondante ${ }^{44}$, marquée néanmoins par une nette préférence accordée à l'histoire de l'enseignement secondaire des filles et à celle des enseignantes ${ }^{45}$. L'histoire de la formation professionnelle des filles et de leur accès à l'enseignement supérieur est de ce fait encore en germe ${ }^{46}$. Or c'est entre ces deux types de formation que se situe celle des sages-femmes, même si elle présente avec les structures d'enseignement secondaire féminin un trait commun qui est l'adoption quasi générale de l'internat ${ }^{47}$.

On retrouve ainsi, dans les deux tendances historiographiques dont participe l'histoire de l'instruction des accoucheuses, la partition entre appartenance de genre et appartenance professionnelle. Cette distance ne peut se combler qu'en replaçant l'instruction obstétricale dans la logique prééminente de l'institution scolaire française telle qu'elle se développe de la Révolution à la Troisième République ${ }^{48}$. Distincte du niveau primaire dans un contexte où, avant 1867 , l'enseignement secondaire féminin n'est pas encore fondée ${ }^{49}$, la formation des sages-femmes est à rapprocher d'autres enseignements spéciaux

42. Léonard J., Les Médecins de l'Ouest..., op. cit. ; C. Bonah, auteur d'Instruire, guérir, servir..., op. cit., est lui-même médecin.

43. Mayeur F., L'Enseignement secondaire des jeunes filles sous la Troisième République, Paris, Presses de la Fondation Nationale des Sciences Politiques, 1977.

44. Mayeur F., «L'éducation des filles en France au XIX $X^{e}$ siècle : historiographie et problématiques », dans Problèmes de l'histoire de l'éducation. Actes des séminaires organisés par l'École française de Rome et l'Università di Roma-La Sapienza (janvier-mai 1985), Rome, École française de Rome, 1988, p. 79-90 ; Rogers R., «L'éducation des filles : un siècle et demi d'historiographie », Histoire de l'éducation, 2007, no II5-II6, p. 37-79.

45. Ce tropisme vers les professions enseignantes est tel que l'article de Rebecca Rogers ne retient de la thèse de Pascale Barthélémy sur les sages-femmes et les institutrices en AOF que la partie consacrée aux institutrices, voir «L'éducation des filles... », art. cit., p. 67.

46. Thivend M. (dir.), Apprentissage et formations techniques et professionnelles de filles et de garçons, XIX ${ }^{e}-X X^{e}$ siècles, Cabiers Pierre Léon, $\mathrm{n}^{\circ}$ 6, Lyon, LARHA, 2005 ; Hulin N. (dir.), Les Femmes et l'enseignement scientifique, Paris, PUF, 2002 ; Tikhonov Sigrist N., « Les femmes et l'université en France, I860-I914. Pour une historiographie comparée », Histoire de l'éducation, 2009, $\mathrm{n}^{\circ}$ I22, p. 53-70.

47. Rogers R., Les Bourgeoises au pensionnat. L'éducation féminine au XIX siècle, Rennes, PUR, 2007.

48. Mayeur F., Histoire générale de l'enseignement et de l'éducation en France, 3. De la Révolution à l'École républicaine (1789-1930) [1981], Paris, Perrin, 2004.

49. Mayeur F., L'Enseignement secondaire des jeunes filles..., op. cit. 
comme les écoles vétérinaires ou les écoles d'art et métiers ${ }^{50}$. On assiste ainsi à un découplage précoce entre structure universitaire dont la part est minoritaire dans la formation totale des accoucheuses et structure scolaire spécifique, fait extrêmement rare dans l'enseignement médical européen ${ }^{51}$. Ce choix institutionnel s'explique par une méfiance persistante des élites politiques vis-à-vis des universités. Celle-ci s'exprime dès avant la Révolution et se confirme pendant la décennie 1790 avec la dissolution des facultés, point essentiel de la politique éducative révolutionnaire $e^{52}$. Les formes choisies pour remplacer les anciennes structures d'enseignement sont directement placées dans la dépendance des autorités administratives et politiques : écoles centrales à l'échelle départementale (après la dissolution des collèges) et grandes écoles (École normale supérieure, École polytechnique, etc.) à l'échelle nationale constituent alors un système éducatif à deux niveaux, généraliste pour les premières, spécialisé pour les secondes ${ }^{53}$. L'enseignement des accoucheuses hérite de ce système dual même lorsque les réformes napoléoniennes remplacent les écoles centrales par les lycées (I806) et réinstaurent le primat universitaire (I808) ${ }^{54}$. La création

50. Hubscher R., Les Maîtres des bêtes. Les vétérinaires dans la société française (XVIII $X X^{e}$ siècles), Paris, Jacob O., 1999 ; Day C. R., Les Écoles d'arts et métiers. L'enseignement technique en France, $X I X^{e}-X X^{e}$ siècles [1987], Paris, Belin, I99I.

5I. Les sages-femmes allemandes sont ainsi formées dans un cadre universitaire, aux côtés des étudiants en médecine, voir à ce sujet les articles de J. Schlumbohm, en particulier « Geschichte der Geburt. Das Entbindungshospital der Universität Göttingen und seine Patientinnen, I75Ica. I830 », dans Glatz F. (dir.), Europäische und nationale Interessen, Budapest, Europa Institut, 2002, p. 55-67; id., "Comment l'obstétrique est devenue une science », Actes de la recherche en sciences sociales, 2002, vol. I43, $\mathrm{n}^{\circ}$ I, p. I8-30 ; id., «Les limites du savoir : médecin et femmes enceintes à la maternité de l'université de Göttingen aux alentours de I800 », RHMC, 2005, 52-I, p. 64-94 ; id., « The Practice of Practical Education: Male Students and Female Apprentices in the Lying-in Hospital of Göttingen University, I792-I8I5 », Medical History, 2007, 5I, p. 3-36.

52. Charle C., Verger J., Histoire des universités, Paris, PUF, « Que sais-je ? », 2007, p. 53 sq. ; Brambilla E., «Lycées et Université impériale. Innovations éducatives en France et influence sur l'instruction des élites en Italie (I789-18I4) », Rives méditerranéennes, 2009, nº 32-33 [en ligne].

53. Sur les écoles centrales, voir Compère M.-M., Du collège au lycée (1500-1850), Paris, Gallimard-Julliard, 1985 ; Julia D., Les Trois Couleurs du tableau noir. La Révolution, Paris, Belin, 198I, p. 249-282. Sur les grandes écoles, voir entre autres Belhoste B., Dahan-Dalmedico A. (dir.), La Formation polytechnicienne, 1794-1994, Paris, A. Picon, 1994 ; Sirinelli J.-F., École normale supérieure : le livre du bicentenaire, Paris, PUF, 1994.

54. Boudon J.-O. (dir.), Napoléon et les lycées. Enseignement et société en Europe au début du XIX siècle. Actes du colloque des 15 et 16 novembre 2002, Paris, Nouveau Monde Éditions/ Fondation Napoléon, 2004 ; Karady V., « De Napoléon à Duruy : origines et naissance de l'Université contemporaine », dans Verger J. (dir.), Histoire des Universités en France, Paris, Privat, 1986, p. 26I-28I. 
de l'école de sages-femmes de l'Hospice de la Maternité de Paris en I802 et l'obligation de fonder des cours départementaux d'accouchement au titre de la loi du I 9 ventôse an XI constituent à cet égard l'ultime rejeton des conceptions révolutionnaires de l'éducation.

Ce double système a la caractéristique de ne pas être hiérarchique. Il n'existe pas d'obligation de passer par une école départementale d'accouchement pour accéder à l'Hospice de la Maternité de Paris, et le choix de certains départements d'utiliser l'institution parisienne comme une école de perfectionnement à la suite de la scolarité dans leur propre établissement local ne minore en rien la solidité et le dynamisme de l'échelon départemental. Le cours d'accouchement au chef-lieu de département est donc bien la cellule de base de la formation des sages-femmes au XIX ${ }^{e}$ siècle. Il est à cet égard l'exact reflet du fonctionnement administratif et politique de la France post-révolutionnaire et préfectorale qui fait du département son horizon essentiel, le constituant en véritable acteur politique. En I896, le rapporteur du conseil général de la Gironde peut dire, en évoquant l'école départementale d'accouchement de Bordeaux, «notre œuvre $e^{55}$ ». Dans ce «nous » se résume un siècle d'action conjointe des conseillers généraux et des préfets autour d'un même objectif : la formation des sages-femmes dans et par le département.

Pour comprendre le processus de consentement des sages-femmes à leur mise en formation, pour suivre la dynamique qui fait de la sage-femme un nouvel agent sanitaire et pour mesurer enfin les résultats concrets de la diffusion des sages-femmes diplômées, il faut donc revenir aux sources, à ce dernier quart du XVIII ${ }^{e}$ siècle qui promeut l'accoucheur et invente l'élève sage-femme (chapitre I). Lorsque la Révolution éclate, le choix de la sage-femme est définitivement fait, tout comme celui de son statut : une praticienne diplômée possédant le monopole de son art. Reste à adapter sa formation aux besoins définis par le nouveau gouvernement révolutionnaire, entre expérimentations provinciales et lenteurs législatives (Chapitre II). La maturité réglementaire et institutionnelle arrive au début du Consulat, avec la double mise en place d'une institution nationale de formation, l'Hospice de la Maternité de Paris, et d'une définition légale de la sage-femme et de ses modalités d'instruction par la loi du I9 ventôse an XI (Chapitre III).

Au temps de la définition et de la normalisation de l'enseignement obstétrical succède celui de l'organisation. La formation des sages-femmes est un 
impératif social et politique que remplissent avec conscience les administrations départementales par la mise en place de cours locaux ou l'envoi d'élèves sages-femmes à l'extérieur du département (Chapitre IV). Les écoles drainent alors dans leurs classes nombre d'élèves boursières, prêtes à faire du savoir leur moyen de subsistance, au point de l'ériger en patrimoine intellectuel et professionnel (Chapitre V). Ces élèves réelles sont choisies en fonction d'un idéal de la future sage-femme. Jeunes, célibataires, vertueuses et fidèles aux devoirs que leur impose l'appartenance au personnel médical, les élèves sages-femmes sont formées à devenir l'instrument bienveillant des politiques sanitaires publiques, au plus près des populations (Chapitre VI).

Mais entre le choix de l'élève et les premiers pas de son exercice professionnel s'étend le temps de l'école. L'enseignement obstétrical se révèle alors un lieu ambigu de reconnaissance et de subordination de la sage-femme associée au médecin dans la transmission du savoir. À leurs côtés, religieuses et membres des commissions de surveillance complètent le strict encadrement des élèves (Chapitre VII). Les programmes de la formation des sages-femmes s'étendent au fil du siècle pour répondre aux attentes croissantes auxquelles sont confrontées les praticiennes. Le savoir de l'accoucheuse s'étend ainsi en amont et en aval de la définition traditionnelle de l'art des accouchements (Chapitre VIII). Ces évolutions imposent en 1892-1893 une réforme de la formation dans un contexte où l'édifice du personnel médical bâti par le Consulat est sérieusement ébranlé. Dans ces nouvelles conditions, la dernière décennie du xıxe siècle marque la consécration des écoles départementales adaptées aux nouvelles exigences de l'enseignement réformé (Chapitre IX). 



\section{" Il se croit dispensé d'entrer dans aucun détail sur la nécessité d'un cours d'accouchement ${ }^{1}$ »}

Instruire les sages-femmes, former de bonnes accoucheuses : en I789, le discours est déjà installé, ancien, rebattu même. Jacques Gélis en a montré les racines, puis l'extraordinaire floraison dans la seconde moitié du XVIII ${ }^{e}$ siècle, des ouvrages savants d'accoucheurs repris et simplifiés dans des périodiques comme La Gazette de Santé ou le Journal de Médecine ${ }^{2}$. Le besoin de sagesfemmes compétentes, relayé dès les années 1760 par les administrateurs royaux qui font du discours une politique, naît d'une appréhension mal informée des réalités démographiques françaises et d'un rapport nouveau à la mise au monde et à ses risques. La période révolutionnaire correspond à un temps d'amplification et de consolidation du discours, qui ancre à tous les niveaux de la société française et jusqu'à l'autre bout du siècle les craintes qui ont présidé à son élaboration. Si l'argumentaire n'est ni univoque ni immobile, c'est l'accentuation du discours sur la nécessité de formation au tournant des XVIII ${ }^{e}$ et $\mathrm{XIX}^{\mathrm{e}}$ siècles qui forme le pivot des politiques ultérieures.

\section{Sur toutes les bouches...}

\section{La diffusion du discours}

Du discours d'Ancien Régime sur la formation des sages-femmes à celui de la Révolution, l'évolution se fait tout en nuance et en continuité ; question de degré plus que de nature, d'ampleur de diffusion que d'arguments fondamentaux. Plus que les mots, ce sont les bouches dont ils émanent qui changent progressivement.

\footnotetext{
I. AD Charente, L I55.

2. Gélis J., La Sage-femme ou le médecin..., op. cit., p. 99.
} 
Dès les années 1730, timidement, puis avec une assurance croissante et triomphante à partir des années 1750 , administrateurs et hommes de l'art dénoncent et réclament. Ils joignent pour ce faire les deux versants inséparables du discours sur la matrone coupable et la sage-femme à instruire ${ }^{3}$. Les plumes savantes se déchaînent sur la question. En un mot, le sujet est à la mode.

Il rebondit des médecins et chirurgiens aux philosophes des Lumières. Dans le grand'œuvre qu'est l'Encyclopédie, l'article «Accouchement » est co-signé en I75I du médecin anatomiste Pierre Tarin, du naturaliste Louis Daubenton et de Denis Diderot. Quatre ans plus tard, Louis de Jaucourt signe l'article «Enfantement » et en 1765 , l'article «Sage-femme » est rédigé par le chirurgien Antoine Louis ${ }^{4}$. Quittant les débats imprimés, le discours se transpose dans l'action des administrateurs ${ }^{5}$ : intendants à l'instar de Turgot $^{6}$ ou Ballainvilliers ${ }^{7}$, subdélégués, officiers municipaux ; mais aussi des clercs, prélats en tête comme l'archevêque de Narbonne, président des États de Languedoc ${ }^{8}$. La parole administratrice et réglementaire se développe et se diffuse à mesure que sont instaurés des cours d'accouchement d'un bout à l'autre du royaume. Les annonces des cours, les lettres circulaires, plus largement la correspondance qui se noue entre intendants et subdélégués, subdélégués et syndics ou curés, sont autant de terrains où se lisent les raisons de l'organisation des cours d'accouchement, leur nécessité et son urgence :

[...] il n'y a qu'une nonchalance blamable qui ait pu faire négliger à vos paroissiens cette occasion de se procurer une ressource aussi nécessaire pour la conservation de leurs femmes et de leurs enfans. Je ne vous dissimule pas que je suis affligé, de ce qu'ils n'ont point profité du service important que je désirois leur rendre $[\ldots] .^{9}$

La portée de ce discours se mesure à l'audience inégale des cours de démonstration, de l'affluence à l'obligation pour l'administration de rappeler à l'ordre communautés urbaines et villageoises, maigres pourvoyeuses d'élèves sagesfemmes, comme c'est le cas à Limoges en 1763.

3. Ibid., p. IO2-IO3.

4. Diderot D., Alembert J. Le Rond (d'), Encyclopédie ou Dictionnaire Raisonné des Sciences, des Arts et des Métiers, 1751-I772, texte reproduit à partir de la première édition, dans le cadre du projet ARTFL de l'université de Chicago, articles «Accouchement », « Enfantement » et « Sage-femme ».

5. Gélis J., La Sage-femme ou le médecin..., op. cit., p. 92-94.

6. AD Corrèze, $\mathrm{C}_{\mathrm{I}}$.

7. AD Aisne, C 629 .

8. AD Tarn, L 343 ; ainsi que Gélis J., La Sage-femme ou le médecin..., op. cit., p. 94-96.

9. $\mathrm{AD}$ Corrèze, $\mathrm{C}$. 
Qu'en est-il deux décennies plus tard ? L'enquête de 1786 sur les sagesfemmes modifie le point de vue, faiblement encore, mais significativement ${ }^{10}$. Lancée à l'initiative conjointe du Contrôle général des finances et de la Société royale de médecine, dans la foulée d'une enquête sur les médecins et les chirurgiens du royaume, cette enquête comporte une entrée où peut s'élever une voix nouvelle : les observations sur la façon dont les accoucheuses exercent leur état.

L'identité des répondants est floue, masquée par les réécritures successives des subdélégués puis des intendants. Certains se sont cependant révélés plus bavards et ont pris la peine de citer leurs sources. En Limousin, le «public » reste une masse indistincte et l'apparition épisodique des chirurgiens survalorise leur appréciation ${ }^{11}$. En revanche, dans la généralité de Soissons ${ }^{12}$ ou dans l'élection de Troyes $^{13}$, les mentions sont plus précises : «la paroisse », « les paroissiens » et, plus intéressant encore, «les femmes». Les filtres restent épais qui emprisonnent la spontanéité des locuteurs dans des formules stéréotypées, mais ils laissent percer à l'occasion l'opinion des hommes et des femmes de ces paroisses sur leurs accoucheuses : «à la satisfaction des personnes qui l'emploient », « à la satisfaction des femmes de la paroisse ${ }^{14}$ », ou encore «les femmes s'en louent et l'employent », « les habitants s'en louent ${ }^{15} »$.

Le concert de louanges n'est pourtant pas uniforme. De certaines femmes, «on ne dit rien », ou « on ne s'en plaint pas ${ }^{16}$ ». L'éloge ne s'adresse pas systématiquement à des sages-femmes reçues par une communauté de chirurgiens, ou à tout le moins instruites par le suivi d'un cours de démonstrateur. Ainsi à Bouresches (généralité de Soissons), Marguerite Parmentier, âgée de 66 ans, sage-femme non reçue, est " très estimée et surtout très désintéressée ${ }^{17}$ ». À Bailly (idem), à la sage-femme instruite, « les femmes [... préfèrent deux vieilles femmes sans expérience qui continuent de travailler contre les ordres de feu M. le subdélégué ${ }^{18} »$. L'expérience est ici détournée de son sens premier puisqu' elle est confondue avec le savoir théorique, pour, paradoxalement, mieux rejeter l'empirisme.

\footnotetext{
Io. Voir Gélis J., «L'enquête de I786 sur les sages-femmes du royaume », art. cit., p. 299-343.

II. Bibl. de l'Acad. de Médecine, SRM, carton 85 .

I2. $\mathrm{AD}$ Aisne, $\mathrm{C} 632$.

I3. $\mathrm{AD}$ Aube, $\mathrm{C}$ ir67.

I4. AD Aisne, C 632, généralité de Soissons.

15. AD Aube, $\mathrm{C}$ ir67, élection de Troyes.

I6. Ibid.

17. AD Aisne, C 632.

I8. Ibid.
} 
L'attitude ambivalente des populations à l'égard de la politique de formation est perceptible dans ces réponses en demi-teinte. Les sages-femmes instruites et reçues sont en général appréciées, mais les matrones «sans principes » sont tout aussi souvent estimées par la population. À ses interrogations, le gouvernement reçoit des réponses moins conformes à la doxa des intendants, dont l'interprétation finale des résultats de l'enquête est toujours plus catastrophiste que l'impression qui ressort de la lecture des tableaux ${ }^{19}$. L'initiative de l'enquête est à ce titre remarquable. Elle provoque une parole qui réussit à se libérer partiellement du discours médico-administratif, et, sans le vouloir, laisse s'entrouvrir une béance entre les objectifs de ce discours et la réalité perçue par les contemporains.

Deux ans plus tard les cahiers de doléances prennent le contre-pied de ces réponses nuancées. Les conditions de rédaction des cahiers semblent pourtant favorables à une expression moins prise dans les fils de la parole savante et administrative qu'une enquête du Contrôle général des finances puisque le roi invite ses sujets à lui faire connaître leurs doléances et remontrances, sans cadre imposé, sans formulaire pré-imprimé.

L'impéritie des matrones et la nécessité de former des sages-femmes sont très largement présentes dans les cahiers de doléances. Absentes des cahiers des corporations de médecins et de chirurgiens, les défaillances dans l'art des accouchements apparaissent au cœur de ceux des communautés villageoises ou urbaines, voire de la noblesse et du clergé. De l'Orléanais à la Picardie, de l'Angoumois à la sénéchaussée de Draguignan, du Cotentin à la Lorraine, les plaintes se répètent, selon des formulations si proches qu'elles semblent coulées dans un même et unique moule $\mathrm{e}^{20}$ :

(Sauxemesnil, bailliage de Cotentin) N'est-il pas triste que, dans la campagne surtout, des mille de malheureuses mères soient contraintes, n'ayant pas le moyen d'appeler un médecin ou chirurgien, de confier leur vie et celle de leurs enfants à des personnes ignorantes. ${ }^{21}$

\footnotetext{
19. Les résultats de l'enquête conservés dans les dépôts d'archives départementales présentent un état moins abouti que ceux envoyés par les intendants au Contrôle général des finances et à la Société royale de médecine. Les écritures y sont multiples (subdélégation de Noyon), et l'emploi du formulaire pré-imprimé n'est pas systématique (élection de Troyes).

20. Pulz W., «Aux origines de l'obstétrique moderne... », art. cit., p. 593-617. L'auteur montre à travers l'exemple du dénigrement quasi-systématique de l'ouvrage de Justina Siegemund, sagefemme de la cour de Brandebourg, par les chirurgiens et médecins ultérieurs, les mécanismes de délégitimation du savoir traditionnel des accoucheuses.

2I. Cabiers de doléances du bailliage de Cotentin (Coutances et secondaires) pour les États généraux de 1789, t. 2, publiés par É. Bridrey, Paris, 1908, CDIHÉRF, p. 502.
} 
(Aups, sénéchaussée de Draguignan) [...] un bon nombre de familles et d'enfants qui tous les ans sont les malheureuses victimes de l'impéritie et de l'ignorance la plus crasse. ${ }^{22}$

Aux drames mis en avant répondent deux solutions complémentaires : la formation des sages-femmes et leur assignation dans une paroisse contre rémunération.

(Derchigny, bailliage d'Arques) Pour le soulagement de l'humanité, la communauté fait des vœux pour la continuité des cours d'accouchement établis par les assemblées provinciales. ${ }^{23}$

(Clergé, bailliage d'Amiens) Chirurgiens et sages-femmes. Cet objet est des plus intéressants pour la religion et pour l'humanité ; il est important que les chirurgiens et les sages-femmes soient instruits et placés à des distances convenables, suivant la population et le besoin des cantons, dans plusieurs endroits ; il leur faudrait assigner des émoluments et donner des encouragements pécuniaires à raison de la pauvreté des habitants et de l'étendue des lieux qu'ils auraient à soigner ou à secourir. ${ }^{24}$

L'omniprésence de cette préoccupation révèle plusieurs processus. Les enquêtes de 1786 sur les différents types de soignants ont exprimé la sensibilité des populations à une notion en cours d'élaboration : l'encadrement médical. La forme de l'enquête, sa définition d'un personnel médical, son inscription géographique dans des ressorts administratifs qui se muent en circonscriptions de référence pour l'estimation du ratio entre soignants et population, sont à la base d'une politique de santé publique. Trois ans plus tard, lors de la rédaction des cahiers de doléances, des cours d'accouchement ont été réorganisés (Lyon ${ }^{25}$ ou Nancy), ou créés (généralité de Limoges qui s'étend de l'Angoumois à la $\left.\mathrm{Marche}^{26}\right)$. Dans une grande partie du reste du royaume, la formation

22. Cabiers de doléances des communautés de la sénéchaussée de Draguignan, voux du clergé et de la noblesse, publiés par F. Mireur, Draguignan, I889, p. 50.

23. Cabiers de doléances du bailliage d'Arques (secondaire de Caudebec) pour les États généraux de 1789, t. I, publiés par E. Le Parquier, Lille, 1922, CDIHÉRF, p. I94.

24. Laurent É., Mavidal J., Archives parlementaires de 1787 à 1860 (citées AP), 1. Cabiers des États généraux (clergé, noblesse, tiers état), classés par lettres alphabétiques de bailliages et de sénéchaussées, Paris, $1868, \mathrm{p} \cdot 736$.

25. Gutton J.-P., " Matrones, chirurgiens et sages-femmes en Lyonnais aux $\mathrm{XVII}^{\mathrm{e}}$ et XVIII ${ }^{e}$ siècles », dans Robin I., Poussou J.-P. (dir.), Histoire des familles, de la démographie et des comportements, en hommage à Jean-Pierre Bardet, Paris, PUPS, 2007, p. II2.

26. Sage Pranchère N., "Étude comparée de deux projets de cours d'accouchement à la fin du xviII ${ }^{e}$ siècle », HES, 2009-2, Paris, Armand Colin, p. 37-58; AD Haute-Vienne, C 270, et AD Charente, $\mathrm{I}_{4}$. 
des sages-femmes fonctionne avec régularité depuis au moins le début de la décennie 1780, faisant du démonstrateur et de l'élève sage-femme des figures familières. Le cours d'accouchement et ses effets positifs sur la baisse de la mortalité maternelle ont sans doute modifié les attentes vis-à-vis des accoucheuses ${ }^{27}$. Leur présence dans les cahiers de doléances est de fait le reflet de leur irruption concrète et symbolique dans le quotidien des populations ${ }^{28}$. À cet égard, 1786 prépare 1789 .

\section{Duplication du discours d'Ancien Régime : une parole captive?}

Pourtant le portrait nuancé des accoucheuses non formées, le poids de l'ancienneté et de la confiance patiemment construite ne peuvent pas avoir leur place dans les cahiers. La doléance implique un désordre d'où découle l'homogénéisation de la parole constatée plus haut car il existe un formulaire de la plainte et remontrance. L'organisation sous forme d'articles, leur caractère énumératif rapprochent les discours et font émerger une norme collective qui est celle des intendants et des chirurgiens. De ce point de vue, le discours des cahiers de doléances est l'aboutissement stéréotypé de la parole savante sur l'art des accouchements et la formation des sages-femmes, aboutissement d'un demisiècle de publications scientifiques et de pamphlets enflammés, aboutissement aussi de trente ans de vulgarisation pédagogique obstétricale.

Il serait cependant faux de ne voir dans ces cahiers qu'un point d'arrivée puisqu'ils sont tout autant un point de départ, celui du discours de la France des États généraux proclamés Assemblée nationale. Nœud rhétorique qui lie l'Ancien Régime à la Révolution et plus largement à tout le siècle suivant, les traits essentiels de ce discours reposent sur la reprise d'un nombre limité de motifs argumentaires et sur la réitération stylistique qui progressivement fossilise l'expression. La consultation de 1789 est unique en son genre, la scène devenue nationale a vu se multiplier les acteurs avant que le mandat du représentant et la refonte de l'administration ne réduisent de nouveau le champ d'élaboration et de déclaration du discours et que la parole, appauvrie, ne revienne à ceux qui en disposaient auparavant de façon privilégiée ou du moins à ceux qui les remplacent.

27. Beauvalet S., Renard J., « Des sages-femmes qui sauvent les mères ? », HES, I994, vol. I3, $\mathrm{n}^{\circ}$ 2, p. 279-280 : les auteurs ont montré que, pour la période I777-I807 en Normandie, le taux de mortalité maternelle est de 5,38 pour mille lorsqu'une sage-femme opère, tandis qu' il est de 8,69 pour mille lorsqu'il s'agit d'une matrone.

28. Léonard J., Les Médecins de l'Ouest..., op. cit., p. 205-206. 
Les administrateurs, des ministres aux citoyens présents à la tête des districts communaux, les médecins et les chirurgiens, de la Société royale de médecine au simple officier de santé, mêlent leurs voix pour rappeler la nécessité de former des sages-femmes compétentes. Ainsi, dès 1790, les assemblées administratives des départements mettent en œuvre des projets de cours d'accouchement dans un élan qui est bien plus un rebond sur l'héritage immédiat qu'une véritable réponse aux demandes des cahiers.

(Arrêté du I9 novembre 1790) L'assemblée administrative du département de la Côte-d'Or considérant que de tous les établissements que l'humanité et la justice sollicitent en faveur des habitants du département, il n'en est pas de plus nécessaire que ce cours [d'accouchement] [... $]^{29}$

(Arrêté du Io décembre 179I, Sarthe) Sur le rapport du bureau du Bien public, l'Assemblée [administrative du département] considérant que les malheurs trop fréquens, qui arrivent dans les campagnes, par l'ignorance des sagesfemmes, doivent faire rechercher tous les moyens qui peuvent y remédier $[\ldots]^{30}$

Les niveaux intermédiaires de la hiérarchie administrative (administration de district d'arrondissement et de district cantonal) relaient les décisions de l'autorité départementale jusqu'à la cellule de base qu'est la commune :

(29 janvier 1791, Pontarlier) Le directoire du département vient de nous informer, que le Conseil Général dirigé par des principes de bien public, d'humanité et de bienfaisance, a, dans sa dernière session, délibéré de procurer un cours gratuit d'accouchemens $[\ldots]^{31}$

La nécessité de l'instruction des accoucheuses n'est pas moins ressentie au plus bas degré de l'échelle, même si les bonnes volontés se heurtent aux difficultés matérielles de l'organisation des cours et du recrutement des élèves sages-femmes :

(I7 frimaire an III) La municipalité de Tréméreuc, aux administrateurs composant le directoire du district de Dinan, en vertu de votre lettre du 29 brumaire dernier qui considérant [que] l'humanité a chaque jour à gémir de l'ignorance des sages-femmes; nous vous faisons savoir que nous n'en avons en notre commune qu'une seule qui refuse d'aller se faire [former] à Saint-Brieuc. ${ }^{32}$

\footnotetext{
29. AD Côte-d'Or, L 542 .

30. AD Sarthe, $\mathrm{L} 32$.

31. AD Doubs, $\mathrm{L}_{1343}$.

32. AD Côtes-d'Armor, 3 L 4 I.
} 
Le tournant politique du Consulat et les modifications de l'organigramme administratif ne changent pas le discours. Les sessions des conseils d'arrondissement et des conseils généraux inaugurent en l'an virı une longue litanie de demandes d'ouverture de cours d'accouchement ou tout au moins le rappel continuel de l'utilité de ces fondations. Ainsi dans le département de l'Aveyron où, de Saint-Affrique à Rodez en passant par Villefranche-de-Rouergue et Espalion, le cours d'accouchement s'invite dans chaque délibération ${ }^{33}$.

Soutenus par la volonté politique et dans la continuité naturelle des pratiques d'Ancien Régime, les membres du personnel médical se posent en interlocuteurs privilégiés du pouvoir gouvernemental et administratif. La Société royale de médecine ouvre la marche dès le 25 novembre 1790 avec son adresse à l'Assemblée nationale et la lecture par son fondateur Vicq d'Azyr de son Nouveau plan de constitution pour la médecine en France ${ }^{34}$ :

Elle a vu que les sages-femmes sont dépourvues, presque partout, des connaissances qui leur sont indispensables [...]. La Société de médecine propose des moyens pour remédier aux abus qu'elle dévoile. ${ }^{35}$

Quelques années plus tard, l'École de Santé de Paris, instituée en frimaire an III, annonce pour le mois de pluviôse an v l'ouverture d'un cours d'accouchement à destination des sages-femmes dans une lettre aux administrations départementales et rappelle :

Vous savez, citoyens, de quel intérêt il est pour l'humanité de répandre les connaissances d'un art dont les secours sont si utiles et si importants. L'École a dû songer dès lors aux moyens de faire participer le plus grand nombre possible d'élèves à l'instruction que leur offre le gouvernement. ${ }^{36}$

Partout en France, les anciens démonstrateurs d'accouchement ou de jeunes officiers de santé prêts à endosser ces fonctions multiplient les courriers aux administrations de département. L'officier de santé Raillard envoie le II messidor an IV un projet de cours aux administrateurs du Cher et déclare qu'il se trouverait « trop payé si [ses] efforts pouvaient contribuer au progrès de l'art, et au bien de l'humanité souffrante ». Trois ans plus tard, en pluviôse de

\footnotetext{
33. $\mathrm{AD}$ Aveyron, $\mathrm{I} \mathrm{N}_{3}{ }^{*}$ à $5^{*}$.

34. Marais de Beauchamp A., Enquêtes et documents relatifs à l'enseignement supérieur, XXVIII, Médecine et pharmacie, 1789-1803, projet de lois recueillis et publiés par A. de Beauchamp, (cité EDRES) Paris, I888, Imprimerie nationale, p. I-I58.

35. Ibid., p. I-2.

36. AD Marne, I L I248.
} 
l'an vir, l'officier de santé Mérilhon d'Angoulême annonce qu'il établira des cours chez lui si le département accepte d'encourager les futures sages-femmes à se rendre à ses démonstrations ${ }^{37}$. Dans ces correspondances, le bien de l'humanité côtoie de près l'intérêt personnel comme lorsque le chirurgien parisien Antoine Dubois adresse en mai 1793 une lettre circulaire aux directoires départementaux pour vanter les qualités d'un mannequin de démonstration qu'il a mis au point et qui est, d'après lui, utilisé avec bonheur par tous ses disciples dans le cadre des cours qu'ils dirigent ${ }^{38}$. L'enthousiasme des années 1770-1780 pour la direction des cours d'accouchement ${ }^{39}$, la mise en valeur astucieuse des publications et inventions pédagogiques perdurent sous la Révolution qui offre au personnel médical les mêmes possibilités de manifester son intérêt pour la formation obstétricale.

Dès le début de la période révolutionnaire et tout au long de celle-ci (Consulat inclus), le discours sur la nécessité de l'instruction des sages-femmes fleurit, signe d'une redécouverte des besoins de la population en matière d'encadrement de l'accouchement, à laquelle s'ajoute un regard nouveau porté sur l'enfant à naître, futur citoyen ${ }^{40}$. Les espoirs portés par le nouveau régime imposent de faire aussi bien que la ci-devant administration dans la dénonciation des lacunes de l'art des accouchements et dans les remèdes à y apporter, voire de ne pas hésiter devant la surenchère verbale.

\section{Trame, fil et navette : le tissage d'un discours}

\section{Matrones, sages-femmes, accoucheuses : flou du vocabulaire et sévérité du jugement}

Les années 1770-I850 correspondent à un temps de flottement dans la désignation de l'auxiliaire féminine de l'accouchement alors que le discours se polarise sur deux figures antagonistes : la mauvaise et la bonne praticienne de l'accouchement. La production lexicographique, littéraire et documentaire du temps propose trois termes, «accoucheuse », « matrone » et «sage-femme», dont les relations (synonymie, antonymie, hiérarchie) different en fonction du contexte d'utilisation. Les ouvrages de lexicographie permettent de suivre l'évolution

\footnotetext{
37. AD Charente, L 155 .

38. AD Bas-Rhin, I L 840, Antoine Dubois est en 1793 professeur public d'anatomie, chirurgien en chef de l'Hospice aux Écoles de chirurgie, et professeur en l'art des accouchements à Paris.

39. Gélis J., La Sage-femme ou le médecin..., op. cit., p. 123-I29.

40. Ibid., p. 221-223.
} 
d'un vocable sur le temps long, et de saisir les inflexions fines de signification et d'usage qui peuvent le toucher, comme un écho assourdi des emplois dans les documents de la pratique. Pour cette raison, le corpus retenu couvre une période volontairement large et comporte trois catégories :

- Dictionnaires de la langue française : Dictionnaire de l'Académie française (I694; I762 ; I798 ; I835); Dictionnaire universel de Furetière ${ }^{41}$; Dictionnaire critique de la langue française de Jean-François Féraud ${ }^{42}$ et Dictionnaire de la langue française de Littré ${ }^{43}$.

- Encyclopédies : Encyclopédie de Diderot et d'Alembert ${ }^{44}$ et Grand dictionnaire universel du XIX $X^{e}$ siècle de Larousse ${ }^{45}$.

- Dictionnaires de médecine : Dictionnaire de chirurgie de Le Vacher $(1767)^{46}$, l'Encyclopédie méthodique (1787-I830) ${ }^{47}$; Dictionnaire des sciences médicales édité par Panckoucke à partir de $1812^{48}$; Dictionnaire des termes de médecine, chirurgie, art vétérinaire, etc., dirigé par Bégin en $1823^{49}$; Dictionnaire de médecine, de chirurgie, de pharmacie, des sciences accessoires et de l'art vétérinaire de Nysten (éditions de I 833 et I855) ${ }^{50}$ et Dictionnaire de médecine usuelle de Beaude (I849) ${ }^{51}$.

La recherche au sein de ce corpus s'est limitée aux trois termes évoqués plus haut (accoucheuse, matrone, sage-femme) ${ }^{52}$. Ils se sont révélés présents de manière inégale dans le corpus. L'article « sage-femme » bénéficie toujours d'une entrée, quel que soit l'ouvrage considéré, tandis que le terme " accoucheuse »

4I. Furetière A., Dictionnaire universel, contenant généralement tous les mots françois tant vieux que modernes, et les termes de toutes les sciences et des arts, La Haye, A. et R. Leers, I69o.

42. Féraud J.-F., Dictionnaire critique de la langue française, Marseille, Mossy, I787-I788.

43. Littré É., Dictionnaire de la langue française, Paris, L. Hachette, I873-1874.

44. Diderot D., Alembert J. Le Rond (d'), Encyclopédie..., op. cit.

45. Larousse P., Grand dictionnaire universel du XIX $x^{e}$ siècle : français, historique, géographique, mythologique, bibliographique..., Paris, Administration du Grand dictionnaire universel, I866-I877.

46. Le Vacher de la Feutrie T., Moysant F., La Macellerie, Dictionnaire de chirurgie, Paris, Lacombe, 1767 .

47. Société de médecins, Encyclopédie méthodique, médecine, Paris, Panckoucke, 1787-1830.

48. Société de médecins et de chirurgiens, Dictionnaire des sciences médicales, Paris, Panckoucke, I812-I822.

49. Bégin L.-J., et al., Dictionnaire des termes de médecine, chirurgie, art vétérinaire, pharmacie, histoire naturelle, botanique, physique, chimie, etc., Paris, Crevot, Béchet, Baillière, 1823.

50. Nysten P.-H., et al., Dictionnaire de médecine, de chirurgie, de pharmacie, des sciences accessoires et de l'art vétérinaire, Paris, J. S. Chaudé/Montpellier, Sévalle, I833 ; Nysten P.-H., Littré É., Robin C., Dictionnaire de médecine, de chirurgie, de pharmacie, des sciences accessoires et de l'art vétérinaire, Paris, J.-B. Baillière, I855.

5I. Beaude J.-P., Dictionnaire de médecine usuelle, 2 tomes, Paris, Didier, I849.

52. L'usage d'autres termes est rarissime, à l'unique exception du terme « tatonneuse », AD Isère, $\mathrm{L} 532$. 
est parfois couplé au terme "accoucheur »(Furetière, Dictionnaire de l'Académie française à partir de sa $5^{\mathrm{e}}$ version de 1835 , Littré, Larousse) ou absent (Beaude). Quant au terme «matrone », il fait en général l'objet d'une entrée, à l'exception du Dictionnaire critique de la langue française de Féraud et du Dictionnaire de médecine usuelle de Beaude. Le Dictionnaire de chirurgie de Le Vacher se contente pour sa part de renvoyer des termes « accoucheuse » et « matrone » vers celui de « sage-femme », sans autre forme de définition. Les renvois pour plus ample information se rencontrent plutôt dans les ouvrages de type encyclopédique : ainsi à la fin de l'article «matrone » de l'Encyclopédie de Diderot et d'Alembert vers l'article «sage-femme », de même qu'à la fin de l'article « accoucheuse » de l'Encyclopédie méthodique ${ }^{53}$; mais les dictionnaires y ont aussi recours : renvoi à l'article « accoucheur » pour « accoucheuse » dans le Dictionnaire de Féraud, ou encore complément de l'article « accoucheuse » par l'article "sage-femme » dans le Dictionnaire des sciences médicales et le Dictionnaire de médecine de Pierre-Hubert Nysten (première édition).

L'explication du mot pose des équivalences de signification qui fonctionnent en priorité de « matrone » vers « sage-femme » (Furetière, Dictionnaires de l'Académie, Bégin, Nysten, Larousse) et plus rarement de « matrone » vers " accoucheuse » (Bégin et Nysten). L'équivalence « accoucheuse »/《sagefemme », soit l'emploi du premier pour définir le second, est moins fréquente (Le Vacher, Féraud), tandis que le recours à « matrone » pour définir « sagefemme » n'est présent que chez Furetière au tout début de la période. La prééminence du vocable « sage-femme » apparaît nettement. D'un point de vue qualitatif, les mentions d'histoire de l'usage linguistique tendent quasiment toutes à faire du terme « sage-femme » la référence courante et contemporaine de la rédaction, réduisant l'usage d' " accoucheuse » et de "matrone » à une pratique obsolète ou spécialisée (juridique en l'occurrence dans ce second cas) :

Accoucheuse : on dit plutost sage-femme (Académie, 1694 ; Encyclopédie); on dit plus communément sage-femme (Académie, I762 et suivantes, Féraud) ; le mot sage-femme, qui est synonyme, est plus usité (Nysten, I833); on dit plus souvent sage-femme (Nysten, I855); on dit plus ordinairement sage-femme (Larousse).

Matrone : est aussi le nom de celle qu'on appelle proprement sage-femme (Furetière) ; qu'on appelle vulgairement sage-femme (Encyclopédie); un usage assez ancien a fait succéder en France au nom de matrone, celui de sage-femme

53. Dans ce dernier cas, le développement explicatif prend place dans l'article intermédiaire " matrones, sages-femmes, accoucheuses », paru en I808, presque vingt ans avant la parution de l'article «sage-femme». 
(Encyclopédie méthodique); il n'a d'usage qu'en termes de pratique (Académie, I762 et I798) ; aujourd'hui, il n'est plus guère usité qu'en termes de pratique (Dictionnaire des sciences médicales, Panckoucke).

La hiérarchie lexicale place donc la sage-femme au-dessus de la matrone et, au bout du compte, au-dessus de l'accoucheuse. Le statut de ce dernier terme n'est cependant pas aussi tranché et l'usage comme sa fixation normative hésitent entre infériorité et stricte équivalence avec «sage-femme ». «Accoucheuse » correspond autant à une fonction qu'à une profession, comme le rappelait en I788 le cahier de doléances d'Aups (sénéchaussée de Draguignan) : « qu'il ne soit permis à aucune sage-femme d'exercer la délicate fonction d'accoucheuse sans avoir fait un cours d'accouchement ${ }^{54}{ }_{\text {. }}$ À ce titre, le mot revêt une certaine neutralité qui pousse le rédacteur de l'article dans le Dictionnaire des sciences médicales à déclarer : "Ce nom convient mieux que sage-femme ou matrone à celle qui assiste la femme pendant le travail et qui donne les premiers soins à l'enfant. »Cette préférence n'est pas isolée puisque la motion d'ordre présentée au Conseil des Cinq-Cents par le député de la Creuse, Jean-François Baraillon, le I4 nivôse de l'an $\mathrm{v}$, sur les établissements relatifs à l'art de guérir, le mode d'admission du personnel médical et la police de la médecine, n'emploie que le terme accoucheuse ${ }^{55}$. Quelle explication donner à cette tentative de substitution lexicale ? Rapprocher la dénomination féminine de la dénomination masculine a pu manifester la volonté de relever le prestige de la profession, ou de subordonner plus étroitement les accoucheuses aux accoucheurs devenus officiers de santé en imposant un nom que les sages-femmes n'utilisent en général pas pour se désigner.

Qu'en est-il alors de la matrone? Qu'en est-il surtout de la comparaison entre norme et pratique? Au corpus lexicographique correspond un corpus documentaire composé d'une part d'extraits des cahiers de doléances de I788-1789 et d'autre part d'un ensemble de textes rédigés entre 1790 et $1803^{56}$.

54. Cabiers de doléances des communautés de la sénéchaussée de Draguignan..., op. cit., p. 50.

55. Motion d'ordre de Jean-François Baraillon, séance du I4 nivôse an v (3 janvier I797), EDRES, op. cit., p. $222 \mathrm{sq}$.

56. Ces extraits sont au nombre de 28 entre 1790 et février 1803 . Ils émanent de députés au Corps législatif (2, Creuse et Haute-Garonne), de la Société royale de médecine (I), du ministre de l'Intérieur (I), d'administrations centrales de départements (6, Cantal, Ille-et-Vilaine, Gers, Côted'Or, Rhône, Isère), de conseil général de département (I, Lozère), d'administrations de districts (5, Aurillac, Mauriac et Saint-Flour dans le Cantal, Saint-Marcellin dans l'Isère, Dinan dans les Côtes-du-Nord), d'administrations municipales (2, Saint-Georges d'Espéranche dans l'Isère, Dôle dans le Jura), de préfets (I, Ariège), enfin, de médecins et de chirurgiens ( 9 , Icart du Tarn, Dubois des Côtes-du-Nord et du Finistère, Bonnieu des Côtes-du-Nord, Raillard du Cher, Mahé d'Ille-etVilaine, Bonnet de l'Aude, Pilhès de l'Ariège). 
Ces extraits s'inscrivent dans une rhétorique de dénonciation des manques obstétricaux et des abus dans ce domaine pour réclamer la mise en place d'un enseignement. C'est le visage sombre de l'auxiliaire de l'accouchement qui est ici présenté.

Le résultat de l'enquête sur " matrone » dans le groupe des dictionnaires a abouti à une appréciation plutôt neutre du vocable. Assez tôt vieilli, et cantonné dans une utilisation renvoyant à l'expertise judiciaire (vérification de la virginité, de la grossesse ou de l'impuissance masculine), il n'est jamais négativement connoté et bénéficie même, dans l'article «matrones, sages-femmes, accoucheuses » de l'Encyclopédie méthodique, d'une présentation positive :

Ces femmes qui par état facilitent l'accouchement, assistent les femmes en couches, reçoivent les enfants à leur naissance, ont reçu chez tous les peuples un nom qui annonce assez le haut degré de considération dont ont joui celles de ces sages-femmes qui ont mérité la confiance publique. Chez les Grecs, on les appelait maia iatrina, mère médecin ; chez les Espagnols, comadre ou partera, commère, seconde mère ou accoucheuse ; en France, matrones, dames ou mères $[\ldots]$.

À l'inverse, c'est l'accoucheuse qui fait l'objet de l'anathème le plus féroce dans l'article de l'Encyclopédie qui dénonce, en reprenant les propos de Boerhaave, son imprudence et sa témérité, et n'hésite pas à rapporter le propos de La Mettrie selon lequel « il vaudroit mieux pour les femmes qu'il n'y eût point d'accoucheuses ».

Le corpus documentaire fait en revanche clairement apparaître une utilisation négativement connotée du terme « matrone ». Absent des cahiers de doléances dont la vocation est plus prescriptive que descriptive, il apparaît à neuf reprises dans l'ensemble d'extraits à partir de 1790, toujours associé à un adjectif dépréciatif ou à un récit critique :

[...] les suites ont été funestes par la mauvaise manœuvre des matrones $(1792)^{57}$; quelque matrone dont l'ignorance dans cette partie saisit de crainte $(\mathrm{I} 792)^{58}$; comme l'ignorance est toujours présomptueuse, les matrones de nos jours ne doutent de rien $(\mathrm{an} \mathrm{II})^{59}$; des matrones ygnorantes $(\mathrm{an} \mathrm{IV})^{60}$;

57. AD Isère, L 532 .

58. AD Cantal, L 587 .

59. AD Côtes-d'Armor, I L 594.

60. AD Cher, I L 625 . 
les mains meurtrières des matrones $(\mathrm{an} \mathrm{VI})^{61}$; l'impéritie de la plupart des matrones $(\mathrm{an} \mathrm{VI})^{62}$; l'ignorance de nos matrones $(\mathrm{an} \mathrm{x})^{63}$.

Cette récurrence dessine le fossé qui commence à se creuser entre «sagefemme » et « matrone », mais ce fossé est encore mouvant et les occurrences du terme « sage-femme » sont aussi, dans 15 cas sur 17 , associées à une qualification péjorative $^{64}$.

Une évolution semble pourtant se faire jour dans l'usage de la dénomination de "sage-femme ». L'instruction est devenue un point de référence, comme le rappelle cette lettre du président de l'administration départementale de l'Isère :

Je dois vous faire observer que vous ne devez comprendre dans ce tableau que les sages-femmes qui ont suivi les cours d'accouchement, et non celles qui n'ont pour principes qu'une routine aveugle et imprévoyante [...]. ${ }^{65}$

Des nuances viennent compléter le terme pour différencier l'idéal de la réalité défaillante. Préciser l'origine rurale de la sage-femme amoindrit d'emblée la valeur de la personne évoquée. Se lit souvent aussi l'idée d'usurpation de fonction dans la désignation de la sage-femme : "soi-disant sages-femmes ${ }^{66}$ », "matrones, qui sous le nom de sages-femmes ${ }^{67}$ », « certaines femmes qui sans titre se donnent pour accoucheuses ${ }^{68}$ » (terme relayé par « sage-femme » dans le même paragraphe), etc. La période qui suit la loi sur l'exercice de la médecine du I9 ventôse an XI (1803) voit perdurer ces formulations : " prétendues sagesfemmes ${ }^{69}$ » (1808), « celles qu' on nomme très improprement sages-femmes ${ }^{70}$ » (1834). Mais la clé de cette évolution linguistique réside dans ce tournant normatif de l'an XI qui sanctionne le choix officiel et définitif d'un terme, "sagefemme », au détriment des deux autres. La pratique lexicale subit dès lors une inflexion forcée puisque «sage-femme » n'est plus seulement un nom de métier, sujet à variations éventuelles, mais un titre qui porte la reconnaissance

\footnotetext{
61. AD Ille-et-Vilaine, L 965.

62. AD Rhône, I L 531.

63. AD Lozère, i $\mathrm{N}$ io3*.

64. L'autodésignation par le terme " matrone », rare, existe cependant : Gabrielle Gouïvou Dupluvinage signe en I79I « matrone de Lesneven », AD Finistère, Io L I63.

65. AD Isère, $\mathrm{L}$ i27.

66. AD Côte-d'Or, L 542.

67. AD Rhône, I L 53I.

68. AN, Fi7/2462, Jura.

69. AN, Fi7/2457, Ariège.

70. AD Alpes-de-Haute-Provence, 5 M 6.
} 
légale d'une formation et le droit exclusif à l'exercice d'une profession. La ligne de démarcation entre matrone et sage-femme passe au cœur de l'article $35 \mathrm{du}$ titre VI :

Six mois après la publication de la présente loi tout individu qui continuerait d'exercer la médecine ou la chirurgie, ou de pratiquer l'art des accouchements, sans être sur les listes, dont il est parlé aux articles 25,26 et 34, et sans avoir de diplôme, de certificat ou de lettre de réception, sera poursuivi et condamné à une amende pécuniaire envers les hospices.

\section{Routine et impéritie, aux deux sources du discours dénonciateur}

La dénonciation des accoucheuses se situe dans la stricte continuité des textes d'Ancien Régime ${ }^{71}$. De ce point de vue, le tournant des XVIII ${ }^{\mathrm{e}}$ et $\mathrm{XIX}^{\mathrm{e}}$ siècles n'invente rien, il amplifie un discours antérieur porté par le corps médical et chirurgical et permet à une nouvelle catégorie d'auteurs de s'en saisir : les administrateurs. Les attaques contre l'incompétence des sages-femmes ne sont pas neuves et, à la différence de ce qui se produit au cours du XviII ${ }^{\mathrm{e}}$ siècle et de ce qui perdure au-delà, elles ne font, entre les $\mathrm{XV}^{\mathrm{e}}$ et $\mathrm{XVII}{ }^{\mathrm{e}}$ siècles, aucune distinction entre accoucheuses formées ou non formées, englobant l'ensemble des auxiliaires féminines de l'accouchement dans une même critique et réproba$\operatorname{tion}^{72}$. L'exemple de Louise Bourgeois, sage-femme de Marie de Médicis, victime d'une cabale de chirurgiens qui l'accusent d'ignorance et d'incurie après la mort en couches de Marie de Montpensier en I627, montre à quel point même un office prestigieux ne suffisait pas à protéger les sages-femmes des critiques ${ }^{73}$. Ces critiques se perpétuent et se précisent dans le courant du Xviri ${ }^{e}$ siècle. Dans les années 1780-1790, des thématiques récurrentes scandent le propos des administrateurs et des hommes de l'art. Trois grands types de discours peuvent être mis en lumière qui se recoupent parfois ou se complètent : le discours stéréotypé fonctionnant par formules toutes faites, la rhétorique doloriste et enfin l'argumentaire pragmatique refusant de céder à la tentation du pathos.

71. Gélis J., La Sage-femme ou le médecin..., op. cit., p. IO2 sq.; Laget M., Naissances..., op. cit.

72. Voir par exemple Chalk D. L., "Savior, Witness, and Comic Relief : The Midwife in English Texts of the Fifteenth and Sixteenth Centuries", Studies in Philology, 2015, vol, II2, n I, p. 93-I13 ; Pulz W., «Aux origines de l'obstétrique moderne... », art. cit.

73. Gélis J., « Louise Bourgeois (1563-1636). Une sage-femme entre deux mondes », art. cit. ; Perkins W., Midwifery and Medicine in Early Modern France, Louise Bourgeois, Exeter, University of Exeter Press, 1996. 
Dans la dénonciation des déviances de l'art des accouchements, les formules sont répétitives, incantatoires : "impéritie meurtrière », "routine aveugle », « coupable ignorance » ou « affreuse témérité » reviennent encore et toujours, reprenant quasiment sans modification le formulaire du " procès des sagesfemmes » décrit pour le XVIII ${ }^{\mathrm{e}}$ siècle $^{74}$. Le discours qu'elles construisent semble dès lors tourner partiellement à vide. Mais cette première lecture ne peut toutefois laisser de côté quelques évolutions quantitativement mineures mais significatives. La classification thématique établie par l'historienne Mireille Laget comprenait, pour ce qui relève des accoucheuses elles-mêmes, le vocabulaire de l'incapacité, de la violence et de la méchanceté, ce dernier très socialement connoté par l'appartenance au «bas peuple». Le corpus documentaire de la période révolutionnaire réactive les deux premières thématiques en laissant de côté la dernière, qui n'est plus de mise après 1789. L'origine sociale des sagesfemmes, qui n'évolue pas fondamentalement, ne peut plus faire l'objet d'une dénonciation en tant que telle, à travers la stigmatisation de défauts physiques et moraux comme la grossièreté, la lourdeur physique et mentale ou la laideur. À ce titre, le discours révolutionnaire est sans doute plus pragmatique et moins lyrique que ses prédécesseurs.

Cette transformation des sensibilités s'exprime dans la coexistence de deux tendances du discours médico-administratif : la déploration détaillée des accouchements malheureux et l'hésitation devant ce recours à l'émotion et à l'indignation faciles. La première tendance s'inscrit dans une longue généalogie du récit horrifique, du pamphlet anglais anonyme de 175I, The Petition of the Unborn Babies, à sa reprise par le chirurgien Icart de Castres en 178I sous le titre de la Requête pour les enfants à naître ${ }^{75}$. Les mémoires qui parviennent aux intendants et à la Société royale de médecine pendant la décennie 1780 en sont d'autres exemples ${ }^{76}$. Certains médecins et chirurgiens poursuivent dans cette voie sous la Révolution. Dans son Mémoire sur l'établissement des cours gratuits d'accouchement pour l'instruction des sages-femmes de la campagne, adressé aux administrateurs du département du Tarn, Jean-François Icart reprend comme premier argument celui qu'il avait utilisé quelques décennies plus tôt pour justifier l'ouverture de cours d'accouchement à Castres :

74. Laget M., Naissances..., op. cit., p. 202 et 206-207.

75. Gélis J., La Sage-femme ou le médecin..., op. cit., p. 105.

76. Voir le Mémoire dans lequel on s'efforce de démontrer l'utilité de la nécessité de l'établissement d'une école de sages-femmes dans la capitale de la province de Jean-Baptiste Lamoureux, cité dans Hacquin F., Histoire de l'art des accouchements en Lorraine, des temps anciens au XX $x^{e}$ siècle, Nancy, Librairie lorraine, 1979, p. 127-134. 
Il commençait à méditer en 1764 sur les moyens les plus prompts et les plus efficaces de délivrer la patrie d'un fléau aussi dangereux que nuisible lorsque à nos portes une paisanne de Saint Amans diocèse de Lavaur implora le secours d'une matrone de son village. Cette femme trouva les pieds de l'enfant, s'en saisit, tira avec autant de force que de précipitation, la tête ne put résister à la violence des secousses et se sépara du tronc. [... Ce double assassinat pénétra le sieur Icart d'horreur. ${ }^{77}$

Quelques années plus tard, peu avant le vote de la loi de ventôse an XI, Pilhès, de l'Ariège, ancien démonstrateur, développe les mêmes images :

On les voit journellement déchirer les chairs, meurtrir les viscères, mutiler, arracher les membres et séparer la tête du corps des tendres enfans. On pourroit les peindre encore un crochet de fer à la main, instrument de douleur et de mort, cherchant au hazard dans les entrailles d'une femme éperdue le cher objet de sa tendresse qu'ils y assassinent. C'est la faulx de la mort entre les mains homicides de l'ignorance, qui frappe au milieu des ténèbres. Le nombre des victimes immolées à la brutalité de ces manœuvres a de quoi émouvoir les cœurs les moins sensibles, et fait vivement juger que l'art de secourir un être naissant, ne doit être exercé que par des personnes habiles à lui frayer un libre passage, à travers les dangers dont il est entouré. ${ }^{78}$

Certains auteurs cherchent cependant à éviter ces faciles effets de rhétorique pour poser en termes concrets le problème de la formation des sages-femmes et de ses modalités. Ce renoncement aux longues descriptions d'accouchements tragiques, aussi violentes envers les accoucheuses que généralement complaisantes envers le rôle salvateur des accoucheurs ${ }^{79}$, s'exprime toutefois de manière hésitante, comme sous la plume de Bonnet, ancien démonstrateur à Narbonne, en l'an vir ${ }^{80}$ qui commence ainsi :

Faute de connaissances sur les moyens qu'il faut mettre en œuvre pour redresser les enfants quand ils viennent mal, ne voit-on pas fréquemment des chirurgiens et sages-femmes ne faire aucune difficulté de les mutiler ? Ces destructeurs du genre humain arrachent impitoyablement les membres de ces malheureuses victimes en se servant de crochet, instrument dont le nom seul fait horreur à l'humanité.

\footnotetext{
77. AD Tarn, $\mathrm{L} 343$.

78. AN, Fi7/2457, Ariège.

79. Laget M., Naissances.., op. cit., p. 209-210.

80. AD Aude, I L 537.
} 
Puis, saisi par la pudeur, poursuit :

Il n'est que trop vrai que je pourrais rapporter des accouchements de cette nature faits par des chirurgiens ignorants même jusqu'aux principes de leur art, mais je les passe sous silence, ils ne serviraient qu'à affliger les âmes sensibles.

La principale raison avancée pour cette subite réserve est la sensibilité du lecteur que les auteurs souhaitent désormais épargner après l'avoir fortement malmenée dans les décennies précédentes. Puisque la compétence des accoucheurs n'a plus besoin, pour être reconnue, de ces narrations oscillant entre la tragédie et l'héroïsme, la répétition des récits dramatiques semble désormais n'avoir pour résultat que de provoquer le malaise chez les interlocuteurs des médecins et des chirurgiens. À l'heure où la vision de la mort et de son incarnation dans le corps malade et le corps mort se révèlent des spectacles moins stö̈quement supportés que dans le passé ${ }^{81}$, la puissance évocatrice de l'écrit risque de s'avérer contre-productive.

Dernier aspect du discours dénonciateur : l'égratignement des chirurgiens. L'accoucheur a établi sa réputation sur les ruines de celle de la sage-femme ${ }^{82}$, ce qui n'a pas empêché quelques vives réactions contre les accoucheurs incompétents, si isolées qu'elles soient par rapport aux attaques précédentes ${ }^{83}$. Les écrits de la période révolutionnaire ne consacrent pas non plus la complète apothéose du médecin ou du chirurgien accoucheur. L'intérêt précoce pour la réforme des études médicales ne met à l'abri des critiques aucune catégorie du personnel médical et, de texte en texte, une voix discrète mais tenace rappelle les lacunes de ceux qui revendiquent la prééminence dans l'exercice de l'art des accouchements. Les cahiers de doléances peignent un tableau contrasté du rôle des chirurgiens : démonstrateurs habiles et compétents d'un côté, personnages incapables à la limite du charlatanisme de l'autre ${ }^{84}$. Les remontrances et les exigences se rapprochent donc de celles observées pour les sages-femmes :

(Derchigny) La communauté, sous le même rapport, fera ses plus vives complaintes sur l'ignorance des chirurgiens de villages et désirerait que plus d'étude de leur part soit constaté pour conserver la vie des hommes. ${ }^{85}$

8I. Gélis J., «La formation des accoucheurs et des sages-femmes aux $\mathrm{XVII}^{\mathrm{e}}$ et XVIII ${ }^{\mathrm{e}}$ siècles. Évolution d'un matériel et d'une pédagogie », $A D H, 1977$, p. 168.

82. Gélis J., La Sage-femme ou le médecin..., op. cit., p. IO2 ; M. Laget, Naissances..., op. cit., p. 206.

83. Gélis J., La Sage-femme ou le médecin..., op. cit., p. I04-105.

84. Léonard J., Les Médecins de l'Ouest..., op. cit., p. 173-174 et 176.

85. Cabiers de doléances du bailliage d'Arques (secondaire de Caudebec) pour les États généraux de 1789, t. I, publiés par E. Le Parquier, Lille, 1922, CDIHÉRF, p. 194. 
Sous le Directoire, les accusations contre les chirurgiens refleurissent, portées parfois par les chirurgiens eux-mêmes. En l'an vi, le démonstrateur breton Mahé les traite de "routiniers ${ }^{86}{ }$. L'année suivante, au sud du pays, dans l'Aude, le démonstrateur Bonnet, déjà cité, souligne les irrémissibles défauts de certains de ses confrères : ignorance et cupidité ${ }^{87}$.

Moins fréquent que celui qui cloue au pilori les sages-femmes, le discours sur les chirurgiens montre néanmoins, par son existence même, la primauté de l'inquiétude populationniste sur les luttes internes du personnel médical. Mêlées aux enjeux de savoir et de pouvoir, les craintes pour l'avenir de la population française forment un socle immuable de la justification de la formation obstétricale.

\section{"Dans un pays où tous viennent au monde égaux et libres, chaque naissance est une époque importante ${ }^{88}$ »}

Le $\mathrm{xvIII}^{\mathrm{e}}$ siècle est le siècle de la découverte scientifique de la population, de ses évolutions, de la baisse redoutée à l'augmentation souhaitée ou critiquée. Y naissent aux mêmes sources d'une statistique encore balbutiante l'angoisse populationniste de Montesquieu et Damilaville et les théories de Malthus dans son Essai sur le principe de population publié pour la première fois en $1798^{89}$. Dans le même temps, en France, le discours sur la population la définit comme une source de puissance, guettée par de multiples périls ${ }^{90}$. La concomitance et l'opposition des thèses développées de part et d'autre de la Manche soulignent la prégnance de l'idéologie populationniste dans la France révolutionnaire ${ }^{91}$. Rappelant que la grandeur d'un État réside dans le nombre de ses sujets, comme l'écrivait déjà au XVII ${ }^{\mathrm{e}}$ siècle Antoine de Montchrétien ${ }^{92}$, les arguments fondamentaux se perpétuent avec des formulations identiques : « [... ] le grand

\footnotetext{
86. AD Ille-et-Vilaine, L 935.

87. AD Aude, I L 537.

88. AD Cantal, L i7.

89. Malthus T., Essai sur le principe de population, Londres, J. Johnson, 1798. Sur la postérité de la pensée malthusienne, voir Fauve-Chamoux A. (dir.), Malthus hier et aujourd'bui, Paris, Éditions du CNRS, 1984.

90. Gélis J., La Sage-femme ou le médecin..., op. cit., p. 22I.

9I. Le populationnisme est une constante des penseurs politiques de l'époque moderne en France puis, tout autant et contre l'évolution objective de la population, du $\mathrm{XIX}^{\mathrm{e}}$ et du $\mathrm{XX}^{\mathrm{e}}$ siècle.

92. Montchrétien A. (de), Traité de l'économie politique dédié en 1615 au Roi et à la Reine mère du Roi [1615], Paris, Plon, I889.
} 
nombre d'individus fait la richesse d'un état ${ }^{93} » ;$ « La population est la vraie source de la grandeur des empires ${ }^{94}$.

L'aphorisme ne résume cependant pas à lui seul la rhétorique populationniste. Celle-ci se charge d'un ensemble de notions complémentaires issues du discours révolutionnaire. L'État n'est plus, dans le discours sur l'art des accouchements, le seul objet des effets d'un abondant peuplement. À ses côtés, émerge la patrie qui unit les citoyens en un corps englobant et non plus surplombant : «[...] favoriser un établissement qui en éloignant la mort de l'enfance conserveroit des citoyens à la Patrie $[\ldots]^{95}$ »; «C'est l'art des accouchements qui fournit à la patrie des bras $[\ldots]^{96}+{ }^{\prime}$

À partir du mois de septembre I792, la République s'ajoute au concert des entités auxquelles la population vient prêter vie et force, entités qui se modifient en fonction des évolutions politiques : de l'État-royaume de la monarchie constitutionnelle à la République-patrie de la Convention puis au couple gouvernement-société du Directoire. Autre horizon privilégié et continu de ces discours, l'humanité, qui forme le cadre de l'action philanthropique portée par les Lumières. Pour tout cela, la population est instrument de pérennisation, d'enrichissement, de défense aussi. La métonymie des bras est à cet égard pleinement signifiante, qui dit le besoin productif ou militaire d'une Révolution menacée par la faim et l'Europe coalisée. L'Empire des guerres napoléoniennes offre plus tard le même visage d'un tonneau des Danaïdes de la conscription.

(Bouches-du-Weser, I8I2) Je dus être frappé du nombre effrayant de conscrits estropiés qui se présenta devant les premiers conseils de recrutement auxquels j'assistai ; je m'informai de la source d'un mal si grand dont l'humanité avait à gémir, et j’appris avec un vif chagrin, que malheureusement cette source était l'inexpérience des sages-femmes du pays [... $].{ }^{97}$

À tous ces besoins répondent les pertes au berceau que les auteurs n'hésitent pas à chiffrer à l'émotion, jonglant avec les milliers ou les dizaines de milliers de morts, selon une habitude ancienne $e^{98}$ :

(Icart, 1790) [... ] forcé de calculer le nombre de mères et beaucoup plus d'enfans qui périssent anuellement par leurs mains, le sieur Icart n'a pu voir sans

\footnotetext{
93. AD Gers, L 280.

94. AD Cantal, L i7.

95. AD Doubs, $\mathrm{L}_{1343 .}$

96. $\mathrm{AD}$ Isère, $\mathrm{L} 532$.

97. AN, $\mathrm{F}_{7} / 2457$, Bouches-du-Weser.

98. Gélis J., La Sage-femme ou le médecin..., op. cit., p. IO3.
} 
frémir que par l'aproximation la moins hazardée il devoit la porter annuellement dans le royaume de vingt cinq à trente mille. ${ }^{99}$

(Dubois, I790) Le suppliant a observé qu'il périssait au moins par chaque paroisse l'une portant l'autre dix individus par an, tant de mères que d'enfants, ce qui fait environ quinze mille sujets dont la Bretagne se voit privée, triste calcul pour des âmes sensibles. ${ }^{100}$

Lorsque l'expertise de l'homme de l'art local ne semble pas suffire, c'est à l'Europe démographe et médicale que l'auteur fait appel, ainsi Eyméoud, chirurgien dans les Hautes-Alpes :

S'il falloit accumuler des preuves sur des faits déjà trop certains, il suffiroit, Messieurs, de vous rappeler les travaux de plusieurs sçavans de l'Europe amis de l'humanité, qui se sont fortement élevés contre les abus de ce genre et ont prouvé par des observations exactes qu'il meurt près de la moitié des enfans par l'ignorance des sages-femmes de la campagne et que par la même raison, il meurt aussi beaucoup plus de femmes que d'hommes, toutes choses égales d'ailleurs. ${ }^{101}$

En convoquant au banc des arguments une foule de victimes, l'accusateur sait qu'il ne peut laisser son lecteur indifférent. Pourtant cette lamentation du malheur collectif ne doit pas occulter l'émergence tout aussi nette d'une préoccupation pour l'individu justifiant d'autant plus la politique à mettre en œuvre. La rhétorique révolutionnaire définit l'être humain comme une métonymie de la patrie, mais elle le définit aussi d'un point de vue relationnel, pris dans un réseau familial et social, approfondissant un motif antérieur. Le chirurgien Desfarges voyait en 1786 dans la femme enceinte, l'épouse, la fille et la future mère ${ }^{102}$. À son instar, hommes de l'art et administrateurs des décennies révolutionnaires rappellent que dans la parturiente qui succombe se trouve une mère, mère d'enfants déjà nés ou de celui en train de naître, nécessaire rempart d'un être en devenir : "Alors seulement on ne voiera plus les femmes lutter plusieurs jours contre les douleurs de l'enfantement, y succomber le plus souvent sans donner le jour à l'être prétieux qui devait lui donner le doux nom de mère $[\ldots]^{103}$, »

\footnotetext{
99. AD Tarn, L 343 .

Ioo. AD Finistère, io L 163 .

IOI. AD Hautes-Alpes, L I062.

I02. Sage Pranchère N., «Étude comparée de deux projets de cours d'accouchement... », art. cit., p. 39-40.

I03. AD Côtes-d'Armor, I L 594 .
} 
Mais à côté de la mère, pilier de la famille, se tient « l'épouse chérie », pilier du couple. La vision romanesque de l'amour conjugal est passée par là, qui place l'harmonie affective dans le mariage comme garante de la stabilité de la société. La mort en couches et le deuil parfois inconsolable des veufs ${ }^{104}$, mais tout autant l'infirmité des suites de couches et ses répercussions sur la vie intime des couples sont des éléments de malheur personnel et de désordre familial et social : « $[\ldots]$ ou bien n'échapper aux tourments de leurs bourreaux, qu'accablées d'infirmités souvent dégoûtantes, qui écartent des ménages l'amour et la paix, troublent l'ordre et l'harmonie de la société $[\ldots]^{105} »$.

Mère, épouse, citoyenne bien sûr, dont la fécondité appelle la bienveillance de l'État. L'enfant naissant n'est pas en reste, lui aussi pris au cour d'une dense toile familiale, « bon fils, bon mari, bon frère, bon père ${ }^{106}$ ». Mais aussi .. « bon citoyen ${ }^{107}$ », et à ce titre plus déjà que «bras » au service de la République. Avant le resserrement du Code civil qui fonde la famille comme cellule de la société, la désignation de l'enfant comme citoyen constitue l'atome de la construction révolutionnaire, irréductible et indispensable. L'égalité devant la loi légitime l'individu et son droit à survivre à sa naissance, elle impose des devoirs à ses concitoyens et plus encore à ceux qui sont en charge de l'administration révolutionnaire ou du soin médical : « toutes les fois que cette main aura sauvé la mère et l'enfant, elle aura bien mérité de la patrie ${ }^{108} »$. Les images qui fleurissent dans les procès-verbaux d'assemblée départementale présentent le corps social mais n'en oublient pas la cellule primordiale et affirment son égale importance : «[... combien les administrateurs citoyens doivent-ils protéger l'homme dans sa personne, surtout au moment où il arrive au port de la vie ! ${ }^{109} »$

I04. Voir l'exemple de Louis Simon, évoqué par É. Arnoul, « La vie sans elle. Veuvage et solitude des hommes dans la France moderne », Bardet J.-P., Arnoul É., Ruggiu F.-J. (dir.), Les écrits du for privé en Europe (du Moyen Âge à l'époque contemporaine). Enquêtes, Analyses, Publications, Bordeaux, Presses Universitaires de Bordeaux, 2010, p. 207-225.

105. AD Côtes-d'Armor, I L 594.

Io6. $\mathrm{AD}$ Cantal, $\mathrm{L} 488$.

I07. Ibid.

108. AD Cantal, L 17.

I09. Ibid., L 488. 


\section{"C'est d'elles que dépendent souvent la santé et la vie d'un grand nombre d'individus ${ }^{110}{ }$ '}

\section{La mesure d'une ambition : le choix de la sage-femme}

Faire naître, et plus encore faire naître pour faire vivre, l'objectif est clairement exprimé. Former des sages-femmes capables de mener au «port de la vie » l'enfant en train de naître, la solution semble évidente. La réalité de l'enseignement obstétrical l'est cependant bien moins.

Quelques voix troublent la concorde qui s'est quasiment établie sur la légitimité et la pertinence du choix des sages-femmes pour encadrer l'accouchement. Au cœur du département du Cantal, des doutes s'élèvent lors du conseil de district de Saint-Flour en octobre $1792{ }^{111}$. En décembre précédent, l'assemblée du département réunie à Aurillac a fermement déclaré : «On n’a sans doute pas besoin de grands raisonnements pour faire sentir la nécessité d'avoir des sages-femmes expérimentées ». À Saint-Flour pourtant, le rapporteur du projet d'instaurer dans chaque district un cours d'accouchement pour les sagesfemmes développe une argumentation discordante en s'interrogeant sur trois « inconvénients » du projet : l'exclusivité accordée aux femmes dans le domaine des accouchements, la durée des cours et la rémunération des sages-femmes. L'argumentation se veut concrète et pointe des difficultés supposées insurmontables. Première difficulté et non des moindres :

Le premier [inconvénient] est relatif à la préférence exclusive qu'on donne aux sages-femmes sur des chirurgiens accoucheurs, et cela pour succomber à la modestie des femmes [...]. Hors, citoyens, je ne crois pas que dans nos campagnes qui sont couvertes de trois pieds de neige, pendant six mois au moins, des femmes puissent apporter aux malheureuses qui sont en travail d'accouchement des secours pressants dont elles auraient besoin ; j'ajouterai à cela que des accouchements laborieux exigent une consistance morale et un caractère qu'on trouve rarement chez les femmes.

Le motif climatique avancé ici, difficilement contestable en soi, l'est en revanche beaucoup plus appliqué aux seules sages-femmes, car l'inaccessibilité de certains villages pendant les mois d'hiver fait obstacle à tous, indifféremment. Le premier argument, assurément insuffisant, sert de marchepied à l'idée suivante : l'incapacité féminine à opérer un accouchement laborieux.

IIO. AD Haut-Rhin, L 127.

III. AD Cantal, L 587 . 
La concession de l'adverbe « rarement » vient renforcer le caractère générique et définitif de l'assertion : les femmes n'ont pas la force morale pour faire face à un accouchement qui tourne mal. Le déplacement de la critique de l'inaptitude pratique et éventuellement physique de la sage-femme vers celle d'une lacune morale donne à cet argument une très grande force. Après avoir rapidement évincé l'argument de décence, l'auteur affirme donc que, pas plus qu'elle n'est une garantie de respect de la moralité, l'accoucheuse n'est une garantie de confrontation sereine à l'extraordinaire susceptible de surgir au cours de la parturition, toutes qualités définies en creux comme intrinsèquement masculines. Pire que le défaut de force physique auquel l'habilité peut suppléer, pire que l'ignorance, mère d'impéritie, qu'un enseignement et une pratique préparatoires peuvent pallier, pire encore que l'absence de principes moraux que la parole pastorale peut inculquer, la faiblesse d'esprit disqualifie sans retour la gent féminine pour l'exercice de l'art des accouchements. Mettre une femme enceinte entre les mains d'une autre femme est un aveu d'impuissance, au mieux un pis-aller temporaire : «[... ] dans tous les cas, vous devez presser l'exécution de l'arrêté du ro septembre I79I [...] qu'on puisse bientôt jouir des avantages que cet établissement peut nous permettre, quoiqu'il n'emporte pas avec lui tous ceux qu'on pourrait désirer $»$.

En 1787 , l'article « accoucheuse » paru dans l'Encyclopédie méthodique partait de postulats proches, sans aboutir cependant à une conclusion aussi radicale :

[...] nous ne pouvons pas passer sous silence quelques inconvénients qui résultent de permettre l'art des accouchements aux sages-femmes. Les personnes instruites savent qu'il est des circonstances où l'accouchement, qui présentait un travail facile dans son commencement, devient très dangereux, et ne peut être terminé que par des opérations délicates, qui exigent toute la capacité d'un habile chirurgien. ${ }^{112}$

La différence de compétences est au cœur de la démonstration, mais la mention de l'habileté du chirurgien, qui introduit la notion de talent au sens de qualité personnelle mi-innée, mi-acquise, s'inscrit dans une logique de valorisation de cette figure plutôt que de dessaisissement de la sage-femme à l'inverse de ce que fait le rapporteur de Saint-Flour cinq ans plus tard.

II2. Société de médecins, Encyclopédie méthodique, médecine, op. cit., t. I, article « accoucheuse », p. 86 . 


\section{Seconde difficulté identifiée par l'élu départemental :}

Je trouve un second inconvénient dans l'intervalle trop long qu'on met entre les instructions annuelles qu'on se propose de donner aux élèves. La plupart de ces élèves ne sauront simplement que lire, elles viendront pendant quatre mois recevoir quelques principes qu'elles comprendront à peine la première année, et elles reviendront ensuite pendant huit mois vaquer à leurs occupations ordinaires, et oublier vraisemblablement tout ce qu'elles auront appris, d'où il résultera que chaque année elles seront nouvelles, que chaque année, elles quitteront l'école sans être assez instruites. ${ }^{113}$

Les ruptures dans la continuité de l'enseignement fournissent une raison de remettre en cause le système d'enseignement proposé. La durée choisie pour le cours, quatre mois, n'est pas incriminée ${ }^{114}$ mais rapportée à trois autres éléments.

Premier élément : le niveau d'instruction primaire des futures élèves sagesfemmes de Basse-Auvergne où le pourcentage des femmes maitrisant lecture et écriture reste faible en cette fin de XVIII ${ }^{e}$ siècle $^{115}$. Penser qu'elles savent lire est même redoutablement optimiste. Au manque d'instruction s'ajoute, second élément, le défaut de compréhension, d'une gravité sans commune mesure avec le fait de ne pas savoir lire ou écrire. En un mot, ces femmes ont la tête dure et l'organisation prévue de la formation par répétition annuelle d'un cours de quatre mois, troisième élément, s'apprête à alimenter un cercle vicieux de l'inaptitude et donc de l'inutilité de l'enseignement.

Troisième difficulté :

Il existera encore toujours un troisième inconvénient si ces sages-femmes n'ont pas un salaire public [... ] car citoyens, ne pensez pas que s'il arrive tant de malheurs dans ce genre dans les campagnes, ce soit à défaut de secours : [... ] c'est parce que le paysan épuisé plaint la dépense pour soulager sa malheureuse compagne, et s'il est obligé de payer la sage-femme, il la laissera dans le péril comme auparavant.

I13. AD Cantal, L 587 .

II4. Elle s'inscrit dans une moyenne plutôt haute des formations destinées aux accoucheuses. Dans la Corrèze voisine, le cours de janvier 1789 ne dure qu'un mois, et lorsque le préfet Joseph de Verneilh-Puyraseau décide en germinal an $\mathrm{x}$ de refonder un cours d'accouchement, il lui assigne une durée de deux mois, voir Sage Pranchère N., Mettre au monde..., op. cit., p. I45.

II5. Le taux de signatures des femmes au mariage relevé pour le département du Cantal entre 1786 et 1790 est entre Io et $20 \%$, ce qui constitue un bon indicateur des lacunes d'instruction primaire de cette région, voir Furet F., Ozouf J., Lire et écrire, l'alphabétisation des Français de Calvin à Jules Ferry, Paris, Seuil, I99I, p. 60. 
L'argument met en cause les conditions mêmes d'exercice de l'art des accouchements par les sages-femmes. Selon une perspective intéressante, la sagefemme ne peut qu'être au service du public, pour la bonne et simple raison qu'elle ne peut vivre de son métier en réclamant des honoraires. Là où les honoraires du chirurgien sont perçus comme une rémunération normale, ceux de la sagefemme constituent une innovation inadmissible pour une population particulièrement pauvre. À travers la sage-femme devenue instrument de santé publique, c'est donc la communauté qui doit pourvoir au bien-être de ses membres.

Les inconvénients soulevés par l'élu de Saint-Flour se complètent et s'entremêlent pour composer le tableau d'une sage-femme par défaut, agent sanitaire temporaire, prompt à endosser tous les vices reprochés aux accoucheuses sans principe. Ils répondent aux « inconvénients » du rédacteur de l'article « accoucheuse » de l'Encyclopédie méthodique en forçant davantage le trait.

Qu'en est-il de leur réception ? Premièrement, l'argumentation développée par le rapporteur de Saint-Flour est unique à cette période du moins, dans ce type spécifique de prose que sont les procès-verbaux de délibérations d'assemblées civiles. Deuxièmement, le débat qui a suivi les remarques du rapporteur n'a pas été transcrit, selon l'habitude de l'époque ${ }^{116}$, mais quelques jours plus tard, le 6 octobre 1792, le conseil de district a mis en forme sa délibération de la manière suivante :

Après une légère discussion sur cette matière, le conseil considérant $\mathrm{I}^{\circ}$ qu il est très difficile de voyager dans nos campagnes pendant l'hiver, que la délicatesse du tempérament des femmes s'opposera souvent à ce qu'elles puissent apporter les secours nécessaires aux femmes en couche, et qu'il est cependant instant pour l'humanité souffrante de vaincre tous ces obstacles, en rapprochant les secours autant que les localités pourront le permettre ; $2^{\circ}$ que l'intervalle déterminé entre les instructions annuelles est trop long, qu'il expose les élèves à oublier tout ce qu'elles pourront avoir appris ; $3^{\circ}$ qu'il serait à propos que les sagesfemmes fussent salariées pour pouvoir secourir gratuitement les indigentes $[\ldots]$.

Les trois critiques du rapporteur sont reprises, mais apparaissent désormais sous forme d'«observations », tel est le terme employé, préalables à la déclaration finale qui invite le conseil de l'assemblée départementale à les "peser dans sa sagesse » et à mettre en œuvre le projet de cours d'accouchement « qui promet des avantages aussi essentiels à l'humanité ». Toutes diplomatiques qu'elles soient, les formules rappellent que l'arrêté proposant le cours par arrondissement n'a pas emporté l'unanimité des avis. Pourtant, du rapport à

II6. Il faut attendre I87I pour commencer à rencontrer dans les procès-verbaux de délibérations de conseils généraux la transcription partielle ou in extenso des débats. 
la délibération, la dimension la plus radicale des « inconvénients » a disparu. Le propos a été lissé pour des raisons politiques évidentes mais sans doute aussi par volonté de nuancer une approche trop brutale qui ne pouvait faire l'unanimité. Du strict point de vue concret, contrairement aux affirmations du rapporteur de Saint-Flour, les chirurgiens ne sont ni suffisamment nombreux, ni prêts à opérer la totalité des accouchements du département. Socialement parlant, la prééminence numérique féminine dans ce domaine n'est non seulement pas remise en cause mais, à l'opposé, souhaitée à la fois par les autorités administratives et médicales et par les parturientes.

Revenons à l'Encyclopédie méthodique. Dans l'esprit de l'article «Accoucheuse » de l'Encyclopédie de Diderot et d'Alembert, le texte de 1787 pose l'hypothèse d'une exclusivité chirurgicale de l'obstétrique en développant les « inconvénients » de l'exercice féminin et n'hésite d'ailleurs pas à contester farouchement la pertinence et les effets des cours d'Angélique du Coudray :

Les intendants des provinces ont reçu, il y a quelques années, dans les villes principales de leur ressort, une femme qui prétendait avoir été accoucheuse à l'Hôtel-Dieu de Paris, pour y enseigner l'art des accouchements. [...] je n'ai pas remarqué que les accouchements en fussent mieux pratiqués dans les campagnes ; j'en donnerais un grand nombre de raisons, si elles pouvaient trouver place dans cet article. ${ }^{117}$

L'attaque est d'autant plus violente qu' elle suspend le lecteur au jugement péremptoire de l'auteur. Angélique du Coudray n'est pas nommée, son statut professionnel même est nié, excellent moyen de dénier ensuite toute valeur à son enseignement.

En I808 paraît dans la même Encyclopédie méthodique l'article " matrones, sages-femmes, accoucheuses ${ }^{118} \gg$ qui se propose de préciser l'article paru en I787 en lui donnant « quelques développements et [de] rapporter l'extrait des lois nouvelles sur cet objet important ». Plus qu'un complément à l'article « accoucheuse », le nouvel article adopte un point de vue inverse :

Nous ne traiterons point ici de la question de savoir si l'art des accouchements, considéré relativement à la science, a pu être exclusivement exercé par les femmes. Il y a des accouchements qui exigent avec les connaissances théoriques les plus étendues, avec toute la dextérité dont les femmes sont capables, beaucoup plus de force musculaire qu'elles n'en ont ordinairement.

II7. Société de médecins, Encyclopédie méthodique, médecine, op. cit., t. I, article « accoucheuse », p. 86-87.

II8. Ibid., tome VIII, article « matrones, sages-femmes, accoucheuses », p. 657-658. 
[... Plusieurs sages-femmes se sont fait une réputation, non seulement dans la pratique, mais encore dans la théorie des accouchements : quelques-unes ont publié des ouvrages qui ne sont point indignes de la confiance publique [...]. [Suivent l'évocation de différentes sages-femmes auteures jusqu'à Angélique du Coudray] Elle parcourut successivement toutes les intendances du royaume où elle fit plus de quatre mille élèves, et d'où elle rapporta les témoignages les plus honorables et les plus flatteurs de l'estime et de la confiance publique.

Point ici de discussion sur la légitimité des femmes à exercer l'art des accouchements, point de virulente critique de la plus célèbre d'entre elles en ce début de $\mathrm{XIX}^{\mathrm{e}}$ siècle. Le texte de I808 affirme sans détour le choix de la sagefemme comme recours général des parturientes. Un tel renversement d'opinion s'éclaire par les choix politiques et sociaux confirmés en France depuis la Révolution. La loi de ventôse an XI ( 1803 ) achève d'imposer le discours que tenaient une dizaine d'années plus tôt les autorités administratives françaises. Cinq ans plus tard, l'Encyclopédie méthodique en rend compte :

[...] le soin que prennent aujourd'hui les gouvernements de l'Europe, de ne faire accorder des diplômes aux sages-femmes qu'après des études, des épreuves et des examens convenables, est une garantie suffisante de la confiance qui leur est généralement accordée.

La confrontation des deux visions de la place à donner à la sage-femme s'articule de façon proche, à grande échelle entre le rapport préparatoire du conseil de district cantalien et la délibération qui le reformule et à petite échelle entre deux articles d'une même somme encyclopédique séparés par une vingtaine d'années. L'objet n'est pas d'établir à tout prix une généalogie des références d'un administrateur local en voyant dans l'article de 1787 l'inspiration d'une opinion formulée en 1792, mais plutôt de montrer l'écho local d'une potentialité de choix politique, social et culturel (le chirurgien comme auxiliaire de la naissance), et son rejet nuancé mais ferme. De ce rejet naît la sagefemme, accompagnée pour les décennies à suivre des interrogations soulevées par le choix qui venait d'être exclu.

\section{Mésestime ou lucidité?}

Le chemin désormais ouvert, il faut l'emprunter. Aux sages-femmes, les accouchements naturels, puisque les chirurgiens ne peuvent y pourvoir. En découle l'impératif pédagogique, très précocement et simplement exprimé en 1790 par la Société royale de médecine dans son Nouveau plan de constitution pour la médecine en France : 
Il serait sans doute à désirer que les accouchements ne fussent confiés qu'aux chirurgiens de cantons. Mais comme il paraît que le préjugé qui fait préférer les femmes pour cet objet se perpétuera encore longtemps, il faut s'occuper des moyens d'en former qui soient propres à le remplir. ${ }^{119}$

La nécessité fait loi et la nécessité doit faire le cours. Les dernières phrases du courrier adressé à ses collègues par un membre du département du HautRhin, Chalmy, deux mois avant la présentation du texte précédent, arrivaient aux mêmes conclusions : «[... ] car il en faut ; mais il faut qu'elles soient instruites ${ }^{120} »$.

De fait, les lacunes des futures élèves sages-femmes sont réelles : illettrisme, ignorance générale que la brièveté des cours ne peut combler. En ce sens, les inquiétudes du rapporteur de Saint-Flour sont partagées par nombre d'administrateurs et de médecins, les seconds accédant à partir de la période révolutionnaire de plus en plus fréquemment à la charge des premiers ${ }^{121}$. Le défaut d'instruction primaire ennuie mais la tendance est à tenter d'y remédier par la sélection des rares jeunes femmes munies de ces compétences. La capacité « d'être élève ${ }^{122}$ » en revanche se place sur un plan différent, celui de l'aptitude intellectuelle définie comme individuelle et sans rapport avec le sexe. Tâche à ceux qui choisissent les candidates d'être clairvoyants. C'est ce qu'expriment les administrateurs du district de la Tour du Pin en avril I792: « [... ce choix doit être fait sur la présentation des municipalités qui auront soin de ne mettre sur les rangs que des femmes qui avec des mœurs paraîtront avoir quelque aptitude ${ }^{123} »$.

Ou encore ceux de l'administration départementale de la Côte-d'Or en nivôse an III :

Les directoires de districts sont invités pour fournir le nombre de femmes qui leur est demandé à rechercher dans les campagnes de leur arrondissement, celles qui n'ont point encore profité de cet établissement et qui sont à même d'en tirer parti, par la présentation de sujets capables d'instruction. ${ }^{124}$

\footnotetext{
II9. Société royale de médecine, Nouveau plan de constitution pour la médecine en France, présenté par Vicq d'Azyr, à l'Assemblée nationale le 25 novembre 1790, EDRES, p. 63.

I20. $\mathrm{AD}$ Haut-Rhin, $\mathrm{L}$ I27.

I2I. Gélis J., La Sage-femme..., op. cit., p. I25.

122. AD Doubs, $L_{1343 .}$

123. $\mathrm{AD}$ Isère, $\mathrm{L} 532$.

I24. AD Côte-d'Or, L 542.
} 
La recherche est menée avec lucidité et se révèle souvent vaine. Elle s'inscrit dans une approche socio-géographique des qualités propres à faire la future sage-femme et fait ressortir la distinction ville-campagne dans l'estimation du poids de l'environnement culturel. Chalmy du Haut-Rhin souligne ainsi à quel point «l'éducation cultivée » des élèves chirurgiens creuse un fossé entre eux et les élèves sages-femmes :

Celui qui est chargé du soin d'instruire, s'il veut faire quelques fruits, doit mesurer ses expressions, son style, ses leçons, son tems aux talens, à la capacité, à la foiblesse de ses auditeurs : il doit en tout se prêter, se mettre à leur portée. Quelles sont les dispositions, au sortir du village de celles qu'on destine à être sages-femmes ? Peu ou point de connaissance, et d'usage de la langue soit française, soit allemande, rarement du talent, souvent de l'ineptie, plus souvent encore une fausse honte, qui gêne toujours les opérations de l'esprit et du jugement. En ville elles se trouvent réunies dans un même auditoire aux autres élèves ${ }^{125}$ : elles assistent à des leçons préparées pour tous à la vérité ; mais dont le langage leur est inintelligible, conséquemment le fruit perdu pour elles. ${ }^{126}$

S'adapter à son public implique donc de ne préjuger de rien, leçon d'humilité pour le démonstrateur plus encore que critique du niveau des élèves. Mais l'enjeu n'est pas seulement de transmettre un savoir et très souvent, il faut, pour ce faire, corriger l'existant :

Je ne dois pas laisser échapper ici une considération bien intéressante, c'est que les femmes de la campagne, pour qui ce cours est particulièrement destiné, ne sont point accoutumées à l'étude, [...] elles ont peu ou point d'idées de la chose qu'elles vont entreprendre, et ce qui est encore pis, elles en ont de fausses ou de mauvaises. ${ }^{127}$

La fausse science des accoucheuses sans principes, voilà l'ennemi. Une alternative non exclusive s'offre pour le combattre : interdire l'exercice de la profession à ces femmes qui pratiquent déjà ou les former pour les faire correspondre aux attentes morales, scientifiques et politiques. Elle est magistralement formulée en 179I par le chirurgien Eyméoud dans le mémoire qu'il remet aux administrateurs du département des Hautes-Alpes :

S'il n'était pas de craindre que nos accoucheuses villageoises voulussent conserver l'usage de leurs topiques, de leurs secrets superstitieux et ridicules,

125. Il s'agit ici des élèves chirurgiens.

126. AD Haut-Rhin, L I27.

I27. AD Marne, i L 1248. 
je proposerois encore que ce fut parmi elles qu'on fit choix des élèves qu'on voudroit instruire à cause de l'habitude où elles sont de servir les malades, et d'une certaine expérience qu'elles ont dû acquérir, et dont elles pourroient tirer parti moyennant une bonne théorie, bien entendu que je n'y comprends pas celles qui ne sçauroient pas lire, ou qui auroient vieilli sous les harnois d'une gotique routine. Quant à celles qui sous quelque prétexte que ce fut refuseroient de se rendre à ces invitations, il leur seroit fait inhibition expresse de pratiquer dorénavant les accouchemens. ${ }^{128}$

L'option de la formation des matrones, est une constante dans l'organisation des cours d'accouchement et le recrutement des élèves et s'explique par deux raisons : les matrones ont de leur côté la confiance préalablement acquise des femmes de leur village ou de leur paroisse. Le réemploi des procédures communautaires de désignation mis en avant par le même Eyméoud l'année suivante est une manière de confirmer ce jugement populaire en l'orientant dans le sens voulu :

Chaque municipalité rassembleroit à jour fixe les femmes du lieu où il faudroit élire un sujet et après leur avoir fait entrevoir les vues paternelles de l'administration dans un établissement de cette nature, leur laisseroit le soin de faire choix d'un sujet qui réunisse les qualités requises pour se rendre capable dans la profession d'accoucheuse. ${ }^{129}$

La seconde raison réside dans les connaissances préexistantes. Ces femmes ont l'habitude de pratiquer les accouchements, leur savoir est empirique au sens le plus strict du terme et à ce titre susceptible de constituer le socle d'une formation plus abstraite. Les brèves descriptions qui accompagnent la présentation des candidates aux cours d'accouchement sont révélatrices de cette dimension positive de l'expérience. La pratique antérieure d'accouchements est de fait une garantie de sang-froid, de qualités d'initiative et d'adaptation. Il se crée ainsi une catégorie intermédiaire entre la mauvaise et la bonne praticienne de l'accouchement : la mauvaise praticienne en voie de rédemption par la connaissance. L'appel d'Eyméoud en I79I ne reste d'ailleurs pas sans lendemain puisqu'en floréal de l'an vir, la commune de La Bâtie-Neuve désigne comme élève sage-femme Élizabeth Saret : «[...] femme de Jean Ceinturier dit Morgand, propriétaire, demeurant au Grand Ancelle, âgée de quarante-cinq ans ayant deux enfans et faisant quelque fois le métier d'accoucheuse ${ }^{130}$ ».

128. AD Hautes-Alpes, L Io62.

I29. Ibid.

130. Ibid. 
Parmi ces femmes qui accèdent à une formation obstétricale, certaines ont bénéficié d'un apprentissage ancien non officiellement sanctionné, sans parler ici de la transmission intra-familiale entre accoucheuses. L'influence d'un chirurgien sur la pratique de ces matrones est patente, comme le suggère en I79I, la municipalité franc-comtoise de Frasne :

[...] de vouloir bien accepter Marguerite Françoise Courlet natif de Pontarlier, âgé d'environ trente cinq ans demeurant audit Frasne depuis passé dix-huit ans, étant la femme qui nous a paru la plus propre de notre paroisse, qui nous a dit en avoir beaucoup de disposition et même peut faire une seigné dans les circonstances $[\ldots] .{ }^{131}$

La pratique de la saignée, plus encore que celle des accouchements laborieux, est réservée à la corporation des chirurgiens. Elle correspond à une technique spécifique qui ne s'improvise pas sans risque de mettre en réel danger la vie du malade. Les dispositions évoquées pour Marguerite Françoise Courlet et la mention de cet autre talent signent les leçons d'un homme de l'art.

La matrone, pour n'être pas reçue par une communauté de métier, est quasi automatiquement définie comme "sans principes », mais elle n'en est pas moins parfois une sage-femme arrêtée à mi-chemin. L'exemple de l'auvergnate Gilberte Delarbre est à ce titre encore plus révélateur :

La municipalité assemblée remontre [...] qu'elle désireroit que Gilberte Delarbre, cy-devant domestique pendant douze ans du Sieur Amy, chirurgien, fut admise au concour établi près du département du Pui-de-Dôme : cette fille, d'un certain age, de bonnes mœurs a déjà accouchée trois ou quatre femmes sous les yeux de son cy-devant maitre, ses opérations ont été heureuses. La municipalité désireroit qu'elle s'établit à Manzac chef-lieu du canton et c'est l'intention du sujet qui a beaucoup d'aptitude pour cette profession. ${ }^{132}$

La générosité scientifique du chirurgien qui forme sa domestique s'explique par la volonté de compléter et d'élargir sa pratique en épargnant son temps. Dans la recherche éperdue de candidates aux cours d'accouchement que mènent les administrateurs locaux, de la municipalité au département, ces fruits de la vocation démonstratrice individuelle sont des bénédictions, conciliant politique intégratrice et garantie de compétences.

I3I. AD Doubs, $\mathrm{L}$ 1343.

132. AD Puy-de-Dôme, L 5323. 
L'appel au « recyclage des matrones ${ }^{133}$ », bonnes volontés potentielles déjà en exercice, est relayé à chaque niveau de la pyramide administrative. Il peut même arriver que le public visé par les cours soit restreint, sous la plume du rédacteur, au seul public déjà en activité. Dans les Côtes-du-Nord en 1792, les élèves du futur cours de Saint-Brieuc sont définis comme « toutes les personnes du département qui se livrent à cette partie intéressante de la chirurgie ${ }^{134} » . \mathrm{La}$ force de l'attente départementale ou plus généralement politique se mesure au degré d'autorité exprimé dans ces avis, arrêtés ou circulaires. Les exemples du début des années 1790 privilégient la formule de l'invitation, qui inscrit le rapport à la matrone dans un contexte pacifié tandis que les exemples de la période du Directoire révèlent des attentes beaucoup plus fermes. En Charente, l'arrêté départemental du I2 ventôse an vir fait « injonction aux citoyennes, qui, sans connaissance, se livrent à l'art des accouchements [...] d'assister aux cours gratuits ${ }^{135}$ ». Dans le Rhône, un arrêté de même nature daté du 7 prairial an vi annonce dans son article premier :

Il est enjoint à toutes les matrones, gardes de femmes en couche, ou autres citoyens exerçant l'art des accouchements sans y être autorisés par diplôme des écoles de santé ou des ci-devant collèges de chirurgie, de se faire inscrire audit cours, et de le suivre avec exactitude. ${ }^{136}$

Dans les années 1798-I799, le recyclage diplomatique des matrones a vécu, dans le discours du moins, et l'assistance à la formation obstétricale est devenue une obligation morale pour l'heure, légale bientôt. Or l'obligation morale implique la mise au point d'un argumentaire qui fait appel au sens éthique des accoucheuses tout en relevant la valeur de leur rôle social et médical. C'est chose faite en Haute-Normandie en l'an vir, lorsque l'administration départementale transmet la nouvelle de l'ouverture d'un cours d'accouchement pour les sages-femmes à l'École de Médecine de Paris :

Cette destination spéciale pour le sexe prouve combien le gouvernement attache de prix à ce que cet art ne soit exercé que par des mains habiles, et nous ne pouvons trop inviter les sages-femmes à aller puiser, dans cette première école, les lumières qui doivent diriger leurs opérations.

133. Gélis J., La Sage-femme.., op. cit., p. I40.

134. AD Côtes-d'Armor, i L 594.

135. AD Charente, L 155 .

136. AD Rhône, I L 53I. 
En conséquence, nous prévenons les personnes du sexe qui se livrent à l'étude de l'art des accouchements, que le premier messidor prochain, l'école de Médecine de Paris ouvrira un cours public en faveur des sages-femmes : celles surtout qui ont déjà des notions premières, doivent profiter de cette occasion de terminer fructueusement leur instruction ; c'est un sacrifice qu'elles doivent à l'humanité, et un devoir que leur impose leur propre conscience ; elles ne peuvent trop bien posséder la théorie d'une profession où l'on ne peut errer sans outrager la nature. ${ }^{137}$

Cette exigence ne peut cependant naître que dans le renoncement à la critique véhémente du métier de sage-femme dont la mauvaise réputation, abondamment rappelée à la Révolution lorsqu'il s'est agi de justifier l'organisation des cours, porte en elle son paradoxe. Pour former, il faut prouver qu'il y a matière à réforme, mais pour former, il faut aussi prouver que le jeu en vaut la chandelle et que le métier ne porte pas en lui-même son propre germe de dysfonctionnement. Ce n'est pas une mince tâche et les hommes de l'art chargés des cours l'exposent avec un brin de désarroi :

Une autre cause paroit aussi contrarier l'établissement et s'opposer aux vues bienfaisantes de l'administration, c'est un préjugé populaire qui fait de la profession d'accoucheuse un état méprisable. ${ }^{138}$

Méprisable, ce métier l'est aux yeux de toute une partie de la population car c'est dans les campagnes et dans les bourgs, soit dans la quasi-totalité du pays, un métier du déclassement social : «il est peu de femmes dans nos campagnes qui pensent à embrasser cet état avant l'âge de 40 ans et avant de se trouver réduites à ne pouvoir faire autre chose pour vivre ${ }^{139} »$. Le dernier tiers du XVIII ${ }^{e}$ siècle a vu naître concurremment l'ambition dans le recrutement de l'élève sage-femme et la lucidité vis-à-vis d'un état qui n'attire pas ${ }^{140}$. La Révolution et le Consulat sont confrontés aux mêmes désaffections, témoignages des limites d'un discours qui s'est pourtant depuis longtemps ravisé en insistant sur la figure de la sage-femme, mère des peuples. En l'an x en Corrèze, une élève pressentie renonce à suivre le cours. Le maire de sa commune rapporte, que, fille de chirurgien, elle « ne pourrait se résoudre à travailler et exercer son état à venir pour de médiocres honoraires ${ }^{141} »$.

\footnotetext{
137. AD Seine-Maritime, L II65.

138. AD Hautes-Alpes, L 1062.

139. Ibid.

I40. Gélis J., La Sage-femme..., op. cit., p. I40.

I4I. Sage Pranchère N., Mettre au monde..., op. cit., p. I46.
} 
De 1786 à 1803 , la parole bâtie autour des sages-femmes et de leur formation est abondante, multiple, mais presque unanimement tendue vers ce grand projet, esquissé au XVIII ${ }^{e}$ siècle et construit pour le $\mathrm{XIX}^{e}$ siècle, de déposer une naissance reconsidérée entre les mains d'une accoucheuse désormais femme de l'art. Mieux, c'est l'enchaînement et le jeu de miroirs entre discours qui donnent vie à ce grand projet, imposant tour à tour l'exclusion de la matrone meurtrière, l'apothéose de la sage-femme formée et durablement légitimée par cette formation, et la rédemption de l'accoucheuse clandestine, dépouillée de ses oripeaux routiniers pour en faire surgir l'élève tant attendue. Démêler l'imbroglio discursif est indispensable pour comprendre la complexité des héritages et la subtilité des évolutions, pour isoler la basse continue d'une parole médico-administrative que l'approche strictement institutionnelle pourrait dissocier à tort. 

Chapitre 2

\section{Sages-femmes en Révolution}

Penser la formation obstétricale en termes révolutionnaires implique de faire la part de l'héritage et du projet. Les discours produits pendant cette période ont affirmé un besoin, celui d'un encadrement obstétrical des populations. Ils ont désigné un instrument de satisfaction de ce besoin, la sage-femme formée et diplômée. Le souhait identifié, il reste dans le même temps pour y répondre à mesurer les acquis et le chemin à parcourir. Pendant une longue dizaine d'années, esquisses règlementaires et expériences concrètes s'interpellent et se répondent avant que le monument législatif de la loi du ig ventôse an XI n'en marque le point d'aboutissement durable. Jamais même n'a-t-on vu une telle effervescence créatrice. Les choix politiques concernant l'enseignement médical oscillent entre libéralisme et encadrement, entre égalité et hiérarchie tant sur le plan humain que géographique. À ce titre, les formes adoptées par la formation des sages-femmes au XVIII ${ }^{\mathrm{e}}$ siècle laissent une empreinte forte sur les propositions et les réalisations de ces années 1790.

\section{L'héritage et ses figures}

\section{Continuité institutionnelle et projet politique}

L'un des premiers soins des constituants à l'été 1789 est de mettre à l'ordre du jour la réorganisation administrative du territoire français. Le 15 février 1790, six mois à peine après le début des discussions, la division de la France en départements et districts est achevée ${ }^{1}$. La Constituante a marché vite, très vite, mais pas suffisamment néanmoins pour ne pas paralyser l'activité d'institutions

I. Godechot J., Les Institutions de la France sous la Révolution et l'Empire, Paris, PUF, 1985, p. 97. 
provinciales déjà condamnées mais qui se survivent encore ${ }^{2}$. Le 9 décembre 1789 , les députés de la commission intermédiaire provinciale de Champagne informent leurs correspondants du bureau intermédiaire de Châlons de leur impossibilité d'ordonnancer aucune dépense dans l'attente de réformes imminentes. Les cours d'accouchement sont touchés par le gel des dépenses :

Plusieurs bureaux intermédiaires nous ont proposé, Messieurs, d'ouvrir le
$\mathrm{I}^{\text {er }}$ janvier prochain le cours gratuit d'accouchement, mais cette dépense ne
pouvant être acquittée que des fonds libres ou variables de I79o, le nouvel
ordre de chose nous prive de la faculté d'ordonner aucune dépense relative à
cet exercice, sans être assurés que ces fonds seront continués, que nous serons
chargés de leur emploi, ou sans y être autorisés par l'assemblée nationale ou
par le ministre ; tout semble annoncer que les nouvelles assemblées de dépar-
tement seront bientôt organisées, que la province éprouvera une division qui
entraînera celle des fonds destinés à ces établissements ; nous rappelons à
M. le contrôleur général celui du cours gratuit d'accouchement, son utilité
reconnue, mais nous vous prions d'attendre sa réponse avant de prendre
aucun engagement pour l'ouverture de celui qui a lieu dans votre ville depuis
plusieurs années.

Il y a du désarroi dans cette réponse. Accablement lié aux sollicitations permanentes qui assaillent la commission intermédiaire, impuissance née de l'ignorance du rythme des changements prévus, de leur degré de conservation des hommes en charge et de poursuite des pratiques existantes, tels sont les sentiments qui s'expriment ici d'autant plus ouvertement que les interlocuteurs sont, au degré inférieur, dans une situation équivalente de vide administratif et juridique. Paralysie, le mot est assumé plus au sud, dans le Tarn où les répercussions du blocage des anciennes administrations se font sentir longtemps. C'est ce que souligne le mémoire de Jean-François Icart adressé le 23 novembre 1790 à l'administration du district d'Albi :

[...] en conséquence quoique le premier cours eut commencé en 1786 et dut finir en 1789 inclus, il fut cependant pourvu sur la demande du diocèse et par délibération des États de l'ancienne province à la même imposition de I 200 livres pour l'année 1789 , mais la révolution survenue ayant paralisé l'ancienne administration, cette somme de I 200 livres et un reliquat de 39r livres 4 sous de l'année précédante, se trouvent encore sans emploi dans la caisse du receveur de l'ancien diocèse. ${ }^{4}$

2. Legay M.-L., « La fin du pouvoir provincial (4 août I789-2I septembre I79I) », AHRF, nº 332, avril-juin 2003, p. 25-53.

3. AD Marne, $2 \mathrm{~L} 215$.

4. AD Tarn, $\mathrm{L}_{343 .}$ 
Le calendrier d'installation des nouvelles administrations départementales et de district (décret du 22 décembre 1789) compte plusieurs étapes : le découpage géographique des circonscriptions, l'élection des membres du conseil général de département au printemps $1790^{5}$. Les premières sessions des conseils généraux n'ont donc lieu qu'à la fin de l'automne. Avant cela intervient l'examen des comptes des administrations « sortantes $^{6}$ ». À Tours, dans l'hôtel de l'intendance devenu hôtel du département de l'Indre-et-Loire, au fil de la matinée du 15 septembre 1790 , l'administration révolutionnaire advient au sens concret et au sens symbolique du terme $e^{7}$. Subdélégué général de l'intendance de la généralité de Tours représentant l'intendant, membres des commissions intermédiaires générale et provinciale d'un côté, commissaires des départements de l'Indre-et-Loire, du Loir-et-Cher, du Maine-et-Loire, de la Mayenne, de la Sarthe et de la Vienne de l'autre, les représentants d'un présent déjà révolu et ceux d'un futur qui prend corps s'assemblent pour passer le témoin de la survivance administrative. Avec un souci nettement exprimé « d'éviter à l'avenir les abus qui auroient pu s'introduire dans le régime de l'ancienne administration », les commissaires des départements nouveau-nés vérifient avec minutie comptes et pièces justificatives. Parmi eux, assignés aux fonds « libres», les « frais de cours de démonstration en l'art des accouchemens » côtoient les frais des bureaux d'agriculture, ceux d'entretien pour les sourds et muets et les gratifications pour la destruction des loups. L'inventaire des attributions peut sembler disparate, il forme pourtant, avec celui des fonds variables, le socle de la répartition en chapitres des budgets des futurs conseils généraux de département.

La mise par écrit des obligations et le passage de relais qui s'opère en ce I5 septembre 1790 à Tours, et à la même période dans l'ensemble des anciennes provinces françaises, sont l'assurance de la pérennisation des choix politiques de l'ancien mode de gouvernement. Les départements de la ci-devant généralité de Tours ont précocement réglé la succession. Dans de nombreuses régions, ce sont les deux derniers mois de l'année 1790 qui sont consacrés à cette nécessité. Dans l'Allier, le I8 novembre, on rapporte sur les comptes de la commission intermédiaire du Bourbonnais ${ }^{8}$. En Bretagne, quatre jours plus tard, les commissaires du département des Côtes-du-Nord députés à Rennes pour la

\footnotetext{
5. Godechot J., Les Institutions de la France..., op. cit., p. I03.

6. Legay M.-L., «La fin du pouvoir provincial... », art. cit., p. 47.

7. AD Sarthe, L 32 ; Grevet R., « D'actifs relais administratifs du pouvoir exécutif. Les 32 bureaux d'intendance à la fin du Xviır siècle », $A H R F, \mathrm{n}^{\circ} 332$, avril-juin 2003, p. 36 .
}

8. AD Allier, L 54. 
liquidation des anciennes affaires de la province, écrivent à leurs collègues pour les informer qu'ils « examinent successivement les diverses branches de l'administration ${ }^{9} »$. Les archives sont un allié précieux de cette transition, même si les départements dont le chef-lieu est directement héritier du siège des ci-devant intendances sont privilégiés par rapport à leurs voisins issus du découpage des généralités et que la transmission se fait parfois de manière chaotique ${ }^{10}$. Le « carton » réservé au cours d'accouchement est connu de tous et des démonstrateurs en premier lieu :

$[\ldots]$ cette pièce [ 15 pages in folio des renseignements donnés à l'assemblée provinciale] se trouve dans le carton des cours d'accouchemens au district. [...] ce que démontre sans réplique un mémoire de 4 pages adressé à Monsieur Rose, procureur sindic de l'assemblée provinciale le 27 janvier 1789 (il est dans le carton) $[\ldots] .{ }^{11}$

La mémoire de l'action des administrateurs d'Ancien Régime, l'apurement des comptes en suspens, la présence des archives sont autant de liens qui contraignent les choix des nouveaux hommes en charge des affaires locales. Lourde succession pour des administrations jeunes qui cumulent des compétences auparavant dispersées et dont l'activité est largement subordonnée au pouvoir central ${ }^{12}$, mais aussi rassurante simplicité des chemins déjà balisés lorsque se pose la question du maintien de structures comme celles des cours d'accouchement. Les mentions abondantes des administrations antérieures dans les textes produits par les instances nouvelles prouvent d'ailleurs ce besoin passionné d'affirmer la continuité institutionnelle.

Dans le Cantal, l'assemblée de district d'Aurillac réunie le 20 septembre 1790 ouvre la voie à l'assemblée départementale qui se tient deux mois plus tard:

L'assemblée réunie, lecture faite de la précédente délibération, l'un des membres a dit, que l'assemblée devoit solliciter la réalisation du projet formé par l'ancienne administration d'un établissement utile à l'humanité tel qu'un cours d'accouchements, qu'une institution aussi bienfaisante avoit déjà fixé l'attention de l'assemblée provinciale de la ci-devant province d'Auvergne, et de celle de département fixé en cette ville d'Aurillac, que les anciens administrateurs avoient, sensiblement émus des malheurs qu'occasionne l'impéritie des sages-femmes, soit dans les villes, soit dans les campagnes, qu'ils avoient

9. AD Côtes-d'Armor, I L 594 .

Io. Legay M.-L., « La fin du pouvoir provincial... », art. cit., p. 49.

II. AD Marne, I L I248.

I2. Godechot J., Les Institutions de la France..., op. cit., p. I03. 
en conséquence voté l'établissement d'un cours annuel d'accouchements durant six mois pour vingt-huit élèves dans quatre différents hôpitaux, que la division de la province en départements nécessite quelques changements dans le plan proposé, mais qu'il n'en est pas moins certain que l'on doit faire des vœux pour l'exécution de cet établissement. ${ }^{13}$

Tout est posé, le bien-fondé du projet précédent, le bénéfice d'antériorité de l'assemblée provinciale, la nécessité de mener à bien le dessein laissé en suspens puisque l'objet n'a rien perdu de sa légitimité. Seul le cadre géographique change, simple détail au regard de l'importance accordée à la mise en place d'un cours d'accouchement.

Un peu partout ailleurs, la relève se prend dans un même mouvement qui apparaît simple, naturel. Dans l'Isère, on invoque pour voter la conservation du cours d'accouchement en 1790 la mémoire des «ci-devant intendants ${ }^{14}$ », dans les Hautes-Pyrénées, on perpétue en I79I les cours institués par les " administrateurs de la ci-devant province de Bigorre ${ }^{15}$ », dans le Calvados encore, on arrête la création de cours " après avoir fait lecture des observations consignées à ce sujet dans le procès-verbal de l'Assemblée provinciale de Haute-Normandie ${ }^{16}{ }$. Est-ce à dire que nulle voix discordante ne s'élève pour contester la succession ou pour planter le décor d'une ambition révolutionnaire plus vaste, plus juste que les œuvres de l'Ancien Régime ? L'opinion est partagée qui voit dans l'héritage pré-1789 tantôt un modèle, tantôt un repoussoir, selon les cas. Toutes les raisons développées jusqu' ici poussent à privilégier le modèle, puisqu' il faut parfois bien reconnaître que les prédécesseurs n'ont pas complètement failli :

Vos commissaires députés à Rennes examinent successivement les diverses branches de l'administration et tout en gémissant sur les abus qu'elles occasionnoit, ils doivent cependant vous instruire que quelques objets de première et générale utilité n'y étoient pas entièrement négligés. Des écoles d'anatomie, des cours d'accouchements étoient établis et fondés dans les villes de Rennes et de Nantes [...] l'ancienne administration avait ajouté à ces établissements un cours d'accouchement que le sieur Dubois donnoit successivement dans divers villes. ${ }^{17}$

\footnotetext{
13. AD Cantal, L 426 .

14. $\mathrm{AD}$ Isère, $\mathrm{L}$ 54.

15. AD Hautes-Pyrénées, L I24.

I6. $\mathrm{AD}$ Calvados, $\mathrm{L} 600$.

I7. AD Côtes-d'Armor, I L 594.
} 
La continuité fait dès lors œuvre de légitimation. Le passé y gagne une fonction d'émulation, d'appel à remettre sur le métier l'ouvrage entamé « qui n'a fait que languir »:

(Hautes-Alpes, I79I) Si les mêmes motifs qui avoient engagé d'autres administrateurs à former un tel établissement subsistent donc encore, que ne devons-nous pas attendre de ceux que la confiance générale a mis à leur place dans notre département ? $^{18}$

Réitération du discours d'Ancien Régime, nous le disions, en vue d'améliorer l'action du nouveau gouvernement. La proclamation de la République le 2r septembre 1792 fait de la réorganisation des cours un devoir intrinsèquement lié à la nature du régime qui vient de naître : "(Charente, an viII) Il appartient à la République d'égaler l'ancien gouvernement dans tout ce que la nécessité seule lui faisait faire de bien, et de le surpasser sous tous les rapports qui portent le cachet de la générosité et de l'humanitée ${ }^{19}$.»

Avec l'abolition de la royauté, l'appréciation de l'Ancien Régime s'est cependant nettement infléchie. Une critique ouverte peut désormais s'exprimer. Elle témoigne d'une ampleur d'analyse politique souvent supérieure à celle des premières années de la Révolution puisque son objet est rapporté à un système et non plus à une administration locale. Mais le tournant n'est ni brutal, ni général. De premières piques ont fleuri sous les plumes en 1790, dans le cadre modeste d'assemblées départementales : " (Saint-Flour, 1790) [...] il n'y a pas jusqu'au despote, qui ne voye naître avec plaisir l'infortuné que la servitude attend et pour qui la vie même est un malheur ${ }^{20} »$. Mais la jeune monarchie constitutionnelle n'est pas la monarchie absolue, le rappel est ferme. Deux ans plus tard, dans la même ville, la chute de la royauté a pourtant achevé de délier les langues : « Depuis longtemps on avait été frappé de l'importance de remédier à un pareil fléau, mais l'ancien régime qui ne s'occupait que des moyens de se procurer de l'argent en vexant le pays, ne s'était jamais occupé de ces maux de détails ${ }^{21}$, »

En Bretagne, on passe de la même façon de la concession bienveillante de commissaires pour la liquidation des affaires de l'ancienne province à la lettre d'un chirurgien nommé Bonnieu quinze jours à peine avant la prise des Tuileries : «Cette voix lente et respectable [les cris de l'humanité], presque toujours étouffée sous le règne de l'injustice et de la tyrannie, s'est enfin fait

\footnotetext{
I8. AD Hautes-Alpes, L I062.

19. AD Charente, L I55.

20. AD Cantal, L 17 .

2I. Ibid., L 587 .
} 
entendre ${ }^{22}$. » Les années passent et le ton se durcit. À Poitiers, le I4 messidor de l'an II, les affiches annonçant l'ouverture du cours d'accouchement proclament : «Le bonheur de l'homme n'intéressoit pas le despotisme : il y avait toujours assez d'esclaves, il ne sauroit y avoir maintenant trop de républicains ${ }^{23}{ }^{2} \gg$ Dans le Cher en messidor de l'an Iv, l'officier de santé Raillard s'écrie :

Sous l'Ancien Régime, lorsque des tirands couronné nous traittoient en esclaves ; sous les apparences de l'humanité et du bien publique, il s'occuppoient parfois de notre sort ; sans doute pour se conserver un plus grand nombre de mercenaires $[\ldots] .{ }^{24}$

Au Conseil des Cinq-cents, le i4 nivôse an v, le député de la Creuse, JeanFrançois Baraillon, lors de sa présentation d'une motion d'ordre, déclare au sujet de la formation des sages-femmes : «L'ancien gouvernement s'en était occupé, mais d'une manière si stupide, d'une manière si mesquine, que toutes ses peines en ce genre étaient à peu près perdues ${ }^{25}$. " La remise en cause est sans détour, mais la formation des sages-femmes n'est qu'une occasion parmi d'autres, et peut-être moins que d'autres, de broder sur le despotisme et la tyrannie dont la bêtise et l'illégitimité sont des qualifications récurrentes. L'émergence d'un rejet de l'héritage pré-révolutionnaire n'est pas à négliger. Elle apparaît toutefois révélatrice d'une tendance de fond à la revendication par le gouvernement républicain d'une différence radicale avec le régime déposé, plutôt que d'une vision spécifique de la politique à mener en matière d'enseignement obstétrical. La faiblesse argumentaire des discours et leur absence d'homogénéité en sont des preuves. Le ton radicalement inverse de la lettre circulaire adressée par le ministre de l'Intérieur aux administrations départementales le I4 fructidor an vi confirme l'absence d'unanimité dans la critique :

Plusieurs départements ont maintenu jusqu'à ce jour l'activité des cours d'accouchements et d'anatomie établis dans quelques communes. Les ci-devant administrations provinciales avaient eu soin de faire encourager ces fondations par l'ancien gouvernement, leur avantage doit surtout frapper l'attention du gouvernement républicain. ${ }^{26}$

22. AD Côtes-d'Armor, I L 594. La formule d'ouverture (« la voix lente et respectable ») est tirée du Catéchisme sur l'art des accouchements d'Amable Augier du Fot, Paris, Soissons, 1775.

23. AD Vienne, L 210.

24. AD Cher, I L 625 .

25. Motion d'ordre de Jean-François Baraillon, séance du I4 nivôse an v (3 janvier I797), EDRES, p. 232.

26. AD Charente, L 155 et AD Seine-Maritime, L II64. 
Lorsqu'une institution existe et prouve son utilité, il est de bonne police de la conserver. Les cours d'accouchement sous l'Ancien Régime n'ont certes pas rempli tous les objectifs attendus mais le chantier reste ouvert, fort des expériences accumulées.

\section{«Attendons de nos législateurs... ${ }^{27}$ "}

La rédaction des cahiers de doléances puis la réunion des États généraux ont fait monter l'attente réformatrice. Les espoirs sont immenses et les réformes à engager d'une ampleur proportionnelle. Le passage de flambeau entre les administrations d'Ancien Régime et celles nées de la Révolution ne doit pas faire sous-estimer le caractère provisoire de bien des décisions prises en I790. La loi du 22 décembre 1789 attribue aux administrations départementales « l'inspection et l'amélioration du régime des hôpitaux, hôtels-Dieu », « la surveillance de l'éducation publique », ainsi que « la manutention et [...] l'emploi des fonds destinés en chaque département [...] à toute espèce de bienfaisance publique », tous domaines dont relève partiellement ou intégralement la formation des sages-femmes. L'intervention de Lebrun, rapporteur sur la question de l'instruction des sages-femmes à l'Assemblée nationale le 4 septembre suivant, précise le texte précédent :

L'instruction des sages-femmes est une partie importante de l'enseignement public ; mais il faut que cette instruction se trouve partout, et ce n'est pas un seul individu qui peut la répandre dans tout le royaume. Chaque département doit avoir la sienne ; ce n'est que par là qu'elle sera réellement utile. Ce n'est plus alors une charge nationale, mais une charge propre à chaque département ; elle doit être acquittée ou par les départements, sur des fonds particuliers, ou sur la portion de fonds publics qui seront destinés aux dépenses de l'éducation publique. ${ }^{28}$

La perpétuation de la compétence locale s'inscrit cependant dans un contexte nouveau de rationalisation administrative où l'Assemblée constituante et ses suivantes s'affirment comme la source désormais unique du droit et du projet politique français. De là découle une nouvelle attente, aux objets proches de ceux des cahiers de doléances, mais dont les porte-parole sont désormais les administrateurs de département.

27. AD Cantal, $\mathrm{L} 488$.

28. AP, recueil complet des débats législatifs et politiques des chambres françaises, Première série, 1787 à 1799, t. I8, Paris, P. Dupont, I884, p. 560. 
La commission intermédiaire provinciale de Champagne disait en décembre 1789 son impuissance dans l'attente des réformes. Une fois adopté le nouveau découpage administratif du royaume, l'hésitation perdure, prise entre la nécessité quotidienne et la crainte d'aller contre le grand plan national. Dans nombre d'assemblées départementales, les voix s'élèvent pour espérer, interpeller, soumettre leurs vœux aux députés. L'attente se nourrit d'informations lacunaires, de promesses :

(Saint-Flour, 24 septembre 1790) Nos moyens, malheureusement trop bornés, ne nous permettent guère de nous livrer à cet objet de dépense, quoique fort utile ; et nous croyons qu'il serait plus prudent, avant de rien décider sur cet objet, d'attendre les instructions qui nous seront probablement bientôt envoyées par l'assemblée nationale qui a déjà annoncé qu'elle s'occuperait des établissements relatifs à la santé des citoyens. ${ }^{29}$

À mesure que les mois et les années passent, que les gouvernements se succèdent, l'espérance en la proximité du texte de loi grandit, jusqu’à devenir conviction de la réalité d'une réforme à venir. Celle-ci n'arrive jamais mais réussit à suspendre certaines initiatives locales. À Rennes, en mars 1792, le collège des chirurgiens répond plein d'embarras à l'administration départementale qui vient de décider la création de cours itinérants confiés à un démonstrateur départemental d'accouchements :

Si le collège avoit été consulté sur le projet, avant que son exécution eut été décidée, il auroit certainement posé les questions suivantes : $\mathrm{I}^{\circ}$ doit-on songer à un nouvel établissement d'une instruction publique, avant que l'Assemblée nationale, qui est sur le point de prononcer en ait fixé le mode d'une façon invariable et permanente ? $^{30}$

En l'an v, à deux mois et demi d'intervalle, le ministre de l'Intérieur refuse aux départements de la Marne et du Cher l'ouverture de cours d'accouchement au motif que le corps législatif s'en occupe ${ }^{31}$. La nécessité de préserver le champ libre pour l'exécution des décisions nationales prime sur l'utilité immédiate et l'urgence des besoins n'apparaît pas comme un motif recevable. Du côté départemental, l'espoir et la confiance ne sont toutefois pas exempts d'une certaine lucidité qui s'exprime assez précocement :

\footnotetext{
29. AD Cantal, L 583 .

30. AD Ille-et-Vilaine, $\mathrm{L} 965$.

31. AD Marne, I L I248; AD Cher, I L 625 .
} 
Vous devez donc, Messieurs, pour le bien de l'humanité, ne pas économiser trop sévèrement cette partie de la dépense publique ; car l'espoir de voir l'assemblée nationale la comprendre dans les fraix de l'enseignement, ne peut pas encore se réaliser. ${ }^{32}$

La lassitude des interlocuteurs locaux, le constat des lenteurs, des blocages innombrables ne laissent cependant pas complètement indifférents les élus du peuple. Alors qu'il défend en l'an v devant le Conseil des Cinq-Cents une motion d'ordre sur l'enseignement de la médecine et la police médicale, JeanFrançois Baraillon déplore avec lyrisme les conséquences dramatiques des retards mis dans la conception et l'application d'une réforme :

Il est donc urgent de s'en occuper. Cependant on attend depuis sept mois le rapport de la commission sur l'organisation et le placement des écoles spéciales, dont les écoles de santé font partie. La République entière souffre et gémit de ce retard ; l'imprudence remplace partout le talent et l'impunité enhardit le crime ; des gyrovagues, des funambules, des barbiers, jusqu'à des cochers sont devenus tout à coup, non des officiers de santé, mais des messagers de la mort. [...] Depuis quatre ans, les réclamations se multiplient et depuis quatre ans on ne répond aux besoins des uns, à l'impatience des autres que par un silence obstiné. ${ }^{33}$

Pourtant les projets législatifs existent, ils fourmillent même entre I790 et I803, au rythme d'un ou plusieurs par an pendant cette période, signe de la volonté de prise en main de cette question par l'échelon national.

\section{Pénélope à son ouvrage : les législateurs révolutionnaires}

4 septembre 1790. Le comité de Constitution et le comité de Mendicité sont désormais en charge de présenter à l'Assemblée nationale un plan pour l'instruction des sages-femmes dans les départements.

I9 ventôse an XI. Le Corps législatif vote la loi relative à l'exercice de la médecine qui fixe jusqu'en I892 les modalités de formation et d'exercice des accoucheuses.

Entre ces deux dates s'étend tout l'œuvre des législateurs de la Révolution, de plans en projets, de lois mal appliquées en réformes repoussées. Treize ans de maturation, de propositions, de repentirs, treize ans d'étude de l'existant aussi, d'affirmation de principes désormais réalisables. L'analyse de la politique médicale révolutionnaire a suscité de multiples approches, de la critique

32. AD Cantal, L 20.

33. Motion d'ordre de Jean-François Baraillon, séance du I4 nivôse an v, dans EDRES, p. 223-224. 
virulente des démantèlements corporatistes à l'enthousiasme pour l'irruption de la clinique dans le champ du savoir ${ }^{34}$. Mesurer le travail règlementaire de la Révolution en matière de formation des sages-femmes nécessite d'examiner le contexte plus général des projets concernant l'enseignement médical, et au-delà la place qu'occupe cet enseignement dans le tableau de l'instruction publique.

L'été 1790 concentre tous les commencements. Le 20 août, l'Assemblée nationale réclame aux académies et parmi elles à la Société royale de médecine, un nouveau projet de règlement. Dans le même temps la Société travaille à établir un plan pour l'instruction médicale et l'exercice des professions relevant de la médecine et trouve dans la création, le I2 septembre, du comité de Salubrité une nouvelle tribune où porter ses propositions ${ }^{35}$. Le secrétaire du comité, Jean-Gabriel Gallot, y défend ainsi le 6 octobre, lors de la première séance, les $V$ ues générales sur la restauration de l'art de guérir ${ }^{36}$ qu'il avait présentées devant la Société le 3i août précédent.

Du travail commun de Gallot, de Guillotin, président du comité de Salubrité, et d'hommes comme Tenon, Baudelocque, Louis ou encore Vicq d'Azyr, naît le Nouveau plan de constitution pour la médecine en France, déposé par ce dernier devant l'Assemblée nationale le 25 novembre $1790^{37}$. Ce texte, après une introduction pessimiste, consacre sa première partie à « l'enseignement de la médecine et [à] tout ce qui le concerne ». Deux niveaux de formation sont envisagés pour les médecins, l'un national, appuyé sur quatre ou cinq collèges, et l'autre départemental « où doivent être principalement formés les

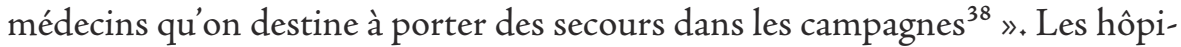
taux tiennent dans le second niveau une place essentielle «car c'est en quelque sorte plus par les yeux que par les oreilles qu'on doit instruire les élèves de ce genre $^{39}$ ». L'enseignement est unifié sous l'égide de la médecine mais les pratiques pédagogiques de la chirurgie viennent avec bonheur le compléter, et la clinique est désormais devenue indispensable ${ }^{40}$.

34. Léonard J., Les Médecins de l'Ouest..., op. cit., p. 204-205 et Faure O., Histoire sociale de la

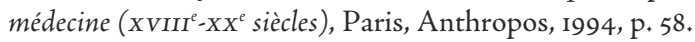

35. Léonard J., Les Médecins de l'Ouest..., op. cit., p. 2II-2I2.

36. Gallot J.-G., Vues générales sur la restauration de l'art de guérir, lues à la séance publique de la Société de médecine, le 31 août 1790, et présentées au Comité de salubrité de l'Assemblée nationale, le 6 octobre; suivies d'un Plan d'hospices ruraux pour le soulagement des campagnes, Paris, Didot le jeune, I790.

37. EDRES, p. 29.

38. Ibid., p. 53 .

39. Ibid., p. 55 .

40. Ibid., p. 8 . 
La place des sages-femmes n'est pas négligeable dans ce plan de formation. Elle occupe toute la troisième section de la première partie ${ }^{41}$. Il est prévu que les élèves suivent les cours d'accouchement dans un hôpital, sous la direction d'un chirurgien, et qu'elles soient établies dans des communes précises après leur réception lors d'un examen public. Comme pour les médecins, la primauté de la clinique est clairement revendiquée :

[...] les élèves sages-femmes seraient entretenues, logées, nourries et défrayées de tout dans un hôpital où des femmes grosses seraient reçues pour accoucher ; à Rouen, à Lyon et à l'Hôtel-Dieu de Paris on trouve de semblables établissements qui ont du succès. Cette méthode parait préférable aux cours que le Gouvernement a quelquefois chargé différentes personnes de faire dans les provinces, parce que, dans le premier cas, l'observation est placée près du précepte, et que c'est en pratiquant surtout que les femmes fixent leur attention sur des détails qui échapperaient à la plupart, si le professeur s'en tenait à la simple exposition sans recourir à la nature.

Ces propositions n'ont rien que de très banal au regard des pratiques d'Ancien Régime. Leur seule nouveauté est de faire entrer l'instruction des sages-femmes dans un plan national et général, répondant ainsi au souhait formulé par l'Assemblée nationale le 4 septembre. Cependant, entre cette date et la présentation du Nouveau plan de constitution pour la médecine en France à la fin du mois de novembre, le rythme et les modalités de la réforme ont pris un tour nouveau :

(I3 octobre 1790) L'Assemblée nationale décrète $: \mathrm{I}^{\circ}$ qu'elle ne s'occupera d'aucune des parties de l'instruction, jusqu'au moment où le comité de Constitution, à qui elle conserve l'attribution la plus générale sur cet objet aura présenté son travail relatif à cette partie de la Constitution $[\ldots]^{42}$

Présidé par Talleyrand, le comité de Constitution a en charge la préparation d'un décret sur l'instruction publique qui en inclut toutes les parties, y compris l'enseignement médical. Du I3 octobre I790 au Io septembre I79I, tout est donc suspendu à l'avancée des travaux de Talleyrand et Mirabeau, principaux rédacteurs du projet de décret présenté à partir de l'automne i79I. Pendant trois jours, les IO, II et I9 septembre I79I, Talleyrand lit devant l'Assemblée son rapport sur l'instruction publique. À l'issue de sa lecture, sont déposés le texte 
imprimé d'un discours de Mirabeau sur le même sujet ${ }^{43}$ et le rapport du docteur Guillotin au nom du comité de Salubrité, enfin autorisé à faire entendre sa voix. Soumis à la Constituante quelques mois après le vote des lois d'Allarde ( 2 et 17 mars) et Le Chapelier (I4 juin) sur le libre exercice des métiers, ces différents textes en précisent la lettre pour en perpétuer l'esprit. En contradiction apparente avec la loi d'Allarde, l'exercice des différentes professions médicales est conditionné à la réussite aux examens (articles 7 et I5 de la section « écoles de médecine », communs au projet de Talleyrand et au projet de Guillotin ${ }^{44}$ ):

La nécessité de ces examens doit être rigoureusement maintenue ; car il faut ici surtout défendre la crédule confiance du peuple contre les séductions du charlatanisme. Il faut donc donner une caution publique à la profession de cet état ; mais en même temps vous voudrez que les anciennes lois coercitives, qui fixaient l'ordre et le temps des études, soient abolies. Vous ne souffrirez pas qu'aucune école s'érige en jurande : ainsi ce ne sera plus le temps, mais le savoir qu'il faudra examiner ; on ne demandera point de certificats, on exigera des preuves ; on pourra n'avoir fréquenté aucune école et être reçu médecin ; on pourra les avoir parcourues toutes, et ne pas être admis. ${ }^{45}$

Pour comprendre l'apparent paradoxe de cette argumentation, il faut rappeler que le projet initial du décret d'Allarde prévoyait le non assujettissement des « médecins, chirurgiens, accoucheurs et sages-femmes » à la patente et leur soumission aux règles spécifiques de leurs professions. La suppression de cette exception dans la version finale du décret est cependant nuancée par la mention dans l'article 7 du caractère contraignant d'une possible réglementation ultérieure :

À compter du $\mathrm{I}^{\mathrm{er}}$ avril prochain, il sera libre à tout citoyen d'exercer telle profession, art ou métier qu'il trouvera bon, après s'être pourvu d'une patente et en avoir acquitté le prix suivant les taux ci-après déterminés, et à la charge de se conformer aux règlements qui pourront être faits. ${ }^{46}$

C'est cette précision qui emporte la suppression sans contestation de l'exception explicite concernant le corps médical. Du point de vue de l'organisation en corps professionnel, les deux projets présentés à l'Assemblée nationale en septembre I79I divergent. Prudent, Joseph-Ignace Guillotin fait le choix de

43. Mirabeau est décédé le 2 avril, le texte de son discours est retrouvé dans ses archives et les Constituants décident de le faire imprimer et présenter à l'Assemblée dans le cadre de ce débat.

44. AP, op. cit., t. 30, p. 487 et Annexes, p. 27-28.

45. Ibid., p. 458.

46. AP, op. cit., t. 23, p. 218, c'est moi qui souligne. 
passer sous silence tout élément relatif à cette exception. À l'inverse, le projet du comité de Constitution, prééminent à ce titre aux yeux des constituants, confirme les dispositions du décret Le Chapelier :

Tous corps de médecine, de chirurgie et de pharmacie, connus sous les noms de facultés, de collèges, de communautés ; toutes charges, tous privilèges, relatifs à l'art de guérir ou à la pharmacie, sont supprimés, à dater du présent décret ; toutes réceptions de médecins, de chirurgiens et de pharmaciens sont interdites jusqu'à l'établissement des nouvelles écoles de médecine. ${ }^{47}$

Qu'en est-il dans tout cela des sages-femmes ? Elles semblent à cette époque quasi systématiquement associées aux décisions générales visant le corps médical. Guillotin leur consacre tout le titre VI de son projet de loi. En six articles, le médecin député affine le cadre proposé par la Société royale de médecine le 25 novembre 1790. La formation s'effectue dans une école départementale (art. I), les élèves sont choisies par leur municipalité d'origine et, en fonction de leur résidence, défrayées par le département pendant la durée des cours (art.2), le suivi de deux cours de trois mois, dont les dates sont à la discrétion du directoire de département, est obligatoire pour se présenter aux deux examens de théorie et pratique des accouchements (art. 3 à 5), et enfin, l'enregistrement préalable au greffe de la commune d'installation est indispensable pour exercer (art. 6). On retrouve ici les grandes lignes de ce qui s'applique déjà en province.

L'approche de la fin des débats de la Constituante, fixée au 30 septembre 179I, emporte pourtant la décision de repousser toute discussion sur l'instruction publique à la législature suivante. Les députés Le Chapelier et d'André demandent et obtiennent toutefois le maintien en exercice des établissements d'instruction ${ }^{48}$. C'est donc un statu quo qui s'instaure, durable puisqu'il est reconduit à chaque nouvelle étude de ces questions devant le corps législatif. Bien sûr, le décret du I8 août I792, en supprimant les congrégations hospitalières et enseignantes, ébranle le système universitaire et le système hospitalier, pourtant couronné comme l'espace pédagogique médical par excellence ${ }^{49}$. Mais l'existence même des hôpitaux n'est jamais remise en cause, même lors de l'intégration de leur patrimoine aux biens nationaux avec la loi du 23 messidor an $\mathrm{II}^{50}$. Plus radicale encore, l'Assemblée nationale, sur pétition du département de Paris, décrète le 15 septembre 1793 que « les collèges de plein

47. AP, op. cit., t. 30, p. 487.

48. AP, op. cit., t. 3I, p. 340 .

49. Léonard J., Les Médecins de l'Ouest..., op. cit., p. 2 I8.

50. Faure O., Histoire sociale de la médecine..., op. cit., p. 65-66. 
exercice et les facultés de théologie, de médecine, des arts et de droit, sont supprimés sur toute la surface de la République ${ }^{51} »$. Dès le lendemain cependant, le décret est suspendu car, comme le souligne le conventionnel Romme, «il ne faut pas supprimer les collèges et ne les remplacer par aucun établissement ${ }^{52} »$. Une fois de plus, le débat est alors renvoyé au traitement général de la question de l'éducation nationale, qui conserve l'enseignement médical dans ses prérogatives comme le montrent les exposés successifs de Romme, Bouquier et Fourcroy entre octobre et décembre 1793. Chacun prend soin de proposer dans son projet un article veillant au maintien « jusqu'à ce qu'il en ait été autrement ordonné » de « toutes les écoles actuellement subsistantes, où l'on enseigne les sciences et les arts, et surtout l'histoire naturelle, la médecine des hommes et des animaux ${ }^{53}[\ldots] »$. Officiellement donc, aucune structure d'enseignement ne disparaît, mais le manque de finances, l'épée de Damoclès continue d'une suppression ou d'une réorganisation, la désertion des étudiants pèsent lourd sur le devenir des institutions médicales.

La situation se dénoue à la fin de l'année 1794 avec le vote, le I4 frimaire de l'an III, par la Convention thermidorienne d'un décret établissant trois écoles de santé à Paris, Strasbourg et Montpellier ${ }^{54}$. La reconstitution d'un enseignement médical français est désormais en bonne voie même si elle progresse lentement ${ }^{55}$. Le règlement de l'école de santé de Paris ne date que du i4 messidor an IV, soit plus d'un an et demi après sa création ${ }^{56}$. En l'an v, le Conseil des Cinq-Cents est saisi à trois reprises de ce sujet (motion d'ordre de JeanFrançois Baraillon «sur les établissements relatifs à l'art de guérir ${ }^{57}$ », rapport de Daunou sur l'organisation des écoles spéciales ${ }^{58}$, rapport de Calès sur l'organisation des écoles spéciales de médecine ${ }^{59}$ ), mais ces interventions, toutes accompagnées de projets précis, restent lettre morte. Deux ans plus tard, le ballet des projets reprend avec le rapport de Cabanis ${ }^{60}$ sur l'organisation des

\footnotetext{
5I. AP, op. cit., t. 74, p. 238 .

52. Ibid., p. 269. Léonard J., Les Médecins de l'Ouest..., op. cit., p. 219.

53. Projet de Fourcroy présenté le 9 décembre 1793 à l'Assemblée nationale, dans AP, op. cit., t. 8I, p. 234 .

54. Marais de Beauchamp A., Recueil des lois et règlements sur l'enseignement supérieur : comprenant les décisions de la jurisprudence et les avis des conseils de l'Instruction publique et du Conseil d'État, (cité RLRES) Paris, Delalain frères, I880-I9I5, t. I, I789-I847, p. 29-3I.

55. Léonard J., Les Médecins de l'Ouest..., op. cit., p. 224.

56. RLRES I, p. 42-55.

57. EDRES, p. 222-252.

58. Ibid., p. 256-267.

59. Ibid., p. 27I-292.

6o. Ibid., p. 44I-46I.
} 
écoles de médecine, présenté le 29 brumaire de l'an vir. Le même sort l'attend. Le rythme s'accélère en l'an IX avec le dépôt à quelques mois d'intervalle d'un projet de loi sur l'enseignement et la police de la médecine (29 pluviôse) et d'un projet d'arrêté concernant les écoles de médecine (23 prairial) ${ }^{61}$, sans plus de succès. Le seul texte voté comportant une mesure aux potentielles conséquences sur le paysage de la formation médicale est la loi du ir floréal an $\mathrm{x}$ (art. 25) qui envisage la création de trois écoles de santé supplémentaires destinées à compléter le décret de l'an $\mathrm{III}^{62}$.

L'abondance de ces textes plaide contre tout soupçon de désintérêt pour la médecine et sa transmission de la part des révolutionnaires. L'ampleur du chantier, les difficultés financières, les changements politiques, la guerre omniprésente sont autant de freins à des réformes souhaitées et longuement mûries. La place tenue par la formation des sages-femmes dans la brouettée des projets législatifs est toutefois marginale et dispersée entre les productions propres aux questions médicales et celles relevant de l'instruction publique. Du côté médical, cinq ans de silence séparent les propositions de Talleyrand et de la Société royale de médecine de deux résolutions portées, lors de la séance du I4 nivôse de l'an v, par la motion d'ordre de Baraillon:

Première résolution : établissements relatifs à l'art de guérir, leur organisation et leur placement. Titre IV : cours public d'accouchements en chaque département. Art. I. Il se fait chaque année, dans les communes où sont placées les écoles centrales, un cours public sur le régime des femmes enceintes, le manuel des accouchements, les suites de couches, l'allaitement, le sevrage et l'éducation physique des enfants. [... ]

Deuxième résolution : du mode d'admission des officiers de santé et des accoucheuses. Titre IV : examen et admission des accoucheuses. Art. I. Nulle citoyenne n'est réputée accoucheuse et ne peut en exercer la profession, si elle n'a fait preuve de capacité par deux examens publics, par devant le professeur d'accouchement, assisté de deux membres au moins du conseil de salubrité du département. ${ }^{63}$

Pourtant à cinq ans de distance, les textes semblent étonnamment proches (défense de la liberté d'accès à n'importe quel métier, examen comme seule preuve de la capacité à exercer). Il faut attendre, pour voir rappeler que l'examen suit le ou les cours, le rapport de Calès : « les citoyennes qui auront suivi le cours d'accouchement et qui voudront exercer cet art seront tenues de subir deux

6I. Ibid., p. 489-497 et 498-504.

62. RLRES I, p. 84 .

63. EDRES, p. 24I et 245. 
examens ${ }^{64} \gg$. Cette affirmation trace la route des rédacteurs ultérieurs, lorsque le Consulat ouvre son chantier de réformes. Dans la production relative à l'instruction publique, c'est le rattachement des cours d'accouchement aux écoles centrales qui est envisagé dès l'an III (rapport de Lakanal devant la Convention), ouvrant la voie aux projets jamais réalisés d'aligner le corps des démonstrateurs sur celui des professeurs des écoles centrales (Baraillon, Calès, Daunou).

Pourquoi au bout du compte une présence aussi faible des sages-femmes dans le corpus législatif révolutionnaire ? Pour quelles raisons ce métier qui provoque tant de discours par ailleurs, tant d'attentes, semble-t-il si peu inspirer les députés de cette décennie 1790 ? Parce que les révolutionnaires l'assimilent au reste du corps médical et le fondent dès lors dans leur réflexion générale sur ces professions? En partie, mais ce n'est pas là une raison suffisante. Les sagesfemmes ont avec les chirurgiens et les médecins une différence essentielle : elles ne forment pas à elles seules un corps, une communauté autorégie. À ce titre, elles ne peuvent pas faire l'objet d'un démantèlement, et le grand ménage de la loi Le Chapelier ne les touche qu'indirectement à travers la suppression des communautés de chirurgiens dont ne dépend nominalement qu'une part restreinte des sages-femmes urbaines. Moins menacées que les médecins et les chirurgiens qui ont des privilèges à conserver et sont largement représentés dans les assemblées successives, les sages-femmes n'ont au fond rien à défendre, hormis leur droit d'exercer.

Autre hypothèse : parce que ce sont des femmes ? Plus sûrement. La formation du corps médical concerne un public traversé par une irrémédiable fracture, celle de l'exercice des droits politiques. L'éducation de la citoyenne n'est pas une priorité puisque son domaine réservé est, dans sa jeunesse, la maison paternelle, puis son propre foyer. Le rapport sur l'instruction publique de Talleyrand assigne d'ailleurs aux femmes le strapontin d'honneur du nouveau régime. La sage-femme fait exception, elle dont le rôle est éminemment public et dont on attend qu' elle se voue sans restriction à ses patientes. Pour les législateurs, il faut choisir entre une femme confinée au rôle d'épouse et mère, et une sage-femme élevée au rang de personnage indispensable au bon fonctionnement de la société. La sage-femme y perd un peu, puisqu'elle disparaît temporairement des textes; la femme n'y gagne pas.

Dernière hypothèse : l'existence législative des sages-femmes pendant la période révolutionnaire est discrète parce que leur formation fonctionne déjà avec régularité sur la majeure partie du territoire national ; il n'y a de ce fait pas

64. Ibid., p. 287. 
d'urgence à refonder ce qui existe déjà. C'est là sans doute la raison principale. De fait, la légitimité de la production règlementaire locale, source d'inspiration pour le niveau national, ne fait aucun doute pour les démonstrateurs qui poursuivent leur œuvre :

L'Assemblée nationale soit dans cette législature, soit dans les suivantes, s'occupera certainement d'un établissement aussi avantageux à l'humanité, et laissera aux départements le soin de la meilleure forme à donner à ce cours d'instruction. ${ }^{65}$

Cette production est diverse : des départements qui, loin de se sentir liés à l'absence de norme nationale en la matière, n'hésitent pas à remettre en usage la réglementation ancienne pour pallier temporairement le vide juridique :

Le préfet du département de la Moselle, informé que, contrairement au Règlement du 28 février 1730, sur l'exercice de la chirurgie, et dont les dispositions relatives à la police, ne sont point abrogées ; des individus des deux sexes, sans études et sans expérience, se sont érigés en accoucheurs ; que par leur impéritie, ils occasionnent souvent la mort des mères de famille et de leurs fruits,

Considérant que des abus de cette espèce, dégénèrent en crimes ; que l'humanité commande de prendre des mesures promptes pour en empêcher la continuation, et que le seul moyen d'y parvenir, est de remettre provisoirement en vigueur, les anciens règlements, jusqu'à ce que des lois nouvelles auront pourvu à régler les épreuves que devront subir ceux qui se destinent à l'art de guérir $[\ldots]^{66}$

À ceux qui, concrètement, en Côte-d'Or, en 1790 et $1793^{67}$, dans les Côtesdu-Nord en $1793^{68}$, dans le Bas-Rhin en l'an $\mathrm{Iv}^{69}$, ou encore dans le Rhône en l'an $\mathrm{vI}^{70}$, mettent en place la formation des sages-femmes en faisant défense d'exercer à celles qui ne la suivraient pas.

À la veille de la rédaction de la grande loi du ig ventôse an XI, l'arsenal règlementaire est prêt, fruit de plus d'une décennie d'attentes locales mais aussi d'initiatives indépendantes des atermoiements législatifs. La Révolution a fait en ce domaine son meilleur miel de l'Ancien Régime ; elle a su, malgré les aléas, tirer parti des structures qu'elle a maintenues ou mises sur pied.

\footnotetext{
65. AD Marne, i L I248.

66. AN, Fi7/2464, Moselle.

67. AD Côte-d'Or, L 542.

68. AD Côtes-d'Armor, I L 594 .

69. AD Bas-Rhin, I L 840 .

70. AD Rhône, I L 53I.
} 


\section{Les cours d'accouchement avant la loi de l'an XI : approche humaine et matérielle}

\section{Maintenir, créer, financer : les coulisses des cours d'accouchement}

Mesurer la réalité concrète de l'enseignement obstétrical pendant les années 1790-1803 n'est pas une mince affaire. Si les toutes premières années de la Révolution, jusqu'en 1792, parfois I793, sont bien documentées, la période de l'an III à l'an vi en revanche est souvent la parente pauvre des ressources archivistiques. L'exhaustivité est donc impossible, mais la confrontation des données survivantes permet cependant de proposer une cartographie des cours en activité sous la Révolution sur une base départementale et indépendamment de l'existence concomitante de plusieurs cours au sein d'un même département. Un ou multiple, le cours d'accouchement est l'émanation d'une même politique sanitaire départementale, marquée par la volonté de faire bénéficier l'ensemble du département de toute formation organisée. Les cours d'accouchement professés à titre privé ne sont pas pris en compte car ils n'apparaissent qu'incidemment dans les archives. C'est donc une cartographie des cours publics d'accouchement au sens actuel du terme, que je propose, c'est-à-dire des cours que les administrateurs de département ont choisi de maintenir ou de créer, qu'ils encadrent et qu'ils financent. Aux côtés des cours concrètement organisés, apparaissent les projets et les vœux de création de cours, car l'intérêt porté à la formation des sages-femmes se manifeste aussi par un nombre non négligeable de projets non réalisés, de sommes votées et non utilisées.

La Révolution et le passage de relais entre administrations ont interrompu un certain nombre de cours. Néanmoins, l'arrêt d'un cours dans ces conditions n'équivaut pas à sa remise en cause. L'enseignement obstétrical délivré sous l'Ancien Régime est marqué par des interruptions, des reprises, des déplacements de cours, et rares sont les villes où la formation des sages-femmes s'est institutionnalisée au point d'être parfaitement pérenne et régulière. Ce sont d'ailleurs les villes où elle perdure en dépit des aléas révolutionnaires : Paris (Office des Accouchées de l'Hôtel-Dieu, puis Hospice de la Maternité à partir de 1797 $^{71}$, Rouen (anciennes écoles de chirurgie et Hôtel-Dieu) ${ }^{72}$,

7I. Hucherard, Sausseret, Girault, Mémoire historique et instructif sur l'hospice de la Maternité, Paris, impr. des hospices civils, I808, p. XI-XIV. Beauvalet-Boutouyrie S., Naître à l'hôpital..., op. cit., p. 25-31; 68 ; 108 .

72. Sur les cours à l'Hôtel-Dieu, voir Bardet J.-P., Rouen aux XVII et XVIII siècles, les mutations d'un espace social, Paris, SEDES, I983, p. 367 ; sur les cours aux anciennes écoles de chirurgie, voir AD Seine-Maritime, L ir64, le cours se tient depuis les années I770 pour sa partie théorique dans les locaux des Écoles de chirurgie de Rouen. Il est poursuivi en ce lieu pendant toute la période révolutionnaire. 
Lyon $^{73}$, Angers (hospice des enfants naturels de la Patrie) ${ }^{74}$, Strasbourg (école d'accouchement) $)^{75}$, Bordeaux (hospice de la maternité) ${ }^{76}$, Caen (faculté de médecine) $)^{77}$, Lille (ancienne école de chirurgie) ${ }^{78}$ et Grenoble (hôpital militaire $)^{79}$. Ces villes, chefs-lieux de département, sont des centres anciens de formation médicale (médecine, chirurgie, obstétrique) et disposent des ressources cliniques nécessaires. Là où les cours d'accouchement sont ancrés dans une institution hospitalière, ils survivent mieux. On ne compte cependant qu'une dizaine de cours dans ce cas, rayonnant dans les plus grandes villes (Paris, Lyon, Rouen, Strasbourg), liés à la personnalité hors norme d'un enseignant (Chevreul à Angers, Marguerite Coutanceau à Bordeaux) ou prenant la suite d'une tradition solide de pédagogie médicale (Caen, Lille, Grenoble).

La formation des sages-femmes ne se réduit pas, toutefois, à ces quelques phares. Les années I790-I79I (carte I) s'inscrivent dans la suite de l'Ancien Régime. Les cours sont maintenus, refondés ou réorganisés. Certaines régions présentent une belle densité comme l'Ouest, de la Normandie à la Bretagne orientale et au Maine. Le Sud-Ouest n'est pas en reste avec un arc de cours qui s'étend de la Gironde aux Hautes-Pyrénées. L'est du Massif central et plus au nord la Bourgogne, sont aussi des terres où l'enseignement obstétrical s'obstine à pousser ses rejetons. Le Nord, l'Est champenois et lorrain jusqu'à l'Alsace, régions populeuses où le besoin de sages-femmes instruites a très tôt été ressenti, maintiennent leurs cours. Des projets voient le jour, là où les cours ont été interrompus (Marseille, Castres, Troyes), mais aussi là où la Révolution est l'occasion de fonder une nouvelle structure (Cantal, Bas-Rhin, Hautes-Alpes). Quelques vides persistent néanmoins que ne sillonnent déjà plus les démonstrateurs itinérants : l'Ouest breton, le Sud aquitain ; ou dont les faibles moyens, encore appauvris par le découpage départemental, n'ont pas permis le maintien des cours : rebords méridional, occidental et septentrional du Massif central, Sud-Est du pays. Plus proche sans doute du cour politique battant du pays, et donc plus sensible aux atermoiements législatifs, la zone d'influence parisienne forme un autre espace où les cours d'accouchement sont absents.

73. AD Rhône, I L 53I.

74. Dubreuil-Chambardel L., L'Enseignement des sages-femmes..., op. cit., p. 67 ; AD Maine-etLoire, $8 \mathrm{~L}_{35}$ et I $\mathrm{N}_{2}$.

75. AD Bas-Rhin, $150 \mathrm{~J}$ iı。.

76. AN, $\mathrm{Fi}_{7} / 2295$, et $\mathrm{AD}$ Gironde, I $\mathrm{N}_{\mathrm{I}}{ }^{*}$.

77. Léonard J., Les Médecins de l'Ouest..., op. cit., p. 218-219.

78. Ibid., p. 220.

79. $\mathrm{AD}$ Isère, $\mathrm{L} 532, \mathrm{~L} 54^{*}$. 
Très rapidement cependant, les difficultés financières et politiques entravent la bonne marche des cours. La transformation des assignats en papier-monnaie à l'automne 1790 et leur dépréciation immédiate et continue font fondre à toute vitesse les sommes votées pour l'organisation des cours ${ }^{80}$. La Marne réussit de 1790 à l'an IV à maintenir des cours « qui [avaient] lieu tous les ans pendant deux mois dans les principales communes du département », soit à Reims, Châlons, Vitry-le-François, Sainte-Menehould, Épernay et Sézanne. Dès l'an III pourtant, la machine s'enraye et le département ne parvient plus à payer suffisamment ses démonstrateurs qui s'en plaignent amèrement auprès des administrateurs ${ }^{81}$. Mais la situation empire encore en l'an IV puisque ce sont désormais les secours aux élèves sages-femmes qui sont versés avec retard. Le 15 thermidor, le chirurgien Robin ${ }^{82}$ prend de nouveau la plume :

En prérial dernier je vous ai fait passer l'état du cours d'accouchement : les élèves n'ont pas encore été payées de ce que vous leur avez accordé par votre délibération du 23 ventôse présente année, parce que la municipalité n'étoit pas autorisée à m’en faire délivrer le montant comme le district l'avoit fait les années précédentes. Ces femmes ont des besoins très pressants et elles ne cessent de m'importuner pour être remboursées de leurs avances ${ }^{83}$.

Le département se trouve finalement dans l'incapacité d'acquitter son dû $^{84}$. La tentative en l'an $\mathrm{v}$ pour obtenir du ministère de l'Intérieur le versement de 6000 francs en espèces métalliques pour la remise en place des cours visiblement suspendus à Vitry, Sézanne, Épernay et Sainte-Menehould depuis l'an III, se solde par une fin de non recevoir. Elle manifeste plus généralement la quasi impossibilité de faire face aux besoins de la formation obstétricale au temps des assignats ${ }^{85}$.

Les aléas politiques entravent eux aussi le bon fonctionnement des cours d'accouchement. Avant même la chute de la royauté, les démonstrateurs se plaignent que des nostalgiques de l'Ancien Régime entravent le bon déroulement de leur mission. En juillet 1792, le chirurgien Bonnieu, qui vient de

80. Soboul A., La Révolution française, nouvelle édition revue et augmentée du Précis d'bistoire de la Révolution [1982], Paris, Gallimard Tel, 1984, p. 207-208.

8I. AD Marne, I L I248.

82. Gélis J., « La pratique obstétricale dans la France moderne : les carnets du chirurgienaccoucheur Pierre Robin (1770-1797) », Annales de Bretagne et des pays de l'Ouest, 1979, vol. 86, nº 2, p. I9I-210.

83. AD Marne, I L I248.

84. Ibid.

85. Ibid. 
commencer son enseignement à Saint-Brieuc pour seulement deux élèves sages-femmes, s'emporte : " D'où vient donc une pareille insouciance pour cet établissement ? [... ] elle peut dépendre encore, des conseils perfides de ces traîtres, qui font envisager la constitution comme un fléau, et ses bienfaits comme des crimes ${ }^{86}[\ldots] »$.

Après le io août en Côte-d'Or, le refus du chirurgien Énaux de satisfaire aux obligations de la loi du I4 août I792 en prêtant serment « d'être fidèle à la nation, et de maintenir la liberté et l'égalité » entraîne son remplacement en I793 par deux autres démonstrateurs, Chaussier et Hoin ${ }^{87}$. En Ille-et-Vilaine, François-Jean Mahé, démonstrateur d'accouchement, écrit, dans une lettre à l'administration départementale en septembre 1792 :

Vous scavez, comme moi, Messieurs, que le quart d'heure actuel n'est guères propice pour donner à l'instruction tout l'essort qui lui convient; cela ne pourra même avoir lieu que l'ordre ne soit un peu rétabli et que les nuages du fanatisme ne soient en partie dissipés. ${ }^{88}$

L'aggravation de la guerre qui oppose la France à l'Europe coalisée est un autre facteur de dysfonctionnement. Le même Mahé est d'ailleurs « obligé de suspendre ses opérations par l'effet des insurrections » le 20 juillet $1793^{89}$. Dans les Côtes-du-Nord, Bonnieu est appelé en l'an II pour être chirurgien de première classe dans l'Armée de Sambre-et-Meuse ${ }^{90}$.

Toutes ces difficultés expliquent l'étiage atteint par le nombre de cours d'accouchement en l'an IV (carte 2) ${ }^{91}$. La formation bourguignonne s'effondre, et de la même façon, les cours charentais ou limousins. Dans le Sud, seules les Hautes-Pyrénées et l'Aquitaine résistent vaillamment mais l'Aude et le Gard ne parviennent pas à maintenir leur enseignement quand le Cantal renonce à projeter des cours. À l'opposé, l'Ouest breton, angevin et normand perpétue ses traditions locales qui vacillent pourtant, à l'instar de la Champagne. La volonté de former des sages-femmes ne sombre pourtant pas avec la réalité des cours. Les vœux et les projets d'organisation de cours renaissent, encouragés par les avancées du travail législatif dont les fruits, loi sur les écoles centrales et loi sur les écoles de santé, mûrissent lentement.

\footnotetext{
86. AD Côtes-d'Armor, i L 594.

87. AD Côte-d'Or, L 542.

88. AD Ille-et-Vilaine, L 965.

89. Ibid.

90. AD Côtes-d'Armor, i L 594.

91. Gélis J., La Sage-femme ou le médecin..., op. cit., p. 224.
} 
Le tournant se prend en l'an vir, et d'une façon plus évidente encore, en l'an VIII. Le retour à la monnaie métallique, le changement de régime politique avec la mise en place du Consulat, la reprise en mains de l'administration départementale avec la création des préfets, l'éloignement des champs de bataille sont autant de facteurs favorables à la réorganisation de la formation obstétricale. Des cours se remettent en place, généralement dans des départements où ils avaient existé pendant les premières années de la Révolution, mais aussi dans d'autres où toute velléité de former des sages-femmes avait disparu depuis l'Ancien Régime comme la Corrèze ou la Haute-Garonne. L'interruption n'a parfois duré que peu de temps comme en Côte-d'Or où les cours ont cessé pendant deux ans. Le nombre de départements où des cours d'accouchement fonctionnent augmente de nouveau pour connaître un apogée en l'an x (carte 3). L'Aquitaine, vieille terre de démonstrateurs, campée aux heures les plus difficiles sur les points d'ancrage solides de la Gironde et du Lotet-Garonne, s'est élargie aux Landes et au Gers. Le Languedoc, où les États avaient multiplié les cours d'accouchement dans la décennie I780, compte de nouveau des écoles en Haute-Garonne, dans l'Hérault et dans l'Aveyron. Plus au nord, la Bourgogne et la Lorraine renouent avec la formation obstétricale, à l'instar de la Touraine et de la Beauce. Les lacunes sur la carte sont encore réelles mais un phénomène nouveau se fait jour. Aux côtés des départements où médecins, chirurgiens ou sages-femmes professent l'art des accouchements, se multiplient les départements où préfets et conseils généraux réclament le droit d'en organiser autant. Le centre de la France, du Cher à la Haute-Vienne en passant par l'Indre, la Creuse et la Vienne, n'a qu'une voix pour demander la mise en place de cours locaux. En Lozère, on se souvient que jadis des démonstrateurs ont porté la bonne parole obstétricale, et l'on souligne en l'an x que « la nécessité d'un cours de cette nature se fait sentir de plus en plus dans ce département ${ }^{92} \gg$. En Vendée la même année, l'attente est identique :

Le conseil avoit dans ses précédentes sessions demandé l'établissement d'un cours d'accouchement ; l'absence de tout secours en ce genre dans les communes de campagne de ce département en sollicite de toute part la mise à exécution. ${ }^{93}$

Ces vœux, ces projets, ces votes prévisionnels de fonds montrent la montée de l'exigence. L'accélération du processus législatif qui mène à la loi du I9 ventôse an XI s'explique aussi par l'impatience des départements qui s'exprime

92. AD Lozère, I $\mathrm{N}$ IO3*.

93. AD Vendée, i $\mathrm{N}$ I. 
par la voix des conseils généraux réformés. Le paragraphe « cours d'accouchement » ou «sages-femmes » devient alors, pour longtemps, un passage obligé des procès-verbaux de délibérations. Il révèle l'accord profond qui se manifeste d'emblée entre le préfet, émanation du pouvoir central, et les assemblées. Représentant du gouvernement dans le département mais aussi seul agent exécutif du département, rarement en poste plus de deux ou trois ans, le préfet prend toutefois très à cœur les destinées du territoire qui lui est confié. Il est l'intermédiaire privilégié entre le ministère de l'Intérieur et l'assemblée départementale : dans l'Indre en l'an viII, le conseil prie le gouvernement « par l'organe du citoyen préfet d'établir dans le chef-lieu de ce département un cours temporaire d'accouchement ${ }^{94}{ }^{2}$. En l'an Ix, dans l'Aude, préfet et ministre sont sollicités de concert pour qu'un « établissement de cette nature [... ] soit incessamment formé ${ }^{95}$ ».

Mais le préfet n'est pas une simple courroie de transmission, et il devance souvent les lenteurs ministérielles et législatives du début du Consulat, en rédigeant les arrêtés réglementaires des futurs cours d'accouchement, en proposant des sommes à voter au conseil général, en rappelant même les conseillers à leurs engagements d'une année sur l'autre :

(Bas-Rhin, an Ix) On s'est occupé de cet important objet; mais l'arrêté projeté pour un cours d'accouchement n'a point encore été livré à l'impression ; il sera communiqué, si le conseil le désire, comme pièce de renseignement au $3^{\mathrm{C}}$ bureau et je recevrai avec plaisir toutes les observations qui pourront m'être faites. ${ }^{96}$

(Cher, an $\mathrm{x}$ ) Vous avez énoncé le vœu, dans vos précédentes sessions, qu'il fut établi dans le département un cours d'accouchement. L'humanité réclame que vous exécutiez cette année un projet aussi utile. Je demande qu'un fond de 3000 francs soit effectué à cette dépense. ${ }^{97}$

L'entente est complète, y compris lorsqu'il s'agit, comme à Rennes, d'écarter un démonstrateur en supprimant son cours et ses honoraires, tout en prévoyant de faire immédiatement renaître l'institution supprimée :

(An xI) J'ai supprimé le traitement de l'ancien professeur d'accouchements, et je l'ai révoqué, ainsi que vous en avez témoignéle désir ; jespère que vous partagerez cependant mon opinion sur l'établissement d'un cours d'accouchement

\footnotetext{
94. AD Indre, $\mathrm{N} 9$.

95. AD Aude, i $\mathrm{N}_{4}$.

96. AD Bas-Rhin, I $\mathrm{N} 4$.

97. $\mathrm{AD}$ Cher, $\mathrm{N} 4$.
} 
dans la ville de Rennes, afin d'instruire des sages-femmes pour les campagnes où l'impéritie occasionne de nombreux accidents. ${ }^{98}$

Dans un système où le préfet est censé être la main du gouvernement, l'opinion du ministre de l'Intérieur est toutefois souvent prise de vitesse par les initiatives préfectorales. Deux méthodes peuvent être employées : faire montre de diplomatie ou imposer ses vues. Proche de Bonaparte, Claude-Laurent Bourgeois de Jessaint, préfet de la Marne, privilégie en l'an Ix l'approche négociatrice :

Comme je prévois qu'il pourra se passer encore plusieurs mois avant que le travail des conseils généraux ait reçu la sanction du gouvernement, et que le moindre délai dans cette circonstance peut être fatal, y aurait-il de l'indiscrétion de ma part de vous demander s'il ne serait pas possible de faire reprendre sur le champ les cours d'accouchements. ${ }^{99}$

Mais tous ses collègues n'ont pas cette patience. Dans les Hautes-Alpes, Charles-François de Ladoucette prend le 4 frimaire an XI un arrêté d'ouverture d'un cours d'accouchement à Gap, prévu pour le I $\mathrm{I}^{\text {er }}$ nivôse suivant. Le 30 frimaire, veille du début du cours, il informe in extremis son ministre Chaptal de sa décision et lui demande son approbation. Le temps que le courrier arrive à Paris, le ministre est mis devant le fait accompli.

Si le préfet est l'ordonnateur des dépenses variables départementales, l'autorisation du ministre de l'Intérieur pour mettre en place un cours d'accouchement reste indispensable même lorsque les fonds existent en théorie et que le conseil général a décidé et voté leur emploi. Cette toute-puissance ministérielle impose parfois d'user d'expédient comme dans le Maine-et-Loire où le conseil général rappelle en l'an $\mathrm{x}$ que le ministre n'a accordé aucune somme pour le cours d'accouchement et déclare qu'il « serait préférable de prendre la somme destinée au cours d'accouchement, sur quelque article de la dépense relative aux arts et aux sciences spéculatives ${ }^{100} »$. Le silence ministériel est opportunément interprété comme un consentement jusqu'à preuve du contraire.

Le chapitre budgétaire auquel est rapportée l'allocation pour les cours d'accouchement varie pendant les premières années du Consulat et de l'Empire : dépenses de préfecture parfois (Haute-Garonne) ${ }^{101}$, mais le plus souvent instruction publique dans la continuité des tentatives législatives de rattachement de ces cours aux écoles centrales menées entre l'an in et l'an Ix. Très

\footnotetext{
98. AD Ille-et-Vilaine, $\mathrm{I} \mathrm{N} \mathrm{I}^{*}$.

99. AD Marne, I L I248.

Ioo. AD Maine-et-Loire, I $\mathrm{N}_{3}$.

IoI. AD Haute-Garonne, I $\mathrm{N} \mathrm{I}^{*}$.
} 
concrètement, il arrive que les frais des cours d'accouchement soient prélevés sur les fonds de l'école centrale comme c'est le cas en Ille-et-Vilaine en l'an vi (le professeur obtient du ministre que « cet établissement entrât dans les dépenses de l'École Centrale $\left.e^{102} »\right)$. L'assimilation est telle que l'ariégeois Pilhès en l'an XI affirme sans le moindre doute qu'il « y avait par la dernière organisation de l'instruction publique un professeur de l'art des accouchemens dans chaque école centrale $e^{103} »$. Cette convergence entre les propositions législatives et une pratique générale dans la rédaction des budgets confirme la pertinence de l'échelle départementale pour l'organisation de la formation des sages-femmes. La pression exercée par les départements sur le gouvernement à travers la multiplicité des vœux, quand les chirurgiens provinciaux ne vont pas jusqu'à proposer un projet de loi prêt à voter ${ }^{104}$, n'est pas seulement un rappel insistant de la nécessité d'une telle formation, mais une justification de leur compétence pour l'accueillir et la faire fonctionner.

\section{Le fonctionnement des cours}

Pendant la décennie qui sépare le début de la Révolution de la loi de l’an XI, l'enseignement obstétrical à destination des sages-femmes reste, dans les formes, relativement fidèle à ce que l'Ancien Régime avait mis au point ${ }^{105}$. Les variations, dans l'ensemble mineures, sont le résultat de l'expérience accumulée au cours du quart de siècle précédent.

\section{Durée et fréquence des cours}

La brièveté des leçons est une caractéristique récurrente de la formation des sages-femmes avant 1789 : six semaines souvent, huit semaines lorsqu'intendants, États ou assemblées provinciales se montrent généreux ou lorsque les démonstrateurs réussissent à plaider la cause d'un cours plus long ${ }^{106}$. Les cours d'une durée supérieure sont rares : trois mois en Haute-Guyenne, six mois à

I02. AD Ille-et-Vilaine, L 965.

I03. AN, $\mathrm{F}_{7} / 2457$, Ariège. Le décret régissant le fonctionnement des écoles centrales a subi un certain nombre de modifications lors du vote de la loi du 3 brumaire an IV, mais le professeur d'accouchement n'a pas été réintégré au nombre des professeurs des écoles centrales, voir Guillaume J. (éd.), Procès-verbaux du Comité d'instruction publique..., op. cit., t. 6, p. 794-795.

I04. Ibid., projet de loi en treize articles.

105. Gélis J., La Sage-femme ou le médecin..., op. cit., p. 130-154.

I06. Il peut arriver que les démonstrateurs complètent d'eux-mêmes gratuitement la durée du cours comme le fait le chirurgien Mangin à partir de I788, voir AD Marne, I L I248. 
Mâcon et Arras ${ }^{107}$. Sur ce point, la Révolution correspond à une légère évolution puisque les cours d'accouchement d'une durée inférieure à deux mois sont désormais exceptionnels. La Côte-d'Or avec son mois de formation détient la palme de la rapidité pédagogique, à peine compensée par la répétition biannuelle du cours ${ }^{108}$. Le Doubs poursuit l'habitude antérieure en proposant deux mois d'enseignement annuels, mais la durée qui revient désormais très fréquemment dans les projets est celle d'un trimestre : Sarthe (I79I $)^{109}$, Ille-etVilaine $(\mathrm{I} 792)^{110}$, Isère $(\mathrm{I} 793)^{111}$, Puy-de-Dôme (an III $)^{112}$; tandis que les cours semestriels sont rares : Côtes-du-Nord (1792) ${ }^{113}$. Le doublement du cours, pratique de plus en plus fréquente sous l'Ancien Régime mais qui ne constituait pas une obligation, fait ainsi son entrée dans le champ réglementaire local, en adéquation avec les vœux de la Société royale de médecine en I790.

Dans les faits et lorsque l'indemnité les défraie suffisamment de leurs dépenses, les élèves reviennent sans difficulté poursuivre les cours d'une année sur l'autre. L'exemple du Gers qui propose à ses accoucheuses une session de deux mois au printemps (avril-mai) et une seconde à l'automne (octobrenovembre) montre que certaines femmes font bien plus que doubler leur cours. En novembre 1793, Barthélémie Lannelongue du district de Mirande et Josèphe Soulés du district d'Auch entament leur cinquième session de formation. À l'issue de ce cours qui s'achève en avril 1794 après six mois d'enseignement ininterrompu, ces deux jeunes femmes ont suivi les démonstrations pendant I4 mois répartis entre le printemps I79I et le printemps I794. Ces exemples ne sont en rien isolés puisque sur les 16 élèves gersoises du semestre 1793-1794, près de la moitié ont fait au minimum deux cours avant celui-ci ${ }^{114}$.

Unique mais porteur d'inspirations ultérieures, le cours de Mâcon est fondé en 1782 par une délibération des États pour une durée d'une année au total, répartie en deux semestres d'internat. Il se poursuit jusqu'en l'an III avant d'être interrompu, faute de fonds ${ }^{115}$. De manière plus surprenante peut-être, Paris est à la traîne du strict point de vue de la durée des cours.

\footnotetext{
I07. Gélis J., La Sage-femme ou le médecin..., op. cit., p. I36.

I08. AD Côte-d'Or, L 542.

I09. $\mathrm{AD}$ Sarthe, $\mathrm{L} 32$.

IIo. AD Ille-et-Vilaine, L 965.

III. $\mathrm{AD}$ Isère, $\mathrm{L} 532$.

II2. AD Puy-de-Dôme, L 2207.

II3. AD Côtes-d'Armor, I L 594 .

II4. $\mathrm{AD} \mathrm{Gers,} \mathrm{L} 280$.

II5. AD Saône-et-Loire, C 525 ; N 82
} 
Le temps de formation à l'Office des Accouchées est de trois mois ${ }^{116}$, et à partir de l'an v, le cours d'accouchement organisé pour les sages-femmes à l'École de santé de Paris ne dépasse pas deux mois, alors que celui réservé aux étudiants en médecine est de quatre mois ${ }^{117}$. La qualité de la formation - et surtout de la formation clinique - ainsi que la sélection des élèves opérée par la maîtresse sage-femme à l'Office des Accouchées compensent cependant en grande partie la brièveté des cours. À l'École de santé, les aspirantes se caractérisent généralement par un niveau d'instruction primaire supérieur. Les élèves sages-femmes de ces deux institutions sont de ce fait plus instruites et plus attachées à la réussite de leur apprentissage que la plupart de leurs collègues provinciales, car elles constituent une infime élite par rapport à l'ensemble des femmes formées dans le pays.

\section{Recrutement et rémunération des démonstrateurs}

Là où les cours n'ont pas cessé entre l'Ancien Régime et la Révolution, les professeurs nommés par les intendants et les assemblées provinciales sont restés en place : Énaux à Dijon, Nedey à Besançon, Chevreul à Angers, tout comme Robin à Reims et Mangin à Châlons. Seule différence : la perte des privilèges associés au statut de démonstrateur de l'art des accouchements (exemptions fiscales, exemption du logement des gens de guerre, etc.) qui disparaissent lors de la nuit du 4 août ${ }^{118}$. Ne reste plus que le traitement extrêmement variable fixé par les administrations départementales.

La définition des attributions du démonstrateur entre en ligne de compte et la perspective d'un cours annuel de deux ou trois mois comparée à celle d'un enseignement continu et ambulant de district en district tout au long de l'année aboutit à des montants très différents qui au fil de la période s'adaptent au «surhaussement des denrées ». En décembre I79I, le département de la Sarthe décide d'accorder 500 livres à son professeur ${ }^{119}$. Moins généreuse, l'Aube ne prévoyait l'année précédente qu'un traitement de 400 livres pour une durée d'enseignement équivalente ${ }^{120}$. À l'inverse, la Bretagne se montre d'une grande libéralité. Que ce soit en Ille-et-Vilaine où le citoyen Brione reçoit en I79I

II6. Beauvalet-Boutouyrie S., Naître à l'hôpital..., op. cit., p. 27.

II7. AD Marne, I L I248; RLRES I, op. cit., p. 43.

II8. Gélis J., La sage-femme ou le médecin..., op. cit., p. 127-I28.

II9. $\mathrm{AD}$ Sarthe, $\mathrm{L}_{32}$.

I20. $\mathrm{AD}$ Aube, $5 \mathrm{M}_{32}$. 
et 1792 un traitement annuel de I ooo livres ${ }^{121}$, et où son collègue, Mahé, en perçoit le double ${ }^{122}$, ou dans des Côtes-du-Nord où le chirurgien Bonnieu est rémunéré I 500 livres par an ${ }^{123}$, les honoraires paraissent calculés en fonction d'un dévouement exclusif du démonstrateur à sa tâche. S'il ne lui est en aucune manière interdit de pratiquer plus largement son art, les administrations de ces départements attendent néanmoins du professeur de l'art des accouchements qu'il consacre le principal de son temps à la formation de ses élèves.

Les obligations inhérentes à la fonction de professeur de l'art des accouchements (ou professeur d'accouchement) relèvent d'une forme de « service public ». Lorsque la charge pédagogique occupe le médecin ou le chirurgien à plein temps, son assimilation à un fonctionnaire est évidente, comme le souligne Jean-Marie Vincent des Côtes-du-Nord, dans sa demande d'augmentation en l'an III ${ }^{124}$. Mais même quand la durée des cours est plus limitée dans le temps, la conscience d'œuvrer pour le bien commun et de mériter à ce titre la reconnaissance pécuniaire de l'État est présente sous la plume des démonstrateurs : "Quoique nous ne soyons ni fonctionnaires publics, ni commis salariés par la Nation, ne remplissons-nous pas des fonctions aussi utiles que sacrées ? ${ }^{125} »$

Plus remarquable encore, l'intégration dans la fonction publique peut à l'occasion s'élargir aux élèves sages-femmes, en général simplement défrayées de leur entretien pendant le temps de la formation par l'administration départementale ${ }^{126}$. Au mois de ventôse an III, les élèves du cours d'accouchement de Châlons adressent à l'administration centrale de la Marne une pétition pour réclamer la révision de leur indemnité, réduite à peau de chagrin par la flambée ininterrompue des prix. Les administrateurs ne balancent pas pour accorder l'augmentation souhaitée et la justifient ainsi :

Vu aussi l'avis du district de Chalons qui estime, vu le surhaussement des denrées, qu'il y a lieu d'accorder trois livres par jour à chacune des élèves qui se rendra à Chalons pour y suivre le cours d'accouchement.

Vu la loi du 4 pluviôse qui détermine le mode des indemnités à accorder aux fonctionnaires publics, les administrations civiles et aux employés,

Le directoire du département de la Marne ; considérant que ceux des citoyens dont les traitements sont au-dessous de la $\mathrm{IO}^{\mathrm{e}}$ classe, doivent recevoir en

\footnotetext{
I2I. AD Ille-et-Vilaine, L 965.

122. Ibid.

I23. AD Côtes-d'Armor, I L 594 .

124. Ibid.

I25. AD Marne, I L I248.

126. Gélis J., La Sage-femme ou le médecin..., op. cit., p. 150.
} 
indemnité une somme égale à leur traitement actuel, que ces dispositions quoi que non nommément dispositives aux élèves des cours d'accouchements peuvent néanmoins leur être appliquées de manière que d'après les principes qui se trouvent consignés dans la loi surénoncée, l'indemnité de ces élèves qui les années précédentes étoit fixée à 15 s. doit être fixée à trente. ${ }^{127}$

Tentative maladroite pour fonder en droit civil la décision du département ou conviction que le futur personnel obstétrical des campagnes est quoi qu'il arrive au service de la patrie, dans les deux cas, le lien établi entre fonctionnariat et place d'élève sage-femme s'inscrit dans une généalogie de la vocation publique de la sage-femme qu'a rappelée Guillotin dès $179 \mathrm{I}^{128}$. En envisageant, pour des raisons certes conjoncturelles, un statut d'élève fonctionnaire, le département de la Marne inaugure une définition nouvelle et riche d'avenir de la sage-femme en formation, définition peu appréciée sur le moment, par Mangin, le professeur du cours :

D'après l'énoncé cy-contre du département [arrêté du 26 ventôse ci-dessus], je crois pouvoir vous observer que ces administrateurs ont mal saisis la loi du 4 pluviôse, qui ne me paroit, et à beaucoup d'autres nullement applicable aux élèves du cours d'accouchement, ni à ce qu'on leur donne à titre de subsistance, elles ne sont rien, elles n'ont ni qualités, ni caracthère public, encor moins des appointemens annuels; ce sont de pauvres femmes de campagne à qui l'on accorde très petitement de quoi subsister les deux mois que dure le cours dans une ville où les commestibles sont hors de prix [... ${ }^{129}$

\section{La voie du concours}

L'affirmation d'un " caracthère public » se double enfin d'une manière nouvelle, bien que non systématique, de recruter les démonstrateurs pour les cours d'accouchements : le concours. Loin d'en faire une loi générale, les administrateurs départementaux n'ont recours à cette méthode que dans des circonstances bien précises : en cas d'interruption temporaire des cours et donc de vacance du poste de professeur. Le concours ouvre alors la charge pédagogique obstétricale à des hommes qu'on peut qualifier de nouveaux, dans la mesure où ils ne sont pas passés par les réseaux d'influence de l'Ancien Régime, même si ce sont en revanche des praticiens confirmés.

I27. AD Marne, I L I248.

I28. AP, op. cit., t. 30, Annexes, p. 40.

I29. AD Marne, i L 1248. 
La notion de concours au sens de compétition pour l'obtention d'une place est ancienne. Les Dictionnaires de l'Académie française, en proposent tous, à peu de chose près, la définition suivante : «On dit, Mettre au concours une Chaire de Théologie, de Droit, de Médecine, etc, pour dire, la mettre à la dispute entre plusieurs prétendans, pour la donner à celui qui aura le plus de capacité ». Le concours implique l'égalité des candidats et son résultat sanctionne la seule prééminence de l'aptitude et du savoir. Il est l'antithèse de la nomination, le remède à l'arbitraire, et s'inscrit naturellement, à ce titre, dans la logique révolutionnaire qui a décrété dans la Déclaration des droits de l'homme et du citoyen l'égale admissibilité de tous à tous les emplois (article 6) ${ }^{130}$.

Sans reposer sur une base législative précise, la décision de mettre au concours les chaires d'accouchement est pourtant prise par plusieurs départements au début des années I790. Dans les Côtes-du-Nord, deux concours ont successivement lieu en 1790 et en l'an III. Le chirurgien Bonnieu obtient l'un des deux postes prévus initialement par l'administration départementale, le second n'étant pas pourvu. Le second concours, qui a lieu les $\mathrm{I}^{\text {er }}$ et 2 brumaire an III, est nécessité par l'appel de Bonnieu aux armées ${ }^{131}$. Le jury est composé d'officiers de santé désignés par les administrateurs du département, mais le concours est public et ouvert à des candidatures de toutes origines. On y trouve François-Jean Mahé, élu démonstrateur dans l'Ille-et-Vilaine en mai I792, forcé à l'automne 1793 d'interrompre ses fonctions et devenu entre-temps agent national du district de Port-Malo ${ }^{132}$. Face à lui, trois candidats «locaux »: Charles Marie Beuscher de Quintin, le sieur Connen et Jean-Marie Vincent de Port-Brieuc. Les modalités du concours sont parfaitement connues par le procès-verbal qu'en dressent les jurés et par la lettre de contestation du résultat qu'écrit François-Jean Mahé le jour même de sa proclamation ${ }^{133}$. Les postulants ont jusqu'à la veille du concours pour faire connaître leur participation et présenter leur certificat de civisme conformément à l'arrêté du 4 mars $1793^{134}$. Le jour dit, ils sont individuellement examinés par les jurés qui leur posent les questions «qui pouvaient le mieux [les] instruire de leurs connoissances, tant sur la théorie et la pratique des accouchemens, que sur les maladies des femmes

\footnotetext{
I30. Léonard J., Les médecins de l'Ouest..., op. cit., p. 713.

I3I. AD Côtes-d'Armor, i L 594.

132. Le décret du I4 frimaire an II remplace tous les administrateurs départementaux par des agents nationaux, il est rapporté par la loi du 28 germinal an III qui supprime ces agents.

133. AD Côtes-d'Armor, i L 594.

I34. Ibid.
} 
qui y sont relatives ${ }^{135} »$. L'examen se fait entièrement à l'oral, ce qui provoque a posteriori la fureur de Mahé, candidat malheureux :

Sans remonter à la singulière méthode avec laquelle on a ourdi les questions auxquelles tu étais présent, au vice d'une telle manière d'examiner, au refus formel qui m'a été fait de prendre les demandes par écrit avant que d'y répondre [... ${ }^{136}$

La vérification des connaissances ne prévoit aucune épreuve pratique ou clinique. La confiance dans les qualités d'accoucheurs des candidats est acquise ; c'est leur aptitude pédagogique qui est évaluée. L'immédiate et violente remise en cause de l'honnêteté des examinateurs par Mahé est révélatrice de l'attente exigeante qui entoure désormais le recrutement par concours :

[...] sans m'étendre, dis-je, sur l'incompétence de trois officiers de santé de classe ordinaire, pour procéder à la nomination d'un professeur, sans mettre en évidence des abus dont je déchirerai le rideau à la première sommation légale qui m'en sera faite, je m'arrête à un passage du procès-verbal relatif au prétendu concours [...]. Je finis par protester contre le procès-verbal qui ne respire que l'arbitraire et la partialité. Je déclare la volonté de me pourvoir devant qui aura droit de frapper de nullité un concours aussi irrégulier $\left[\ldots . .{ }^{137}\right.$

Dans ces formules véhémentes se lit la détestation de tout ce qui rappelle l'Ancien Régime. Les mots d'arbitraire et de partialité sont lourds de sens. Pour annuler ce concours qui à ses yeux n'en est pas un, Mahé en appelle à un autre concours qui, du moins l'espère-t-il, répondra à ses souhaits autant qu'à l'idéal d'égalité dont ce type d'épreuve doit être porteur :

[...] pour mettre dans le plus grand jour tout le défectueux d'une pareille décision, je provoque individuellement et collectivement les trois examinateurs de choisir sous le délai d'une décade et aux frais de quiconque échouera, soit Paris, Caen, Angers ou Rennes pour mesurer nos connoissances respectives en la matière du concours et faire statuer sur la supériorité et l'infériorité de chaque d'entre nous.

Le recours à une instance extérieure pour rejuger le cas témoigne chez le candidat malheureux d'une culture juridique de l'appel, puisqu'il s'agit de s'adresser à des examinateurs dont l'appréciation est réputée libre de toute attache particulière et surtout d'en appeler à la sagacité d'hommes de l'art pratiquant

135. Ibid.

136. Ibid.

137. Ibid. 
dans des cités où existe un enseignement médical. L'appartenance préalable de Mahé au "corps » des démonstrateurs en fait un candidat d'une exigence redoutable, que le choix des examinateurs briochins dégrade au sens le plus littéral du terme. Sa contestation clairement placée sur le terrain du droit tend à faire jurisprudence en imposant le choix de jurés dont il requiert la même expérience et les mêmes compétences que celles réclamées aux postulants.

Nouveauté donc que ces concours ; nouveauté rare mais précieuse, qui entend lier, dans le droit, égalité républicaine, service public et excellence scientifique. Concrètement, le bouleversement reste limité. Symboliquement, dans le domaine de l'enseignement obstétrical et au-delà, il est majeur. En 1789, le démonstrateur de l'art des accouchements nommé par l'intendant remercie pour la grâce qui lui est faite. En 1794, le candidat écarté selon lui à tort invoque la science et les principes de la Révolution et réclame l'organisation d'un nouveau concours.

\section{Se porter au-devant des élèves : beurs et malbeurs du cours itinérant}

En 1759, Angélique du Coudray, «sage-femme errante ${ }^{138}$ », armée de sa « poupée » et de son manuel, chausse ses bottes de sept lieues pour parcourir la France. Lorsqu' elle donne son dernier cours à Bourg-en-Bresse en 1783 avant de s'installer en Aquitaine auprès de ses neveux Coutanceau, elle a accompli un exploit unique en France et en Europe. Un quart de siècle d'enseignement itinérant, à l'échelle d'un royaume dans sa quasi intégralité, des milliers d'élèves, la reconnaissance, parfois agacée mais réelle, de l'administration royale et du personnel médical masculin, autant de réussites que peuvent lui envier tous les accoucheurs de son temps ${ }^{139}$. Si l'exemple est remarquable, la portée de la méthode employée est toutefois restreinte. Dans l'esprit d'Angélique du Coudray, se porter au-devant des élèves pour délivrer de loin en loin une formation minimale est déjà un pis-aller de très loin inférieur au cours régulier et géographiquement stable. Pendant les années I790-I803, le cours itinérant jette ses derniers feux et au moment du vote de la loi de ventôse an XI, il n'est plus guère de voix pour le défendre. L'abandon du cours d'accouchement ambulant est, s'il en est une, la vraie rupture dans la formation obstétricale à l'époque révolutionnaire.

Avant toute chose, il faut différencier formellement cours itinérant et cours de district. La caractéristique du premier est d'être assuré par un seul et même démonstrateur qui se transporte à intervalles plus ou moins réguliers de ville en ville ou en village. Il est fréquent que les « arrêts » du démonstrateur se fassent

I38. Gélis J., La Sage-femme ou le médecin..., op. cit., p. II3.

I39. Ibid., p. II3-I23. 
dans les chefs-lieux des districts d'un département. En cela le cours itinérant est cours de district. Mais cette dernière appellation concerne aussi les cours fixes organisés annuellement dans les chefs-lieux de districts et assurés par des démonstrateurs différents. Pour cette raison, la dénomination « cours de district » leur sera réservée. Pendant la période révolutionnaire, quelques départements accordent leur préférence à cette multiplication des cours, calquée sur le découpage administratif. C'est le cas de la Marne (Reims, Châlons, Épernay, Sainte-Menehould et Sézanne) ${ }^{140}$, c'est aussi le cas de l'Isère (Grenoble, Vienne, Saint-Marcellin et Crémieu) en $179 \mathrm{I}^{141}$. Cours itinérant et cours de district relèvent de la même logique : il s'agit de rapprocher l'enseignement obstétrical des élèves sages-femmes.

En général adaptation aux circonstances, l'itinérance enseignante est aussi défendue comme une méthode pédagogique par quelques démonstrateurs dans les années 1790-1803. La justification théorique la plus avancée est adressée au ministre de l'Intérieur, à quelques semaines du vote du ig ventôse an XI, par le médecin Pilhès, professeur de l'art des accouchements à Pamiers en Ariège jusquà la Révolution ${ }^{142}$. Il s'agit du Mémoire sur la nécessité de l'établissement de cours d'accouchemens et sur le mode d'instruction de cet art, le plus avantageux au public ${ }^{143}$.

Les cours ambulans d'accouchemens utilement organisés, sont seuls propres à procurer ces avantages réels. L'expérience a appris que cette instruction immobile dans une commune de chaque département ne se répendra jamais. Les habitans des campagnes n'en retireront aucune utilité. La décence et les bonnes mœurs ont partout établi l'usage de livrer aux femmes, le soin de secourir leurs semblables, dans le travail de l'enfantement. Ces femmes, soit par insouciance, soit que le moyen d'entretien leur manque, soit qu'elles ne puissent se résoudre à rompre les liens, les affections et les habitudes domestiques, n'abandonneront point leur ménage pour aller chercher au loin les connoissances nécessaires à la pratique de l'art dont elles se sont emparées. Il faut rapprocher l'instruction de leur résidence, la promener dans le département, parce que cet art étant d'un besoin indispensable, il doit aller vers l'artiste qui s'en éloigne.

L'auteur développe une rhétorique du mouvement, opposant l'immobilité du cours et la stagnation des connaissances, à l'alliance bienheureuse de l'ambulance et de la diffusion du savoir. Point d'enseignement clinique, le cours

\footnotetext{
I40. AD Marne, I L I248.

I4I. $\mathrm{AD}$ Isère, $\mathrm{L} 55^{*}$.

I42. AN, Fi7/2457, Ariège; AD Gard, C 708.

143. $\mathrm{AN}, \mathrm{F}_{17} / 2457$, Ariège.
} 
d'accouchement est ici entendu dans sa définition la plus traditionnelle, celle du cours de démonstration où le mannequin vient au mieux apporter l'esquisse du geste à la répétition des leçons. La dévolution de la pratique des accouchements aux femmes est présentée de manière ambivalente. Incontestable conséquence d'une décence à préserver, elle est aussi dépossession, accaparement d'un art par des mains sans savoir ni savoir-faire. À charge donc pour le démonstrateur de pallier ces lacunes pour rendre à l'accoucheuse sa nécessaire et juste place. Les arguments qui complètent la justification sont plus pratiques : habitudes féminines casanières, indigence probable des élèves potentielles, autant de raisons qui font obstacle au déplacement des postulantes.

Mais la beauté du discours bute sur la réalité. Le projet de Pilhès a toute l'apparence d'une proposition longuement mûrie et retenue pour ses qualités scientifiques et pratiques :

C'est dans ces vues bienfaisantes qu' il doit être enjoint au professeur de se transporter tous les ans dans quatre chefs-lieux des justices de paix, désignés par le préfet, pour faire dans chacun, un cours d'accouchements de la durée de quarante-cinq jours, pendant lequel il donneroit deux leçons par jour, qui sont suffisantes pour instruire les élèves, tant sur la théorie que sur la pratique de l'art.

[... Les frais qu'entraînera l'institution des cours d'accouchemens doivent tenir le premier rang dans l'ordre des dépenses que le gouvernement fait pour la prospérité du peuple. Leur durée même ne sera que de quelques années, car aussitôt que toutes les communes de la République seront pourvues de sages-femmes instruites, le nombre des professeurs peut être réduit à un par arrondissement de tribunal d'appel. ${ }^{144}$

Mais tout médecin et ancien démonstrateur qu'il soit, Pilhès est dépassé par l'évolution des exigences dans l'enseignement de son art. Tout dans son texte renvoie à un passé révolu : le cours de six semaines soi-disant suffisant, la prétendue fin de la mission du professeur une fois la dernière élève formée. Les treize années d'interruption des cours ariégeois ont figé un discours bâti sur les souvenirs de l'auteur, souvenirs d'autant plus trompeurs qu'ils sont ceux d'un cours non-itinérant, celui de Pamiers. Pilhès n'a jamais mis en pratique ce qu'il préconise et il transpose dans les premières années du gouvernement napoléonien une réflexion sans doute entamée dans les années 1780 pour remédier aux difficultés rencontrées à l'époque. Sa constatation de départ est juste : l'Ariège et plus largement la France manquent de sages-femmes, mais sa conclusion 
est biaisée par une appréciation faussée de l'organisation concrète des cours d'accouchement dans le pays pendant la décennie précédente. La justification théorique du cours d'accouchement itinérant manque sa cible, précédée par les échecs de toutes les tentatives concrètes dans ce domaine.

Deux régions opposées, les Alpes et la Bretagne, deux démonstrateurs pareillement lancés sur les chemins pour porter la bonne nouvelle obstétricale aux accoucheuses de campagne : deux déceptions et deux abandons au bout du compte. En I791, le chirurgien Eyméoud de Saint-Bonnet adresse aux administrateurs du département des Hautes-Alpes un mémoire sur la formation des sages-femmes ${ }^{145}$. Après avoir longuement rappelé le peu d'efficacité du cours institué sous l'Ancien Régime par les États du Dauphiné à Grenoble, l'auteur déclare avoir trouvé le parfait remède à ces défaillances :

Mais si au lieu d'appeler à grands frais dans un point central fort éloigné, plusieurs sujets que vous destinés à l'instruction, vous appliqués (je ne dirai pas ces mêmes frais) mais peut-être la moitié moins, au déplacement unique de l'homme de l'art qui sera commis pour les instruire.

S'ensuit quantité de calculs destinés à prouver les économies que ce choix permet de réaliser, manière de se concilier les bonnes grâces des trésoriers de ce département pauvre, tout en vantant la rapidité des résultats envisageables (200 élèves sages-femmes en sept ans).

L'enthousiasme des administrateurs est au rendez-vous. Sans tarder, Eyméoud reçoit la charge de professeur de l'art des accouchements et est invité à procéder ainsi qu'il l'a lui-même proposé dans son mémoire. Un an plus tard arrive l'heure du bilan. Quatre cours ont eu lieu dans les différents districts des Hautes-Alpes et le préambule de la lettre qu'adresse le chirurgien à ses commettants se veut la preuve de l'accomplissement de sa tâche : «Les premiers objets que je dois vous présenter sont sans doute les preuves qui constatent l'utilité de l'établissement et la manière dont j'ai rempli mes fonctions ${ }^{146}$. »

Mais les belles certitudes sur l'économie des cours itinérants ont cédé la place à des considérations aussi diplomatiques qu'inquiètes sur la dépréciation de l'assignat, la cherté des vivres et du matériel pédagogique, la perte d'une situation établie, le tout rapporté à un traitement de I 200 livres qui « ne sçauroient suffire au plus strict nécessaire ». Une augmentation de 300 livres rendrait tout juste, eu égard aux circonstances, ce traitement « modique ». Les qualités du cours ambulant ont sombré dans l'expérience et, sans hésitation, le

145. AD Hautes-Alpes, L 1062.

I46. Ibid. 
démonstrateur change son fusil d'épaule, prêt à prêcher la stabilité au chef-lieu avec autant de conviction qu'il prêchait l'itinérance :

J'aurois une résidence fixe, je fairois un cours par an de la durée de trois mois, dans la saison où les travaux de l'agriculture sont le moins pressés, j'instruirois vingt ou vingt-quatre élèves pris au nombre de 5 ou de 6 dans chaque district. [... Le système de permanence que je viens de proposer réunit encore l'économie à tous les avantages moraux car 24 élèves pendant trois mois à 25 sols par jour ne coûteroient au département que 2700 livres à quoi il faudroit ajouter roo livres pour les prix, les frais de route des élèves et enfin le traitement que l'administration jugeroit convenable de m'accorder.

Que n'y avait-on pensé plus tôt ? Vienne une objection sur le peu d'entrain à quitter leur village de ces femmes pour qui, Eyméoud le disait l'année précédente, « 30 lieues d'éloignement sont une Méditerranée à traverser », la réponse est toute trouvée: "Il leur importera peu de faire quelques lieues de plus pour s'instruire, étant surtout défrayées de la route ». L'expérience d'un an a suffi à avoir raison du cours itinérant.

Dans les Côtes-du-Nord, l'idée du cours itinérant prend sa source dans l'œuvre du chirurgien Jacques Dubois qui officie ainsi pendant vingt-deux ans, de 1768 à 1790. Malgré une demande de prolongement de sa charge aux administrations départementales du Finistère et des Côtes-du-Nord à l'automne I790, ce démonstrateur n'est pas reconduit dans ses fonctions. Le département des Côtes-du-Nord organise alors un concours pour recruter deux professeurs dont la mission est de faire cours tout au long de l'année dans les différents districts, concours à l'issue duquel seul le chirurgien Bonnieu est choisi. Commence pour lui le calvaire d'un enseignement itinérant (difficulté à se loger, éloignement familial pesant, perte de revenus) qui ne dure néanmoins que quelques mois puisque, nommé au printemps 1792, il obtient à l'automne de se fixer à Saint-Brieuc. Entre mars et juin 1792, il n'adresse cependant pas moins de six lettres au directoire de département ${ }^{147}$, témoignant toutes d'un désespoir croissant à la perspective de devoir « courir d'un bout du département à l'autre », de Loudéac à Rostrenen ou plus loin encore ${ }^{148}$. Miné par le silence obstiné des administrateurs qu'il inonde de courriers, parfois à quarante-huit

I47. Les six lettres sont envoyées de Quintin les 20 mars et 4 avril I792, de Loudéac les 16 et I8 avril, 4 mai et $\mathrm{I}^{\text {er }}$ juin suivants, il est probable qu'une au moins datée du mois de mars, citée par Bonnieu dans son courrier du 4 avril, ne soit pas parvenue à l'administration départementale ou n'ait pas été conservée.

I48. AD Côtes-d'Armor, I L 594. 
heures d'intervalle, le démonstrateur s'emploie surtout à persuader ses interlocuteurs muets qu'aucun résultat n'est au bout de sa route :

(20 mars) Au reste, s'il m'était de donner mon avis, sur la manière la plus avantageuse et la plus sûre de peupler les campagnes de sages-femmes instruites, il me serait facile de démontrer que ce n'est pas par la voie que l'on a choisie.

( $\mathrm{I}^{\mathrm{er}}$ juin) Cette circonstance me fait désirer plus que jamais que l'administration prenne les moyens efficaces d'opérer sûrement le bien qu'elle s'est proposée, et jaurais à ce sujet bien des observations à lui faire pour y parvenir.

Au bout de six mois, les administrateurs se rendent à l'évidence et acceptent la solution de Bonnieu : un semestre de cours à Saint-Brieuc et huit lits ouverts à l'hôpital de la ville pour accueillir des femmes en couches.

Un an dans les Hautes-Alpes, six mois dans les Côtes-du-Nord, le cours itinérant apparaît rapidement dans les deux cas comme une perte de temps, un gouffre financier et un cadre pédagogique insuffisant. Mais la fin des cours itinérants ne signifie pas la fin du débat sur le degré de proximité souhaitable entre cours d'accouchement et élèves sages-femmes. Plus qu'un renoncement à faire coïncider l'enseignement obstétrical avec un cadre géographique « à taille humaine », c'est le rejet d'un modèle, vivant symbole d'une époque où l'art de la démonstration en était à ses balbutiements. Le résultat de quarante ans de cours ambulants ou stables consacre logiquement la disparition des premiers au profit des seconds, seuls aptes à offrir aux aspirantes sages-femmes les connaissances et le cadre d'apprentissage nécessaires à une formation réussie, alliant théorie et pratique ouverte sur la clinique.

Quel bilan tirer de ces années révolutionnaires ? En 1988, Jacques Gélis écrivait : « la crise de la fréquentation doit être ramenée à sa juste proportion, car il est tout de même des réussites ${ }^{149} »$. Chiffrer les résultats des cours pendant cette période est impossible, trop de listes sont perdues, trop d'incertitudes perdurent sur le rythme de certains cours, leur maintien ou leur disparition. Certitude minimale : des centaines de sages-femmes sont formées entre 1790 et I803, et l'instruction qu'elles reçoivent est de bonne qualité, puisée à l'expérience de démonstrateurs de l'art des accouchements rompus à sa pratique et à son enseignement. Certes, les années vides du cœur de la Révolution sanctionnent un déficit d'accoucheuses compétentes, mais ces années passent rapidement et toutes les sages-femmes instruites pendant la décennie précédente

I49. Gélis J., La Sage-femme ou le médecin..., op. cit., p. 226. 
ne disparaissent pas dans l'intervalle. À ce titre, le bilan en demi-teinte ouvre sur un avenir plus souriant lorsque s'amorce le grand mouvement de réouvertures et de réclamations des cours au début du Consulat.

Plus important, au-delà du nombre de cours, d'élèves, de professeurs, audelà de la rémunération des unes et des autres, la décennie révolutionnaire fait œuvre maîtresse en amenant à maturité la plupart des fruits fleuris sous l'Ancien Régime. La formation des sages-femmes n'est plus et ne peut plus être une préoccupation charitable ou philanthropique : c'est désormais un devoir national, avec tout l'appareil qu'il implique. Le débat ne porte plus sur la nécessité de former mais sur le lieu où l'on doit former et la façon dont on doit le faire. La création de l'Hospice de la Maternité de Paris et la loi sur l'exercice de la médecine du I9 ventôse an XI posent les termes de ce débat. 



\section{De l'institution à la loi : naissance de la sage-femme française}

Entre 1802 et 1803 , le paysage de l'enseignement obstétrical français connaît un bouleversement sans précédent. L'école de l'Hospice de la Maternité de Paris est créée le II messidor an $\mathrm{x}$, puis la loi du I9 ventôse an XI dispose expressément, en son titre v, De l'instruction et de la réception des sages-femmes. À l'orée d'une nouvelle époque, les méthodes de formation obstétricale les moins efficaces et les plus coûteuses ont été écartées, les exigences scientifiques et sociales ont été posées. La sage-femme est devenue un instrument-clé dans l'accomplissement d'un devoir politique envers la vie.

Dans l'émergence simultanée du modèle de l'école nationale, l'Hospice de la Maternité de Paris, et du modèle du cours d'accouchement départemental, l'idéal et la pratique se confrontent. Il en surgit une identité professionnelle, vite érigée en référence exportable dans tous les espaces sous influence ou domination française.

\section{École exceptionnelle, école unique : l'Hospice de la Maternité de Paris}

\section{Et Paris?}

Alors que de toute la France, annonces de cours d'accouchement, projets de cours, demandes d'autorisation remontent au ministre de l'Intérieur, Paris semble formellement en retrait de la riche variété des lieux d'apprentissage de l'obstétrique qui s'y côtoyaient sous l'Ancien Régime. Au regard des règlements qui entrent en vigueur en ce tout début de $\mathrm{XIX}^{\mathrm{e}}$ siècle, les trois villes sièges des écoles de médecine (Paris, Strasbourg et Montpellier) ne sont pas 
censées disposer d'autre établissement de formation médicale, ces écoles remplissant en théorie tous les besoins, et aucune exception n'étant prévue, même pour la capitale. Qu'en est-il dans les faits ?

Le monde de l'enseignement privé d'avant la Révolution, avec ses cours d'accouchement au domicile du chirurgien, du médecin ou de la sage-femme, perdure $^{1}$. La liberté de métier, la quasi disparition des anciennes institutions enseignantes, la lenteur à les remplacer forment un terreau particulièrement riche pour la floraison de démonstrateurs libres. Les cours privés les mieux connus sont ceux destinés aux étudiants en médecine et en chirurgie, mais les apprenties sages-femmes en bénéficient tout autant ${ }^{2}$. Exemple parmi d'autres, qui met en scène un des accoucheurs les plus véhéments et les plus controversés de la place de Paris : le cours théorique et pratique d'accouchement du chirurgien Jean-François Sacombe ouvert pour la vingt-et-unième année le $\mathrm{I}^{\mathrm{er}}$ germinal an vir, rue Gît-le-Coeur ${ }^{3}$. Sacombe se présente comme professeur de médecine et de chirurgie des accouchements au «Palais national des sciences et des arts », c'est-à-dire au Louvre.

Il existe par ailleurs à Paris une tradition ancienne de formation institutionnelle des sages-femmes ${ }^{4}$. Depuis le $\mathrm{xIV}^{\mathrm{e}}$ siècle, le service de maternité de l'Hôtel-Dieu, l'Office des Accouchées, accueille des apprentisses. Celles-ci sont en petit nombre (cinq à six) jusqu'au XVIII ${ }^{e}$ siècle et suivent pendant trois mois les leçons et les démonstrations de la maîtresse sage-femme. En I735, une réforme double les effectifs et met en place deux cours simultanés, un réservé aux élèves sages-femmes souhaitant s'installer à Paris, et l'autre, à celles qui veulent exercer en province. Une vingtaine d'accoucheuses instruites sort désormais annuellement de cette institution qui devient une référence européenne par la qualité de l'enseignement qu'elle dispense et l'exceptionnelle formation clinique à laquelle les élèves ont accès ${ }^{5}$. Néanmoins, l'installation de ce service au sein de l'Hôtel-Dieu laisse fortement à désirer et les accouchées y sont, selon le Mémoire sur les hôpitaux de Paris de Jacques-René Tenon,

I. Fosseyeux M., «Sages-femmes et nourrices à Paris au XviII ${ }^{\mathrm{e}}$ siècle », La Revue de Paris, I92I, septembre-octobre, p. 538 et 544-545.

2. Delaunay P., La Maternité de Paris, Paris, Librairie Jules Rousset, 1909, p. 368 ; Huard P., «L'enseignement libre de la médecine à Paris au $\mathrm{XIX}^{\mathrm{e}}$ siècle », Revue d'bistoire des sciences, 1974, t. 27, $\mathrm{n}^{\circ} \mathrm{I}, \mathrm{p}$. 45-62.

3. Delaunay P., «Les chirurgiens-accoucheurs en chef de la Maternité de Paris, titulaires et prétendants », BSFHM, 1906, n 5, p. 330.

4. Gélis J., La Sage-femme ou le médecin..., op. cit., p. 56 à 64.

5. Delaunay P., La Maternité..., op. cit., p. IV de la préface du docteur Porak. 
dans une «situation déplorable $e^{6}$. Promiscuité, entassement, proximité entre femmes en couches, femmes enceintes et femmes malades font de ce service un repoussoir pour les hygiénistes et un « mouroir » en temps d'épidémie ${ }^{7}$.

La législation sociale des débuts de la République souligne la nécessaire association entre aide aux femmes en couches et lutte contre l'abandon des nouveau-nés ; elle encourage le rapprochement de l'Office des Accouchées et de la Maison de la Couche devenue Hospice des Enfants trouvés ${ }^{8}$ qui aboutit malgré quelques rebondissements au déménagement en 1795 des deux services, réunis sous le nom d'Hospice de la Maternité, dans les bâtiments de PortRoyal et de l'Oratoire (ill. I) ${ }^{9}$. Au sein de la nouvelle organisation, les cours à destination des sages-femmes sont les derniers à retrouver leur place ${ }^{10}$.

La formation des accoucheuses s'interrompt donc quelques mois avant de reprendre à l'identique sous la houlette de Marie Dugès, sage-femme en chef de l'Hôtel-Dieu depuis $1775^{11}$, et de sa fille, Marie-Louise Lachapelle qui remplit depuis 1795 les fonctions d'adjointe de sa mère avant de lui succéder en 1798 (ill. 2). Le nombre de sages-femmes instruites à l'Hospice de la Maternité pendant ces années reste cependant limité ${ }^{12}$. La dernière " promotion » d'apprentisses quitte l'hospice le 2 nivôse an IX, quelques mois après la publication du décret de création de la nouvelle école ${ }^{13}$.

L'autre pôle d'enseignement obstétrical parisien est l'École de santé. Le cours magistral d'accouchement est un cours semestriel qui se tient pendant l'été, de germinal à vendémiaire ${ }^{14}$. Selon l'art. 8 du règlement du $\mathrm{I} 4$ messidor an IV, il se divise en un cours pour les étudiants en médecine et les élèves de la patrie pendant les quatre premiers mois et un cours pour les élèves sages-femmes pendant

\footnotetext{
6. Tenon J.-R., Mémoire sur les hôpitaux de Paris, Paris, Royez, libraire, I788, p. 238-239.

7. Beauvalet-Boutouyrie S., Naître à l'hôpital..., op. cit., p. 33.

8. Ibid., p 59-62.

9. Hervé G. (Dr), «Un mémoire de Hombron sur l'Hospice de la Maternité en I8oI », BSFHM, 1913, $\mathrm{n}^{\circ}$ 12, p. 524.

Io. Chaussier F. (Dr), Notice sur la vie et les écrits de $M^{\text {me }}$ Lachapelle, décédée sage-femme en chef de la maison d'accouchement, Paris, imprimerie de Madame Huzard, I823, p. 8-9.

II. Delacoux A., Biographie des sages-femmes célèbres, anciennes et modernes, Paris, Trinquart, 1834, p. 73.

I2. Chaussier F. (Dr), Notice sur la vie et les écrits de $M^{m e}$ Lachapelle..., op. cit., p. 9 ; P. Delaunay, La Maternité..., op. cit., p. 256.

13. Delaunay P., La Maternité,.., op. cit., p. 280-28I.

I4. Prévost A., La Faculté de médecine de Paris, ses chaires, ses annexes et son personnel enseignant de 1790 à 1900, Paris, A. Maloine, I900, p. I6.
} 
les deux mois restants ${ }^{15}$. La chaire d'accouchements est conjointement détenue par le médecin Alphonse Leroy et le chirurgien Jean-Louis Baudelocque (ill. 3), respectivement professeurs titulaire et adjoint ${ }^{16}$.

Après un cours annulé en thermidor de l'an $\mathrm{IV}^{17}$, le premier cours pour les sages-femmes débute, sur proposition d'Alphonse Leroy, le $\mathrm{I}^{\mathrm{er}}$ pluviôse an $\mathrm{v}$ et se tient dans l'amphithéâtre de perfectionnement pour la clinique. Il peut être ouvert à quelques étudiants en médecine « laissant à [la] prudence [du professeur] à en faire le choix, à en fixer le nombre, et le chargeant, sous sa responsabilité, d'y faire régner la décence ${ }^{18} »$. Soucieuse d'obtenir la plus large audience, l'École de santé fait annoncer le cours par des affiches et par une lettre circulaire envoyée à l'ensemble des départements appartenant au ressort de l'établissement.

L'enseignement est finalement confiéà Jean-Louis Baudelocque qui remplace le professeur titulaire, façon de ménager l'amour-propre des deux praticiens en leur offrant à chacun un domaine d'exercice précis. Or, Baudelocque est le plus apte à assurer ce cours. Ses Principes de l'art des accouchements sont, depuis leur première édition en 1775 , une référence essentielle des manuels d'obstétrique pour les sages-femmes ${ }^{19}$. Son expérience pédagogique (collège de chirurgie de Paris depuis 177I) n'a d'égale que son expérience pratique et il conserve pendant la Révolution à Paris une clientèle nombreuse ${ }^{20}$. De son côté, Alphonse Leroy, ancien docteur régent de la Faculté de médecine de Paris, s'est toujours montré plus sensible au développement de la formation obstétricale des médecins quà celle des sages-femmes. Son projet présenté à l'Assemblée nationale en 1790 et intitulé Motifs et plan d'établissement, dans l'hôpital de la Salpêtrière, d'un séminaire de médecine pour l'enseignement des maladies des femmes, des accouchements et de la conservation des enfants n'est destiné qu'aux étudiants en médecine. Après le rejet de cette première proposition, Leroy persiste en rédigeant un second mémoire adressé à la municipalité parisienne où il envisage l'ouverture d'un « séminaire de médecine » couplé à l'école vétérinaire d'Alfort, déménagée

15. RLRES I, p. 43. Les élèves de la patrie sont des jeunes gens choisis dans chaque district départemental par des officiers de santé. La scolarité de ces jeunes gens est prise en charge par l'État et ils reçoivent un traitement égal à celui des élèves de l'École centrale des travaux publics.

16. Prévost A., La Faculté de médecine de Paris..., op. cit., p. 28-29.

17. AD Marne, I L I248.

I8. Prévost A., L’École de santé de Paris..., op. cit., p. II8.

19. Baudelocque J.-L., Principes de l'art des accouchements par demandes et réponses, en faveur des élèves sages-femmes, $7^{\mathrm{e}}$ édition augmentée, Paris, Germer-Baillière, I837, avec reprise de l'avertissement de l'auteur pour la $3^{e}$ édition, p. XI.

20. Delaunay P., «Les chirurgiens-accoucheurs en chef de la Maternité de Paris... », art. cit., p. 327-328. 
à Paris dans les locaux de l'ancienne abbaye Saint-Victor ${ }^{21}$. Nulle mention de sages-femmes dans ces deux projets, et un rejet très clair de ce que Leroy considère comme une mainmise indue de la chirurgie sur l'obstétrique. Rien d'étonnant donc à le voir quelques années plus tard conserver la haute main sur les cours réservés aux étudiants en médecine de l'École de santé.

La claire partition de l'enseignement obstétrical dans cette institution, qui ouvre sur une chaire des accouchements bicéphale, efface la traditionnelle distinction entre professeur titulaire et professeur adjoint (ou prétendant) : le médecin et le chirurgien sont professeurs à part entière. Dès le 2i floréal an vi, à la demande de Jean-Louis Baudelocque, la durée du cours pour les sages-femmes passe de deux à trois mois et les élèves masculins en sont exclus. Il obtient en outre qu'en lieu et place du certificat de présence et d'assiduité habituellement délivré à la fin du cours, les élèves accoucheuses reçoivent un certificat de capacité, rétablissant ainsi la délivrance d'un diplôme ${ }^{22}$.

Malgré une durée équivalente, une différence fondamentale sépare le cours de l'Hospice de la Maternité et celui de l'École de santé : l'accès à un enseignement clinique. Les élèves de Jean-Louis Baudelocque doivent, comme les étudiants en médecine, se contenter d'un cours magistral ${ }^{23}$, même si le Conseil des hospices de Paris autorise le II thermidor an $\mathrm{x}$ quelques-unes des élèves de l'École à assister, en présentant une carte d'entrée, aux cours professés par Baudelocque à l'Hospice de la Maternité, sans les admettre toutefois aux exercices pratiques ${ }^{24}$.

L'enseignement institutionnel parisien de l'obstétrique avant 1802 est donc pris entre deux établissements aux réelles insuffisances dont la complémentarité ne va pas de soi. L'École de santé, structure de référence du nouvel enseignement médical révolutionnaire, n'a pas les moyens des ambitions qu'on entend lui faire porter. Par ailleurs, en perpétuant à l'identique la tradition d'assistance et de transmission professionnelle de l'Office des Accouchées dans le jeune Hospice de la Maternité, la Convention conserve à Paris un établissement exceptionnel dans ses potentialités pédagogiques mais incapable en l'état de répondre aux besoins quantitatifs d'accoucheuses instruites.

Dans les projets législatifs de l'an Ix, la réforme tant attendue de l'enseignement médical n'intègre pas cette bipolarité parisienne et de ce point de vue, la création par Chaptal de l'école de l'Hospice de la Maternité de Paris

21. AN, F ${ }^{15} / 1861$.

22. Prévost A., L'École de santé de Paris..., op. cit., p. 29.

23. Beauvalet-Boutouyrie S., Naître à l'hôpital..., op. cit., p. I08.

24. Delaunay P., La Maternité..., op. cit., p. 290. 
en messidor de l'an x n'entre pas dans le schéma initial des législateurs. Elle se comprend plutôt dans une généalogie française et parisienne, celle déjà évoquée de l'Office des Accouchées, mais aussi dans un mouvement européen de fondation et de développement des maternités-écoles, et enfin comme un espace d'élaboration d'une définition spécifique de la sage-femme.

\section{Maintien et invention de la Maternité dans la constellation européenne}

L'arrêté du II messidor an $\mathrm{x}$ naît d'un projet d'organisation du service de la maternité présenté par le Conseil d'administration des hospices de la ville de Paris au ministre de l'Intérieur ${ }^{25}$. Ce projet et l'arrêté qui en découlent ont pour objet de fixer les deux principaux aspects du service qui sont $:$ l'instruction des élèves sages-femmes et le service des enfants trouvés.

En I802, l'école de l'Hospice de la Maternité de Paris prend donc sans solution de continuité la suite des cours donnés aux apprentisses par la sage-femme en chef de l'Hôtel-Dieu. Le principe d'une école où le volet clinique constitue l'axe structurant de l'enseignement est conservé. Mais le personnel enseignant et la taille des classes n'ont plus rien à voir avec la transmission quasi familiale du savoir par la sage-femme en chef à ses quelques élèves. Les leçons sont désormais données pour la théorie par le chirurgien-accoucheur en chef et pour le «manuel des accouchemens » par la sage-femme en chef (art. 8 et 9). Quant au nombre d'élèves, il est fonction de ce que les bâtiments peuvent accueillir (art. 2). L'arrêté-règlement prévoit même qu'en cas de dépassement de ce nombre, le conseil d'administration des hospices trouve des logements supplémentaires «si mieux n'aiment les élèves se loger à leurs frais » (art. 4). La durée de formation est doublée (six mois), voire quadruplée lorsque les élèves suivent deux cours consécutifs (art. 5 et 6).

$\mathrm{Au}$ bout du compte, le changement d'échelle est spectaculaire. Numériquement, on passe d'une dizaine d'élèves à une centaine par an pendant les premières années d'existence de l'école ${ }^{26}$. Pédagogiquement, l'adjonction d'un autre enseignant à la sage-femme, le chirurgien-accoucheur en chef, semble rompre avec la logique d'un enseignement strictement féminin. Géographiquement, le ressort de l'école de l'Hospice de la Maternité de Paris est l'ensemble de la France, soit le ressort des trois écoles de médecine. Dernière

25. RLRES I, p. 87-89, arrêté-règlement du ministre de l'Intérieur sur les divisions du service de la Maternité, II messidor an $\mathrm{x}$.

26. Beauvalet-Boutouyrie S., Naître à l'hôpital..., op. cit., p. I37. 
caractéristique : l'établissement n'est ouvert qu'aux élèves féminines, après que la proposition du service de santé des hôpitaux de Paris d'y admettre des étudiants en médecine a été repoussée $e^{27}$.

La principale raison donnée de cette éviction des hommes est la préservation de la pudeur et de la moralité des élèves. Marie-Louise Lachapelle s'insurge contre la perspective d'un enseignement mixte ${ }^{28}$, et plus tardivement, c'est encore cette raison qui revient sur les lèvres des obstétriciens parisiens lorsqu'ils évoquent la fermeture de la Maternité à la gent masculine ${ }^{29}$.

Encadrement pédagogique renforcé, élargissement de l'audience de la formation, approfondissement du savoir délivré : l'établissement nouvellement créé acquiert une place à part dans le réseau européen des maternités-écoles. Pour prendre la mesure de cette place, il faut revenir sur celle de l'Office des Accouchées avant lui. La primauté et l'antériorité de l'établissement parisien en font l'ancêtre et le point de mire de toutes les institutions européennes de formation obstétricale.

L'Italie est un excellent exemple de cette influence française. Dans la continuité de la tradition savoyarde d'appel à des sages-femmes françaises, la maternité de Turin fondée en 1720 met à sa tête une ancienne élève de l'Hôtel-Dieu et huit ans plus tard, une réforme en fait une véritable école de sages-femmes sur le modèle parisien ${ }^{30}$. Aux marges du royaume de France et de là, dans l'Empire, l'inspiration puisée à l'Office des Accouchées de Paris est réinventée à la lumière de l'importance accordée à l'enseignement universitaire. Strasbourg, sous la houlette de Jean-Jacques Fried et du prêteur royal Klinglin, réforme entre 1728 et 1737 le statut des accoucheuses de la cité et leur formation ${ }^{31}$. La création en I737 d'une véritable école pratique dans les locaux de l'hôpital civil ${ }^{32}$ offre à la ville son «Office des Accouchées » rhénan, «école mère de toutes celles de l'Allemagne $e^{33} »$. Elle inaugure dans l'espace germanique une association, alors

\footnotetext{
27. Ibid., p. I08 ; Delaunay P., La Maternité..., op. cit., p. 28I.

28. Beauvalet-Boutouyrie S., Naître à l'hôpital..., op. cit., p. I37.

29. Siebold E. C. J. (von), Lettres obstétricales, traduites de l'allemand par Alphonse Morpain, avec une introduction d'Alexis Stoltz, Paris, Baillière, I866, p. 76.

30. Ibid., p. I78 ; Filippini N. M., «Sous le voile : les parturientes et le recours aux hospices de maternité à Turin, au milieu du XIx ${ }^{\mathrm{e}}$ siècle », RHMC, t. 49, nº I, janv.-mars 2002, p. I79 ; Pancino C., Il bambino e l'acqua sporca..., op. cit., p. 93-97.

31. Gélis J., La Sage-femme ou le médecin..., op. cit., p. 297-298.

32. AD Bas-Rhin, I50 J IIo, manuscrit de Joseph-Alexis Stoltz sur l'école d'accouchement de Strasbourg, notes inédites.

33. Siebold E. C. J. (von), Essai sur l'histoire de l'obstétricie, Göttingen, I839 (t. I), I845 (t. 2), Paris, G. Steinheil, I89I, t. 2, p. 37I, citation d'Osiander, professeur d'obstétrique et directeur de la maternité de Göttingen entre 1792 et 1822.
} 
inédite mais appelée à un bel avenir : celle de la réunion, dans un même établissement d'enseignement, des sages-femmes et des étudiants en médecine. La création de l'école pratique est ainsi confortée par la création conjointe d'une chaire extraordinaire de l'art des accouchements à la faculté de médecine, détenue par le Hebammenmeister (professeur de l'art des accouchements) puis par son adjoint. Le lien entre université et école d'accouchement est posé, même s'il faut attendre la création de la maternité-école de Göttingen en I75I pour qu'une institution de ce type ait officiellement un statut universitaire ${ }^{34}$. Élève et compatriote de Fried à Strasbourg, Johann George Roederer reçoit lui aussi le titre de professor extraordinarius ${ }^{35}$. L'enseignement de l'obstétrique entre donc par la bande - un statut de professeur extraordinaire ${ }^{36}$ - dans le paysage des facultés de médecine. L'association officielle entre un établissement d'accueil des parturientes et le cursus universitaire devient le nouveau modèle de l'enseignement obstétrical, semant l'Empire d'une multitude de maternités-écoles dans la seconde moitié du siècle : Berlin (hôpital de la Charité, I75I), Cassel (1763), Brunswick (I768) et tant d'autres dans la décennie $177 \mathrm{O}^{37}$.

Mais l'émergence d'une formation clinique à destination des étudiants en médecine et en chirurgie, de plus en plus fréquemment inscrite dans le cadre universitaire, renvoie de facto les sages-femmes au second rang des préoccupations pédagogiques affirmées, comme le résume en I800 Osiander, successeur de Roederer à la tête de la maternité de Göttingen : « Le centre d'accouchement de Göttingen a d'abord pour but de former des obstétriciens compétents, dignes du nom de Geburtshelfer. Son deuxième objectif est de former des sages-femmes ${ }^{38} »$.

La diffusion de ce nouveau modèle est remarquable et résulte d'un triple mouvement. Le premier aspect est politique et institutionnel, dans un espace germanique où l'université est un instrument d'affirmation des micro-États impériaux ${ }^{39}$. La diffusion du nouveau modèle est en second lieu individuelle et érudite, par la circulation perpétuelle des hommes de sciences à travers l'espace

34. Schlumbohm J., "Comment l'obstétrique est devenue une science », ARSS, 2002, vol. I43, $\mathrm{n}^{\circ}$ I, p. 18 et 20.

35. Ibid., p. I9.

36. Le statut de professeur extraordinaire ne donne droit à aucune rémunération de l'université.

37. Siebold E. C. J. (von), Essai sur l'bistoire de l'obstétricie, op. cit., p. 397, 40I, 4II.

38. Schlumbohm J., «Comment l'obstétrique... », art. cit., p. 2I.

39. Saada A., « De Halle à Göttingen. Processus d'institutionnalisation et développement intellectuel », dans Bödeker H. E., Büttgen P., Espagne M. (dir.), Göttingen vers 1800, l'Europe des sciences de l'homme, Paris, Cerf, 2010, p. 3I-32. 
germanique et, plus largement, à travers l'Europe ${ }^{40}$. Le mouvement, enfin, est scientifique, avec l'apothéose d'un savoir-faire - l'art des accouchements - en savoir - l'obstétrique ${ }^{41}$. Il ne s'agit plus seulement d'aider à terminer un accouchement lorsque la nature fait défaut mais bien de comprendre les mécanismes les plus profonds de ce phénomène ${ }^{42}$. L'obstétrique opératoire n'est plus qu'une facette parmi d'autres de cette spécialité médicale ${ }^{43}$.

Toutefois, la pertinence d'un enseignement strictement réservé aux sagesfemmes à la fois du point de vue temporel (cours à une période précise de l'année) et institutionnel (maternité-école spécifique) n'est au fond pas complètement écartée par le modèle universitaire. Strasbourg accueille à partir de I779 une école d'accouchement pour les élèves sages-femmes de la campagne abritée dans les locaux de l'hôpital militaire ${ }^{44}$. Au-delà, l'espace germanique compte aussi quelques maternités-écoles pour les seules futures accoucheuses quand nombre d'établissements veillent à faire alterner pendant l'année les cours pour chacun des publics.

L'éducation des accoucheuses reste un objet de grand intérêt pour les élites politiques et médicales. L'exemple de Göttingen, étudié par Jürgen Schlumbohm, est révélateur des enjeux différenciés que recouvrent l'instruction des futurs médecins et celle des futures sages-femmes. La comparaison entre les effectifs des deux groupes qui suivent les cours de Friedrich Benjamin Osiander entre 1792 et 1800 révèle une large disproportion en faveur des étudiants en médecine (600), tandis qu'à peine une centaine de sages-femmes reçoivent leur instruction dans le même cadre ${ }^{45}$. Mais seules les secondes sont réellement destinées à fournir l'encadrement obstétrical des villes et villages du Hanovre. L'autorisation d'exercer n'est délivrée désormais qu'aux femmes qui ont suivi auparavant le cours trimestriel de l'université. De surcroît, à la maternité de Göttingen, les futures sages-femmes bénéficient bien plus que les étudiants en médecine d'une vraie formation pratique (examen, accouchement) hebdomadaire voire bi-hebdomadaire, signe qu'à l'opposé des professions de

40. Gélis J., La Sage-femme ou le médecin..., op. cit., p. 292-294.

41. Schlumbohm J., "Comment l'obstétrique... », art. cit. ; id., « Les limites du savoir : médecin et femmes enceintes à la maternité de l'université de Göttingen aux alentours de I800 », RHMC, 2005, 52-I, p. 64-94.

42. Schlumbohm J., «Les limites du savoir... », art. cit., p. 75 sq. ; Gélis J., La Sage-femme ou le médecin..., op. cit., p. 254 sq.

43. Schlumbohm J., «The Practice of Practical Education: Male Students and Female Apprentices in the Lying-in Hospital of Göttingen University, 1792-1715 », Medical History, 2007, 51, p. 13.

44. AD Bas-Rhin, I50 J IIo.

45. Schlumbohm J., «The Practice of Practical Education... », art. cit., p. 6. 
foi d'Osiander sur la nature universitaire de son enseignement, la dimension pratique de ce dernier bénéficie avant tout à celles qui en ont le plus besoin ${ }^{46}$.

En Russie, c'est encore la formation des sages-femmes (strictement séparée de celle des étudiants en médecine) qui est privilégiée : fondations des impératrices Élisabeth Petrovna, Catherine II et Maria Feodorovna entre I754 et I800 à Saint-Pétersbourg et à Moscou, scolarité longue en instituts fermés, désignation d'élèves boursières ensuite envoyées dans les provinces ${ }^{47}$. La réforme de I80o fait par ailleurs de l'Institut moscovite une école pionnière puisqu'à l'issue de trois ans de cours, les élèves peuvent échanger leur attestation de capacité de l'Institut contre un diplôme de l'université de $\mathrm{Moscou}^{48}$.

Au bout de ce chemin se trouvent Paris et son école de l'Hospice de la Maternité. L'école créée par Chaptal est l'aboutissement d'une évolution circulaire. Dans les années i720, l'Office des Accouchées répand son modèle en Europe ; au début du XIX ${ }^{e}$ siècle, le modèle revient affûté aux armes de plusieurs générations d'accoucheurs et de pédagogues. De Moscou à Paris, en deux ans, la légitimité d'une grande institution toute réservée aux élèves sages-femmes a refait vigoureusement surface. Que la résurgence ait lieu dans des États fortement peuplés et très majoritairement ruraux où l'encadrement médical de la naissance ne peut matériellement et moralement pas passer par des mains masculines n'est pas un hasard. À l'opposé d'un espace germanique où le pullulement des États leur impose de chercher un relais de puissance dans les institutions non strictement politiques que sont les universités, France consulaire et Russie tsariste, marquées par la force croissante $\mathrm{du}$ pouvoir central, appliquent, pour l'encadrement de l'accouchement, une démarche qui refuse tout intermédiaire entre le gouvernement et la sagefemme, instituée agent protecteur des peuples à naître. Conserver pour les seules accoucheuses le vaste champ clinique de l'Hospice de la Maternité de Paris manifeste alors l'individualisation d'un corps professionnel, celui des sages-femmes, volontairement soustrait pour son recrutement et sa formation au contrôle médical universitaire.

46. Ibid, p. I6.

47. Siebold E. C. J. (von), Essai sur l'histoire de l'obstétricie, op. cit., p. 546-547 ; Lefort L., Des Maternités, étude sur les maternités et les principales institutions charitables d'accouchement à domicile dans les principaux pays états de l'Europe, Paris, Victor Masson et fils, I866, p. 156-158.

48. Lefort L., Des maternités..., op. cit., p. I67 et I7I. 


\section{Une seule école pour former la sage-fermme française : le ministre et le médecin}

\section{Le plaidoyer du ministre}

Depuis l'an III, les écoles de santé forment en théorie des sages-femmes. Depuis l'an viII, des cours départementaux d'accouchement se multiplient de nouveau dans tout le pays. Fonder à Paris l'école de l'Hospice de la Maternité impose donc au ministre de l'Intérieur, Chaptal, de justifier sa décision, ce qu' il fait dans sa lettre-circulaire du 9 thermidor an $\mathrm{x}$. L'argumentaire n'y consacre qu'une mince place à la déploration traditionnelle des méfaits des matrones, car l'intérêt du ministre réside dans la substitution d'une seule école nationale aux institutions départementales.

Après avoir salué la « sollicitude » des préfets qui ont tenté d'établir des cours $^{49}$, le ministre ne s'étend pas sur les défauts des créations précédentes, privilégiant la description des avantages de la jeune institution, tout en assénant l'interdiction à peine voilée de fonder de nouveaux cours :

La mesure que je vous indique est préférable à l'ouverture des cours d'accouchemens dans chaque arrondissement, puisque, indépendamment d'une instruction plus étendue, plus conforme aux principes, elle vous donne aussi, par l'économie dans la dépense, le moyen de former un plus grand nombre d'élèves. ${ }^{50}$

Se saisir de l'argument financier à une période où l'autorisation ministérielle est indispensable au fonctionnement d'un cours est un appel à la bonne gestion autant qu'une menace. Le fond de la circulaire développe pourtant une réflexion bien plus profonde. La description de la formation délivrée dans la nouvelle école de l'Hospice de la Maternité consacre une pédagogie et fonde une exigence :

Tout, dans ce règlement, a été calculé pour la meilleure instruction possible à donner aux élèves sages-femmes. Là, non seulement elles recevront des leçons théoriques et élémentaires, mais elles y seront aussi exercées au manuel des accouchemens; elles pourront même être appelées à tour de rôle à opérer dans quelques uns des cas difficiles. L'établissement, où près de deux mille accouchemens ont lieu par année, en offre tous les moyens ; il offre de plus la facilité d'y puiser la connaissance des observations et de tous les cas extraordinaires qui peuvent intéresser l'étude des accouchemens. Ainsi, de cette réunion de la

49. AD Aveyron, 3 X 45 .

50. Ibid. 
pratique à la théorie, les élèves retireront nécessairement un grand avantage, et retourneront dans leur domicile avec des principes solides et bien développés, qui pourront faire enfin cesser les maux et les accidens que l'inexpérience n'a que trop souvent produits dans cette partie de l'art de guérir. ${ }^{51}$

En I802, dans bien des cours d'accouchements, le « recyclage » (Gélis) des matrones est encore le seul horizon. La création de Chaptal bouscule ce fatalisme et propose un idéal : une sage-femme pleinement compétente et légitime dans son rôle d'accompagnement des parturientes et des accouchées. L'enseignement, conçu selon cet idéal, rassemble toutes les facettes de l'obstétrique opératoire : la transmission des connaissances théoriques, celle du savoir pratique de base (mannequin) et son approfondissement par l'apprentissage clinique. L'Hospice de la Maternité, avec ses « deux mille accouchemens par année », est l'instrument privilégié de l'observation, puisqu'en six mois ou un an, les futures accoucheuses voient plus de naissances qu'en une décennie de carrière pour certaines. La répétition à cette échelle de l'observation offre une réplique en miniature des fantaisies de la nature. L'accouchement dystocique y est ramené à sa juste place, une relative rareté, mais reste suffisamment fréquent pour devenir une difficulté que la combinaison du savoir, de l'observation et de l'expérience peut résoudre.

\section{Défense et illustration de l'Hospice de la Maternité par son professeur}

Deux textes postérieurs soulignent l'ambition et l'originalité de la Maternité : $l^{\prime}$ « avertissement de l'auteur » en tête de la troisième édition des Principes sur l'art des accouchements de Jean-Louis Baudelocque paru en $1806^{52}$ et le Mémoire bistorique et instructif sur l'Hospice de la Maternité (I808), œuvre collective de l'agent de surveillance de l'établissement, Hucherard, du préposé à l'état civil, Sausseret, et du contrôleur du mouvement intérieur de l'hospice, Girault ${ }^{53}$.

Le texte de Baudelocque, rédigé en 1805 , alors que son auteur occupe depuis trois ans le poste de chirurgien-accoucheur en chef de l'Hospice de la Maternité pose un premier bilan de la toute jeune institution. Ouvrage ancien (1775), les Principes sur l'art des accouchements sont devenus en 1806 indissociables

\footnotetext{
5I. Ibid.

52. Baudelocque J.-L., Principes sur l'art des accouchemens..., op. cit. ; l'ouvrage a été consulté dans sa $7^{\mathrm{e}}$ édition qui reproduit l'avertissement de l'auteur paru dans la $3^{\mathrm{e}}$ édition de 1806.

53. Hucherard, Sausseret, Girault, Mémoire historique et instructif sur l'hospice de la maternité, Paris, I808. Dès sa parution, cet ouvrage est mis au nombre des livres fournis aux élèves sagesfemmes à leur entrée dans l'établissement.
} 
de l'institution dont ils sont le manuel de référence. L'avertissement en est la preuve, qui lie étroitement méthode et institution, enseignement obstétrical et Hospice de la Maternité :

[... ] mais que pour atteindre ce but, il falloit changer quelque chose à l'organisation des nouvelles écoles, et en restreindre le nombre au lieu de les multiplier comme on le faisoit $[\ldots]$; que cette instruction ne pouvoit être donnée que dans les grands hospices où l'on reçoit habituellement beaucoup de femmes enceintes : plus de deux cents élèves, sorties de celui de la Maternité de Paris, depuis trois années, avec le degré de savoir qui convient aux sages-femmes pour rendre de grands services à l'humanité, ne me laissant aucun doute en ce moment sur la possibilité d'en procurer de bonnes à toute la France $\left[\ldots . .{ }^{54}\right.$

L'école parisienne est définie comme une réalisation exemplaire, sans être pourtant destinée à demeurer unique, la seule condition d'éventuels nouveaux établissements étant d'égaler la perfection de l'institution princeps. Dans ce cadre sans rival peut éclore la nouvelle sage-femme, pour qui le manuel de Baudelocque sera un aide-mémoire, le rappel simplifié du cours et de l'expérience clinique acquise :

Notre intention d'ailleurs n'a jamais été qu'elles apprissent cet ouvrage par cœur, et qu'elles le récitassent littéralement, mais qu'elles l'étudiassent à loisir, qu'elles le méditassent de même, [...] enfin qu'elles pussent y retrouver en tout temps, et se retracer à l'esprit tout ce qui aura pu leur être enseigné dans les cours d'accouchemens; ce qu'elles auront vu faire, et pu opérer ellesmêmes, soit au lit des femmes en couches, soit sur les mannequins. ${ }^{55}$

Le chirurgien-accoucheur en chef ne fixe par ailleurs aucune limite à la curiosité des élèves qu'il entend susciter sans prétendre la satisfaire par cet ouvrage. Borner le savoir des futures sages-femmes porte en germe le risque de ne pas reconnaître le danger et de laisser l'accouchement tourner au tragique par une "perfide tranquillité ». Au contraire, Baudelocque préconise un savoir qui libère la décision de la sage-femme d'agir ou de ne pas agir, de demander du secours ou de terminer l'accouchement par sa seule habileté ${ }^{56}$. Conscient des périls que signe le recours au chirurgien accoucheur, son souhait est de former au mieux les sages-femmes pour que leurs diagnostics avisés réduisent aux seuls accidents indépendants des savoir et savoir-faire de l'accoucheuse (hémorragie, éclampsie, bassin excessivement resserré) l'intervention de ses collègues :

54. Baudelocque J.-L., Principes sur l'art des accouchemens..., op. cit., p. XIII-XIV.

55. Ibid., p. XVIII.

56. Ibid., p. XXIV. 
S'ils [les accouchements dystociques] paroissent encore assez fréquens aujourd'hui, ils le deviendront bien moins par la suite, à mesure que ces connoissances, qui doivent faire la base de l'éducation de sages-femmes, se répandront davantage : peut-être même ces cas deviendront-ils si rares qu'alors on oubliera qu'il fut un temps où l'accouchement [... étoit [regardé] comme une des plus importantes opérations de chirurgie, et ne devoit être [confié] qu'à des hommes d'un grand talent. ${ }^{57}$

Alors seulement le chirurgien revient dans sa sphère, qui n'est pas et ne doit pas être l'accouchement physiologique. Le travail de la sage-femme et du praticien est complémentaire, correspond à deux espaces contigus de compétences :

Si l'on retranche de ces accouchemens qu'on s'est vu dans la nécessité d'opérer, ceux que la mauvaise conformation du bassin, et son défaut de proportion avec la tête du foetus, ont rendus difficiles, et le cas de grossesse extra-utérine, dont il a été parlé, il n'en est pas un seul peut-être qui n'ait pu être terminé par une sage-femme intelligente, comme ils l'ont été presque tous par celle qui est en chef à l'Hospice de la Maternité. ${ }^{58}$

L'exemple de Marie-Louise Lachapelle, qui a toute la confiance de Baudelocque, vient à point nommé prouver la capacité féminine. La latitude d'intervention de la maîtresse sage-femme s'étend à l'usage d'instruments tels que le forceps qu' elle applique sans en référer parfois au chirurgien-accoucheur, comme l'y autorise l'article I6 du premier règlement de l'établissement ${ }^{59}$. L'appel au chirurgien tient alors de la marque de politesse entre collègues, sans qu'y entre une subordination particulière :

[...] aussi toutes les fois qu'il [Baudelocque] était appelé à l'Hospice pour quelques accouchemens laborieux, il confiait à Madame Lachapelle le soin de les terminer elle-même. Il aimait beaucoup la voir opérer sous ses yeux, et ne manquait jamais d'applaudir à ses succès. ${ }^{60}$

Le duo formé par le chirurgien-accoucheur en chef et la sage-femme sous les auspices duquel l'école de l'Hospice de la Maternité vit ses premières années, est la parfaite incarnation de la complémentarité qu'envisage l'auteur, et sa source d'inspiration. Du respect d'un champ d'exercice propre aux sages-femmes et donc des compétences respectives naîtra, selon Baudelocque, le progrès obstétrical, soit la recherche et l'obtention des meilleures conditions possibles de l'accouchement.

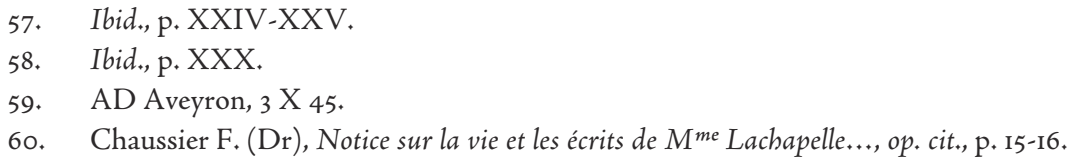




\section{La diversification des enseignements}

Une fois reconnues les capacités des accoucheuses, il reste à leur permettre de maittriser les pratiques thérapeutiques qui complètent leur rôle d'auxiliaire de la naissance, pendant la grossesse, et dans les soins à l'accouchée et au nouveau-né. L'évolution du programme d'enseignement de l'école de l'Hospice de la Maternité est très rapide et dès I808, le Mémoire historique et instructif rend compte des ajouts à la formation des élèves sages-femmes depuis la fondation de l'établissement :

L'enseignement des élèves s'est progressivement étendu, à mesure que l'ordre s'est établi dans l'école, et que l'expérience a démontré la possibilité d'accroître les connaissances dont les sages-femmes pouvaient faire avec utilité l'application, dans l'exercice de leur état $:$ la théorie et la pratique des accouchements ; la vaccination ; la phlébotomie ou l'art de saigner : l'étude des plantes usuelles. ${ }^{61}$

L'élargissement de l'instruction à la lutte contre la variole est une proposition qui remonte aux années $1780^{62}$. Le remplacement de la technique de l'inoculation par celle de la vaccination (Jenner, 1798) réactive cette volonté ${ }^{63}$. Un hospice central de vaccine est créé à Paris et des liens privilégiés s'établissent entre cette institution et l'Hospice de la Maternité64.

Les attributions de la sage-femme, traditionnellement circonscrites aux soins des premières heures ou des premiers jours, s'étendent par ce biais à la petite enfance. Les raisons de leur confier cette pratique (inoculation puis vaccination) n'ont pas changé depuis la fin du XviII ${ }^{\mathrm{e}}$ siècle :

Est-il un moyen plus sûr de parvenir à déraciner le préjugé que les gens de la campagne ont contre la vaccine ; l'expérience, les conseils même des officiers de santé ne parviennent que lentement à le détruire, mais cette confiance qu' inspirera tout naturellement une sage-femme, qui le plus souvent se trouve parente ou alliée de presque tous les habitants de sa commune, les amènera pas à pas et sans contrainte à faire jouir leurs enfants du bienfait de cette découverte ${ }^{65}$.

6I. Hucherard, Sausseret, Girault, Mémoire historique et instructif.., op. cit., p. 60.

62. Cette maladie tue encore près de 80 ooo personnes par an à la fin du Xviri ${ }^{\mathrm{e}}$ siècle, voir Darmon P., "L'odyssée pionnière des premières vaccinations françaises au XIX ${ }^{\mathrm{e}}$ siècle », HES, I982, vol. I, n ${ }^{\circ}$ I, p. Io6.

63. Darmon P., «Vaccins et vaccinations avant Jenner : une querelle d'antériorité », HES, 1984, vol. $3, \mathrm{n}^{\circ} 4$, p. 58 .

64. Hucherard, Sausseret, Girault, Mémoire historique et instructif..., op. cit., p. 6I.

65. Ibid. 
La scientificité du savoir de la sage-femme s'est accrue dans l'intervalle, et son rôle d'intermédiaire culturel s'est accentué dans les mêmes proportions, puisque le milieu social d'origine ne s'est guère modifié ${ }^{66}$. La sage-femme a sur les médecins l'avantage de ne pas tenir rang parmi les notables et d'être une femme, double gage de confiance pour les paysans, artisans et boutiquiers du monde rural et des petites villes, et pour les mères.

Autre facette de la formation élargie : la pratique de la saignée, qui fait encore, au début du $\mathrm{XIX}^{\mathrm{e}}$ siècle, partie intégrante de l'arsenal thérapeutique de la grossesse $e^{67}$. Malgré des débats passionnés sur l'opportunité de saigner les femmes enceintes, les tenants des risques abortifs de cette pratique ne l'ont pas emporté, même si l'habitude à l'Hospice de la Maternité, sous la conduite du docteur Chaussier, est de limiter autant que possible le recours à la saignée ${ }^{68}$. L'apprentissage de cette technique se fait donc dans un cadre très précis et en rapport direct avec les soins dus à la femme enceinte ${ }^{69}$.

L'influence du docteur François Chaussier, médecin en chef de l'Hospice ${ }^{70}$, se lit dans un troisième et dernier accroissement du corpus de connaissances : l'étude des plantes usuelles. Dès sa prise de poste en I804, il souligne l'intérêt pour les accoucheuses de posséder quelques notions de botanique. Cette science si étroitement liée à la pharmacopée a fait l'objet d'une diffusion notable depuis son inscription au programme des écoles centrales créées en l'an III et la création conjointe d'un jardin botanique dans chacune d'elles ${ }^{71}$. Son entrée dans la formation des sages-femmes s'éclaire par cette promotion de la botanique au rang des savoirs utiles et nécessaires. Elle s'inscrit aussi dans la volonté d'encadrer et de préciser des pratiques empiriques de recours aux plantes pour soulager femmes enceintes et accouchées :

[...] l'administration n'a pas entendu que ces élèves feraient un cours de botanique, mais que, se renfermant dans un cercle de 150 à 200 plantes, on pourrait leur apprendre à comparer les plantes fraîches, avec les plantes sèches, et leur

66. Gélis J., « L'accoucheuse rurale au XviII ${ }^{e}$ siècle : transformation du rôle d'un intermédiaire entre culture rurale et culture urbaine », art. cit., p. 127-137.

67. Voir Berthiaud E., "Attendre un enfant ». Vécu et représentations de la grossesse aux XVIII et $X_{X} X^{e}$ siècles (France), thèse pour le doctorat en histoire, Université de Picardie-Jules-Verne, 20II, p. $435-446$.

68. Beauvalet-Boutouyrie S., Naître à l'hôpital..., op. cit., p. 193-194.

69. Hucherard, Sausseret, Girault, Mémoire historique et instructif..., op. cit., p. 62.

70. Beauvalet-Boutouyrie S., Naître à l'hôpital..., op. cit., p. 125.

7I. Guillaume J. (éd.), Procès-verbaux du Comité d'instruction publique..., op. cit., p. 307. Le Mémoire historique et instructif signale qu' un « jardin pharmaceutique » est établi pour servir de base à cet enseignement. 
en indiquer l'usage, ou par infusion, ou par décoction ; elle a pensé qu'il serait très avantageux pour les sages-femmes de savoir distinguer ces plantes partout où elles les trouveraient, de les choisir avec plus de soin lorsqu'elles iraient en faire l'achat, et enfin de les conserver avec précaution parce qu'elles en apprécieraient mieux l'importance. ${ }^{72}$

La variété de la formation délivrée donne aux sages-femmes une position très particulière, aux confins des différentes spécialités médicales : médecine, chirurgie, mais aussi pharmacie et herboristerie (ill. 4). L'usage autorisé d'un nombre non négligeable de plantes aux vertus médicinales constitue pour les accoucheuses un embryon de droit de prescription. Le caractère atypique des ressources savantes accordées à cette profession fait de la sage-femme sortie de l'Hospice de la Maternité de Paris une figure à part, et régulièrement égratignée pour cela par les plumes acides du corps médical français ou étranger ${ }^{73}$.

Si la situation française est spécifique, c'est grâce à l'existence de la sagefemme en chef de l'Hôtel-Dieu, devenue sage-femme en chef de l'Hospice de la Maternité de Paris. En 1802, dans le principal service de maternité français, le champ n'est pas libre et il n'est envisageable ni pour les accoucheurs parisiens, ni pour le conseil général des hospices, ni pour le ministre de l'Intérieur, de dessaisir Marie-Louise Lachapelle du poste qu'elle occupe par la légitimité de l'expérience et du talent. Serait-ce alors un concours de circonstances qui a présidé à la naissance d'une sage-femme française, instruite et autonome ? Il apparaît plus sûrement que le niveau d'instruction s'est naturellement élevé à la hauteur des compétences de l'enseignante puisqu'il était impossible d'imposer à la sage-femme en chef de brider sa pratique pour transmettre un savoir expurgé. Les murs de Port-Royal ont donc vu la rencontre d'un choix antérieur et général, celui de la sage-femme plutôt que du chirurgien, et d'une individualité remarquable, susceptible d'inspirer les traits de l'accoucheuse idéale.

\section{Des ambitions à la pratique}

\section{9 ventôse an $\mathrm{XI}$}

La création de l'école de l'Hospice de la Maternité en messidor an x instaure un cadre pour l'enseignement des sages-femmes mais ne résout pas les problèmes inhérents à l'exercice de cette profession. Il faut attendre le vote de la loi du I9 ventôse an XI pour qu'un texte règlementaire national pose les bases de ce

72. Hucherard, Sausseret, Girault, Mémoire historique et instructif.., op. cit., p. 62.

73. Siebold E. C. J. (von), Essai sur l'histoire de l'obstétricie, op. cit., p. 479-480. 
métier, de la formation à l'exercice pratique. L'objet de la loi de ventôse est la réforme de l'enseignement de la médecine et de la police de cet art tant attendue depuis l'an in et la création des trois écoles de santé. Porté par le même rapporteur, Fourcroy, ancien conventionnel devenu conseiller d'État, ce texte a trois objectifs : renforcer les structures pédagogiques ; réintroduire l'obligation du diplôme pour exercer ; réintégrer du même coup praticiens d'Ancien Régime et révolutionnaires dans un corps médical unifié autour des titres de docteur et officier de santé ${ }^{74}$. Le texte passe ainsi traditionnellement pour le point de départ de la dichotomie médicale appliquée à tous les types de personnels (des médecins aux pharmaciens en passant par les sages-femmes) qui traverse le XIX ${ }^{e}$ siècle.

La loi du 19 ventôse consacre aux sages-femmes son titre $\mathrm{V}$, intitulé De l'instruction et de la réception des sages-femmes et composé de 5 articles ${ }^{75}$. Deux discours avaient dessiné les objectifs avant le vote final : l'exposé des motifs de la loi lu par Fourcroy devant le Tribunat le 7 ventôse ${ }^{76}$ et l'intervention du tribun Jard-Panvilliers devant le Corps législatif le jour du vote ${ }^{77}$.

Fourcroy reprend en les résumant les principales dispositions du titre $\mathrm{V}$, confirmant le choix de la sage-femme comme agent de l'encadrement obstétrical du pays ${ }^{78}$. La loi de ventôse paraît ainsi dans l'exposé des motifs le prolongement naturel de la fondation de l'école de l'Hospice de la Maternité créé quatre mois plus tôt. Une surprise cependant : cet établissement d'élite scientifique et pédagogique n'y est jamais explicitement mentionné, pas plus que dans les articles de la loi. Même silence dans le discours de Jard-Panvilliers :

Quoique la nature se suffise le plus ordinairement à elle-même dans la reproduction des êtres vivants, il est des cas assez fréquents où elle a besoin des secours de l'art ; mais ces secours, loin de lui être utiles, ne peuvent que lui devenir funestes lorsqu'ils sont administrés mal à propos ou par des mains inhabiles, comme cela n'arrive que trop souvent dans les campagnes, où la pratique de l'art des accouchements est presque exclusivement livrée à des sagesfemmes sans instruction. Il y a déjà longtemps que le mal à cet égard était parvenu à un tel point qu'il avait fixé l'attention de l'ancien Gouvernement, qui avait envoyé des sages-femmes instruites dans quelques provinces pour y former des élèves. Depuis ce temps, on a vu des chirurgiens instruits qui, de leur propre mouvement, par zèle pour les progrès de l'art et pour le bien

\footnotetext{
74. Léonard J., Les médecins de l'Ouest..., op. cit., p. 261 sq.

75. RLRES I, p. 99-100.

76. Ibid., p. 90-93.

77. EDRES, p. 554-567.

78. RLRES I, p. 93.
} 
de l'humanité, ou sur l'invitation de quelques préfets, ont ouvert des cours gratuits d'accouchements ; mais ces moyens isolés et, pour ainsi dire, momentanés, en éclairant quelques individus, n'ont point dissipé l'ignorance presque générale des sages-femmes dans les campagnes : le projet dont j’ai l'honneur de vous entretenir aura sans doute un résultat plus avantageux. ${ }^{79}$

Tous les topoï sont rassemblés : l'évocation de la nature généreuse mais aux caprices imprévisibles, l'aide nécessaire pour y remédier et les dangers de l'ignorance, mais surtout la désignation des coupables : les sages-femmes «sans instruction », ce qui dédouane la profession du reproche d'irrémédiable incompétence.

Le bref historique des cours d'accouchement instaurés sous et depuis l'Ancien Régime, laisse de côté l'épisode révolutionnaire, reprenant l'esprit de l'exposé de Fourcroy : "L'anarchie seule, qui ne respecte aucune institution, a pu méconnaître l'importance de l'art de guérir ${ }^{80}$. » Entre Angélique du Coudray et l'action des préfets, règne donc le néant, à peine traversé d'initiatives individuelles de «chirurgiens instruits ». Nier l'action des administrations départementales pendant la décennie 1790 ajoute encore à l'opposition entre anarchie et civilisation sur laquelle le Consulat fonde son cuvre législatrice. De plus, face à la multiplicité des cours d'accouchement de la période révolutionnaire, les législateurs ont sans doute du mal à mesurer leurs traits communs, leur qualité et leur audience. Le bilan qu'ils en tirent est miné par l'impression d'éparpillement et de provisoire des structures de formation. Au-delà, il y a une vraie logique à l'œuvre dans la dépréciation des efforts de formation antérieurs, logique qui sous-tendait déjà l'argumentaire chaptalien dans la circulaire annonçant la création de l'Hospice de la Maternité.

Qu'en est-il toutefois de l'oubli, volontaire ou non, de l'Hospice de la Maternité de Paris, à cette date la plus grande école française de sages-femmes ? L'auteur de la loi du I 9 ventôse an XI peine visiblement à placer l'établissement dans l'organigramme qu'il propose, ruminé depuis une quinzaine d'années. L'Hospice de la Maternité pose problème car il a détaché l'enseignement à destination des sages-femmes du grand corps de l'enseignement médical. C'est de l'extérieur qu'il fournit un modèle (l'école au sein d'une maternité), que Fourcroy reprend et adapte sans le revendiquer. Car au cœur de la loi de ventôse, il y a les écoles de médecine, nées des écoles de santé de l'an III, et qui forment les relais nationaux de la formation des sages-femmes :

79. EDRES, p. 566.

80. RLRES I, p. 90 . 
Art. 30. Outre l'instruction donnée dans les Écoles de médecine, il sera établi dans l'hospice le plus fréquenté de chaque département un cours annuel et gratuit d'accouchement théorique et pratique, destiné particulièrement à l'instruction des sages-femmes. ${ }^{81}$

L'article ne dit rien d'une éventuelle hiérarchie des institutions d'instruction. La formulation prévoit avant tout un élargissement du réseau d'établissements de formation, sans évoquer de distinction entre deux catégories de sages-femmes en fonction de leur lieu d'apprentissage. Les exigences de formation envisagent trois voies spécifiques pour se présenter à l'examen (art. 3I). La première voie est entendue dans le cadre des cours départementaux prévus à l'article 30 et porte l'obligation d'avoir suivi deux cours et vu pratiquer pendant neuf mois, la loi ne tranchant pas sur le caractère successif ou concomitant de ces formations. Les deux voies suivantes posent que la pratique personnelle, en hospice ou auprès d'un professeur, même sans enseignement théorique préalable ou complémentaire, équivaut au premier cursus, selon le principe appliqué aux officiers de santé pour qui six ans d'apprentissage chez un docteur ou cinq ans de pratique dans un hôpital équivalent à trois ans d'études dans une école de médecine ${ }^{82}$.

La légitimation de ces différents modes d'acquisition des savoirs reconnaît la valeur de l'expérience pratique et celle de la transmission interpersonnelle. Elle maintient en théorie la possibilité d'un enseignement privé dépendant du bon vouloir des seuls docteurs. Au-delà, cette latitude de formation hors d'un parcours scolaire et institutionnel est en fait reconnaissance a posteriori des femmes en exercice comme elle l'est pour les officiers de santé ${ }^{83}$. De ce point de vue, la loi de ventôse vaut consécration du savoir clinique.

Inscrire dans la loi la diversité des voies d'accès à l'examen constitue néanmoins un élément de fragilité pour les cours d'accouchement projetés, puisque l'hospice de maternité n'est pas présenté comme seul modèle légitime d'acquisition du savoir. La ligne de fracture intellectuelle et scientifique au sein de la formation prévue pour les accoucheuses passe donc entre celles qui fréquenteront des cours publics et les autres, c'est-à-dire entre l'enseignement scolaire et la mise en apprentissage. À l'issue de l'instruction cependant, l'examen est identique :

Art. 32. Elles seront examinées par les jurys sur la théorie et la pratique des accouchements, sur les accidents qui peuvent les précéder, les accompagner et les suivre, et sur les moyens d'y remédier. Lorsqu' elles auront satisfait à leur examen, on leur délivrera gratuitement un diplôme, dont la forme sera déterminée par le règlement prescrit par les articles 9 et 20 de la présente loi. ${ }^{84}$

\footnotetext{
8I. Ibid., p. 99 .

82. Ibid., p. 96 .

83. Léonard J., Les médecins de l'Ouest..., op. cit., p. 270.

84. RLRES I, p. 99.
} 
Unicité de l'examen, unicité du diplôme pour un seul corps des sagesfemmes : la loi du I9 ventôse an XI maintient les positions des projets de l'an $\mathrm{Ix}^{85}$. La gratuité pour l'obtention du diplôme constitue même une avancée par rapport aux frais de réception envisagés en ventôse et prairial an IX (Ioo francs $)^{86}$. Les jurys qui décident d'accorder ou non le diplôme sont identiques à ceux qui examinent les officiers de santé (art. I6 et I8) ${ }^{87}$. L'alignement sur les officiers de santé est toutefois à double tranchant. À leur image, les sages-femmes sont subordonnées aux docteurs pour certains actes. Là où l'officier de santé ne peut " pratiquer les grandes opérations chirurgicales que sous la surveillance et l'inspection d'un docteur » (art. 29), l'accoucheuse ne peut «employer les instruments, dans les cas d'accouchements laborieux, sans appeler un docteur ou un médecin ou chirurgien anciennement reçu » $(\operatorname{art} .33)^{88}$. La tolérance officielle prévue par le règlement de l'Hospice de la Maternité de Paris en cas d'urgence disparaît du texte législatif. Sage-femme et officier de santé sont donc placés sur le même plan car le second n'est pas du nombre des recours possibles en cas d'accouchement dystocique ${ }^{89}$. La loi de ventôse fait de la sage-femme un membre à part entière du personnel médical, comme le prouve son recensement sur les listes préfectorales $(\operatorname{art} .34)^{90}$. En la tirant du côté de l'officier de santé, elle l'intègre toutefois au second ordre de praticiens et au type de médecine que Fourcroy destine aux classes populaires ${ }^{91}$. Le type d'examen, les modalités d'instruction, tous ces éléments laissent penser que la loi de ventôse projette de cantonner la profession de sage-femme aux limites d'exercice qu'elle a assignées à celle d'officier de santé : subordination au docteur, rayon d'exercice départemental. La seule exception concrète et préexistante, si dérangeante que le texte omet de la citer, est la sage-femme d'élite de l'école de l'Hospice de la Maternité de Paris.

Pourtant, la sage-femme définie par le titre $\mathrm{V}$ de la loi du I9 ventôse an XI n'est pas le symbole d'un retour en arrière. L'accoucheuse-type dessinée par la loi est au contraire l'aboutissement logique d'un processus général de redéfinition du monde médical. Cela ne signifie pas que soient exigées d'elle moins de connaissances fondamentales. L'accoucheuse de ventôse doit être instruite pour être accoucheuse. À ses côtés, l'élève de la Maternité naît du

85. EDRES, p. 494, projet de loi sur l'enseignement et la police de la médecine, 29 pluviôse an Ix, art. 28 ; ibid., p. 50 I, projet d'arrêté concernant les écoles de médecine, 23 prairial an IX, art. 15.

86. Ibid.

87. RLRES I, p. 96.

88. Ibid., p. 98 et Ioo.

89. Léonard J., Les médecins de l'Ouest..., op. cit., p. 279.

90. RLRES i, p. Ioo.

9I. Léonard J., Les médecins de l'Ouest..., op. cit., p. 28I. 
dérapage enthousiaste des espoirs scientifiques et pédagogiques des deux plus belles figures de l'obstétrique française de ce temps, nourries aux innovations européennes du demi-siècle précédent. L'enfant symbolique de Marie-Louise Lachapelle et des maternités allemandes est la sage-femme d'exception que n'auraient pas su ni voulu créer les écoles de médecine et qui trouble l'homogénéité socio-professionnelle de ce corps conçu à l'aune de l'accoucheuse ordinaire. La loi de ventôse ne consacre pas la dualité de la profession, elle tente au contraire une dernière fois de nier l'évidence que l'exception parisienne ne peut manquer de faire éclater. L'évolution décisive se situe entre le ig ventôse et le 20 prairial de l'an XI, entre la loi et son arrêté d'application.

\section{Dans le sillage parisien, obstination de la politique ministérielle}

Trois mois ont suffi pour intégrer l'école de l'Hospice de la Maternité de Paris dans le plan de Fourcroy. Trois mois pour doubler la dualité docteur/officier de santé d'une dualité sage-femme nationale/sage-femme départementale. L'arrêté du gouvernement portant règlement pour exercice de la médecine du 20 prairial an XI rassemble dans son paragraphe 7 , De la réception des sagesfemmes, les fils laissés épars par le vote du mois de mars précédent :

Art. 42. Les élèves sages-femmes seront soumises, dans les jurys, à un examen dans lequel elles répondront aux questions qui leur seront faites et exécuteront sur le fantôme les opérations les plus simples des accouchements. Il leur sera délivré gratuitement un diplôme, suivant le modèle $\mathrm{n}^{\circ} 3$, joint au présent arrêté.

Art. 43. - Celles des élèves sages-femmes qui se présenteront aux Écoles de médecine pour leur réception seront soumises à deux examens; elles devront avoir suivi au moins deux cours de l'École ou de l'hospice de la Maternité à Paris. Les frais pour leur réception seront de 120 francs. Les sages-femmes ainsi reçues pourront s'établir dans tous les départements. ${ }^{92}$

La complémentarité hiérarchique ainsi obtenue s'explique de diverses manières. Le premier cours de l'Hospice de la Maternité est à la veille de se terminer. Le mode d'examen défini aux articles 24 et 25 de son règlement ne correspond pas à celui imposé par la loi de ventôse ${ }^{93}$, puisqu'il ne permet pas à lui seul la délivrance d'un diplôme mais la remise d'un certificat de capacité, désormais insuffisant pour exercer. Il est donc urgent de statuer sur le devenir de ces élèves pour que la formation parisienne leur soit comptée

\footnotetext{
92. RLRES I, p. II5.

93. Ibid., p. 89 .
} 
comme une instruction suffisante et leur ouvre droit à l'examen devant un jury médical. D'autre part, l'équivalence entre Hospice de la Maternité et cours de l'École de médecine s'incarne très concrètement en la personne de Jean-Louis Baudelocque qui professe à Paris dans les deux établissements. Traiter différemment ses élèves ne se justifie pas.

Rapprocher ainsi l'Hospice de la Maternité du cours purement théorique de l'École de médecine revient certes à ne pas lui reconnaitre sa spécificité (enseignement pratique de la sage-femme en chef), mais la décision l'intègre au groupe des établissements universitaires, c'est-à-dire au niveau le plus haut de la formation médicale. Ce degré supérieur d'instruction offre à celles qui y accèdent une prérogative de poids (le droit d'exercice national) à laquelle la loi du I9 ventôse fournit le modèle tout trouvé des docteurs en médecine et en chirurgie. La sage-femme de ventôse, y compris l'ancienne élève des écoles de médecine, était attachée à son terroir ; la sage-femme de prairial peut espérer faire fortune loin de sa terre natale et user du prestige de sa formation dans les plus grandes villes de France.

Enfin et surtout, après l'épisode législatif, l'initiative revient dans le camp du ministre de l'Intérieur, Antoine Chaptal, « chargé de l'exécution du présent arrêté $^{94}$ », bien décidé à ne pas laisser péricliter sa création. Dès l'envoi de la circulaire du 9 thermidor an $\mathrm{x}$, Chaptal a prôné l'envoi d'élèves sages-femmes à Paris comme la seule formation viable. Les préfets ont dans l'ensemble assez rapidement réagi à la sollicitation ministérielle, parfois avec enthousiasme comme dans la Drôme :

La mesure que vous avez adoptée me paroît infiniment préférable aux cours locaux, la plus part du tems assez insignifians, toujours insuffisans et trop dispendieux pour des moyens aussi limités que ceux de ce département. Elle a le cachet de l'attention éclairée qui distingue tous vos actes, spécialement lorsqu'ils ont pour but les intérêts de l'humanité. ${ }^{95}$

Cependant, les refus sont nombreux et leurs raisons, multiples : distance, crainte de voir les élèves dévergondées par la grande ville, non-maitrise de la langue française. Face à ces réactions polies mais négatives, l'attitude du ministre est d'une rare intransigeance, réaffirmant le caractère national de l'établissement parisien. Le ministre tient sur l'impératif d'en passer par l'école qu'il vient de fonder : «Je vous invite, de nouveau, à exécuter mon arrêté précité

94. Ibid., p. II6.

95. AD Drôme, 5 M I8. 
du II messidor » écrit-il au préfet de l'Aveyron ${ }^{96}$. Ses deux arguments phares sont l'incompétence ou du moins la compétence inférieure des praticiens de province, et l'absence dans le reste du pays de centre d'enseignement clinique équivalent à celui de Port-Royal. Sur le fond, la loi du I9 ventôse ne change rien à l'affaire. La reprise en mains du texte par le ministère dès l'arrêté d'application permet de maintenir, sans varier, le cap antérieur. Après le mois de prairial, qui renouvelle toutefois la décision de création de cours dans les hospices, on cherche, en vain, une circulaire encourageant les départements à mettre en œuvre les prescriptions législatives. Au mois de septembre suivant, Chaptal, dans un courrier aux préfets, daigne une allusion au texte de ventôse :

Les cours particuliers d'accouchement dont la loi du Ig ventôse an XI autorise la création dans les départements, pourront être avantageux pour les femmes des campagnes [...] ; mais ces cours n'offriront jamais les mêmes sources d'instruction et la même abondance de lumières que ceux de la Maternité. ${ }^{97}$

Le détour rhétorique par la loi sur l'exercice de la médecine n'est qu'une pirouette imposée par l'impossibilité d'ignorer complètement ce texte. Mieux, l'évocation ambiguë de cours " particuliers», sur la nature desquels le qualificatif fait planer un doute (cours publics ou privés ?), est une occasion supplémentaire de réitérer le jugement déjà porté sur le manque d'habileté des enseignants et les lacunes de l'enseignement pratique. Tout projet de cours départemental se discrédite donc par son incapacité intrinsèque à atteindre le niveau de formation dispensé à Paris. À Orléans, toutes les tentatives de l'administration pour prouver l'existence d'un champ réel d'instruction pratique se soldent par une rebuffade :

Je ne puis trop vous répéter, citoyen, que quelles que soient les ressources que présente la ville d'Orléans pour l'instruction dans l'art des accouchements, il n'est pas possible que l'enseignement y soit aussi complet qu'à la maternité. ${ }^{98}$

Le point n'est pas de savoir si les élèves provinciales ont ou non accès à une expérience clinique pendant leurs études, mais de considérer que toute expérience clinique n'ayant pas l'envergure parisienne perd automatiquement sa valeur. Cet élitisme impose une double transgression : transgression du modèle médical de l'accoucheuse ordinaire tel que l'envisage la loi de ventôse et

96. AD Aveyron, 3 X 45 .

97. Beauvalet-Boutouyrie S., Naître à l'hôpital..., op. cit., p. II3, extrait de la circulaire ministérielle du 30 fructidor an $\mathrm{XI}$.

98. $\mathrm{AN}, \mathrm{F}^{17} / 2463$, Loiret. 
transgression du modèle social afférent, celui de la paysanne tout juste dégrossie dont on attend qu'elle serve ses semblables sans espérer y gagner sa subsistance. En un mot, là où le texte du ig ventôse n'envisage qu'une sage-femme départementale, le discours et les actions du ministère n'acceptent qu'une sagefemme nationale : première classe contre deuxième classe même si l'opposition n'est pas encore posée en ces termes.

Pour réduire les obstacles, l'obstination ministérielle déploie des trésors de mauvaise foi, ce qu'illustre une note du cabinet à l'intention du chef de la $3^{\mathrm{e}}$ division du ministère de l'Intérieur, Barbier-Neuville :

La loi du I9 ventôse ordonne l'établissement d'un cours d'accouchement dans l'hospice le plus fréquenté de chaque département. Le ministre n'a pas cru devoir exécuter cette disposition, parce qu'il est persuadé que l'art des accouchements ne peut être enseigné, avec succès, qu'à Paris... Il a constamment répondu dans ce sens aux demandes particulières des préfets, ayant pour objet d'être autorisés à établir des cours dans leurs départements. Il eût été bon de dire un mot de ces cours particuliers dans la circulaire dont le projet est ci-joint, mais comme cette circulaire sera imprimée et adressée à plus de 80 préfets, la matière devient délicate à traiter, vu qu'il s'agit de paralyser l'effet d'une loi. ${ }^{99}$

À bout d'arguments cependant, et après trois ans de manifestations d'autorité, le successeur de Chaptal, Champagny finit par lancer une enquête sur les établissements hospitaliers susceptibles de recevoir un cours d'accouchement $^{100}$. Tout en manifestant un intérêt immédiat pour ces questions, il s'interroge sur la politique intransigeante de Chaptal. Sans avis préconçu, le nouveau ministre écarte un projet de décret inspiré par l'École de médecine de Paris, prévoyant la création de dix cours d'accouchement pour l'Empire, car ses services sont « convaincus qu'il n'y a pas un plus grand nombre de villes qui offrent des professeurs assez habiles et des faits assez nombreux pour l'instruction des élèves ${ }^{101}$ ». Un modèle Port-Royal à peine élargi, en somme. Soucieux de ne pas se lier à ces vœux pas plus qu'aux décisions antérieures de Chaptal, mais attentif aux préventions qui les ont dictés, Champagny choisit la via media de l'enquête. Dans un contexte de fortes attentes départementales, la circulaire du 18 vendémiaire an XIV qui transmet le questionnaire semble prendre pour la première fois en compte les sollicitations préfectorales et annoncer une application, contrôlée mais réelle, de la loi de ventôse. Ce que le texte législatif établit

99. $\mathrm{AN}, \mathrm{F}^{17} / 2468$, Seine.

IOO. Flottes L., Enquête de l'an XIV : prémices d'une formation organisée pour les sages-femmes, mémoire pour le diplôme d'État de sage-femme, École de sages-femmes Baudelocque, 2014.

IOI. $\mathrm{AN} \mathrm{F}^{17} / 2460$, Finistère. 
comme un devoir des départements (l'ouverture d'un cours d'accouchement dans un hospice) et ce qui apparaît de fait comme un droit dans l'esprit des préfets et des assemblées départementales, devient sous la plume du ministre de l'Intérieur une tolérance sous conditions. Champagny se fait seul juge de la conformité des ressources aux exigences définies depuis la fondation de l'école de l'Hospice de la Maternité.

Le formulaire de l'enquête est conçu en fonction des principes pédagogiques mis en valeur depuis 1802 . Les quatre premiers points portent ainsi sur l'estimation des capacités de l'hospice en matière de formation pratique (salle propre aux femmes en couches, nombre de lits réservés, nombre d'accouchements). Le second ensemble de l'enquête (questions 5-6) est consacré au futur personnel enseignant (nature ; inscription ou non dans un cadre institutionnel). Le questionnaire se préoccupe aussi des conditions d'études des futures élèves sagesfemmes en évaluant les possibilités d'établir des internats dans les hospices choisis (question IO). Les cinq autres questions posent enfin le problème du financement du cours d'accouchement dans ses différentes parties : traitement du professeur, dépendant ou non de l'hospice (question 7$)^{102}$, frais annexes d'installation et recettes disponibles (questions 8-9) et enfin frais de logement et nourriture des élèves sages-femmes et recettes utilisables pour cet objet (questions II-I2).

Les résultats du questionnaire remontent assez rapidement au pouvoir central et les conclusions qu'en tire le ministère de l'Intérieur sont pleinement significatives des intentions prudentes et restreintes de départ. Dans le détail des réponses, Champagny trouve l'arme pour refuser avec aplomb la régularisation de nombreux cours déjà en place :

(Au préfet de la Côte-d'or, juin 1807) Cette institution ne me paraît point, Monsieur, pouvoir remplir le but de la loi du I9 ventôse an XI, [...] soit parce qu'elle n'est point organisée d'après les bases déterminées par cette loi, soit parce qu'il est impossible que des élèves sages-femmes prises dans les campagnes puissent acquérir dans six semaines, les connaissances nécessaires pour exercer sans danger l'art difficile des accouchemens, à peine pourrait-on en aussi peu de temps s'assurer des dispositions de celles dont l'esprit a été le mieux cultivé ; et l'expérience prouve que ce n'est qu'après six mois, même une année entière de résidence à l'hospice de la maternité où l'on donne des leçons tous les jours et où la pratique est en permanence, que les élèves de cette école peuvent être en état de se présenter devant le jury d'examen. ${ }^{103}$

I02. La distinction faite entre les deux types de professeurs est liée à l'obligation de payer une rétribution beaucoup plus forte au chirurgien qui exerce « en libéral » qu'au chirurgien de l'hospice, déjà défrayé pour le reste de sa charge.

I03. AD Côte-d'Or, M7 n I/I. 
Pour contester la validité du cours dijonnais, le ministre reprend l'extrait d'une délibération des professeurs de l'École de médecine de Paris du 23 avril précédent où ces derniers repoussaient l'opportunité d'un projet de cours à $\mathrm{Nancy}^{104}$. La durée minimale de cours est désormais incompressible $:$ six mois et plus nécessairement un an, à l'image de ce qui se pratique désormais régulièrement à l'Hospice de la Maternité ${ }^{105}$.

En février 1807 , la première révision du règlement intérieur de Port-Royal permet d'ailleurs à Champagny, en pleine étude des dossiers départementaux de rappeler la qualité indépassable de cet établissement phare, le « [seul] de ce genre qui puisse exister en France », tout en dénonçant les lacunes des cours locaux qui «ne peuvent exister dans les départements avec succès, ni même sans danger ${ }^{106}$. » La pression sur les préfets est constante, accentuée encore par les articles du Règlement révisé qui présentent l'envoi d'élèves sages-femmes à Paris comme une obligation (art. I). Les commissions administratives des grands hospices, seuls susceptibles d'accueillir des cours locaux, sont à leur tour mises à contribution pour fournir à Port-Royal leur contingent d'élèves :

Art. 3. Les Commissions administratives des hospices civils dont les ressources annuelles s'élèvent à 20000 francs, entretiendront également chaque année, sur leurs revenus, à l'école de la Maternité une élève accoucheuse, choisie de préférence parmi les filles élevées dans ces établissements. ${ }^{107}$

Et pourtant : malgré la prose parisianocentrée de Champagny, un tournant sensible se prend à cette date. Certes, l'enquête de l'an xiv favorise souvent le contournement des prescriptions de la loi du I9 ventôse an XI, mais en donnant aux préfets l'occasion de justifier, selon les critères ministériels, les qualités de leurs initiatives, elle accorde pour la première fois une valeur à leurs décisions. Une brèche est ouverte dans l'exigence d'unicité, et les lendemains de l'enquête débouchent sur une tolérance inédite puisque les préfets sont désormais autorisés à tenter de s'approcher du modèle parisien en soumettant au ministère de l'Intérieur des règlements calqués sur ses structures. Le 6 juin I807, passée la charge brutale contre le cours de Dijon, le ton de Champagny s'adoucit dans la conclusion :

\footnotetext{
I04. AN, $\mathrm{F}^{17} / 2463$, Meurthe.

105. Le passage d'une scolarité de six mois à un an se fait lors de la deuxième révision du Règlement, en I8Io.

I06. $\mathrm{AD}$ Corrèze, I X I6I. C’est le ministre qui souligne.

107. Ibid.
} 
Dans ces circonstances, Monsieur, il devient indispensable de vous occuper, sans délai de l'organisation régulière et légale d'un cours d'accouchements dans l'hospice le plus fréquenté de la ville de Dijon. Je vous invite en conséquence à me soumettre un projet de règlement à ce sujet, basé sur les dispositions du titre 5 de la loi du 19 ventôse an XI et sur celles de mon arrêté du I7 janvier dernier, concernant l'hospice de la maternité, autant toutefois que les localités le permettront. ${ }^{108}$

Ces quelques lignes concentrent toute la politique ultérieure du gouvernement : d'école destinée à rester unique, l'Hospice de la Maternité devient école modèle de toutes les écoles à créer. La concession aux capacités des « localités » est plus qu'un geste politique. Elle brise le lien entre instruction exigible d'une sage-femme et supériorité éminente de l'institution parisienne. Le rêve d'un seul établissement national de formation a vécu ${ }^{109}$, mais il n'abdique son monopole que pour mieux affirmer sa prééminence, dans les frontières traditionnelles de la France, et au-delà dans les territoires réunis sous l'Empire.

\section{L'enseignement obstétrical français à l'épreuve du Grand Empire}

L'espace territorial français connaît entre 1792 et I815 un élargissement remarquable. Progressivement, la Révolution, le Consulat et l'Empire agrègent provinces et États à l'ancien royaume, jusquà former l'immense continuité de la mer du Nord à l'Italie centrale qu'est, en I8II, l'Empire des I30 départements. L'entrée sous autorité française, dans le cadre administratif du département, de régions dotées de très fortes identités entraîne des confrontations avec la volonté politique impériale. La « police médicale ${ }^{110}$ » constitue un champ de rencontre des pratiques françaises et étrangères, en un domaine où la volonté de marquer les nouveaux départements de l'empreinte française s'exprime très intensément. Le développement de la formation des sages-femmes, qui a passionné toute l'Europe dans la seconde moitié du xvirI ${ }^{e}$ siècle ${ }^{111}$, forme un terrain privilégié où s'opposent à partir de 1802 le modèle de l'Hospice de la Maternité et les habitudes antérieures.

L'intégration progressive des départements italiens correspondant aux anciennes républiques Cisalpine et Ligurienne, puis celle en I8II du royaume

Io8. AD Côte-d'Or, M7 n I/I.

I09. Beauvalet-Boutouyrie S., Naître à l'hôpital..., op. cit., p. II7.

IIo. Hudemann-Simon C., « La politique sociale de l'État français sur la rive gauche du Rhin occupée puis annexée, I794-I8I4 », HES, 1996-4, p. 602.

III. Gélis J., La Sage-femme ou le médecin..., op. cit., p. 85-I07 ; 173-194. 
de Hollande et enfin la réunion d'une partie des territoires du Saint-Empire, fait entrer dans le giron français des traditions diverses de transmission du savoir obstétrical. La réaction du pouvoir central face à ces situations divergeant du modèle qu'il cherche à promouvoir est variable d'une région à l'autre. Elle exprime toutefois de façon constante la certitude de proposer la meilleure méthode pour fournir à ces populations un encadrement obstétrical de qualité, niant des complémentarités qui transcendaient naguère les frontières politiques.

L'incorporation dans l'Empire français nationalise et territorialise tout à la fois l'enseignement obstétrical. La rupture avec la tradition germanique des migrations éducatives se lit bien dans ces lettres envoyées à Paris par les préfets de l'Ems Supérieur et des Bouches-du-Weser :

(Ems Supérieur) Dans la partie de ce département qui précédemment appartenait au pays d'Hanovre, on envoyait les élèves sages-femmes à Celle où elles recevaient des leçons théoriques et pratiques dans l'art de l'accouchement. Ceci a cessé vû que la ville de Celle fait toujours partie du royaume de Westphalie. ${ }^{112}$

(Bouches-du-Weser) Avant la réunion de ces contrées à l'Empire français, les personnes qui vouloient s'adonner à l'art des accouchemens se rendaient à Celle dans le royaume de Westphalie [...]. Mais depuis la formation des départemens hanséatiques, on n'admet plus à l'école de Celle les élèves sagesfemmes de ces départemens $[\ldots] .{ }^{113}$

La rupture intervient dans un contexte d'États-frères, puisque depuis le traité de Tilsitt en I807 le royaume de Westphalie est placé sous l'autorité de Jérôme Bonaparte. Il ne s'agit donc pas seulement de marquer une frontière nette entre l'Empire et ses voisins, tout fraternels soient-ils, mais plutôt d'affirmer l'emprise de la pratique pédagogique française, par la dissociation des complémentarités précédentes et le rejet des pratiques anciennes sur le territoire de l'Empire élargi. Dans le département de l'Arno, la ville de Florence perpétue l'héritage grand-ducal en matière de formation des sages-femmes et des accoucheurs ${ }^{114}$. Depuis $176 \mathrm{I}$, l'Ospedale di Santa Maria Nuova abrite les cours dispensés aux accoucheuses et aux étudiants en chirurgie. Les vicissitudes politiques n'interrompent pas les cours d'accouchement. Mais l'influence française

II2. $\mathrm{AN}, \mathrm{F}^{17} / 2459$, Ems Supérieur.

II3. AN, $\mathrm{F}^{17} / 2457$, Bouches-du-Weser.

II4. Sur la mise en place d'une formation des accoucheuses à Florence au XVIII ${ }^{\mathrm{e}}$ siècle, voir Brau J., «La professionnalisation de la santé dans la Toscane des Lumières, I765-I8I5 », RHMC, t. 4I, nº 3, juil.-sept. 1994, p. 430 sq. 
sur les professeurs florentins est patente puisque Giuseppe Vespa et Francesco Valli comptent parmi les disciples d'André Levret, et que le gouvernement toscan conserve tout au long du siècle l'habitude d'envoyer ses enseignants se former à Paris, comme le rappelle Giovanni Bigeschi dans un courrier au ministre de l'Intérieur français au début des années $1810^{115}$. L'enseignement se déroule dans un hospice et les principes de l'obstétrique sont tirés de la science française. Pourtant, le jugement de Fauchet, second préfet de l'Arno, rapporté par le ministre Montalivet, est extrêmement critique :

Vous ajoutez, enfin, que l'instruction des sages-femmes, dont le nombre est, d'ailleurs, insuffisant dans votre département, n'est point donnée d'après la bonne méthode d'où il résulte de très fréquents accidents dans les campagnes. ${ }^{116}$

L'état sanitaire de l'unique service de maternité florentin laisse aussi à désirer et l'administration travaille rapidement à y remédier en envisageant son transfert de Santa Maria Nuova à l'Ospedale degli Innocenti. Mais la sévérité du préfet se lit à l'aune de l'alignement prescrit sur le modèle parisien, bien plus que comme un jugement impartial des efforts toscans en matière de formation des sages-femmes.

À l'autre bout de l'Empire, dans le département des Bouches-de-la-Meuse, né de l'annexion en I8II du royaume de Hollande, le relais du gouvernement français à La Haye, Goswin de Stassart porte un regard moins critique sur les institutions locales à destination des sages-femmes : (juillet I8I2) «Il y a des ressources dans plusieurs villes du département pour procurer de l'instruction aux femmes qui se vouent à l'art des accouchemens ${ }^{117}$. »Un an plus tard, en août I8I3, lorsqu'il répond à l'enquête de l'an XIV, il admire le « vrai mérite » des professeurs, tout en soulignant qu'à Leyde, «il n'y a point de dépenses à faire puisque les choses sont déjà établies sur un bon pied », qu’à La Haye, «il y a un local convenable » pour les cours théoriques tandis que «les leçons pratiques se donnent à domicile», et que ce système peut être adopté provisoirement à Rotterdam et Gorcum ${ }^{118}$.

S'il prend la précaution de reconnaître dans chacun de ses courriers la supériorité de l'enseignement délivré à l'Hospice de la Maternité de Paris, le préfet

\footnotetext{
II5. $\mathrm{AN}, \mathrm{F}^{17} / 2457$, Arno.

II6. $\mathrm{AN}, \mathrm{F}^{17} / 2457$, Arno.

II7. $\mathrm{AN}, \mathrm{F}^{17} / 2457$, Bouches-de-la-Meuse.

II8. Ibid.
} 
temporise lorsqu'il reçoit l'ordre de supprimer les cours de Leyde, La Haye et Rotterdam et réclame du ministre une nouvelle confirmation de la décision ${ }^{119}$.

Son collègue des Bouches-du-Weser se montre moins timoré, annonçant en janvier I8I2 qu'il a " provisoirement autorisé M. Gramberg à continuer son cours » à Oldenbourg, après avoir rappelé que son département était auparavant pour l'enseignement de la médecine et de la chirurgie dans l'orbite de l'université de Göttingen ${ }^{120}$. Le ministre de l'Intérieur reste circonspect et se contente d'envoyer un exemplaire du règlement parisien pour inciter à réformer l'institution oldenbourgeoise, qu'il encourage dès l'année suivante à délaisser au profit d'un projet neuf à Brême ${ }^{121}$.

Plus au nord, dans les Bouches-de-l'Elbe, la démonstration préfectorale du fonctionnement régulier et efficace du cours de Lübeck ${ }^{122}$, ne suscite du ministère que la demande d'envoi d'élèves à Port-Royal ${ }^{123}$.

Avec le décalage chronologique propre à la date d'entrée des nouveaux départements dans le giron français, le ministre de l'Intérieur formule donc les mêmes exigences que celles qu'il destinait à l'Hexagone des années 1802-1806, en invitant encore et toujours ses préfets à envoyer leurs futures sages-femmes à l'Hospice de la Maternité de Paris. De l'autre côté, le même argument évident revient sous la plume des préfets pour refuser l'envoi : les futures élèves ne parlent pas français.

Les instances ministérielles cèdent toutefois assez rapidement devant la barrière de la langue : «Les femmes de vos communes n'entendent point encore la langue française », reconnaît Montalivet dans un courrier au préfet des Bouches-du-Rhin en $1812^{124}$. À l'opposé, les préfets des régions non-francophones tentent des prouesses pour répondre aux souhaits du ministre. En I8I2, Patrice de Coninck, en poste à Hambourg, dit son espoir « que d'ici à l'ouverture du cours d'accouchement de l'année prochaine, quelques élèves se seront rendues habiles à profiter de la faveur qui leur est offerte ${ }^{125} »$. En I8I3, l'essai est transformé dans l'ancien royaume de Hollande, puisque deux élèves originaires des Bouches-de-la-Meuse suivent les cours de l'Hospice de la Maternité ${ }^{26}$. Ces prodiges restent cependant des exceptions.

\footnotetext{
II9. Ibid.

120. $\mathrm{AN}, \mathrm{F}^{17} / 2457$, Bouches-du-Weser.

I2I. Ibid.

122. $\mathrm{AN}, \mathrm{F}^{17} / 2457$, Bouches-de-l'Elbe.

123. Ibid.

124. $\mathrm{AN}, \mathrm{F}^{17} / 2457$, Bouches-du-Rhin.

125. AN, $\mathrm{F}^{17} / 2457$, Bouches-de-l'Elbe.

126. $\mathrm{AN}, \mathrm{F}^{17} / 2457$, Bouches-de-la-Meuse.
} 
La persévérance du ministre de l'Intérieur à proposer, avant toute autre solution de formation, l'envoi des élèves sages-femmes à Paris ne tient aucun compte des difficultés matérielles et linguistiques (même si les départements italiens semblent partiellement dispensés ${ }^{127}$ ). Elle s'ancre dans la volonté de conserver la primauté symbolique de l'Hospice de la Maternité. Les départements réunis avant le Consulat, qui plus est dans des régions francophones, suivent l'évolution des «vieux » départements français et obtiennent une autonomie plus précoce en matière de formation obstétricale que les espaces conquis sous le Consulat et l'Empire. Il en est de même pour les départements créés sur la rive gauche du Rhin, et dont l'assimilation administrative se fait progressivement entre 1798 et le décret consulaire du 30 juin $1802{ }^{128}{ }^{\text {. Dès I } 807-}$ I808, le ministre de l'Intérieur ordonne la mise en place d'écoles départementales d'accouchement à Cologne (Roer), Mayence (Mont-Tonnerre) et Trèves $(\text { Sarre })^{129}$. Pour les départements intégrés après la proclamation de l'Empire, la circulaire du I8 vendémiaire an XIV est simplement ressortie des archives ${ }^{130}$.

La loi de ventôse portait dans son article 30 que devait être choisi l'hospice le plus fréquenté du département pour accueillir le cours d'accouchement. La correspondance ultérieure du ministre de l'Intérieur spécifie l'abstraction législative en indiquant le volume de la fréquentation (nombre de femmes enceintes admises dans l'établissement), et en définissant même, à l'issue des premières réponses à l'enquête de l'an XIV, un seuil minimal de lits réservés à ces femmes dans l'hospice (Io à I2) ${ }^{131}$. Ce seuil, officialisé par une communication ministérielle à valeur de circulaire d'application, constitue dès lors l'horizon minimal et indispensable de tout cours d'accouchement conforme aux principes de ventôse revus et corrigés à la lumière de Port-Royal. Il justifie par exemple d'imposer à l'automne I8I2 au préfet de Jemmapes de revoir sa copie pour son projet de cours à l'hospice de Mons ${ }^{132}$.

Pourtant, de la théorie à la pratique, se déploie toute la gamme des petits arrangements particuliers. En frimaire de l'an XIV, à la question sur « l'hospice

127. $\mathrm{AN}, \mathrm{F}^{17} / 2460$, Gênes : " L'éloignement où votre département se trouve de la capitale et la difficulté d'y rencontrer des sujets assez familiarisés avec la langue française pour profiter des leçons qu'on donne dans cette langue à la maternité, ne vous permettent probablement pas, Monsieur, d'exécuter mon arrêté du 17 janvier ».

128. Hudemann-Simon C., «La politique sociale de l'État français... », art. cit., p. 602.

129. Ibid., p. 605. Sur le département de la Sarre, voir Labouvie E., Beistand in Kindsnöten..., op. cit., p. $269 \mathrm{sq}$.

130. $\mathrm{AN}, \mathrm{F}^{17} / 2463$, Méditerranée.

13I. $A N, F^{17} / 2462$, Jemmapes.

132. Ibid. 
le plus fréquenté quant aux accouchements », le préfet du Léman répond : «Il n'en existe aucun qui ait cette destination. L'hôpital de Genève en particulier n'a que peu ou point de femmes à recevoir pour $y$ faire leurs couches ${ }^{133}$, » A près ce constat, il poursuit :

L'établissement d'un cours d'accouchement dans un hôpital entraîne presque nécessairement celui d'une chambre pour les accouchemens illégitimes, puisqu' il n'y a guère que cette espèce de sujets qu'on ait le droit d'exposer à une inspection publique ; les petites villes présentent sur un pareil établissement des considérations toutes différentes que celles que fournissent les grandes cités. [...] Il y a trop de considérations locales et morales qui s'opposent à cet établissement dans l'hôpital pour calculer ce qu'il pourrait coûter.

De telles observations semblent appeler une fin de non-recevoir à la poursuite du cours d'accouchement professé sur demande du préfet par le docteur Jurine, qui « trouve dans les domiciles de particuliers ou chez les sages-femmes les sujets de ses leçons de pratique ». Malgré cet empêchement apparemment dirimant, le ministre de l'Intérieur, dans une lettre du 6 juin 1807, déclare «qu'on ne peut trop se hâter d'organiser dans cette ville le cours gratuit ».

Il existe donc deux poids et deux mesures. Le préfet de l'Ems Oriental se voit ainsi refuser en I8I3 le rétablissement officiel d'un cours poursuivi depuis 1797 par le professeur von Halem sur des bases modestes mais rigoureuses incluant un minimum de formation clinique ${ }^{134}$, alors que le Simplon est autorisé la même année à organiser à Sion un cours d'accouchement de trois mois dont les fondements pratiques sont inexistants ${ }^{135}$.

La contradiction se résout dans l'attitude vis-à-vis des traditions de formation antérieures à l'installation française. Pour être pérennisée, l'institution doit déjà relever du modèle français. C'est le cas à Bruges où la continuité de l'enseignement a été rompue près de dix ans avant l'enquête de l'an XIV et où son rétablissement est projeté dans un hospice accueillant près de 120 accouchements par an ${ }^{136}$. Plus encore, c'est le cas à Turin où l'influence française a présidé à la naissance de l'école-maternité en 1728. En I800, les troupes de Bonaparte reprennent le Piémont et la République subalpine remplace la République piémontaise de 1798. Cette année-là, la maternité est séparée de l'hôpital et sa direction est confiée à un accoucheur, cumulant les soins aux femmes enceintes

133. $\mathrm{AN}, \mathrm{F}^{17} / 2462$, Léman.

134. AN, $\mathrm{F}^{17} / 2459$, Ems Oriental.

135. Vouilloz-Burnier M.-F., L'accouchement entre tradition et modernité..., op. cit., p. 134-135.

I36. AN, $\mathrm{F}^{17} / 2463$, Lys. 
et la formation obstétricale, préfiguration de l'organisation de l'Hospice de la Maternité de Paris ${ }^{137}$. Au moment de la départementalisation de la République subalpine, le pouvoir central ne remet nullement en cause le fonctionnement d'un établissement qui répond à tous les critères souhaités par Paris.

En revanche, lorsqu'il doit choisir entre le maintien et l'adaptation d'un établissement ancien ne relevant pas de la filiation française et une création, le ministre de l'Intérieur choisit la seconde solution qui répond mieux à la volonté politique impériale. La pertinence immédiate des structures créées est donc sacrifiée dans certains cas à l'application rigide d'un modèle idéologique. Mais cette approche volontariste se fonde aussi dans une perspective à long terme qui juge l'efficacité des cours à l'aune de leur développement futur. L'hospice principal de Genève ne reçoit pas de femmes enceintes? Qu'à cela ne tienne, l'offre entraînera la demande - sans considération pour les intentions moralisantes du préfet - et les ressources cliniques inexistantes finiront par se multiplier avec les années.

Le destin de l'Empire ne s'accorde toutefois pas avec ses objectifs. La retraite de Russie en I8I2, la reconstitution de l'alliance européenne contre la France en I8I3 et la guerre qui occupe la fin du régime interrompent net la politique d'intégration des nouveaux départements, tous perdus dès I8I4. Le bilan est mitigé. De nombreux projets sont restés en suspens : Brême, Bois-le-Duc, Amsterdam, Sion, Florence... en cours d'organisation au moment où tout s'écroule. Dans les départements de la rive gauche du Rhin, les résultats des écoles mises en place à Cologne, Mayence et Trèves ne sont pas à la hauteur des espérances, et c'est la poursuite, illégale, des cours d'accouchement sur le modèle ancien dans le département du Rhin-et-Moselle qui porte les meilleurs fruits pendant la durée de l'occupation française ${ }^{138}$. La décennie 1800 sous domination française interrompt des dynamiques antérieures, qu'elle délégitime au motif qu'elles ne correspondent pas à la définition impériale de l'instruction des sages-femmes. Elle fige les initiatives en interdisant le maintien de cours dans l'attente d'un hypothétique envoi dans une institution adéquate. Le projet de cours toujours repoussé à Amsterdam dans le Zuydersée bride les autres départements de l'ancien royaume de Hollande, invités à patienter et à envoyer leurs élèves " près les cours d'accouchement qui seront établis dans les principales villes des départements réunis ${ }^{139} »$. Ce sont autant d'accoucheuses qui ne sont pas instruites dans l'intervalle, même s'il faut nuancer l'obéissance aux ordres de suppression des formations existantes.

137. Filippini N. M., « Sous le voile... », art. cit., p. I80.

138. Hudemann-Simon C., « La politique sociale de l'État français... », art. cit., p. 605-606.

139. AN, $F^{17} / 2457$, Bouches-de-l'Escaut. 
Quelle postérité de l'eldorado parisien tant vanté par les ministres successifs ? La distance, la non maîtrise du français en ont éloigné bien des sagesfemmes potentielles, mais la persévérance des préfets a réussi à faire entrer quelques dizaines d'élèves dans le giron de l'école. Entre l'an XI et avril I808, 40 futures accoucheuses issues des départements de l'Empire élargi passent les portes de Port-Royal ${ }^{140}$. Elles viennent pour 36 d'entre elles de régions francophones (départements des Forêts, de Jemmapes, de l'Ourthe, de Sambre-etMeuse et du Mont-Blanc), annexées à la France entre I792 et I795. La participation des nouveaux départements ( $8 \%$ des élèves sages-femmes admises entre l'ouverture de l'école et I808) reste néanmoins modérée, comparée à l'élargissement qu'a connu la France pendant ces années et à la fréquentation générale de l'Hospice de la Maternité de Paris.

L'intégration des républiques italiennes et du royaume de Hollande ne modifie pas en profondeur le recrutement de l'établissement qui accueille en I8IO-I8II 36 futures sages-femmes originaires de huit départements du Grand Empire $^{141}$, mais parmi lesquels on retrouve les principaux pourvoyeurs des années précédentes (Jemmapes, Forêts, Sambre-et-Meuse). Les départements néerlandophones de l'Escaut et des Deux-Nèthes envoient chacun une élève. L'ancien royaume de Sardaigne, départementalisé entre 1792 et I802, est représenté par une élève du Mont-Blanc et quatre de la Stura. Les années suivantes ne connaissent aucune modification radicale de la fréquentation de l'Hospice de la Maternité dont le recrutement ne s'accroît jamais vraiment au-delà de la Wallonie et de la Savoie.

Là où l'emprise scientifique et pédagogique est ancienne, là aussi où elle a rencontré d'autres traditions comme à Milan où se mêlent à l'Ospedale Santa Caterina alla Ruota influences parisienne et viennoise, l'adaptation des structures locales aux principes de l'occupant se fait sans trop de difficultés. À Bologne, la création en 1805 du royaume d'Italie coïncide avec le début officiel des cours confiés à Maria Dalle Donne ${ }^{142}$. La formation des sages-femmes qu'elle dirige est à cette date séparée de l'Istituo delle Scienze où Tarzisio Riviera continue d'enseigner les étudiants en chirurgie. L'instruction clinique doit, selon les plans d'origine, prendre place dans un établissement hospitalier.

140. Hucherard, Sausseret, Girault, Mémoire historique et instructif..., op. cit., p. 66-67.

I4I. Deux-Nèthes, Escaut, Forêts, Jemmapes, Mont-Blanc, Ourthe, Sambre-et-Meuse, Stura, voir Beauvalet-Boutouyrie S., Naître à l'hôpital..., op. cit., p. 138.

142. Berti Logan G., "Women and the Practice and Teaching of Medecine in Bologna in the Eighteenth and Early Nineteenth Centuries », Bulletin of the History of Medicine, vol. 77, n 3, 2003, p. 517 sq. 
Le cas bolonais est symptomatique de la transposition en Italie des principes fondateurs de l'Hospice de la Maternité. L'enseignement est scindé en deux structures, correspondant à deux métiers clairement sexués, et l'enseignante choisie par le gouvernement républicain dès 1804 est docteur en médecine, soit une femme au savoir très largement supérieur à celui exigé pour ce poste. Ce décalage entre les diplômes de Maria Dalle Donne et son rôle de maîtresse sage-femme peut s'interpréter autant comme un cantonnement dans une fonction traditionnellement dévolue à son sexe, que comme la reconnaissance des compétences nécessaires au projet ambitieux de cette école d'accouchement.

Le départ des Français ne signe pas la fin de tous les mouvements lancés pendant la période d'occupation et l'influence se fait sentir bien au-delà de la domination impériale. Florence en est la preuve. Entre i8Io et I8I4, le préfet Faucher prépare avec Montalivet la mise en place d'une institution conforme aux principes de ventôse an XI et de l'Hospice de la Maternité. En janvier I8I4, un rapport au ministre de l'Intérieur dresse l'état des lieux : l'emplacement du futur établissement est défini et ne restent à approuver que les nominations du professeur et de la sage-femme ${ }^{143}$. Seuls des obstacles matériels surmontables (financement et local) entravent la bonne marche du projet ${ }^{144}$.

Après la défaite de Napoléon face à l'Europe coalisée, le traité de Paris du 30 mai I8I4 ramène la France à ses frontières de I792. Au Congrès de Vienne en I8I5, Florence et la Toscane sont rendues à l'ex-grand-duc Ferdinand III. Quelques mois plus tard, une école-maternité voit le jour dans l'Ospedale degli Innocenti ${ }^{145}$, et Giovanni Bigeschi, approuvé le I3 janvier I8I4 comme professeur d'accouchement de la future école du département de l'Arno par le ministre français de l'Intérieur ${ }^{146}$, peut enfin prendre ses fonctions, confirmées par le pouvoir grand-ducal ${ }^{147}$. La continuité est parfaite, signe de l'appropriation, hors de toute pression politique étrangère, du modèle parisien refondé en 1802.

\section{La légitimité départementale : résistances locales et appropriation de la loi de ventôse}

La dynamique qui porte la formation des sages-femmes pendant le premier quart du $\mathrm{XIX}^{\mathrm{e}}$ siècle n'émane pas toute entière de la capitale. Les départements jouent une partition propre. L'accélération des recréations de cours

\footnotetext{
143. $\mathrm{AN}, \mathrm{F}^{17} / 2457$, Arno.

144. Ibid.

145. Brau J., «La professionnalisation de la santé dans la Toscane des Lumières... », art. cit., p. 43I.

146. $\mathrm{AN}, \mathrm{F}^{17} / 2457$, Arno.

147. Siebold E. C. J. (von), Essai sur l'histoire de l'obstétricie, op. cit., p. 674.
} 
d'accouchement à partir de l'an viII tient un rôle décisif dans la vocation nationale donnée par Chaptal à l'école de l'Hospice de la Maternité, de même qu'elle inspire Fourcroy lorsqu'il rédige le titre $\mathrm{V}$ de la loi du I9 ventôse an XI. Une même cause aboutit à deux projets différents. Dans le premier cas, il s'agit de couper court à la multiplication d'institutions disparates pour privilégier une forme spécifique d'instruction incarnée dans un établissement unique. Dans le second, la même volonté de contrôle des structures provinciales de formation est à l'œuvre mais passe par la réduction législative de la variété primitive à un seul mode de transmission des connaissances. Le texte de ventôse prend acte de l'acquis et ouvre la voie à une continuité maîtrisée. Il justifie et légitime l'échelle départementale, fondant l'aspiration de ces collectivités à disposer d'un établissement spécial d'instruction. D'enjeu sanitaire, le cours départemental d'accouchement devient enjeu de pouvoir. À ce titre, la défense de l'enseignement local est un travail de longue haleine qui pose longtemps et avec insistance la question des rapports entre patrie et « petite patrie».

\section{Paris comme repoussoir}

Aux origines des cours départementaux il y a le refus de Paris ${ }^{148}{ }^{1}$ « L'éloignement de la capitale est un grand obstacle à l'accomplissement des vues de Votre Excellence ${ }^{149}$. Paris est loin, pour les paysannes toscanes ou flamandes, mais tout autant pour les Françaises qui vivent dans les limites anciennes du pays. La distance ne se mesure d'ailleurs pas uniquement en kilomètres effectifs, sinon les départements frontaliers feraient, seuls, grief à l'Hospice de la Maternité de son éloignement (Hautes-Pyrénées, Hautes-Alpes ${ }^{150}$ ). Mais les départements proches de Paris ne sont pas en reste pour dire l'impossibilité du déplacement. Le préfet du Loiret souligne la cherté des frais de voyage « dont la quotité exclurait un grand nombre ${ }^{151}$ », s'attirant le rappel irrité du ministre de l'Intérieur de la proximité du département.

C'est pourtant surtout le dépaysement qui nourrit les inquiétudes des élèves potentielles comme de leur entourage ${ }^{152}$. Les préfets ont conscience de l'effort fourni par les femmes venues suivre un cours au chef-lieu du département,

\footnotetext{
148. Beauvalet-Boutouyrie S., Naître à l'hôpital..., op. cit., p. II4-II6.

149. AN, $F^{17} / 2462$, Jura.

150. AD Hautes-Pyrénées, I N 2* $;$ AN, F F 72457 , Hautes-Alpes.

I5I. AN, $\mathrm{F}^{17} / 2463$, Loiret.

152. J. Gélis a montré combien le changement d'échelle du cadre quotidien pouvait décourager les futures accoucheuses, voir La Sage-femme ou le médecin..., op. cit., p. I49-150.
} 
point extrême de leur capacité d'éloignement ${ }^{153}$. Les courriers au ministre de l'Intérieur disent tous l'exception parisienne. Le nom de la capitale est à lui seul justification du refus, car à chaque ligne, Babylone point derrière Paris :

(Nord) Les parents tremblent pour les mours de leurs enfants abandonnés dans l'âge des passions à tous les dangers d'une ville comme Paris. ${ }^{154}$

(Meurthe) $[. .$.$] qu'on décidera difficilement une femme ou fille honnête et$ domiciliée à quitter ses foyers, pour un tems un peu long, aux risques de sa santé et de ses mours (car Paris passe aux yeux des bonnes gens de campagne pour une ville immonde sous plusieurs rapports) $[\ldots] .{ }^{155}$

Surgit l'image de la dépravation comme maladie dont Paris est le haut-lieu de fermentation et d'infestation. La sage-femme contaminée par l'immondice parisien est vecteur de contagion d'immoralité, aussi dangereuse aux yeux du médecin lorrain que l'impéritie d'accoucheuses peu ou mal formées. La préservation de l'honnêteté passe par le refus du séjour à Paris. Par ricochet, l'opprobre est jeté sur les candidates potentielles, soupçonnées de vouloir aller nourrir leur vice à la source (« des aventurières ») ou d'être trop bêtes pour saisir le péril qui les guette (« d'ineptes protégées »). La contagion des mauvais principes contractés dans la capitale se retrouve dans le repentir d'un courrier du préfet de la Côte-d'Or au ministère :

[...] si on imposait aux élèves sages-femmes l'obligation de ne s'instruire désormais qu'à l'école de la Maternité, $[\ldots]$ on $[\ldots]$ ne procurerait à la grande partie de celles qui se voueraient à la profession d'accoucheuse, que l'occasion de perdre leurs moeurs et de corrompre, à leur retour, celles de leurs compatriotes. ${ }^{156}$

Les préfets se contentent alors de mettre en avant les préoccupations morales des familles. En l'an XI, les parents de Marguerite Lafon-Duroux, élève corrézienne choisie pour rejoindre l'école de Port-Royal, font dépendre leur consentement de la certitude que « les élèves sont logées ensemble à l'hospice » et que « leur conduite sera sévèrement surveillée ${ }^{157}$ ». De fait, l'institution a des failles, rares mais terriblement gênantes pour la commission administrative des hospices civils de Paris. Le II mai I806, le membre de la commission

153. Dupâquier J., «Sédentarité et mobilité dans l'ancienne société rurale. Enracinement et ouverture : faut-il vraiment choisir ? », Histoire et Sociétés Rurales, ${ }^{\circ}{ }^{18}$, 2002, p. 122-123.

154. $A N, F^{17} / 2464$, Nord.

155. AN, $\mathrm{F}^{17} / 2463$, Meurthe.

156. AD Côte-d'Or, M 7/n I/I. Le passage en italiques correspond au morceau de phrase raturé dans le brouillon de la lettre.

157. Sage Pranchère N., Mettre au monde..., op. cit., p. I6I. 
« spécialement chargé de l'Hospice de la Maternité », Alhoy, écrit au préfet de l'Ardèche pour l'informer de "faits pénibles ${ }^{158}$ ». La demoiselle Frugier, boursière du département, a dû être éloignée de l'école pour cacher sa grossesse. Or cette jeune femme n'a pas été admise enceinte dans l'établissement. Alhoy intercède pour que l'argent destiné au paiement de la pension soit versé à la demoiselle Frugier afin de lui permettre de subvenir à ses besoins jusquà la date des examens qu' elle est autorisée à passer. La jeune femme doit pouvoir poursuivre sa vie d'avant la faute et pour cela, le préfet doit « rester le seul confident de ce secret ». L'enfant, s'il a vécu, a probablement été abandonné. L'oubli de l'affaire est une chance pour l'élève ardéchoise, et un impératif pour la réputation de l'établissement. Sept mois plus tard, le nouveau règlement de l'Hospice de la Maternité prévoit désormais que l'externat est soumis à l'autorisation écrite de la sage-femme en chef après vérification de la respectabilité de la maison choisie (titre IV, art. 3 et 4$)^{159}$. Une même autorisation est indispensable pour toute sortie d'élève interne (titre IV, art. 6). En I8Io, la possibilité de l'externat n'est plus évoquée et les sorties sont drastiquement limitées, dépendant du bon vouloir de l'agent de surveillance et de la présence d'un proche parent (père, mère ou époux) (titre IX, art. 2 à 5$)^{160}$.

Autant considérer dès lors que la scolarité à Port-Royal correspond à une année de claustration complète puisque les familles ne se déplacent pas, ce qui est un motif supplémentaire de réticence chez les candidates potentielles : filles ou épouses, « les personnes qui se livrent à cette profession sont toutes peu aisées, et presque toujours nécessaires à une famille qu' elles ne peuvent quitter très longtemps ${ }^{161} »$. Les pourcentages de femmes mariées parmi les élèves de l'établissement parisien sont révélateurs de l'obstacle exprimé par les correspondances, puisqu'entre I8IO et I8I9, ces femmes représentent I8, I \% de l'effectif total ${ }^{162}$. L'ennui, l'absence de nouvelles pour l'élève comme pour sa famille sont des réalités particulièrement pesantes, surtout dans des milieux peu lettrés. Le malaise décrit, la « répugnance », sont autant moraux que physiques. C'est la raison qui rend sans doute le plus précisément compte du ressenti des futures élèves parisiennes. De là l'impuissance des maires et des préfets à vaincre une aversion qui résiste à presque toutes les tentatives de persuasion.

\footnotetext{
158. $\mathrm{AD}$ Ardèche, $5 \mathrm{M} 30$.

159. $\mathrm{AD}$ Corrèze, I X 16I.

I6o. Ibid.

I6I. $\mathrm{AN}, \mathrm{F}^{17} / 2463$, Loiret.

162. Beauvalet-Boutouyrie S., Naître à l'hôpital..., op. cit., p. 136.
} 
Paris l'immorale, Paris l'ogresse, Paris l'étrangère aussi... où la provinciale court le risque de ne pas être comprise et de ne pas pouvoir se faire comprendre ${ }^{163}$. La non francophonie est une réalité quotidienne de la France du XIX ${ }^{e}$ siècle $^{164}$. Les régions les plus concernées sont les marges du pays (Bretagne, Alsace), mais aussi le midi occitan dont la frontière septentrionale court de la Charente à l'Ain ${ }^{165}$. L'argument linguistique du refus est alors commun aux élèves pressenties et à l'administration. Les préfets, les conseils généraux ne cessent d'affirmer au ministre de l'Intérieur l'inutilité de l'envoi à Paris, son aberration même puisqu'il ne serait que temps et argent perdus. S'il faut consacrer des fonds à la formation des sages-femmes, ces dernières doivent comprendre ce qu'on leur enseigne. D'autre part, les principes qui guident la réflexion des préfets et des conseils généraux sont ceux qui définissent le « recyclage des matrones». S'ensuit un cercle vicieux : la seule élève possible à leurs yeux est une femme qui exerce déjà l'art des accouchements, et les caractéristiques culturelles de cette élève sont en complète contradiction avec les exigences de l'Hospice de la Maternité. La conclusion des préfets et des conseils généraux est recevable dans le cadre précis de leur raisonnement. Mais la prémisse fausse l'ensemble du raisonnement, puisque rien n'impose à la future élève sage-femme de PortRoyal qu'elle ait une quelconque expérience du métier qu'elle part apprendre.

Autre obstacle : les ressources départementales ne sont pas extensibles. Le prix de la pension à payer pour le semestre de cours à l'Hospice de la Maternité passe de 250 francs en l'an x (art. 3) à 300 francs en I 807 (art. 8) ${ }^{166}$. Lorsque la durée de la formation passe à un an, la somme est automatiquement doublée et aux 600 francs annuels s'ajoutent les achats d'ouvrages obligatoires, les frais de blanchissage et les frais de voyage alors laissés à la convenance des préfets et des commissions administratives des hospices $(67,75 \text { francs })^{167}$. Immédiatement, l'usage contredit l'économie promise par Chaptal aux départements en 1802 et les correspondants du ministère sont unanimes à affirmer que l'établissement de Port-Royal est incapable de pourvoir au manque chronique d'accoucheuses diplômées. Pied à pied, avec une diplomatie redoutable, les préfets bataillent pour défendre leur politique locale. Avec précision, ils alignent les besoins des départements, leur capacité d'envoi à Paris et les résultats réels ou probables

163. Ibid.

164. Weber E., La fin des terroirs, la modernisation de la France rurale, 1870-1914, Paris, Fayard, 1983, p. I08-I09 et 84I sq.

165. Sage Pranchère N., Mettre au monde..., op. cit., p. I3I-I32.

I66. RLRES I, p. 87, arrêté-règlement du ministre de l'Intérieur sur les divisions du service de la Maternité, II messidor an $\mathrm{x}$; AD Corrèze, I X I6I.

167. AD Corrèze, i X I6I. 
d'une école de chef-lieu. L'argumentation du préfet de l'Eure dans sa réponse à la circulaire ministérielle de février I807 est un modèle du genre :

[... ] il faudrait au moins trente réceptions par année pour subvenir aux besoins des communes rurales [...]. Or il est impossible que trente élèves sortent du département pour l'école de la maternité. La plupart des filles qui embrassent cette profession sont extrêmement pauvres, une fille de bon laboureur dans ce département dédaigne l'état de sage-femme, il n'y avait donc que la pension gratuite qui pourrait attirer des élèves à Paris, mais pour la procurer, deux de nos hospices, Vernon et Louviers, en ont seuls la faculté. Je n'ai pour cette dépense aucune ressource. $\mathrm{I}^{\circ}$ le Conseil général n'a point voté de fonds pour les cours d'accouchement, et je n'ai pas l'espoir d'en obtenir en I808. $2^{\circ}$ les fonds affectés aux dépenses variables sont annuellement absorbés. $3^{\circ} \mathrm{Le}$ produit des rétributions provenant des officiers de santé $[\ldots]$ pourrait tout au plus pourvoir à l'entretien d'une élève chaque année. Voici trois élèves à pension gratuite, supposons deux élèves à leurs frais, ce qui est bien supposition, total cinq élèves par an pour le département de l'Eure ; penserez-vous, Monseigneur, que l'instruction de ces cinq élèves, quelque perfectionnée qu'elle soit, puisse pour l'intérêt de l'humanité, s'acheter aux dépens de celle de trente femmes qui sans autre déplacement que de se rendre au chef-lieu puiseraient dans des cours périodiques au moins les premiers élémens de leur art et des notions suffisantes pour travailler dans les cas ordinaires. ${ }^{168}$

Qui, dès lors, est « dangereux », du cours départemental modeste mais régulier ou du ministre campé sur ses principes ? Et quand bien même l'argent coulerait à flot, l'Hospice de la Maternité n'a pas la possibilité matérielle d'accueillir toutes les élèves que les départements ont la nécessité de faire former. Le ministère de l'Intérieur finit d'ailleurs par l'admettre : "On est bien persuadé que l'école de l'Hospice de la Maternité ne suffit pas pour fournir des sagesfemmes à tout l'Empire ${ }^{169}$. »

Dans ce face-à-face du pouvoir central et de son plus fidèle représentant renaît la tension contradictoire entre les modèles de Port-Royal et de ventôse an XI. Malgré l'obéissance due, l'ancrage local fait, la plupart du temps pencher le préfet du côté du texte législatif contre son ministre de tutelle. Ceci posé, le refus de Paris est un refus fécond qui ouvre la voie à la justification positive de l'enseignement provincial et à l'invention d'une complémentarité entre la capitale et les départements.

168. $\mathrm{AN}, \mathrm{F}^{17} / 2459$, Eure.

169. $\mathrm{AN}, \mathrm{F}^{17} / 2458$, Charente-Maritime. 


\section{Défense et illustration de l'enseignement obstétrical de province}

La loi du I9 ventôse an XI ouvre pour les institutions départementales de formation obstétricale, lorsqu' elle est connue, des perspectives qu'on croyait oubliées depuis Chaptal. La diffusion du texte suit les voies législatives normales, grâce à $L a$ Gazette nationale ou Moniteur universel qui retranscrit quotidiennement, avec quelques jours de décalage, les débats au Conseil des Cinq-Cents. Certains maires ne le découvrent pourtant que très tardivement. En thermidor an XIII, le maire de la commune audoise de Cuxac-Cabardès fait part à son préfet de sa science visiblement toute neuve :

La lecture de la loi du I9 ventôse an XI, relative à l'exercice de la médecine a relevé mes espérances. [... ]. Il résulterait, Monsieur le Préfet, de l'exécution de ces dispositions de la loi du ig ventôse que le but où tendait en l'an ix le conseil général du département, et vers lequel josais viser dans ma lettre du ıo floréal an Xıı que vous avez daigné accueillir, serait atteint. ${ }^{170}$

La fondation de l'Hospice de la Maternité de Paris et l'unicité du centre de formation retenue par le ministre de l'Intérieur ont créé, avant le vote de mars I803, une situation inédite d'illégalité pour les cours départementaux. L'absence de tout texte règlementaire antérieur les protégeait, mais la fondation de l'école de Port-Royal les place en porte-à-faux avec les nouvelles exigences du gouvernement. La loi sur l'exercice de la médecine permet la réintégration potentielle de toutes les structures pédagogiques existantes. L'enjeu pour les départements est donc d'obtenir l'application de cette loi en s'offrant d'en prouver la légitimité pratique. Mais avant même de justifier les modalités possibles d'exécution des prescriptions législatives, les administrations départementales doivent rappeler le caractère contraignant du texte, dans une remarquable inversion de rôles avec le ministre. La circulaire de février 1807 qui transmet le nouveau règlement modifié de l'Hospice de la Maternité de Paris met le feu aux poudres. L'adjectif «dangereux », appliqué à tous les cours d'accouchement qui ne suivent pas l'enseignement donné à Port-Royal, suscite des répliques immédiates et encourage la résistance des institutions provinciales. La réaction est d'autant plus forte qu'elle succède au regain d'espoir qu'avait provoqué l'enquête de l'an xIV. L'interrogation est simple : pourquoi faire une loi si c'est pour ne pas l'appliquer? La réponse ministérielle l'est tout autant : la loi n'est pas appliquée car les conditions locales d'enseignement ne le permettent pas.

170. $\mathrm{AD}$ Aude, $5 \mathrm{MD}$ i6. 
C'est donc sur ce problème des conditions de l'enseignement que peut se construire un contre-argumentaire provincial. Il faut faire la différence entre les raisons pratiques mises en avant par les préfets pour garder leurs élèves sages-femmes dans le département et les raisons pédagogiques avancées pour prouver le bien-fondé d'une instruction non parisienne. Ce sont les médecins qui développent ces dernières, parfois à la demande des administrateurs. Parmi eux, le docteur Edme Romieux, professeur du cours d'accouchement de La Rochelle, rédige en I8I3 un Mémoire sur l'utilité des cours d'accouchement dans les départements à l'attention du ministre de l'Intérieur ${ }^{171}$.

Le passif du cours rochelais est lourd : trois rejets catégoriques du projet préfectoral, deux condamnations sans appel de l'École de médecine de Paris entre I806 et I8I2 ; autant dire un véritable camouflet pour le professeur. Il y a dans les 28 pages manuscrites qui parviennent au ministère une part de justification personnelle. L'entrée en matière est une attaque en règle contre Jean-Louis Baudelocque, présenté comme l'ennemi acharné des cours départementaux:

Feu M. Baudelocque occupoit alors le premier rang parmi les accoucheurs ; il a vu d'un œil défavorable les cours d'accouchement des départements et il a travaillé à leur suppression. [...] M. Baudelocque ! [... Plein de votre mérite comme accoucheur, jaloux surtout de la grande réputation que vous vous étiez faite en cette qualité, vous teniez à la conservation, et tout ce qui pouvoit y donner de l'étendue combloit votre cœur des plus douces jouissances.

En clouant Baudelocque au pilori, Edme Romieux se trompe pourtant de cible. Par ses cours à l'École de médecine de Paris, l'homme de Port-Royal est jusqu'à sa mort confronté à un enseignement sans clinique, réduit aux mots et au mannequin. L'introduction à l'édition de 1806 des Principes sur l'art des accouchements révèle un Baudelocque sans préjugé sur les projets portés par la loi de ventôse :

[...] si les élèves sages-femmes savent profiter des sources d'instruction qui s'ouvrent partout en leur faveur, d'après la loi du I9 ventôse an XI, et surtout si on exécute ponctuellement cette loi $[\ldots] .{ }^{172}$

Au-delà d'un portrait à charge de feu Baudelocque, calculé pour épargner les autres rédacteurs potentiels des avis de l'École de médecine, l'intérêt du mémoire rochelais tient aux réponses de fond qu'il apporte aux critiques de l'École de médecine qui soulèvent les risques d'une instruction au rabais qui

I7I. AN, $\mathrm{F}^{17} / 2458$, Charente-Inférieure.

172. Baudelocque J.-L., Principes sur l'art des accouchemens..., op. cit., p. XVII et XXXIII. 
peuplerait le pays de demi-savantes sûres de leur droit. L'auteur défend l'article 30 de la loi du I9 ventôse an XI, rejetant tout antagonisme entre prescriptions législatives et objectifs du corps médical :

La loi du I9 ventôse an XI n'a pas été faite sans la participation des membres les plus renommés, les plus sages et les plus influents du corps médical de la capitale [...]. Comment se fait-il que, peu de temps après, l'école soutienne que non seulement ces cours sont inutiles mais même qu'ils sont dangereux ? Cette différence d'opinion n'a pu être décidée par l'expérience. ${ }^{173}$

Le point fondamental de l'argumentation réside dans le parallèle établi entre les cours départementaux et les « cours particuliers de la capitale qui ont formé presque tous les accoucheurs répandus dans les différents pays de la France » (cinq mentions). Docteur en médecine de la faculté de Paris, l'auteur fait de l'instruction qu'il a reçue une référence exemplaire et réactive ainsi une solidarité d'étudiants-accoucheurs exclus de l'Office des Accouchées puis de l'Hospice de la Maternité :

À Paris les professeurs particuliers d'accouchement rassemblent chez une sage-femme, une fois par semaine, dix à douze femmes enceintes qu'ils soumettent au toucher. Les professeurs des départements n'ont-ils pas souvent dans leurs hospices, un pareil nombre de femmes enceintes ? [...] Dans les départements, les élèves peuvent acquerrir sur ce point de pratique, autant de lumière que ceux qui suivent les cours particuliers de la capitale.

Le caractère restreint voire insuffisant des occasions d'observation clinique est soigneusement passé sous silence ${ }^{174}$. Edme Romieux s'appuie sur un raisonnement tautologique et corporatiste : les accoucheurs sont bien formés car ils sont accoucheurs et les cours particuliers parisiens délivrent un enseignement de qualité parce qu'ils sont le lieu principal d'instruction des accoucheurs.

Ceci posé, Romieux développe une argumentation riche et originale, en s'appuyant opportunément sur la plus importante somme obstétricale de son époque : L'Art des accouchements, principal ouvrage de celui qu'il a désigné comme le contempteur de l'enseignement provincial $^{175}:$ « Je vais démontrer,

173. $\mathrm{AN}, \mathrm{F}^{17} / 2458$, Charente-Inférieure.

174. À la même époque, le directeur de la maternité de Göttingen, Benjamin Osiander, voit au contraire un atout dans la taille réduite de son établissement, voir Schlumbohm J., "Comment l'obstétrique... », art. cit., p. 24.

175. Baudelocque J.-L., L'Art des accouchements, Paris, Méquignon l'ainé, I78I. Il est probable que l'édition utilisée par Edme Romieux soit la troisième (I796) ou la quatrième (I807). 
l'ouvrage de M. Baudelocque à la main, que tout ce qui regarde l'art d'accoucher peut être enseigné dans les départements ${ }^{176}$. »

Le choix de ce qu'on appelle à l'époque le "Grand Baudelocque » n'a rien d'anodin. Le médecin rochelais vise au plus haut des connaissances obstétricales accumulées dans le demi-siècle précédent. Reprenant l'ouvrage du maitre en suivant strictement son plan, l'auteur s'interroge à chaque étape sur le matériel pédagogique nécessaire, sur la manière la plus simple et la plus efficace de présenter les connaissances relatives à ce sujet, puis sur les qualités requises du professeur et enfin sur la possibilité, tous ces aspects combinés, de donner cet enseignement dans un cours départemental. Lorsque l'auteur se heurte à des éléments complexes de l'art des accouchements, l'enjeu du mémoire est alors de séparer ce qui relève de la recherche fondamentale en obstétrique et ce qui relève de l'obstétrique appliquée. Les moyens de reconnaître précocement la grossesse et le développement du foetus pendant ses premiers mois sont par exemple opposés, car considérés comme superflus, au savoir sur le déroulement final de la gestation et sur les présentations de l'enfant à l'accouchement, définis comme essentiels. Le champ de l'utilité est circonscrit au fil du texte. Certains domaines en sont bannis, par exclusion de la compétence des sagesfemmes (médecine légale) ou du savoir obstétrical (théories de la conception).

Romieux remet à l'honneur le rôle fondamental du cours théorique, en insistant sur l'importance des qualités oratoires du professeur. Il définit ainsi un certain nombre de sections de l'ouvrage dont l'enseignement passe avant tout par la parole : les transformations occasionnées par la grossesse à l'utérus, celles entrầnées par le déclenchement de l'accouchement, les accidents de la délivrance et les causes des accouchements contre nature. Sur ces deux derniers points, il nuance d'ailleurs l'apport de l'observation clinique. La supériorité numérique évidente des cas étudiés par les élèves sages-femmes de l'école de Port-Royal est reconnue pour ses avantages quantitatifs (pratique plus fréquente du toucher) mais contestée quant à son apport réel pour l'étude des accouchements dystociques qui demeurent rares, même à l'Hospice de la Maternité.

S'ensuit une seconde remise à l'honneur : celle de la démonstration sur le mannequin puisque le recours à cet instrument est au cœur de la pédagogie prônée par Romieux. La « nature vivante » voit dans le discours de l'auteur sa place réduite à la portion congrue. La part respective de l'entraînement sur mannequin (pratique artificielle) et de l'équivalent au lit des femmes en couches

176. $\mathrm{AN}, \mathrm{F}^{17} / 2458$, Charente-Inférieure. 
(pratique clinique) dans l'instruction des sages-femmes est alors conçue en fonction des possibilités offertes aux accoucheurs français et européens ${ }^{177}$.

La faiblesse clinique d'un enseignement «à la Romieux » n'échappe cependant pas à son auteur et sa contestation du monopole national de l'Hospice de la Maternité ne le dispense pas de proposer un moyen d'améliorer les capacités cliniques des cours départementaux. L'enquête de l'an xiv a donné une image figée et surtout rétrospective du public des hospices destinés à accueillir les cours d'accouchement. Nombre de départements ont répondu qu'aucun de leurs hospices ne recevait de femmes en couches ou que leur présence était trop rare pour justifier l'existence de salles spécifiques ${ }^{178}$, sans en déduire toutefois d'empêchement au développement de cette activité. L'exemple de l'Eure est révélateur puisqu'après avoir signalé que l'hospice d'Evreux n'a jamais admis de femme en couches, le préfet propose d'ouvrir une salle à cet effet pour permettre la mise en place de l'instruction des sages-femmes ${ }^{179}$. Dans un esprit similaire, Edme Romieux défend dans son Mémoire l'idée d'un élargissement de l'accueil des hospices, arguant du rétablissement récent de la Société de Charité maternelle ${ }^{180}$. La proposition révèle à quel point la reconnaissance de la formation provinciale des sages-femmes dépend du vivier de cas cliniques appelé à se constituer dans les hospices. Ce qu'Edme Romieux réclame au fond, c'est que soit laissé à l'enseignement départemental le temps de faire la preuve de son efficacité et à la loi de ventôse an XI, le temps de mettre correctement en ouvre ses dispositions.

L'apport du texte du médecin rochelais est ambigu. À l'échelle nationale, les mémoires de ce type sont rares et leur qualité ne suffit pas à compenser leur petit nombre. À l'échelle de la Charente-Maritime, il précède immédiatement la reconnaissance ministérielle du cours dirigé par Romieux (arrêté du 24 février I8I3). À l'échelle de la France, il intervient à une période où le ministre

177. Dénoncée par Osiander lors de son passage à Paris au début du siècle, la faiblesse de la formation des praticiens au lit des parturientes est confirmée par Eduard Caspar Jacob von Siebold vingt ans plus tard, voir Essai sur l'bistoire de l'obstétricie, op. cit., p. $628:$ «Un cours durait ordinairement un trimestre, pendant lequel il y avait dix ou quinze accouchements; chaque auditeur inscrit avait le droit de pratiquer un accouchement normal ».

178. Flottes L., Enquête de l'an XIV : prémices d'une formation organisée pour les sages-femmes, op. cit., p. 22-25.

179. AN, $\mathrm{F}^{17} / 2459$, Eure.

I80. Berthiaud E., «Les sociétés de charité maternelle : de la charité à l'assistance médicale », dans M.-C. Dinet-Lecomte, S. Beauvalet, Lieux et pratiques de santé du Moyen Âge à la Première Guerre mondiale, Encrage, 2013, p. 167-197. Fondée à Paris en 1788, la Société, disparue pendant la période révolutionnaire, est refondée sous les auspices de l'impératrice Marie-Louise par décret impérial du 5 mars I8IO. 
de l'Intérieur a déjà renoncé au monopole de l'Hospice de la Maternité de Paris pour travailler à imposer son modèle à taille réduite dans les départements. À ces deux égards, le Mémoire sur l'utilité des cours d'accouchements dans les départements n'initie pas un mouvement, il lui offre plutôt son grand texte récapitulatif de défense et illustration. En parallèle, les grands hommes de PortRoyal ont souffé à l'oreille du pouvoir central la seule solution pour pérenniser la primauté de l'établissement : faire de l'école de la Maternité le sommet de l'enseignement, en lui donnant le rôle d'une «école de perfectionnement ${ }^{181}$ », complémentaire des formations départementales ${ }^{182}$. Le recrutement parisien se maintient donc par ce moyen qui renforce, par la subordination explicite qu'il engendre, la distinction entre sages-femmes de première et de deuxième classe.

L'exemple rochelais éclaire un espace trouble d'illégalité tolérée par le pouvoir central ou maintenue contre ses avis. En six ans, le ministre de l'Intérieur refuse à trois reprises la régularisation d'un cours d'accouchement au chef-lieu de la Charente-Maritime. Or, pendant toutes ces années, depuis l'an XIII voire depuis l'an xi si l'on suit le témoignage d'Edme Romieux, la formation des sages-femmes fonctionne et des accoucheuses sont autorisées à exercer à l'issue de ce cours qui se revendique comme la simple application de la loi du ig ventôse an $\mathrm{XI}^{183}$. Ce cas qui n'est pas si particulier correspond à l'une des nombreuses manières dont les départements tranchent le dilemme entre obéissance au ministère de l'Intérieur et exécution des prescriptions législatives. La décennie I8Io constitue cependant un temps de conciliation des modèles d'enseignement - parisien et monopoliste, départemental et multiple - dans un système déconcentré d'adaptation du règlement de l'Hospice de la Maternité à des terrains moins naturellement favorables. La conciliation institutionnelle porte d'ailleurs en elle le compromis hiérarchique mis au point pour préserver le champ d'action et de savoir de la sage-femme de Port-Royal dont l'aura rayonne jusqu'à envelopper l'accoucheuse instruite en province. Mais dans la duplication à l'infini de la Maternité parisienne se joue bien plus que le prestige de l'établissement ou la fierté du ministre de l'Intérieur. L'unicité de la profession et la légitimation de son appartenance au corps médical y puisent, armées de l'intransigeance gouvernementale, leurs meilleurs arguments contre la piètre réputation d'une fonction déconsidérée.

18I. AN, $\mathrm{F}^{17} / 2457$, Calvados.

I82. Beauvalet-Boutouyrie S., Naître à l'hôpital..., op. cit., p. II7.

183. $\mathrm{AN}, \mathrm{F}^{17} / 2458$, Charente-Inférieure. 



\section{Mailler la France d'écoles}

Le débat sur la multiplication des écoles d'accouchement est tranché dans la première décennie du $\mathrm{XIX}^{\mathrm{e}}$ siècle, lorsque le ministre de l'Intérieur renonce à l'unicité de l'Hospice de la Maternité de Paris. De cet assouplissement et de cet élargissement, la loi de ventôse et l'exemple parisien fixent en théorie chaque détail. Les cours éclosent cependant selon des rythmes propres, en fonction des héritages locaux, de l'action parfois individuelle d'un préfet ou d'un médecin, de la bonne ou mauvaise volonté ministérielle. Leur répartition géographique et surtout chronologique répond à des logiques diverses, qui font intervenir différents niveaux d'échelle et soulignent la souplesse d'un système en perpétuelle recomposition. Créations, suppressions, réformes sont le lot commun des cours d'accouchement de 1803 à I893, et ces variations redessinent continuellement la carte de la formation obstétricale. Elles imposent de reconstruire, en fonction de facteurs pédagogiques, sociaux ou financiers, l'évolution des politiques locales et de déterminer les manières dont les départements remplissent leurs obligations budgétaires. L'établissement autorisé devient la cellule de base de la transmission du savoir obstétrical, sans qu'on puisse cependant en conclure à la complète victoire de l'officiel sur l'individuel et le spontané.

\section{Les cours d'accouchement français au XIX ${ }^{e}$ siècle}

\section{L'éclosion des lieux d'enseignement, une évolution non linéaire}

Évoquer l'éclosion des cours d'accouchement implique certes de chercher un début suffisamment précis pour constituer une chronologie fiable ${ }^{1}$, mais ćest $^{\prime}$

I. Voir pour une première tentative de cartographie des créations de cours d'accouchement au XIX ${ }^{e}$ siècle, Beauvalet-Boutouyrie S., Naître à l'hôpital..., op. cit., p. 207. 
aussi bien renoncer à trouver des commencements univoques pour tirer les fils qui unissent les entreprises pédagogiques de la Révolution et des lendemains de I803, de l'Ancien Régime et des recréations du XIX ${ }^{e}$ siècle. Évoquer cette éclosion, c'est surtout élargir la focale jusqu'à intégrer les proto-cours, voire les cours posthumes, ces extensions indissociables de la formation officielle, qui précèdent l'autorisation du ministre ou survivent au couperet du conseil général. La limite entre cours privés et cours publics est donc mouvante et la distinction entre une initiative pédagogique individuelle et un enseignement tacitement reconnu par les autorités administratives s'éclaire au moment charnière de l'officialisation. L'enquête se fait alors en amont de l'approbation ministérielle, dans l'espace de tolérance locale qui est aussi champ d'essai de la formation à enraciner.

Un long catalogue des itinéraires de cours départementaux ne présente guère d'intérêt. Saisir la part des continuités et la rapidité des officialisations permet au contraire de peser les rôles des différents acteurs de la formation obstétricale. Mais, l'autorisation obtenue, cet enseignement ne se fige pas et c'est dans les péripéties qui scandent la vie des cours, dans le questionnement quasi permanent sur leur utilité ou leur maintien que s'élaborent les approches politiques de la transmission d'un savoir et de la formation d'une profession médicale.

La création ex nibilo n'existe pas. L'instruction obstétricale du XIX ${ }^{e}$ siècle, quelle que soit sa forme, s'inscrit toujours dans une généalogie qui remonte à la seconde moitié du XVIII ${ }^{\mathrm{e}}$ siècle, ou pour les plus récentes, à la période révolutionnaire. Peu importe que le cours perpignanais sous l'Ancien Régime n'ait jamais réuni que des élèves venues des alentours immédiats de la ville, il est présenté comme l'ancêtre direct et nécessaire du cours départemental des Pyrénées-Orientales au début du $\mathrm{XIX}^{\mathrm{e}}$ siècle $^{2}$.

Ancrer les cours dans une origine géographiquement identique mais chronologiquement lointaine est un moyen de justifier la légitimité de l'enseignement vis-à-vis des prétentions parisiennes. Ce rappel est d'autant plus important lorsque l'interruption de la formation s'est prolongée plusieurs années voire décennies. Au moment où la possibilité de rouvrir un cours se profile dans le Gard en 1827 , le préfet revient sur l'expérience d'enseignement qui a eu lieu au chef-lieu pendant la période révolutionnaire :

Une considération que je ne dois pas omettre non plus, c'est que ce cours avait déjà existé et avait obtenu des succès à Nismes, antérieurement à l'an XII. Il fut discontinué, à cette époque, à cause tant de la mort du professeur, frère du célèbre Larrey, que de l'établissement de l'école de la Maternité de Paris, etc. ${ }^{3}$

\footnotetext{
2. AD Pyrénées-Orientales, 5 M 29.

3. $\mathrm{AN}, \mathrm{F}^{17} / 2460$, Gard.
} 
Le cours passé n'a pas été supprimé, il s'est interrompu, faisant du projet porté par le préfet une simple reprise à l'image de la plupart des fondations/ refondations qui ponctuent le siècle. Cette prégnance de la filiation des entreprises pédagogiques se nourrit de l'argumentaire aiguisé pendant la période révolutionnaire pour maintenir l'acquis. Tant de villes ont accueilli des démonstrateurs qu'il est toujours possible d'affirmer renouer avec une tradition ${ }^{4}$. La période révolutionnaire s'est saisie de ce foisonnement pour le circonscrire aux relais de l'administration territoriale : chefs-lieux d'arrondissement ou préfectures. L'après-ventôse an XI privilégie ce dernier niveau, à quelques exceptions qui méritent d'être signalées.

\section{Ressort et siège du cours}

Le cours d'arrondissement est une survivance, la butte témoin d'une géographie administrative d'Ancien Régime et des méthodes pédagogiques d'avant l'Hospice de la Maternité de Paris et la loi de l'an XI. Il résiste plus ou moins longtemps, mais cède en général la place au monopole du chef-lieu de département dès les années 1830. Quatre départements mettent en place des cours à ce niveau d'échelle au long du siècle (Corrèze, Hérault, Mayenne et Var). En I8I9, le conseil général de l'Hérault présente le cours d'arrondissement comme une résurgence du cours itinérant ${ }^{5}$. Cela rappelle les choix breton et alpin de la période révolutionnaire, sans que cette expérience ne se révèle plus pérenne. En I824, le passage du cours d'accouchement de Montpellier au régime de l'internat met fin aux tournées du professeur dans le département, sans susciter la moindre protestation des conseillers généraux ou des administrateurs d'arrondissements ${ }^{6}$.

Les autres départements pourvus de cours dans les sous-préfectures ne relèvent pas de ce modèle. Ils s'inscrivent au contraire dans une logique de fonctionnement autonome de chacune des initiatives de formation. Pour la Corrèze, l'étape « arrondissement» (Meymac, Brive-la-Gaillarde et Tulle) est une solution économique qui permet la réimplantation dans le département de structures d'enseignement obstétrical à partir de 1827 jusqu'à la fondation en I834 d'une école départementale à Tulle ${ }^{7}$. La Mayenne fonde en 1809 trois

4. J. Gélis évalue la « postérité » d'Angélique du Coudray à quelques deux cents démonstrateurs dans toute la France, soit au moins autant de cours et sans doute bien plus dans le cas des cours itinérants, voir La Sage-femme ou le médecin..., op. cit., p. I23 et I26.

5. AD Hérault, I $\mathrm{N}_{2}$.

6. Delmas P., Sept siècles d’obstétrique à la faculté de médecine de Montpellier, Montpellier, Coulet-Dubois et Poulain, 1927, p. 52.

7. Sage Pranchère N., Mettre au monde..., op. cit., p. I73-197. 
cours, à Laval, Mayenne et Château-Gontier. Le premier s'enrichit en I8I3 d'une annexe pratique lors de la création de l'hospice de la maternité, les deux autres restant purement théoriques, ce qui n'empêche pas leur maintien jusqu'assez tard dans les années I830, en parallèle du cours officiel et autorisé qui se tient au chef-lieu. C'est ici un principe de complémentarité et de tolérance qui préside à la coexistence des trois lieux d'instruction pendant une trentaine d'années, durée étonnamment longue en comparaison d'autres exemples.

Un seul et dernier exemple présente une physionomie comparable, quoiqu'encore plus exceptionnelle : le Var. Après deux vaines tentatives de créer un cours au début du siècle, le département du Var met en place en I83I deux enseignements parallèles, à Draguignan, préfecture, et à Toulon, souspréfecture cinq à neuf fois plus peuplée au cours du XIX ${ }^{\mathrm{e}}$ siècle. Mise à part une interruption de ce fonctionnement double pendant la décennie I870, la bicéphalie structure pendant tout le siècle la formation obstétricale varoise, s'expliquant par la répartition de l'audience potentielle des cours : à Draguignan la partie montagneuse du département, à Toulon la façade maritime.

Quatre autres départements, le Morbihan, le Finistère, les Landes et les Hautes-Pyrénées, rompent complètement avec la primauté de la ville préfecture. Ce décentrage n'est que partiellement surprenant puisqu'il répond aux dispositions de la loi de ventôse qui demande l'établissement des cours « dans l'hospice le plus fréquenté du département ». Or, à l'instar du cas varois, les principaux centres de population des deux départements bretons ne coïncident pas avec leurs préfectures, ce qui explique le choix de Brest en I8I6 et de Lorient en 1820 pour mettre en place l'instruction des sages-femmes. C'est une raison similaire qui explique le choix de Dax contre Mont-de-Marsan dès I805 et de Bagnères-de-Bigorre contre Tarbes en $1818^{8}$. Le souvenir d'un enseignement tarbais ne pèse pas suffisamment lourd face aux nécessités de la formation pratique. Le cours fonctionne donc à Bagnères-de-Bigorre de 1818 à I892, date à laquelle il est supprimé et la maternité transférée à l'hospice de Tarbes.

La localisation prédominante reste néanmoins l'implantation dans la ville préfecture, à proximité des centres de décision administratifs et politiques et au contact du pôle démographique principal d'un département. Ceci posé, s'ils font tous ou presque de la formation des accoucheuses un point fort de leur intérêt, les quatre-vingt-neuf départements ne suivent pas une voie uniforme dans la politique de diffusion du savoir obstétrical.

8. Quartararo-Vinas A., Médecins et médecine dans les Hautes-Pyrénées au XIXe siècle, Tarbes, Sources et travaux d'histoire haut-pyrénéenne, 1982, p. 4I-42. 


\section{Typologie des créations de cours}

Trois groupes se dessinent, indépendamment des chronologies de créations ou de suppressions des cours ${ }^{9}$. Le premier, que je désignerai comme groupe A, compte vingt-quatre départements et se caractérise par un choix spécifique d'enseignement local corrélé à l'absence de politique d'envoi d'élèves sagesfemmes à l'extérieur $(\text { carte } 4)^{10}$.

Dans ce groupe, il faut néanmoins isoler les départements savoyards (AlpesMaritimes, Savoie et Haute-Savoie) dont le destin en matière de formation des accoucheuses dépend entre i815 et I860 des choix du royaume de PiémontSardaigne ${ }^{11}$. Dans les Alpes-Maritimes, l'encadrement obstétrical est défaillant tout au long du siècle. À l'exception d'un cours à Sospel entre l'an XII et l'an $\mathrm{XIII}^{12}$, et malgré l'insistance du ministre de l'Intérieur avant $\mathrm{I} 8 \mathrm{I} 5^{13}$, aucune formation n'est mise en place pendant les décennies suivantes. Après la réunion à la France, le conseil général ne prend jamais l'initiative de voter le moindre subside en ce sens ou pour l'envoi d'élèves sages-femmes dans une école voisine. Les départements alpins connaissent une évolution apparemment plus linéaire. Dans le droit fil de l'Ancien Régime, le département du Mont-Blanc, qui comprend sous la Révolution et l'Empire les territoires formant après I860 la Savoie et la Haute-Savoie, fait renaître en 1808 un cours à Chambéry, la préfecture. En I857, un généreux mécène, le comte Pillet-Will, fonde dans la même ville, en référence au cours gratuit du chevalier Rey en I808, un internat pour l'instruction des futures sages-femmes destiné à rayonner sur toute la Savoie francophone $e^{14}$. La préexistence de cette structure au moment du rattachement à la France et son maintien ultérieur justifient le fonctionnement « en interne » des départements savoyards.

Parmi les autres départements du groupe $\mathrm{A}$, on retrouve des départements qui ont réussi à faire perdurer un cours d'accouchement pendant toute la période révolutionnaire (Seine, Rhône, Maine-et-Loire, Bas-Rhin, Gironde, Isère), et

9. Voir Cartes 4 à 6. Ces cartes rassemblent les données présentées dans les pages suivantes sur la base d'une carte de France telle qu'elle se présente avant 1870 (sans le territoire de Belfort).

Io. Alpes-Maritimes ; Ariège ; Corse ; Côte-d'Or ; Eure-et-Loir ; Haute-Garonne ; Gironde ; Hérault ; Isère ; Loire-Inférieure ; Maine-et-Loire ; Marne ; Haute-Marne ; Meurthe ; HautesPyrénées ; Pyrénées-Orientales ; Bas-Rhin ; Haut-Rhin ; Rhône ; Saône-et-Loire ; Savoie ; HauteSavoie; Seine ; Vaucluse. Voir carte 4.

II. Pancino C., Il bambino e l'acqua sporca..., op. cit., p. 161-167 ; Filippini N. M., « Sous le voile... », art. cit.

I2. AD Alpes-Maritimes, CE M 0257.

13. $\mathrm{AN}, \mathrm{F}^{17} / 2456$, Alpes-Maritimes.

14. Messiez M., «Frédéric-Michel Pillet-Will, mécène de la Savoie, 1787-I860 », étude publiée sur le site internet de la Société Savoisienne d'Histoire et d'Archéologie, décembre 2006, p. I4-I5. 
d'autres qui forment, avec les précédents, les bases de la carte de l'enseignement médical français au XIX ${ }^{\mathrm{e}}$ siècle puisqu'y coexistent une faculté ou une école préparatoire de médecine et un cours d'accouchement (Côte-d'Or, Hérault, Meurthe, Marne, Loire-Inférieure, Haute-Garonne). La préférence accordée à la formation sur place s'explique aussi par un certain isolement géographique et linguistique : c'est le cas de la Corse, mais aussi du Bas-Rhin, des Pyrénées (Hautes-Pyrénées, Ariège et Pyrénées-Orientales) et du Vaucluse. S'ajoutent enfin trois départements aux traditions bien ancrées : l'Eure-et-Loir, la HauteMarne et la Saône-et-Loire, que la proximité de grands centres de formation (Paris bien sûr, mais aussi Le Mans et Orléans dans un cas, Reims, Épinal, Nancy dans l'autre et Lyon, Bourg-en-Bresse, Dijon dans le dernier) semblent conforter dans leur préférence départementale, comme une revendication symbolique de petit Poucet. On touche là au cœur de l'instruction à échelle humaine, dans cet espace qui échappe obstinément à l'orbite parisienne pour exalter la qualité de ses professeurs et de ses capacités d'accueil pédagogique.

Mais ce noyau ne résume pas à lui seul la dynamique des initiatives locales de formation, et un second groupe s'y adjoint, dit groupe B, qui rassemble 46 départements (carte 5$)^{15}$. La caractéristique de ce deuxième pôle est de faire alterner ou coexister au fil du siècle enseignement sur place et envois d'élèves sages-femmes hors du département. La concomitance stricte de deux niveaux de formation, encouragée par le ministère qui souhaite faire de Paris une école de perfectionnement, n'est cependant pas si fréquente et ne concerne que six départements (Calvados, Corrèze, Nord, Puy-de-Dôme, Seine-Inférieure et Vienne). La durée de coexistence des deux modes d'instruction est variable entre Io et 43 ans - et son interruption correspond toujours à un repli sur la sphère locale ${ }^{16}$. Les départements en question sont dans la plupart des cas le siège d'une école de médecine, à l'exception de la Corrèze, et l'envoi d'élèves sages-femmes à l'Hospice de la Maternité de Paris, unique destination extérieure, perdure soit jusqu'à la mise en place dans le département d'une école au lieu d'un cours (Clermont-Ferrand, I816 ; Poitiers, I834), soit jusqu'au constat d'une amélioration (Tulle en I844, Caen en I852, Rouen en I868) et d'une

15. Ain, Aisne, Allier, Basses-Alpes, Hautes-Alpes, Aube, Aveyron, Bouches-du-Rhône, Calvados, Charente, Charente-Inférieure, Cher, Corrèze, Doubs, Eure, Finistère, Gard, Gers, Ille-et-Vilaine, Indre, Indre-et-Loire, Landes, Loir-et-Cher, Loire, Loiret, Lot, Lot-et-Garonne, Mayenne, Meuse, Morbihan, Moselle, Nord, Oise, Pas-de-Calais, Puy-de-Dôme, Basses-Pyrénées, Sarthe, SeineInférieure, Deux-Sèvres, Somme, Tarn, Var, Vienne, Haute-Vienne, Vosges, Yonne. Voir carte 5. I6. Les périodes de concomitance sont les suivantes : 1809 à I 852 pour le Calvados ; I827 à 1844 pour la Corrèze ; I 860 à I 882 pour le Nord ; 1807 à I8I7 pour le Puy-de-Dôme ; 1830 à I 85 I puis I 862 à 1868 pour la Seine-Inférieure; 1807 à I 834 pour la Vienne. 
consolidation du niveau d'études de l'institution locale (intégration du cours d'accouchement dans le cursus de la faculté de médecine de Lille en I876).

L'alternance est en revanche infiniment plus fréquente : succession simple d'un cours extérieur à un cours local (ou vice-versa) ou alternance multiple entre formation locale et envois à l'extérieur. La succession simple lorsqu' elle aboutit à la pérennisation d'un cours au chef-lieu de département s'appuie quasi systématiquement sur une première étape parisienne, aux deux exceptions que sont la Loire (Paris puis Bourg-en-Bresse avant Saint-Étienne) et le Tarn (Paris puis Toulouse avant Albi). Sur les onze départements dans cette configuration, sept possèdent un cours d'accouchement pendant la période révolutionnaire; il se poursuit parfois quelque temps sous le Consulat et l'Empire (Tours jusqu'en I808), avant que le ministre de l'Intérieur n'en ordonne la suppression au profit de l'envoi d'élèves à Paris ${ }^{17}$. Le basculement de la capitale vers la province s'opère lorsque l'administration préfectorale réussit finalement à justifier la conformité de la formation souvent préexistante avec les exigences ministérielles. La reconnaissance illustrée par l'autorisation du règlement calqué sur celui de l'Hospice de la Maternité de Paris intervient entre les années I8Io et les années I830 (hormis le Loiret, I808, et la Loire, après I890), dans un étalement tout à fait révélateur de l'opiniâtreté ministérielle mais aussi de la constance des volontés locales, couronnée par un maintien de presque tous ces cours jusqu'au début $\mathrm{du} \mathrm{xx}^{\mathrm{e}}$ siècle.

Le cas inverse (clôture d'un établissement départemental pour envoi à l'extérieur) ne bénéficie pas systématiquement à l'Hospice de la Maternité de Paris. Les fermetures d'écoles permettent souvent à d'autres cours d'audience régionale d'attirer une partie de ce public désormais sans point de chute local. Cette situation pose la question non plus seulement des créations mais des suppressions et donc de la durée d'existence des institutions. La représentation cartographique des établissements de formation obstétricale français est à ce titre forcément trompeuse puisqu'elle omet la plasticité de ce réseau, où certains cours parfaitement constitués survivent deux ans (Auxerre, I8I8-I819 ; Moulins, I8I9-I82I), tandis que d'autres, aberrants au vu des exigences de la loi de 1803 , traversent gaillardement le siècle (Chartres). Nombre de fondations disparaissent avant même la réforme des études de I893, et la décennie I850 connaît une véritable hécatombe : Metz et Nîmes (I850); Angoulême (I852);

17. Les onze départements concernés sont l'Ain, l'Aisne, les Bouches-du-Rhône, le Doubs, le Gard, l'Ille-et-Vilaine, l'Indre-et-Loire, la Loire, le Loiret, les Basses-Pyrénées et le Tarn. À l'exception des Bouches-du-Rhône et des Basses-Pyrénées, ils disposent tous d'un enseignement de l'art des accouchements pendant la période révolutionnaire. 
Le Mans (1854) et Troyes (1859). Certains cours pourtant anciens comme Bagnères-de-Bigorre (I8I8-I892) ou La Rochelle (I806-I888) disparaissent à leur tour à la fin du siècle dans un contexte où le besoin de sages-femmes se fait moins pressant grâce aux résultats des écoles et où la condition sociale des aspirantes sages-femmes, légèrement améliorée, les rend mieux à même d'aller chercher leur formation dans d'autres établissements.

Toute la complexité de ces processus de créations/réorganisations/suppressions se rassemble dans un cas : l'Aveyron, qui cumule en un seul département les aléas que l'on rencontre dispersés ailleurs. La capitale du Rouergue accueille dès les années 1780 un cours d'accouchement qui se poursuit jusqu'en I792, puis est recréé par un arrêté du 7 pluviôse an vi. Il est probable que ce cours se perpétue, en semi-clandestinité, jusquà la réorganisation officielle de I813, visée par le ministre de l'Intérieur. En I846, le conseil général prend la décision de supprimer le cours à la rentrée suivante au profit d'un envoi d'élèves boursières à Montpellier. Douze ans plus tard, repentir général : le préfet, approuvé par l'assemblée départementale, remet en place une formation pour les sagesfemmes à Rodez, en la confiant au même professeur, au motif que les élèves instruites à Montpellier et de ce fait reçues sages-femmes de première classe délaissent leur département de naissance. En 1867 cependant, le conseil général se trouve de nouveau devant le choix de maintenir ou supprimer le cours d'accouchement dont l'immeuble acquis récemment n'est pas encore complètement payé. Convaincu par les arguments développés sur la faiblesse de l'enseignement clinique, les conseillers acceptent une nouvelle suppression, définitive cette fois et choisissent alors d'envoyer leurs boursières à Lyon. En moins de soixante-dix ans, l'Aveyron a donc connu quatre créations officielles de cours d'accouchement, deux suppressions et expérimenté l'instruction dispensée dans deux établissements extérieurs, preuve, s'il en est, de l'attachement des instances locales à fournir à leurs administrées des accoucheuses compétentes.

Résumons-nous (carte 7) : 24 départements qui forment exclusivement leurs sages-femmes à l'intérieur de leurs frontières, 46 qui tentent de manière plus ou moins continue cette aventure de l'enseignement au plus près. Cela signifie aussi 2I départements qui renoncent à organiser des cours et délèguent dès l'an $\mathrm{x}$ à l'école parisienne ou à leurs voisins la tâche de produire leurs propres sages-femmes ${ }^{18}$. Tel est le groupe C (carte 6) ${ }^{19}$. Parmi ces départements,

I8. Ardèche ; Ardennes ; Aude ; Cantal ; Côtes-du-Nord ; Creuse ; Dordogne ; Drôme ; Indre ; Jura ; Haute-Loire ; Lozère ; Manche ; Nièvre ; Orne ; Seine-et-Marne ; Seine-et-Oise ; HauteSaône ; Tarn-et-Garonne ; Vendée ; Territoire de Belfort.

19. Voir carte 6. 
certains ont pourtant accueilli des cours sous l'Ancien Régime - le Jura, la Lozère ou encore la Vendée - ou sous la Révolution - la Dordogne, l'Aude ou les Côtes-du-Nord - mais la continuité se rompt suite de la redistribution des pouvoirs de la province aux cadres nés de la Révolution, à cause aussi de l'exigence de formation pratique à laquelle la plupart sont incapables de répondre. Après 1870 , le territoire de Belfort, ancien arrondissement du HautRhin, n'a pas les moyens de former ses élèves sur place et choisit de les envoyer à Besançon et à Nancy.

Le renoncement à la formation locale est tôt prononcé, dès la réponse à l'enquête de l'an xiv dans les Ardennes ${ }^{20}$. La Manche se résigne dans des intervalles similaires. En Seine-et-Marne et en Seine-et-Oise, la proposition d'une formation sur place n'est pas même évoquée tant le projet paraît vain, eu égard à la proximité parisienne. Ailleurs cependant, aussi nul qu'en soit le résultat, l'obstination à réclamer l'instauration d'un cours porte les déclarations des conseillers généraux, de session en session. En Vendée de l'an viı à l'an XIII, en Creuse de l'an x à I807, en Lozère de l'an x à 1816, les délibérations et les votes de fonds se succèdent inlassablement, jusqu'au point d'abandon que sanctionne généralement la réorientation des sommes allouées vers le paiement d'une pension à l'Hospice de la Maternité de Paris. De loin en loin, dans les décennies suivantes, des projets restent sans suite (Ardèche, Creuse, Jura, Dordogne, Vendée ou Aude).

Les départements dont l'histoire obstétricale est celle d'une longue délégation sont souvent pris dans l'inertie de leur profonde ruralité, qui bride leurs ambitions hospitalières et la mobilité spontanée de leurs élèves sages-femmes. Pauvres de fonds et de population, ces recoins de France manifestent cependant une ténacité remarquable à maintenir une ou plusieurs bourses, plutôt parisiennes pendant la première moitié du siècle, plus voisines passées les années I840, malgré quelques cas de fidélité séculaire à Port-Royal comme le Tarn-et-Garonne.

\section{Le rayonnement des centres d'enseignement}

Le destin contrarié de multiples cours, tout comme les velléités pédagogiques sans lendemain de nombreux départements supposent une nécessaire péréquation entre établissements pour permettre la formation des cohortes de sagesfemmes indispensables à l'encadrement obstétrical du territoire français. La

20. $\mathrm{AN}, \mathrm{F}^{17} / 2457$, Ardennes. 
conséquence immédiate en est l'élargissement de l'audience de certains cours qui acquièrent de fait un rayonnement régional. Pour remonter aux sources de ce phénomène, il faut rappeler les réflexions qui suivent la fondation de l'Hospice de la Maternité sur la possibilité de créer d'autres pôles d'enseignement obstétrical régionaux. Le cours d'accouchement d'Amsterdam, sous l'Empire, est à cet égard l'Arlésienne de ce mouvement, perspective toujours poursuivie et toujours repoussée d'une institution susceptible de rayonner sur tous les départements néerlandophones. Le lien structurel établi par la loi de ventôse entre le cadre hospitalier et la formation des accoucheuses place au premier rang des projets de ce type les villes pourvues d'hospices très largement fréquentés. L'idée, partiellement acceptée par le ministère à partir de 1807, est d'envisager un système de circonscriptions sur lesquelles un nombre restreint d'écoles pourrait rayonner.

L'exemple le plus documenté est celui de Bordeaux, dont l'hospice de la maternité fondé par le couple Coutanceau à la fin du Xviri ${ }^{e}$ siècle constitue un point d'appui remarquable pour un établissement de rang régional, hypothèse évoquée dès 1802 dans la correspondance entre le ministre de l'Intérieur et le préfet de la Gironde ${ }^{21}$. Les principaux arguments en faveur de cette création reposent sur la dimension clinique de la formation et, plus que tout, sur les qualités d'enseignante de Marguerite Coutanceau ${ }^{22}$. Celle-ci n'hésite d'ailleurs pas à prendre la plume en 1808 pour défendre la portée régionale de ses cours en proposant au ministre de faire de Bordeaux une succursale de Paris pour les départements du Gers, des Landes, des Basses-Pyrénées, de la Dordogne et de la Charente. L'année suivante, la direction de l'hospice de la maternité travaille à un agrandissement susceptible d'accueillir toutes les élèves du sud-ouest. En I8I4 enfin, le conseil général pleinement convaincu des capacités bordelaises en la matière prend la délibération suivante :

$I^{\circ}$ Que le gouvernement devra être supplié [... de concéder les bâtiments de l'ancien monastère notre-Dame, situé à Bordeaux, rue Ségur, pour y établir l'hospice de la maternité et les cours d'accouchement; d'ordonner les mesures convenables pour que la translation de cet établissement dans ce local ait lieu le plus tôt possible, et de faire de l'école d'accouchement de Bordeaux une institution centrale pour les départements de l'Ouest conformément aux vues du ministère de l'Intérieur. ${ }^{23}$

2I. Béchir F., Accoucheuses, matrones, sages-femmes à Bordeaux au xvirI e siècle, maitrise d'histoire, Bordeaux III, 1999 ; Penot C., L'école d'accouchement de Bordeaux au XIX siècle, maîtrise d'histoire, Bordeaux III, 2003. AN, F F/246I, Gironde.

22. Ibid.

23. AD Gironde, $\mathrm{I} \mathrm{N}_{2}$. 
Les effets de cette campagne pour un «Port-Royal » bordelais sont toutefois quasi inexistants. L'aura de l'école dirigée jusqu'en 1820 par la nièce d'Angélique du Coudray ne dépasse pas les limites du département de la Gironde, tout en conservant un prestige national réel.

Au milieu du siècle, l'école de Marseille prétend à son tour à l'obtention d'une circonscription officielle (Var, Basses et Hautes-Alpes, Vaucluse, Corse, Algérie). Les raisons sont moins ici de justifier l'existence du cours que de garantir sa pérennité et son recrutement. C'est en ce sens que le conseil général des Bouches-du-Rhône, pourtant peu soucieux de l'entretien de cet établissement, forme deux vœux, en I849 et I850. Pas plus que les projets bordelais des années I800-I810, les ambitions marseillaises n'ont de suite concrète. Le découpage territorial pourtant à l'honneur dans les années 1850 avec le décret impérial du 22 août I854 sur l'organisation des académies et des établissements d'enseignement supérieur ne touche qu'à la marge le fonctionnement des cours d'accouchement $^{24}$. L'horizon reste départemental et seule l'étape finale de la réception est soumise aux circonscriptions définies pour les facultés et écoles préparatoires de médecine par l'arrêté du 23 décembre 1854 . Cette absence de politique nationale d'aménagement de l'espace pédagogique obstétrical se situe dans la droite ligne de l'acceptation au tournant des années I8Io de voir appliquées les prescriptions de ventôse an XI. Elle explique en grande partie le caractère non linéaire et non continu de l'élargissement du rayonnement de certaines écoles.

La fondation ou refondation d'un cours d'accouchement donne très souvent lieu à un courrier circulaire à l'ensemble des préfets des départements alentour pour en signaler la date d'ouverture, les modalités d'admission et l'ouverture à des élèves extérieures au département. Ainsi en I8I6, le préfet de l'Hérault écrit à son homologue de l'Aude pour lui signaler la tenue prochaine d'un cours d'accouchement au dépôt de mendicité de Montpellier : «Si votre département manque de sages-femmes, je me ferai un plaisir, Monsieur et cher collègue, de faire admettre aux cours une ou deux élèves que vous me désignerez ${ }^{25}$. » Plus qu'une simple information, la politique suivie par ces préfets est celle d'un recrutement d'emblée étendu aux départements les plus proches. La proposition de réserver des places à de futures élèves, accordant ainsi une importance particulière aux relations entre espaces limitrophes, est une constante des correspondances préfectorales ; on la retrouve chez le préfet des Bouches$\mathrm{du}$-Rhône auprès de son collègue des Basses-Alpes en $1826^{26}$. Ces efforts pour

24. Mayeur F., Histoire générale de l'enseignement et de l'éducation en France..., op. cit., p. 467 et 735.

25. AD Aude, 5 MD i6.

26. AD Alpes-de-Haute-Provence, 5 M 6. 
attirer à soi des élèves d'origines diverses sont parfois couronnés de succès : c'est le cas des élèves cantaliennes envoyées en Corrèze dès I834, soit l'année même de la création de l'école de Tulle. L'étude du rayonnement de quelques établissements particuliers souligne l'importance de la publicité menée par certains préfets autour de leur création.

L'exemple du Cher est sur ce point révélateur des stratégies déployées pour faire connaître une institution naissante. Au terme de presque deux décennies d'incessantes réclamations auprès du gouvernement, le marquis de Villeneuve obtient en I8I7 de pouvoir organiser un hospice de maternité et d'y accoler un cours d'accouchement. Le conseil général, déjà convaincu du bien-fondé de la chose, apporte avec enthousiasme son soutien et l'inauguration a lieu le 4 janvier I818. Dès le mois de décembre I8I7, le préfet a annoncé à ses collègues l'ouverture imminente de l'école. Un mois plus tard, il leur adresse le texte imprimé de son discours d'inauguration, accompagné du règlement de l'hospice de la maternité de Bourges ${ }^{27}$. Le résultat ne se fait pas attendre et dès la première rentrée, trois départements envoient des élèves boursières : l'Indre, la Corrèze et l'Ardèche. En I823, la Creuse décide à son tour d'y faire admettre ses futures sages-femmes. Parmi ces différents départements, deux sont frontaliers du Cher, l'Indre et la Creuse, mais les deux autres sont beaucoup plus éloignés, la Corrèze bien sûr et plus encore l'Ardèche, située de l'autre côté du Massif Central. Ces choix révèlent d'une part la diffusion ambitieuse de l'information pratiquée par l'administration du Cher et d'autre part la faible importance de la distance comme critère d'élection d'un centre de formation. C'est la qualité supposée de l'enseignement, associée à la modestie de la pension exigée qui emportent la décision des conseils généraux. Toutefois, la constellation berruyère est instable et les départements pourvoyeurs d'élèves ne restent pas tous fidèles à l'école pendant sa durée d'existence (I818-1836). La Corrèze en I820 et la Creuse en 1828 cessent d'envoyer leurs boursières pour privilégier, temporairement pour la première et plus durablement pour la seconde, l'admission à l'Hospice de la Maternité de Paris.

Autre exemple, celui de l'école d'accouchement de l'Ain, fondée en I819 et dirigée avec fermeté et persévérance par le docteur Pacoud ${ }^{28}$. Département marginal et assez pauvre, l'Ain n'est à tous égards pas le mieux placé pour susciter et maintenir une école d'accouchement florissante. Pourtant, dix ans après sa création, une lettre au ministre de l'Intérieur dresse du cours de Bourg-enBresse le portrait suivant :

27. AD Corrèze, i X 162.

28. Jean V., L'école des sages-femmes de l'Ain au XIX siècle, maîtrise d'histoire, Lyon III, 1996. 
Ici, peut-être seroit-ce le cas de faire observer à Son Excellence, le parti qu'on pourroit tirer d'un établissement tout formé, existant depuis dix ans et dont les succès ne sauroient être contestés, en l'étendant aux besoins des départements circonvoisins, qui déjà, spontanément, commencent à en profiter [... ${ }_{*}{ }^{29}$

Comme l'école de Bourges dont elle est quasiment contemporaine mais à laquelle elle survit très largement, l'école de Bourg-en-Bresse draine des élèves d'un département limitrophe, le Jura, mais aussi de départements plus lointains, la Loire et la Drôme. Cette extension est d'autant plus remarquable que l'établissement est cerné d'autres institutions anciennes et solidement implantées (Lyon, Grenoble et Mâcon). C'est ici paradoxalement la taille réduite de la ville d'implantation, contre les grands hospices lyonnais ou grenoblois, et surtout la rigueur extrême de l'encadrement des élèves qui justifient le choix des autres départements ${ }^{30}$. La réduction de la sphère d'influence est progressive et se fonde sur des considérations variées : économiques pour le Jura qui décide en 1876 d'envoyer désormais ses élèves à Besançon puisque c'est le siège de l'école où elles se font recevoir, indépendamment de leur lieu de formation ${ }^{31}$; économiques sans doute aussi pour la Loire qui fonde un cours à Saint-Étienne en $1889^{32}$; de science et de conscience enfin pour la Drôme qui oriente à partir de 1892 ses boursières à Lyon pour préserver leur sensibilité protestante, malmenée par le catholicisme flamboyant des gestionnaires de l'école de Bourg ${ }^{33}$.

Mais l'extension d'une aura ne repose pas seulement sur le travail accompli par les administrateurs d'un département. Elle est aussi tributaire de l'évolution des institutions voisines, créations ou suppressions, qui affecte son aire de rayonnement. Ainsi, la mise en place du cours d'accouchement d'Albi en 1825 remet-elle en cause l'envoi des élèves sages-femmes du Tarn à Toulouse, tel qu'il était pratiqué depuis $182 \mathrm{I}^{34}$. Les fondations d'écoles n'affectent cependant que peu les établissements non parisiens, c'est à l'inverse les suppressions de cours ou les renoncements aux envois à Port-Royal qui dessinent progressivement des zones de recrutement. L'institution angevine reçoit ainsi à partir de I834 les boursières vendéennes qui fréquentaient avant cette date l'école niortaise, puis en 1865 , les jeunes filles anciennement admises au cours du Mans

\footnotetext{
29. AN, $F^{17} / 2456$, Ain.

30. RD CG Ain, 1848.

31. RD CG Jura, 1876 .

32. RD CG Loire, 1906, p. 43I ; Dubesset M., Zancarini-Fournel M., Parcours de femmes, op. cit., p. I89-20I.

33. AD Drôme, 5 M 20.

34. AD Tarn, $\mathrm{I} \mathrm{N}_{12}{ }^{*}$.
} 
(après quelques années d'envois à Paris), et à partir de 1876 les élèves de la Mayenne après la fermeture du cours de Laval ${ }^{35}$.

Le rayonnement régional des centres de formation obstétricale est donc le fruit d'initiatives particulières, de regroupements aléatoires suscités par les évolutions propres à la politique de chaque département. L'étude des espaces d'influence respectifs déjoue les attentes de continuité territoriale stricte au profit de réseaux plus souples, fondés sur la réputation et les conditions de réception des élèves.

\section{Les dynamiques interdépartementales}

L'absence de ligne directrice nationale dans le développement des établissements de formation obstétricale laisse, assez logiquement, une place importante aux relations interdépartementales et à l'action personnelle des administrateurs et des médecins dans le processus des créations ou des réorganisations de cours. La correspondance préfectorale est au cœur de la circulation de l'information et du partage des modèles d'établissements. L'itinéraire professionnel, les mobilités de la «carrière » des préfets ajoutent encore à cette facilité du recours au département voisin, voire à l'ensemble des départements français, pour informer une situation locale. Les dynamiques interdépartementales sont essentielles pour saisir les phénomènes de miroirs, d'émulation voire de rivalité qui traversent les entreprises pédagogiques à destination des sages-femmes. Il n'est plus dans ce cas question de rayonnement ou de circonscription d'un établissement supérieur, mais de coopération entre départements, de mise en commun d'un outil conçu comme une co-propriété. La logique de co-gestion d'une institution d'enseignement, rarement mise à l'étude et surtout quasiment jamais concrétisée, est toutefois révélatrice de l'intérêt bien pensé qu'il peut y avoir à réduire les frais d'entretien d'une école en multipliant ses élèves. Au cours du siècle, trois exemples permettent d'illustrer trois facettes de cette pratique.

En I85I, le préfet de l'Isère propose à ses homologues des Hautes-Alpes et de la Drôme de partager « la dépense annuelle du professorat ${ }^{36}$ ». Cette démarche vise à élargir le champ de recrutement du cours grenoblois aux limites du Dauphiné d'Ancien Régime, et à rendre le cours annuel (au lieu de biennal). Si le préfet des Hautes-Alpes s'engage - vainement - à soumettre cette proposition au conseil général de son département, la Drôme n'y donne aucune suite. La tentative reste néanmoins intéressante puisqu'elle fait porter

35. AD Vendée, I N 7 ; AD Sarthe ; RD CG Mayenne, avril 1876.

36. AD Drôme, $5 \mathrm{M}$ i9. 
la participation collective sur une dépense symbolique, le traitement du professeur, et non sur les locaux ou les frais de fonctionnement généraux.

Autre exemple : en 1877, le conseil général des Vosges met en débat la suppression de l'école d'Épinal (créée en I802). Le préfet consulte alors ses collègues les plus proches sur les conditions de formation des sages-femmes dans leur département ${ }^{37}$. Le préfet de la Haute-Marne saisit la balle au bond pour proposer une gestion conjointe de son établissement départemental. Quelques semaines auparavant, il a donné communication au département de l'Aube de la disponibilité de l'école chaumontoise à recevoir des élèves boursières. C'est donc ici aussi un projet tripartite qui est envisagé sur des bases plus larges que celles précédemment évoquées pour le cas grenoblois :

Le département de la Haute-Marne est en négociation avec celui de l'Aube qui envoie ses élèves sages-femmes boursières à la clinique de Paris. Il admettrait probablement les élèves de l'Aube et même les élèves des Vosges, moyennant des bourses fixées à 400 francs par an et par élève ou bien des élèves boursières à 250 francs pour les deux années scolaires [...] à la condition que le département des Vosges ou de l'Aube ou les deux prendraient dans les frais généraux de l'école une part correspondante au nombre de leurs élèves.

La poursuite de la correspondance entre Chaumont et Épinal permet d'entrer dans le détail des prévisions budgétaires. Les dépenses communes concerneraient la location des bâtiments, les traitements du professeur, de la directrice et de la domestique, les frais de bouche, d'éclairage et de chauffage des résidentes dans l'école (directrice, domestique, élèves) ainsi que l'entretien de l'établissement et de son mobilier. Le projet du préfet de la Haute-Marne prévoit le doublement des effectifs de l'école (ro élèves de la Haute-Marne et ro élèves des Vosges), permettant, sans modifier la localisation de l'institution ni les salaires de son personnel, de réaliser de substantielles économies (" 550 francs environ au lieu de 700, prix actuel de la dépense par élève »). La proposition n'est toutefois pas retenue par l'assemblée départementale vosgienne, qui décide finalement en I879 d'envoyer ses élèves sages-femmes à Nancy ${ }^{38}$.

Au bout du compte, le seul exemple réussi d'établissement co-géré par deux départements est l'école d'accouchement de Chambéry, dite Institut PilletWill, dont les statuts de fondation en 1857 prévoient un recrutement étendu à toute la Savoie francophone. La réussite ultérieure de cette école bidépartementale est d'ailleurs intimement liée à l'histoire de cette région non française

37. AD Haute-Marne, II7 T I.

38. RD CG Vosges, 1877,1878 et 1879. 
et non départementalisée entre I8I5 et I860. Le siège de l'école se trouve en Savoie, mais la moitié des dix places d'élèves financées par les revenus de la fondation du comte Pillet-Wil est réservée à chacun des départements savoyards. Il en découle l'obligation pour la Savoie et la Haute-Savoie de pourvoir au traitement du professeur, soit 800 francs au total, puisque cette somme n'est pas couverte par le financement originel de l'établissement. Le caractère inhabituel de cette institution commune n'est pas immédiatement compris par les administrateurs français. Le préfet de Haute-Savoie propose ainsi en I86I d'envoyer des élèves sages-femmes à Paris ou à Chambéry sans percevoir la compétence « omnisavoyarde » du deuxième établissement. L'année suivante néanmoins, l'erreur est « réparée » et le préfet s'enthousiasme alors de la complémentarité à l'œuvre : « Nous participons donc largement aux bénéfices de l'institution. Dans tous les cas, la moitié des places nous est assurée ${ }^{39} . »$

La nature exceptionnelle de cette communauté scolaire constitue la pointe émergée de l'ensemble des intenses relations qu'entretiennent les préfets entre eux. La pratique de l'enquête circulaire, la demande plus spécifique d'informations, l'inspiration recherchée dans les réalisations du voisin sont autant de manifestations de la transversalité du réseau préfectoral.

En I865 et I887, le département de la Haute-Marne adresse à l'ensemble des départements un questionnaire portant sur l'existence ou non d'une école d'accouchement sur leur territoire, sur le personnel, ses fonctions et sa rémunération, ainsi que sur le nombre d'élèves accueillies, l'organisation des locaux et plus généralement le coût d'entretien de l'établissement ${ }^{40}$. La première demande s'inscrit dans un contexte de réforme de cette école, et aboutit à l'arrêté de modification du règlement du 15 février $1866^{41}$. La seconde s'insère probablement dans la suite des conclusions tirées au niveau national de l'enquête de 1885 sur les maternités et les écoles d'accouchement ${ }^{42}$.

En 1892, le Puy-de-Dôme lance à son tour une consultation élargie ${ }^{43}$. Les préfets sont interrogés sur le régime d'admission des élèves, sur les locaux de l'école s'il en existe, sur la politique de subvention des boursières et sur les

\footnotetext{
39. RD CG Haute-Savoie, 1862.

40. AD Haute-Marne, iI8 T I.

4I. Ibid., $4 \mathrm{~N}$ I26.

42. La Haute-Marne n'est pas le seul département à ouvrir une enquête dans cette période, voir aussi le cas de la Corrèze en I880 (AD Loire-Atlantique, 127 T I) et celui de la Saône-et-Loire avec la circulaire du I5 juin I889 (AD Saône-et-Loire, M 2085). Après I893, on note de nouveau le recours à ces questionnaires diffusés nationalement : enquêtes du préfet du Gard en date du 3I mai I 898 et du préfet de la Somme le I8 juin suivant (AD Maine-et-Loire, 47 M 2I).
}

43. AD Vaucluse, $5 \mathrm{M}$ I7. 
liens entre une éventuelle maternité et l'école d'accouchement. Du point de vue local, cette enquête correspond à l'ouverture d'un débat devant l'assemblée départementale lors de sa session d'octobre I89I au sujet de l'insalubrité de l'école de sages-femmes et des moyens d'améliorer la situation. Lors de la session suivante, le préfet rend ainsi compte des résultats de ses recherches :

D'après l'enquête poursuivie à ce sujet au moyen d'un questionnaire appelant des réponses nettes et précises sur les divers éléments à grouper dans une étude de ce genre, très peu de départements possèdent, comme le Puy-deDôme, une école d'accouchement présentant une organisation complète, avec un personnel de professeurs, de sages-femmes, de préposés aux soins intérieurs de l'école et avec toutes les conséquences heureuses qui en découlent pour le succès des élèves dans leurs études. ${ }^{44}$

Ces enquêtes sont la version systématique des échanges moins formels que l'on rencontre régulièrement entre préfets. Ces derniers se fondent sur la proximité géographique, comme dans le cas du Gers et des Landes à la fin des années I820. Le préfet du Gers s'occupe à cette période de la rédaction du règlement du cours qui fonctionne à Auch depuis plus de vingt ans, il sollicite son collègue de Dax pour que celui-ci lui adresse un exemplaire du règlement de l'Hospice de la Maternité de Paris (1807) et lui signale les modifications apportées pour l'établissement du règlement du cours d'accouchement de $\mathrm{Dax}^{45}$. Le produit de ces contacts est remarquable : l'arrêté du 30 mai 1829 qui fixe le fonctionnement du cours d'Auch est démarqué mot à mot du règlement dacquois ${ }^{46}$.

L'itinéraire personnel d'un préfet peut aussi mettre en lien des territoires distants. François-Emmanuel Camus du Martroy, préfet de l'Ain en I819 lors de la fondation de l'école de Bourg-en-Bresse, préside à la réorganisation du cours d'accouchement de Clermont-Ferrand en I82I après son arrivée dans le Puy-de-Dôme ${ }^{47}$. Des filiations se créent ainsi, par l'intermédiaire des agents itinérants de l'État qui transportent leur expérience et la renommée des établissements qu'ils ont contribué à fonder ou faire prospérer. En 1825, le docteur Pacoud, professeur de l'école d'accouchement de l'Ain, présente un résumé des travaux de l'institution pour l'année précédente:

44. AD Puy-de-Dôme, 2 BIB 2527/37.

45. AD Gers, 5 M 6 .

46. Ibid.

47. AD Puy-de-Dôme, 3 BIB 457/3. 
Influence de l'école hors du département. Les bienfaits de notre école ne se bornent point aux limites de notre département. Plusieurs autres, à notre exemple, ont créées des institutions analogues. [...

L'école du Puys de Dôme qui nous a suivis de plus près traite la nature de l'école modèle et les professeurs s'empressent d'adopter toutes les améliorations que nous avons conçues et exécutées successivement. Nous avons nous même en passant à Dijon l'année dernière donné une heureuse impulsion à celle de la Côte-d'Or. Le département de la Meurthe reçut il y a deux ans tous les renseignements nécessaires et son école commence à marcher. Cette année, $M$. le préfet du Pas-de-Calais a également adressé à M. le préfet de l'Ain une demande pareille pour en instituer une à l'instar de la nôtre. ${ }^{48}$

S'il y a un brin de vantardise chez ce médecin à s'attribuer le fonctionnement régulier des cours de la Côte-d'Or ou de la Meurthe, la réputation de l'établissement bressan n'est cependant pas à faire. Lors de la session du conseil général de la Vendée en I833, cet établissement est d'ailleurs cité en exemple comme prélude à une proposition de création de cours à Bourbon-Vendée ${ }^{49}$. L'influence réelle de ce cours aboutit même à la mise en place d'un patronage assidu du cours voisin de Mâcon. La correspondance entre le docteur Carteron, en charge du cours mâconnais, et le docteur Pacoud de Bourg tisse une longue suite de conseils et de reproches bienveillants du second au premier. D'un ton éminemment directif, Pacoud dispense sur tous les sujets ses recommandations aux allures de prescriptions :

(Novembre 1836) Mon cher confrère et ami,

Vous vous donnez beaucoup de peine et de soucis, et vous n'obtiendrez que des résultats peu satisfaisants parce qu'il me semble que vous vous y prenez mal. Après votre logement assuré, vous auriez dû penser à une religieuse ou deux et même trois pour diriger l'économat de votre école. [...] Avec une religieuse telle que j’aurai pu vous la fournir dans le temps où j’aurais pu la choisir sur plusieurs centaines, vous auroit épargné bien des peines et économisé de belles sommes $[\ldots] .^{50}$

Cet attachement à exporter un modèle d'enseignement au-delà des frontières du département, particulièrement sensible chez les responsables de l'école de Bourg, souligne a contrario la variété d'un cours à l'autre. Le besoin récurrent de se référer aux pratiques des voisins, autant voire plus quà l'exemple parisien toujours

\footnotetext{
48. AN, $\mathrm{F}^{17} / 2456$, Ain.

49. AD Vendée, i $\mathrm{N}_{5}$.

50. AD Saône-et-Loire, $\mathrm{M} 2085$.
} 
trop lointain et trop corrélé aux inamovibles principes ministériels, est un moteur essentiel de la perpétuelle recomposition du paysage obstétrical, dans la redistribution de ces institutions et dans l'évolution continue de leur fonctionnement.

\section{Le fonctionnement des cours : formes et financement}

\section{De la tolérance à l'autorisation}

L'histoire d'un cours d'accouchement est souvent celle d'une longue et progressive transmutation. Deux points de vue se côtoient alors : l'œil du national et l'œil du local. Regarder de Paris, c'est-à-dire du gouvernement, le paysage français de la formation obstétricale, c'est voir les fruits mûris ou avortés de la loi du I9 ventôse an XI. Regarder des préfectures, c'est voir, aux côtés des fruits, leurs fleurs et tous les rejetons sauvages qui les entourent. Peut se poser alors la question du stade à partir duquel un cours d'accouchement peut être considéré comme un « vrai » cours.

La légitimité d'un cours est dans tous les cas tranchée par le choix national français de former des accoucheuses, puisque le besoin prime. Sa légalité censée constituer autour de lui une barrière puissante se révèle pendant les premières décennies du siècle d'autant plus inopérante que la référence législative de 1803 ne place en théorie hors-la-loi aucun mode d'acquisition du savoir obstétrical. Seul est passible de sanctions l'exercice illégal de l'art des accouchements. La menace de mise à l'écart par les jurys médicaux des élèves sages-femmes formées dans le cadre de cours non autorisés ne se rencontre guère avant la fin de la décennie I8Io, ainsi dans l'Aube en I8I6 lorsque le docteur Jacquier demande que son cours annuel dans l'hospice de la Maternité de Troyes soit reconnu car « sans cette formalité, les sages-femmes qui ont suivi le cours de la maternité ne pourroient se présenter aux examens du jury médical qui va s'assembler incessamment, et n'ayant pas de droits à un diplôme, elles perdroient le fruit de leurs peines et de leurs travaux ${ }^{51} »$.

Reste au bout du compte un critère peu officiel et difficilement quantifiable mais qui s'avère néanmoins le plus pertinent pour classer les différents types d'instruction des sages-femmes, le degré de publicité d'un cours. Par ce terme de publicité, j'entends d'une part, très concrètement, la diffusion de l'information autour d'un cours et, d'autre part, son caractère public plus ou moins reconnu ou revendiqué. C'est sur cette base mince mais solide que s'est appuyée ma présentation initiale de la carte des cours d'accouchement en France au XIX ${ }^{\mathrm{e}}$ siècle. 
Les désignations choisies pour les formations obstétricales sont souvent riches d'enseignements. Les formules " cours théorique et pratique », dans leurs différentes versions, que ce soit « cours gratuit théorique et pratique » ou « cours public théorique et pratique », voire « cours public et gratuit d'accouchement», signalent toutes un niveau élevé de reconnaissance sociale et administrative. L'enseignement dispensé par Jean-Marc Duclos, chirurgien toulousain, en l'an Ix porte le nom de « cours public et gratuit d'accouchement ». À l'issue des leçons, le démonstrateur confirme le lien entre la formation et la municipalité toulousaine en remettant au corps de ville assemblé un manuscrit de son cours ${ }^{52}$. Les cours du docteur Delzeuzes à Évreux sont annoncés de la même façon ${ }^{53}$. La nuance qui distingue cours publics et cours publics autorisés passe en général dans la présence ou l'absence de l'adjectif « départemental » dans l'intitulé. Seul l'accord ministériel permet aux préfets de revendiquer ouvertement un cours d'accouchement comme partie des institutions départementales. Des tournures de substitution existent toutefois. En I805, une affiche placardée sur les murs de Nancy et dans le département de la Meurthe place le cours du docteur Bonfils « sous les auspices de Monsieur le Préfet du département de la Meurthe ${ }^{54} »$. Le soutien du préfet est renouvelé à la fin d'un prospectus par le texte d'un arrêté pris le 5 septembre I806 encourageant les maires des communes rurales du département à envoyer leurs candidates au cours nancéen tout en annonçant le financement départemental de deux élèves. L'ensemble, affiches et prospectus, est d'ailleurs probablement imprimé et diffusé aux frais de la préfecture.

Cette présence tutélaire de l'administration départementale n'empêche pas ces cours de se présenter comme des initiatives individuelles, nées de l'intérêt des médecins accoucheurs pour la sauvegarde des populations :

Aussi le Médecin de cet hospice [la maison de secours de Nancy], versé depuis longtemps dans la pratique et l'enseignement privé de l'art des accouchemens, a pensé qu'il était de son devoir d'utiliser des moyens aussi précieux pour l'instruction. ${ }^{55}$

Les cours s'identifient donc à leurs enseignants, et avant que les instances départementales ne les institutionnalisent en obtenant pour eux l'aval du

52. Barbot J., Les chroniques de la faculté de médecine de Toulouse du XIII au XXe siècle, Toulouse, Librairie Charles Dirion, 1905, p. 50-5I.

53. AD Eure-et-Loir, $3 X_{43}$.

54. AN, Fi7/2463, Meurthe.

55. Ibid. 
ministère, les préfets et leurs administrés parlent dans la Meurthe du cours du docteur Bonfils, dans l'Aube du cours du docteur Pigeotte ou Jacquier, dans les Landes de celui du docteur Durozier ${ }^{56}$. La personnalisation de l'enseignement est d'ailleurs telle que les conseillers généraux de l'Indre dans leur session de l'an xi parlent du « cours d'accouchement de la dame Lachapelle à Paris ${ }^{57}$ ».

L'ambiguité sur la nature réelle du cours est volontairement cultivée par les professeurs et les administrateurs, les premiers y trouvant un prestige particulier, les seconds un système a priori provisoire mais efficace qui leur fournit des sages-femmes sans imposer l'autorisation préalable de leur hiérarchie. D'un point de vue matériel, le coût de ces cours varie en fonction des exigences salariales des professeurs et des secours éventuellement apportés aux élèves. Dans la Meurthe, le préfet s'engage en 1806 à former deux bourses d'élèves, mais cette générosité n'a rien d'automatique et dans le Lot-et-Garonne, au moment de l'officialisation du cours, les élèves ne reçoivent « aucun secours du département ${ }^{58}$ ».

Concernant les professeurs, il apparaît régulièrement que ces hommes remplissent déjà par ailleurs un certain nombre de fonctions rémunérées ${ }^{59}$. C'est le cas de Bonfils cité plus haut, de François Larrey, professeur du cours d'accouchement de Nîmes (chirurgien en chef des hospices de la ville ${ }^{60}$ ), ou de Mérilhon à Angoulême (chirurgien de la salle d'accouchements des maisons d'arrêt et de détention $\left.{ }^{61}\right)$. Ces ressources étrangères à la fonction strictement enseignante leur permettent pourtant de professer gratuitement ou de continuer à le faire après la suppression de leurs émoluments. La brève existence de chaires d'accouchements attachées aux écoles centrales sous la Révolution a laissé, après leur disparition, les titulaires dans une situation de vacance qu' ils ont souvent remplie en poursuivant leur tâche, à l'instar de François Larrey dans le Gard :

Depuis sa suppression, j’ai continué chaque année un cours gratuit d'accouchements, et il m'est permis de dire que c'est à lui que le département du Gard doit de nombreuses sages-femmes qui, à une routine meurtrière, ont fait succéder dans leurs contrées des connaissances précieuses pour leurs concitoyens. ${ }^{62}$

56. AD Landes, H Dép i G I7.

57. AD Indre, $\mathrm{N}_{9}$.

58. AD Lot-et-Garonne, Recueil des actes administratifs, département du Lot-et-Garonne, $\mathrm{n}^{\circ} 54$.

59. À partir de l'exemple du médecin des prisons au XIX ${ }^{e}$ siècle, J. Léonard souligne ce phénomène d'accumulation des charges officielles, voir «Les médecins des prisons », dans Médecins, malades et société dans la France du XIX siècle, Paris, Sciences en situation, I992, p. IOO.

60. AD Gard, $5 \mathrm{M} 23$.

6I. $\mathrm{AN}, \mathrm{F}^{17} / 2458$, Charente.

62. $\mathrm{AN}, \mathrm{F}^{17} / 2460$, Gard. 
La recherche d'une reconnaissance financière n'est pas le seul moteur de l'action pédagogique. Le discours sur la nécessité de former les accoucheuses est dans la bouche et sous la plume des médecins et des chirurgiens une conviction, qui justifie souvent leur désintéressement. La lenteur avec laquelle ils réclament leurs honoraires en est la preuve. Le docteur Prieur professe à Auch des cours à partir de 1807 . Ce n'est que dix ans plus tard qu'il fait transmettre au ministre de l'Intérieur une pétition pour obtenir un traitement assis sur un brevet de professeur départemental d'accouchement ${ }^{63}$.

Dans les Pyrénées-Orientales, on observe une situation semblable puisque c'est seulement en I8I4, à la suite d'une demande de renseignements du préfet, que le docteur Bonafos, professeur du cours d'accouchement, rappelle dans un historique de cette formation les années d'enseignement sans rémunération :

L'école de la Maternité établie, le ministre raya du budget la dépense du cours d'accouchement $[\ldots]$. On nous pria en même instant de ne pas cesser ; nous assurant que nous recevrions le salaire y attaché. Notre zèle est connu. Nous continuâmes à faire comme par le passé ; nous ne fûmes pas payés. [...] Nous osons espérer, le cours ayant été fait, que nous recevrons ce qui nous est dû. ${ }^{64}$

Ces aléas, entre reconnaissance effective et fonctionnement souterrain, s'expliquent en partie par la politique équivoque du ministre de l'Intérieur. Entre approbation, autorisation exceptionnelle, et autorisation définitive, la frontière est mince et chaque bout de la chaîne administrative joue de l'interprétation possible selon son intérêt. Les exemples gersois et pyrénéen, comme celui de la Meurthe, sont révélateurs des hésitations et changements d'avis ministériels. Une lettre ambiguë, une absence de refus explicite d'organisation d'un cours suffisent en général à un préfet pour en déduire un accord, voire la promesse d'un soutien. Parfois, une forme d'autorisation existe, comme en I807 dans ce courrier du ministre Champagny au préfet du Gers :

Monsieur le Préfet, d'après la demande que vous en avez faite, je consens que la somme de treize cent soixante-dix-sept francs restée en dépôt dans la caisse de l'hospice de la ville d'Auch, et provenant des réceptions d'officiers de santé en l'an XII et l'an XIII, soit consacrée aux frais d'un cours d'accouchemens dans ladite ville. ${ }^{65}$

63. AD Gers, $5 \mathrm{M} 6$.

64. AD Pyrénées-Orientales, 5 M 29.

65. AD Gers, 5 M 6 . 
Une note attachée à cette lettre développe l'idée du récipiendaire : « Ne peut-on pas considérer comme une autorisation au moins implicite la lettre cijointe du ministre de l'Intérieur du 22 juillet 1807 ? ». Ou comment transformer une approbation ponctuelle en un blanc-seing définitif pour l'organisation d'un cours. Parfois, la reconnaissance passe par d'autres instances, plus révélatrices encore de l'ambivalence du rapport à ces enseignements semi-clandestins. Lorsque le docteur Durozier prend en charge le cours d'accouchement de Dax en l'an XIII, il manque de matériel pédagogique; cette formation est censée se dérouler dans l'hospice de Dax, sans toutefois quaucune autorité gouvernementale n'ait donné son aval. Pourtant, très naturellement, le médecin professeur s'adresse, pour se procurer les objets nécessaires, à l'Hospice de la Maternité de Paris ${ }^{66}$. La disponibilité concrète de Baudelocque pour une initiative qui va à l'encontre des principes énoncés pour le recrutement de l'Hospice de la Maternité de Paris montre le respect d'un homme, nourri aux cours de démonstration de l'Ancien Régime, pour les efforts d'instruction d'un collègue qui tente de s'approcher au plus près des méthodes mises en œuvre à Paris.

Le temps de latence entre cours localement public et cours officiel est variable. L'attente rochelaise dure huit ans, régulièrement ponctuée de refus ministériels, délai relativement court si on le compare aux vingt-deux ans du cours d'accouchement du Gers, dont la première approbation remonte en 1807 et qui ne voit son règlement autorisé qu'en $18299^{67}$. Ces intervalles sont la réponse des départements à l'exclusivisme parisien du début de siècle. Instruisons, instruisons, il en restera toujours quelque chose : telle pourrait être la devise de ces professeurs et de ces administrateurs qui ont toujours plus de succès à défendre un acquis, aussi peu conforme soit-il, quà recréer du révolu.

Et sans doute faudrait-il partager cette devise avec le groupe aux contours plus flous des professeurs de cours privés d'accouchement. La frontière avec les précédents est souple mais néanmoins plus clairement perceptible que celle entre cours public et cours autorisé. Là où les archives donnent à voir dans ces derniers cas une continuité d'hommes à la tête d'une formation qui ne change généralement ni de durée, ni de local, le cours privé est l'oublié omniprésent de l'histoire de l'obstétrique : oublié car son initiateur ne reçoit ni reconnaissance publique, ni rémunération, omniprésent car il se lit au détour des lettres de motivation des aspirantes sages-femmes. En I8I2, Antoinette Desruols, accoucheuse à Annonay, demande au préfet une autorisation provisoire d'exercer, qu'elle justifie par ses 25 ans d'expérience et le fait « quà l'époque où jai commencé

66. AD Landes, H Dép i G I7.

67. AD Gers, 5 M 6. 
d'exercer mon état, il n'étoit point nécessaire d'avoir fait un cours théorique d'accouchement, que j'avois fait alors et que j'ai continué depuis un cours pratique sous les yeux de M. Soulières, chirurgien accoucheur distingué68 $»$.

Trente ans plus tard, Élisabeth Carol de Tarascon-sur-Ariège, elle-même sage-femme, souligne qu'en plus de ses propres cours, sa fille aspirante accoucheuse, a « reçu les leçons particulières qui lui ont été données par un médecin recommandable du pays ${ }^{69}{ }$. Des médecins prennent donc l'initiative, çà et là, de former les jeunes filles de leur voisinage. Il n'est guère possible de savoir s'ils font payer leur enseignement, s'ils organisent pour une ou deux élèves un véritable cours théorique ou s'ils se contentent de se faire accompagner dans leur pratique par les futures accoucheuses, comme cela semble le cas du docteur Soulières à Annonay ${ }^{70}$. Au tout début du XIX ${ }^{e}$ siècle, ils sont encore nombreux, à l'auditoire plus ou moins fourni. Dans le Haut-Rhin, la préfecture fait établir en 1802 un «état des communes [... ] dans lesquelles il existe des sages-femmes, avec indication si elles ont été instruites ou non [...] et de qui elles ont reçu leur instruction ${ }^{71} \gg$. La liste dressée pour l'arrondissement de Belfort fait apparaître un total de 153 accoucheuses, dont 78 ont eu accès à un enseignement obstétrical. Parmi celles-ci, 8 ont été formées par leur propre mère sage-femme, 21 par une autre sage-femme en exercice et 30 par un chirurgien de leur commune ou d'une commune proche. Les femmes instruites dans un cadre scolaire sont donc à cette date très largement minoritaires puisqu'elles ne sont que ig (I7 à Strasbourg, une à Colmar et une à Besançon) et on ne rencontre pas de cas de double formation (privée et publique). Les hommes de l'art qui accueillent des élèves semblent avoir des auditoires variables et le nom qui revient le plus fréquemment est celui du chirurgien Thaller de Masevaux (13 cas). Une lettre du maire de la commune de Lauw adressée au préfet du Haut-Rhin en vendémiaire an $\mathrm{x}$ complétée d'une copie de délibération municipale du $\mathrm{i}^{\mathrm{er}}$ frimaire suivant précise que ce médecin « demande pour ses peines et soins que son instruction lui occasionnera, la somme modique de 48 francs, entendant que cette femme viendra tous les jours chez lui jusquà ce qu'elle soit au fait dans l'art en question ${ }^{72} »$. Il s'agit donc là d'un véritable cours, quotidien, avec une dimension théorique, et l'aura du professeur est telle qu'il apparaît pour les

\footnotetext{
68. AD Ardèche, $5 \mathrm{M}_{30}$.

69. $\mathrm{AN}, \mathrm{F}^{17} / 2457$, Ariège.

70. AD Ardèche, 5 M 30.

7I. AD Haut-Rhin, $5 \mathrm{M} 15$.

72. Ibid.
} 
magistrats municipaux alentour comme une référence comparable aux cours d'accouchement de Colmar ou de Strasbourg.

L'exemple alsacien introduit par ailleurs à une autre réalité : celle de l'enseignement privé de l'obstétrique par les sages-femmes. La transmission mèrefille n'épuise pas ce mode d'instruction, et nombre d'accoucheuses allient à leur pratique une dimension pédagogique. Elles accueillent des élèves qui ne sont quasiment jamais désignées comme des apprenties, les logent souvent dans leur propre domicile, et leur dispensent un savoir mi-théorique, mi-pratique qui sert fréquemment de propédeutique à l'admission dans une école de sages-femmes. Certaines d'entre elles revendiquent même une reconnaissance publique de leur enseignement, sans pourtant prétendre se poser en professeurs officiels, au sens départemental. En I837, le sous-préfet de Brest transmet au préfet du Finistère une demande d'information sur une requête déposée quelques mois plus tôt par une sage-femme de la ville, « la dame Perusquet qui a sollicité il $y$ a huit mois l'autorisation d'ouvrir à Brest un cours particulier théorique et pratique d'accouchement ${ }^{73} \gg$.

Cette pétition présentée par une accoucheuse urbaine s'inscrit dans une prise en main par les praticiennes d'une filière parallèle d'enseignement de l'obstétrique, hors des institutions départementales. C'est surtout en milieu urbain et au cœur des villes importantes qu'on rencontre ces sages-femmes qui s'intitulent professeurs d'accouchement, jusqu'assez tard dans le siècle. À Paris, Siebold les cite lors de son voyage au début des années I830, aux côtés de médecins et de chirurgiens, ouvrant leurs maisons pour pallier avant I834 l'absence de clinique à destination des étudiants en médecine et des aspirantes sages-femmes de la faculté. On les retrouve plus tardivement encore dans les en-têtes des publications qu'elles produisent $\mathrm{la} \mathrm{dame} \mathrm{Bretonville,} \mathrm{installée} \mathrm{rue}$ Neuve-des-Petits-Champs en 1843 s'intitule « professeur d'accouchement de la faculté de médecine de Paris », Virginie Messager, rue de Rivoli en 1859, se dit "professeur d'accouchement », à l'instar de la dame Menne-Vaulot, avenue de la Grande Armée, en $1869^{74}$.

Tout un monde d'initiatives pédagogiques existe donc à côté des établissements autorisés. La taille modeste de ces formations, l'exigence incontournable pour une élève sage-femme après la suppression des jurys médicaux, et souvent même avant leur disparition, d'avoir suivi un cours organisé et reconnu par les

73. $\mathrm{AD}$ Finistère, $5 \mathrm{M} 22$.

74. Bretonville (Mme), Confidence aux femmes, Paris, chez l'auteur, I843; Messager V., Guide pratique de l'âge critique ou conseils aux femmes, Paris, chez l'auteur, I859; Menne-Vaulot (Mme), Mesdames enceintes, malades ou infécondes, Paris, chez l'auteur, 1869. 
autorités politiques, placent ces leçons particulières en position de préparation ou de complément à l'instruction officielle. Il n'en reste pas moins que pour un professeur privé d'accouchements, qu'il soit médecin ou sage-femme, l'intégration aux structures départementales d'enseignement est inenvisageable s'il ne bénéficie pas dès le début de la protection des autorités départementales. En septembre I8I6, le docteur Molinier de Carcassonne adresse directement au ministre de l'Intérieur une proposition de créer un cours d'accouchement «à [ses] frais et dépens », rappelant qu'il a enseigné pendant deux ans l'obstétrique à la faculté de Montpellier ${ }^{75}$. Son interlocuteur balaie d'un revers de main le projet, en rappelant la nécessité de l'attacher à un hospice. C'est sans compter sur la ténacité du médecin qui se rappelle quelques jours plus tard à son bon souvenir en précisant sa pensée :

Sachant combien un cours d'accouchement simplement théorique serait peu avantageux, je me proposais aussi de le rendre pratique [...]. Je voulais prendre pour modèle l'établissement de Montpellier : et à cet effet, j'aurais eu un local convenable (mais à mes frais) où les femmes de mon département auraient été reçues gratis, dès le cinquième mois de leur grossesse [...].

L'absence du préfet comme intermédiaire privilégié de la discussion autour de ce projet à ses débuts hypothèque lourdement l'avenir de la proposition, finalement reprise par l'administrateur départemental dans les mois et les années suivantes sous une forme réduite (cours seulement théorique) et élargie à d'autres médecins professeurs ${ }^{76}$. Rien n'aboutit en fin de compte, malgré le soutien financier affirmé du conseil général. La tentative ratée de création d'un cours audois n'a pas suivi les étapes nécessaires d'enracinement et de consolidation d'un enseignement, l'initiative individuelle ayant affaibli le processus en amont.

Nombreuses au tout début du siècle alors que les cours départementaux sont encore en pleine phase d'organisation et de consolidation, ces structures d'enseignement privé tendent à s'effacer progressivement des sources passées les années 1820. Les exemples des sages-femmes parisiennes qui revendiquent d'enseigner l'art des accouchements ne rencontrent guère d'écho en dehors de la capitale. En déduire de manière univoque la disparition des cours privés d'obstétrique au-delà des années 1860 est sans doute excessif. Il est probable en revanche que ces formes d'enseignement aient intégré la prééminence réglementaire des écoles d'accouchement et qu'elles se soient pour cette raison contentées du modeste rôle d'appoint pédagogique à l'instruction officielle.

75. AN, $\mathrm{F}^{17} / 2457$, Aude.

76. Ibid. 


\section{Les cadres officiels de la formation publique}

Du cours privé au cours semi-public puis au cours pleinement autorisé, la gradation qualitative est a priori évidente : le troisième est censé correspondre autant que possible aux préconisations du règlement de l'Hospice de la Maternité de Paris. Dans les faits, les nuances sont beaucoup moins nettes et il n'existe pas de cadre unique de la formation obstétricale publique au XIX $^{e}$ siècle. Le contraste est d'ailleurs surprenant entre la volonté ministérielle d'homogénéisation de l'instruction des sages-femmes par l'alignement sur le modèle parisien et les réalisations pédagogiques concrètes dans les départements.

L'observation des structures adoptées par les différentes institutions d'enseignement obstétrical au long du siècle révèle deux tendances de fond : la constante bonne volonté des autorités départementales vis-à-vis de la formation des sages-femmes et la tout aussi constante adaptation de ces mêmes autorités aux moyens du bord. Organiser l'instruction des accoucheuses suppose de trouver et d'entretenir un local et un personnel. Or cela suppose aussi d'accueillir élèves sages-femmes et femmes enceintes, plaçant l'entreprise pédagogique dans le champ du médical et compliquant de ce fait singulièrement la tâche des administrateurs. Le cours d'accouchement est, par la volonté du législateur, en relation organique avec les autres institutions de soin et d'assistance de la ville où il fonctionne. Savoir si cette relation implique ou non l'intégration de la formation obstétricale aux structures préexistantes et quelles conséquences doivent être tirées de l'une ou l'autre configuration résume au fond des décennies de débats dans les conseils généraux et d'ajustements permanents des administrations de tutelle.

On peut distinguer deux formes principales d'organisation des cours d'accouchement : sans internat dispensé en hospice avec une formation clinique réduite; avec internat attaché à un hospice ou correspondant à une école d'accouchement installée dans un établissement particulier. Les possibilités de réception des femmes en couches en parallèle de cet enseignement, de la simple infirmerie au service pérenne de maternité, ajoutent encore à la complexité et à la variété des situations locales. La difficulté lorsqu'on étudie ces grands ensembles d'institutions réside dans la souplesse avec laquelle les départements passent d'une forme à l'autre, et dans la variété des dénominations qui désignent parfois sous le terme "école d'accouchement » un enseignement sis dans un hospice, ou sous celui de « cours d'accouchement», une instruction parfaitement indépendante de toute structure hospitalière. 


\section{Hospices et cours d'accouchement}

La loi de ventôse an XI prévoit l'établissement des cours d'accouchement dans les hospices les plus fréquentés par les femmes en couches. Cela suppose concrètement qu'il existe au moins un service de maternité par département, et que l'établissement où il est installé, ait la place d'accueillir l'enseignement obstétrical dans ses locaux. L'enquête de l'an XIV a fourni au ministre de l'Intérieur une première carte des institutions de ce type ${ }^{77}$. Néanmoins, la présence d'un établissement recevant des accouchées ne suffit pas à toujours permettre l'implantation conjointe d'une structure de formation. À Metz à partir de 1843, la maison d'accouchement de la Société de Charité maternelle n'est pas accessible aux élèves sages-femmes pour préserver la sensibilité des parturientes ${ }^{78}$. À Laon, lorsque le préfet soumet en I832 au maire et à la commission administrative des hospices son projet de créer un cours pour les sages-femmes, il se heurte à l'impossibilité pratique de le mener à bien :

Il existe à l'hôtel-Dieu une salle spécialement affectée aux femmes en couches, elle peut contenir 3 lits au plus. [...] Il serait de toute impossibilité de fournir un emplacement pour le logement de 30 élèves sages-femmes à l'hôtel-Dieu. [...] Quant à un emplacement pour la tenue du cours, il ne s'en trouve à l'hôtel-Dieu qu'un seul qui pourrait convenir à cette destination $[\ldots]$ nous nous empresserions d'offrir ce local pour le cours d'accouchement, si nous ne savions qu'il est notre unique ressource comme salle de secours. ${ }^{79}$

Entre fausse bonne volonté et franche hostilité, les administrateurs laonnois justifient leur refus par le manque d'espace. Ils soulignent aussi le risque de «confusion » dans le fonctionnement de l'hôtel-Dieu si son personnel devait faire face à la présence quotidienne d'une multitude d'élèves sages-femmes. Cette crainte d'un service entravé, d'une désorganisation matérielle susceptible de déboucher sur un désordre moral est présente dans nombre d'établissements. L'essai adressé par le docteur Pacoud au préfet de l'Ain en avril I820 sur les premiers succès de l'école de Bourg-en-Bresse évoque des difficultés similaires lorsqu'il s'est agi de fonder le cours dans l'hôpital de Bourg :

D'après les dispositions de l'arrêté [...] en date du cinq octobre I8Ig, relatif à l'établissement d'un cours annuel et gratuit d'accouchement, les élèves de l'école devoient être nourries, chauffées, éclairées et logées à l'hôpital de Bourg, aux frais du département, mais la crainte que deux établissemens

77. Beauvalet-Boutouyrie S., Naître à l'hôpital..., op. cit., p. 20I-203.

78. AN, Fi7/2464, Moselle.

79. AD Aisne, E Dép 04015 I 2. 
dont le but n'est pas précisément le même, ne se nuisissent mutuellement, la difficulté du logement, l'impossibilité d'empêcher un contact dangereux des personnes du dehors, des employés de la maison et même des malades avec les élèves accoucheuses ; la facilité avec laquelle ces dernières auroient pu se soustraire à une surveillance active $[. .$.$] toutes ces considérations engagèrent$ Monsieur le Préfet à prendre une autre détermination. ${ }^{80}$

Ces obstacles ne sont toutefois pas généraux. Nombre d'administrations départementales travaillent en bonne intelligence avec les commissions des hospices pour remplir les exigences législatives. Le cours d'accouchement de Laon trouve finalement place, après quelques mois de négociations, dans l'hôtel-Dieu, à l'instar des cours de Chartres, Reims, Bagnères-de-Bigorre, Angers ou Pamiers, entre autres.

La collaboration entre le département et l'émanation hospitalière des municipalités se révèle souvent fructueuse et les deux autorités expérimentent des formules originales pour répondre aux nécessités de l'enseignement dans le cadre des possibilités immobilières des hospices. L'esprit de la loi de I803 se dissout parfois dans les petits arrangements entre préfet et administrateurs municipaux et le lien entre admissions de femmes enceintes et fonctionnement des cours d'accouchement se distend par impossibilité de les associer concrètement. À l'automne I8I3 à Rodez, le préfet est informé par le professeur que l'enseignement ne peut avoir lieu, comme à l'habitude, dans les deux salles de l'hôtel-Dieu réservées à cet usage (une pour les femmes en couches et une pour les leçons théoriques). En contrepartie, la commission des hospices propose sa translation dans une de ses maisons, rue Sainte-Marthe, qui doit être spécialement affectée au cours, à la grande satisfaction du professeur, le docteur Amiel ${ }^{81}$.

Dans un contexte plus favorable, beaucoup de municipalités affectent au sein de leur patrimoine hospitalier un bâtiment complet à la formation des accoucheuses. En fonction des villes, ce bâtiment est entretenu sur les fonds municipaux (hospice de la Maternité de Marseille ou hospice de la Charité de Lyon $^{82}$ ). Ailleurs, il peut être soumis à un loyer versé annuellement par le département : c'est le cas en Saône-et-Loire où le cours est installé en I820 dans l'Hospice de la Providence de Mâcon. En plus du loyer, le département participe même pendant plusieurs années consécutives aux frais d'appropriation du

80. AN, Fi7/2456, Ain.

81. AD Aveyron, 3 X 47 .

82. Faure O., Genèse de l'hôpital moderne. Les hospices civils de Lyon de 1802 à 1845 , Paris, Éditions du CNRS, Lyon, Presses universitaires de Lyon, 198I, p. 238. 
local ${ }^{83}$. Le département du Puy-de-Dôme recourt à la même méthode lors de la construction au début des années I89o de la nouvelle maternité à laquelle est jointe une annexe destinée à recevoir l'école d'accouchement. Le loyer prévu se monte alors à 4500 francs $^{84}$.

Aux côtés des hospices, un certain nombre d'établissements d'assistance, d'administration municipale ou départementale, pallient l'absence de structures spécialisées dans l'accueil des femmes en couches. Dépôts de mendicité ou maisons de correction admettent ainsi filles-mères et prostituées en leurs murs, sous la garde de laïques moins promptes à refuser leurs secours à ce type de population que les congréganistes. Sans que cela ne constitue une finalité initiale de ces institutions, elles sont bien souvent au début du XIX ${ }^{\mathrm{e}}$ siècle l'un des lieux où se déroulent le plus d'accouchements dans une ville et sont de ce fait mieux placées que bien des hôpitaux pour fournir le volet clinique de l'enseignement obstétrical. C'est là que se déroulent les cours de Metz jusqu'en I8II et de Montpellier avant $1819^{85}$. Dans ce dernier cas, la fermeture du dépôt de mendicité n'entraîne d'ailleurs pas le déplacement du cours puisque les locaux sont immédiatement réaffectés à l'hôpital général pour y maintenir la maternité.

L'un des effets quasi immédiats des cours d'accouchement est d'ailleurs l'augmentation notable de la fréquentation des services de maternités dans les hospices. Un conflit surgit d'ailleurs à ce sujet entre les hospices de Laon et le département. Avant la création d'une formation pour les sages-femmes au sein de l'hôtel-Dieu laonnois en I832, cette institution réservait six lits aux femmes en couches (pour une moyenne de I2 accouchements annuels). L'arrêté de fondation du cours impose l'entretien de dix lits. Au-delà, la volonté d'accroître l'instruction pratique des futures accoucheuses a justifié pour le département plusieurs mesures destinées à augmenter le nombre d'admissions à l'hôtelDieu qui sont passées « en termes moyens à 5I par année ${ }^{86}$ » à partir de 1833 . La commission administrative des hospices exige d'être intégralement défrayée pour toutes les réceptions de ce genre, à peine de demander la translation du cours d'accouchement dans d'autres locaux et la remise en état par le département des salles utilisées. Un compromis est finalement trouvé en I843, aux termes duquel le conseil général vote annuellement une allocation correspondant à quatre dixièmes des frais de journées des femmes enceintes, reconnaissant que l'instruction des sages-femmes a contribué à augmenter les dépenses

\footnotetext{
83. AD Saône-et-Loire, N 84.

84. AD Puy-de-Dôme, N 469 .

85. AN, $\mathrm{F}^{17} / 2464$, Moselle; $\mathrm{AD}$ Hérault, I $\mathrm{N}_{2}{ }^{*}$.

86. AD Aisne, RD CG Aisne, 1842.
} 
des hospices. La somme est calculée au prorata des lits obligatoirement entretenus par l'hôtel-Dieu et de ceux prévus par l'arrêté du 27 septembre I832. La mise en place d'un enseignement obstétrical a bien initié une multiplication de l'accouchement hospitalier.

\section{Le choix de l'autonomie institutionnelle : l'école d'accouchement et sa maternité}

Il arrive par ailleurs que les autorités départementales privilégient une politique d'autonomie vis-à-vis des hospices et gèrent directement les questions immobilières afférentes aux cours. Ce choix prend alors deux formes, celui de la location d'une maison particulière ou celui de l'achat. La location correspond parfois à une étape préalable à l'achat. C'est le cas en Corrèze où l'école occupe deux maisons louées entre I834 et I848 avant de s'installer dans une troisième, acquise par le département en $1848^{87}$; et en Haute-Marne où le préfet présente sa décision ainsi : «[... je me suis arrêté à celui d'établir l'école dans un local particulier, que louerait le département, en attendant qu'il pût en devenir propriétaire $^{88} »$. Mais la location peut aussi constituer une pratique pérenne, comme à Bordeaux dès le début du siècle ${ }^{89}$.

La décision d'acheter coïncide parfois avec des refondations de cours. L'adjonction à la structure pédagogique d'un espace concret renforce alors l'école renaissante et lui donne une visibilité accrue dans l'espace urbain. La recréation du cours d'accouchement de Rodez en 1859 provoque très rapidement la décision du conseil général de faire l'acquisition d'une maison.

Il y a à cette autonomie de l'école de sages-femmes un corollaire d'importance : l'obligation d'assurer l'admission de femmes enceintes auprès du cours, puisque celui-ci n'est pas intégré au fonctionnement préalable d'un service de maternité. Les administrations départementales désignent alors ces excroissances pratiques des cours sous la dénomination «salle d'accouchement » ou « infirmerie », et affirment leur but essentiellement pédagogique. Cependant, ces salles annexes de maternité reçoivent rapidement de manière régulière des filles-mères ou des indigentes mariées qui imposent progressivement une modification du statut originel de ces structures. Le premier règlement du cours de Bourg-en-Bresse prévoit dans ses articles i4 et I 6 l'accueil des femmes et filles enceintes, conditionnant leur réception à l'autorisation du professeur ${ }^{90}$.

87. N. Sage Pranchère, Mettre au monde..., op. cit., p. 323-332.

88. AD Haute-Marne, in $\mathrm{T}$ I.

89. $A N, F^{17} / 2461$, Gironde.

90. AD Saône-et-Loire, M 2088. 
Près de quarante ans plus tard, le conseil général est saisi du problème croissant qu'occasionne la limitation de l'admission des parturientes à la durée du cours d'accouchement (quatre mois de novembre à février):

[...] aussi, les filles et femmes enceintes indigentes du département étaientelles obligées pendant huit mois de l'année, de recourir aux établissements charitables des départements circonvoisins. Cet état de choses était depuis longtemps l'objet de réclamations fondées de la part des administrateurs de ces établissements, dans lesquels les filles indigentes du département affluaient $[\ldots] .^{91}$

Sur proposition du préfet, l'assemblée départementale décide alors d'ouvrir l'infirmerie des femmes en couches pendant les huit autres mois de l'année. Ce changement entraîne le vote d'une subvention particulière, la réorganisation du service et le recrutement pendant cette période de sages-femmes supplémentaires pour pallier les lacunes de personnel. Il s'agit, les conseillers généraux en ont clairement conscience, de fonder l'ébauche d'une maternité départementale.

On note en Corrèze un processus similaire qui bouleverse même la dénomination de l'établissement, créé sous l'intitulé « école d'accouchement » et désigné à partir de la seconde moitié des années 1840 comme « hospice de la maternité $^{92} \gg$. La maternité départementale survit en I895 à la fermeture de l'école, comme c'est le cas presque à la même période du service transféré à Tarbes, après la suppression de l'école de sages-femmes de Bagnères-de-Bigorre.

La formation obstétricale change donc profondément la donne de l'accouchement hospitalier. Cette tendance est visible à l'échelle nationale et transcende la distinction entre cours en hospice et école d'accouchement. Elle rencontre, malgré des objectifs de départ différents, les politiques départementales d'assistance aux mères indigentes et de lutte contre les abandons d'enfants ${ }^{93}$.

\footnotetext{
9I. RD CG Ain, I855.

92. Sage Pranchère N., Mettre au monde..., op. cit., p. 214.

93. Sur ces sujets, voir Enfance abandonnée et société en Europe, $X I V^{e}-X X^{e}$ siècle. Actes du colloque international de Rome (30 et 31 janvier 1987), Rome, École française de Rome, I99I ; et Fuchs R. G., Mock L. P., « Pregnant, Single and Far from Home. Migrant Women in Nineteenth Century Paris », The American Historical Review, 1990, t. 95, nº 4, p. 1007-1031 ; Fuchs R. G., Poor and Pregnant in Paris. Strategies for Survival in the Nineteenth Century, New Brunswick, New Jersey, Rutgers University Press, I992 ; Rollet-Échallier C., La politique à l'égard de la petite enfance sous la III République, Paris, INED, 1990 ; Cova A., Maternité et droits des femmes en France (XIXe et $X X^{e}$ siècles), Paris, Anthropos-Economica, 1997 ; De Luca V., Rollet C., La pouponnière de Porchefontaine. L'expérience d'une institution sanitaire et sociale, Paris, L'Harmattan, 1999.
} 
Le but pédagogique initial ouvre aux hôpitaux un nouveau champ de compétences; nouveau par son ampleur qui n'a plus rien à voir avec les salles de gésine du XVIII ${ }^{\mathrm{e}}$ siècle; nouveau par la spécialisation accrue de son personnel, précocement professionnalisé et laïcisé. Sa brusque remise en cause en I858 par la dénonciation des risques d'infection puerpérale dans le cadre hospitalier est le signe paradoxal de cet élargissement de la fréquentation des maternités par les femmes enceintes ${ }^{94}$. Le basculement tardif de l'accouchement à domicile vers l'accouchement hospitalier au milieu du $\mathrm{xx}^{\mathrm{e}}$ siècle ne doit pas cacher la progression de la maternité comme espace de refuge pour les mères pauvres et/ ou illégitimes et après 1880 pour les grossesses pathologiques ${ }^{95}$. Paris est à cet égard un exemple précoce et extrême de cette évolution ${ }^{96}$. Le développement d'un réseau d'établissements de formation clinique des sages-femmes accélère donc dans de nombreux départements la concrétisation d'une politique d'assistance aux femmes en couches.

\section{La durée des cours d'accouchement :}

entre impératif pédagogique et contrainte pratique

Ces différentes implantations de l'enseignement obstétrical impliquent des formes spécifiques de transmission du savoir. Les écoles directement louées ou possédées par les départements sont systématiquement corrélées à la présence d'un internat. Le cadre hospitalier est moins propice à l'accueil permanent des élèves sages-femmes et certains cours d'accouchement maintiennent un système d'externat tout au long du siècle (Chartres, Nîmes).

La durée de la formation exerce aussi une forte influence sur la forme retenue. À Chartres, le cours dure trois mois au total sur l'année, réparti en deux cours de six semaines ; l'internat ne se justifie donc aucunement ${ }^{97}$. Il en est de même à Dijon où il faut attendre I834 pour que le cours passe de deux sessions annuelles d'un mois à un bloc continu de cinq mois ${ }^{98}$, et I 845 pour que l'allongement à un semestre de la durée des leçons impose l'instauration d'un régime d'internat ${ }^{99}$.

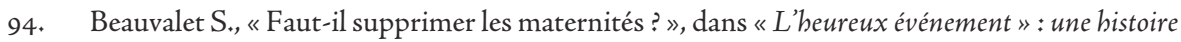
de l'accouchement, Musée de l'Assistance publique-Hôpitaux de Paris, 1995, p. 64-73.

95. Knibiehler Y., Accoucher. Femmes, sages-femmes et médecins..., op. cit., p. 32.

96. Beauvalet-Boutouyrie S., Naître à l'hôpital..., op. cit., p. I42-156 ; 319 sq. ; Lefaucheur N., "La création des services de maternité et des accoucheurs des hôpitaux parisiens », dans «L'heureux événement »..., op. cit., p. 75-84.

97. AD Eure-et-Loir, $3 X_{44}$

98. $\mathrm{AN}, \mathrm{F}^{17} / 2458$, Côte-d'Or.

99. AD Côte-d'Or, M 7 n I/2. 
Le caractère extrêmement divers des durées de cours est à rapporter aux difficultés d'interprétation que pose l'article 3I de la loi de ventôse : deux cours consécutifs et neuf mois d'observation de la pratique ou six mois de pratique personnelle, autant de temps de formation qui se mélangent dans les arrêtés préfectoraux de création et d'organisation des cours. Le modèle parisien met un semblant d'ordre dans ces hésitations en proposant tout d'abord une formule semestrielle de cours, rapidement étendue en 1807 à une année obligatoire (soit deux cours consécutifs de six mois) ${ }^{100}$. Le format des six mois répétés est adopté par nombre de règlements : Ariège, Calvados en I809, Doubs en I812, Charente en I813, Bouches-du-Rhône en I8I8, Aisne en I832, etc. ${ }^{101}$. Certains départements restent néanmoins durablement en dessous de cette durée : l'Eure-et-Loir déjà évoqué, l'Ain qui maintient jusqu'au bout du siècle un cours annuel de quatre mois ${ }^{102}$, ou encore le Gard qui prescrit en 1827 deux cours de trois mois et allonge en 1883 l'instruction à deux cours de trois mois et demi ${ }^{103}$. D'autres enfin la dépassent allègrement : six mois de cours pendant trois années consécutives dans l'Aveyron avant $1847^{104}$, ou en Corrèze avec deux cours de neuf mois en 1834 , et trois cours de dix mois en $1887^{105}$.

\section{Un enseignement médical en marge de l'enseignement de la médecine}

La variété des durées de cours est aussi révélatrice du fonctionnement très indépendant de ces établissements, y compris vis-à-vis des institutions qui pourraient en théorie leur servir de modèle : les écoles et les facultés de médecine. En théorie, le seul lien explicité par les textes législatifs intervient au niveau des examens de réception, à l'exception de la faculté de Paris où un cours est annuellement professé à destination des sages-femmes. Cette situation aurait dû être partagée par les facultés de Montpellier et Strasbourg mais dans les deux cas le choix est fait de séparer nettement la formation des accoucheuses du reste de l'enseignement : le 20 mars 1807 , le décret dit d'Ostende supprime la chaire d'accouchements de l'école de médecine de Montpellier et transfère l'instruction à l'hôpital Saint-Éloi ${ }^{106}$. La chaire est cependant recréée

I00. Beauvalet-Boutouyrie S., Naître à l'hôpital..., op. cit., p. II9.

IOI. AN, $\mathrm{F}^{17} / 2457$, Ariège ; $\mathrm{AN}, \mathrm{F}^{17} / 2457$, Calvados ; $\mathrm{AN}, \mathrm{F}^{17} / 2459$, Doubs ; $\mathrm{AN}, \mathrm{F}^{17} / 2458$, Charente; AD Alpes-de-Haute-Provence, 5 M 6 ; AD Aisne, RD CG Aisne, 1842.

I02. AD Drôme, 5 M 20.

I03. AD Gard, H Dépôt I2 $297 ; 5$ M 25.

I04. AD Aveyron, Per 545.

105. $\mathrm{AN}, \mathrm{F}^{17} / 2458$, Corrèze ; AD Corrèze, I X 177.

I06. Delmas P., Sept siècles d’obstétrique à la faculté de médecine de Montpellier, op. cit., p. 38-4I. 
en I824 mais la formation des sages-femmes continue à fonctionner dans un établissement à part ${ }^{107}$. La réunion en 1859 de la formation des étudiants et des sages-femmes entre les mains du professeur de clinique obstétricale de la faculté n'entraîne pas la fusion des institutions ${ }^{108}$. À Strasbourg, l'ancienneté de l'école d'accouchement justifie son maintien comme une entité départementale indépendante, même si le professeur est commun avec la faculté de médecine ${ }^{109}$. La situation des écoles secondaires de médecine est moins nette, et le lien avec les cours d'accouchement passe rarement par une intégration de cette formation à l'école elle-même, hormis dans des établissements comme Caen ou Rouen. Il arrive fréquemment, en revanche, qu'à l'instar du cas strasbourgeois, l'enseignant fasse les cours aux étudiants pendant une partie de la semaine ou de l'année et aux élèves sages-femmes le reste du temps (Angers, Bordeaux). L'autonomie jusqu'en 1849 de l'établissement bordelais explique le caractère tardif de son évolution vers une mise en commun du professeur avec un autre établissement. En 1854, il est finalement rattaché à l'hospice de la maternité de Bordeaux, retrouvant d'une certaine manière son unité originelle, alors que l'enseignant cumule la charge de chirurgien et de professeur à l'école préparatoire de médecine ${ }^{110}$. Dans les villes sièges d'écoles de médecine, des liens avec l'école d'accouchement finissent toujours par s'établir au cours de la seconde moitié du XIX ${ }^{e}$ siècle. Les cours d'accouchement y perdent cependant rarement leur autonomie et la mise en commun du personnel enseignant permet d'éviter dans la mesure du possible les phénomènes de rivalité entre professeur de l'école de médecine et professeur du cours d'accouchement.

\section{Contributeurs et allocations budgétaires}

Les postes budgétaires consacrés à l'enseignement obstétrical semblent, au vu du développement des dépenses annexes, s'alourdir au fil du siècle. La situation n'est cependant pas homogène. À la variété des politiques départementales de formation des sages-femmes répond une variété tout aussi grande des sommes votées par les conseils généraux. Pour remonter aux sources, il est utile de rappeler le mode de fonctionnement préconisé par la loi de 1803 : « Le traitement du professeur et les frais du cours seront pris sur la rétribution payée pour la réception des officiers de santé » (article 30). La situation semble donc parfaitement

\footnotetext{
107. Ibid., p. 45.

I08. Ibid., p. 56-57.

I09. AD Bas-Rhin, I $\mathrm{N}_{301^{*}}$.

IIo. $\mathrm{AD}$ Bordeaux, $5 \mathrm{M} 556$; I $\mathrm{N} 48^{*}$.
} 
simple au premier abord : le financement des cours d'accouchement est assuré par les droits d'examen d'autres membres du corps médical. En théorie, la destination de ces sommes est immuable. Il est donc d'autant plus nécessaire d'éclairer les obstacles qui rendent très vite illusoire un tel financement.

L'arrêté du 20 prairial an XI impose aux officiers de santé pour leur réception le versement d'une somme de 60 francs pour leur premier examen et 70 francs pour les deux suivants (article 4I), mais sur ces sommes sont prélevés tous les frais de déplacements des jurys et de déroulement de la session. À supposer donc que le nombre de candidats soit suffisant pour justifier la tenue d'une session d'examens, encore faut-il que le paiement des différents frais laisse un reliquat à reverser dans les caisses départementales. Dès l'an XII, les préfets contestent cette méthode et demandent qu'on lui substitue un apport de fonds plus réguliers. Et le préfet de l'Allier de détailler l'exemple de son propre département :

Cette année, la portion prise sur la rétribution payée pour la réception des officiers de santé, et réservée aux frais du cours d'accouchement à ouvrir dans l'hospice le plus fréquenté du département, et au traitement du professeur, ne s'élève qu'à 2175 francs, il est à présumer qu'elle sera inférieure à la session de l'an XiII et années suivantes. Il conviendroit donc que l'administration générale affectât spécialement pour cette dépense, infiniment utile, une somme fixe par chaque année. ${ }^{111}$

Dès l'enquête de l'an xiv, l'espoir de s'appuyer sur ces fonds a quasiment disparu des réponses des préfets. À cela, deux raisons : d'une part, ces revenus sont aléatoires et très faibles dans les départements ruraux sans tradition d'enseignement médical; d'autre part, l'habitude antérieure à l'an XI de voter des subsides pour le fonctionnement des cours d'accouchement sur les fonds départementaux est bien ancrée. Parmi les départements qui semblent encore compter sur cette ressource, se trouve l'Aveyron mais il est l'un des seuls ${ }^{112}$. Un usage restreint de ces droits de réception est néanmoins parfois envisagé dans les réponses à l'enquête, en complément d'autres ressources : ainsi dans l'Aude, le préfet propose de les consacrer à l'achat du matériel pédagogique du cours ${ }^{113}$, tandis que d'autres départements prévoient d'associer ces sommes à des subventions votées par les conseils généraux (Charente-Inférieure, Meuse) ${ }^{114}$.

\footnotetext{
III. $\mathrm{AN}, \mathrm{F}^{17} / 2456$, Allier.

II2. $\mathrm{AD}$ Aveyron, $3 \mathrm{X} 45$.

II3. $\mathrm{AN}, \mathrm{F}^{17} / 2457$, Aude.

II4. $\mathrm{AN}, \mathrm{F}^{17} / 2458$, Charente-Inférieure ; $\mathrm{AN}, \mathrm{F}^{17} / 2464$, Meuse.
} 
Les autorités départementales ne sont toutefois pas à court d'idées lorsqu'il s'agit d'appuyer leurs projets de cours. Les modes de financement proposés sont relativement variés, du classique financement par allocation du conseil général (Aude, Cher, Charente) ${ }^{115}$ au recours à la générosité des hospices ou des municipalités, entendus comme deux contributeurs différents, à égalité avec le département (Loire, Sarthe) ${ }^{116}$, ou en reportant sur eux l'intégralité des frais (Haute-Garonne) ${ }^{117}$, ou encore à l'appui sur les circonscriptions bénéficiaires de l'enseignement obstétrical comme les arrondissements et les communes $(\text { Nord })^{118}$. On rencontre aussi des formules originales comme les prêts municipaux du Finistère, solution temporaire mais potentiellement efficace que le préfet compte rembourser grâce aux futurs fonds accordés par le gouvernement ${ }^{119}$.

Il arrive cependant que l'appréciation des ressources locales aboutisse à un constat d'incapacité, propre aux finances du département ou des hospices : "Il est démontré [...] que les hospices ne peuvent subvenir à cette dépense extraordinaire » (Alpes-Maritimes) ${ }^{120}$. Ce constat peut correspondre à un certain désintérêt ou un certain fatalisme devant l'impossibilité d'organiser une formation à destination des accoucheuses, à moins qu'il ne débouche plus simplement sur un appel à la « munificence du gouvernement» (Nièvre $)^{121}$.

L'enquête de l'an xiv demeure toutefois un document ambigu : s'y mêlent à égalité des renseignements sur des pratiques locales déjà enracinées et des projets de ressources plus ou moins réalisables. L'appréciation des frais occasionnés par les cours d'accouchement dépend aussi en grande partie de l'expérience locale de la formation obstétricale ${ }^{122}$. Là où un enseignement a déjà lieu, les dépenses, hors traitement du professeur, promettent d'être extrêmement limitées. Dans le Rhône, le préfet considère que « les choses peuvent rester dans l'état où elles sont », à moins d'envisager un changement de lieu et d'échelle du cours ${ }^{123}$. En Charente-Inférieure et dans les Pyrénées-Orientales, les frais nécessaires ont déjà été faits ${ }^{124}$. Dans l'Ain et l'Eure-et-Loir enfin, le coût

\footnotetext{
II5. $\mathrm{AN}, \mathrm{F}^{17} / 2457$, Aude; $\mathrm{AN}, \mathrm{F}^{17} / 2458$, Cher et Charente.

II6. AN, F $F^{17} / 2462$, Loire ; AN, F $F^{17} / 2467$, Sarthe.

II7. $\mathrm{AN}, \mathrm{F}^{17} / 2460$, Haute-Garonne.

II8. $\mathrm{AN}, \mathrm{F}^{17} / 2464$, Nord.

II9. $\mathrm{AN}, \mathrm{F}^{17} / 2460$, Finistère.

I20. AD Alpes-Maritimes, CE M 257.

I2I. $\mathrm{AN}, \mathrm{F}^{17} / 2464$, Nièvre.

122. Voir la question 8 de l'enquête : «Quelles seraient les autres dépenses que pourrait occasionner dans l'hospice l'établissement de ces cours ? ».

123. $\mathrm{AN}, \mathrm{F}^{17} / 2466$, Rhône.

124. $\mathrm{AN}, \mathrm{F}^{17} / 2458$, Charente-Inférieure; $\mathrm{AN}, \mathrm{F}^{17} / 2466$, Pyrénées-Orientales.
} 
ne dépasse pas celui du chauffage et de la lumière ${ }^{125}$. Ailleurs, les préfets ne manquent pas d'ambitions et associent à la mise en place (ou à l'amélioration) du cours d'accouchement celle d'une salle d'accouchement. Les sommes en jeu sont alors bien plus importantes :

(Charente) Si la maison des ci-devant cordeliers était cédée à l'hospice, ces cours pourraient être mis en activité au moyen d'une somme de 8000 francs. ${ }^{126}$

(Finistère) Les frais de premier établissement consistant en l'achat de $25 \mathrm{ou}$ 30 lits ; car on peut faire coucher les élèves deux à deux et il resterait encore des lits pour celles qui seraient à l'infirmerie. Les dépenses nécessaires pour la confection de plusieurs portes, etc., l'ouverture d'une cheminée, l'acquisition de livres élémentaires, du mannequin, de quelques ustensiles, lits, meubles, tels que chaises, tables, chandeliers, vaisselle en terre cuite, cuillère et fourchettes en fer et autres menus objets. Les appointements d'une dame supérieure, d'une dame assistante et d'une portière, leur nourriture et celle des élèves. ${ }^{127}$

De ces deux départements, seule la Charente a l'expérience d'un cours fixe : ses demandes n'ont donc pour objet que de le mettre en conformité avec les prescriptions de la loi de ventôse. Le Finistère n'a connu aucun cours depuis l'Ancien Régime et encore était-il itinérant. Ses propositions exigeantes et perfectionnistes ont le défaut des débutants, persuadés qu'il n'est point de salut en dehors d'une reprise minutieuse du modèle proposé par le ministre.

L'organisation des cours d'accouchement aux lendemains de l'enquête de l'an XIV ne reprend que très partiellement certains projets ingénieux avancés par les préfets (recours aux taxes d'octroi, etc.). Aborder la question du financement et des parts respectives des contributeurs signifie définir les différents postes. Ceux-ci se répartissent en plusieurs catégories : traitements du personnel (enseignant et non enseignant) ; secours aux élèves sages-femmes ; frais matériels du cours et entretien des femmes admises pour faire leurs couches dans le cadre de l'instruction.

Parmi ces différents éléments, deux sont officiellement à la charge de l'administration départementale : le mobilier du cours et le salaire du professeur d'accouchement ${ }^{128}$. Le mobilier des cours appartient, au regard de la loi, aux départements qui les instituent. Cependant, hors cette pétition de principe, aucun

125. $\mathrm{AN}, \mathrm{F}^{17} / 2456$, Ain ; AN, $\mathrm{F}^{17} / 2460$, Eure-et-Loir.

126. $\mathrm{AN}, \mathrm{F}^{17} / 2458$, Charente.

127. $\mathrm{AN}, \mathrm{F}^{17} / 2460$, Finistère.

128. Macarel L.-A., Boulatignier J., De la fortune publique en France, et de son administration, vol. 2, Paris, Pourchet, I840, p. 333. 
texte ne définit réellement son statut. L'obligation de traitement des professeurs d'accouchement se place dans la continuité des chaires d'accouchements dans les écoles centrales. Le paiement était déjà à la charge des départements avant le Consulat. Cette obligation perdure au cours du siècle mais de manière moins systématique que son caractère légal pourrait le faire supposer. Dès 1807 , le règlement revu de l'Hospice de la Maternité de Paris modifie provisoirement cette obligation. L'article $\mathrm{I}^{\text {er }}$, développé par la circulaire ministérielle attachée, alloue aux préfets des ressources spécifiques pour l'instruction des sagesfemmes et leur impose d'user de toutes les sommes originellement destinées aux frais des cours locaux, et particulièrement au salaire d'un professeur, pour le paiement de pensions d'élèves sages-femmes à Port-Royal. L'assouplissement des exigences du ministère de l'Intérieur et les autorisations de plus en plus nombreuses accordées aux préfets pour instruire leurs accoucheuses sur place reviennent sur cette prescription de 1807 et permettent de nouveau aux conseils généraux d'imputer leurs fonds aux postes qu'ils souhaitent.

Le récapitulatif des sommes votées par les départements pour l'enseignement obstétrical en 1809 montre bien le basculement en cours. Si 57 départements allouent des subventions pour les envois d'élèves à Paris, 32 consacrent une somme à la mise en place de cours locaux, 7 d'entre eux cumulant les deux objets ${ }^{129}$. Par la suite, le contexte institutionnel joue un rôle non négligeable dans le paiement du professeur par le département : dans les villes sièges d'écoles de médecine, le titulaire de la chaire d'accouchements pour les élèves officiers de santé est souvent le professeur du cours départemental. Cette double charge ne donne pas toujours lieu à une double rémunération et l'enseignant ne reçoit alors que son traitement de l'école de médecine sans supplément du département (Loire-Inférieure jusqu'en I863, Calvados, Seine-Inférieure). À l'inverse, dans le Nord, le département paie à partir des années 1840 et au moins jusqu'aux années i 880 le salaire du professeur d'accouchement attaché à l'école secondaire puis à la faculté de médecine de Lille ${ }^{130}$.

Aux différents types de postes correspondent différents contributeurs dans la mesure où le financement se répartit fréquemment entre plusieurs payeurs institutionnels. Seule exception partielle : l'école savoyarde qui fonctionne sur les revenus d'une fondation privée (Pillet-Will) mais dont le professeur est payé sur des fonds départementaux. L'implication des départements est a priori la plus repérable et la plus évidente puisque c’est celle que la législation

I29. $\mathrm{AN}, \mathrm{F}^{17} / 2468$, Seine.

I30. RD CG Nord, décennies 1850 à 1880 . 
met en avant. Néanmoins, les formes variées d'organisation des cours correspondent à des combinaisons aussi variées de formes de financement.

Les écoles strictement départementales, installées dans des bâtiments spécifiques, sont intégralement subventionnées par les conseils généraux, qui déboursent alors des sommes importantes au regard de leurs ressources. L'Ain vote ainsi 6 ooo francs en I848, 6300 en 1854 et 7050 en I856, qui se ventilent de la manière suivante : traitements, nourriture et entretien des résidents dans l'école (élèves, religieuses, enseignantes, femmes enceintes) et « dépenses diverses ${ }^{131} »$. La Charente-Inférieure fait de même en allouant en moyenne 5000 francs pour son école d'accouchement dans les années I840-I850, avant de doubler cette somme dans les années $1860-1870^{132}$. Le détail du budget accordé à l'école d'accouchement fait apparaître des postes similaires à ceux de Bourg-en-Bresse mais précise ce que le préfet de l'Ain désignait sous la formule « dépenses diverses ». Entre donc dans cette catégorie tout ce qui constitue le budget spécial de l'établissement : l'achat de livres pour les études des élèves, pour les remises de prix et pour la bibliothèque, de pièces anatomiques, d'instruments et l'entretien des instruments mais aussi les frais d'imprimés et de bureau ainsi que l'entretien du mobilier et des ustensiles de ménage. Le total en est variable selon les années de 194 à 566 francs dans les années 1850. S'ajoute enfin un poste essentiel en fonction de la période de l'année à laquelle se déroule le cours : le chauffage et l'éclairage.

L'ensemble de ces dépenses pèse sur le budget du département (environ $4 \%$ des recettes de la $2^{\mathrm{e}}$ section du budget de l'Ain en 1848 ). Le choix d'y pourvoir complètement s'inscrit toutefois dans une revendication particulière du rôle de cet échelon territorial dans la formation des sages-femmes. Le département peut dès lors pleinement s'approprier les succès de l'école d'accouchement. Le choix de la subvention intégrale concerne fréquemment des départements sans pôle urbain important et sans tradition hospitalière prestigieuse. Leurs conseillers généraux voient dans l'institution de formation obstétricale une forme de compensation à une certaine marginalité économique et sociale, tout comme ils ont logiquement conscience d'être la seule institution susceptible de porter matériellement ce type de projet.

À l'inverse, l'inscription de l'instruction à destination des sages-femmes dans un cadre urbain très structuré, tendant à polariser fortement l'espace départemental, limite l'implication financière du conseil général. Là où les commissions administratives des hospices s'appuient sur des patrimoines

I3I. RD CG Ain, I848.

132. AD Charente-Maritime, I N. 
considérables et sur une solide histoire de leurs établissements, le département peut se contenter de remplir ses seules obligations légales (voire ne pas les remplir !), en laissant à la charge de l'institution d'accueil des cours d'accouchement les frais de fonctionnement. Toulouse, Marseille, Lille ou Lyon comptent ainsi des hospices nombreux et pourvus d'abondantes ressources comme l'hospice Saint-Jacques et l'hospice de la Grave à Toulouse, ou l'hospice de la Charité de Lyon : leur administration forme quasiment un État dans l'État à l'intérieur des instances municipales ${ }^{133}$. La conséquence immédiate de ce poids particulier de la commission des hospices est la modicité de la contribution départementale. Dans le Rhône, en Haute-Garonne ou dans les Bouches-du-Rhône, le conseil général restreint au vote de quelques bourses en faveur des élèves sages-femmes sa participation au fonctionnement de l'école d'accouchement, soit quelques centaines ou à peine plus d'un millier de francs.

Le contraste avec les allocations de plusieurs milliers de francs qu'on rencontre dans certains départements est particulièrement accusé. Plutôt généreux dans les années 1830 , le conseil général des Bouches-du-Rhône réduit en I843 sa subvention aux boursières de l'école de Marseille de moitié, passant de 3000 à I 500 francs. En I848, la somme est tombée à 900 francs, équivalant à deux bourses entières dans l'établissement. Il faut attendre I873 pour qu'à la suite d'une demande de revalorisation du prix de la pension par la commission des hospices, le conseil général augmente l'allocation de 300 francs, passant de 900 à I 200 francs ${ }^{134}$. Pire encore, dans la Haute-Garonne, aucune bourse n'est votée pour une élève du cours toulousain avant $1858^{135}$. Le chiffre de l'allocation se monte finalement à I 600 francs annuels, ce qui ne constitue pas un effort démesuré de la part du département et le place à la même date et pour la même dépense derrière ses voisins du Gers (2 000 francs), du Tarn (I 800 francs), et des Hautes-Pyrénées (I 800 francs). Ces écarts de générosité soulignent a contrario la richesse de la région de Toulouse par rapport aux départements alentour. Si le conseil général limite à quatre bourses son encouragement à l'encadrement obstétrical de son territoire, c'est que les aspirantes capables de payer leur scolarité sont en règle générale suffisamment nombreuses pour faire tourner l'école d'une part et pourvoir les communes en accoucheuses compétentes d'autre part.

133. Monroziès M., Au service des femmes : les services de gynécologie et d'obstétrique de l'Hôpital de la Grave à Toulouse : 250 ans d'histoire, 1729-1979, Toulouse, Privat, 1980 ; Faure O., Genèse de l'hôpital..., op. cit.

134. RD CG Bouches-du-Rhône, I843, I848 et I873.

135. AD Haute-Garonne, i $\mathrm{N} 83^{*}$. 
Les choix financiers des départements présentent des nuances. Pour les saisir dans une approche plus générale, je présenterai leur distribution en ayant recours à deux coupes chronologiques au cours du siècle. Le récapitulatif ministériel de 1809 fournit une première coupe, à une date précoce où l'enseignement local n'a pas encore atteint son plein développement ${ }^{136}$. Cette source intègre toutefois un nombre non négligeable de sommes votées mais jamais dépensées, faute d'autorisation d'ouverture d'un cours, ce qui constitue un biais susceptible d'accroître artificiellement la place des cours locaux. Cette coupe du début du siècle est complétée du montant des allocations votées par les conseils généraux pour le même objet en I860. Les résultats tirés de cette comparaison correspondent donc à une base géographique identique, les données concernant les départements du Grand Empire pour 1809 ayant été écartées des calculs :

\begin{tabular}{|l|c|c|}
\hline Départements & $1809^{137}$ & I860 \\
\hline Non renseignés & 20 & $9^{138}$ \\
\hline Aucun vote de crédit & 0 & 10 \\
\hline Bourses d'élèves envoyées hors du département & 42 & 29 \\
\hline Cours local & 18 & $4 \mathrm{I}$ \\
\hline Envoi de boursières et cours local & 8 & 0 \\
\hline Total & 88 & 89 \\
\hline
\end{tabular}

Tableau 1. Politiques de financement de la formation des sages-femmes en France, 1809 et 1860.

Le tableau récapitulatif des financements en 1809 et I860 pose une difficulté qui tient à la présence de départements pour lesquels on ne dispose d'aucune information. Si dans le cas de l'année I860, la part des «non renseignés » s'élève à Io \% de l'effectif total des départements, en I809, l'absence de renseignements concerne 20 départements sur 88 . Le récapitulatif ministériel omet tout

136. $\mathrm{AN}, \mathrm{F}^{17} / 2468$, Seine.

137. Le total des départements en I809 est de 88 car la Savoie ne correspond alors qu'à un seul département (Mont-Blanc). En I860, elle est divisée en Savoie et Haute-Savoie.

138. Ces neuf non renseignés ne sont en fait que huit puisque parmi eux est compté pour plus de commodité le département de la Seine qui est géré directement par l'État. 
bonnement de les mentionner, or, l'ampleur des lacunes rend peu probable un oubli des services ministériels. Ces absences d'informations peuvent en revanche refléter la négligence des administrations départementales qui n'ont pas fourni en temps voulu les éléments nécessaires ou une absence de délibération du conseil général sur cet objet. Les données de l'année I860 sont d'une nature différente puisqu'il s'agit de données reconstituées où les départements « non renseignés » signalent en fait des manques dans la documentation de base. Il est toutefois possible d'associer ces départements à un profil particulier de politique de formation : cours locaux pour la Seine bien sûr mais aussi la Meurthe, la Somme et la Meuse ; envois à l'extérieur pour les Ardennes, le Cher, la Drôme, l'Oise et la Seine-et-Oise. La modification du paysage de l'enseignement obstétrical apparaît clairement entre les deux dates. La pratique de la double politique d'envois extérieurs et de cours locaux disparaît et les cours départementaux sont désormais largement majoritaires. Intéressons-nous aux sommes votées par les départements à ces deux dates :

\begin{tabular}{|l|c|c|c|c|}
\hline \multirow{2}{*}{} & \multicolumn{2}{|c|}{ I809 } & \multicolumn{2}{c|}{ I860 } \\
\cline { 2 - 5 } & $\begin{array}{c}\text { Somme } \\
\text { moyenne }\end{array}$ & $\begin{array}{c}\text { Somme } \\
\text { médiane }\end{array}$ & $\begin{array}{c}\text { Somme } \\
\text { moyenne }\end{array}$ & $\begin{array}{c}\text { Somme } \\
\text { médiane }\end{array}$ \\
\hline $\begin{array}{l}\text { Bourses d'élèves } \\
\text { envoyées hors du } \\
\text { département }\end{array}$ & I 945,60 & I 575 & I 398,90 & I 300 \\
\hline Cours locaux & 2 oII,I0 & I 900 & 3780,30 & 2975 \\
\hline $\begin{array}{l}\text { Envoi de boursières } \\
\text { et cours local }\end{array}$ & I 955,75 & 2025 & & Néant \\
\hline Total & I 964,10 & I 800 & 2793,75 & I 800 \\
\hline
\end{tabular}

Tableau 2. Allocations (en francs) votées par les conseils généraux en 1809 et $1860^{139}$.

Dans un siècle où la valeur du franc germinal n'évolue quasiment pas, la comparaison des sommes votées souligne d'une part la permanence de l'importance accordée à la formation des sages-femmes et la progression globale des montants consacrés à cet objet. Les allocations pour l'envoi d'élèves sagesfemmes dans une école extérieure ou pour les cours d'accouchement locaux

139. Les départements «non renseignés » sont exclus des calculs présentés dans ce tableau. 
représentent souvent le poste le plus important du chapitre « Encouragements et secours », dans la deuxième section des dépenses variables du budget départemental où elles sont associées à d'autres dépenses de même type (bourses d'élèves à l'école des arts et métiers d'Aix ou d'Angers; d'élèves vétérinaires à Alfort, Lyon ou Loudun, etc.). Cette partie du budget départemental est financée par les centimes additionnels aux contributions directes votés par les conseils généraux pour leurs dépenses facultatives. Indispensables dès le début du siècle au bon fonctionnement de l'administration centrale, des départements et des communes, ces impositions complémentaires connaissent une diversification et une augmentation constantes pour subvenir aux besoins croissants des administrations ${ }^{140}$. La courbe des dépenses pour la formation des sages-femmes suit donc une courbe générale d'accroissement des dépenses facultatives dans les départements et d'accroissement de la pression fiscale ${ }^{141}$.

Une première constante se dégage cependant : les sommes destinées à l'envoi extérieur de boursières sont en moyenne plus basses que celles votées pour l'entretien de cours départementaux. La différence entre les deux types de moyenne est relativement faible en I809, la différence entre les médianes correspondantes atteint plus de 300 francs. Elle est encore plus significative en 1860 puisqu'elle se monte à près de 2400 francs dans le premier cas et I 675 francs dans l'autre. Ces chiffres donnent au premier abord raison à l'argumentaire ministériel, développé dès les lendemains de l'an XI sur l'économie évidente qu'il y a à faire instruire les sages-femmes dans un établissement extradépartemental. Les fonds consacrés par les départements à l'entretien de leurs cours sur place sont en effet largement supérieurs à ceux votés pour un envoi extérieur. La ligne de défense précoce des préfets vient toutefois nuancer cette constatation, dans la mesure où le nombre d'accoucheuses formées par l'une ou l'autre de ces politiques est radicalement différent, régulier mais faible pour les boursières extérieures, beaucoup plus important dans le cadre des cours locaux. Le calcul de la dépense par élève vient alors à la rescousse du choix de l'instruction sur place : la bourse toulousaine coûte 400 francs tandis que celle de l'Hospice de la Maternité de Paris en coûte 750 dans les années I860.

Seconde constante : le chiffre médian des sommes votées par les différents départements. Indépendamment de la politique suivie entre le début et la seconde moitié du siècle, celui-ci s'établit à I 800 francs. Cette régularité de la médiane éclaire a contrario l'explosion d'un petit nombre de budgets dont les

140. Vignes É., Traité élémentaire des impôts en France, Paris, P. Dupont, 1868, p. 48-50.

I4I. Barge-Meschenmoser É., L'administration préfectorale en Corrèze (1800-1848): limites et effets de la centralisation, Limoges, PULIM, 2000, p. 365-372. 
hauts niveaux expliquent l'augmentation de la moyenne des allocations pour les cours départementaux en 1860. Dans les années i860, aucun département ne dépense ainsi plus de 3600 francs pour envoyer ses futures sages-femmes se former dans une école voisine, le plus généreux étant la Moselle dont la politique d'envois spécialisés en fonction de la langue augmente le nombre de boursières. Au contraire, 16 départements sur les $4 \mathrm{I}$ à entretenir une formation locale dépensent plus de 3850 francs pour cet objet. Parmi les plus généreux, qui dépassent les 6000 francs d'allocation annuelle, on rencontre les collectivités suivantes : Aveyron, Côte-d'Or, Corrèze, Vienne, Haute-Marne, Isère, Saône-et-Loire, Ain, Haut-Rhin, Puy-de-Dôme et Charente-Inférieure. En I809, aucune subvention n'atteint un tel niveau et les plus prodigues sont ceux qui votent de 3000 à 5000 francs par an, soit le Cher, la Côte-d'Or, l'Isère, la Saône-et-Loire et la Gironde. Il n'est pas impossible que les possibilités financières des départements se soient ressenties de la guerre contre la cinquième coalition qui prend fin après la bataille de Wagram en juillet de cette année-là.

La liste des départements qui votent les plus grosses sommes correspond logiquement à celle des départements qui s'impliquent le plus dans le fonctionnement et la gestion de leur école d'accouchement. Leur profil est partiellement redondant : départements ruraux et parfois enclavés (Massif central et ses abords), départements pauvres aussi, dans l'ombre de grandes villes voisines (Bordeaux, Lyon). L'accumulation des notations confirme donc l'idée d'un attachement spécifique des petits départements (Ain, Corrèze, CharenteInférieure) à leur institution de formation obstétricale, établissement d'enseignement médical dont la réussite fait la gloire d'espaces oubliés de la carte des écoles de médecine. Les sommes dépensées pour la pérennité de ces cours départementaux d'accouchement révèlent ainsi une volonté affirmée de hisser l'instruction délivrée dans ce cadre à la hauteur, voire au-dessus de celle dispensée dans les grandes villes auprès des grands hospices.

La formation des sages-femmes apparaît donc nettement dans toute une série de départements comme un enjeu de poids. L'importance des subventions, leur durée et leur régulière augmentation sont autant de signes d'une appropriation très forte des cours par leur environnement institutionnel et géographique. Le sort de ces petites écoles, qui s'organisent et se maintiennent malgré la pression parisienne, gouvernementale et scientifique, malgré aussi la multiplication d'établissements fortement liés au réseau de l'enseignement médical et à la frange supérieure du réseau hospitalier, apporte une preuve supplémentaire de la spécificité de l'échelle départementale au XIX ${ }^{e}$ siècle. Dans l'histoire complexe et foisonnante de la fondation des cours d'accouchement 
pendant cette période, la transversalité des événements politiques nationaux compte sans doute moins que la trajectoire individuelle des départements. Certes, en I8I5, parfois 1830 et souvent I870, les conseils généraux ne siègent pas, ou extraordinairement, peu soucieux alors de l'instruction des accoucheuses. Seule la Révolution de 1848 ne fait pas de «trou » dans la chronologie des sessions. Ces interruptions dans le cours des histoires départementales ne sont pourtant que temporaires. L'intérêt renaît, les votes reprennent dès que la structure porteuse retrouve son rythme ordinaire. Sécuriser la naissance est un choix partagé, de régime en régime. La forme donnée à l'instruction des auxiliaires de la naissance, de la centralisation exclusive à la dispersion locale, des bienfaits modestes d'un savoir seulement théorique à l'indispensable clinique, éveille bien sûr des débats. Passées les années I8Io toutefois, la question perd son caractère national pour se discuter au cas par cas, entre les murs des assemblées départementales. L'attention se concentre alors, au-delà des questions de fonds, sur le personnel que forment ces politiques d'instruction des sages-femmes. 
Chapitre 5

\section{L'élève sage-femme : un portrait social}

Advenir sage-femme, devenir sage-femme, être sage-femme : trois modes d'incarnation d'une fonction qui devient profession. La matrone advient au hasard d'un premier accouchement de voisinage, l'élève devient par la fréquentation du cours et le contrôle de son savoir, mais des deux, seule la seconde peut, à partir de I803, être sage-femme aux yeux de la loi. Le tournant des XVIII ${ }^{\mathrm{e}}$ et XIX ${ }^{\mathrm{e}}$ siècles est temps d'institution de la sage-femme, au double sens du terme : enseignement de l'élève et installation sociale, publique de la sage-femme. Ce processus scientifique et législatif crée un modèle. Mais cette production réglementaire n'est pas d'un seul tenant ; c'est l'alliage composite de l'héritage du XVIII ${ }^{\mathrm{e}}$ siècle, des prescriptions du XIX ${ }^{e}$ siècle et de l'aspiration de plusieurs milieux sociaux à faire entrer leurs filles dans le giron d'un corps médical redéfini. L'étude de l'origine des élèves accoucheuses présente la réponse de la population française aux sollicitations d'une politique sanitaire, car le substrat à partir duquel les sagesfemmes sont façonnées n'est pas inerte. Homogénéité sociale ? Homogénéité culturelle ? Dynamiques familiales à l'œuvre? Autant de facteurs sur lesquels la volonté gouvernementale n'a guère de prise mais dont l'observation confirme l'adoption générale d'une profession désormais reconnue comme telle.

\section{«Cet état si méprisable »(Pierre Eyméoud, 179I) ${ }^{1}$}

Dans l'entrelacement des motifs qui fondent la nécessité urgente de semer le territoire français d'écoles pour les sages-femmes, deux éléments principaux émergent : la dénonciation de la matrone et la mauvaise réputation de l'état

I. AD Hautes-Alpes, L Io62. 
d'accoucheuse. La première reste l'argument maître, au point de se perpétuer bien au-delà de la création des structures de formation ${ }^{2}$. D'un point de vue lexical, la loi a fixé les usages respectifs des termes matrone et sage-femme, mais n'a pas complètement libéré cette dernière du poids de la réprobation qui semble s'attacher à sa fonction.

En I79I le démonstrateur gapençais Pierre Eyméoud confie aux administrateurs du département des Hautes-Alpes que le fait d'être sage-femme est en soi un obstacle au recrutement des élèves. Il emploie alors très justement le mot « état ». La mauvaise réputation de l'accoucheuse serait donc inhérente au rôle qu' elle occupe auprès de la femme en travail. Plus qu'une profession dont on peut se défaire en cessant de la pratiquer, accepter de «lever » des enfants marque celle qui accompagne l'entrée dans la vie.

En 1786, le chirurgien Joseph Desfarges de Meymac écrit que « l'accouchement est l'opération la plus dégoûtante de la chirurgie ${ }^{3}$ ». À la même période, un de ses collègues limougeauds déclare pareillement qu'il s'agit de la «partie la plus basse et sale de la chirurgie ${ }^{4} »$. Faible attirance pour la répétition routinière d'un phénomène physiologique ? Ennui face au peu d'intérêt d'un accouchement qui, lorsqu'il se déroule naturellement, ne permet de faire montre d'aucun talent particulier ? Cela ne suffit pas à expliquer la répugnance - « dégoûtant », "sale »- que fait naître la parturition chez des hommes pourtant accoutumés à la vue du sang et des humeurs corporelles. Ce discours de rejet, produit par les praticiens, se double d'un discours de constat du rejet, propre aux figures d'autorité spirituelle et séculière. Tout en la déplorant pour ses conséquences démographiques, prêtres et officiers se posent en témoins d'une prévention populaire vis-à-vis de celle qui assiste la femme en couches ${ }^{5}$. Passée la Révolution, les nouveaux administrateurs ne disent pas autre chose :

(Aveyron, an Ix) Un préjugé funeste avait jusqu'à présent inspiré de la répugnance à remplir une fonction aussi utile $[\ldots]^{6}$. (Aude, an XIII) $[\ldots]$ on attache à la profession de sage-femme une espèce de honte ou de pudeur qui la fait regarder comme une des fonctions basses de la société ${ }^{7}$. (Gironde, I806) [...] qu'un préjugé aussi condamnable par la Religion que par l'humanité, écarte les

2. Au milieu du siècle encore, certains conseils généraux (Ain, Nièvre) continuent de dénoncer les méfaits des matrones.

3. Bib. Acad. de Méd., SRM, cart. 85.

4. Gélis J., L'Arbre et le fruit. La naissance dans l'Occident moderne (XVI ${ }^{e}$-XIX ${ }^{e}$ siècles), Paris, Fayard, 1984, p. 183 .

5. Ibid.

6. AD Aveyron, 3 X 45 .

7. AD Aude, 5 MD 16. 
personnes du sexe en ce pays de prendre l'utile et honorable profession de sagesfemmes ; $2^{\circ}$ qu'il est de toute nécessité de tâcher de vaincre ce préjugé $[\ldots]^{8}$.

«Répugnance », « honte », et « pudeur » répondent ainsi à « l'opprobre » et "l'aversion » des décennies précédentes. Les termes sont forts ; ils déplacent l'analyse du côté des sensibilités, de leur historicité ou de leur permanence. Le jugement de ces administrateurs éclaire maladroitement une dimension anthropologique des comportements qu'ils peinent à expliquer et d'où découle sans doute le caractère laconique et sentencieux de leurs formulations.

Prosaïquement marqué par l'écoulement du liquide amniotique et du sang, vécu concrètement et symboliquement comme un passage pour la mère et l'enfant, l'accouchement vu par les administrateurs justifie sans doute de recourir à la notion de tabou, si informulée qu'elle soit dans l'esprit des rédacteurs en question ${ }^{9}$. Le contact avec la femme en couches place l'accoucheuse sur le double seuil de l'impureté et du sacré. Par le toucher du corps en travail, de l'enfant naissant, elle participe de cette association, mais s'en extrait du même mouvement puisque son second rôle, aussi essentiel que le premier, est de laver l'enfant, de donner les soins nécessaires à l'accouchée, et donc de réduire cet espace du tabou ${ }^{10}$. À ce titre, l'auxiliaire de l'accouchement se trouve placée à la fois en marge et au centre de la communauté, et cette position ambiguë est interprétée comme celle d'une réprouvée par ceux qui écrivent à son sujet ${ }^{11}$.

Cependant la réprobation qui frappe l'accoucheuse ne se situe pas tant du côté des patientes et de leurs familles que, du point de vue individuel, lorsque se pose la question d'embrasser cette activité. Or c'est peut-être dans ce choix de la profession que réside la réponse à l'incompréhension des administrateurs devant les refus. Pour choisir d'exercer un métier, il faut le percevoir comme tel, et il est probable qu'il n'en aille pas ainsi dans de larges couches de la population rurale. L'espace urbain et le monde rural ne sont, sur le plan de l'encadrement des couches, pas égaux. Le premier a vu éclore au début du XviII ${ }^{\mathrm{e}}$ siècle

\footnotetext{
8. AD Gironde, $5 \mathrm{M} 550$.

9. L'usage de la notion de tabou comme instrument méthodologique doit beaucoup aux recherches de C. McClive sur la portée des interdits religieux sur les relations sexuelles pendant les menstruations, voir «Engendrer pendant les menstrues : devoir conjugal et interdit sexuel à l'époque moderne », dans Redon O., Teisseyre-Sallmann L., Steinberg S. (dir.), Le Désir et le goût : une autre bistoire (XIII ${ }^{e}$-XVIII $I^{e}$ siècles), Vincennes, Presses universitaires de Vincennes, 2005, p. 245-263.

Io. Gélis J., L'Arbre et le fruit..., op. cit., p. 178, 248-250, 254-256. Pour le lien entre la fonction d'accoucheuse et celle de laveuse, voir Verdier Y., Façons de faire..., op. cit., p. 83-I56. AD CharenteMaritime, $3 \mathrm{X}_{30 \mathrm{I}}$.

II. La place de la sage-femme dans la société danoise est interprétée d'une manière équivalente, voir Løkke A., « The Antiseptic Transformation of Danish Midwives », dans Marland H., Rafferty A.-M., Midwives, Society and Childbirth..., op. cit., p. Io9.
} 
la sage-femme rémunérée, par les particuliers d'une part, mais avant tout par les autorités municipales. La sage-femme y exerce une profession, contrôlée par des règlements, des instances juridiques; elle se rattache à la corporation des chirurgiens, préfigurant son intégration dans le personnel médical avec la loi de $1803^{12}$. Les campagnes, au contraire, sont terre de flou règlementaire et d'absence de contrôle, terre d'accoucheuses choisies par le hasard et confirmées par la répétition d'une aide dont la rémunération ne se calcule pas sur une grille d'honoraires, comme le décrit le sous-préfet de Langres en I8I7 :

Il faut donc qu'il y ait beaucoup de femmes qui se livrent à la pratique [des accouchements] sans autre vocation qu'une dextérité naturelle; sans autre mission que la nécessité; sans autre instruction que quelques observations plus ou moins grossières, recueillies au hazard et que l'expérience éclaire peu à peu. ${ }^{13}$

La postérité les retient comme matrones, mais aussi may-dou-sou ou mayresajo c'est-à-dire la mère de soi ou la mère sage ${ }^{14}$, pendants occitans de la « bonne mère » évoquée dans les régions francophones. Ces femmes qui reçoivent l'enfant et délivrent la mère sont dans une relation de proximité quasi-affective avec la parturiente et sa famille. Cette relation naît en général de la vicinité ou de la parenté, dans l'esprit de ce que l'administration américaine définit un siècle plus tard comme les «neighbor women midwives ${ }^{15}$ ». La pratique de l'accouchement est donc épisodique, limitée par l'aire restreinte d'exercice de cette voisine-accoucheuse qui ne sort qu'exceptionnellement de son village. Elle réclame de la disponibilité pendant le temps de l'enfantement mais n'est au fond qu'une systématisation de la présence habituelle des femmes du voisinage ou de la famille pendant une naissance ${ }^{16}$. L'exemple nord-américain, si postérieur qu'il soit, éclaire la fréquence de cette « activité ». Parmi les neighbor women midwives recensées à la fin du $\mathrm{XIX}^{\mathrm{e}}$ siècle, la plupart font moins d'une dizaine d'accouchements par an, et beaucoup en ont fait moins dans toute leur existence ${ }^{17}$. C'est donc une fonction qu'elles revendiquent en se déclarant sages-femmes mais, en aucun cas, une profession.

12. Gélis J., La Sage-femme ou le médecin..., op. cit., p. 40-45.

13. AD Haute-Marne, II7 T I.

14. Sage Pranchère N., « Grossesse, naissance et obstétrique, quelle place dans la langue occitane ? », dans Lemaître J.-L., Vielliard F. (éd.), L'occitan, une langue du travail et de la vie quotidienne $d u X I I^{e}$ au XXI siècles, Ussel, Musée du Pays d'Ussel/Centre Trobar, Paris, Diffusion De Boccard, 2009, p. 185-189.

15. Borst C. G., Catching Babies..., op. cit., p. 14-15.

I6. Gélis J., L'arbre et le fruit..., op. cit., p. 172-175.

17. Borst C. G., Catching Babies.., op. cit., p. 54-67. 
La nuance n'est cependant pas perçue par le personnel médical de la seconde moitié du XVIII ${ }^{e}$ siècle, et c'est paradoxalement ce qui permet aujourd'hui de la faire ressortir. Médecins et chirurgiens, et à leur suite les administrateurs royaux, raisonnent en professionnels du soin, dont la subsistance repose sur la rémunération de chacun des gestes curateurs. L'entrée de l'accouchement dans le champ de leurs compétences, qu'il s'agisse d'accouchements laborieux mais plus encore d'accouchements naturels, a modifié leur perception de cet événement physiologique ${ }^{18}$. À l'objet ponctuel d'une aide désintéressée car susceptible de s'insérer dans un tissu plus large d'échanges de services, les hommes de l'art substituent une opération médicale, dont le nouveau statut entraîne la codification (scientifique et pratique) et la tarification. De là l'incompréhension devant le peu d'enthousiasme à profiter des enseignements créés pour former les sages-femmes, de là surtout la cristallisation de la matrone/sage-femme en figure issue de la classe sociale la plus basse. Ce qui n'est, à la fin du XVIII ${ }^{\mathrm{e}}$ siècle, que constatation d'une homogénéité d'appartenance sociale entre les femmes des communautés villageoises et celles qui les accouchent, se mue en élaboration d'un profil désormais quasiment nécessaire : " (Aveyron, an XII) Les femmes qui se livrent à cet état sont généralement peu fortunées ${ }^{19}[\ldots]$ ». L'accoucheuse est donc une femme « dans le besoin », et cette observation de départ a des répercussions immédiates et constantes, pendant la majeure partie du $\mathrm{XIX}^{\mathrm{e}}$ siècle, sur la délimitation de l'origine sociale des élèves sages-femmes :

(Gers, I848) [...] cette profession n'est embrassée que par des filles appartenant à des parents très peu fortunés et incapables, par conséquent, de subvenir aux frais de leur instruction spéciale. ${ }^{20}$

(Calvados, I863) [...] les élèves sages-femmes du département qui appartiennent, en général, à des familles dénuées de ressources $[\ldots]^{21}$

La modestie de fortune des accoucheuses, d'abord associée à un état social, devient une caractéristique du recrutement. En liant intimement pauvreté et exercice de l'art des accouchements, par l'anticipation de la faiblesse des revenus, le discours administratif finit par faire de l'indigence le vivier essentiel des

I8. Gélis J., La Sage-femme ou le médecin..., op. cit., p. 305-327; id., Accoucheur de campagne sous le Roi-Soleil : le traité d'accouchement de G. Mauquest de la Motte, Toulouse, Privat, 1979, p. 28-30.

19. $\mathrm{AD}$ Aveyron, $\mathrm{I} \mathrm{N}_{7}^{*}$.

20. $\mathrm{AD}$ Gers, $\mathrm{I} \mathrm{CG}_{32} / 4$.

21. RD CG Calvados, I863. 
futures sages-femmes. La conviction est si profonde qu'en 1822, le préfet des Pyrénées Orientales annonce fièrement au ministre de l'Intérieur la nomination de sa première élève à l'Hospice de la Maternité de Paris par ces mots :

Il n'avait pas été possible jusqu'ici de trouver, soit parmi les filles élevées dans l'hospice de Perpignan, soit parmi celles qui appartiennent à la classe indigente des sujets capables de profiter de l'instruction qui se donne à l'école de la maternité. ${ }^{22}$

Être née de parents « peu fortunés » prédispose donc à cette profession. La pauvreté familiale impose d'une part aux jeunes femmes de subvenir rapidement et honorablement à leur propre subsistance. D'autre part, le mode de choix et d'entretien des élèves privilégie progressivement le profil de la boursière, communale ou départementale. Cette évolution résulte du constat de l'incapacité des parents à verser leur dû. Ainsi, dans l'Aube en I849 : "Contrairement à ce qui a eu lieu pendant plusieurs années, les familles ne concourent plus à l'entretien des élèves, et le département pourvoit seul à l'intégralité des dépenses ${ }^{23}$. » L'élargissement continu de l'attribution de bourses d'études finit par réduire l'accès à cette profession aux seules filles de la classe défavorisée, au point de refuser dans certains départements l'admission d'élèves payantes. La liberté financière des élèves payantes paraît ainsi incompatible avec l'obéissance et le respect exigés vis-à-vis du règlement et de la maîtresse sage-femme. En Corrèze, la commission de surveillance de l'école refuse d'ailleurs à deux reprises, en 1863 et 1874 , des candidatures de jeunes filles prêtes à suivre la scolarité à leurs frais ${ }^{24}$.

\section{"Tirer les élèves de la classe des pauvres ${ }^{25}$ »}

Préciser l'origine sociale des sages-femmes en France au cours du XIx ${ }^{\mathrm{e}}$ siècle ne peut passer que par l'étude de quelques corpus départementaux (Corrèze, Côtes-du-Nord, Haute-Marne, Maine-et-Loire) ou régionaux (ressort de l'hospice de la Charité de Lyon, ressort de l'école de médecine de Bordeaux) car aucune source ne permet une approche séculaire et nationale de la population concernée. Les approches envisagées sont complémentaires, qu'il s'agisse

\footnotetext{
22. $\mathrm{AN}, \mathrm{F}^{17} / 2466$, Pyrénées Orientales.

23. AD Aube, i N rog.

24. Sage Pranchère N., Mettre au monde..., op. cit., p. 388.

25. Bib. Acad. de Méd., SRM, cart. 85.
} 
de l'origine géographique de l'élève (commune rurale ou urbaine), de son statut au sein du cours (élève gratuite, boursière complète ou partielle, payante), et du milieu socio-professionnel dans lequel elle a grandi.

\section{D'où viennent les sages-femmes?}

L'envoi à Paris

La localisation du cours influe sur l'origine des candidates à la formation obstétricale. L'envoi d'élèves sages-femmes à Paris est encadré par les circulaires ministérielles des 9 thermidor an $\mathrm{x}$ et 30 fructidor an $\mathrm{XI}$ et par les prescriptions des règlements successifs de la Maternité sur l'âge et les capacités de lecture et d'écriture des élèves sages-femmes. Les vœux des candidates potentielles y perdent donc en portée face à ceux des autorités. Néanmoins, dans une situation de pénurie nationale de bonnes volontés, les souhaits préfectoraux doivent composer avec la réalité culturelle et l'intensité des vocations de leurs administrées. L'origine géographique reflète cette rencontre d'intérêts, illustrée par l'exemple des Côtes-du-Nord (I807-I840) et de la Corrèze (I803-I830).

Après un bref épisode d'enseignement local pendant la Révolution, les Côtes-du-Nord adoptent, à partir de 1807 et jusqu'à la fin du siècle, une politique d'envoi annuel d'élèves sages-femmes à l'Hospice de la Maternité de Paris. En I840, une liste récapitule les 94 élèves admises dans la capitale. La Corrèze, pour sa part, adopte précocement une politique similaire en faisant admettre des élèves à Paris dès l'an xi et de manière quasi-exclusive jusqu'en I830 (34 envois), date à laquelle des cours d'accouchement locaux renaissent dans les trois arrondissements.

On observe une prééminence nette des élèves sages-femmes originaires de communes assumant une fonction administrative. Dans les Côtes-du-Nord, les chefs-lieux de canton forment, indépendamment de la préfecture ou des sous-préfectures, presque $50 \%$ des élèves envoyées. En Corrèze, ils forment $45 \%$ des mentions, à égalité avec les sous-préfectures, Brive et Ussel. Au total, $61,5 \%$ des boursières des Côtes-du-Nord et $90 \%$ des boursières corréziennes sont nées ou résident dans un chef-lieu de circonscription administrative (canton ou arrondissement), communes qui concentrent abondance de population et structures d'instruction primaire féminine et font à ce titre l'objet d'une veille plus attentive des pouvoirs publics. Leur surreprésentation en Corrèze s'explique par l'urgence à pourvoir les principaux centres de population en accoucheuses dès lors qu'aucun enseignement obstétrical pérenne n'a été délivré dans le département depuis janvier 1789 . 
Les Côtes-du-Nord sont dans une position différente. La tradition des cours d'accouchement, solidement ancrée dans cette région, a perduré jusqu'en l'an v. Les sages-femmes instruites avant ou pendant la Révolution sont, pour nombre d'entre elles, encore en exercice lors du passage au nouveau régime médical ${ }^{26}$. Ce vivier originel d'accoucheuses dans le département justifie sans doute que les chefs-lieux administratifs ne concentrent pas, à eux seuls, le recrutement des élèves sages-femmes. Dans un espace où les principales communes sont déjà pourvues, de plus petites communes se font progressivement une place ${ }^{27}$. De surcroit, dans cette zone majoritairement francophone, l'obstacle linguistique est moins important et le niveau d'alphabétisation un peu supérieur à celui de la Corrèze ${ }^{28}$. Pensée comme un système pyramidal, la dispersion d'élèves sages-femmes de l'Hospice de la Maternité de Paris dans un département réserve en priorité ces praticiennes aux centres importants de population, d'où leur savoir est censé rayonner alentour. L'élargissement du bassin de recrutement et d'installation aux simples communes est le signe d'un assouplissement des nécessités et de l'intérêt croissant pour cette profession, y compris dans des zones de moindre circulation et de moindre ouverture économique et culturelle.

L'envoi à Paris, perçu comme l'accès à une école d'élite, ne fonctionne cependant pas à l'instar du recrutement des écoles départementales. Les boursières sont peu nombreuses et choisies avec soin. La future élève née dans un chef-lieu de canton, et plus encore celle qui a grandi dans une sous-préfecture ou une préfecture, ont un rapport plus immédiat aux réalités urbaines, et sont donc moins rétives au « voyage de Paris».

\section{Les cours départementaux}

L'origine géographique des élèves de cours départementaux ne reflète a priori pas les mêmes attentes. Pour l'illustrer, reprenons le corpus corrézien, divisé en deux périodes (1827-I833, cours d'arrondissement de Tulle, Meymac et Brive ; I834-I890, école départementale d'accouchement de Tulle), et comparé aux corpus des écoles de Chaumont (I834-I845), d'Angers (I839-I848) et des élèves du Rhône admises à l'hospice de la Charité de Lyon (I860-I90I).

\footnotetext{
26. AD Côtes-d'Armor, $5 \mathrm{M} 2$.

27. Sur les I9 sages-femmes enregistrées entre I803 et I8II, 4 résident à Saint-Brieuc et 8 dans des communes devenues chefs-lieux de canton, soit I2 sur 19.

28. Furet F., Ozouf J., Lire et écrire..., op. cit., p. 6I-62.
} 
Malgré les dissemblances chronologiques des corpus, des pistes d'interprétation émergent, liées aux terreaux locaux de la formation obstétricale et au profil démographique des départements. Avec la fondation de cours d'accouchement dans les trois arrondissements corréziens (1827), le taux d'élèves sages-femmes originaires d'une commune chef-lieu (canton, arrondissement, département) passe de $90 \%$ à 6r \%. Le but de ces cours (rapprocher l'enseignement des élèves) est donc en partie atteint puisque le bassin de recrutement intègre désormais un nombre croissant de "simples » communes. Le recentrage de l'enseignement sur la préfecture en 1834 n'interrompt donc pas le mouvement initié et l'étude poursuivie jusqu'en 1890 montre l'accentuation du phénomène amorcé depuis 1827. Les simples communes envoient désormais la moitié des aspirantes sages-femmes à Tulle. Le rééquilibrage se fait en fonction d'une baisse non négligeable du poids des chefs-lieux de cantons (de 48 à $35 \%$ ) et d'une infime augmentation du poids des chefs-lieux d'arrondissement, la préfecture se taillant désormais la part du lion. La Corrèze connaît donc une ruralisation progressive du recrutement des sages-femmes, sans doute corrélée à une amélioration des moyens de circulation (réseau routier secondaire) qui comprime les distances et à une diffusion croissante, à partir des années I850, de l'instruction primaire.

Qu'en est-il pour le Maine-et-Loire et la Haute-Marne ? Ces deux cours s'inscrivent dans une tradition ancienne d'enseignement de l'art des accouchements. Le corpus saisit donc dans les deux cas une situation construite par plus de soixante ans d'instruction locale des accoucheuses. Que les élèves viennent, pour 75 à $90 \%$ d'entre elles, de simples communes rurales témoigne ainsi de la réussite de la politique départementale. Néanmoins, la continuité de l'enseignement obstétrical ne suffit pas à expliquer le décalage entre ces deux départements et la Corrèze. Il faut sans doute y ajouter la vitesse de diffusion de l'alphabétisation féminine, beaucoup plus lente dans ce dernier département ( $30 \%$ en I866), que dans le Maine-et-Loire ( 50 à $60 \%$ à la même date) et en Haute-Marne (90 à Ioo \%). C'est la combinaison de la tradition pédagogique et de l'instruction qui fait des campagnes un vivier de recrutement des accoucheuses.

Dernier exemple : celui des élèves sages-femmes nées dans le Rhône, et admises entre I860 et I90I à l'hospice de la Charité de Lyon. Les chiffres que fournit le registre des entrées affirment le poids écrasant de la métropole lyonnaise où naissent $38,8 \%$ des élèves sages-femmes (97 sur 250). À l'opposé, 46,5\% des admises rhodaniennes ont vu le jour dans de simples communes (II6 sur 250), dont un cinquième seulement dépasse les 2500 habitants. La spécificité 
rhodanienne s'exprime dans une structure bipolaire de concentration de population où les niveaux intermédiaires sont attirés dans l'orbite lyonnaise et quasiment absorbés au fil du siècle.

L'étude de l'origine géographique des élèves sages-femmes confirme donc un succès, celui d'avoir porté au cœur des campagnes françaises l'accès à un savoir particulier et à une profession dont l'attrait social croît au cours du siècle ${ }^{29}$. Le premier élément du profil que l'on peut établir est donc ce lent mouvement d'une future accoucheuse plutôt urbaine à une vraie rurale désormais alphabétisée et que la perspective du dépaysement effraie moins. Dans un contexte de second $\mathrm{XIX}^{\mathrm{e}}$ siècle marqué par les débuts de l'exode rural, le recrutement des cours d'accouchement suit un chemin inverse, irriguant désormais en profondeur bourgs campagnards et petites communes.

\section{Boursière ou "à ses frais "? Pouvoir payer son instruction}

La capacité matérielle des futures sages-femmes à financer leur formation constitue un trait supplémentaire de leur portrait social. La décision départementale ou communale d'accorder un subside aux élèves sages-femmes prend la suite des secours aux élèves de l'Ancien Régime ${ }^{30}$. La répartition entre élèves subventionnées et payantes éclaire les milieux sociaux d'origine de ces femmes. L'homogénéité du terreau de recrutement peut toutefois être artificiellement accentuée lorsque les autorités de tutelle des établissements font le choix de limiter leur recrutement aux élèves subventionnées, comme c'est le cas de la Corrèze $^{31}$. Mais la dévolution systématique d'une bourse n'est pas générale et dans d'autres départements, l'étude de la diversité des origines passe bien par celle des différents statuts d'élèves. Deux ensembles de données illustrent cette recherche : le registre des élèves de l'école départementale d'accouchement de la Haute-Marne (I834-I845) et celui des élèves de l'Hospice de la Charité de Lyon (I860-I90I).

Les élèves sages-femmes de Chaumont peuvent être boursières (de la commune ou du département), payantes, et semi-payantes. Cette dernière catégorie repose sur l'obtention d'une demi-bourse des collectivités déjà citées. À l'hospice de la Charité de Lyon, trois statuts cohabitent : payante et boursière,

29. Beauvalet-Boutouyrie S., Naître à l'hôpital..., op. cit., p. I4I.

30. Gélis J., La Sage-femme ou le médecin..., op. cit., p. I45-I5I ; Sage Pranchère N., Mettre au monde..., op. cit., p. I20-I22.

3I. Ibid., p. 386-390 ; 395-396. 
mais aussi élève gratuite, statut spécifiquement lyonnais ${ }^{32}$, seules les premières acquittant les 500 francs annuels de la pension.

À l'école départementale d'accouchement de la Haute-Marne et à l'hospice de la Charité de Lyon, les jeunes femmes dont la scolarité est intégralement prise en charge sont très largement majoritaires $(84,3 \%$ pour la Haute-Marne et $8 \mathrm{I} \%$ pour Lyon). Le statut de demi-boursière est plus rare et parmi les élèves lyonnaises, seules la Haute-Loire (3 élèves) et la Drôme ( 9 élèves) y recourent. Mais la différence entre boursière entière et demi-boursière repose plus sur les capacités institutionnelles de financement que sur l'écart de fortune entre les postulantes. Marie Viardat, élève admise à Chaumont en I84I avec une demi-bourse départementale, se révèle incapable de payer la moitié des frais restés à sa charge ; elle demande et obtient alors du département une remise des sommes dues ${ }^{33}$.

En théorie, l'attribution des bourses ne repose pas uniquement sur la situation de fortune familiale, et le mérite personnel peut y prendre une part comme le montre l'exemple bordelais où pendant le dernier quart du XIx ${ }^{e}$ siècle, la commission départementale combine pour le recrutement concours d'entrée et dossier, associant niveau d'instruction et niveau de ressources pour juger de l'allocation d'une bourse :

(I880) $\mathrm{I}^{\circ}$ Laffiteau, 55 points ${ }^{34}$, dix-huit ans ; son père, préposé des douanes, a de faibles appointements, et subvient aux besoins de deux enfants dont l'un en bas âge ;

$2^{\circ}$ Dupuy, 54 points, vingt et un ans ; son père vieux, presque aveugle, a pour toutes ressources une pension de retraite de 600 francs ;

$3^{\circ}$ Moutinard, 52 points, a eu des points supplémentaires en géographie et en histoire. Petite fille d'une sage-femme ; fille d'une sage-femme exerçant sa profession avec un désintéressement et un dévouement constatés par un certificat du médecin des enfants assistés à La Tresne ;

$4^{\circ}$ Mano, 47 points ; son père, pauvre résinier, joint à sa demande sa feuille d'impôts qui est de 12 francs ;

32. «Les élèves gratuites doivent être nées dans le département du Rhône, ou y être domiciliées depuis deux ans au moins. Elles peuvent être inscrites dès l'âge de seize ans révolus, mais leur admission ne peut être prononcée quà l'âge de dix-huit révolus, à tour de rôle et suivant les besoins du service ».

33. AD Haute-Marne, II7 T I.

34. Les huit notes additionnées portent sur l'orthographe, l'écriture, le calcul, le style, la lecture, la grammaire, la géographie et l'histoire, les deux dernières matières étant subsidiaires. AD Gironde, 5 M 560 . 
$5^{\circ}$ Bernard, 4I points, née à Agen mais habitant Bordeaux depuis vingt ans ; dès l'âge le plus tendre, elle a perdu son père ; sa mère, remariée, a plusieurs enfants du second lit ;

$6^{\circ}$ Cazeneuve, femme Lescouzières, vingt-neuf ans, 4I points, séparée de corps et de biens d'avec son mari ; elle vit à Bazas avec des parents peu aisés. Sa demande est appuyée par M. le Sous-Préfet et M. le Maire de Bazas [... . ${ }^{35}$

Le vote de la commission confirme le classement du rapporteur qui suit l'ordre des résultats au concours d'entrée, toutes les postulantes obtenant une bourse. La composition de ces dossiers n'a rien d'original : certificats d'autorités locales (maire et plus rarement sous-préfet) pour témoigner de la respectabilité des postulantes et attester «leur défaut absolu de moyens ${ }^{36}$ »; données de l'administration fiscale. Les arguments les plus forts sont puisés dans la situation sociale et professionnelle des familles : métiers aux revenus trop modestes, chômage, maladie, infirmité, vieillesse, mais aussi abondance d'enfants, ou veuvage. La formation obstétricale devient alors l'échappatoire rêvée, le moyen pour les familles de "donner une profession », c'est-à-dire tout à la fois un savoir, une nourriture et un état. Ces candidatures reflètent une volonté de s'extraire durablement de l'indigence. S'il y a espoir d'ascension sociale, il reste modéré. La bourse devient alors le moyen de cette minime élévation sociale autant que la récompense d'une misère « décente » et honorable. Filles de pauvres, les sages-femmes sont avant tout, dans le choix qu'en font les administrations, des filles de «bons » pauvres.

\section{De la terre à la boutique}

L'exemple bordelais dessine l'arrière-plan familial et social des futures accoucheuses. Dignes veuves vivant d'une " petite industrie », pères petits fonctionnaires, ou petits artisans, telles seraient les familles des sages-femmes ${ }^{37}$. Pour la fin du XviII siècle, les recherches de Jacques Gélis soulignent une amorce d'évolution du milieu d'origine des accoucheuses, désignant l'agriculture comme berceau privilégié des matrones, tandis que l'artisanat fournit plutôt les sages-femmes formées. Un autre trait émerge à la même période : l'association de la sage-femme aux chirurgiens, fille ou épouse ${ }^{38}$. Le corpus des

\footnotetext{
35. AD Gironde, I N 81*.

36. AD Gironde, $5 \mathrm{M} 550$.

37. Faure $\mathrm{O}$, « Les sages-femmes en France au XIX ${ }^{e}$ siècle : médiatrices de la nouveauté », dans Bourdelais P., Faure O., Les Nouvelles Pratiques de santé..., op. cit., p. I6I.

38. Gélis J., La Sage-femme ou le médecin..., op. cit., p. 200-202.
} 
sages-femmes corréziennes et celui des élèves de l'hospice de la Charité de Lyon ont permis de prolonger ces pistes pour le $\mathrm{XIX}^{\mathrm{e}}$ siècle.

\section{De la Corrèze...}

De l'an x à 1894 , le nombre de sages-femmes formées dans le département de la Corrèze (ou à ses frais) se monte à 370, nées entre 1745 et 1872. Les données collectées sur l'origine sociale portent sur la profession des parents et sur celle de l'époux. L'extension chronologique offre ainsi le portrait séculaire d'une politique départementale de formation des accoucheuses.

Les professions des pères sont relativement bien renseignées $(267$ mentions soit $68, \mathrm{I} \%$ du total) et offrent un éventail assez large (69 professions ou « états » différents $\left.{ }^{39}\right)$. Le premier trait marquant à l'échelle quasi-séculaire est la présence relativement faible des cultivateurs, entendus au sens large (propriétaire cultivateur, fermier, journalier) : 22,4 \% du total des métiers paternels connus, soit un pourcentage deux à trois fois inférieur au poids de ce groupe parmi les actifs français à la même période ( $65 \%$ en I 85 I puis $44 \%$ en I89I $\left.{ }^{40}\right)$. La Corrèze des sages-femmes, département pourtant majoritairement agricole, présente donc au miroir de la stratification socio-professionnelle une image déformée. Ce chiffre global confirme donc l'impression acquise aux exemples bordelais d'une certaine distance entre le monde paysan et celui des sages-femmes.

Cette impression générale doit être nuancée puisqu'on observe un accroissement quasi constant de la place des filles de cultivateurs parmi les élèves. Les résultats de la période 1870-I890 (professions exercées dans les années 1850I870), sont inférieurs à la moyenne nationale mais signalent une évolution remarquable. Vers I880, plus d'une sage-femme sur trois sort d'une famille d'agriculteurs $(38,9 \%)$, ce qui était le cas de moins d'une sur vingt $(4,3 \%)$, cinquante ans plus tôt. À cela plusieurs raisons : le passage de l'école nationale (I803-I826) aux cours d'arrondissement (I827-1833) multiplie par quatre la place des filles de cultivateurs. Dans cette constatation se noue le lien entre origine géographique et origine sociale. L'élargissement du recrutement aux «simples » communes, vu plus haut, se double d'une ouverture à une catégorie professionnelle mise à l'écart du vivier parisien. Autre raison qui conforte la première : les relatifs progrès de l'alphabétisation du département à partir des années I840. Lecture et écriture font très lentement leur entrée dans le monde

39. Les 69 mentions rassemblent les différentes professions mais aussi les niveaux d'exercice de la profession (maitre, ouvrier) ou les professions doubles (cultivateur menuisier ; maçon marchand, etc.). 40. Marchand O., Thélot C., Deux siècles de travail en France, Paris, Études INSEE, I99I, p. I82. 
rural, touchant progressivement au cœur agricole de ces espaces ${ }^{41}$. Des pères qui savent désormais lire sont autant de possibles promoteurs de l'accès de leur fille à une certaine instruction. La part des cultivateurs parmi les pères d'élèves admises entre 1870 et 1890 se hausse à près de $40 \%$, signe d'une évolution culturelle majeure de ce groupe.

Mais qu'en est-il plus largement des professions paternelles des élèves envoyées à Paris (1803-1826) ? 23 mentions recouvrent en fait I7 états distincts. Le nombre très restreint d'occurrences incite à la prudence. Ressortent pourtant la place des artisans ${ }^{42}$ et des marchands (I2 sur 23 ) ; la présence du corps médical (4 occurrences de chirurgiens et/ou d'accoucheurs) et celle de petits fonctionnaires ou petits lettrés (huissier, géographe, instituteur). Le milieu qui se dessine est celui d'hommes plutôt instruits, résidant par l'exercice de leur métier dans des zones de concentration de population, et pour certains, assez proches des lieux d'exercice des pouvoirs locaux. L'instruction des pères explique ici en partie l'intérêt pris à l'instruction des filles, surtout quand la seule dot envisageable réside dans la transmission d'une éducation soignée et la capacité à procurer une profession. Cette pratique observée aux siècles précédents en régime de succession inégalitaire prend ici son sens dans l'absence même de profession à léguer ${ }^{43}$. Avançons dans le temps (I827-1890).

Le basculement géographique de 1827 se lit dans le tassement du niveau social des professions paternelles. Le corps médical disparaît, à l'exception d'un pharmacien. La rupture avec la complémentarité professionnelle esquissée entre chirurgien et sage-femme dans les décennies précédentes est consommée puisque les nouveaux officiers de santé perdent leur compétence obstétricale. La bourgeoisie de talent et le fonctionnariat perdent en importance relative, même si leur profil se diversifie : notaire, facteur, gendarme, garde-champêtre apparaissent aux côtés des huissiers et des instituteurs ${ }^{44}$. Les artisans et les commerçants accroissent leur place et, parmi eux, cinq métiers forment à eux

4I. Corbin A., Archaïsme et modernité en Limousin au XIX siècle (1845-1880), [1975], Limoges, PULIM, I999, p. 332-335.

42. Entre autres : faiseur de chaises (3), maçon (I), maître chapelier (I), sellier (I), serrurier (I), tailleur (2).

43. Voir Burgière A. (et al.), dir., Histoire de la famille, 3. Le choc des modernités, Paris, Armand Colin, 1986, p. 87.

44. Mis en place sous la monarchie de Juillet, le premier réseau des bureaux de poste est relayé dans les communes non pourvues par des piétons ou facteurs ruraux. Les premiers exemples de pères d'élèves sages-femmes exerçant ce métier sont strictement contemporains de cette institution, puisqu'ils apparaissent après I834, voir Duby G., Wallon A. (dir.), Histoire de la France rurale, 3. A pogée et crise de la civilisation paysanne, de 1789 à 1914, Paris, Seuil, 1976, p. 289. 
seuls un quart des mentions de professions : maréchal-ferrant (8), menuisier (I4), aubergiste (I3) cordonnier (8), tailleur (7). Si l'on y ajoute l'ensemble des autres professions artisanales et de boutique, la part des pères appartenant à ce milieu se monte à 53,I \%. Les futures sages-femmes grandissent donc dans un milieu où les savoirs primaires sont mieux partagés qu'ailleurs et où le temps d'apprendre leur est plus volontiers accordé. Bien sûr, ces échoppes ne sont souvent pas si éloignées des exploitations agricoles, et l'activité même de ces artisans dépend pour la plus grande part des cultivateurs, mais là où la fille de paysan va garder les vaches, la fille d'aubergiste fréquente les bancs d'une petite école ${ }^{45}$. Dans cette région où la proto-industrialisation textile n'a guère de prise et où les salariés de l'industrie sont en général alphabétisés ${ }^{46}$, les filles d'ouvriers se retrouvent parfois à suivre la même voie que les filles d'artisans et de boutiquiers. Distinguer artisanat et industrie dans ces cas est quasiment impossible, à cette caractéristique près que les ouvriers n'ont, encore plus souvent que les artisans, ni terre ni commerce à léguer.

Les professions des époux d'accoucheuses corréziennes confirment en partie cette appartenance sociale et sa perpétuation par le mariage. Durant toute la période (fin XVIII ${ }^{\mathrm{e}}$ siècle-I890), le taux de cultivateurs (I8,6 \%) reste en deçà des chiffres paternels, montrant une réticence des accoucheuses à épouser des agriculteurs, peut-être en raison du poids du travail paysan et tout autant du décalage culturel produit par le contenu et le temps de la scolarité. Les sagesfemmes ont été capables de rompre avec leur milieu familial pour suivre un enseignement exigeant, dans un contexte très éloigné de leur monde d'origine ; elles y ont sans doute forgé une indépendance qui justifie leur souhait de poursuivre l'exercice de la profession apprise, difficilement compatible avec l'obligation d'entretenir à plein temps une exploitation agricole.

Mais comme chez les pères et tout au long du siècle, la place prépondérante est occupée par les artisans et commerçants qui forment $50 \%$ des mentions. Les petits fonctionnaires, généralement agents des collectivités publiques (agent voyer, buraliste, employé de préfecture, facteur, huissier, piqueur des ponts et chaussées), sont présents (5,6\%). De nouveaux ensembles émergent à partir des années I860, avec une fortune spécifique : les militaires (gendarmes, soldats) ( $7,3 \%)$, les ouvriers spécialisés (manufacture d'armes et imprimerie) $(3,4 \%)$, ou encore les professions particulièrement qualifiées : instituteur, professeur et comptable ( $5 \%)$. Enfin, se rencontrent quelques cas plus originaux

45. Duby G., Wallon A. (dir.), Histoire de la France rurale..., op. cit., p. 316-3I7 ; Mayeur F., Histoire générale de l'enseignement et de l'éducation en France..., op. cit., p. 249 sq.

46. Corbin A., Archaïsme et modernité..., op. cit., p. 33I sq. 
liés au monde artistique (musicien) ou à l'essor des nouveaux moyens de transport (employé de chemin de fer). De tout cela il ressort que les sages-femmes épousent en général des hommes plus instruits (pour des raisons chronologiques d'accès à l'école) et un peu plus aisés que leurs propres pères, mais sans changer de milieu. Cette évolution peut tenir au choix de résidence de ces femmes après leur diplôme. En I880, 57,7 \% des sages-femmes corréziennes exercent dans un chef-lieu de canton ou d'arrondissement (plus de $70 \%$ dans l'arrondissement d'Ussel), c'est-à-dire dans un contexte plus urbanisé que celui dont elles viennent à la même époque ${ }^{47}$.

\section{... à Lyon}

Reste à savoir à présent si ces données peuvent être étendues à d'autres régions françaises. Le corpus de l'Hospice de la Charité de Lyon ne présente pas la même homogénéité que le corpus corrézien et ne le recoupe que pour la seconde moitié du siècle (I860-I90I). Parmi les départements fournisseurs d'élèves, ont donc été retenus l'Ain, l'Ardèche, l'Isère, la Loire, la Haute-Loire, le Puy-deDôme, le Rhône et la Saône-et-Loire.

Plus resserré chronologiquement, le corpus de la Charité apparaît aussi moins cohérent que celui d'une école strictement départementale, objet d'une politique spécifique. L'éventail des 132 professions ou états paternels qu'il propose est cependant riche d'enseignements.

Pour les départements (hors Lyon), la répartition des professions fait ressortir une ventilation des métiers paternels se rapprochant de celle observée en Corrèze. Les cultivateurs y forment presque un tiers du total (30,9\%), toutefois dépassés par le groupe des artisans qui atteint 38,5\%. Les conclusions précédemment esquissées semblent donc transposables à la région Rhône-Alpes élargie à une partie de l'Auvergne. Quelques particularités se font néanmoins jour : la présence des activités à caractère industriel, à mettre en relation avec l'activité minière et sidérurgique dans la Loire; la baisse marquée du nombre de mentions d'agriculteurs entre la période I860-1880 et I88I-I9OI (de 37 à $22 \%$ des effectifs départementaux). Ce dernier point constitue une divergence notable avec l'évolution constatée en Corrèze. Cette rupture s'explique peut-être par l'essor industriel de la région qui s'étend très largement au-delà de la ville de Lyon, modifiant en profondeur l'organisation socio-professionnelle de ces départements. Elle s'explique surtout

47. Sage Pranchère N., Mettre au monde..., op. cit., p. 489 sq. 
en entrant dans le détail départemental des admissions d'élèves. La HauteLoire compte, après le Rhône, parmi les plus gros pourvoyeurs de filles de cultivateurs, mais cesse quasiment d'en envoyer après 1884 . Les raisons du recul de la part des cultivateurs dans le milieu d'origine des élèves sagesfemmes sont peut-être à mettre en relation avec la baisse plus générale des effectifs d'élèves admises. Le monde agricole serait le premier touché lorsque le nombre d'élèves boursières se restreint.

Le corpus strictement lyonnais est caractérisé par la quasi absence du monde de l'agriculture : 2 journaliers sur les 3 mentions toutes antérieures à I88I, soit une réalité professionnelle des années I840-I860. La part des artisans, des marchands et de l'industrie atteint $7 \mathrm{I} \%$ des cas. Les ouvriers de la soie y tiennent le haut du pavé (I9 sur 80), reflet de la composition professionnelle de la ville, preuve aussi que les subventions accordées pour la scolarité à la Charité touchent leur cible. Les professions libérales n'occupent qu'une place résiduelle dans le corpus $(3 / 80)$ mais elles appartiennent au personnel médical (deux pharmaciens et un herboriste). Dernière remarque : les évolutions numériques des différents groupes ne découlent pas d'une évolution sociale mais bien de l'élargissement du recrutement local de l'école de la Charité, multiplié par deux pendant la période I88I-I9OI.

L'esquisse bordelaise était donc révélatrice d'un phénomène plus large. Malgré les profils régionaux qui peuvent mettre au premier plan certains métiers plus que d'autres (les marins en Charente-Maritime ou dans les Côtes-d'Armor), les résultats des différentes plongées dans les origines sociales des sages-femmes pointent tous dans la même direction. Le monde paysan, l'atelier et la boutique sont les lieux de recrutement privilégiés des futures accoucheuses. Sans être préférentiel chez les filles d'agriculteurs, ce choix professionnel se maintient au fil du siècle, preuve que le monde paysan ne boude pas la possibilité d'intégrer certaines de ses filles au corps médical. Dans les deux autres cas, la stratégie semble plus affirmée : la fragilité mistructurelle, mi-conjoncturelle de l'atelier et de la boutique paraît un encouragement supplémentaire à ouvrir aux filles les portes de l'instruction primaire et plus tard celles de l'école d'accouchement. Pour mesurer exactement quel élément emporte la décision de commencer cette formation, il faudrait pouvoir replacer les jeunes femmes devenues élèves dans leur cohorte d'âge et leur catégorie sociale. L'origine familiale, ici entendue sous l'angle paternel, complète les effets déjà observés de l'origine géographique. S'y mêlent d'autres critères : influences féminines cette fois (maternelle et sororale), et goûts personnels, par nature moins accessibles. 


\section{Filles et sœurs d'accoucheuses, sages-femmes « par famille»?}

\section{Des mères difficiles à atteindre}

En raison de la spécificité féminine du métier de sage-femme, l'étude de la possible influence des mères d'élèves sur le devenir professionnel de leur fille est indispensable. Face à un métier bien identifié, cité en premier parmi les corps et communautés spécifiquement féminines dans l'article "Femme » de l'Encyclopédie ${ }^{48}$, forte est la tentation d'appliquer aux accoucheuses les modèles interprétatifs classiques de la transmission systématique du métier des parents aux enfants. L'Instruction à ma fille de Louise Bourgeois, sagefemme de Marie de Médicis, semble illustrer au début du XVII ${ }^{\mathrm{e}}$ siècle une telle tendance, parfait exemple d'une transmission professionnelle mère-fille éclairée et concrétisée par l'écriture ${ }^{49}$. Mais la généralisation de ce cas se heurte toutefois à plusieurs obstacles.

Premier obstacle : les schémas de la reproduction socio-professionnelle, élaborés pour rendre compte de la relation père-fils et des modalités de réception et de perpétuation d'un patrimoine familial entendu comme masculin et paternel${ }^{50}$, peinent à embrasser la spécificité d'un métier féminin. Second obstacle : le métier de sage-femme est « récent ». Les débuts de son contrôle par les autorités civiles et médicales remontent en Europe au XVI ${ }^{\mathrm{e}}$ siècle, et à l'échelle de la France, sa codification par le pouvoir royal n'intervient pour la première fois qu'en 1692 avant d'être reprise et confirmée en $1730^{51}$. À ce titre, il n'a pas ni l'ancienneté suffisante pour avoir développé des mécanismes de transmission intergénérationnelle des maîtrises, ni l'autonomie nécessaire en raison de sa dépendance visà-vis de la communauté des chirurgiens. Dernier obstacle : les exigences concernant l'âge (avancé) et le statut matrimonial (mariée ou veuve) des accoucheuses pèsent sur l'accès à la profession et limitent la transmission mère-fille ${ }^{52}$.

\footnotetext{
48. «Il y a certains commerces et métiers affectés aux femmes et filles, lesquelles forment entre elles des corps et communautés qui leur sont propres, comme les Matrones ou Sages-femmes [...] », Diderot D., Alembert J. Le Rond (d'), Encyclopédie..., op. cit., article « Femme ».

49. Bourgeois L., Récit véritable de la naissance de Messeigneurs et Dames les enfans de France ; Fidelle relation de l'accouchement, maladie et ouverture du corps de feu Madame; Instruction à ma fille, suivie du Rapport de l'ouverture du corps de feu Madame. Remontrance à Madame Bourcier, touchant son apologie, textes établis et annotés par F. Rouget et C. H. Winn, Genève, Droz, 2000.

50. Voir Delumeau J., Roche D. (dir.), Histoire des pères et de la paternité, Paris, Larousse, 1990, p. 266-269.

5I. Gélis J., La Sage-femme ou le médecin..., op. cit., p. 40-45.

52. Ibid., p. 63.
} 
Malgré tout cela, qu'en est-il d'une éventuelle reproduction professionnelle chez les sages-femmes de la fin de l'époque moderne ? L'ouverture du « recrutement » intervient au cours de la deuxième moitié du XVIII ${ }^{\mathrm{e}}$ siècle et dessine un nouveau profil de sage-femme, délivrée de l'obligation matrimoniale et dont la jeunesse est désormais une qualité éminente. Cette ouverture prend racine dans la pratique urbaine croissante des mises en apprentissage de jeunes femmes auprès de maîtresses sages-femmes ${ }^{53}$. Fondée sur une transmission interpersonnelle, elle trouve son corollaire familial chez les filles de sages-femmes qui se forment auprès de leurs mères. À l'image de ce qu'on peut observer chez d'autres maîtres artisans, la logique à l'œuvre n'est pas celle de l'héritage mais admet un temps de concomitance puisque ces femmes commencent à exercer leur profession du vivant de leur mère, même si elles le font généralement après leur mariage $e^{54}$.

La reproduction professionnelle existe donc, mais ne dépasse pas le cadre spécifique des villes à communautés de métiers. Dans les campagnes, la matrone tient sa confiance de sa disponibilité et de son expérience, autant de critères qui échappent à tout processus d'acquisition progressive d'un savoir dans le cadre familial. Passées les années 1750, le choix des élèves pour les cours de démonstration répond à deux objectifs urgents (recycler les matrones, former de jeunes sages-femmes) qui n'accordent pas de place à la légitimité d'une succession mère-fille. La scolarisation continue de l'accès au savoir obstétrical, amorcée avec Angélique du Coudray et sanctionnée par l'application de la loi du I9 ventôse an XI, brise le début du mouvement d'apprentissage intra-familial signalé plus haut. Là où un fils de cordonnier peut encore apprendre la cordonnerie auprès de son père en I830, l'équivalent est devenu impossible pour une sagefemme depuis un bon demi-siècle. Cette dissociation des lieux de la formation et de l'exercice du métier est profonde. L'élève sage-femme n'accède pas à l'art des accouchements par le biais d'une naturalisation in situ. Le seul apprentissage qui lui soit légalement reconnu est celui qu' elle reçoit loin du cadre familial et/ou professionnel, dans le contexte particulier des maternités-écoles. Dans ces conditions, la reproduction professionnelle, perdant l'un de ses principaux vecteurs, repose sur des bases plus ténues : celles de la vocation transmise et de la perspective de reprendre une clientèle, perspective de plus en plus lointaine à mesure que l'âge de l'instruction s'abaisse et que l'espérance de vie augmente. Les corpus corrézien et lyonnais illustrent cette évolution.

53. Voir les statuts de I730, Gélis J., La Sage-femme ou le médecin..., op. cit., p. 45.

54. Gélis J., «Sages-femmes et accoucheurs : l'obstétrique populaire aux XVII ${ }^{e}$ et XVIII ${ }^{e}$ siècles », Annales. Histoire, Sciences Sociales, 1997, 32-5, p. 933. 
La sous-représentation du travail féminin dans les actes d'état civil est très forte au $\mathrm{XIX}^{\mathrm{e}}$ siècle. L'enregistrement s'améliore toutefois légèrement avec le temps et les mères des élèves corréziennes admises entre I870 et I890 sont dans l'ensemble mieux connues. Dans le cas des admises à l'hospice de la Charité de Lyon, les actes de naissance permettent de renseigner $44 \%$ des professions ou états des mères, soit deux fois plus qu'en Corrèze. Les résultats ne permettent donc que des interprétations partielles (à l'exception des mères lyonnaises).

Le tableau ci-dessous rassemble à titre indicatif les groupes professionnels représentés parmi les mères des élèves sages-femmes corréziennes et de la Charité (mis à part les « sans profession » et les ménagères).

\begin{tabular}{|l|c|c|c|}
\hline Groupes professionnels & $\begin{array}{c}\text { Corrèze } \\
\text { (Fin XVIII }{ }^{\mathrm{e}} \text {-1890) }\end{array}$ & $\begin{array}{c}\text { Départements } \\
\text { (1860-190I) }\end{array}$ & $\begin{array}{c}\text { Lyon } \\
\text { (1860-190I) }\end{array}$ \\
\hline Cultivatrice & $\mathrm{I} 9$ & 24 & $\mathrm{I}$ \\
\hline Couturière & 4 & 23 & 53 \\
\hline Domestique & 0 & $\mathrm{I}$ & 3 \\
\hline Ouvrière & 0 & 2 & $\mathrm{I}$ \\
\hline Marchande & 7 & 7 & 6 \\
\hline Sage-femme & 32 & $\mathrm{I} 3$ & 67 \\
\hline Total & 62 & 70 & 4 \\
\hline
\end{tabular}

Tableau 3. Répartition des professions et états maternels par groupes professionnels, corpus Corrèze (fin xvIII siècle-1890) et Charité (1860-1901).

À l'instar des pères, le travail de la soie et l'industrie textile occupent une place essentielle dans l'activité de ces mères lyonnaises. Les futures sages-femmes nées à Lyon grandissent dans un contexte où leurs mères participent à l'entretien du ménage par une activité rémunératrice et revendiquée. L'accès des filles à une certaine instruction primaire puis à la formation obstétricale et l'intégration subséquente dans le personnel médical constituent la deuxième étape d'un parcours d'ascension professionnelle féminine qui s'étend sur plusieurs générations.

Dans les départements proches ou dans la plus lointaine Corrèze, les conclusions suscitées par les données recueillies pâtissent trop du sous-enregistrement pour apporter plus qu'une esquisse de l'éventail professionnel possible

55. Cette colonne correspond aux élèves de la Charité de Lyon ne venant pas de la ville de Lyon mais des départements alentour. 
pour une femme dans cette période. Les cultivatrices y sont logiquement plus présentes qu'à Lyon, représentant environ un tiers des mentions en Corrèze ou dans les départements du ressort de la Charité et répondant à la part des pères cultivateurs. La variété globale est faible : quasiment pas de domestiques, quelques «marchandes », un nombre conséquent de « couturières » dans le ressort de la Charité, mais moindre en Corrèze, où le textile n'est pas la plus fréquente des industries. Aucune profession ne dessine dans ces départements un profil aussi précis que le corpus lyonnais. Dans la capitale des Gaules, la sagefemme est fille d'artisan et d'ouvrière du textile; dans les régions limitrophes ou plus à l'ouest, la profession maternelle reste trop floue pour lui accorder une valeur déterminante et systématique, à l'exception d'une, celle de sage-femme.

\section{Mère-fille, tante-nièce, quelle transmission?}

Venons-en donc aux filles de sages-femmes : 32 sur 62 pour la Corrèze, soit 5I,6 \%, et I9 sur 137 , soit $13,9 \%$ pour le corpus Charité.

Première évidence : le pourcentage d'accoucheuses parmi les mères est très largement supérieur à la part qu'occupe ce métier parmi les professions féminines $\left(\mathrm{O}, \mathrm{I} \%\right.$ des professions d'épouses dans l'enquête $\left.\mathrm{TRA}^{56}\right)$. Deuxième évidence : par-delà la différence flagrante de pourcentage entre les deux corpus, l'exercice de la profession de sage-femme par les mères influence favorablement l'entrée des filles dans les écoles d'accouchement. Le corpus corrézien est marqué par une prédominance absolue des mentions de mères sages-femmes jusqu’à la fin des années I860, qui tient à la faible densité de population et au cadre départemental strict du recrutement. Le recul des années I870-I890 découle en partie de l'amélioration de l'état civil et d'une diversification de l'origine des élèves. Du côté de la Charité de Lyon, la largeur du ressort géographique réduit l'impact des stratégies familiales mais la part des mentions de mères sages-femmes reste stable pendant les quarante dernières années du siècle et se répartit de façon assez homogène entre départements.

Mieux que l'approche statistique, l'étude des lettres de candidature ou de recommandation illustre le rapport à la profession de sage-femme dans la succession familiale. À quelques cas rarissimes près de rejet d'une profession acceptée « avec répugnance et pour obéir à la volonté de ses parents ${ }^{57}$ », d'un bout à l'autre de la France et du siècle, c'est l'attirance pour la profession de

56. L'enquête TRA ou enquête dite des 3000 familles a permis un suivi longitudinal de toutes les familles françaises dont le patronyme commence par TRA au xIx ${ }^{e}$ siècle.

57. AD Corrèze, I X I69. 
sage-femme qui s'exprime, mêlant aux motifs généraux une dimension familiale très forte :

(Corrèze, I827) [... elle vous supplie de la faire nommer élève interne dans une maison d'accouchement ; afin de prendre les connaissances qui lui sont nécessaires pour se perfectionner dans un art que sa grand-mère et sa mère avaient exercé en rendant à l'humanité des services signalés [... ${ }^{58}$

(Charente-Inférieure, 1874) Fille et petite-fille de sage-femme, ma fille, Marie Boinot, âgée de vingt ans, veut avoir la même profession. ${ }^{59}$

La qualité maternelle dans l'exercice du métier est le principal « titre » mis en avant. Vocation forgée dans la proximité de l'activité maternelle, l'art des accouchements acquiert le statut de caractéristique familiale. Sa transmission relève alors de la nécessité, accrue à chaque génération. L'intégration rhétorique de cette profession au cursus familial est d'autant plus essentielle que sa pérennisation dépend d'un tiers, détenteur d'une autorité publique. Toutefois la vocation prend naissance dans un contexte d'imprégnation précoce mais limitée, qui ne prétend jamais se substituer à l'instruction officielle: " (Pyrénées Orientales, 1822) L'exposante n'est pas tout à fait étrangère à la carrière qu' elle se voue. Elle en a suivi la pratique dès l'enfance auprès de sa mère ${ }^{60}$, »

De leur côté, les autorités de tutelle des établissements d'enseignement obstétrical font de l'instruction « sous les yeux de la mère » une qualité subsidiaire justifiant l'admission d'une candidate. S'opère ainsi une réconciliation partielle des modalités classiques de transmission des compétences professionnelles dans un cadre familial et du système de formation scolaire né au XVIII ${ }^{e}$ siècle. Au-delà de l'obligation de scolarité, pleinement acceptée, le prolongement et la spécialisation de la scolarité deviennent un complément souhaitable voire nécessaire. La préférence accordée à une formation parisienne, après deux ans passés dans une école départementale, montre la hiérarchie établie entre les lieux d'apprentissage, de la maison maternelle à Paris, hiérarchie assimilée y compris par la clientèle, susceptible de vivre comme un recul le passage d'une mère, diplômée à Paris, à sa fille, diplômée à Tulle ${ }^{61}$.

Le patrimoine mouvant que constitue la clientèle des sages-femmes, c'est-àdire la confiance des femmes d'une commune ou d'un canton, est un puissant motif de reprise du métier maternel, autant qu'un aiguillon à transmettre sa

\footnotetext{
58. Ibid., I X 163.

59. AD Charente-Maritime, $3 X_{305}$.

60. AN, $\mathrm{F}^{17} / 2466$, Pyrénées-Orientales.

6I. AD Corrèze, I X I66.
} 
profession. Mère et fille sont intéressées à parts égales dans ce processus où la confiance acquise auprès des parturientes repose sur la capacité à préparer au mieux sa propre succession. La lignée de sages-femmes peut alors devenir, au fil des décennies, point de référence de familles entières, dans une logique d'incarnation successive, «à chaque fois ni tout à fait la même, ni tout à fait une autre », de cette fonction.

La Corrèze fournit, avec la descendance de l'accoucheuse Marguerite Poulot, une illustration exceptionnelle de ce phénomène. Formée à la fin du XVIII ${ }^{e}$ siècle, Marguerite Poulot obtient l'admission de ses trois filles, Claudine, Françoise et Marguerite, à l'Hospice de la Maternité de Paris. Les deux aînées y achèvent leurs études, la troisième est renvoyée pour maîtrise insuffisante de la lecture et de l'écriture. À la génération suivante, six des petites-filles, Marguerite, Françoise, Marie, Marguerite et Jeanne Queyriaux, et leur cousine Marguerite Saint-Germain, entrent en école d'accouchement et pour quatre d'entre elles exercent par la suite comme sages-femmes. L'arrière-petite-fille enfin, Marie Madesclaire, est admise à l'école de Tulle en I865.

Rare par l'ampleur et la durée du phénomène de reproduction professionnelle, l'exemple témoigne du fonctionnement matriarcal de cette famille, dont le patrimoine professionnel féminin constitue l'axe pérenne. Le hasard d'une descendance majoritairement féminine pour l'aïeule Marguerite Poulot (un fils) et sa fille ainée Claudine (deux fils) initie cette dynamique de transmission et place au cœur des préoccupations familiales une stratégie de reprise et de diversification des clientèles obstétricales. L'invalidité puis le décès précoce de Jean Queyriaux, époux de Claudine Martin, font de la profession de cette dernière le seul moyen de subsistance pour la veuve et les six enfants. Se dessinent alors des trajectoires complémentaires. Des deux filles de Marguerite Poulot, l'aînée reprend la clientèle maternelle, quand la seconde s'installe dans un autre canton. Des quatre filles de Claudine Martin, l'aînée, invalide très jeune, renonce à sa profession d'accoucheuse pour se faire institutrice, la deuxième s'installe dans une autre commune, la troisième change de département dans un mouvement migratoire auquel s'associe le second fils, la quatrième enfin succède à sa propre mère. L'intégrité du patrimoine est préservée par la dispersion géographique d'une partie des filles.

Dans d'autres circonstances, la transmission peut se faire par l'alliance. Jeanne Queyriaux, née vers 1745 , exerce à Ussel pendant le dernier quart du $\mathrm{XVIII}^{\mathrm{e}}$ siècle. Son fils illégitime, François, épouse à la fin des années 1790 une enfant trouvée de l'hospice d'Ussel, Marianne. Cette dernière commence alors son apprentissage auprès de sa belle-mère avant de suivre le cours d'accouchement organisé à Tulle en l'an $\mathrm{x}$. Une sage-femme sans fille se «fabrique » une 
héritière dans la personne d'une fille sans mère. Ce phénomène d'agrégation se retrouve ailleurs. Dans l'Aube, au milieu des années i820, le préfet reçoit d'un fabricant de bas résidant à Troyes la demande suivante d'admission à l'Hospice de la Maternité de Paris :

Disant Monsieur le Préfet que depuis près d'un siècle l'état de sage-femme s'est transmis dans sa famille entre ses plus proches parentes, que sa grandmaman décédé il y a environ dix ans, l'a exercé pendant au moins soixante ans à Bar-sur-Seine, que deux de ses tantes l'exercent également depuis trente ans, qu'une d'elle suit encore, et avec succès, cette profession à l'Andriville ; qu'enfin sa sœur a succédé à cet état à l'une de ces tantes décédé il y a six ans, à Bar-sur-Seine, qu'excité par cette sœur et par d'autres personnes infiniment recommandables, il désirerait que la nommée Magdelaine Mélique, son épouse, âgé de I9 ans, et sans état, apprit celui-ci, pour l'exercer dans cette ville ou dans le lieu qui lui sera désigné $[\ldots]^{62}$

La vocation de sage-femme s'acquiert donc par le sang et par le mariage. Dépossédées du droit de transmettre directement leur art, les accoucheuses réussissent néanmoins, pour une part d'entre elles, à asseoir la nécessité scolaire sur un acquis familial, qui est aussi moral et social. Dans ce processus, une bonne réputation, une longue durée de pratique sont sûrement des facteurs aussi importants que difficiles à saisir. Ils préparent la reprise filiale de cette fonctionprofession et facilitent l'enracinement au-delà de la première génération.

Moins fréquent que le lien mère-fille, le lien avunculaire s'inscrit dans une transmission diagonale qui met à l'honneur la symétrie de genre. La spécificité du lien tante-nièce a été étudiée pour le $\mathrm{XvIII}^{\mathrm{e}}$ siècle par Marion Trévisi qui a montré son importance en cas de défaillance de la parenté proche ${ }^{63}$. Au $\mathrm{XIX}^{\mathrm{e}}$ siècle, dans le cas des sages-femmes, il n'est qu'anecdotiquement documenté mais quelques exemples, comme celui du fabricant de bas troyen, sont pourtant révélateurs de la prise en main par la tante de la destinée professionnelle de sa nièce lorsqu'elle n'a pas d'héritière. Proportionnellement plus fréquente chez les oncles et neveux, l'institution d'une succession professionnelle pour combler une carence filiale fonctionne sur le même modèle dès lors que le métier de sagefemme est réglementé et dans la mesure où il le reste grâce à la loi de ventôse.

L'affection et l'admiration d'une nièce pour sa tante peuvent occuper une place très importante dans l'influence exercée par la seconde sur la première. Le 22 octobre 1873, Jeanne Decoux, après trois années à l'école d'accouchement

\footnotetext{
62. AD Aube, $5 \mathrm{M} 27$.

63. Trévisi M., « Les relations tantes, nièces dans les familles du nord de la France », ADH, 2006-2, p. 9-3I ; ead., Au cour de la parenté, oncles et tantes dans la France des Lumières, Paris, PUPS, 2008, p. 304-319.
} 
de Tulle, se fait recevoir sage-femme de deuxième classe à Bordeaux. Née à Masseret en 1852, sa mère est modiste, et son père arquebusier. Elle appartient donc au premier abord à la grande masse d'élèves sages-femmes dont la mère n'exerce pas cette profession. Un examen plus poussé révèle qu'elle est par son père la nièce de Jeanne Decoux, sage-femme diplômée à Tulle en I828, et par sa mère, celle de Nina Relier, diplômée en I836. La jeune femme recueille donc une double succession. Or, celle-ci fait le choix de se faire recevoir pour le département de la Gironde, preuve que le choix de poursuivre une vocation familiale ne s'ancre pas seulement dans l'espoir d'hériter d'une clientèle mais bien dans un attachement moral. Ce cas ouvre sur la plasticité des influences familiales féminines qui sont loin de se limiter à une dynamique verticale.

\section{Sororité professionnelle, une voie à part}

En I840, Jeanne Valéry est admise à l'école d'accouchement de Tulle. En i847, Jeanne Valéry entre à l'école d'accouchement de Tulle. En I850, Jeanne Valéry commence sa formation à l'école d'accouchement de Tulle. Dans les registres des naissances de la préfecture corrézienne des décennies suivantes, les noms de déclarantes se répètent, Jeanne-s Valéry-s, entrelacés aux noms d'épouses, seuls éléments distinctifs.

Cette sororie homonymique pose la question du retour adelphique dans le processus d'apprentissage obstétrical. Celui-ci peut certes s'interpréter comme un avatar de la transmission lignagère, en particulier lorsqu'il relève d'une stratégie maternelle, mais l'originalité de ces dispositifs de germanité professionnelle ne doit pas être sous-estimée ${ }^{64}$. Les récentes études sur les frères et sœurs ont rappelé le poids de ce lien à l'époque pré-industrielle, lorsque la faible espérance de vie promeut une relation caractérisée par sa contemporanéité ${ }^{65}$. Le $\mathrm{XIX}^{\mathrm{e}}$ siècle est une charnière en ce domaine, où l'orphelin est encore fréquent, confié à la sollicitude de l'aîné de ses frères ou sœurs.

Quel pourcentage de sœurs parmi les élèves sages-femmes admises aux écoles ? Le poids des élèves sœurs dans les établissements d'enseignement obstétrical est variable : plutôt faible du côté de la Charité de Lyon (45 sœurs, soit $8,5 \%$ des admises), il est plus significatif dans l'espace corrézien ( 55 sœurs, soit

64. Voir Sage Pranchère N., «Sages-femmes et sœurs en France au XIx ${ }^{e}$ siècle. La voie à part de la sororité professionnelle », dans Boudjaaba F., Dousset-Seiden C., Mouysset S. (dir.), Frères et sœurs du Moyen Âge à nos jours, Bern, Peter Lang, 2016, p. 403-423.

65. Lett D., Frères et sceurs, histoire d'un lien, Paris, Payot, 2009, p. IO-II. Voir aussi Oris M., Brunet G., Widmer É., Bideau A. (dir.), Les Fratries, une démographie sociale de la germanité, Francfort-sur-le-Main etc., Peter Lang, 2007. 
15,8 \% des admises). L'écart entre ces deux pourcentages s'explique par l'espace de recrutement des écoles. La répétition horizontale du métier gagne en fréquence chez les élèves originaires du département où est située l'école, c'est le cas en Corrèze, c'est aussi le cas dans le Rhône où le taux de sœurs s'élève à 13,I \%. La proximité de l'établissement d'enseignement à la commune de naissance est donc un facteur favorable à l'admission consécutive de deux ou trois élèves d'une même famille. À la proximité géographique s'ajoutent les caractéristiques de la politique d'envoi de boursières pratiquée par les départements alentour. Le nombre relativement restreint de bourses, la cherté de la scolarité justifient de ne pas concentrer les secours sur les mêmes têtes et d'éviter le financement de sorories. À l'inverse, dans un cadre strictement départemental comme la Corrèze, une politique de subventionnement systématique des élèves sages-femmes n'exclut pas d'admettre des sœurs, les autorités locales comptant sur la capacité de régulation géographique des familles pour ne pas surcharger une commune en praticiennes obstétricales.

La fréquence des cas de sorories tend toutefois à baisser au fil du siècle. À la Charité, il passe de Io \% pour les élèves nées avant I 860 à 7,I \% pour celles nées après. En Corrèze, il reste stable (une élève sur cinq) pour celles nées pendant la première moitié du siècle, avant d'être divisé par trois $(6,3 \%)$ dans les décennies suivantes, s'approchant alors du taux observé à la Charité de Lyon. L'influence familiale (maternelle ou sororale) s'estompe donc à mesure que le siècle avance jusqu'à ne constituer pour la transmission adelphique qu'un phénomène peu significatif.

Reste à comprendre ce qui pousse une femme à exercer le même métier qu'une de ses sœurs. Sur 24 cas de sorories professionnelles en Corrèze, il a été possible de reconstituer 17 fratries complètes, de la date de mariage des parents à la naissance du dernier enfant. Les futures sages-femmes naissent dans des familles plutôt nombreuses (6,9 enfants en moyenne, 7 en médiane) et surtout très majoritairement composées de filles ( 4,8 en moyenne, 5 en médiane). Le grand nombre de filles dont il faut assurer l'avenir impose aux parents de diversifier les moyens de procurer un état à leur progéniture. Dans un contexte de non-reconnaissance quasi systématique du travail féminin, la profession de sage-femme acquiert un statut propre par sa reconnaissance officielle de 1803 et son intégration au personnel médical. À ce titre, elle s'ajoute à la palette des métiers possibles et devient au XIX ${ }^{\mathrm{e}}$ siècle, avec le métier d'institutrice, une voie privilégiée offerte aux jeunes femmes sans fortune familiale mais issues d'un milieu relativement alphabétisé. Dans ces conditions, on peut considérer que les chances de voir une fille se tourner vers la formation obstétricale s'accroissent parallèlement au nombre de naissances féminines dans une famille. 
Cette progression n'est cependant pas un processus mécanique qui ferait choisir les futures accoucheuses parmi les dernières nées d'une fratrie. Le rang de naissance des sages-femmes au sein des 17 fratries reconstituées montre la prédominance des aînées (de famille - Io sur 17 - ou des filles - I3 sur 17). Le coût de la fratrie en termes de nourriture, de vêtements, d'éducation atteint en effet son plus haut niveau alors que l'aînée sort de l'adolescence. Son admission dans une école d'accouchement, à Paris ou Tulle, aux frais du département, soulage le budget familial d'une bouche adulte à nourrir. D'autre part, la coexistence de la fratrie complète rend plus immédiate la nécessité d'établir au mieux et au plus vite la première des filles, que son rang de naissance a souvent privilégiée pour l'acquisition d'une instruction primaire. À l'inverse, lorsqu'elle n'est pas l'aînée de sa fratrie, la future sage-femme occupe a priori un rang moins significatif. Parmi les exceptions, citons l'exemple de Marie Cécile et Marie Céleste Pomarel, avant-dernière et dernière filles de leur fratrie. Le choix obstétrical intervient tardivement pour ces jeunes femmes qui ont reçu comme tous leurs frères et sœurs une éducation soignée et il est présenté comme le remède à des revers de fortune familiaux. La profession de sage-femme est alors un maigre palliatif à la descension sociale pour deux jeunes femmes que leurs parents n'ont pas les moyens de doter.

L'exemple de Marie Cécile et Marie Céleste Pomarel présente une répétition professionnelle immédiatement consécutive, mais cette configuration n'est pourtant pas la plus fréquente (4 cas sur 17). Le calcul de l'écart d'âge entre les sœurs sages-femmes permet de préciser la nature des relations entre germaines qui choisissent d'apprendre le même métier. Pour le corpus corrézien, la moyenne est de 7,65 ans (médiane : 7,5 ans). Chez les sœurs du corpus Charité, la moyenne est proche $: 7,2$ ans, mais la médiane en revanche plonge à 5 ans. Ces chiffres dessinent deux situations distinctes. En Corrèze, les sagesfemmes se suivent dans une même famille à une longue période d'intervalle. Les aînées ont terminé leurs études lorsque leurs cadettes commencent la formation. Le rang de naissance des deuxièmes sages-femmes est dans la moitié des cas égal ou supérieur au cinquième enfant (c'est même la benjamine dans 8 familles sur 17). La relation adelphique fondamentale est donc celle de l'aînée à sa cadette, dans un rapport de modèle et d'imitation.

La décision d'entamer un cours d'accouchement relève en général pour l'aînée d'une volonté parentale. Mais dans le processus de choix, la seconde sagefemme d'une famille dépend plus sûrement de l'appartenance professionnelle de sa sœur aînée, passant d'une influence verticale à une influence horizontale. L'important écart d'âge qui caractérise les sorories corréziennes donne à la plus jeune un aperçu de la formation reçue par sa sœur et des premières années 
d'exercice. La transmission se fait au sein d'une même génération en bénéficiant de ce décalage. Elle peut même, en cas de décès maternel, donner lieu à une substitution symbolique par l'aînée qui se manifeste dans la répétition professionnelle. L'accès de certaines sages-femmes à des postes d'enseignement obstétrical renforce encore les effets de l'aînesse. En 1854, en Charente-Maritime, Amélie Bézille, maîtresse sage-femme de l'école rochelaise, demande au sous-préfet de Marennes une place gratuite au cours pour une de ses sœurs ${ }^{66}$.

Ces configurations de sœurs enseignantes prenant en charge la scolarité de leur cadette rejouent dans un cadre institutionnel et public les tentatives inabouties d'apprentissage interpersonnel et intrafamilial. Mais cette reprise sororale du rôle maternel n'est pas comparable à la transmission verticale. L'adoption d'un même métier est ici le résultat d'une démarche mimétique sans attente matérielle à l'égard de celle qui l'a inspirée. C'est la preuve indirecte de l'a priori positif qui marque la profession de sage-femme dans une famille sans tradition, puisque deux représentantes de la même génération peuvent décider de l'exercer concomitamment. L'entrée dans le personnel médical par ce biais, l'obtention d'un diplôme constituent à eux seuls de puissants motifs, marques d'une promotion sociale pour les milieux qui forment le vivier des élèves accoucheuses.

La différence dans l'écart d'âge médian entre Corrèze et région lyonnaise $(7,5$ ans contre 5$)$ invite à d'autres conclusions. Deux cas de sœurs nées à 25 et 27 ans d'intervalle allongent artificiellement la durée intergénésique, alors que la moitié du corpus présente alors un écart d'âge inférieur ou égal à cinq ans. Les sœurs suivent parfois une scolarité partiellement commune, comme Julie Philomène et Philomène Fettu nées en I866 et I867 et admises en I885 et 1886, ou Geneviève Thérèse et Marie Julie Estéoule, toutes deux admises à l'automne i882, malgré leurs onze ans de différence. Cette fréquente proximité d'âge atténue les effets de l'aînesse en amenant les élèves sœurs à partager plus intensément les péripéties de leurs scolarités respectives.

La majeure partie des sorories concerne des couples d'individus : 2I cas sur 24 cas corréziens et 2I sur 22 cas parmi les élèves de la Charité de Lyon. Quelques cas de sorories plus abondantes existent, comptant entre trois et cinq futures sages-femmes. Elles ne font cependant pas exception au modèle familial défini à partir des sorories corréziennes (de 5 à 9 enfants avec une majorité de filles). Cette constance sororale dans le choix du métier de sage-femme s'inscrit dans une histoire transgénérationnelle des familles, et manifeste la forme la plus aboutie de reproduction professionnelle verticale. Dans ce contexte,

66. AD Charente-Maritime, 3 X 304 . 
la multiplication des admissions en école peut répondre aux défaillances filiales dans la reprise de l'exercice maternel comme dans le cas de la famille Queyriaux. La relation sororale serait alors la conséquence d'une dynamique lignagère plutôt que son propre moteur dans la répétition du choix professionnel. Cette interprétation, très marquée par l'image qu'en donne Claudine Martin, la mère, n'est cependant pas exclusive d'une participation volontaire des filles au schéma familial et d'une liberté individuelle accrue par l'imitation entre sœurs. Parmi les admises à la Charité de Lyon, Marie Jeanne, Julie Philomène et Philomène Fettu, participent dans les années I880 d'un modèle proche, marqué par l'influence de Benoîte Marie Barriquand, leur tante, diplômée à Lyon en 1862. Seule exception à ce schéma : les sœurs Valéry dont la mère n'a pas de métier déclaré et dont le père travaille successivement comme perruquier, fournier puis marchand de vin ${ }^{67}$.

Ces sorories abondantes ont donc la caractéristique de s'inscrire dans une double expansion verticale et horizontale de la profession de sage-femme, et d'être plus généralement les seules, sur l'ensemble des sorories repérées dans les deux corpus, nées d'une sage-femme, à l'exception de Marthe et Lucie Baret, admises à Lyon en I89I et I893 (père pharmacien). La rareté de ce dernier trait confirme l'écart entre deux processus de transmission professionnelle, verticale et horizontale.

Le dernier trait fondamental de la sororité professionnelle réside dans son lien évident avec la forme donnée par les législateurs à l'enseignement obstétrical. La scolarisation de la formation promeut, par la coexistence dans les classes et au sein d'une promotion d'élèves sages-femmes, une sociabilité horizontale, miroir de la germanité. L'école d'accouchement, et plus encore l'internat sur le modèle parisien, abritent un groupe d'élèves envisagées comme des sœurs sous l'autorité « maternelle » d'une maîtresse sage-femme. La scolarité partagée tisse entre camarades d'études des liens humains et professionnels forts. Il en naît progressivement une conscience de corps. Sy inventent aussi des amitiés sororales qui perdurent au point de susciter de nouveaux liens familiaux. En I88I, Marguerite Delon entre à l'école de Tulle. Elle y partage pendant deux ans la classe avec Marie Issoulier, admise en I880. Les deux jeunes femmes sont originaires de communes différentes et plutôt éloignées. Pourtant, le I5 décembre I888, Marguerite Delon épouse Jérémy Issoulier, le frère de sa camarade d'école. Ce surgissement d'alliances dans le milieu des sages-femmes est le rare reflet de relations interprofessionnelles et amicales impossibles à saisir autrement. Quand ces alliances préexistent, elles fonctionnent sur le modèle des sorories, la sage-femme

67. Sage Pranchère N., Mettre au monde..., op. cit., p. 495. 
en exercice dispensant conseils et encouragements à sa jeune belle-sœur, comme le fait Jeanne Favori, diplômée en 1846, pour Marie Boyer, sœur de son époux Antoine, qui intègre à son tour en I85I l'école d'accouchement de Tulle.

Encourager sa sœur cadette à suivre un même cursus consiste donc à faire partager une expérience scolaire, par souci d'offrir une voie professionnelle connue et balisée. C'est aussi resserrer le lien naturel de la germanité en le doublant d'une germanité professionnelle construite et choisie. Contre toute attente, l'institutionnalisation de la formation obstétricale a suscité dans le cadre familial une reproduction professionnelle qui accompagne l'épanouissement de la transmission mère-fille. En libérant les futures sages-femmes du cadre étroit d'un exercice local et dépendant d'un héritage familial, la scolarisation et le diplôme ont permis l'émergence d'un exercice sororal concomitant capable de répondre aux attentes politiques d'un encadrement obstétrical efficace du pays.

«La sage-femme paie son terme quand la nature daigne en fixer un pour quelque enfant à naître ${ }^{68} \gg$. Dans Les Français peints par eux-mêmes, Louis Roux trace en quelques pages enlevées le portrait littéraire de cette profession. Maquillées d'un trait de plume, apparaissent les préoccupations anciennes des autorités administratives, religieuses et médicales sur la modestie sociale nécessaire à l'accoucheuse pour remplir au mieux son rôle. Lorsque l'auteur la peint fixant « ses pénates à un quatrième [étage] », il la maintient dans l'humble place que lui assignent médecins et administrateurs dès lors qu'ils font rimer dévouement avec pauvreté. Pourtant, la profession qui naît du tournant scolaire et législatif du début du XIX ${ }^{e}$ siècle n'est pas que la systématisation d'une bonne ouvre, condamnant celles qui l'exercent à une indigence honorable. Elle suscite vocations et stratégies, devient un enjeu de savoir et de pouvoir relatif. La formation de la sage-femme, devenue l'alpha et l'oméga de son existence légale, imprègne toutes les facettes du choix professionnel. L'école d'accouchement bat au cœur de ce métier. Par sa géographie, elle ouvre peu à peu le recrutement jusqu'aux tréfonds de l'espace rural; par ses modes de financement, elle le destine à des catégories sociales - l'artisanat et la boutique - qui en font progressivement le pré carré de leurs filles ; par ses rythmes et sa symbolique, elle suscite même une dynamique familiale originale, la sororité, qui complète les formes de la transmission lignagère de cette profession.

68. Roux L., «La sage-femme », dans Les Français peints par eux-mêmes, Paris, I840-1842, réédité, Paris, Omnibus, 2003, p. 257. Sur les liens entre enquête sociale et création de types sociaux par la littérature, voir Lyon-Caen J., "Saisir, décrire, déchiffrer : les mises en texte du social sous la monarchie de Juillet », Revue historique, 2-2004, n 630, p. 303-33I. 


\section{L'éclosion de l'agent de santé publique}

La définition de la naissance comme objet médical et but d'une politique sanitaire est à l'origine d'une mutation majeure : la professionnalisation de la sagefemme. La littérature médico-administrative des années 1780-I820 a construit et exemplifié le processus de cette mutation, en opposant le passé-présent de l'accoucheuse comme marginalité réprouvée au futur de la sage-femme comme réalisation de la santé publique. La redéfinition positive de cette figure s'opère en moins d'un demi-siècle, dans le cadre d'une dynamique interne et externe de délimitation du corps médical. L'élaboration d'un idéal de la sage-femme passe par la promotion d'un ensemble de qualités dont la jeunesse n'est pas la moindre. Il s'agit alors d'associer à l'idéal théorique de l'élève, l'écrin éducatif capable de préserver et de sublimer ces qualités. De la matrone méprisée à l'accoucheuse instruite dont on fait la sage-femme «fonctionnaire », l'évolution en jeu n'est pas seulement l'établissement d'une intermédiation culturelle mais l'amorce d'une véritable acculturation à un nouveau paradigme scientifique et social : une santé publique fondée sur une médecine clinique et prophylactique. Il s'agira de dresser le portrait administratif des sages-femmes comme modèle physique et moral et dans ce qu'il révèle des politiques nationales et départementales d'encadrement médical des populations.

\section{Façonner une nouvelle sage-femme}

\section{Un privilège de la jeunesse et du célibat?}

Art. XVI. Les élèves seront mariées, ou l'auront été : elles seront âgées, au moins, de dix-huit ans, et ne passeront pas l'âge de trente-cinq, ce dont elles justifieront par certificat de leur curé, et par leur extrait baptistaire. ${ }^{1}$

I. AD Saône-et-Loire, C 525 . 
En I782, l'école d'accouchement de Mâcon délimite pour l'admission dans l'établissement une tranche d'âge particulière, de 18 à 35 ans. Si, à sa fondation, l'école de l'Hospice de la Maternité de Paris ne prévoit aucune limitation d'âge pour l'admission, cette fourchette I8-35 ans apparaît dès la première révision du texte en 1807.

À l'expérience de la maternité et à la disponibilité comme qualités essentielles, les textes réglementaires préfèrent un savoir d'école, couplé à la jeunesse. Ils fondent en cela une nouvelle idée de la sage-femme pour qui s'ouvre la perspective d'une véritable carrière professionnelle. L'investissement d'un département, d'une commune ou même d'une famille dans les frais d'une instruction ne peut se contenter de quelques années d'exercice. En I806, François Bonfils, professeur nancéen, le résume ainsi dans un courrier au préfet de la Meurthe :

Jeunesse : à cet âge on apprend avec une grande facilité, et les impressions reçues alors s'effacent difficilement. [...] En choisissant un jeune sujet, la commune a l'espoir de jouir plus longtems de ses services. Si donc la décence ne permet pas d'initier à nos mistères une femme au dessous de dix-huit ans, il convient aussi qu'elle n'en ait pas plus de trente. ${ }^{2}$

Cette limitation de l'âge d'entrée dans la formation est un des signes de la transformation progressive de la fonction en profession. Être sage-femme est désormais le résultat d'un apprentissage initial qui ouvre le temps d'exercice autorisé. La possibilité d'entrer au-delà de 35 ans dans l'école est une tolérance, une concession au recyclage des matrones et aux habitudes des populations. Or, une telle exception est vouée à la disparition la plus rapide possible et ne concerne quasiment pas l'école parisienne $e^{3}$.

Parmi les cours et les écoles d'accouchement, il n'y a cependant pas d'unanimité sur le modèle parisien dans la définition des limites d'âge. Sur 70 règlements de cours d'accouchement rédigés et approuvés entre 1790 et I896, 47 imposent une limite basse (de 17 à 25 ans), 37 précisant même une limite haute (de 25 à 40 ans) ${ }^{4}$. Parmi eux, $40 \%$ (I9) reprennent la fourchette du règlement parisien. L'âge plancher de 18 ans est commun à $70 \%$ (33) de ces règlements, un seul département autorisant l'admission d'élèves plus jeunes : le Morbihan à 17 ans. En revanche, ce « plancher » peut monter à 20 (7), 2I (2) ou 25 ans (4).

\footnotetext{
2. AN, Fi7/2463, Meurthe.

3. Beauvalet-Boutouyrie S., Naître à l'hôpital..., op. cit., p. I36 : après I830, on n'observe plus d'exemple de ce type à l'Hospice de la Maternité de Paris, et avant, les femmes concernées suivent la formation à leurs frais.
}

4. Certains règlements prévoient une limite plancher sans plafond et vice-versa. 
Ce choix de relever la barrière d'admission à la formation obstétricale ne répond pas à une logique régionale, les plus exigeants étant le Calvados, le Doubs, le Finistère et la Haute-Marne. Il en est de même pour les départements qui retiennent 20 ou $2 \mathrm{I}$ ans comme limite basse $e^{5}$. Il n'y a donc dans ces choix ni dynamique territoriale, ni bloc confessionnel à l'œuvre puisque les zones concernées font alterner pays catholiques (Finistère, Morbihan, Aveyron) et pays à forte minorité protestante (Tarn, Charente, Doubs).

Ces âges plus tardifs traduisent peut-être une sensibilité particulière aux seuils de majorité. La loi du 20 septembre 1792 puis le Code civil ont imposé une majorité civile uniforme, fixée à $2 \mathrm{I}$ ans, précédée d'une majorité pénale à 16 ans pour les actes délictueux ou criminels. Fixer l'admission dans une école de sages-femmes à 18 ans, c'est se placer au-delà de la majorité pénale. Repousser l'entrée dans la formation à 20 ou $2 \mathrm{I}$ ans, c'est s'assurer que le début de l'exercice de la profession correspond à la majorité civile, comme c'est le cas pour d'autres corps de métiers (direction d'une école primaire de filles) ${ }^{6}$. La réforme de la formation des sages-femmes en 1893 prévoit d'ailleurs pour cette raison de repousser à 19 ans l'âge d'admission aux études ${ }^{7}$.

Au-delà des seuils juridiques, une hésitation perdure à admettre des jeunes filles à l'exercice de ce métier. Le Calvados précise dans l'arrêté de création du cours en 1809, que « celles qui ne seront pas mariées devront être âgées de vingt-cinq au moins ${ }^{8}$ », révélant la gêne devant l'accès de jeunes femmes célibataires à un savoir délicat ${ }^{9}$. Cette gêne n'est toutefois pas un empêchement et la disparition du mariage comme critère d'admission est une rupture de taille. Cette rupture, signe d'une précoce laïcisation, n'est toutefois pas généralisable à l'ensemble de l'Europe, puisque la réforme de la formation des sages-femmes espagnoles qui intervient tardivement en I86I impose que les aspirantes soient impérativement mariées ou veuves ${ }^{10}$. Au Danemark c'est seulement en I883 que ce débat émerge lors de la réunion annuelle de la Société médicale danoise ${ }^{11}$.

5. Aube, Morbihan, Charente, Tarn, Basses-Pyrénées, Loire-Atlantique, Aveyron et Loiret.

6. Les postulantes au brevet de capacité ne doivent pas avoir moins de 20 ans, Gréard O., La législation de l'instruction primaire en France depuis 1789 jusqu'à nos jours : recueil des lois, décrets, ordonnances, arrêtés, règlements, t. II, I833-1847, Paris, impr. de Delalain frères, I889-1902, p. 253 (ordonnance du 23 juin 1836).

7. RLRES 5, p. 419-420 : circulaire relative à la limite d'âge imposée aux aspirantes élèves sagesfemmes, I5 novembre 1894 .

8. AN, Fi72457, Calvados.

9. Gélis J., L'Arbre et le fruit..., op. cit., p. 178-179.

Io. Ortiz T., Martinez Padilla C., « How to be a Midwife in Late Nineteenth-Century Spain », dans Marland H., Rafferty A.-M., Midwives, Society and Childbirth..., op. cit., p. 62-63.

II. Løkke A., «The antiseptic transformation of Danish midwives, I860-1920 », art. cit., p. II5-II6. 
En France, être mariée peut freiner l'accès à la formation obstétricale. Premier obstacle : la nécessaire autorisation maritale pour suivre les cours, absente du règlement parisien, prend rapidement place dans les règlements départementaux. En Corrèze, cette obligation apparaît dans l'annonce préfectorale du cours aux maires le 6 février $1834^{12}$. On la retrouve dans le règlement de l'école de Lyon en I876 et dans celui de Lorient deux ans plus tard ${ }^{13}$. Ses effets sont difficiles à repérer puisque le refus marital intervient généralement en amont de la candidature et ne laisse aucune trace documentaire. L'époux peut néanmoins changer d'avis a posteriori comme l'illustre l'exemple de Marie Fournial-Damartin, sœur de la directrice de l'école d'accouchement de Tulle en I834. Son mari accepte qu'elle suive le cours d'arrondissement à titre d'élève externe mais s'oppose à son admission comme élève interne de la nouvelle école départementale ${ }^{14}$.

Autre obstacle : le risque de grossesse. Paris ouvre la voie dans ce domaine, en interdisant l'envoi d'élèves enceintes à l'Hospice de la Maternité ${ }^{15}$. L'interdiction est relayée dans les textes départementaux (Toulon, I814; Niort, I832 ; Tulle, 1833 , etc. $)^{16}$, mais avec une efficacité toute relative puisque quelques élèves mariées (ou non) mettent au monde leurs enfants dans ces établissements ${ }^{17}$.

Dernier obstacle enfin : lorsque l'état matrimonial devient un motif d'empêchement en soi. Cette mesure est assez rare, mais son existence confirme l'évolution radicale du métier. En 1857, un membre du conseil général de la Corrèze fait la proposition de ne plus recevoir comme élèves de femmes mariées, et reçoit l'assentiment immédiat de ses collègues puis du préfet ${ }^{18}$. On touche là en moins d'un siècle à une inversion complète des principes de recrutement. Cet exemple reste néanmoins exceptionnel par sa rigidité, et certains départements conservent dans leur pratique une préférence marquée pour les femmes mariées.

La marge entre règlements et pratique sur les limites d'âge et sur le statut matrimonial se mesure à partir des listes d'élèves. À l'Hospice de la Maternité de Paris, l'âge moyen des élèves a été calculé à partir des procès-verbaux de distribution des prix. Les célibataires sortent de l'établissement entre 22 et 23 ans, avec une légère tendance au vieillissement des promotions entre les années

\footnotetext{
12. Sage Pranchère N., Mettre au monde..., op. cit., p. 38I.

13. AD Aveyron, $3 \mathrm{X}_{52}$; AD Morbihan, 5 M 44 .

14. Sage Pranchère N., Mettre au monde..., op. cit., p. $38 \mathrm{I}$.

15. RLRES I, p. 305, Règlement pour l'école d'accouchement établie à l'Hospice de la Maternité à Paris, 8 novembre I8Io, titre II, art. 5 .

16. AD Var, $9 \mathrm{M}_{2}$ 5/1; AD Deux-Sèvres, $6 \mathrm{M}$ rob ; AN, Fi7/2458.

17. Voir Sage Pranchère N., Mettre au monde..., op. cit., p. I64 et 382.

I8. AD Corrèze, I X I69.
} 
I8IO-I819 et I870-I879, liée à la transformation de l'école en lieu de perfectionnement après une scolarité départementale, et à l'augmentation des exigences de formation initiale primaire. Les femmes mariées ont en général quelques années de plus, mais leur âge moyen ne varie guère sur le siècle, se maintenant au-dessus de 29 ans. Les veuves forment enfin une catégorie nettement plus âgée, autour de 34 ans au début du siècle, entre 30 et 32 cinquante ans plus tard, mais qui doit être nuancée par la rareté des cas (toujours moins de $2 \%$ des élèves ${ }^{19}$. Ces données ont été croisées avec celles d'autres lieux de formation (Angers, Tulle, Lyon ou Bordeaux).

\begin{tabular}{|l|c|c|c|c|c|c|}
\hline $\begin{array}{l}\text { Cours } \\
\text { d'accouchement }\end{array}$ & $\begin{array}{c}\text { Pourcentage } \\
\text { de non } \\
\text { renseignés }\end{array}$ & $\begin{array}{c}\text { Moyenne } \\
\text { d'âge } \\
\text { Célibataires }\end{array}$ & $\begin{array}{c}\text { Moyenne } \\
\text { d'âge } \\
\text { Mariées }\end{array}$ & $\begin{array}{c}\text { Moyenne } \\
\text { d'âge } \\
\text { Veuves }\end{array}$ & $\begin{array}{c}\text { Moyenne } \\
\text { d'âge } \\
\text { générale }\end{array}$ & $\begin{array}{c}\text { Âge } \\
\text { médian }\end{array}$ \\
\hline $\begin{array}{l}\text { Bordeaux } \\
(1807-1817)^{20}\end{array}$ & $0 \%$ & - & - & - & 24,8 ans & 23 ans \\
\hline $\begin{array}{l}\text { Angers } \\
(\text { I839-I848) }\end{array}$ & $31,1 \%$ & 22,8 ans & 26,5 ans & 29 ans & 24,8 ans & 25 ans \\
\hline $\begin{array}{l}\text { Tulle } \\
(1857-1866)\end{array}$ & $0 \%$ & 19,2 ans & - & - & 19,2 ans & I8 ans \\
\hline $\begin{array}{l}\text { Charité de Lyon } \\
(\text { I860-I90I })\end{array}$ & $0,7 \%$ & 20,5 ans & 25,4 ans & 29,3 ans & $21, I$ ans & 20 ans \\
\hline $\begin{array}{l}\text { Réceptions } \\
\text { à Bordeaux } \\
(\text { I855-I878) }\end{array}$ & $3,3 \%$ & 22 ans & 29,8 ans & 29 ans & 24 ans & 2 ans \\
\hline
\end{tabular}

Tableau 4. Âge moyen des élèves sages-femmes au début de leur formation (sauf Bordeaux, 1855-1878).

Chez les célibataires, un abaissement de l'âge à l'admission apparaît assez nettement entre la première et la seconde moitié du xix ${ }^{e}$ siècle. Bordeaux au début du siècle et Angers conservent une moyenne d'âge assez haute, de deux à trois ans au-dessus de la moyenne parisienne, tandis que la Corrèze emporte la palme de la jeunesse des postulantes pour le tournant des années 1850-I860.

19. Beauvalet-Boutouyrie S., Naître à l'hôpital..., op. cit., p. I36.

20. AD Gironde, $5 \mathrm{M} 55 \mathrm{I}$.

21. AD Maine-et-Loire, $47 \mathrm{M}$ i9, le fort pourcentage d'âges non renseignés s'explique par l'absence de dates de naissance dans le registre pour les élèves admises entre I843 et I845.

22. L'âge moyen est calculé à partir des données enregistrées à la réception, c'est-à-dire à l'issue de la formation, soit deux ans plus tard qu'ailleurs. 
Les admises à l'hospice de la Charité de Lyon et les élèves reçues à Bordeaux sont à peine plus âgées, puisqu'elles commencent leur formation autour de 20 ans. Un rajeunissement progressif global s'opère donc au fil des décennies, à l'opposé des conclusions parisiennes.

L'entrée dans les écoles d'accouchement se fait dès que les règlements l'autorisent. Le cas de la Corrèze est à ce titre exemplaire puisque l'âge médian d'admission des élèves correspond à l'âge " plancher »: I8 ans. La tendance illustrée par les textes est donc confirmée dans la pratique. Le choix de la profession est précoce, et relève d'une vocation professionnelle qui ne doit rien au hasard d'un parcours de vie. Ce sont les femmes mariées qui apparaissent les moins certaines de leur décision. La candidature à la formation d'accoucheuse intervient pour elles plus tard, dans un contexte de difficultés matérielles que l'accès à cette profession permet de pallier. Le décalage de 5 à 7 ans observable entre célibataires et femmes mariées témoigne du caractère compensatoire de ce choix professionnel pour les secondes, alors que les candidates sont souvent déjà mères d'un ou plusieurs enfants.

Un dernier point mérite d'être souligné l la perméabilité de la limite inférieure d'admission. Si certaines institutions sont extrêmement sévères sur l'application des règlements dans ce domaine, comme la Corrèze qui refuse la participation au concours d'entrée de jeunes femmes n'ayant pas i8 ans révolus au cours des années $1860^{23}$, d'autres accordent sans difficulté des dispenses d'âge. La liste des élèves envoyées par les Côtes-du-Nord à l'Hospice de la Maternité de Paris fait apparaître trois cas de jeunes filles âgées de 17 ans lors de leur admission. En I832, le préfet de la Seine transmet au ministre du commerce et des travaux publics une réclamation du conseil général des hospices à ce sujet, car la multiplication des cas d'élèves arrivant avant 18 ans dans l'établissement pose problème :

En fesant de cet âge une condition pour l'admission des élèves, on a pensé qu'il était peu convenable d'initier trop tôt une jeune personne dans l'art des accouchements et qu'il importait d'ailleurs de placer auprès des femmes en couches des élèves dont les forces physiques et morales leur permissent de se livrer avec calme et succès à des travaux d'une nature souvent pénible. Il est encore juste de dire qu'une élève âgée de moins de I8 ans ne saurait inspirer soit à l'administration, soit aux malades la confiance nécessaire. ${ }^{24}$

L'importance accordée à la résistance physique et nerveuse des élèves témoigne d'une conscience précise des obligations du service obstétrical. Les

23. Sage Pranchère N., Mettre au monde..., op. cit., p. 380.

24. AN, Fi7/2468, Seine. 
heures de veille, les accouchements très ou trop longs, les emplois du temps extrêmement chargés des futures sages-femmes en amènent certaines à l'épuisement physique en quelques mois, voire quelques semaines.

Dans les années I870, l'hospice de la Charité de Lyon impose I8 ans comme limite basse, mais prévoit une latitude en amont de ce " plancher» par le système des élèves gratuites pouvant entrer dans l'établissement dès l'âge de I6 ans sans être toutefois admises officiellement. Dans les faits, 6,8 \% des élèves admises entre I860 et I90I commencent leur période d'études réglementaire avant $\mathrm{I} 8$ ans, et pour trois d'entre elles, l'achèvent à l'âge où elles auraient dû débuter. C'est aussi le cas de 10,3\% des élèves reçues à Bordeaux entre 1855 et 1878. Ces pourcentages restent faibles, preuve que l'âge plancher rencontre un assentiment largement majoritaire. Les autorités susceptibles d'accorder ces dispenses d'âge sont le préfet pour l'essentiel des établissements départementaux, et le ministre dans certains cas. Ce dernier émet un avis favorable pour tous les cas présentés. Les dispenses demandées sont en fait minimes et justifiées par le risque de perdre plus d'une année avant d'être de nouveau en position de poser une candidature. La situation matérielle de la future élève entre prioritairement en ligne de compte et les demandes de dispense constituent en fait autant de réponses à des circonstances de détresse sociale.

\section{Du plomb en or : l'alchimie du choix de l'élève}

Les demandes de dispense interrogent les raisons d'une candidature à un cours d'accouchement. Au-delà de l'influence familiale, l'entrée dans une école de sages-femmes est la rencontre de deux volontés : le souhait de la candidate et les vœux de l'administration. Les exigences de l'autorité institutionnelle priment néanmoins sur le projet individuel dès lors que l'inscription dans les cours d'accouchement est soumise à l'appréciation successive des maires, sous-préfets, préfets et professeurs. Aux candidates de se conformer au portrait moral et physique de l'élève sage-femme attendue pour être admises.

Le premier tiers du siècle, riche en créations ou en réorganisations d'institutions, est un grand producteur de textes (règlements, avis d'ouverture de cours, discours, etc.) sur les qualités nécessaires à l'exercice du métier de sagefemme $e^{25}$. Le modèle de ces listes de qualités est ancien (premier chapitre de

25. Sur ce sujet, voir pour la Suisse valaisanne : Vouilloz-Burnier M.-F., L'accouchement entre tradition et modernité..., op. cit., p. 260. 
l'Abrégé d'Angélique du Coudray $\left.{ }^{26}\right)$, et prend progressivement place dans les textes règlementaires comme à Mâcon en $1782^{27}$.

En 1806 , le docteur nancéen, François Bonfils, médecin de la maison de secours, soumet au préfet de la Meurthe le programme du cours qu'il projette d'ouvrir ${ }^{28}$. Après l'exposé de la partie théorique puis pratique de son cours, le médecin en vient aux qualités nécessaires à l'exercice de la profession et donc à celles dont les autorités et le démonstrateur doivent s'assurer lors du choix de l'élève. Il organise son propos entre dispositions physiques et dispositions morales auxquelles il ajoute un passage sur les «talents accessoires » et l'état matrimonial.

En I835, lors de l'inauguration de l'école départementale d'accouchement de l'Aube, à Troyes, le docteur Teissier fait devant l'assistance réunie un discours intitulé : Discours sur l'histoire de l'art des accouchements depuis son origine jusqu'à nos jourss ${ }^{29}$. Passé le récit historique, le médecin en vient à la description des qualités indispensables aux jeunes femmes désirant se vouer à cette carrière. Comme François Bonfils un quart de siècle plus tôt, Teissier place les qualités physiques en amont de sa présentation. Deux éléments sont mis en avant par les auteurs : l'adresse et la force.

(Bonfils, I806) Force : les soins à donner aux femmes en travail, surtout dans les accouchemens dits contre nature, exigent souvent un développement de forces dont ne serait pas capable une femme chétive, délicate, trop âgée, ou dans l'état de grossesse et de malaise.

Taille avantageuse : ces soins exigent aussi des attitudes et des mouvemens variés trop fatiguans quelquefois pour une petite femme, et pour celle d'une taille excessivement grande.

Agilité : s'il est quelques circonstances des accouchemens qui demandent un certain développement de forces, toutes exigent de l'adresse, de la souplesse, de la délicatesse, de l'agilité. ${ }^{30}$

(Teissier, 1835) Il faut mettre au premier rang les qualités physiques ou corporelles, l'agilité du corps, la souplesse des membres, l'adresse de la main, la délicatesse du tact. [...] si vous n'êtes forte, agile et souple, comme réussirezvous à extraire l'enfant quand il faut opérer la version et le tirer par les pieds ou l'arracher avec le forceps ? ${ }^{31}$

26. Coudray A. (Le Boursier du), Abrégé de l'art des accouchements, Paris, Veuve Delaguette, I759, P. I-6.

27. Gélis J., La Sage-femme ou le médecin..., op. cit., p. I40.

28. AN, Fi7/2463, Meurthe.

29. AD Aube, $5 \mathrm{M}_{33}$.

30. $\mathrm{AN}, \mathrm{F}_{17} / 2463$, Meurthe.

3I. AD Aube, $5 \mathrm{M}_{33}$. 
Au fil de ces paragraphes, les médecins définissent un type physique particulier à la profession de sage-femme, puisé aux nécessités de l'exercice professionnel. Les qualités marient des données invariables (taille du corps et de la main) et des capacités (agilité, adresse, force). Dans le cas de la sage-femme, force, robustesse et bonne santé sont requises de la candidate, autant de qualités qui sont censées faire défaut aux femmes en général. Entre la faible femme, éternelle malade à contrôler pour la protéger, et l'accoucheuse active dont on attend qu'elle soit pilier et soutien du renouveau démographique français, le paradoxe physique rejoint le paradoxe éducatif et social.

L'accoucheuse doit toutefois posséder la délicatesse des mains, qui « doivent être longues, minces, exemptes de roideurs et des callosités que produisent ordinairement les travaux rustiques » (Bonfils). L'importance du toucher, sa « délicatesse exquise » (Teissier), se différencient de l’adresse proprement dite. La main est l'œil de l'accoucheuse, ce que ne cessent de répéter les démonstrateurs depuis Angélique du Coudray ${ }^{32}$. Dans un contexte où l'examen gynécologique et le suivi de la progression de l'accouchement se font «à l'aveugle », sous les jupons de la parturiente ou sous un drap, le sens du toucher est sollicité pour l'observation autant que pour le diagnostic ${ }^{33}$. L'acuité de la sensibilité doit donc être préservée puisqu'il s'agit du seul medium dont dispose la sagefemme. En un temps où la clinique s'établit sur le fait de voir, sur l'évidence qui naît de l'observation ${ }^{34}$, la vue dans l'art des accouchements vient en simple appoint du toucher, qualifiée de sens « ordinairement inutile ${ }^{35} »$. Elle ne peut être que secondaire car le recours à ce sens est contraire à la décence et ne concerne que les suites de la parturition : examen de l'enfant et du placenta. La sage-femme est donc tenue éloignée de la réalité visible du corps en travail, guidant ses mains d'après le souvenir des planches longuement méditées et des entraînements sur le mannequin. La communauté de sexe n'est pas suffisante pour justifier la nudité de la femme en couches ${ }^{36}$ et ce refus de laisser voir est une façon de ménager la pudeur. Par ailleurs, l’œil de la parturiente aussi doit

32. Gélis J., La Sage-femme ou le médecin..., op. cit., p. II4.

33. Carol A., "L'examen gynécologique, $\mathrm{XVIII}^{\mathrm{e}}-\mathrm{XIX}^{\mathrm{e}}$ siècle : techniques et usages », dans Bourdelais P., Faure O. (dir.), Les Nouvelles Pratiques de santé..., op. cit., p. 60-65 ; Arnaud-Lesot S., «Pratique médicale et pudeur féminine au XIx ${ }^{e}$ siècle », Histoire des sciences médicales, 2004, t. 38, $\mathrm{n}^{\circ}$ 2, p. 207-218, et «Pudeur et pratique obstétricale au XIX ${ }^{\mathrm{e}}$ siècle », Histoire des sciences médicales, 2009, t. 43, no I, p. 39-48.

34. Foucault M., Naissance de la clinique, Paris, PUF, 1963.

35. AN, Fi7/2463, Meurthe.

36. Gélis J., L'Arbre et le fruit..., op. cit., p. 198. 
être protégé des spectacles pénibles. De là découlent les préoccupations sur l'apparence de la sage-femme :

(Bonfils, I806) L'absence de toute difformité, maladie habituelle ou contagieuse, dégoûtante comme hernie ou descente, foetidité d'haleine, de transpiration, épilepsie, migraine, goutte, asthme, ulcères, cautères, dartres, galle, humeurs froides, maux vénériens, disposition à un embonpoint excessif, etc. etc. : les difformités et les infirmités déplaisent, répugnent, repoussent avec raison la confiance, et nuisent surtout au développement et à l'agilité. [...] L'embonpoint excessif détruit l'agilité et augmente le volume de la main et de l'avant-bras, de manière à causer un juste effroi aux femmes en travail. ${ }^{37}$

Tout est lié, l'infirmité repoussante à l'œil étant souvent le résultat d'une affection chronique susceptible d'être invalidante pour la sage-femme ou potentiellement contagieuse. Le portrait physique est donc celui de la pleine santé, rassurante pour la future mère.

Mais ces qualités ne sont qu'une base concrète à l'épanouissement des vertus morales et des capacités intellectuelles. Bonfils cite successivement l'intelligence et la mémoire, le jugement, le sang-froid et l'activité, la probité, la discrétion, la chasteté, la sobriété, la charité et le désintéressement, la sensibilité, le dévouement et la modestie, et enfin, la piété « douce et raisonnable ».

Le portrait idéal de la sage-femme mêle ainsi vertus cardinales (prudence, courage) et théologales (charité, piété), qualités « féminines» (modestie, chasteté ou décence, douceur, sensibilité, dévouement) et conduites imposées par la profession (sang-froid, discrétion, sobriété), toutes justifiées par leur utilité au lit des femmes en couches et l'intérêt bien compris de la sage-femme. La prudence éloigne la tentation de présumer de son savoir et de ses forces. La douceur, comme le rappelle le professeur rochelais Romieux, ne soulage pas, mais apaise l'âme et aide à supporter les douleurs ${ }^{38}$. De même, le sang-froid réduit les craintes de la parturiente et le dévouement suscite sa confiance. La modestie et la décence, nourries d'un solide savoir, peuvent faire préférer l'accoucheuse aux hommes de l'art : «Sages-femmes, rendez vous donc recommandables par des vertus et des talents; rendez inutile dans les fonctions de la maternité le ministère des hommes ; renvoyez-les au siècle dernier ${ }^{39}$ ».

La survie matérielle de la praticienne passe par la sauvegarde d'une réputation qui se nourrit des différentes qualités évoquées. Dans un domaine où l'enjeu est, à proprement parler, vital, tous les gestes et toutes les paroles de 
la sage-femme sont sous la surveillance assidue des familles et plus largement de la société : "C'est appeler la confiance que d'être sage, c'est déclarer qu'on en est indigne que d'être imprudente. N'est-ce pas d'ailleurs le moyen de vous éviter les reproches d'une conscience révoltée des fautes que vous pourriez commettre et ceux encore des victimes que vous pourriez faire $?^{40} »$

La science dont l'accoucheuse est détentrice fait peser sur elle la double responsabilité de son expertise et des limites de celle-ci, le savoir qu' elle acquiert dans l'intimité des patientes lui fait un devoir ambigu de silence ou de parole sous peine de poursuite pénale. Cette vertu de discrétion est même obligation professionnelle de secret (article 378 du Code pénal), et la médecine légale débat jusqu'à la fin du siècle pour savoir « où s'arrête le secret professionnel et où commencent les révélations que la loi peut exiger ${ }^{41} »$.

Enfin, les dispositions intellectuelles, la capacité « d'être élève » sont dès l'époque révolutionnaire un élément discriminant dans le choix des candidates. Si Romieux n'y accorde guère d'importance, Bonfils place l'intelligence et la mémoire au premier rang des dispositions morales : « elles se développent par l'exercice et on les rencontrera plus ordinairement dans les femmes qui ont reçu une éducation plus soignée qu'elle l'est communément dans nos campagnes ». Teissier les exalte à son tour, tout en nuançant lui aussi leur égale distribution :

La pénétration d'esprit est un pur don de nature ; mais la science est le fruit de l'étude, qui fera l'objet de notre enseignement. Toutes personnes ne sont pas propres à l'étude; et quoiqu'en aient dit certains philosophes, il y a des qualités particulières, qui distinguent les gens de lettres des gens du monde et des simples manœuvres. Et avec au premier rang de ces qualités la mémoire que les Grecs ont honoré comme la mère des Muses, et l'attention sans laquelle il n'y a rien à espérer d'aucune sorte d'étude. ${ }^{42}$

La conscience d'une inégalité repose néanmoins sur des bases distinctes : Bonfils y voit le résultat éducatif de la différence sociale, Teissier y lit une inégalité native et irrémédiable. La mémoire occupe une place équivalente à l'intelligence, dans l'optique d'un enseignement par questions et réponses méthodiquement apprises. Au nombre des qualités primordiales, nul ne semble compter les savoirs primaires que Bonfils qualifie de «talents accessoires » tout en reconnaissant que « '́ 'est avec raison que ces talents sont exigés ${ }^{43} »$ Ne nous

40. Ibid.

41. Coffignon A., Paris vivant. L'enfant à Paris, Paris, E. Kolb, i889, p. 27-29.

42. AD Aube, $5 \mathrm{M}_{33}$.

43. AN, Fi7/2463, Meurthe. 
méprenons pas sur cette absence, lire et écrire sont des préalables indispensables à la formation obstétricale mais leur méconnaissance peut être corrigée.

Cette accumulation de qualités crée un modèle et les administrateurs (souspréfets ou préfets) chargés de choisir l'Élève comptent alors sur les éléments fournis par les certificats de bonnes vie et mœurs délivrés par les maires, les curés ou les notables des communes d'origine $e^{44}$. Certains règlements, comme celui du cours de Dijon en I820, consacrent un article spécifique au sérieux qui doit présider à l'enquête administrative préalable aux certificats ${ }^{45}$. Le soin qu'apportent les maires à la délivrance de ces certificats est malheureusement aléatoire. En I821, la commission administrative des hospices de Reims se plaint qu'au nombre des élèves « il s'en est trouvé qui avoient antérieurement tenu une conduite déréglée et scandaleuse ${ }^{46} \gg$. Le préfet écrit alors immédiatement aux sous-préfets pour signaler « l'indulgence et la facilité déplorables » avec laquelle les maires distribuent les certificats et demander « que l'abus signalé ne se renouvelle plus ».

C'est dans ce contexte que certains départements usent de l'état matrimonial comme d'un filtre social. Si le célibat tend à devenir la référence en matière de recrutement d'élèves accoucheuses, le mariage reste en divers endroits « la sauvegarde des bonnes mœurs ${ }^{47}$ ». Et François Bonfils de poursuivre : « Il développe les vertus sociales, il fait perdre cette légèreté, cette insouciance, cet égoïsme qui caractérisent les célibataires, il mûrit, il centuple l'expérience. » L'étude du recrutement de certaines écoles en fonction du statut matrimonial apporte néanmoins un éclairage concret et très concordant avec ces déclarations de principe. Les études sur l'Hospice de la Maternité de Paris ou sur l'école maternité de Tulle ont souligné la prédominance écrasante des célibataires ${ }^{48}$. L'élargissement du corpus comparatif à d'autres établissements montre la place privilégiée sinon prioritaire des femmes mariées ou veuves à Dijon au début des années I 820 (59,4\% de mariées ; 4,4\% de veuves) et à Angers entre I 839 et I 862 ( $48,2 \%$ de mariées, $6 \%$ de veuves). Pourtant aucun des règlements conservés pour ces établissements n'exprime de préférence explicite à l'égard des femmes mariées. Le choix n'est pas théorisé, ce qui ne réduit pas son effet très concret

44. Voir Sage Pranchère N., Mettre au monde..., op. cit., p. 152-155.

45. AN, Fi7/2458, Côte-d'Or.

46. AD Marne, $32 \mathrm{X}_{24}$.

47. AN, Fi7/2463, Meurthe.

48. En Corrèze, après I834, les cas d'élèves mariées sont résiduels ; à Paris, le taux d'élèves célibataires passe de 79,5\% des admises en I8IO-I819 à 86,7 \% en I870-I879, voir Beauvalet-Boutouyrie S., Naître à l'hôpital..., op. cit., p. 136. Les corpus de sages-femmes reçues à Bordeaux et d'élèves admises à Lyon confirment la tendance. 
sur la physionomie des promotions de sages-femmes et sur l'image plus générale prise par la profession dans le Maine-et-Loire et la Côte-d'Or.

La sage-femme partageant avec ses patientes l'expérience matrimoniale et maternelle, n'a donc pas perdu de son charme aux yeux de certaines autorités locales. Maine-et-Loire, Côte-d'Or, mais aussi Lot-et-Garonne et Aveyron, entre autres, le traduisent par un recrutement favorisant les élèves mariées ; la force du catholicisme dans certains de ces départements (Maine-et-Loire, Aveyron) n'est sans doute pas étrangère à cette préférence et aux choix qui en découlent. L'avancée dans le siècle ne s'accompagne pas forcément d'une préférence accrue pour les célibataires. La déclaration du conseil général de la Loire lors de sa session de I888 en est la meilleure preuve :

[La commission départementale] est d'avis d'écarter provisoirement les aspirantes de cette catégorie [moins de 2I ans], et de donner de préférence les bourses vacantes à des femmes d'un certain âge, et particulièrement aux femmes d'ouvriers, mères de famille. ${ }^{49}$

Face à ces attentes qui sont celles de l'administration de tutelle des établissements, les candidates ont leur partition à jouer. Dans un cadre fortement contraint par les exigences physiques, morales et intellectuelles, les jeunes femmes influent à leur façon sur les choix de recrutement par les arguments de leurs lettres de candidature qui constituent en partie une réponse à la formule leitmotiv des textes règlementaires : l'élève doit être prise parmi les femmes « qui se destinent à l'état d'accoucheuse ${ }^{50}$ ». La place accordée à cette vocation dans les lettres de candidature à l'Hospice de la Maternité de Paris est discrète mais parfois directement formulée, comme le montrent ces extraits qui émanent pour la plupart de jeunes femmes originaires de Paris et de ses environs ${ }^{51}$ :

(I8I7) Je sens une telle vocation pour l'art de l'accouchement, que je me serois déjà occupée à l'étudier si j’avois le moyen de faire les frais que nécessite ce genre d'étude.

(1826) Ma fille, Ernestine Elisabeth Bénassis, âgée de 26 ans, [... ] annonce une intention ferme, une vocation décidée pour l'état d'accoucheuse.

(1845) Ma fille Suzanne Anatole Avenel, âgée de 20 ans, se sent une vocation prononcée pour les études médicales et son désir le plus vif serait de suivre les cours de la Maternité, afin d'obtenir le diplôme de sage-femme.

49. RD CG Loire, 1888.

50. RLRES I, p. 304, Règlement pour l'école d'accouchement établie à l'Hospice de la Maternité

à Paris, 8 novembre I8Io, titre II, art. 2.

5I. AN, Fi7/2469. 
Dans ces courriers, l'intérêt pour la profession, le goût, naissent souvent de la fréquentation d'une sage-femme, tandis que la présentation du métier insiste sur son utilité pour les femmes, et plus largement pour l'humanité, selon des formulations proches des circulaires annonçant les ouvertures de cours. La vocation est donc vécue comme un élan altruiste, et la dimension d'appel impérieux vers un état, parallèle de la vocation religieuse, n'est pas utilisée au hasard même si elle désigne ici un choix professionnel ${ }^{52}$. Vocation ou goût sont toujours placés dans une temporalité longue, parfois même contredite par le reste de la lettre :

Victoire Françoise Deulot, épouse du Sieur Bouvalot (Jean Claude), marchand de vin, $[\ldots]$ a l'honneur d'exposer très humblement à Votre Excellence qu'ayant dès sa tendre jeunesse montré des dispositions à devenir sage-femme, elle a suivi avec exactitude les cours théoriques d'accouchement à la maternité, depuis le $\mathrm{I}^{\mathrm{er}}$ janvier $\mathrm{I} 8 \mathrm{i5}$, jusqu'à ce jour. [...] Les circonstances malheureuses dans lesquelles se trouvent son mari et deux enfants en fort bas âge, par le défaut de commerce, ont fait, Monseigneur, qu'après avoir tout sacrifié pour faire honneur à ses affaires, l'exposante n'a plus de ressources que dans cet état, et qu'elle s'est tout à fait décidée à suivre le cours des élèves sages-femmes. ${ }^{53}$

Car l'élan vers la profession est souvent contemporain d'une tension financière, comme c'est le cas pour les demandes de dispenses d'âge. C'est même le point commun le plus frappant de ces correspondances : la formation obstétricale comme planche de salut d'une famille. Parents âgés, invalides et souvent veufs, abondantes fratries sont le lot de presque toutes les jeunes femmes qui présentent leur candidature à l'Hospice de la Maternité.

Les considérations sur les nécessités familiales occupent la majeure partie des lettres de candidature, très loin devant les déclarations de vocation. Est-ce à dire que ces dernières relèvent de la proclamation de principe? Pas plus sans doute que les tirades sur les obligations filiales, qui ne sont pas dépourvues d'une certaine mise en scène de l'amour et du dévouement envers les siens, modèle du dévouement envers les autres. Évoquer son appel intérieur vers l'art des accouchements et son souhait de porter secours à sa mère veuve et chargée d'enfants n'a rien de contradictoire, puisque ces deux attitudes répondent au portrait idéal tracé par les administrateurs et les médecins : l'accumulation des motifs vise à s'assurer la bienveillance du récipiendaire. Ces expressions personnelles éclairent les mécanismes du choix, entre individualité et pensée de groupe, en parfaite complémentarité avec l'approche généalogique et sociale développée au chapitre précédent.

52. Chevandier C., "Vocation professionnelle : un concept efficient pour le $\mathrm{xx}^{\mathrm{e}}$ siècle ? ", Annales de Bretagne et des pays de l'Ouest, 2009, II6-3, p. 95-108.

53. $\mathrm{AN}, \mathrm{F}_{17} / 2469$. 


\section{L'élaboration d'un modèle d'éducation pour un idéal socio-professionnel}

Définir l'élève idéale et la trouver n'est cependant pas suffisant. Encore faut-il préserver les qualités si précieuses de ces jeunes femmes. La scolarité devient donc le lieu d'exaltation et de consolidation des vertus. Lors de l'examen final, mêlées au contrôle général des connaissances anatomiques des questions spécifiques viennent rappeler l'exigence morale. En l'an xiII, le démonstrateur Darantière fait imprimer, sous les auspices du préfet de la Haute-Marne, les questions posées lors de l'examen public des élèves sages-femmes du cours de Chaumont. Le premier paragraphe de la «matière de l'examen » s'intitule : «Qualités d'une sage-femme » et comprend les questions suivantes :

Quelles sont les qualités qu'une sage-femme doit avoir ?

Ces belles qualités suffisent-elles pour rendre une sage-femme parfaite ? $?^{54}$

Ces interrogations perdurent puisqu'en I8I6, la demoiselle Lacoste, élève de Marguerite Coutanceau à Bordeaux, est interrogée sur les « qualités d'une sagefemme » lors de l'examen de fin d'année ${ }^{55}$. Vingt ans plus tard, le programme des examens de l'école départementale de l'Ain place en tête de sa description ces différents points : «Ce qu'on appelle sage-femme. - Connaissances qu'elle doit posséder. - Ses qualités physiques, morales, religieuses. - Influence qu' elle peut exercer ${ }^{56} »$.

Ce rappel en fin de scolarité n'est pas superflu. La mauvaise réputation de la profession de sage-femme est relayée au $\mathrm{XIX}^{\mathrm{e}}$ siècle par la mauvaise réputation de la formation obstétricale. La qualité du savoir n'est pas en cause. C'est à son objet même et à sa bienséance pour des jeunes filles que les critiques s'adressent. L'expression « jeune fille » pour désigner la jeune femme non mariée s'impose d'ailleurs à cette époque, parallèlement à un mouvement d'enfermement éducatif des filles des classes urbaines moyennes et aisées ${ }^{57}$. L'éducation dispensée à ces adolescentes jusqu'aux premières années $\mathrm{du} \mathrm{xx}^{\mathrm{e}}$ siècle impose une chape de silence sur tout ce qui peut de près ou de loin se rapporter à la sexualitée ${ }^{58}$.

\footnotetext{
54. AD Haute-Marne, 117 T 5.

55. AD Gironde, 5 M 55 I.

56. AD Saône-et-Loire, $\mathrm{M} 2088$.

57. Bernos M., « La jeune fille en France à l'époque classique », Clio. Histoire, femmes et sociétés, I994-4 [en ligne].

58. Knibiehler Y., «L'éducation sexuelle des filles au $\mathrm{xx}^{\mathrm{e}}$ siècle », Clio. Histoire, femmes et sociétés, I994-4 [en ligne].
} 
L'ignorance devient une norme, une nécessité conjointement reconnue par la société, les parents et les futurs époux ${ }^{59}$.

L'enseignement obstétrical vient heurter de plein fouet cette exigence de secret. La description anatomique des cours d'accouchement tronque certes les femmes en les réduisant au minimalisme du mannequin de démonstration, mais ouvre à celles qui y ont accès un univers de connaissances jugées sulfureuses ${ }^{60}$. L'élève sage-femme célibataire est, par obligation professionnelle, l'inverse de l'oie blanche. On dépose entre ses mains, au début de sa formation, des ouvrages complétés d'illustrations, qui lui apprennent, jusqu'au détail le moins obstétrical qui soit, la fin de chacune des parties de la génération ${ }^{61}$. Pour tout cela, s'attache à sa personne une tentation de moqueries égrillardes qui désespère les médecins en charge de l'instruction. Le docteur Pacoud, professeur d'accouchement à Bourg-en-Bresse, s'en désole dans un mémoire qu'il remet au préfet de l'Ain en 1820 :

Il n'entre point dans le but que je me suis proposé dans ce mémoire de rechercher les causes de l'opinion publique si peu favorable sous ce rapport, aux élèves sages-femmes, quelle que soit l'école à laquelle elles appartiennent. En vain l'autorité prend-elle à cet égard toutes les mesures que conseillent la prudence et l'intérêt social, en vain les élèves arrivent-elles avec les témoignages les plus honorables de la part des maires, et de celle des ministres de la religion, Dieu encore n'a pu altérer favorablement cette injuste opinion $!^{62}$

Un quart de siècle plus tard, le préfet de la Corrèze, lors d'un discours aux élèves sages-femmes après leurs examens, rappelle cette épée de Damoclès qui pèse sur la réputation des futures accoucheuses:

Le monde exige beaucoup des femmes avant de leur accorder son estime [...]. Vous aurez d'autant plus à faire pour vous rendre son opinion favorable que les études de votre profession, en vous initiant aux secrets les plus mystérieux de la nature, peuvent au premier moment lui inspirer la crainte que vous n'ayez éloigné de vous cette fleur de modestie dont les parfums nous sont si doux. ${ }^{63}$

59. Knibiehler Y., Bernos M., Ravoux-Rallo É., Richard É., De la pucelle à la minette, les jeunes filles de l'âge classique à nos jours, Paris, Messidor/Temps actuels, 1983, p. 107-108.

6o. Sage Pranchère N., Mettre au monde..., op. cit., p. 475-478.

61. Baudelocque J.-L., Principes sur l'art des accouchemens..., op. cit., p. 60 : « Le clitoris est la plus sensible de toutes les parties extérieures de la génération. Il se gonfle et se roidit aux moindres attouchements voluptueux ».

62. AN, Fi7/2456, Ain.

63. AD Corrèze, $43 \mathrm{~T} 5$. 
Concilier le savoir et la pudeur, telle est la volonté exprimée par tous les responsables des écoles d'accouchement. L'inquiétude est permanente du faux pas qui nuirait à l'établissement et à l'avenir des élèves. Lorsque les célibataires sont majoritaires, il faut inlassablement rassurer sur le respect pointilleux dont font preuve ces jeunes femmes vis-à-vis des exigences morales. En de rares circonstances, d'autant plus scandaleuses pour les établissements, les élèves sagesfemmes déposent plainte elles-mêmes contre l'indécence de leur professeur. En mars i89o, le docteur Jallet, en charge du cours d'accouchement de Poitiers, est dénoncé par ses élèves et le personnel féminin de la maternité pour ses propos :

Depuis le commencement des leçons, je trouvais les cours insignifiants et indécents. Vendredi 24 mai, M. Jallet nous a fait les temps de l'accouchement. Il a comparé l'effort du mari pendant la nuit de noce à celui de l'enfant près de naître. Il accompagnait ces propos de gestes indécents. [...] M. Jallet m'ayant interrogée, je répondis mal; il me dit : vous ne savez donc pas ce que vous avez entre les jambes, $\mathrm{f}^{* * *}$ tez $\mathrm{y}$ donc la main, bougre d'âne. Mes compagnes l'ont entendu comme moi. J'ai cru reconnaître que le cours était fait dans un sens non scientifique. ${ }^{64}$

Dans cette charge contre un enseignant qui leur « faisait honte ${ }^{65} »$, les futures sages-femmes défendent le sérieux de leur profession et l'honneur de leur savoir. Ce continuel besoin de justifier leur moralité, d'apporter des preuves de leur sérieux est révélateur des craintes que charrie l'image fantasmée de l'élève sage-femme. Les rumeurs et les préjugés rejaillissent même sur le quotidien des futures accoucheuses, qui sont préventivement traitées avec une grande sévérité. Donner prise à la calomnie risque de réduire le champ de recrutement de l'établissement d'enseignement et de mettre en danger son existence. Les refus des préfets d'envoyer des élèves à l'Hospice de la Maternité de Paris pendant la première décennie du siècle sont l'écho de ces risques. Les critiques sur la moralité des élèves peuvent même entrer dans la décision d'interrompre un cours, comme lorsque le conseil général de l'Aveyron vote en 1846 la suppression du cours d'accouchement de Rodez :

Un trop grand nombre d'élèves, et quelques unes de moralité équivoque, y sont successivement admises, et il en résulte quau lieu de se rendre utiles dans les campagnes par la pratique de leur art [...] elles y servent d'intermédiaire pour la disparition et l'exposition des enfants trouvés. ${ }^{66}$

64. AD Vienne, 9 T I7I.

65. Ibid. À la suite de ces plaintes, le docteur Jallet est révoqué de son poste de professeur d'accouchement.

66. AD Aveyron, Per 545 . 
Sensibles à ces relents de scandale, les parents doivent être rassurés sur l'encadrement rigoureux de leurs filles pour accepter de les laisser partir. L'admission à un cours d'accouchement ou dans une école ne repose toutefois pas sur les mêmes principes que la mise en apprentissage ou en domesticité aux siècles précédents ${ }^{67}$ malgré l'appartenance des futures élèves à des milieux sociaux peu fortunés. L'accès à une formation scientifique, puis l'exercice d'une profession reconnue modifient la temporalité traditionnelle de l'entrée féminine dans l'âge adulte. Les efforts des administrations pour reconstituer autour des élèves sages-femmes un cadre protecteur et capable de suppléer à l'autorité parentale s'inscrivent dans une tentative de limiter les effets de ce bouleversement.

L'autonomie morale, intellectuelle et matérielle qui découle de l'entrée dans une école d'accouchement inquiète institutions, famille et société, et impose l'établissement de règles de conduite strictes. La solution est donc trouvée dans le pensionnat, qui prend son essor dans le domaine de l'enseignement obstétrical au début du XIX ${ }^{e}$ siècle. Les cours de la seconde moitié du XviII ${ }^{e}$ siècle avaient posé le problème aigu du logement des élèves ${ }^{68}$. Exceptions dans ce paysage : l'Office des Accouchées bien sûr et l'école de Mâcon qui dispose d'une « maison » où les élèves vivent « en communauté ${ }^{69}$ ». La création de l'école d'accouchement de l'Hospice de la Maternité de Paris reprend cette pratique pour l'ériger en modèle. La vie commune des élèves est prévue dès le règlement de l'an $\mathrm{x}$, avec une tolérance pour les femmes qui préféreraient « se loger à leurs frais et dépens ${ }^{70} »$, rapidement supprimée au profit de l'internat obligatoire ${ }^{71}$. L'enquête de l'an XIV et les correspondances entre préfets et ministres qui s'ensuivent marquent une étape importante dans la progression de ce modèle du pensionnat. À compter de cette date, chaque projet de cours d'accouchement doit prévoir le logement commun des élèves ou du moins justifier l'impossibilité d'installer un internat.

La conversion au système du pensionnat n'est cependant ni immédiate ni générale, car des obstacles matériels s'opposent souvent à la réalisation des prescriptions ministérielles : manque de place dans les institutions qui accueillent les cours, impossibilité pour la collectivité départementale de louer

67. Hufton O., « Le travail et la famille », dans Zemon Davis N., Farge A. (dir.), Histoire des femmes en Occident, $\mathrm{XVI}^{e}{ }^{-}$XVIII ${ }^{e}$ siècles [199I] Paris, Perrin, 2002, p. 27 ; Sonnet M., "Une fille à éduquer », ibid., p. I42-I44.

68. Gélis J., La Sage-femme ou le médecin..., op. cit., p. I5I-I52.

69. AD Saône-et-Loire, C 525.

70. RLRES I, p. 87, Règlement sur les cours d'accouchement à l'Hospice de la Maternité de Paris, II messidor an $\mathrm{x}$, titre $\mathrm{I}^{\text {er }}$, art. 3 et 4 .

7I. Beauvalet-Boutouyrie S., Naître à l'hôpital..., op. cit., p. II9-I20. 
ou d'acheter un local suffisamment grand pour cet objet, etc. De plus, les internats ne suffisent pas toujours pour recevoir toutes les élèves du cours, créant ainsi deux catégories : les internes, généralement boursières, et les externes, moins surveillées et moins favorisées dans l'accès à la formation clinique que leurs condisciples. C'est le cas à Angoulême en I8I3 avec six places réservées aux élèves gratuites et à Dijon en 1845 où le règlement prévoit un nombre maximal de 20 élèves dont io ont la possibilité d'être boursières et internes ${ }^{72}$. Caen en 1809, Angoulême en 1813, La Rochelle en I840 font de même, réservant à moins d'une dizaine de jeunes filles la possibilité d'être logées sur le lieu des cours ${ }^{73}$. Les nécessités de la discipline remettent parfois en cause cette division des élèves, comme à Lyon, où l'internat est étendu à l'ensemble des élèves sages-femmes en $1855^{74}$.

Sur l'ensemble du siècle, 47 institutions d'enseignement obstétrical font le choix de l'internat, soit la majorité des établissements de formation. Cependant, les dates d'ouverture des pensionnats ne coïncident pas toujours avec la création des cours. La Gironde, où les cours débutent avec l'installation de Marguerite Coutanceau à la fin du XVIII ${ }^{e}$ siècle, ne met en place d'internat clos qu'en $1854^{75}$. La Côte-d'Or maintient des cours en externat jusqu'à la réorganisation de $1845^{76}$. L'Ariège, où la tradition d'enseignement obstétrical de Pamiers est relevée avec l'approbation ministérielle dès 1809 , ne s'inquiète de la nécessité de loger ses élèves qu'en $1878^{77}$.

La chronologie des ouvertures de pensionnats s'étale donc largement sur le siècle, des créations précoces des années I800 (Paris, Strasbourg, Nantes, Orléans, Angers, Nancy, Caen, Besançon, Toulouse ou Reims) à celles de la seconde moitié du siècle (Brest, Bordeaux, Chambéry, Rodez, Limoges, Pamiers ou encore Pau). Elle s'articule avec les événements (recréations, réformes réglementaires) qui rythment la vie des écoles : en I834, les cours d'arrondissement corréziens sont remplacés par la création d'une école internat sise à la préfecture ${ }^{78}$; à Rodez, c'est le rétablissement du cours en 1859 qui justifie l'achat d'une maison pour loger élèves sages-femmes et femmes en

72. AN, Fi7 $/ 2458$, Charente; AN, Fi7/2458, Côte-d'Or.

73. AN, Fi7/2457, Calvados; AN, Fi7/2458, Charente; AD Charente-Maritime, 3 X 299.

74. AM Lyon, fonds de l'administration centrale des Hospices Civils de Lyon, 7 K P I.

75. AD Gironde, I N 48. Avant I854, les élèves sages-femmes de l'école d'accouchement de Bordeaux sont logées dans l'établissement mais n'y sont pas nourries et ont donc toute liberté de sortir pour se procurer leur nourriture.

76. AN, Fi7/2458, Côte-d'Or.

77. RD CG l'Ariège, $\mathrm{I} 878$.

78. Sage Pranchère N., Mettre au monde..., op. cit., p. 202-206. 
couches $^{79}$. La mise en place d'un pensionnat enracine le cours d'accouchement en lui offrant, par la clôture, une nouvelle respectabilité. Mais le résultat n'est pas toujours à la hauteur des attentes et la transformation en école-internat ne protège pas des suppressions comme c'est le cas à Rouen en $1830^{80}$.

Prendre la mesure de cet engouement pour le pensionnat impose aussi d'évoquer les projets inaboutis. En I857, le préfet du département du Nord attire l'attention du conseil général sur une demande du directeur de l'école préparatoire de médecine et de pharmacie de Lille faisant « mention des avantages qui résulteraient de l'établissement d'un internat pour les élèves sagesfemmes ${ }^{81}{ }$. En 1859 , il renouvelle ce vœu en annonçant qu'il va en saisir la commission administrative des hospices de Lille pour l'inviter à y apporter une réponse concrète. Un an plus tard, le dossier semble toujours à l'étude et le conseil général prend la décision de voter une allocation pour l'entretien de deux bourses d'élèves à l'Hospice de la Maternité de Paris ${ }^{82}$. Le dossier de la « maternité » de Lille devient alors un véritable serpent de mer des débats départementaux, sans que jamais l'opposition des institutions hospitalières municipales ne se relâche.

Sans être le modèle unique, l'école-internat correspond à la configuration la plus fréquente et à l'organisation privilégiée de l'enseignement. Elle répond en cela à une évolution plus large et plus ancienne des institutions féminines d'éducation. L'essor du séjour conventuel à l'adolescence touche des catégories sociales de plus en plus variées dans le Paris des Lumières ${ }^{83}$. Le siècle suivant signe l'apothéose de la pension. En maintenant un vide législatif sur la question de l'enseignement secondaire féminin, la Convention thermidorienne et le Directoire allègent les contraintes qui auraient pu peser sur les maîtresses de pension. Dès lors, les établissements se multiplient (70 institutions pour demoiselles à Paris en $1808^{84} ; 3480$ établissements pour 83 départements dans les années 1860 dont les deux tiers sont tenus par des religieuses ${ }^{85}$ ), imprégnant profondément les principes et les exigences de l'éducation féminine au XIX ${ }^{\mathrm{e}}$ siècle.

\footnotetext{
79. AD Aveyron, Per 545.

80. AD Seine-Maritime, $5 \mathrm{M} 42$.

8I. RD CG Nord, I857.

82. Ibid., I858, I859 et I860.

83. Sonnet M., L'Éducation des filles au temps des Lumières, Paris, Le Cerf, 1987, p. 195-201.

84. Rogers R., Les Bourgeoises au pensionnat..., op. cit., p. 69.

85. Ibid., p. 212-215.
} 
Il faut attendre la circulaire Duruy en 1867 pour que l'organisation d'un enseignement secondaire féminin soit réellement prise en compte dans le débat législatif ${ }^{86}$. Il est un domaine pourtant où l'État encourage précocement la mise en place d'un enseignement scientifique exigeant dans le cadre contraignant du pensionnat, c'est celui de la formation des sages-femmes (bien avant les institutrices dans les années $1840^{87}$ ). Alors qu'il laisse à la bourgeoisie le soin de déterminer les programmes qu'elle souhaite pour ses filles et aux maîtresses de pension toute latitude pour répondre aux souhaits de cette clientèle, l'État, par la référence de l'Hospice de la Maternité de Paris, impose l'internat comme contexte indispensable à la réussite scolaire des accoucheuses. Il en va de l'honorabilité d'une profession, partie intégrante du corps médical, comme de l'efficacité de l'acculturation et du contrôle social qu' ont en charge les sagesfemmes. Dans ces pensionnats, le modèle éducatif rapproche néanmoins les futures praticiennes des demoiselles au couvent. Le ministre de l'Instruction publique n'hésite d'ailleurs pas à écrire dans les années i 850 que « les élèves de la maternité [sont] littéralement cloîtrées et soumises à des règles de conduite très austères ${ }^{88}$ ». Mêmes exigences vestimentaires, mêmes lourdeurs des emplois du temps ${ }^{89}$, même rigueur morale, et parfois mêmes congrégations religieuses, les ressemblances sont trop fortes pour ne pas faire émerger, dans ces internats d'écoles d'accouchement, les linéaments d'une bourgeoisie du savoir, née au cœur du prolétariat.

\section{Sage-femme sous le voile}

L'essor de la formation obstétricale produit un rejeton original, qui conjugue avec la vie régulière les attentes morales, l'esprit charitable et le dévouement au service du prochain que doivent incarner les sages-femmes : les sœurs accoucheuses de la Maternité de Metz ${ }^{90}$. L'association des «filles» puis sœurs de la Maternité naît dans la préfecture mosellane au début du XIX ${ }^{\mathrm{e}}$ siècle.

86. Mayeur F., L'Enseignement secondaire des jeunes filles..., op. cit., p. 172 sq. ; Rogers R., Les Demoiselles de la Légion d'honneur : les maisons d'éducation de la Légion d'honneur au XIX siècle, Paris, Plon, 1992 et Les Bourgeoises au pensionnat..., op. cit.

87. Mayeur F., «La formation des institutrices avant la loi Paul Bert. Les cours normaux », Revue d'bistoire de l'Eglise de France, 1995, n² 206, p. 123-I24.

88. AN, Fi7/2464, Moselle.

89. Sur les costumes des élèves sages-femmes, voir Beauvalet-Boutouyrie S., Naître à l'hôpital..., op. cit., p. I22 ; Sur les emplois du temps, voir ibid., p. I65-167 et Sage Pranchère N., Mettre au monde..., op. cit., p. 462-466.

90. AN, Fi7/2464, Moselle ; S. Beauvalet-Boutouyrie, Naître à l'hôpital..., op. cit., p. 203. 
À l'origine de cette communauté on trouve l'initiative d'un accoucheur, le docteur Morlanne, en charge du cours départemental qui se met en place dans les mêmes intervalles. Praticien renommé de Metz, il encourage, dans la logique de l'ancienne Société de Charité maternelle, l'accès de religieuses à une profession qui vient d'acquérir ses lettres de respectabilité avec la loi de ventôse an XI. Cette création, unique par le caractère laïc de son fondateur, s'insère néanmoins dans le grand mouvement de multiplication des congrégations dès le début de la période napoléonienne ${ }^{91}$. L'ordonnance qui reconnaît son existence et fixe son fonctionnement n'est toutefois promulguée que le 2 décembre I8I4, sous la Première Restauration, avant que l'association, placée sous l'égide de sainte Félicité, ne soit dotée d'un règlement en $1822^{92}$. Le contenu de l'ordonnance confirme le but initial de la communauté fondée par Morlanne : la congrégation a pour objet de «former des gardes-malades sages-femmes ». L'article 4 de ce texte leur fait obligation de suivre les principes établis par la loi de ventôse en prévoyant que « les sœurs ne pourront pratiquer les accouchements, hors de la Charité maternelle, qu'après avoir été reçues sages-femmes », soulignant si besoin était la spécificité de cet art que nulle lettre d'obédience ne peut suppléer.

Les sœurs sages-femmes messines s'inscrivent donc dans une dynamique plus générale, même si leur transformation officielle en congrégation diocésaine n'intervient qu'en $1884^{93}$. Les domaines d'intervention des religieuses s'élargissent avec l'essor des congrégations féminines : éducation, hôpitaux, mais aussi desserte des prisons ou assistance à domicile. Les « bonnes sœurs » deviennent des figures familières de la société française du $\mathrm{xIX}^{\mathrm{e}}$ siècle ${ }^{94}$, qui n'hésitent pas à élargir leur rôle lorsqu'elles en ressentent la nécessité comme Jacques Léonard l'a montré pour les religieuses pharmaciennes de l'Ouest de la France ${ }^{95}$. À ce titre, les sœurs sont présentes au sein des écoles d'accouchement, ou dans les institutions hospitalières qui accueillent les cours, exerçant un rôle d'encadrement ou de gestion de l'établissement. Cette implication des religieuses n'est pourtant pas si naturelle que l'exemple messin pourrait le suggérer. L'attitude des congréganistes hospitalières à l'égard de certaines

9I. Langlois C., Le catholicisme au féminin. Les congrégations françaises à supérieure générale au XIX ${ }^{e}$ siècle, Paris, Le Cerf, I984, p. III-II8 et surtout p. I66.

92. AN, Fi7/2464, Moselle.

93. Jouffroy C., "La maternité de Metz », Mémoires de l'Académie nationale de Metz, 2005, p. 291-359.

94. Langlois C., Catholicisme, religieuses et société. Le temps des bonnes saurs, XIX ${ }^{e}$ siècle, Paris, Desclée De Brouwer, 20II ;

95. Léonard J., "Femmes, religion et médecine. Les religieuses qui soignent, en France au $\mathrm{xIX}^{\mathrm{e}}$ siècle », Annales. ÉSC, 1977, vol. 32, nº 5, p. 887-907. 
catégories d'admis est marquée tout au long du siècle par une profonde ambivalence. Au nom de leur proximité supposée avec le péché et le vice, filles-mères et vénériennes sont fréquemment l'objet d'un refus de soin, au point que les conventions passées entre religieuses et commissions administratives des hospices stipulent parfois expressément leur non acceptation dans l'établissement desservi par les sœurs ${ }^{96}$. Au sein des maternités, elles encouragent pareillement la ségrégation en fonction du statut matrimonial ${ }^{97}$.

Dans ce contexte, la congrégation de la Charité maternelle détonne par son choix d'étendre le rôle traditionnel de soin dévolu aux religieuses à l'intervention obstétricale, avec tout l'apprentissage que cela implique. La bonne sœur sage-femme est dès lors, plus encore que la jeune fille, l'antithèse absolue de l'accoucheuse justifiée par son expérience personnelle de la maternité. La qualité de la sage-femme repose ici sur la profondeur et la constance d'un engagement premier envers Dieu. Un des articles des statuts de I822 affirme que « lorsqu'une sœur de la Maternité remplit son devoir d'accoucheuse, c'est là qu'est pour elle son obligation la plus sacrée ». Vœux religieux et obligations professionnelles se confondent dans l'exaltation d'un dévouement à la Maternité, forme de la dévotion mariale, sublimation du célibat par l'aide apportée à la bonne naissance.

L'intrication des vocations religieuse et obstétricale n'est cependant pas exempte de répercussions sur l'enseignement. Les cours d'accouchement du département de la Moselle portent la marque de la coexistence d'élèves laïques et congréganistes. En I808, le préfet transfere les cours du dépôt de mendicité vers la maison des anciens Trinitaires, propriété de la municipalitée ${ }^{98}$. C'est l'occasion d'une première division de l'enseignement et de la réception des femmes enceintes. Les sœurs de la Charité maternelle s'installent dans la nouvelle maison qui accueille à partir de cette date les protégées de la Société de Charité maternelle locale, c'est-à-dire les femmes mariées ; le dépôt de mendicité continuant d'admettre les filles-mères jusqu'à sa fermeture en I8II. Les sœurs obtiennent d'être, au détriment des élèves laïques, les seules bénéficiaires de l'enseignement pratique dispensé dans l'établissement et le restent jusqu'à la suppression du cours départemental en 1850 . Les élèves sages-femmes non religieuses sont soumises pour leur formation clinique aux vicissitudes de l'accueil des filles-mères. Elles fréquentent de I8II à I83I la maison de correction

96. Jusseaume A., "Soigner des femmes en couches : un interdit levé pour évangéliser ?" 》, Chrétiens et sociétés, 2012, $\mathrm{n}^{\circ}$ I9, p. II7-153.

97. Léonard J., «Femmes, religion et médecine... », art. cit., p. 894-895.

98. AN, Fi7/2464, Moselle. 
avant que le docteur Morlanne ouvre son propre établissement, défrayé par le département pour la pension des sages-femmes et des filles-mères. En I843, il renonce à tenir cette maison et un nouveau déménagement intervient : les élèves sages-femmes sont désormais logées aux Trinitaires chez les sœurs et les filles-mères dans une maison d'asile, succursale des hospices de Metz. Cette réunion des élèves laïques et religieuses sous un même toit n'entraine cependant pas de réunion de l'enseignement.

La vocation des religieuses se limite donc aux mères « honorables » qui seules ont droit de cité aux Trinitaires. De la même manière, les accouchements faits à l'extérieur par les sœurs ne le sont qu'auprès de femmes mariées indigentes. Cette restriction donne à l'assistance maternelle messine un profil particulier, défini par le règlement des desservantes de l'hospice de la maternité. L'exclusion des filles-mères aboutit à leur confusion systématique avec les prostituées, contribuant à l'accélération de leur déclassement social et moral.

À terme, la dualité et l'inégalité de l'enseignement obstétrical à Metz ont raison de la formation des sages-femmes laïques. En I850, le conseil général de la Moselle vote, sur proposition du préfet, la suppression du cours et son remplacement par des bourses aux écoles de Paris et Strasbourg. Les sœurs de la Charité maternelle y perdent dans la foulée leur possibilité de formation. Elles entament alors une longue négociation avec le préfet et le ministre de l'Instruction publique pour obtenir l'autorisation de faire tenir des cours dans leur institution, à titre privé et pour leur seul bénéfice. La réponse du ministre qui arrive en septembre 1853 est une fin de non-recevoir polie : « [... ] je ne puis admettre que l'assiduité à ce cours tienne lieu de la scolarité légale. Ce serait créer en faveur d'un ordre particulier un privilège dont on pourrait se plaindre avec raison. »

Trois ans après la loi Falloux, une telle démonstration de principes est particulièrement savoureuse. Le dossier consacré aux sœurs de sainte Félicité dans les archives du ministère s'interrompt malheureusement sans que l'on sache quelle via media a pu permettre aux religieuses de poursuivre leur activité. Il est possible que les congréganistes, se pliant à la nécessité impérative d'une formation pratique, aient finalement surmonté leur répugnance à se former dans un établissement accueillant essentiellement des filles-mères et accepté de suivre une scolarité régulière dans une école d'accouchement. C'est le cas ultérieurement de certaines religieuses (hospitalières des hospices de SaintChamond et de Villefranche-sur-Saône) qui entrent à l'hospice de la Charité de Lyon à l'orée du $\mathrm{xx}^{\mathrm{e}}$ siècle $^{99}$. 
Toujours est-il que les sœurs de la Charité maternelle perdurent malgré la suppression du cours messin, obtiennent la protection des autorités françaises et allemandes après 1870 et qu'on les retrouve en I878 à Lille ${ }^{100}$. Dans cette ville où l'école préparatoire de médecine vient de se muer en faculté mais où les élèves sages-femmes demeurent externes malgré les demandes réitérées du professeur d'accouchement, la congrégation venue de Metz travaille à l'établissement d'une «école chrétienne de sages-femmes ${ }^{101}$ ». Le projet décrit dans un prospectus prévoit de placer l'école sous le patronage de l'université catholique de Lille et sous la direction des sœurs de la Charité maternelle. Après avoir rappelé l'installation des religieuses dans la préfecture du Nord en 1872 et la création d'une maternité en 1874 , le prospectus souligne :

Il est donc indispensable que la sage-femme reçoive non seulement une bonne instruction, mais une solide éducation chrétienne. [...] Si, comme tout permet de l'espérer, les Soeurs arrivent à fournir chaque année aux populations des villes et des campagnes de notre province ecclésiastique quinze élèves vraiment chrétiennes et instruites, dignes de leur titre de sage-femme, on peut entrevoir combien, en quelques années, on aura introduit d'éléments de bien dans notre société, et quelle digue puissante on aura élevée pour arrêter la corruption des mours.

L'objet est désormais de doubler le système public d'enseignement de l'obstétrique par une institution confessionnelle formant des sages-femmes chrétiennes. La complète prise en main de la formation obstétricale par l'État ou ses représentants depuis le dernier tiers du XVIII ${ }^{\mathrm{e}}$ siècle a progressivement exclu

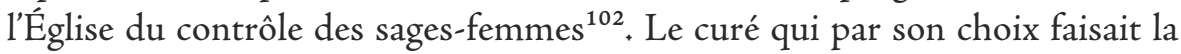
sage-femme au siècle précédent se contente de recommander une candidate à la bienveillance du préfet au XIX ${ }^{e}$ siècle. Les religieuses n'exercent qu'un rôle extérieur au processus pédagogique et professionnel, à l'exception notable mais numériquement minime de la congrégation de la Charité maternelle. À ce titre, l'influence ancienne du catholicisme est restreinte à sa dimension morale et perdure dans la mesure où les administrateurs et les médecins incluent la foi dans le portrait attendu de l'élève sage-femme. Le vote de la loi relative à la

Ioo. Couvreur I., Delcroix M., François M., La sage-femme à travers les 100 ans d'histoire d'une école, École de sages-femmes, Faculté libre de Lille, 1883-1983, Lille, 1983, p. 3-5.

IOI. Le Projet pour l'établissement d'une Maternité avec internat pour des élèves sages-femmes, sous la direction des soeurs de la Charité maternelle et le patronage de l'université catholique, à Lille est publié, sous forme de prospectus, à Lille chez Lefebvre Ducrocq en 1878 et conservé dans les fonds de la Bibliothèque nationale de France.

I02. Pinell P., «La genèse du champ médical : le cas de la France (I795-1870) », Revue française de sociologie, 2009-2, vol. 50, p. 317. 
liberté de l'enseignement supérieur dite loi Dupanloup, bouleverse, le i2 juillet I875, la situation acquise depuis les années 1780. En mettant fin au monopole de l'État sur l'enseignement supérieur, ce texte dénoue la difficulté rencontrée à Metz en I853. L'Église peut désormais occuper dans le domaine de la formation médicale et en l'occurrence obstétricale une place inédite. La barrière légale tombe, donnant aux sœurs de la Maternité toute latitude pour organiser un cours privé d'accouchement sous la houlette de l'établissement universitaire lillois récemment fondé ${ }^{103}$.

\section{De l'État au département, la sage-femme, agent au service des populations}

\section{La sage-femme, une diplômée de l'État}

L'entrée en scène des institutions catholiques d'enseignement dans le champ de la formation obstétricale n'est que la résultante particulière d'un mouvement plus général de renoncement de l'État à son monopole scolaire, avant la reprise en main laïque du début des années 1880 . Cette diversification des acteurs de l'instruction des sages-femmes se fait néanmoins sur le modèle de la loi du ig ventôse an XI. L'identité des cursus est indispensable à la reconnaissance du diplôme.

L'examen et le diplôme sont au cœur de la définition des sages-femmes. Les modalités d'organisation et de délivrance au début du XIX ${ }^{\mathrm{e}}$ siècle sont le résultat de la place croissante occupée par la validation du savoir à l'issue des cours d'accouchement sous l'Ancien Régime ${ }^{104}$. Au cours de la décennie I790 et jusqu'au vote décisif de I803, l'État travaille à s'arroger le monopole du contrôle des compétences et de la délivrance des attestations nécessaires à l'exercice du métier.

Dès son exposé des motifs, la loi de ventôse an xi pose le caractère essentiel de l'examen et du diplôme ${ }^{105}$. Les articles 16 , I8 et 32, suivis des dispositions de l'arrêté du 20 prairial an XI, fixent pour un demi-siècle les principes d'obtention. Les prescriptions réglementaires se limitent toutefois dans le cas des

I03. La Faculté de médecine et de pharmacie de l'université catholique de Lille ouvre ses portes le 6 juillet 1877 , un an après son équivalent laïc.

I04. Gélis J., La Sage-femme ou le médecin..., op. cit., p. 169-172 ; Sage Pranchère N., Mettre au monde..., op. cit., p. 137-139.

105. RLRES I, p. 9I ; voir aussi Rabier C., "Une révolution médicale ? Dynamiques des professions de santé entre Révolution et Empire », AHRF, janvier-mars 2010, nº 358, p. 142. 
sages-femmes à la définition du contenu (tandis qu' elles déterminent avec précision la nature des examens annuels imposés aux étudiants en médecine $\left.{ }^{106}\right)$, et laissent aux professeurs le soin de contrôler l'acquisition progressive des connaissances. À l'issue de la formation est exigé un seul examen oral portant sur « la théorie et la pratique des accouchements, sur les accidents qui peuvent les précéder, les accompagner et les suivre, et sur les moyens d'y remédier ». En prairial, l'article 43 consacré à la réception des sages-femmes détaille le déroulement de l'examen (interrogation orale et démonstration sur le mannequin).

La division en deux catégories de sages-femmes modifie le nombre d'épreuves pour les élèves appelées à former la première classe de la profession (deux examens). Le jury varie en fonction de la catégorie, composé de professeurs des écoles de médecine pour les aspirantes de première classe et identique à celui qui examine les officiers de santé pour la deuxième classe. Les jurys médicaux constitués aux chefs-lieux des départements rassemblent trois représentants du corps médical nommés par le Premier Consul : un professeur d'une des trois écoles de médecine portant le titre de commissaire et deux docteurs en médecine ou en chirurgie. Les professeurs des écoles de médecine sont dans tous les cas désignés à partir de listes doubles soumises au Premier Consul par les établissements ${ }^{107}$. Les deux docteurs sont pour leur part choisis sur des listes départementales dont la confection est à la charge des préfets ${ }^{108}$.

L'organisation du contrôle final des compétences impose aussi d'établir une géographie du rayonnement des différentes écoles de médecine. L'échelon départemental est la brique de base des circonscriptions parisienne, strasbourgeoise et montpelliéraine, auxquelles s'ajoute sous l'Empire celle de Mayence ${ }^{109}$. Ces circonscriptions définies en prairial an XI sont confirmées par l'arrêté du 2I mai I8I2 qui établit le roulement des présidences de jury et les règles d'admission des candidats aux épreuves ${ }^{110}$. Ces deux dernières préconisations sont emblématiques de la logique centralisatrice à l'œuvre.

Au-delà des découpages administratifs, la validité des jurys repose sur la délégation de l'autorité du gouvernement aux présidents des jurys et aux préfets. Les préfets forment pendant le premier semestre de chaque année

I06. RLRES I, p. IIO-II2, arrêté du 20 prairial an XI, articles 5 à 20.

I07. Ibid., p. II4 (art. 34 et 35).

I08. Ibid., p. II3-II4 (art. 33).

I09. Ibid., p. II8.

IIO. Ibid., p. 346-353 : Arrêté concernant la circonscription des arrondissements des Facultés de médecine pour les Jurys médicaux, l'admission des candidats aux examens, la répartition des droits de réception entre les membres du Jury, les procès-verbaux du Jury et les modèles de certificats et titres des réceptions, 2I mai I8I2. 
la liste des aspirants aux différentes fonctions médicales (officiers de santé, sages-femmes, pharmaciens, herboristes) et les transmettent aux présidents des jurys. Ceux-ci vérifient que toutes les conditions, financières en particulier, sont réunies pour la convocation et la tenue des séances avant d'en informer le ministre de l'Intérieur, seul habilité à ordonner la réunion des jurys $(\operatorname{art.5})^{111}$. L'impossibilité pratique de réunir les jurys, par manque de candidats ou par insuffisance des fonds rassemblés, qui devient une difficulté récurrente, est prévue dans les textes réglementaires. Les candidats inscrits peuvent alors, sur double autorisation du président du jury de l'arrondissement et du préfet, se présenter devant le jury d'un département voisin (art. 7).

Dans les faits cependant, les retards et les empêchements foisonnent. Le nombre souvent restreint d'aspirants réduit à la portion congrue le produit des réceptions et ne suffit pas à défrayer les examinateurs. Dans ces conditions, la tenue du jury est reportée et l'obligation d'aller se faire recevoir dans un autre département entraîne des frais auxquels les candidats et en particulier les futures accoucheuses ne peuvent pas faire face. Au-delà, le calendrier de nombreux cours d'accouchement impose aux élèves sortantes d'attendre plusieurs mois sans exercer avant de pouvoir se faire inscrire auprès de la préfecture pour être examinées par le jury médical. Marie Izard, élève sage-femme de l'université de Montpellier, termine sa scolarité à la fin de l'année I82I. Or le jury du département de l'Aude devant lequel elle souhaite se présenter ne se réunit qu'en octobre. Elle demande alors au préfet « de vouloir bien l'autoriser à opérer des accouchements dans cette ville jusqu'à la réunion de ce jury ${ }^{112}$ ». Le rythme irrégulier des sessions, les décalages entre scolarité et examen officiel produisent donc une réglementation provisoire, laissée à la discrétion du préfet. Ces autorisations accordées sur demande individuelle ou à des promotions entières d'élèves sages-femmes créent une situation d'incertitude légale ${ }^{113}$. Leur durée de validité court en théorie jusqu’à la réunion suivante du jury médical mais tend fréquemment à se prolonger indéfiniment lorsque l'aspirante est prise par ses obligations professionnelles et familiales. En 1859, une affaire de ce type est portée à la connaissance du ministre de l'agriculture, du commerce et des travaux publics :

III. Les conditions financières recouvrent les droits de présence des différents membres du jury (art. 9), les frais de voyage et l'indemnité extraordinaire du président, ainsi que les frais d'impression des titres à décerner et des extraits de procès-verbaux qui sont remplis pendant les examens (art. IO), dans RLRES I, p. 347-348.

II2. $\mathrm{AD}$ Aude, $5 \mathrm{MD}$ i6.

II3. Sage Pranchère N., Mettre au monde..., op. cit., p. 418. 
Jusqu'en i854, les nommées Marie Anne Alrau et Thérèze Barnabé, veuve Mazart, ont exercé leur profession de sage-femme à Rignac, au moyen d'un certificat de capacité qui leur avait été délivré par le professeur du cours d'accouchement. Aucune plainte ne s'était élevée à cet égard. Mais en I856, la nommée Marie Anne Alrau a régularisé sa position devant l'école préparatoire de Toulouse et alors elle s'est plainte de la situation irrégulière de la veuve Mazart. ${ }^{114}$

Les deux femmes ont reçu des certificats de capacité à l'issue de leurs cours d'accouchement en I84I et I842. Pendant quatorze ans, Thérèze Mazart exerce donc sans que nul ne trouve à s'en plaindre et cette situation se serait sans doute prolongée sans la décision de sa collègue accoucheuse de se faire recevoir. Un tel exemple est révélateur de la souplesse des pratiques et surtout de la difficulté qu'ont les élèves sages-femmes à distinguer certificat de fin d'études et diplôme délivré par un jury officiel.

La multiplication des dysfonctionnements nés du système des jurys départementaux de médecine aboutit très précocement à une réflexion sur leur remplacement. Les plaintes sont anciennes, tant sur l'irrégularité des réunions que sur le laxisme qui préside aux délivrances de diplômes. En I825, un projet de loi déposé devant la chambre par Corbière et Cuvier propose leur suppression, mais le gouvernement enterre le texte en refusant une seconde lecture ${ }^{115}$. Huit ans plus tard, une discussion s'élève à ce propos au sein de l'Académie de médecine, sur demande de Guizot ${ }^{116}$. Orfila, doyen de la faculté de médecine de Paris, fort de ses quatorze ans à la tête des jurys de l'arrondissement parisien, tente maladroitement de défendre ce système contre les attaques de plusieurs de ses collègues, mais son évocation du sérieux de certains examinateurs (parmi lesquels, le docteur Flaubert de Rouen) ne fait que souligner l'absence d'unité dans les pratiques de contrôle et renforcer l'opposition farouche des présents ${ }^{117}$.

Il faut attendre I854 pour que soit mise en place une nouvelle géographie de l'enseignement (académies) ${ }^{118}$ et que soit modifié le mode d'examen des personnels de santé. La dernière circulaire du ministre de l'Instruction publique

\footnotetext{
II4. AD Aveyron, $5 \mathrm{M} 8$.

I15. Léonard J., Les médecins de l'ouest..., op. cit., p. 772-774.

II6. Ibid., p. 782-783.

II7. "Académie de médecine. Séance du I6 novembre i833 : discussion sur le rapport de la commission concernant un nouveau plan de réorganisation médicale ", dans Gazette médicale de Paris, journal de médecine et des sciences accessoires, Paris, I833, série 2, nº I, p. 803-804.

II8. Loi sur l'instruction publique du I4 juin 1854. Cette nouvelle géographie donne lieu à une nouvelle répartition des circonscriptions attachées à chaque faculté de médecine et, désormais, à chaque école préparatoire de médecine et de pharmacie.
} 
à autoriser la tenue des jurys médicaux est datée du 15 mai $1854^{119}$. Trois mois plus tard, l'article 17 du décret impérial du 22 août tranche une discussion vieille de plusieurs décennies ${ }^{120}$ :

Les jurys médicaux cesseront leurs fonctions au $\mathrm{I}^{\text {er }}$ janvier prochain, en ce qui concerne la délivrance des certificats d'aptitude pour les professions d'officier de santé, sage-femme, pharmacien et herboriste de deuxième classe.

À partir de cette époque, les certificats d'aptitude pour la profession d'officier de santé et celle de sage-femme seront délivrés, soit par les facultés de médecine de Paris, Montpellier et Strasbourg, soit par les écoles préparatoires de médecine et de pharmacie, sous la présidence d'un professeur de l'une des facultés de médecine. ${ }^{121}$

Ce décret consacre la tutelle des établissements d'enseignement médical sur la formation des sages-femmes par le biais de la délivrance du diplôme, dans un contexte où l'enjeu principal réside dans le relèvement du niveau des officiers de santé $^{122}$. Les notabilités médicales des départements y perdent en reconnaissance. L'appartenance à un corps professoral prime désormais sur la réputation et la pratique locales. Les accoucheuses de première classe continuent d'être reçues devant les jurys des facultés, avec une légère hausse de droits d'examen et de certificat (de I20 à 130 francs) ${ }^{123}$. La réception des sages-femmes de deuxième classe peut se faire de la même façon devant les facultés de médecine et devant les écoles préparatoires de médecine et de pharmacie en versant 25 francs de droits (arrêté du 23 décembre 1854$)^{124}$.

Cette évolution apparemment minimale des modes de réception provoque néanmoins quelques remous à l'Hospice de la Maternité de Paris puisque ses élèves bénéficient depuis l'arrêté du 20 prairial d'un régime dérogatoire qui les assimile à des élèves de la Faculté de médecine. Une circulaire aux recteurs du ministre Fortoul, en date du 23 juin 1856, annonce que la possibilité d'échange

I19. Recueil des lois et actes de l'instruction publique, année 1854, Paris, imprimerie et librairie de Jules Delalain, 1854 : circulaire du ministre de l'Instruction publique et des cultes aux préfets, relative aux sessions des jurys médicaux pour l'examen des aspirants aux titres d'officier de santé, de pharmacien, d'herboriste et de sage-femme, I5 mai 1854, p. 283-285.

120. Léonard J., Les médecins de l'ouest..., op. cit., p. 788-822.

I2I. Recueil des lois et actes de l'instruction publique, année 1854, op. cit., décret impérial, relatif aux établissements publics d'enseignement supérieur et aux rétributions exigibles pour les inscriptions et la collation des grades, 22 août I854, p. 339-340.

122. Léonard J., Les médecins de l'ouest..., op. cit., p. 946 sq.

123. Arrêté du 20 prairial an XI, article 43 ; décret du 22 août I854, article 13 (deux examens soit 80 francs ; certificat d'aptitude, 40 francs ; visa du certificat, io francs).

124. Recueil des lois et actes de l'instruction publique, année 1854..., op. cit., p. 570 sq. 
sans examen du certificat obtenu à la sortie de Port-Royal contre un certificat d'aptitude est maintenue, mais que la gratuité est remplacée par la perception des 25 francs de droits et le rayon d'exercice réduit à celui d'une sage-femme de deuxième classe ${ }^{125}$. Une telle décision rétrograde l'établissement parisien au rang des cours de province, ce que ses professeurs ne peuvent tolérer. La riposte est immédiate et le I9 août I857, une nouvelle circulaire prévoit, dans les mêmes termes pécuniaires, l'échange du certificat de l'école contre un certificat de sagefemme de première classe, restaurant du même coup la compétence nationale des élèves de la Maternité de Paris ${ }^{126}$.

La composition des jurys varie en fonction de l'institution : deux professeurs titulaires et un agrégé choisi par le doyen dans les facultés (art. II $)^{127}$; un professeur titulaire de faculté et deux professeurs titulaires ou adjoints de l'école préparatoire devant laquelle se présentent les candidats (art. IO) ${ }^{128}$. Le seul impératif dans les deux cas est la participation du professeur d'accouchement au jury. Ces formes d'examen restent en usage jusqu'aux décrets de I893 qui modifient en profondeur le cours des études. La décision du jury médical puis des jurys d'écoles est reportée sur des procès-verbaux préimprimés, puis conservée après 1854 dans les archives des établissements d'enseignement supérieur. Le diplôme est délivré aux aspirantes qui ont satisfait aux exigences du jury. Il est rédigé selon un modèle défini dans l'arrêté de prairial an XI et confirmé par l'arrêté de mai I812 $2^{129}$.

L'obtention de ce document ne suffit pourtant pas et les officiers de santé et les sages-femmes ont l'obligation de présenter dans les plus brefs délais leur diplôme au tribunal de première instance, ou à la sous-préfecture de l'arrondissement où elles résident (art. 34 de la loi de ventôse). La mention en est inscrite sur un registre manuscrit dont copie est adressée au préfet pour servir de matrice à la confection des listes départementales de personnel médical ${ }^{130}$. La tenue de ces listes et leur envoi au ministre de l'Intérieur sont d'abord prévus à un rythme annuel en 1803, puis quinquennal à partir de 1812, tout en demandant la publication intermédiaire de listes complémentaires ${ }^{131}$. Ces documents deviennent dès lors le point de référence des autorités. Tout exercice de l'art médical en

\footnotetext{
125. RLRES 2, p. 472.

126. Ibid., p. 499. Beauvalet-Boutouyrie S., Naître à l'hôpital..., op. cit., p. II2.

127. Recueil des lois et actes de l'instruction publique, année 1854..., op. cit., p. 574.

I28. Ibid., p. 573-574.

129. RLRES I, p. II7 (arrêté du 20 prairial an XI) et 350 (arrêté du 2I mai I8I2).

130. Voir pour exemple AD Côtes d'Armor, $5 \mathrm{M}_{2}{ }^{*}$.

I3I. RLRES I, p. 348.
} 
l'absence d'inscription sur la liste du personnel médical est illégal. Au-delà, la diffusion de ces listes est une manière de faire connaitre les noms des praticiens. L'ambivalence d'une profession libérale imprégnée d'obligations publiques ressort dans la double fonction de cet enregistrement préfectoral, du contrôle de légalité au prestige acquis par l'inscription sur ce sésame administratif.

\section{Agent de santé publique $e^{132}$}

L'intensité du contrôle exercé par les autorités politiques sur le corps médical en général et sur les sages-femmes en particulier se mesure aux multiples devoirs légaux qui leur incombent. L'Annuaire des sages-femmes de Paris, publié en 1876 sous la direction du docteur Eugène Verrier, consacre ses quarante premières pages à rappeler les « décrets et règlements à l'usage des sages-femmes ${ }^{133}{ }_{\Perp} \mathrm{Ce}$ long récapitulatif dessine les contours d'un véritable agent de santé publique, dont le rôle social est aussi fortement encouragé par l'État que strictement soumis à la législation ${ }^{134}$. La première obligation légale d'une sage-femme concerne la déclaration des naissances dans les trois jours de l'accouchement et relève des articles 55 et 56 du Code civil de I804, aboutissement du travail législatif mené par les assemblées successives autour de la laïcisation de l'état civil depuis le début de la Révolution et la loi du 20 septembre $1792^{135}$.

La sage-femme acquiert donc, avant même la réforme de l'enseignement et de l'exercice médical, une reconnaissance officielle. Sa présence dans le processus de déclaration des naissances est néanmoins subsidiaire, à l'instar des autres auxiliaires médicaux de l'accouchement, puisqu'elle se limite aux cas d'indisponibilité du mari. Là où l'accoucheuse portait et porte encore quasi systématiquement l'enfant au baptême, elle se trouve placée au second rang à la mairie. Le résultat pratique de cette mesure est de réduire l'action déclarative de la sage-femme aux naissances illégitimes ou, plus exceptionnellement, aux couples temporairement ou définitivement séparés. À ce titre, elle renouvelle

132. Voir Sage Pranchère N., «L'appel à la sage-femme. La construction d'un agent de santé publique (France, $\mathrm{XIX}^{\mathrm{e}}$ siècle) », $A D H, 2014 / \mathrm{I}$, p. I8I-209.

133. Verrier E., Annuaire des sages-femmes de Paris, Paris, aux bureaux de la Gazette obstétricale, 1876.

134. Ce type de rappel est aussi présent en tête de manuels comme celui des docteurs Maunoury et Salmon (1850, I86I et 1874) ou la traduction française de celui de Franz Carl Naegele (I853).

135. Sur le processus d'instauration d'un état civil laïcisé, voir Gourdon V., Les révolutions du baptême en France de 1789 à nos jours. Mémoire original du dossier Métamorphoses de la famille en France, $X V I I^{e}-X_{I} X^{e}$ siècle : biérarchies, réseau, ritualisation, Habilitation à diriger des recherches, Histoire, Paris, Université Paris-Sorbonne, 2014. 
à la sage-femme le soin traditionnel de signaler les naissances hors mariage tel que le lui confiaient certaines autorités municipales d'Ancien Régime ${ }^{136}$.

Cette obligation imposée aux sages-femmes a un pendant $:$ la sanction pénale en cas de non déclaration. Celle-ci tarde cependant à être inscrite dans la loi. C'est le Code pénal de i8io qui prévoit dans son article 346 les poursuites et les peines afférentes à la non déclaration de naissance : emprisonnement de six jours à six mois et amende de 16 à 300 francs. Le principal risque de ce manquement est la menace qu'une inexistence légale fait peser sur la vie de l'enfant (infanticide, abandon). La crainte d'une collusion entre filles-mères malintentionnées et sages-femmes sans scrupule est permanente chez les autorités administratives (ill. 5). En 1837, le conseil général des hospices de Paris prend un arrêté imposant pour l'admission d'un enfant la présentation d'un procès-verbal d'un commissaire de police ${ }^{137}$. Ce texte a pour but revendiqué de réduire la facilité des admissions aux hospices et donc le nombre d'enfants laissés à la charge des secours publics. Un ensemble de circulaires est envoyé dans les semaines suivantes aux accoucheurs, sages-femmes, commissaires de police, préfets des départements environnants (art. 8, 9 et IO). Les courriers adressés par le préfet de police aux sages-femmes à la fin du mois d'octobre 1837 et aux maires et commissaires de police des communes rurales de la Seine le 25 novembre suivant éclairent l'ambivalence du discours sur le rôle des sages-femmes dans ce domaine. La circulaire aux accoucheuses fait appel à leur sens professionnel et aux liens de confiance qu'elles tissent avec leur clientèle, les incitant à « [unir leurs] efforts à ceux de l'administration ${ }^{138}$ », tandis que le courrier adressé quelques semaines plus tard aux maires et commissaires de police souligne l'extrême vigilance dont ces fonctionnaires doivent faire preuve envers les sages-femmes :

Que votre langage, en un mot, soit persuasif, bienveillant avec toutes, mais en même temps qu'il soit ferme et sévère avec celles qui vous paraîtraient peu disposées à déférer à vos observations, ou dont les antécédents prêteraient à la censure. ${ }^{139}$

I36. Lottin A., "Naissances illégitimes et filles-mères à Lille au xviri ${ }^{e}$ siècle », RHMC, I970, avril-juin, p. 280-28I ; Depauw J., " Amour illégitime et société à Nantes au XVIII ${ }^{\mathrm{e}}$ siècle », Annales, ÉSC, 1972, vol. $27, \mathrm{n}^{\circ} 4-5$, p. II57.

137. Travaux de la commission des Enfants-Trouvés instituée le 22 août 1849 par arrêté du ministre de l'Intérieur, t. II, Paris, Impr. nationale, I850, arrêté du 25 janvier 1837, p. 758-759.

138. Verrier E., Annuaire des sages-femmes de Paris, op. cit., p. 20, circulaire de la préfecture de police de Paris aux sages-femmes, s. d. [1837].

139. Travaux de la commission des Enfants-Trouvés..., op. cit., p. 764-765, lettre du préfet de police aux maires et commissaires de police des communes rurales du département de la Seine, 25 novembre 1837 . 
Membre du personnel médical, auxiliaire recherchée de l'administration, la sage-femme suscite néanmoins une méfiance tenace. En I844, saisi par la municipalité lilloise d'une proposition de réouverture du tour d'abandon fermé depuis deux ans, le conseil général du Nord se prononce fermement contre ce projet, et le rapport présenté lors de cette session dénonce à son tour le trafic des accoucheuses :

L'existence des tours sans contrôle donnait lieu à un trafic honteux. [... et comme les bénéfices étaient considérables et le délit impuni, des sages-femmes faisaient le commerce de recruter les filles enceintes. ${ }^{140}$

Pour lutter contre ces tendances, les administrateurs font le choix continu de resserrer les liens entre les sages-femmes et l'autorité, manière d'accentuer le contrôle de la seconde sur les premières. Entre autres domaines, citons d'abord celui de l'expertise judiciaire, déjà en vigueur sous l'Ancien Régime lorsque les matrones jurées attachées aux différentes instances judiciaires (parlements, présidiaux, bailliages) étaient sollicitées pour l'examen des femmes soupçonnées de cacher leur grossesse, celui de la virginité ou la vérification des conditions requises pour le «congrès » conjugal ${ }^{141}$. Au xix ${ }^{e}$ siècle, les interventions des sages-femmes portent plutôt sur les soupçons d'avortement ou d'infanticide. La réforme de l'enseignement de la médecine qui ouvre le siècle confirme la légitimité d'expertise du personnel médical, tandis que l'article 43 du Code d'instruction criminelle de 1808 fixe dans la loi le principe du recours aux experts. Au cours du siècle, trois textes réglementent le tarif des honoraires dus au personnel médical lorsque la justice requiert son intervention : les décrets du I8 juin I8II et du 7 avril I8I3, et l'ordonnance du 28 novembre $1838^{142}$. Les honoraires varient en fonction du statut (médecin ou sage-femme), mais surtout de l'obligation de déplacement, de la distance et de la durée de l'expertise. L'article I8 de l'ordonnance de I 838 prévoit que les visites des sagesfemmes soient payées 3 francs à Paris et 2 francs dans toute autre ville, soit deux fois moins qu'un médecin. Le Code d'instruction criminelle exige qu'un serment soit prêté par les experts, à chaque fois que leur compétence est requise (visite, témoignage devant le juge d'instruction ou la cour), à peine de nullité ${ }^{143}$.

\footnotetext{
I40. RD CG Nord, I879.

I4I. Gélis J., La Sage-femme ou le médecin..., op. cit., p. 47-49 ; Desmaze C., Histoire de la médecine légale en France d'après les lois, registres et arrêts criminels, Paris, G. Charpentier, I880, p. 6.

142. Briand J., Chaudé E., Manuel complet de médecine légale et contenant un Traité élémentaire de chimie légale ( $9^{\mathrm{e}}$ édition), Paris, J.-B. Baillière et fils, I874, p. 57 sq.

143. Ibid., p. I8-20.
} 
Enfin, l'expertise doit donner lieu à un rapport dont la forme est soigneusement définie (préambule, description des faits, conclusions). Eugène Verrier joint en I876 à son Annuaire des sages-femmes de Paris plusieurs modèles de certificats et un modèle de rapport ${ }^{144}$.

Autre domaine public d'activité de la sage-femme : celui des politiques sanitaires et d'assistance mises en place pour les femmes en couches et les enfants du premier âge. Le devoir d'aide aux parturientes indépendamment de leur fortune est un principe fondateur de la profession, depuis l'émergence à la fin du Moyen Âge de l'accoucheuse urbaine, rémunérée par la municipalité pour assister les indigentes ${ }^{145}$. Au moment de la rédaction des cahiers de doléances, la nécessité d'attacher à chaque paroisse une sage-femme formée et payée pour faire des accouchements gratuits est constamment exprimée, et après la Révolution, le premier texte à envisager clairement cette assistance obstétricale locale est le projet de décret sur l'enseignement et l'exercice de la médecine de Guillotin en $1791^{146}$, relayé par l'article I8 de la loi du 24 vendémiaire an II qui prévoit que «tout malade [...] qui sera sans ressources, sera secouru ou à son domicile de fait, ou à l'hospice le plus voisin ${ }^{147}$ ».

Mais cette intention peine à être mise en œuvre. La fondation des bureaux de bienfaisance par la loi du 7 frimaire an $\mathrm{v}$, dans la continuité des bureaux de charité de l'Ancien Régime, offre un cadre à l'assistance médicale aux indigents. Les femmes en couches sont assimilées aux malades, comme le confirme ultérieurement la loi du I5 juillet I893 dans son premier article, ce qui justifie le rattachement de sages-femmes aux bureaux de bienfaisance. Ce système reste néanmoins très inégal pendant la première moitié du siècle, nombre de communes manquant de moyens pour supporter cette charge, même s'il faut souligner les efforts de certaines municipalités pour salarier une sage-femme (Haut-Rhin, Ardèche). Si l'on met à part la capitale où chaque arrondissement possède son bureau de bienfaisance, ce sont les chefs-lieux de département, d'arrondissements et parfois de cantons qui forment la trame plus ou moins serrée des institutions d'assistance ${ }^{148}$. Des projets de réorganisation nationale des secours médicaux existent cependant et les débats sur les médecins

\footnotetext{
144. Verrier E., Annuaire des sages-femmes de Paris, op. cit., p. I7.

145. Gélis J., La Sage-femme ou le médecin..., op. cit., p. 23-27.

146. AP, t. 30, Annexes, p. 40.

147. Pécheyran G., L'Assistance médicale en France et la loi du 15 juillet 1893, Paris, A. ChevalierMaresq, 1899, thèse pour le doctorat en droit, p. 3-4.

I48. Beauvalet-Boutouyrie S., Naître à l'hôpital..., op. cit., p. 313-314. L'auteur signale la présence de II3 sages-femmes attachées aux bureaux de bienfaisance au milieu du siècle. En I876, Eugène Verrier en répertorie 94, Annuaire des sages-femmes de Paris, op. cit., p. 168-172.
} 
cantonaux qui agitent le congrès médical en 1845 en sont le signe ${ }^{149}$. Ce sont finalement les circulaires du I5 août I 854 et du 22 août I 855 qui ouvrent la voie à une gestion semi-centralisée de l'assistance ${ }^{150}$.

Dans ce contexte, les sages-femmes cantonales prennent une importance croissante ${ }^{151}$. Leur rémunération évolue au fil du siècle. Vers I850, les bureaux de bienfaisance parisiens paient 8 francs par accouchement ${ }^{152}$. La mise en place en 1867 du système des sages-femmes agréées par l'administration des hôpitaux parisiens sur proposition des directeurs d'établissement introduit une strate intermédiaire entre le secours gratuit à domicile et l'hospitalisation. Chaque accouchement est rémunéré 15 francs et chaque journée de présence après la naissance rapporte six francs supplémentaires à l'accoucheuse dans les années I880. Cette activité est surveillée avec beaucoup d'attention par l'administration hospitalière et la question du contrôle médical de ces sages-femmes se pose avec acuité dès la création de ce réseau de praticiennes ${ }^{153}$. La loi du 15 juillet I893 sur l'assistance médicale vient enfin combler les lacunes du système de secours et répondre à l'ambition exprimée en l'an $\mathrm{II}^{154}$. Un projet type d'organisation d'un bureau d'assistance, institution qui remplace le bureau de bienfaisance, précise en 1894 le texte de $10 i^{155}$.

Ce sont les départements qui sont à ce stade chargés de rédiger des règlements pour l'application de la loi du i5 juillet. Cette délégation ne favorise pas l'égalité de traitement du personnel médical d'un département à l'autre, comme dans le Morbihan où le Conseil général privilégie l'économie et fixe la rémunération d'un accouchement à 6 francs ${ }^{156}$. Deux systèmes concurrents sont institués : un par circonscriptions médicales dit «système alsacien », et un de

149. "Congrès médical de France. Compte-rendu des travaux de la section de Médecine Médecins cantonaux », Bulletin général de thérapeutique médicale et chirurgicale, $\mathrm{n}^{\circ} 29$, Paris, chez le rédacteur en chef, I845, p. 384-387.

I50. Faure O., "La médecine gratuite au XIx ${ }^{e}$ siècle : de la charité à l'assistance », HES, I984, vol. $3, \mathrm{n}^{\circ} 4$, p. 597-60I.

I5I. Id., « Les sages-femmes en France au XIX ${ }^{\mathrm{e}}$ siècle... », art. cit., p. I69.

152. Beauvalet-Boutouyrie S., Naître à l'hôpital..., op. cit., p. 314-315.

153. Ibid., p. 315-318.

154. Turquan V., Petit manuel de l'assistance publique, des hospices, hôpitaux, bureaux de bienfaisance et des bureaux d'assistance médicale (exécution de la loi du 15 juillet 1893) : textes législatifs et réglementaires, instructions détaillées, commentaires et rapports officiels, statistiques générales, formules et modèles à adopter, Paris, P. Dupont, I894, p. 3-15.

155. Ibid., p. 139-I48.

156. Département du Morbiban. Assistance publique. Règlement pour l'application de la loi du 15 juillet 1893 sur l'assistance médicale gratuite, adopté par le Conseil général dans sa séance du 27 août 1899 et modifié par des délibérations ultérieures, Vannes, Impr. de Galles, 1903, p. 2-4. 
« libre adhésion » dit « vosgien », où tous les membres du personnel médical acceptant de se soumettre au règlement établi par le conseil général sont de plein droit médecins et sages-femmes de l'assistance. Le second système est de loin le plus répandu puisqu'il concerne 65 départements sur $85^{157}$. La rémunération des sages-femmes pour cette activité se fait généralement selon un principe forfaitaire.

Par ailleurs, les sages-femmes élargissent progressivement leur champ d'intervention à deux domaines connexes de l'obstétrique : la vaccination et les soins au premier âge. Leur rôle constant dans la lutte contre la variole a été bien montré, de la charge essentielle de la conservation du fluide vaccin aux épuisantes tournées dans les campagnes pour vacciner des centaines d'enfants ${ }^{158}$. Dans certains départements elles prennent en charge l'immense majorité des vaccinations : c'est le cas en Corrèze où l'on compte en I869 sept médecins pour 33 sages-femmes parmi les vaccinateurs; ou dans le Puy-de-Dôme où elles effectuent « les cinq sixièmes des vaccinations dans les campagnes ${ }^{159}$ ». Mais cette omniprésence suscite parfois la vindicte de médecins furieux de voir leur échapper les indemnités départementales ${ }^{160}$. Dernier domaine enfin où elles sont sollicitées par les autorités : la protection primo-infantile. Le vote de la loi Roussel en I874 institue une surveillance de l'autorité publique sur tous les enfants de moins de deux ans placés en nourrice hors du domicile de leurs parents, et confie à des médecins-inspecteurs le contrôle des nourrices ${ }^{161}$. Suivie d'un règlement d'administration publique publié le 27 février 1877 , cette mesure est l'occasion d'une nouvelle réflexion sur le rôle des sages-femmes dans les soins du premier âge. Les soins aux nourrissons font partie de la formation des accoucheuses et aux lendemains de l'entrée en application de ces textes, des professeurs comme le docteur Raymond à Limoges soulignent combien « les sages-femmes instruites pourraient [... e être les guides naturels ${ }^{162}$ » des crèches qui se multiplient.

157. Faure O., Les Français et leur médecine..., op. cit., p. 179.

158. Darmon P., La longue traque de la variole : les pionniers de la médecine préventive, Paris, Perrin, 1986, p. 175-177; 243-246.

159. Sage Pranchère N., Mettre au monde..., op. cit., p. 37 et 503-504 ; AD Puy-de-Dôme, 2 BIB $2527 / 8$.

I60. Darmon P., «L'odyssée pionnière des premières vaccinations françaises... », art. cit., p. I22-I23. I6I. Rollet C., « Nourrices et nourrissons dans le département de la Seine et en France de I880 à 1940 », dans Population, 1982, vol. 37, n 3, p. 573-575; De Luca V., Rollet C., « Nouvelles pratiques de puériculture. États des savoirs, acteurs, résistances et avancées. France, I880-1930 », dans P. Bourdelais, O. Faure (dir.), Les Nouvelles Pratiques de santé..., op. cit., p. 67-88.

162. AD Haute-Vienne, RD CG Haute-Vienne, I880. 
Certains rapports des inspecteurs des enfants assistés ne manquent toutefois pas de dénoncer les pratiques inadaptées en matière d'alimentation perpétuées par les accoucheuses âgées auprès des mères et des nourrices ${ }^{163}$. Conscients de ces difficultés mais plus optimistes, d'autres encouragent au contraire la collaboration entre le corps des médecins-inspecteurs et les sages-femmes pour une meilleure application des prescriptions législatives.

\section{Des élèves départementales pour des sages-femmes départementales}

L'ensemble des obligations légales qui encadrent et orientent l'action de la sagefemme s'enracine donc dans la responsabilité née du savoir. C'est en vertu de la formation spécifique reçue et de la reconnaissance accordée par les autorités politiques, que l'accoucheuse doit ses services à ses concitoyens. Il faut cependant distinguer entre l'impératif moral qui impose d'assister une parturiente quand on en a les compétences, et l'obligation légale de soin. Si cette dernière n'est jamais officiellement imposée, les politiques départementales de financement d'élèves sages-femmes pour les besoins locaux tendent à la rendre effective.

L'intérêt des préfets et des conseils généraux pour la formation obstétricale tout au long du siècle se manifeste dans les subventions votées aux jeunes femmes qui s'engagent dans cette voie. La règlementation de la pratique de la bourse accordée à des élèves départementales a débuté avec la fondation de l'école de l'Hospice de la Maternité de Paris (règlement de 1807). L'enjeu est alors de diriger vers la capitale le plus grand nombre possible d'aspirantes sages-femmes, dans l'espoir de limiter la portée des cours locaux. Les préfets répondent pour nombre d'entre eux très favorablement à cette sollicitation ministérielle et les envois d'élèves à Paris s'inscrivent dans les principes définis dans le titre XI du nouveau règlement :

Art. 3+ - Les sages-femmes qui auront été instruites à la Maternité aux frais de leur département et qui auront souscrit l'engagement de se fixer dans les communes qui leur auront été désignées par les préfets, seront tenues de s'établir dans ces mêmes communes. Dans le cas où elles n'auraient contracté aucune obligation à cet égard, les préfets les inviteront à aller habiter de préférence les communes où le besoin de bonnes accoucheuses se fera le plus sentir. Celles dont les frais d'instruction ont été supportés par une commune devront y fixer leur résidence. Celles nommées par les Commissions administratives devront, de droit, être attachées à l'hospice d'où elles auront été tirées, s'il s'y fait des accouchements et que leur présence y soit nécessaire. ${ }^{164}$

163. RD CG Nord, i889.

164. AD Corrèze, i X I6I. 
L'article 3 a pour but de maintenir les droits des administrations payeuses (départementales, communales et hospitalières) sur l'exercice professionnel des boursières. Il pose comme préalable, dans le cas des départements, que le préfet ait fait prendre un engagement écrit de résidence à la future élève au moment de sa nomination. Néanmoins, en l'absence d'engagement avant l'admission à l'Hospice de la Maternité, l'invitation du préfet à se fixer dans telle ou telle commune n'a pas de valeur contraignante pour l'élève. La nuance est de taille dans la mesure où les sages-femmes sorties de l'école de Port-Royal échangent leur certificat de capacité contre un diplôme de première classe qui les autorise à exercer dans la localité de leur choix sur l'ensemble du territoire national. Dès lors, seul un engagement sur l'honneur, à peine de remboursement des frais de scolarité, est susceptible de ramener dans leurs pénates et surtout d'y retenir les élèves issues de départements ruraux. L'évolution du rayonnement parisien peut aussi se lire à cette lumière. Entre I8IO et I8I9, décennie faste, soixante-neuf départements envoient des élèves à Paris, avant une baisse dans les années I820, et le maintien jusque vers I880, d'une cinquantaine de départements comme base du recrutement ${ }^{165}$. Le recul est concomitant de la fondation de cours locaux d'accouchement mais aussi de l'hésitation devant la perspective de perdre le fruit des dépenses engagées. En I843, le conseil général de l'Aisne débat de l'avenir du cours fondé en 1832 à Laon. Le préfet propose la suppression de l'enseignement et son remplacement par l'envoi d'élèves à Paris assorti d'un engagement décennal ${ }^{166}$, mais l'idée est fermement rejetée par l'assemblée : «Et même il serait à craindre que les élèves formées à Paris aux frais du département, n'en conservassent pas toujours assez de reconnaissance pour y revenir et s'y fixer définitivement. »

Cette déperdition d'élèves passées par Paris se fait progressivement sentir même dans les départements qui conservent à l'institution parisienne une parfaite fidélité pendant la majeure partie du siècle. La Dordogne se fait longtemps gloire de n'employer les subsides départementaux quà former des sages-femmes de première classe. En I876 cependant, le conseil général décide de ne plus envoyer d'élèves à Paris pour désormais faire admettre ses boursières à Bordeaux :

En effet, les élèves reçues à l'école de Paris pouvaient exercer partout, et il était fréquent de voir des sages-femmes ayant fait leurs études aux frais du département, le quitter pour aller se fixer hors du département, dans des localités qui leur offraient plus d'avantages $[\ldots]^{167}$

165. Beauvalet-Boutouyrie S., Naître à l'hôpital..., op. cit., p. 138-139.

166. AD Aisne, RD CG Aisne, 1843.

167. AD Dordogne, i $\mathrm{N}_{35}$. 
La légitimité d'une telle politique de restriction à l'horizon départemental est parfois contestée au nom de la liberté des accoucheuses de s'établir là où bon leur semble et leur droit à faire des études obstétricales les plus complètes possibles ${ }^{168}$. Pourtant, la préférence accordée aux diplômes de deuxième classe et la souscription d'un engagement d'exercice dans le département sont un trait commun à la plupart des conseils généraux ${ }^{169}$. Des délibérations y sont explicitement consacrées (Cantal, I84I ; Ardèche, I86I $)^{170}$, et de nombreux règlements de cours intègrent une clause minimale de résidence obligatoire : 3 ans à Angers (I808), 5 ou IO ans à Tulle (I833), de manière indéfinie à Agen (I836), etc. ${ }^{171}$

Le respect que manifestent les élèves une fois diplômées envers leurs autorités de tutelle est néanmoins aléatoire. Sa variable la plus évidente réside dans la capacité de la commune imposée par le préfet à subvenir aux besoins de la nouvelle sage-femme. L'impossibilité de gagner sa vie justifie les départs souvent précipités pour la ville voisine, le département limitrophe ou des horizons plus lointains. Deux exemples : en I834, Marie Ollivier, épouse Séguret, fait auprès du ministère de la guerre une demande de passage à Bône en Algérie, deux ans seulement après la prise de la ville. Or, elle a signé un engagement décennal au moment de son envoi à Bourges comme élève départementale. L'autorisation de passage en Algérie lui est donc refusée $e^{172}$. Quelques semaines après la notification de cette décision, Marie Ollivier adresse un courrier au préfet dans lequel elle expose «la pénurie d'occupation dont elle se plaint », prétextant n'avoir pas eu connaissance de la durée de l'engagement pris et demandant à ce qu'un arrêté « la déclare dès à présent libérée du laps de temps qui reste encore à courir et la libère de son engagement ». La requête est appuyée par le maire d'Annonay qui confirme l'abondance de personnel qualifié dans sa commune. L'issue de cette affaire n'est pas connue. Elle souligne néanmoins le caractère pleinement contraignant de l'engagement de résidence.

L'obligation de résidence et d'exercice dans le département est d'ailleurs si profondément assimilée par les anciennes élèves des cours d'accouchement que même les jeunes femmes ayant suivi leur scolarité à leurs frais s'y pensent soumises. La pratique systématique de la nomination des élèves sages-femmes

I68. AD Yonne, I N $33^{*}$ : «M. Duguyot [... s sélève contre la pensée de vouloir former des sagesfemmes à l'usage exclusif du département de l'Yonne. [...] [II] insiste de nouveau pour qu'on ne cherche pas à confiner dans le département des sages-femmes de second degré. Il faut encourager les élèves sages-femmes à faire des études complètes et les laisser libres de s'établir où elles voudront ». 169. Voir Sage Pranchère N., Mettre au monde..., op. cit., p. 390 sq. L'engagement peut aussi être pris devant notaire avant d'être transmis au préfet : AD Gers, 5 M 6.

170. AD Cantal, i N I2 ${ }^{*}$; AD Ardèche, RD CG Ardèche, I863.

171. $\mathrm{AD}$ Aube, $5 \mathrm{M}_{34}$; $\mathrm{AN}, \mathrm{F}_{17} / 2458$, Corrèze ; AD Lot-et-Garonne, $5 \mathrm{M} 8$.

172. $\mathrm{AD}$ Ardèche, $5 \mathrm{M} 3$ I. 
par arrêté préfectoral y est sans doute pour quelque chose ${ }^{173}$. Dans l'Aube en I85I, Henriette Devilliers, sage-femme à Nogent-sur-Seine, demande au préfet l'autorisation de quitter sa commune pour s'installer à Montbard en Côte-d'Or auprès de ses parents ${ }^{174}$. La réponse est immédiate :

Vous avez suivi, à vos frais, les cours de l'école d'accouchement de Troyes, vous n'êtes pas considérée comme élève du département; vous êtes libre d'aller demeurer où bon vous semble, je n'ai donc pas à examiner s'il y a lieu ou non de vous autoriser à changer de résidence.

Et de rappeler à la requérante qu'elle devra se faire recevoir devant le jury médical de son nouveau département pour continuer à exercer sa profession. Le lien très fort noué entre les élèves sages-femmes et l'administration départementale qui les finance ne se limite donc pas aux cas d'envois dans des écoles extérieures au département d'origine. Il concerne aussi les admises aux cours locaux, même si la formation sur place semble moins prompte à susciter "l'émigration progressive des sages-femmes anciennes boursières du département » que dénonce en I879 un conseiller général de l'Yonne ${ }^{175}$. Le nonrespect des engagements suppose une contrepartie financière équivalente aux frais engagés par le département pour la scolarité. Or, les sommes votées par les conseils généraux peuvent s'élever à des montants très importants, en particulier lorsqu'il s'agit d'envoyer des élèves à Paris. Initialement fixé à 250 francs, le montant de la pension à l'Hospice de la Maternité est augmenté en I807 et passe à 675 francs annuels (article 8). Stable pendant une soixantaine d'années, ce tarif bondit en 1875 à I Ioo francs par an ${ }^{176}$, alourdissant brutalement la charge qui pèse sur les finances départementales et justifiant d'autant plus la volonté de conserver le bénéfice des élèves formées. L'issue habituelle des procédures de remboursement est rarement favorable aux conseils généraux, et les relances auprès des sages-femmes « en fuite » aboutissent dans la plupart des cas à l'octroi d'un délai de paiement ou à une remise complète de la dette.

Ces aléas dans les résultats des politiques de financement d'élèves sagesfemmes imposent aux administrations départementales un suivi soigneux de l'encadrement obstétrical des communes. Le préfet ou les commissions présentent régulièrement devant les conseils généraux les résultats d'enquête sur

173. L'admission dans les écoles départementales d'accouchement, comme la désignation comme élève dans une école extérieure au département, quel que soit le mode de financement, donnent lieu à un arrêté préfectoral.

174. $\mathrm{AD}$ Aube, $5 \mathrm{M} 28$.

175. AD Yonne, I $\mathrm{N}_{33}{ }^{*}$.

176. RD CG Nord, 1875 . 
l'état du personnel obstétrical. Il peut s'agir du nombre de sages-femmes formées aux frais du conseil général comme dans l'Ardèche en $1862{ }^{177}$, ou plus largement du nombre de praticiennes en exercice comme dans l'Ain en $1848^{178}$. Le devenir des anciennes boursières préoccupe les conseillers et la rumeur persistante des défaillances impose de rappeler d'une session à l'autre la rassurante nouvelle du retour de ces femmes dans leur canton d'origine.

Dernier sujet à alimenter avec constance les débats des administrations départementales : la répartition des accoucheuses dans les communes. C'est en I858 l'enquête préfectorale sur les cantons privés de sages-femmes qui emporte dans l'Aveyron la décision de rouvrir le cours d'accouchement de Rodez ${ }^{179}$. Dans le Bas-Rhin, le doyen de la faculté de médecine de Strasbourg fait parvenir en I85I au préfet un tableau récapitulatif des communes sans sage-femme, inquiet d'en compter 235 sur $543^{180}$. En Corrèze enfin, le tableau par arrondissement des accoucheuses présenté à la session de 1867 convainc le conseil général de modifier la forme du recrutement en réservant un tiers des places aux candidates venues de cantons dépourvus ${ }^{181}$.

Objet de l'intérêt toujours renouvelé des administrations communales, départementales et ministérielles, la sage-femme dépouille progressivement ses attributs d'Ancien Régime pour se conformer au modèle né de Port-Royal et de la loi de ventôse. La profession y gagne en cohérence, en stabilité. Elle s'appuie désormais sur un personnel jeune, dont la formation signe le début d'une carrière. Elle se dote aussi d'une éthique raffermie, serment d'Hippocrate non dit des accoucheuses, qui dessine les traits idéaux de la praticienne et pose les limites de son exercice. Instruite dans le secret des cloîtres hospitaliers à préserver celui des existences qui lui sont confiées, la future sage-femme y apprend les devoirs qu'impose la connaissance ; elle découvre aussi le poids de la responsabilité qu'implique son appartenance au corps médical. Contrôlée par l'État de son admission en école d'accouchement à la fin de son activité, la sage-femme est un agent au service du public, praticienne très peu libérale dans les bornes soigneusement tracées par la loi, produit revendiqué et approprié d'une politique publique de formation.

177. AD Ardèche, RD CG Ardèche, 1862.

178. RD CG Ain, I848.

179. AD Aveyron, RD CG Aveyron, 1858.

I80. AD Bas-Rhin, I TP Sup I7.

I8I. Sage Pranchère N., Mettre au monde..., op. cit., p. 408-410. 


\section{Le personnel des écoles d'accouchement}

L'institutionnalisation de l'enseignement de l'obstétrique au tournant du $\mathrm{XIX}^{\mathrm{e}}$ siècle multiplie le nombre des acteurs de ces formations. Le tête-à-tête professeur-élève du siècle précédent s'accroît de nouveaux intervenants : le processus de scolarisation de la formation des sages-femmes impose l'adjonction d'un personnel enseignant ou non enseignant, pour veiller sur les destinées matérielles et morales de cette instruction. Autour des élèves sages-femmes, c'est donc un monde nouveau qui se constitue, nécessaire pour répondre aux exigences de l'enseignement (théorique mais surtout clinique), et de l'encadrement dans le contexte de plus en plus fréquent des internats. Au-delà de ce bouleversement numérique du personnel, sa physionomie évolue. Des deux figures qui ont modifié au xviII ${ }^{e}$ siècle l'échelle de la formation obstétricale - l'une, incarnée, Angélique du Coudray, l'autre, archétypal, le démonstrateur accoucheur -, on passe à une répartition hiérarchisée de la transmission du savoir entre des enseignants qui se complètent sans officiellement s'équivaloir : le médecin et la sage-femme. La pratique est plus nuancée, et le triomphe de l'accoucheur à la fin du $\mathrm{XVIII}^{\mathrm{e}}$ siècle aboutit toutefois à un partage du territoire pédagogique, signe d'une reconquête partielle de la sage-femme sur sa propre formation.

\section{Professer l'art des accouchements : un titre, deux postes}

\section{La sage-femme et le professeur : une bicéphalie, entre exception parisienne et adaptations départementales}

La reconnaissance exprimée par l'Assemblée nationale à Angélique du Coudray le 4 septembre 1790 semble clore le chapitre de la démonstration de l'art des accouchements par une accoucheuse, malgré le maintien à Marguerite 
Coutanceau d'une indemnité pour son enseignement. La personnalité de cette sage-femme, le caractère exceptionnel de son itinéraire ont marqué du sceau de l'extraordinaire l'irruption d'une femme dans le champ de l'enseignement obstétrical ${ }^{1}$. Sa postérité masculine, ponctuée de si rares sages-femmes, dessine une nouvelle figure d'enseignant : le démonstrateur, chirurgien et plus rarement médecin, que la Révolution entérine dans ses entreprises pédagogiques². L'étude nécessaire de la place respective occupée par les hommes (docteurs) et les femmes (sages-femmes) dans la formation des élèves sages-femmes ne se réduit cependant pas à l'observation d'une mise à l'écart inéluctable et plus ou moins brutale des secondes au profit des premiers. Le mouvement de conquête des postes de démonstrateurs d'accouchements par les chirurgiens s'interrompt et se transforme. Dès lors, l'appréhension précise des rôles respectifs de ces deux corps médicaux passe par la séparation entre le titre de professeur d'accouchement et la transmission du savoir obstétrical.

Le titre de « professeur d'accouchement » est une invention révolutionnaire mais son profil et ses attributions en font le successeur direct du démonstrateur royal de l'art des accouchements. Le caractère très personnel de la charge évolue néanmoins vers une plus forte intégration dans les nouvelles institutions mises en place par la Convention. Assimilés tout d'abord aux professeurs des écoles centrales, les professeurs d'accouchements voient leur statut et leur rôle se codifier grâce aux textes d'organisation de l'Hospice de la Maternité de Paris et à celui de la loi de ventôse an XI. Ce dernier s'appuie sur la préexistence du titre et son association à un ressort géographique, le département, pour adosser le cours à venir à cette fonction.

Qu'en est-il justement de la référence parisienne ? Le terme " professeur » n'apparaît pas avant le règlement révisé de $\mathrm{I} 807$, sans doute pour ne pas bousculer la tradition de l'Office des Accouchées. C'est l'application de la réforme de 1802 qui consacre l'entrée en scène de Jean-Louis Baudelocque, accoucheur en chef, dans l'instruction des élèves sages-femmes ${ }^{3}$. Le domaine du professeur est celui de la formation théorique (deux leçons par semaine d'une à trois heures), tandis que sa participation à l'instruction pratique se limite à la surveillance éventuelle de leurs gestes lors d'un accouchement difficile (art. II, titre II) et à décider de

I. Gélis J., La Sage-femme ou le médecin..., op. cit., p. II3 sq. ; Gelbart N. R., The King's Midwife..., op. cit., et avant cela du même auteur : «Midwife to a Nation: Mme du Coudray serves France », dans Marland H. (dir.), The Art of Midwifery..., op. cit., p. I3I-I5I.

2. Parmi ces exceptions, on peut néanmoins citer Louise Chemery, démonstratrice à Montagnesur-Aisne dans la Marne, AD Marne, L 1248.

3. Beauvalet-Boutouyrie S., Naître à l'hôpital..., op. cit., p. 124-134. 
leur assistance à une dissection (art. 22, titre II). En I8IO, le professeur obtient la haute main sur le droit de redoublement des élèves sages-femmes (art. 6), auparavant détenu par le jury de santé des hospices (titre VII, art. I et 2$)^{4}$.

Cette infime modification n'empêche pas le maintien de l'accoucheur en chef en marge de l'institution. La sage-femme en chef est la directrice « effective » de l'Hospice de la Maternité dans sa dimension scolaire et hospitalière. Ayant rang de chirurgien ordinaire, elle perçoit une forte rémunération : I 500 francs au début du siècle, auxquels s'adjoignent 30 francs par élève sage-femme, puis 2400 francs à partir de 1824 et toujours 30 francs par élève. En I826, le conseil général des hospices lui garantit un minimum fixe de 3600 francs pour compenser la baisse du nombre d'élèves tout en élevant ses honoraires à 2700 francs 5 . Sa compétence professionnelle est pleinement reconnue et elle est présente à toutes les étapes de l'instruction des élèves. Seul lui manque, et la nuance n'est pas mince dans ses implications extra-parisiennes, le titre de professeur.

Dans le quotidien de l'Hospice de la Maternité, la discrétion de l'accoucheur-professeur s'explique par l'autorité difficilement contestable de la mầtresse sage-femme, qui ne va pas sans occasionner quelques conflits, passé le temps des collaborations respectueuses de Jean-Louis Baudelocque et Antoine Dubois avec Marie-Louise Lachapelle. Mais ces conflits n'ont rien de pédagogique et remettent surtout en cause l'omnipotence de la sage-femme en chef dans la surveillance des accouchées ${ }^{6}$. L'enjeu est hospitalier et vise à imposer le contrôle du corps médical sur le suivi du post-partum ${ }^{7}$. La revendication première des chirurgiens en chef de l'Hospice de la Maternité n'est donc pas de prendre intégralement en charge l'enseignement et la sage-femme en chef n'est jamais écartée de la transmission du savoir. La réforme mise en œuvre par l'arrêté du 3I mai 1895 qui donne au corps des accoucheurs des hôpitaux de Paris la direction de l'Hospice de la Maternité subordonne toutefois officiellement la sage-femme en chef à l'accoucheur en chef : elle « participe à l'enseignement théorique suivant un programme tracé par l'accoucheur en chef » et « assure l'enseignement pratique [... ] sous le contrôle de l'accoucheur en chef ». La formulation place certes les maitresses sages-femmes au second rang, mais maintient leur intervention dans les deux volets de l'instruction des élèves. Le recul acté l'est dans la direction de la maternité proprement dite.

\footnotetext{
4. RLRES I, p. 87-88.

5. Delaunay P., La Maternité..., op. cit., p. 248-249.

6. Beauvalet-Boutouyrie S., Naître à l'hôpital..., op. cit., p. I3I-I32.

7. Lefort L., « Discussion sur l'hygiène des maternités », Bulletin de la société de chirurgie de Paris pendant l'année 1866, Paris, Victor Masson et fils, i867, p. 208-209.
} 
L'exemple parisien fournit dans la pratique et quasiment jusqu'à la fin du siècle un schéma de répartition des tâches pédagogiques entre médecin et sagefemme. Sa mise en valeur par le ministère de l'Intérieur, qui fait du règlement de l'Hospice de la Maternité la référence à suivre pour les créations départementales, se heurte cependant à un terreau provincial qui n'est pas a priori favorable à une dissociation de la fonction enseignante.

Les raisons sont multiples. En premier lieu, le cours d'accouchement se poursuit, se crée ou se recrée dans la continuité d'un cours de démonstration qui fut le cours d'un démonstrateur. Le médecin ou le chirurgien le mieux placé pour prendre en charge le cours est souvent à l'issue de la Révolution celui qui professait avant 1789 ou qui n'a cessé de le faire depuis. De plus, les cours qui s'ouvrent sont toujours dirigés par des hommes. En second lieu, vient la question d'argent : l'unicité du professorat peut s'expliquer par la modestie des fonds alloués par les départements à la formation des sages-femmes pendant la première décennie du XIX ${ }^{e}$ siècle. Enfin, l'absence quasi complète de tradition d'enseignement des sages-femmes par les sages-femmes en dehors de l'Office des Accouchées de l'Hôtel-Dieu pèse lourdement sur la légitimité des accoucheuses à briguer les places de professeurs.

Les articles 30 et $3 \mathrm{I}$ de la loi de ventôse an XI ne précisent pas le genre du professeur à nommer. Mais trois ans plus tard, l'enquête de l'an XIV tranche la question en désignant un chirurgien comme seul titulaire possible du poste de professeur d'accouchement. La seule alternative relève du cadre d'exercice (hospice ou ville). Les préfets ne proposent donc comme enseignants que des chirurgiens, privilégiant dans l'ensemble les praticiens des hospices ${ }^{8}$. Seule exception, très symbolique, le préfet d'Eure-et-Loir souligne que dans le cadre du cours en place à l'hospice de Chartres, la sage-femme « seconde dans ses démonstrations journalières » le professeur ${ }^{9}$.

Tout ceci justifie la primauté des docteurs, en médecine ou en chirurgie, dans l'exercice de la fonction de professeur. Ainsi, la plupart des cours en place avant la loi de ventôse an XI ne voient officier qu'un seul enseignant, en général chirurgien (Troyes, Angoulême, Dijon). Ces situations ne perdurent pourtant guère au-delà de la vague de réorganisations qui touche les cours départementaux. En imposant l'adaptation au règlement parisien, le ministre de l'Intérieur provoque une généralisation de la dualité enseignante sur un principe hiérarchique.

8. Cette préférence se maintient au fil du siècle. Voir Léonard J., La vie quotidienne du médecin de province au XIX ${ }^{e}$ siècle, Paris, Hachette, I977, p. I29.

9. $\mathrm{AN}, \mathrm{F}^{17} / 2460$, Eure-et-Loir. 
Les règlements des cours permettent d'entrevoir l'espace accordé aux sagesfemmes enseignantes, même si beaucoup d'entre eux sont des transpositions quasi littérales de celui de l'Hospice de la Maternité de Paris. La présence d'une sage-femme hospitalière ne précède pas toujours l'instauration d'un cours; et même lorsqu'une accoucheuse est déjà attachée à l'hospice qui accueille l'instruction des sages-femmes (Chartres, Orléans, Chambéry, Bourges, Bar-leDuc, etc.), cela n'implique pas systématiquement qu'elle participe à la formation des élèves. Ainsi à Angoulême où l'enquête de 1806 signale l'aide apportée par une sage-femme au chirurgien des prisons qui dirige la salle d'accouchement, le règlement du cours de 1813 ne la cite pas ${ }^{10}$.

Dans un certain nombre de départements en revanche, la sage-femme apparaît en même temps que le cours, pour prendre en charge une partie de la formation ainsi que les soins aux femmes en couches. Elle est dans la plupart des cas nommée par le préfet mais son recrutement est soumis à l'avis voire à l'initiative du professeur (Ariège, Aveyron ${ }^{11}$ ). Les commissions administratives des hospices peuvent aussi être consultées sur le choix de la future sage-femme en chef. Le processus de recrutement leur donne plus ou moins de latitude, que leur décision confirme la proposition du professeur et n'ait plus qu'à être entérinée par le préfet (Haute-Garonne), ou qu'elles aient en charge de fournir une liste de candidates inspirée par le professeur et laissée à la discrétion du préfet (Côte-d'Or ${ }^{12}$.

En Haute-Garonne, le règlement lui impose de subir « un examen devant le conseil de santé des hospices, en présence du professeur ». Dans plusieurs départements, elle doit avoir été formée à l'Hospice de la Maternité de Paris pour être retenue (Ain, Meuse) ${ }^{13}$. Plus rarement enfin, la sage-femme en chef peut être choisie sur concours. Les candidates sont alors interrogées par un jury composé de médecins enseignants et d'administrateurs ; le résultat est transmis au préfet pour approbation et nomination (Marseille ${ }^{14}$ ). Les départements ont plutôt recours à ce mode de recrutement lors d'un décès ou d'une démission de sagefemme en chef. En I866 à Montpellier, une maladie de la maitresse sage-femme entraîne l'ouverture d'un concours pour lui trouver une remplaçante provisoire. Ces concours donnent lieu à une diffusion de l'information dans toute la France : les archives du Calvados conservent ainsi l'affiche annonçant le concours pour l'emploi de maîtresse sage-femme de Montpellier organisé en $1885^{15}$.

\footnotetext{
Io. $\mathrm{AN}, \mathrm{F}^{17} / 2458$, Charente.

II. $\mathrm{AN}, \mathrm{F}^{17} / 2457$, Ariège ; $\mathrm{AD}$ Aveyron, 3 X 50 .

I2. $\mathrm{AN}, \mathrm{F}^{17} / 2460$, Haute-Garonne ; AD Côte-d'Or, $\mathrm{M} 7 \mathrm{n} \mathrm{I} / 2$.

13. AD Saône-et-Loire, M 2088 ; AD Haute-Marne, II8 T I.

I4. AD Alpes-de-Haute-Provence, 5 M 6.

I5. AD Calvados, $\mathrm{M} 4087$.
} 
Les règlements de cours départementaux insistent presque tous sur l'infériorité hiérarchique de la sage-femme par rapport au professeur. La mise sous tutelle de la sage-femme en chef est exprimée sans ambiguïté : le professeur est « secondé » (Ain), l'accoucheuse est placée « sous ses ordres 》 (CharenteInférieure, Haute-Garonne), voire "sous la surveillance, la direction et les ordres de [l'] accoucheur en chef » (Marne) ${ }^{16}$. Sa présence peut être facultative, soumise à la volonté du professeur (Gers, Landes), et sa capacité à le suppléer est limitée aux cas où aucun professeur adjoint n'est prévu à cet effet (Aube) ${ }^{17}$.

La supériorité hiérarchique est dans l'ensemble nominale, chaque enseignant restant dans son domaine, mais elle peut aussi largement déborder ce cadre et placer la sage-femme en chef sous un régime de vérification permanente : surveillance des répétitions et du cours pratique $\left(\mathrm{Bar}-\mathrm{le}-\mathrm{Duc}{ }^{18}\right)$. Ce cas est néanmoins extrême et le principe même d'une répartition des tâches plaide en faveur d'une maîtrise incontestée de la sage-femme en chef dans certains domaines : enseignement théorique ${ }^{19}$ et répétition, enseignement pratique et encadrement de la formation clinique pour la dimension pédagogique ; surveillance continue des élèves sages-femmes, direction quotidienne de l'établissement pour la dimension fonctionnelle. La maîtresse sage-femme remplit en parallèle des cours théoriques un rôle d'éclaircissement, d'apprentissage et d'illustration. La fonction de répétitrice la met plus fréquemment que le professeur en contact avec les élèves. Là où celui-ci donne en général deux à trois leçons hebdomadaires, la sage-femme en chef dirige chaque jour, voire deux fois par jour les répétitions :

(Charente-Inférieure) Art. 19: Elle donne deux fois par jour des leçons préparatoires. Elle s'assure, en outre, par les questions et les répétitions nécessaires si les leçons du professeur ont été bien comprises et rectifie, au besoin, les idées erronées qu'auraient pu se former les élèves. Dans la leçon suivante du professeur, elle lui en rend compte. ${ }^{20}$

I6. AD Saône-et-Loire, M 2088 ; AD Charente-Maritime, 3 X 299 ; AN, F²/2460, HauteGaronne; AD Marne, 32 X 24.

17. AD Gers, $5 \mathrm{M} 6$, les deux règlements (Auch et Dax) prévoient la possibilité de suppléance du professeur par la sage-femme en chef en cas d'absence ou de maladie; AD Aube, $5 \mathrm{M}_{33}$.

I8. AD Haute-Marne, II8 T I.

19. L'un des seuls exemples de sage-femme en chef dispensant un enseignement théorique est

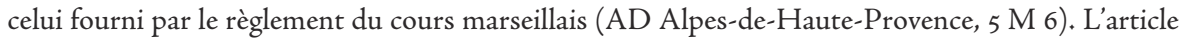
est démarqué du règlement parisien mais soumet le programme des leçons faites par la sage-femme en chef à la décision du professeur.

20. AD Charente-Maritime, 3 X 299. 
(Cher) Art. 28 : Elle fera tous les jours aux élèves, exceptés le dimanche et les fêtes, deux répétitions particulières ou conférences sur les leçons données par le professeur. Chaque conférence devra être d'une heure au moins. L'une se fera le matin et l'autre le soir. ${ }^{21}$

Si l'on ajoute à cela ses interventions dans le cadre de la formation pratique (manuel de l'art des accouchements) et clinique, il s'avère que les heures passées par les élèves en compagnie de la maîtresse sage-femme sont infiniment plus nombreuses que celles passées au contact du professeur. $\mathrm{Au}$-delà du rôle enseignant, la sage-femme a, dans la plupart des cours, la responsabilité de surveiller les élèves, ce qui justifie dans le dernier tiers du siècle la diffusion du titre de « directrice » attaché à ces fonctions. L'attention requise de la maîtresse sagefemme est définie comme « immédiate et continue » (Ain), et s'exerce à tous les instants de la journée, « soit pendant le jour, soit pendant la nuit, soit pendant les repas » (Cher) ${ }^{22}$. Sy ajoute une surveillance équivalente des femmes enceintes, en couches et accouchées présentes dans l'établissement. Tout ceci entraîne de fait l'obligation de résidence, et aboutit à une sévère limitation de la liberté de mouvement de la sage-femme, pour ne pas nuire à la continuité du service : congé accordé par le professeur dans l'Aube ${ }^{23}$; autorisation des sœurs hospitalières dans le $\mathrm{Cher}^{24}$.

Cette rigueur hiérarchique (professeur mais aussi congréganistes) est alors un élément de fragilisation de l'accoucheuse : ses ordres sont toujours susceptibles d'être discutés et son autorité sur les élèves sages-femmes affaiblie. En I85I, le professeur du cours rochelais signale la gêne occasionnée par une telle situation :

[...] quelques modifications apportées au règlement ont soulevé des objections de la part de la maitresse sage-femme qui, par ces nouvelles mesures, se trouve placée dans une dépendance trop étroite de la sœur surveillante. Il me semble que pour conserver à la maîtresse sage-femme l'autorité morale dont elle a besoin pour diriger les élèves elle ne doit pas être placée dans un état de suspicion continuelle vis-à-vis de la commission de surveillance ou des agents de celle-ci ; elle a besoin d'une certaine liberté d'action, elle a besoin qu'on lui témoigne une certaine confiance. Ainsi il a paru très pénible à cette demoiselle d'être assujettie, comme les élèves, à rentrer dans la maison, même dans l'été, avant huit heures du soir, la porte devant être fermée à cette heure-là et la clé remise à la sœur. ${ }^{25}$

\footnotetext{
21. AD Corrèze, I X I62.

22. AD Saône-et-Loire, M 2088 ; AD Corrèze, I X 162.

23. AD Aube, $5 \mathrm{M} 33$.

24. AD Corrèze, I X I62.

25. AD Charente-Maritime, 3 X 297.
} 
Une solution de compromis est trouvée qui convainc la sœur de ne pas appliquer le règlement dans toute sa rigueur à la maîtresse sage-femme. Une telle hiérarchie nécessite en effet des instances de médiation, comme les commissions des hospices, ainsi que le prévoit la révision du règlement troyen en $1835^{26}$.

La coexistence des sœurs et de la sage-femme en chef n'implique cependant pas toujours une subordination de la seconde aux premières. Les champs de compétences respectifs sont alors nettement délimités comme le précise le règlement berruyer en 1817 :

Art. 4 : Le service intérieur sera dirigé, quant à la partie économique, par le régisseur de la maison de Refuge ; quant à l'instruction religieuse et morale, par deux sœurs hospitalières ou de la charité, membres d'une des congrégations que désignera M. l'Archevêque de Bourges ; et quant aux études, par une sage-femme en chef. ${ }^{27}$

Certains cours d'accouchement fonctionnent sur un système dissocié de direction du régime intérieur : propreté, entretien du linge, etc., étant confiés aux sœurs ; alimentation des élèves, bon ordre du pensionnat et mobilier, à la sage-femme en chef. Le mobilier désigne dans ce cas tous les objets acquis sur les fonds du département et souvent, plus précisément, le matériel pédagogique.

Au bout du compte, la sage-femme en chef est une figure essentielle de l'enseignement obstétrical. Dès lors qu'un internat accueille les élèves, la maîtresse sage-femme est présente à leurs côtés nuit et jour, suit leurs progrès, travaille de façon permanente à les former. Son influence joue à plein et la pose, aux yeux des élèves sages-femmes, en équivalent féminin du professeur d'accouchement. L'égalité du duo pédagogique peut d'ailleurs être renforcée par la durée d'exercice des uns et des autres. À Dijon, après une succession rapide des deux premières sages-femmes (I82I-I826 et I826-I829), Bénigne Chicotot occupe cette fonction pendant seize ans, jusqu'en I845, au côté du docteur Guéniard, nommé la même année qu'elle et qui décède en I84I. Un deuxième « duo » se met en place après I 845 avec la titularisation du docteur Naigeon et le recrutement de la demoiselle Lorges ; puis, à partir de 1852, les destinées de l'école d'accouchement sont placées entre les mains du docteur Moyne, ancien professeur adjoint (1845-1852-1879 $\left.{ }^{28}\right)$, et d'Honorine Bouot, épouse Gerbaine (I851-1896) qui s'adjoint en I880 sa petite-fille Maria Coupé, épouse Altenbach (1880-1896-1908), au moment où le docteur Gautrelet (1879-1906) succède à

26. AD Aube, $5 \mathrm{M}_{33}$.

27. AD Corrèze, i X 162 .

28. La date en italiques correspond à l'entrée en fonction comme adjoint-e. 
Moyne ${ }^{29}$. Citons aussi, à Montpellier, le duo constitué dans les années 1890 par le docteur Vallois et la maitresse sage-femme, Jenny Bazin, en poste depuis I888, à la suite d'Agnès Puejac restée elle-même près de vingt ans (I868-I886) et du beaucoup plus bref passage de Marie Faure (I886-I888) ${ }^{30}$. Cette pérennité des collaborations nuance la rigidité des prescriptions règlementaires, et les archives ne fournissent pas de cas d'opposition ouverte entre le professeur et la maîtresse sage-femme. Les rapports présentés annuellement par les médecinsprofesseurs aux conseils généraux ne sont au contraire qu'une longue suite d'éloges adressés à leur collègue féminine.

L'infériorité officielle assignée à la sage-femme se lit néanmoins dans sa rémunération. L'obligation de résidence est compensée par la gratuité du logement, de la nourriture, du chauffage, de l'éclairage et du blanchissage pendant la durée du cours, mais cette prise en charge matérielle justifie le maintien de très faibles traitements : ainsi, dans la Marne et le Loiret, l'indemnité est fixée au début du siècle à 150 francs par $\mathrm{an}^{31}$. Le montant des traitements et leur évolution au fil des décennies sont toutefois très divers. S'y retrouve en partie le niveau de richesse des établissements auxquels sont attachées les sagesfemmes. À Pamiers, la maîtresse sage-femme reçoit en 1809200 francs sans qu'il soit précisé si elle est logée ou non ${ }^{32}$. Il en est de même à Dijon en $1821^{33}$. À Marseille au contraire, elle touche une indemnité de 600 francs en plus de son entière prise en charge ${ }^{34}$. La taille de l'école et le niveau des élèves formées comptent aussi dans la définition de la rémunération. À Montpellier où la sagefemme en chef doit instruire de futures accoucheuses de première classe, le traitement qui vient compléter la gratuité du logement, chauffage et éclairage, s'élève en I86I à I 200 francs annuels, puis à I 500 francs en I866, somme qui ne varie pas pendant les deux décennies suivantes ${ }^{35}$. En retour, la maîtresse sagefemme montpelliéraine a interdiction de conserver une clientèle privée ${ }^{36}$. Cette

\footnotetext{
29. Baron P. (Dr.), Sages-femmes et maternité à Dijon, op. cit., p. 80-82.

30. AD Corrèze, I J 87/10* ; Delmas A., « Origines et jeunesse du professeur Henri-Victor Vallois », Bulletin et Mémoires de la Société d'anthropologie de Paris, 1982, n 9-2, p. 94-95; Dulieu L., La médecine à Montpellier, t. 4, De la Première à la Troisième République, Avignon, Presses universelles, 1988-I990, vol. I, p. 304.

31. AD Marne, $32 \mathrm{X}_{24}$; $\mathrm{AN}, \mathrm{F}^{17} / 2463$, Loiret.

32. $\mathrm{AN}, \mathrm{F}^{17} / 2457$, Ariège.

33. Arrêté préfectoral du in décembre I820, art. 3, cité dans Baron P. (Dr.), Sages-femmes et maternité à Dijon, op. cit., p. 69.

34. AD Alpes-de-Haute-Provence, 5 M 6.

35. AD Hérault, I X 795 ; AD Aveyron, 3 X 51 ; AD Calvados, M 4087.

36. AD Hérault, I X 795.
} 
exclusivité professionnelle de la sage-femme en chef se retrouve dans beaucoup de règlements de cours ${ }^{37}$. À Dijon, l'interdiction est progressive : à partir de I826, elle vaut pour les accouchements au domicile de la sage-femme, mais l'accoucheuse conserve le droit de s'absenter pour faire des accouchements à l'extérieur ; en 1896, cette latitude lui est complètement retirée, compensée par le passage de sa rémunération de 300 à 2000 francs annuels ${ }^{38}$.

La difficile question de l'évolution des traitements ne se résout qu'à l'échelle des institutions. Si certains départements font progresser au cours du XIX ${ }^{e}$ siècle la rémunération de leur sage-femme en chef (Hérault, Aisne), d'autres la laissent stagner. Ainsi la titulaire du poste en Haute-Vienne reçoit un traitement de 300 francs de 1836 à 1867 , date à laquelle la dame Bastin demande une augmentation. Le conseil général décide alors d'élever la somme à 400 francs pour ne plus la modifier jusqu'à la fin du siècle ${ }^{39}$. Quoi qu'il arrive, le principe est de ne jamais attribuer à une sage-femme en chef un traitement supérieur à celui perçu par le professeur d'accouchement, même s'il est fréquent que la différence ne soit pas très considérable et que le défraiement complet de la maitresse sage-femme donne à son traitement plus de valeur que la somme brute ne le laisse présager.

Le poste de sage-femme en chef peut enfin ouvrir droit à une sorte de pension de retraite. Celle-ci n'a rien de systématique ni d'automatique et les conseils généraux sont toujours amenés à délibérer sur la légitimité d'un tel versement et sur son montant qui correspond, au plus, à un tiers du traitement d'activité. En I867, dans l'Ain, l'une des deux maîtresses sages-femmes, la veuve Page, demande à quitter son poste après 45 ans de service. Le préfet, approuvé par l'assemblée départementale, propose alors de lui voter une allocation annuelle de 100 francs, soit le quart de sa rémunération précédente ${ }^{40}$. Dans l'Aisne, le conseil général décide, lors du départ en 1875 de la demoiselle Raguet, maîtresse sage-femme depuis la fondation du cours en I832, de lui verser une pension de 400 francs, soit un tiers de son traitement ${ }^{41}$.

37. Dès lors que la sage-femme en chef est tenue à la résidence continue dans l'établissement, elle perd le droit d'exercer en ville.

38. Baron P. (Dr.), Sages-femmes et maternité à Dijon, op. cit., p. 8I-82.

39. AD Haute-Vienne, I/L III.

40. RD CG Ain, I867.

4I. AD Aisne, RD CG Aisne, I875. Cette maîtresse sage-femme est un des plus beaux exemples de progression salariale par la revendication : elle passe en 1844 de 300 à 450 francs, en I858, de 450 à 600 francs, en I 865 , de 600 à 700 francs et entre cette date et I875, de 700 à I 150 francs. 
Ces discussions montrent les limites du statut de la sage-femme en chef : elle n'a pas droit à une pension de fonctionnaire alors qu' elle remplit les charges correspondantes. Autre limite : l'absence d'un traitement minimum pour toutes les titulaires de ce poste, qui restent soumises au bon vouloir des administrations hospitalières et départementales ${ }^{42}$. Ce bon vouloir est parfois à leur avantage, comme le montre l'exemple de la demoiselle Raguet de Laon, mais l'inverse est aussi vrai. La sage-femme en chef logée, nourrie, etc., est, quel que soit le montant de son traitement, une privilégiée en comparaison de l'institutrice jusque dans les années I860, mais la faiblesse persistante des traitements la place progressivement en retrait de cette autre profession féminine. La sagefemme enseignante, sage-femme d'hôpital, est souvent cachée par les grandes figures parisiennes ou montpelliéraines du temps, ce qui fait oublier la pauvreté dont elle n'est pas toujours si loin, surtout venu le temps de la retraite. Lorsque le conseil général de l'Aisne reconnaît en 1875 à sa sage-femme en chef le droit à « une honnête aisance », il prend ainsi acte du prestige social acquis par l'exercice de ces fonctions mais aussi de l'insuffisance des revenus qu'elles génèrent.

\section{Le professorat, enjeu de pouvoir}

Sage-fermme et professeure, l'exception historique

Assigner à la sage-femme la place de brillante seconde de l'enseignement obstétrical reviendrait toutefois à négliger quelques rares mais remarquables exceptions. Au-delà du cas parisien, ces professeures ou candidates au professorat posent le problème de la légitimité féminine à occuper ce poste, suscitant discussions et écrits. Ceux-ci rejoignent sur le fond les débats qui s'élèvent à partir des années I830 dans l'enseignement secondaire féminin sur la place respective occupée par les professeurs hommes et les enseignantes ${ }^{43}$.

Plus que le contenu de l'enseignement confié à la sage-femme en chef, c'est la dévolution du titre et du statut de professeur qui fait hésiter les administrations. Le XIx ${ }^{e}$ siècle compte pourtant deux exemples de femmes professeures d'accouchement : la Gironde et la Corrèze. Un troisième département envisage sérieusement au début du siècle la dévolution de sa chaire à une sage-femme : le Gers.

42. Daubié J.-V., La femme pauvre au XIX $x^{e}$ siècle, op. cit., p. IOO.

43. Rogers R., "Le professeur a-t-il un sexe ? Les débats autour de la présence d'hommes dans l'enseignement secondaire féminin, I840-I880 », Clio. Histoire, fermmes et sociétés, I996-4 [en ligne]. 
La Gironde recueille l'héritage d'Angélique du Coudray ${ }^{44}$. Marguerite Coutanceau et son époux créent alors leur «Office des Accouchées » de province, l'hospice de la maternité de Bordeaux, offrant à la société les garanties rassurantes d'un établissement à la direction masculine et chirurgicale ${ }^{45}$. La mort de l'époux signe la division durable de la maternité et de l'école d'accouchement, mais n'interrompt l'activité d'aucune de ces institutions. Avant la Révolution, Marguerite Coutanceau est à la fois la survivancière du brevet royal de sa tante mais aussi la détentrice à titre personnel d'un brevet reçu de Louis XVI en I782. En septembre I790, la Constituante confirme la valeur de ces titres ${ }^{46}$. Marguerite Coutanceau se replie néanmoins sur un ressort départemental, et le conseil général de la Gironde la nomme alors « institutrice de l'art de l'accouchement » par arrêté du 16 décembre I79I, au traitement de I 200 livres annuelles, augmenté le 8 février 1792 de 500 livres pour la défrayer de ses dépenses de logement ${ }^{47}$. Marguerite Coutanceau tient donc son titre de professeure d'une double autorité, nationale et départementale.

La fondation de l'école de l'Hospice de la Maternité de Paris ne remet pas en cause l'institution bordelaise, malgré une tentative de suppression du ministre de l'Intérieur ( J'ajouterai aussi qu'il est impossible qu'un cours d'accouchement fait par une femme soit aussi complet et aussi instructif que ceux qui se font à Paris $\left.{ }^{48} »\right)$. Le discours ajoute à la rhétorique ministérielle habituelle une tonalité misogyne spécifique, soulignant une supposée incapacité pédagogique féminine ${ }^{49}$. Cette tentative de suppression se solde toutefois par un échec, prévenue par la réponse fleuve du préfet girondin qui exprime à chaque phrase son enthousiasme pour les qualités de l'enseignante et l'organisation parfaite de la formation, qualifiée de " prodige ${ }^{50} »$. Prenant acte du soutien des instances locales et du repli en bon ordre des menaces de suppression nationale, Marguerite Coutanceau travaille à compter de cette date à faire reconnaître le

44. Gélis J., La sage-femme ou le médecin..., op. cit., p. I23 ; Contis A, « Madame du Coudray et Madame Coutanceau. La création des cours d'accouchement en Aquitaine après 1760 », Revue

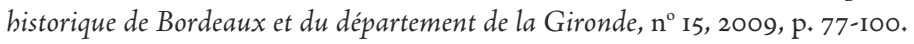

45. Béchir F., Accoucheuses, matrones, sages-femmes à Bordeaux au XviII eiècle, op. cit. ; Penot C., L'École d'accouchement de Bordeaux au XIX ${ }^{e}$ siècle, op. cit. ; Poirier J.-P., Histoire des femmes de science en France, du Moyen Âge à la Révolution, Paris, Pygmalion, 2002, p. 199-200.

46. AD Gironde, 5 M 552 .

47. Ibid.

48. AN, $\mathrm{F}^{17} / 246 \mathrm{I}$, Gironde.

49. Cette argumentation est résumée en 1845 dans le formule d'un professeur de pensionnat pour jeunes filles : «Instituteur a un féminin, professeur n'en a pas », voir Rogers R., « Le professeur a-t-il un sexe? », art. cit.

50. $\mathrm{AN}, \mathrm{F}^{17} / 246 \mathrm{I}$, Gironde. 
prestige de son établissement face à l'institution parisienne. Si ses ambitions d'élargissement régional ne débouchent sur rien de concret, elle obtient en revanche en I8I5 pour ses cours le titre d'École royale d'accouchement grâce à la recommandation de la duchesse d'Angoulême ${ }^{51}$.

Mais 1815 est aussi l'année où Marguerite Coutanceau commence à préparer son départ et sa retraite. L'approche de cette succession fait renaittre les interrogations sur le sexe du remplaçant à nommer. Dès l'annonce certaine de son départ (qui n'intervient qu'en I82I), un chirurgien bordelais s'empresse de transmettre sa candidature au ministère de l'Intérieur, qui demande à son tour au préfet de la Gironde « d'examiner s'il convient mieux de confier la place dont il s'agit, à une sage-femme qu'à un chirurgien ${ }^{52} »$. Le comte de Tournon-Simiane, préfet à cette date, fidèle à la ligne de son prédécesseur, défend l'exception bordelaise :

Je passe à la question relative à la préférence à donner à un homme pour exercer le professorat. Je pense qu'il faut préférer une femme et voici mes motifs : l'école reçoit un grand nombre de jeunes filles pauvres, venant des campagnes. [...] Il semble qu'une telle réunion de jeunes filles est plus convenablement placée sous la protection d'une femme que sous celle d'un homme.

En deuxième lieu, ces filles sont souvent très ignorantes, elles n'entendent que le patois et il faut une extrême patience et des soins assidus pour se faire comprendre d'elles. Une femme est plus propre à descendre à ces soins que ne le serait un homme. ${ }^{53}$

Les arguments avancés sont nettement genrés et s'appuient sur le caractère « maternel » des besoins de l'établissement pour justifier la succession féminine de Marguerite Coutanceau. L'abondante correspondance autour de ce remplacement laisse pourtant filtrer des positions plus arrêtées que le discours convenu tenu au ministre. L'attachement du comte de Tournon à la tradition féminine de l'enseignement bordelais, fondé sur une grande admiration pour la titulaire du poste, se manifeste dans une mise à l'écart persévérante des candidats masculins qui se présentent. L'un d'entre eux, le chirurgien du roi Dupouy, s'en plaint d'ailleurs auprès du comte de Breteuil, successeur de Tournon, dans les jours qui suivent sa nomination à Bordeaux en février I822, assurant qu'il aurait obtenu la place, «si M. de Tournon n'eut témoigné à son Excellence le désir de voir cette place occupée par une femme $e^{54} »$.

51. AD Gironde, 5 M 552.

52. Ibid.

53. AD Gironde, $5 \mathrm{M}_{562 .}$

54. AD Gironde, 5 M 552 . 
Le nouveau préfet ne revient cependant pas sur la décision de son prédécesseur et c'est Caroline Dupéché, qui reprend le poste de Marguerite Coutanceau en I823. Sa nomination a lieu sur concours, et c'est le conseil général qui vote lors de sa session de $1821^{55}$. L'élection de Caroline Dupéché est le triomphe d'un milieu bordelais lié à Marguerite Coutanceau. Lors du vote, la candidate favorite recueille I 6 voix sur I 8 contre 2 pour Cécile Fougerai, ancienne surveillante de l'École royale de Bordeaux, aucune pour Joséphine Rougé, candidate sans appui, et plus surprenant, aucune pour Marie-Anne Boivin, gloire éternellement recalée de l'obstétrique française ${ }^{56}$.

Passé le cap de la succession de Marguerite Coutanceau, s'ouvre une période de relative tranquillité pour l'établissement et son professeur. Les arrêtés préfectoraux de I8I6 et I8I7 ont établi une collaboration entre l'École d'accouchement et l'Hospice de la Maternité, ouvrant aux élèves du cours départemental l'accès à une formation pratique, supervisée par le chirurgien en chef. Cette configuration suscite des ambitions de la part du chirurgien de l'hospice et partant, une opposition sourde au cours départemental et plus encore à son professeur. La campagne contre Caroline Dupéché-Duboscq débute en I842 ; elle part de l'Hospice de la Maternité, empruntant les relais parisiens des ministères de l'Intérieur et de l'Instruction publique pour plaider la mise à l'écart de la sage-femme professeur, au nom de l'irrégularité de l'institution, non conforme aux exigences de la loi de ventôse an XI. Or, à la différence des années 1820 , le préfet y prête cette fois une oreille attentive, encouragé par le ministre de l'Intérieur ${ }^{57}$. Les raisons avancées touchent à un domaine sensible pour une femme : sa réputation morale, or, c'est en partie sur ce point que s'était joué par le passé le maintien d'une femme à la tête de l'enseignement. S'y ajoute l'accusation d'incompétence professionnelle, doublée d'un constat de prétendue déchéance de l'institution.

Douze ans se passent pourtant avant que la réforme ne soit mise en place, à l'issue de cinq ans de fonctionnement mixte pendant lesquels les élèves sagesfemmes suivent leur première année de cours auprès de Caroline Dupéché à l'École et la seconde année à l'Hospice de la Maternité. Pendant ce temps de double professorat, les plaintes continues du docteur Dupouy, chirurgien en chef de l'hospice et ancien candidat malheureux à la succession de Marguerite Coutanceau, visent à réduire les attributions de la sage-femme, au motif que

55. AD Gironde, $\mathrm{I}_{3}{ }^{*}$.

56. AD Gironde, 5 M 552 ; Beauvalet-Boutouyrie S., Naître à l'hôpital..., op. cit., p. 130 ; Carol A., "Sage-femme ou gynécologue ?... », art. cit.

57. AD Gironde, 5 M 554 . 
son cours purement théorique relève d'une méthode datée ${ }^{58}$. Remerciée pour ses « longs services », Caroline Dupéché est mise à la retraite en 1854 avec une confortable pension (I 200 francs annuels). Cette décision met un terme à une situation inédite en France de répartition inversée des rôles pédagogiques, dans laquelle la sage-femme prenait en charge la formation théorique et déléguait au chirurgien en chef toute la dimension pratique. Cette situation aboutissait à un plaidoyer médical en faveur d'un primat de la formation pratique («fruit de l'expérience ») sur la théorie, développé, dès les années I820, par le chirurgien Dupouy $^{59}$. En inversant les hiérarchies locales, l'évolution des années I840I850 à Bordeaux a rebattu les cartes de la «théorie » et de la « pratique » dans le discours de l'enseignement obstétrical.

L'expérience bordelaise n'a en France qu'un équivalent : l'école départementale d'accouchement de Tulle ${ }^{60}$. Parmi les similitudes entre les deux établissements, il faut citer la forte personnalité des sages-femmes enseignantes, aux solides qualités de praticiennes et de pédagogues. Mais cela ne va guère plus loin, puisque les Corréziennes sont pour deux d'entre elles de purs produits de Port-Royal. De plus, lors de la création en I827 de cours d'arrondissement, la Corrèze ne dispose d'aucune tradition hospitalière de réception des accouchées. La solution de continuité entre le cours d'accouchement fait en l'an $\mathrm{x}$ par un démonstrateur et la recréation de 1827 a tué dans l'œuf les ambitions pédagogiques des médecins et chirurgiens corréziens dans un département qui ne compte ni école secondaire ni école préparatoire de médecine. Les conditions sont donc réunies pour que le diplôme de l'école parisienne conferre toute légitimité à occuper le poste de sage-femme enseignante, dans un contexte où le corps médical cherche plus volontiers son prestige dans les fonctions politiques que dans un professorat d'obstétrique. La sage-femme de l'école tulliste reste seule maîtresse à bord jusqu'en 1887 et ne perd sa primauté qu'à la faveur d'une vacance de la place, dont profite à cette date le médecin attaché à l'école.

La valeur du diplôme parisien est à l'origine du dernier cas où s'exprime la tentation d'un professorat féminin : celui du Gers. L'exemple précoce (an XIII) éclaire en amont l'évolution corrézienne et s'inscrit dans une logique proposée par le ministre de l'Intérieur, celle d'une élève formée à l'Hospice de la Maternité de Paris devenant la référence obstétricale de ses consœurs provinciales. Après une première demande en floréal an XIII de création d'un cours, le préfet du Gers renouvelle sa requête en thermidor suivant :

58. AD Gironde, $\mathrm{I} \mathrm{N}_{4} 8^{*}$.

59. AD Gironde, 5 M 552 .

60. Sage Pranchère N., Mettre au monde..., op. cit., p. 257-310. 
Il me paroîtroit également convenable d'admettre $\mathrm{M}^{\text {me }}$ Despez, élève sagefemme de l'école de la maternité qui paroît avoir eu du succès à cette école puisque le jury lui a décerné le premier prix à la clôture du second cours qu'elle y a suivi. D'ailleurs les leçons données en cette partie par une femme seroient mieux écoutées par les filles et femmes qui les suivroient et leur deviendroient plus profitables. ${ }^{61}$

Le ministère fait la sourde oreille, tant à la demande de régularisation du cours (reconnu à demi-mot deux ans plus tard) qu'à la proposition du préfet. Les arguments avancés, proches de ceux du préfet de la Gironde, recoupent la même sensibilité à une attention féminine présentée comme plus adaptée aux élèves. En filigrane se lit une manière genrée de comprendre et d'apprendre, que le préfet désigne sans la définir vraiment. L'accouchement, affaire de femmes et de sages-femmes, impose de contenir tout ce qui y a trait dans le champ clos de l'intertransmission féminine. Pour autant, la candidate sage-femme n'est qu'une parmi tant d'hommes et cette infériorité numérique associée à une tradition masculine de démonstrateurs suffit à la repousser.

Homme et professeur, entre norme symbolique et carrières au long cours

Les contours de la fonction professorale ont évolué depuis l'Ancien Régime. La réduction à la théorie ouvre paradoxalement un espace d'expérimentation pédagogique et de renouvellement scientifique, alors que l'obstétrique est élevée au rang de spécialité médicale. De plus, le réseau des cours départementaux d'accouchement remplit les vides laissés entre les mailles du filet des écoles de médecine ; il permet aux titulaires des postes de professeur de se hausser au niveau de leurs collègues enseignants.

Le gain financier n'est toutefois pas très important et on ne rencontre guère de médecins professeurs rémunérés à la hauteur de Marguerite Coutanceau (3 ooo francs annuels) ou de la veuve Porte à l'école de Tulle au début des années 1880 (I 800 francs annuels). Cette modestie s'inscrit dans une pratique générale de faible rémunération des médecins et chirurgiens attachés aux hôpitaux, fondée sur l'idée qu'il serait « indécent de s'enrichir dans ce service de charité $^{62} »$. Les propositions d'enseignement gratuit du début du XIX ${ }^{e}$ siècle se justifient par le cumul des responsabilités hospitalières et d'une clientèle de ville. Mais à mesure que le siècle avance, ces exemples se raréfient et il faut des circonstances exceptionnelles pour qu'un médecin soit amené à enseigner sans

\footnotetext{
61. AD Gers, 5 M 6.

62. Léonard J., La vie quotidienne..., op. cit., p. I23.
} 
traitement. En Loire-Inférieure, le professeur d'accouchement, par ailleurs professeur à l'école de médecine de la ville, ne reçoit aucune rémunération mais sa situation suscite en 1862 une réclamation du directeur de l'école préparatoire de médecine de Nantes auprès du préfet ${ }^{63}$. À Nîmes en I849, le conseil général du Gard décide la fermeture du cours pour I85I et réduit de 600 à 300 francs la rémunération du professeur avant de la supprimer complètement l'année suivante. Pendant les dix-huit années suivantes, le cours se poursuit toutefois, par la seule bonne volonté du docteur Pleindoux, qui dirige la maternité nîmoise ${ }^{64}$.

Dans la majorité des cas néanmoins, les conseils généraux votent volontiers les traitements des professeurs. Ces rémunérations sont relativement homogènes, puisque la somme la plus souvent allouée s'élève à 600 francs, soit dans la tranche haute des traitements hospitaliers ${ }^{65}$, et très constantes sur le siècle (Albi, Le Mans). Dans les Basses-Pyrénées, le traitement est fixé à 500 francs lors de la fondation du cours à Pau en 1832 ; il ne connaît qu'une seule évolution en I84I lorsque le conseil général vote 200 francs supplémentaires annuels. Dans le département voisin des Hautes-Pyrénées, le professeur perçoit 600 francs de I8I8 à I836, puis 900 francs jusqu'à la fermeture du cours de Bagnères-de-Bigorre en 1892 . Parmi les hautes rémunérations, on trouve des écoles importantes, proche d'une université ou d'une école de médecine (Strasbourg, Montpellier, Poitiers), ou possédant une aura propre (Bourgen-Bresse : 800 francs). Les professeurs de Strasbourg atteignent ainsi les I 000 francs, tandis que le professeur du cours d'accouchement de Montpellier bénéficie de la générosité manifestée envers le premier titulaire de la charge et touche 2400 francs annuels jusqu'en I832, puis I 800 francs par la suite ${ }^{66}$. Les enseignants d'obstétrique ne font pourtant pas fortune avec ces seuls postes. Prises individuellement, leurs indemnités dépassent tout juste en moyenne la rémunération d'un simple employé de préfecture au milieu du XI $x^{\mathrm{e}}$ siècle,

\footnotetext{
63. AD Loire-Atlantique, I27 T I.

64. AD Gard, $\mathrm{I} \mathrm{N}_{21} 3^{*}$.

65. Léonard J, La vie quotidienne..., op. cit., p. I23.

66. Lors de la suppression de la chaire d'accouchements de l'école de médecine de Montpellier en l'an XII, le professeur concerné continue néanmoins de toucher un traitement de 6 ooo francs, soit 3 ooo francs pour la part fixe équivalente à celle de ses collègues restés à l'école de médecine, et autant pour la part casuelle. Se réservant l'enseignement théorique, Senaux, le titulaire du poste, obtient la nomination d'un adjoint appointé à 3000 francs par le conseil général. Il faut attendre la transformation du poste en chaire de professeur du cours départemental d'accouchements et le passage de l'enseignement au système du pensionnat pour que le traitement du professeur soit redéfini et fixé à 2400 francs, voir Delmas P., Sept siècles d'obstétrique..., op. cit., p.50-52 et AD Hérault, I N $3^{*}$ et $5^{*}$.
} 
preuve que l'intérêt de ces charges ne réside décidément pas dans les traitements qui y sont attachés.

La longévité des enseignants à leur poste en fait de véritables figures tutélaires de l'obstétrique locale. Le lien entre professeur et cours d'accouchement est alors si étroit qu'il provoque une intense personnalisation de l'institution. À la mort des professeurs-directeurs dans l'Ain ou dans le Tarn les conseils généraux de ces deux départements se posent même la question du maintien de l'enseignement obstétrical. Dans le cas d'écoles où les enseignants fondateurs restent aux commandes de l'instruction pendant trente, quarante ou cinquante ans, la disparition du professeur semble signer la fin d'une époque et donc la fin d'un établissement. Tout départemental qu'il soit, le cours d'accouchement est alors assimilé à la figure fondatrice et le passage du relais nécessite d'âpres négociations. Aucun n'est toutefois supprimé pour cette raison. Les cours départementaux sont de ce point de vue dans une situation hybride, portés par la légitimité du cadre départemental mais encore très marqués par le processus traditionnel de légitimation de l'institution par les individus ${ }^{67}$.

Ce souci de continuité s'exprime dans le mode de recrutement du professeur. Celle-ci s'oppose à la pratique du concours, qui peine à s'imposer. La pratique du concours peine à s'imposer car cette méthode a contre elle d'ouvrir la porte à l'inconnu, de coûter cher et de mobiliser beaucoup d'énergie pour son organisation. Qui dit concours, dit épreuves longues : celui organisé en I834 à Troyes en comporte quatre et se déroule sur trois journées complètes. Se succèdent une question orale commune aux trois candidats, préparée en 30 minutes et traitée en une heure ; une question écrite en six heures ; une démonstration sur le mannequin d'après les questions du jury pendant une heure complétée d'une seconde question orale à développer pendant la même durée ; et enfin, l'épreuve d'argumentation mutuelle des candidats à partir des textes rédigés pour la question écrite, en une heure aussi ${ }^{68}$. Le jury contrôle les qualités scientifiques et les capacités d'exposition des candidats. À l'inverse, le « concours » peut se réduire à l'étude par une commission des dossiers de candidature au poste, avant que le préfet ne nomme le nouveau titulaire, comme à Pau en $1892^{69}$. Dans ce dernier cas, les restrictions aux candidatures (deux ans d'exercice dans le département) dénaturent la forme choisie pour le recrutement pour répondre aux inquiétudes suscitées par la perspective d'un candidat compétent mais inconnu.

67. Sur ce thème, voir Sage Pranchère N., Mettre au monde..., op. cit., p. 287-288.

68. AD Aube, $5 \mathrm{M}_{33}$.

69. AD Gironde, 5 M 56 I. 
Toutefois, le moyen le plus simple de privilégier les personnalités médicales du cru est de réserver au préfet le choix du futur professeur. Cette méthode a souvent pour résultat de rassembler entre les mêmes mains de multiples responsabilités institutionnelles. La désignation préfectorale accorde aussi une valeur particulière à la succession dynastique et permet au détenteur du poste d'en préparer la reprise par son héritier. Dans le Vaucluse, le docteur Clément fils remplace en 1847 le docteur Clément père ${ }^{70}$. L'obtention du poste s'inscrit aussi dans des réseaux plus larges de familles de médecins comme ceux de la famille Sauvé dans l'ouest de la France ou de la famille Mougeot en Champagne ${ }^{71}$. Les transmissions intrafamiliales sont donc une constante de la période. Elles marquent la capacité des titulaires de postes à anticiper leur succession, ceux-ci n'hésitant pas à chanter au préfet les louanges de leur candidat favori, lorsqu'ils sentent qu'ils ne pourront plus très longtemps poursuivre leur travail.

En effet, la mainmise très longue exercée sur les chaires par certains médecins pose de multiples problèmes dont la difficulté croissante à enseigner n'est pas le moindre : surdité, comme celle qui touche le docteur Romain à Bagnères-de-Bigorre en I825, ou encore impotence comme la « maladie chronique des jambes » dont souffre le docteur Darantière à Chaumont ${ }^{72}$. Des solutions sont dans tous les cas rapidement trouvées pour garantir la continuité de l'enseignement. Beaucoup de règlements de cours d'accouchement ont prévu ces situations en fixant les modalités de nomination d'un professeur adjoint appelé à suppléer en cas d'absence ou de maladie le titulaire (Calvados, Haute-Garonne, $\mathrm{Cher}^{73}$ ).

Comme celle du professeur titulaire, la désignation de l'adjoint est à la discrétion du préfet, même si les commissions administratives des hospices proposent parfois une liste de candidats. La qualité d'adjoint ne correspond pas à une charge hospitalière spécifique, à quelques exceptions près comme celle $\mathrm{du}$ Calvados, et n'ouvre droit à aucune rémunération (Côte-d'Or, Aveyron ${ }^{74}$ ). $\mathrm{Il}$ arrive cependant que les services de cet adjoint soient reconnus sous forme d'un traitement, et celui-ci est alors laissé à la générosité du titulaire (HauteMarne) ou résulte d'un transfert temporaire des émoluments liés au poste

\footnotetext{
70. $\mathrm{AD}$ Vaucluse, $5 \mathrm{M}$ i7.

71. AD Charente-Maritime, 3 X 292 ; AD Haute-Marne, II7 T 2. Voir à ce propos J. Léonard, La vie quotidienne..., op. cit., p. I4.

72. AD Hautes-Pyrénées, I $\mathrm{N}_{3}{ }^{*}$; AD Haute-Marne, II7 $\mathrm{T} 2$.

73. $\mathrm{AN}, \mathrm{F}^{17} / 2457$, Calvados ; $\mathrm{AN}, \mathrm{F}^{17} / 2460$, Haute-Garonne ; $\mathrm{AD}$ Corrèze, I X 162.

74. AD Côte-d'Or, M 7 n I/2 ; AD Aveyron, 3 X 50.
} 
(Charente-Inférieure $)^{75}$. La nomination d'un adjoint peut intervenir concomitamment à celle du professeur titulaire (Côte-d'Or, Puy-de-Dôme), mais aussi se faire dans l'optique de son remplacement. À Chaumont, la nomination du docteur Thivet comme adjoint a lieu tout juste quatre mois avant le décès de Darantière. Dans la quasi-totalité des cas, le poste de professeur est transmis à l'adjoint ou au plus âgé d'entre eux lorsqu'il y en a plusieurs, comme à Clermont-Ferrand dans la seconde moitié du siècle.

Le recrutement de ces médecins fait jouer des réseaux familiaux ou de sociabilité mais ne verse pas dans le népotisme aveugle. Les fils qui succèdent à leur père ont les qualifications pour le faire. Le remplaçant de Paul Pamard à Avignon en 1862 est son fils Alfred, ancien interne des hôpitaux et hospices civils de Paris et chirurgien en chef de l'hôpital d'Avignon. Les qualités scientifiques des candidats à ce type de fonctions ont une réelle importance dans leur recrutement et les titulaires des chaires d'accouchement possèdent tous une expérience hospitalière.

L'écriture scientifique revêt une importance particulière dans le profil des professeurs. Pris entre les praticiens de campagne, souvent de seconde classe, et les références médicales des grandes villes, les professeurs de départements sans école de médecine se différencient des premiers par la volonté tenace de se rapprocher des seconds en publiant. Le docteur Thivet de Chaumont évoque en I869, parmi ses « titres », le fait d'être l'auteur « d'un mémoire sur les grossesses extra-utérines, d'un ouvrage complet sur les fractures et les luxations, d'un traité des dents ${ }^{76}{ }$. Dans le Haut-Rhin, le docteur Morel, titulaire du poste au début du $\mathrm{XIX}^{\mathrm{e}}$ siècle, traduit et fait imprimer en allemand une édition annotée du petit catéchisme de Baudelocque, diffusée à mille exemplaires par la préfecture auprès des sages-femmes et officiers de santé du département ${ }^{77}$. En Corse enfin, le fugace docteur Mattéi qui enseigne à Bastia entre 1852 et 1855 publie un opuscule retraçant son parcours : M. le Dr Mattéi, ses titres et ses travaux jusqu'au $1^{\text {er }}$ mars 1860 , qui rassemble 7 I notices d'ouvrages ou d'articles ${ }^{78}$.

Un contexte favorable comme celui d'une ville moyenne, siège d'une école de médecine, encourage plus encore ces initiatives. Lorsque les professeurs cumulent les cours à destination des étudiants en médecine et des sagesfemmes, ils sont particulièrement bien placés pour publier, à partir de leurs

75. AD Haute-Marne, 117 T 2 ; AD Charente-Maritime, 3 X 292.

76. AD Haute-Marne, II7 T 2.

77. AD Haut-Rhin, I X 94 .

78. Mattéi A., M. le Dr Mattéi, ses titres et ses travaux jusqu'au 1er mars 1860, Paris, impr. de Bailly, Divry et Cie, 1860 . 
leçons, des manuels d'obstétrique dont la diffusion n'est pas négligeable. Le docteur Chevreul, professeur du cours d'Angers depuis les années I780, est ainsi l'auteur en 1782 d'un Précis de l'art des accouchements publié à Angers, ouvrage mis à jour en Précis de l'art des accouchements à l'usage des étudiants en médecine et des élèves sages-femmes édité à Paris en 1826. Onze ans plus tard, une seconde édition, revue, corrigée et augmentée, paraît dans une des plus importantes maisons d'édition médicale parisienne, chez Méquignon-Marvis ${ }^{79}$. À Chartres, les docteurs Maunoury et Salmon, médecins de l'hôtel-Dieu et professeurs du cours d'accouchement, publient en I850 à Paris et chez Baillière un Manuel de l'art des accouchements à l'usage des élèves sages-femmes ${ }^{80}$. L'ouvrage est un succès puisqu'il connaît deux rééditions revues et augmentées, en I86I et I874. Et si la première préface remercie les « confrères de Chartres », celle de I86I soumet l'ouvrage aux « confrères dans l'enseignement de l'obstétrique pour les élèves sages-femmes », signe de l'ampleur nationale prise par cette publication.

L'exercice de la charge professorale en obstétrique ouvre donc potentiellement sur une activité scientifique qui contribue à l'aura pédagogique et au prestige social des médecins concernés. Certains y gagnent des fonctions supérieures, comme Michel Chevreul, qui devient en 1820 directeur de l'école de médecine d'Angers. À Rouen, le docteur Achille-Cléophas Flaubert assume la direction du cours d'accouchement pendant la décennie I820, avant d'accéder à la direction de l'école secondaire de médecine au début des années $1830^{81}$. Ces exemples montrent le niveau de notabilité professionnelle et sociale auquel peuvent prétendre les professeurs d'accouchement. Nombre d'entre eux sont ainsi les archétypes des «bons docteurs », proches de la population par leurs fonctions qui les placent au contact des indigents et des malades dans les hospices, reconnus par leurs pairs pour leurs qualités professionnelles et pédagogiques, et par l'administration qui leur confie en quantité des postes officiels. Le récit des obsèques en 1850 du docteur Amable Rome, professeur du cours d'accouchement de Grenoble et notable de la localité de Voreppe dans l'Isère, mentionne que le cercueil fut porté ouvert dans les rues de la bourgade pour que les habitants puissent le voir une dernière fois ${ }^{82}$.

\footnotetext{
79. Chevreul M., Précis de l'art des accouchements, Angers, impr. de C. P. Marne, 1782.; Précis de l'art des accouchements à l'usage des étudiants en médecine et des élèves sages-femmes, Paris, 1826, Crevot pour cette édition, et Paris, Méquignon-Marvis, 1837, pour la suivante.

80. Maunoury C.-M.-A., Salmon P.-A., Manuel de l'art des accouchements à l'usage des élèves sages-femmes, Paris, J.-B. Baillière, 1850.

8I. Berteau P., Docteurs Flaubert, père et fils, Luneray, Bertout, 2006, p. 28-29.

82. Léonard J., La vie quotidienne..., op. cit., p. 219.
} 


\section{Compléter le savoir des élèves et tenir la maison}

\section{Répétitrices et sous-maîtresses : le ballet des aides}

À l'exception des petits établissements, l'encadrement et la formation des élèves nécessite, au-delà du professeur et de la sage-femme en chef, des intervenants supplémentaires. L'enseignement des différentes matières au programme des écoles (art des accouchements, vaccine, saignée, puériculture) se fragmente alors en une constellation de répétiteurs, répétitrices, sous-maîtresses, etc.

Le professeur se trouve ainsi à la tête d'une équipe pédagogique, majoritairement féminine. Les répétiteurs hommes (étudiants en médecine, tout jeunes praticiens) se rencontrent moins souvent que leurs équivalents féminins, pour des raisons qui touchent au refus de la mixité. À Colmar, le professeur Morel propose en I838 au poste d'adjoint le docteur Engel son répétiteur depuis plusieurs années ${ }^{83}$. À la fin du siècle, les internes de l'Hôtel-Dieu de Nîmes réclament de pouvoir faire le cours d'accouchement lorsque le professeur en est empêché (or, à cette date, il n'y a aucun professeur titulaire) ${ }^{84}$. Cette demande est néanmoins prise en compte deux ans plus tard lorsqu' un cours d'accouchement est réorganisé dans l'hôpital ${ }^{85}$. À Bordeaux enfin, un médecin vient ainsi apprendre aux élèves sages-femmes la pratique de la saignée et de la vaccine, à partir de $1810^{86}$. Cette charge est d'abord remplie par le docteur Arnezan jusqu'en I83I, puis par le docteur Charles Révolat jusqu'à la réforme de l'école en I849. Conformément au niveau des traitements versés dans l'établissement, il perçoit pour ces quelques leçons un salaire honorable de 200 francs dans les années I8IO, porté à 300 francs au plus tard dans les années $1840^{87}$.

La préférence va pourtant au recrutement d'un personnel auxiliaire essentiellement féminin, placé sous les ordres et la surveillance de la sage-femme en chef. Ces aides sont désignées sous les termes de répétitrices, surveillantes ou sous-maitresses, les deux derniers renvoyant au modèle de l'enseignement secondaire féminin et plus précisément aux pensions fréquentées par les jeunes filles de la bourgeoisie ${ }^{88}$. Différence essentielle cependant $:$ la sous-maîtresse

\footnotetext{
83. AD Haut-Rhin, I X 94.

84. AD Gard, H Dépôt I2 297.

85. AD Gard, 5 M 25 .

86. AD Gironde, $5 \mathrm{M} 554$.

87. AD Gironde, $5 \mathrm{M} 552$; I N $43^{*}$.

88. Rogers R., "La sous-maîtresse française au $\mathrm{XIX}^{\mathrm{e}}$ siècle : domestique ou enseignante stagiaire? », Histoire de l'éducation, 2003, n 98, p. 37-60.
} 
d'une école d'accouchement est toujours déjà elle-même une praticienne diplômée pour pouvoir prétendre à cette fonction. Il faut donc différencier clairement ces répétitrices qui appartiennent au personnel du cours d'accouchement des élèves sages-femmes « suffisamment instruites » par lesquelles la maîtresse sage-femme peut «se faire remplacer momentanément pour la répétition [...] lorsqu'elle [est] dans l'impossibilité de la faire elle-même ${ }^{89} »$. Les modèles de ces figures qui peuplent les plus grandes écoles d'accouchement françaises sont à rechercher du côté de l'Hospice de la Maternité de Paris. Très tôt, la sagefemme en chef s'attache une assistante qui reçoit le titre de surveillante, pratique copiée à Bordeaux quelques années plus tard ${ }^{90}$. S' instaure aussi l'habitude de nommer aide de la maitresse sage-femme, une, deux puis trois anciennes élèves ayant reçu la grande médaille d'or ou le premier prix de vigilance clinique à la fin de leur scolarité ${ }^{91}$. Les jeunes femmes commencent ainsi leur exercice professionnel sans quitter le giron de leur établissement de formation, tout en développant savoir pratique et qualités pédagogiques. Cette charge prédestine dès lors à l'obtention d'un poste de maîtresse sage-femme dans les cours départementaux. Plusieurs anciennes boursières du département de la Corrèze la remplissent pendant la première moitié $\mathrm{du} \mathrm{xIx}^{\mathrm{e}}$ siècle dont deux futures professeures de l'école de Tulle: Jeanne Fournial et Céleste Pomarel.

La présence des sous-maîtresses se limite donc aux établissements accueillant beaucoup d'élèves comme Bourg-en-Bresse ou Bordeaux. Le nombre de ces auxiliaires est, tout comme leur choix, à la discrétion des enseignants. À Bourg-en-Bresse, l'école d'accouchement compte pendant ses trente premières années d'activité un personnel d'encadrement pléthorique composé de deux maitresses sages-femmes et trois sous-maîtresses, toutes anciennes élèves du docteur Pacoud, professeur de l'établissement. Ces jeunes praticiennes sont nourries et logées dans l'école au même titre que les maîtresses sages-femmes et les élèves, et reçoivent un traitement de 200 francs pour quatre mois d'enseignement, soit la moitié de la rémunération des maîtresses sages-femmes. Dans l'École royale d'accouchement de Bordeaux, le nombre des répétitrices varie entre deux et trois pendant les années $1810-1820^{92}$.

Le niveau des traitements est dans l'ensemble faible et le salaire de 600 francs accordéà la sous-maittresse colmaroise en I844 ne doit pas faire illusion puisqu' il

\footnotetext{
89. AD Corrèze, I X I62.

90. Beauvalet-Boutouyrie S., Naître à l'hôpital..., op. cit., p. I29.

9I. Paul Delaunay donne à la fin de son ouvrage dans les annexes la liste des aides de la sagefemme en chef, voir La Maternité..., op. cit., p. 425-427.

92. AD Gironde, 5 M 552.
} 
implique que cette dernière paie sa pension à l'hospice ${ }^{93}$. Les perspectives de carrière sont minces et ces postes d'adjointes mènent rarement à la succession de la sage-femme en chef. La fin du siècle voit une accentuation de l'exigence de niveau sans qu'elle s'accompagne d'une augmentation de la rémunération. En I896, l'école bordelaise recrute une répétitrice pour le cours de première année ${ }^{94}$ avec une indemnité annoncée de 300 francs par an, somme qui n'a pas changé depuis au moins $1849^{95}$. En revanche, le choix passe désormais par un concours ouvert aux seules sages-femmes de première classe et des épreuves exigeantes (composition écrite d'anatomie ou de physiologie, dissertation orale de pathologie $)^{96}$. Le jury est composé des trois professeurs attachés au cours départemental d'accouchement et d'un représentant de la commission de surveillance de l'établissement.

Le devenir de ces auxiliaires pédagogiques est difficile à suivre. Généralement jeunes, encore qu'il faille le nuancer pour le premier tiers du siècle ( 30 ans pour Marie-Anne Boivin, 39 pour Cécile Fougeray), les sousmaîtresses, adjointes, répétitrices ou surveillantes sont les petites mains des grandes écoles et bénéficient de leur prestige. Le contenu de leurs fonctions peut se limiter à la stricte répétition des leçons aux élèves, mais aussi s'étendre à l'encadrement plus quotidien des pensionnaires, créant des hiérarchies subtiles sous l'autorité première du professeur, relayée par celle de la sage-femme en chef. Bien d'autres questions demeurent : la durée de cette activité, ses effets sur la suite de leur vie professionnelle, la brigue ultérieure d'un poste de sage-femme hospitalière, attachée ou non à un cours d'accouchement. Les réponses manquent, tant les informations sur ce personnel féminin annexe sont fragmentaires et mal conservées, à l'inverse d'un personnel masculin moins nombreux mais bien documenté, et pour qui ce type d'entrée dans le système hospitalier et d'enseignement médical constitue en général un tremplin professionnel. On peut toutefois envisager qu'avoir rempli pendant quelque temps ces fonctions apporte aux sages-femmes nouvellement diplômées deux avantages objectifs : elles y gagnent quelques années susceptibles de leur assurer la confiance d'une clientèle souvent rétive à s'en remettre à de trop jeunes praticiennes, et elles aiguisent leur sens de l'observation clinique au contact permanent des parturientes.

\footnotetext{
93. AD Haut-Rhin, I X 94.

94. AD Gironde, 5 M 562.

95. AD Gironde, $\mathrm{I} \mathrm{N} 43^{*}$.

96. AD Gironde, $5 \mathrm{M}_{562 .}$
} 


\section{Sous l'autorité des Sours...}

Que Mlle Buellet surveille, suive et fasse suivre votre enseignement, c'est bien ; elle le peut, mais elle est trop jeune et n'a point le costume qui convient pour donner à votre établissement cette garantie que réclament toutes les opinions $[\ldots]{ }^{97}$

Ainsi s'exprime en I836 le docteur Pacoud, fondateur de l'école de Bourgen-Bresse, dans une lettre à son collègue de Saône-et-Loire. L'enseignement des sages-femmes peut être confié à une sage-femme mais pour tout le reste, il faut un « costume », de religieuse s'entend.

La place occupée par les religieuses au sein des cours d'accouchement ne se comprend qu'eu égard à la place qu'elles occupent plus largement dans les institutions de soins, d'assistance et dans les prisons au $\mathrm{XIX}^{\mathrm{e}}$ siècle $^{98}$. L'extension de leur activité aux écoles d'accouchement se fait quasi naturellement, réserve faite des congrégations qui refusent tout contact avec des femmes enceintes. Sœurs de Saint Joseph (Bourg-en-Bresse, Clermont-Ferrand), sœurs de la Charité ou de la Charité de Nevers (Tulle, Bourges, Dax), sœurs de la Sagesse (Toulon), sœurs de Saint-Thomas (Brest) reçoivent ainsi la charge de l'entretien quotidien des cours d'accouchement et des maternités qui y sont annexées ${ }^{99}$. Lorsque l'enseignement obstétrical est dispensé dans un hospice, le choix se porte sur les sœurs déjà attachées à l'établissement; lorsque l'école s'installe dans un local propre, ce sont les préfets qui se mettent en quête de religieuses pour veiller à l'économie de la maison. L'ancrage régional de certaines communautés se fait parfois sentir. Dans la Meuse, l'intendance de l'institution est confiée aux sœurs de Saint-Charles, dont la maison-mère est à Nancy; dans l'Ain, les sœurs de Saint-Joseph viennent de la maison-mère de Lyon ; à Brest, les sœurs attachées à l'école appartiennent à la congrégation de Saint-Thomasde-Villeneuve fondée à Lamballe ${ }^{100}$. Au-delà, les correspondances entre préfets

97. AD Saône-et-Loire, $\mathrm{M} 2085$.

98. Langlois C., Le catholicisme au féminin..., op. cit., p. II2-II3 ; J. Léonard, « Femmes, religion et médecine... », art. cit., p. 889 ; Lalouette J., « Expulser Dieu : la laïcisation des écoles, des hôpitaux et des prétoires », Mots, 1991, $\mathrm{n}^{\circ}$ 27, p. 29-30 ; Langlois C., "L'introduction des congrégations féminines dans le système pénitentiaires français. I839-I880 », dans Petit J.-G., La prison, le bagne et l'histoire, Genève, Méridiens, 1984, p. I29-I40.

99. Ces communautés bénéficient très précocement d'un rayonnement régional ou suprarégional important, voir von Bueltzingsloewen $\mathrm{I}$., « Confessionnalisation et médicalisation des soins aux malades au XIX ${ }^{e}$ siècle », RHMC, 1996, 43-3, p. 636.

Ioo. AD Haute-Marne, II8 T I ; AN, $\mathrm{F}^{17} / 2456$, Ain ; AN, $\mathrm{F}^{17} / 2460$, Finistère ; sur les sœurs de Saint-Charles, voir Leclerc X., La vocation hospitalière des Seurs de Saint-Charles, thèse pour le doctorat en médecine, Nancy I, 1984. 
et entre médecins font circuler la bonne réputation de certaines congrégations : en I844, le préfet de la Corrèze fait transmettre par son collègue de l'Ain aux sœurs de la Charité de Nevers, installées à Bourg, une demande d'envoi de religieuses à l'école de Tulle; en I83i, le préfet du Puy-de-Dôme, lui-même ancien préfet de l'Ain, propose à trois sœurs de Saint-Joseph de prendre la direction et surveillance du cours ${ }^{101}$.

L'installation des religieuses ne coïncide pas toujours avec la fondation du cours car la présence des congréganistes se justifie essentiellement par l'existence d'une maternité et d'un internat. L'approvisionnement en nourriture, linge et mobilier de l'établissement, la surveillance de la confection des repas, celle du blanchissage, l'entretien des infirmeries et des dortoirs constituent une occupation à plein temps et provoquent fréquemment, lorsqu'ils sont laissés à la charge de la maîtresse sage-femme, des conflits entre cette dernière et l'administration départementale, toujours pointilleuse sur l'utilisation des deniers publics. Le récit de l'installation à Clermont-Ferrand des sœurs de Nevers illustre l'abandon d'une gestion laïque au profit d'une congrégation :

Au début de la création de cette école les religieuses de l'école d'accouchement appartenaient à l'ordre des sœurs de la Miséricorde. Et puis - il n'y a rien de nouveau sous le soleil - un beau jour on laïcisa. À la place des religieuses, on installa une directrice, une cuisinière, une servante laïques ; mais l'économe chargé des dépenses de l'école s'aperçut un beau jour que l'anse du panier dansait des pas absolument échevelés. [... Le département du Puy-de-Dôme avait en ce moment à sa tête un préfet qui venait du département de l'Ain et qui avait vu à l'école d'accouchement de Bourg les sœurs de Saint Joseph. Il proposa de faire venir à Clermont quelques-unes de ces sœurs ; la proposition fut acceptée et en I83I, trois religieuses de Saint Joseph remplaçaient les laïques à l'école d'accouchement de la place Sidoine-Apollinaire. ${ }^{102}$

La remise de ces tâches entre les mains de religieuses contre des traitements qui recouvrent frais de nourriture et de vestiaire entraîne une redistribution des rôles à l'intérieur des établissements. La présence de religieuses permet en outre de leur déléguer ou du moins de partager l'encadrement moral des élèves. En l'absence de sage-femme en chef, la supérieure récupère l'ensemble des obligations que fixe, pour la surveillance des élèves internes, le règlement de l'Hospice de la Maternité de Paris. Ainsi, en Charente, le règlement de i813 prévoit, dans le chapitre Police de l'établissement, que la supérieure de l'hospice

IoI. Sur la Corrèze, voir Sage Pranchère N., Mettre au monde..., op. cit., p. 278-279; sur l'école de Clermont-Ferrand, AD Puy-de-Dôme, N 469, L'Avenir du Puy-de-Dôme, I2 octobre 1896.

102. Ibid. 
accueille les élèves, leur accorde d'éventuelles permissions de sortie et fasse régner la discipline au besoin par des sanctions ${ }^{103}$.

Ce type d'organisation remplit pleinement le projet de claustration des élèves, dans une ambiance qui s'approche du noviciat. L'objectif est de faire des congréganistes des modèles complémentaires des sages-femmes enseignantes, capables de transmettre aux futures accoucheuses les vertus chrétiennes qui irriguent la description idéale de la praticienne. On retrouve cette fonction dans la liste des tâches imparties aux sœurs de la Charité à l'Hospice de la Maternité de Bourges, qui résume bien l'accumulation des attentes envers ces dernières :

Art. 8 : Les deux sœurs hospitalières seront spécialement chargées de la partie morale de l'établissement : en conséquence, elles auront l'inspection sur la conduite des femmes enceintes et des élèves sages-femmes : elles devront leur donner à toutes l'instruction religieuse, leur expliquer le catéchisme sous la direction du chapelain, les instruire à administrer le baptême aux enfans en danger de mort, présider à l'accomplissement de leurs divers devoirs dans la maison, $[\ldots]$ et leur apprendre à soigner les malades. ${ }^{104}$

L'instruction religieuse, selon le modèle de l'enseignement primaire et pour permettre l'administration correcte du baptême, tient une place non négligeable dans la formation des sages-femmes ${ }^{105}$. L'assistance régulière au culte est inscrite dans les emplois du temps des élèves : à Bordeaux, le règlement de 1818 précise l'envoi des élèves catholiques à la messe et des élèves protestantes au temple $e^{106}$. On assiste néanmoins à partir des années 1870 à une remise en cause ponctuelle mais de plus en plus fréquente de la place occupée par les devoirs cultuels dans l'emploi du temps des élèves et, dans le même temps, à une progressive mise à l'écart des religieuses. Le mouvement n'est pas propre aux écoles d'accouchement; il s'insère plus largement dans le mouvement de revendication de la laïcisation des espaces scolaires et hospitaliers. La formation obstétricale est à la croisée des chemins, mais suit plutôt la voie

103. $\mathrm{AN}, \mathrm{F}^{17} / 2458$, Charente-Inférieure.

I04. AD Corrèze, I X 162 .

I05. Au cours du $\mathrm{XIX}^{\mathrm{e}}$ siècle, cet apprentissage passe au second plan même s'il est encore régulièrement mentionné dans les manuels. De débats se poursuivent dans le milieu médical sur l'opportunité d'administrer le baptême in utero, voir Fredj C., "Concilier le religieux et le médical. Les médecins, la césarienne post-mortem et le baptême au XIX ${ }^{e}$ siècle », dans Alfani G., Castagnetti P., Gourdon V. (dir.), Baptiser. Pratique sacramentelle, pratique sociale ( $\mathrm{XVI}^{e}-\mathrm{XX}^{e}$ siècles), Saint-Étienne, Publications de l'université de Saint-Étienne, 2009, p. I25-I43.

Io6. AD Gironde, 5 M $552 ; 5$ M 56 I. 
hospitalière, plus lente à se pourvoir d'un personnel laïc en cours d'apparition pendant ces décennies ${ }^{107}$.

Les contestations dénoncent les excès religieux et l'inadaptation des sœurs aux établissements d'enseignement obstétrical. En août I880, une lettre anonymée parvient à la commission départementale de la Drôme sur le régime de l'école de Bourg-en-Bresse où sont envoyées les boursières de ce département. Reprenant l'organisation de l'emploi du temps dans son courrier, la rédactrice exprime de très vives critiques sur le « carcan » religieux que ferait subir la supérieure aux élèves :

$2^{\circ} \mathrm{A}$ cinq heures et quart on se rend à la salle d'études et là jusqu'à six heures, prière d'abord, sermon ensuite débité par la supérieure. Si la prière est un devoir pour quiconque a une croyance, est-ce aussi nécessaire d'écouter chaque matin un sermon ? Quel peut en être le fruit? Pas autre évidemment que celui de provoquer le sommeil et de faire perdre un temps précieux. ${ }^{108}$

Une perte de temps, une perte d'énergie aussi dans un contexte d'études difficiles et exigeantes, telles sont les premières récriminations de l'auteur, bientôt suivies d'aussi vives critiques sur la qualité de l'alimentation, le confort général de l'école et le niveau de la formation. Mais derrière ces premières lignes, perce surtout une conscience heurtée à plusieurs égards :

Puis il faut bien observer que parmi ces élèves, il s'en trouve qui professent des croyances religieuses dissidentes de celles du catholicisme romain, qui sont astreintes comme les autres à prendre part à la prière commune du matin et du soir, à assister à la messe et aux sermons. Toutes pourtant obéissent à l'ordre parce que celles qui s'y refuseraient seraient probablement mal vues et mal notées. [...]

$15^{\circ} \mathrm{Ce}$ rapport ne serait pas complet si j'omettais quelques autres renseignements qui ont bien aussi leur valeur. À savoir : [... $2^{\circ}$ Que Madame la Supérieure ne concentre pas son zèle à prêcher chaque matin sur la religion ou la morale mais qu'en outre elle s'enhardit jusqu'à manifester sa réprobation pour la forme républicaine. Les rois valent mieux, a-t-elle dit, il faudrait pour roi Henri $V$, aux femmes mariées qui l'écoutaient, elle a donné le conseil d'engager leurs maris à voter pour un roi.

I07. Lalouette J., «Expulser Dieu... », art. cit., p. 29-3I ; Brais B., « Désiré Magloire Bourneville and French Anticlericalism during the Third Republic », dans Porter D. (dir.), Doctors, Politics and Society: Historical Essays, Amsterdam, Atlanta, Rodopi, 1993, p. 107-139.

Io8. AD Drôme, 5 M 20. 
Visiblement protestante et républicaine, la jeune femme rejette en bloc tout ce que représente le fonctionnement de l'école de Bourg-en-Bresse. Les dénégations de la préfecture de l'Ain, renforcées de témoignages contradictoires d'autres élèves sages-femmes et du personnel de l'établissement, ne suffisent pas à ramener la pleine confiance chez le préfet et les conseillers généraux de la Drôme. Décision est alors prise d'envoyer dans une autre école les boursières du département.

Second reproche : l'inadaptation, que celle-ci soit dénoncée sur un mode virulent ou apaisé. La laïcisation de l'école d'accouchement de Tulle en I88I est concomitante de la laïcisation des hôpitaux parisiens. Les sœurs de Nevers, encensées quelques années plus tôt pour leurs vertus de pureté, douceur et patience, sont clouées au pilori par les conseillers généraux républicains qui n'hésitent pas à manier la référence égrillarde. De même les crédits consacrés au culte sont supprimés par un tour de passe-passe rhétorique qui redéfinit l'institution en «clinique d'accouchement ». La laïcisation tulliste se déroule dans un climat d'unanimité, ce qui n'est pas le cas à Clermont-Ferrand où le remerciement des sœurs de Saint-Joseph en 1896 donne lieu à une violente campagne de presse contre la décision préfectorale. L'indignation toute politique du journaliste de L'Avenir du Puy-de-Dôme se construit sur une déploration de la « mise à la porte » des religieuses, saintes et martyres de la cause laïcisatrice, pour exploser finalement en imprécations contre les anticléricaux :

C'était vrai : on les chasse. Et sœur Pauline me dit tout cela sans un mot de colère, toujours sur le visage le même sourire, immuablement fixé. Il y a 53 ans qu'elle était à Clermont ; elle était bien jeune, elle avait vingt-trois ans quand elle quitta la maison de Bourg pour venir ici. Il y a quelques années, on célébra ses noces d'or.

Sur ses lèvres le sourire s'est arrêté ; derrière les paupières, on devine les larmes, les vraies larmes qui montent du cœur. [...] Combien de fois depuis vingt ans ai-je entendu les mêmes choses. Sœurs d'écoles, sœurs d'hôpitaux, toutes sont parties, comme sœur Pauline, sans un mot de haine ou de colère, expulsées les unes après les autres sans aucun motif. [... Espère-t-on faire des économies avec des laïques? Allons donc. L'expérience est faite aujourd'hui et les contribuables savent ce qu'elle coûte. La laïcisation de l'école d'accouchement de Clermont n'est donc que la conséquence de la campagne anticléricale qui se poursuit en Auvergne : au moment où le vent est à l'apaisement, à l'union de tous les Français, il est triste de constater que des sectaires viennent troubler la paix intérieure et jeter la division parmi nous. ${ }^{109}$

I09. AD Puy-de-Dôme, N 469, L'Avenir du Puy-de-Dôme, I2 octobre I896. 
De l'Auvergne toute catholique à la Corrèze déjà largement déchristianisée, les conseils privilégient de plus en plus fréquemment une gestion laïque. L'intégration croissante des services de maternité dans les hôpitaux, soutenue par une dynamique architecturale et sanitaire qui renouvelle profondément le visage de l'immobilier hospitalier, participe de ce dessaisissement des congrégations, les écoles suivant les maternités comme c'est le cas à Clermont-Ferrand (ill. 6) ou plus tôt à Bordeaux en I877. Au-delà, la hausse des exigences en matière d'hygiène, l'essor d'un nouveau corps professionnel laïc, celui des infirmières, et un certain recul de l'idéal claustral pour l'éducation féminine contribuent à rendre les religieuses moins nécessaires à ces établissements, moins congruentes à leur évolution sociale et scientifique.

\section{... et sous l'ail des commissions de surveillance}

Le caractère public des cours départementaux d'accouchement ne se réduit pas à la subvention annuelle du conseil général et à la nomination du personnel. Si les professeurs sont parfois désignés comme les «surveillants-nés » de ces cours (Calvados, I808), la haute main reste à l'administration. Souvent directeur en titre de ces établissements, le préfet délègue cette charge en l'inscrivant parmi les compétences d'une des divisions de la préfecture, mais une surveillance directe reste pesante pour le personnel administratif. La méthode la plus simple pour remédier à ces inconvénients est de confier à une commission le soin de veiller aux destinées de l'établissement, puis d'en rendre compte au préfet une ou plusieurs fois dans l'année.

L'intégration de nombreux cours d'accouchement dans le système hospitalier désigne naturellement la commission administrative des hospices comme interlocutrice privilégiée du personnel de la formation obstétricale, des élèves sages-femmes et de l'administration préfectorale. Les règlements fixent alors cette délégation d'attribution (Cher, Aube ${ }^{110}$ ). Le rôle de la commission s'étend bien au-delà de la surveillance du fonctionnement matériel de l'école, puisqu'elle est sollicitée pour le choix du personnel, qu'elle fournit parfois ce personnel, et qu'elle apparaît en cas de conflit interne comme une instance d'arbitrage. Elle peut être amenée à proposer un règlement intérieur et à préciser de ce fait la répartition des domaines d'autorité, quitte à limiter son propre champ d'intervention : " (Saône-et-Loire, I833) Art. 2I. Les devoirs de chacun étant clairement tracés et définis, il est interdit à qui que ce soit de s'immiscer dans ce qui doit lui rester étranger ${ }^{111}$, »

IIo. $\mathrm{AD}$ Corrèze, I $\mathrm{X}$ I62; $\mathrm{AD}$ Aube, $5 \mathrm{M}_{33}$.

III. AD Saône-et-Loire, M 2085. 
Néanmoins, selon la situation de l'école, sa taille, son fonctionnement dans le cadre d'un réseau multiple d'institutions ou au contraire son autonomie, l'appui sur la commission administrative des hospices n'est pas toujours possible. À Dijon, la première décennie d'existence de la maternité annexée au cours d'accouchement s'écoule sous la seule direction du professeur et de la sagefemme, une surveillance molle étant exercée de loin en loin par un membre du conseil municipal ${ }^{112}$. La commission peut signifier son désintérêt pour l'affaire (Aisne ${ }^{113}$ ) ou ne pas avoir la disponibilité nécessaire au suivi de l'établissement. Deux choix se présentent alors : accepter une prise en main directe avec tous les inconvénients qu'elle comporte ou constituer une commission ad hoc, spécifiquement créée pour le cours d'accouchement et qui prend alors l'appellation de «commission de surveillance».

La nomination au sein de la commission administrative des hospices d'un petit nombre de membres (entre trois et cinq) permet à la préfecture de disposer d'interlocuteurs précis et stables, qu'elle a en général elle-même désignés. Le règlement du cours d'accouchement de Toulon (I8I4) opte pour ce système $e^{114}$ et détaille les prérogatives de cette commission qui portent, entre autres, sur les modalités d'admission des élèves (articles 6 à 9). Mais la dualité commission administrative/commission de surveillance complique le fonctionnement au lieu de le simplifier et, lors de la révision du règlement en I832, l'administration des hospices reprend complètement les rênes, sans plus faire mention d'une quelconque commission de surveillance.

Cet abandon prend place, de manière surprenante, au moment où le gouvernement décide de généraliser l'institution de commissions de surveillance auprès des établissements publics d'enseignement et au-delà. L'arrêté du conseil royal de l'instruction publique, en date du 14 décembre 1832, instaure auprès de chaque école normale primaire une commission de ce type pour les aspects «d'administration, d'enseignement et de discipline ${ }^{115}$ ». C'est en substance le résumé des attributions dont disposent les commissions de surveillance des cours d'accouchement jusqu'à la fin du siècle : Tulle (I834), La Rochelle (I850), Rodez (1859). D'autres établissements en créent, à des dates qu'il n'est pas toujours possible de préciser : Bordeaux (I879 au plus tard), Pau (I883 au plus tard). La commission se réunit une ou plusieurs fois par semaine, ses membres

II2. Baron P. (Dr.), Sages-femmes et maternité à Dijon, op. cit., p. 82-83.

I13. AD Aisne, RD CG Aisne, 1834 .

II4. AD Var, $9 \mathrm{M}_{5} 2 / \mathrm{r}$.

I15. Allard M., Recueil méthodique des lois, ordonnances, règlements, arrêtés et instructions, relatifs à l'enseignement, à l'administration et à la comptabilité des écoles normales primaires, Paris, impr. de P. Dupont, 1848 , p. 8I. 
font des visites régulières de l'institution (quotidienne, hebdomadaire ou mensuelle) et rendent compte en séance de leurs observations ${ }^{116}$. Des registres sont tenus qui enregistrent les délibérations et la commission a toute latitude pour se faire présenter tous les documents ayant trait aux dépenses de l'école ${ }^{117}$. Elle exerce en outre un contrôle disciplinaire sur les élèves puisqu' elle est seule à pouvoir infliger certaines punitions (privation de plus de quinze jours de parloir, privation réitérée de sortie, chambre de discipline pour plus de quatre jours) et à proposer au préfet l'exclusion des examens et le renvoi d'une élève ${ }^{118}$.

La composition de ces commissions reste néanmoins floue. Il faut attendre le dernier quart du $\mathrm{XIX}^{\mathrm{e}}$ siècle pour que les textes prennent la peine de définir la nature des membres appelés à entrer dans ce genre de commission. Cette précision accrue se fait souvent au détriment du corps médical ${ }^{119}$, même si quelques exceptions subsistent comme dans le cas de l'école paloise en I883: "Cette commission sera composée de deux dames de la Société de charité maternelle de Pau et de quatre médecins et chirurgiens. Elle sera présidée par le préfet ${ }^{120} »$. La réforme de l'élection des conseillers généraux en I87I accroît le poids des représentants politiques dans les commissions, tandis que s'élève la part des fonctionnaires en charge de services départementaux. Après avoir été gérée depuis I832 par la commission administrative de l'hôpital qui accueille la maternité, l'école d'accouchement de Dijon est dotée en I879 d'une commission de surveillance comprenant deux membres du conseil général, deux membres du conseil municipal et les inspecteurs du service des enfants assistés ${ }^{121}$.

La présence de conseillers généraux au sein des structures de surveillance des écoles d'accouchement marque après I87I la reconnaissance incontournable du poids des élus. Au-delà, le conseiller-membre de la commission est par essence un défenseur de l'institution, susceptible avant 1871 , et plus encore après cette date, de plaider en sa faveur pendant les sessions annuelles. Cette représentation est une preuve supplémentaire de l'ancrage local des établissements de formation obstétricale, fleurons départementaux à préserver et à exalter.

\footnotetext{
II6. AD Charente-Maritime, 3 X 299.

II7. Ibid.; AD Corrèze, I X I77*.

II8. $\mathrm{AN}, \mathrm{F}^{17} / 2458$, Corrèze.

II9. L'exemple corrézien montre un tournant à partir des années I860 : les médecins auparavant majoritaires sont devancés par des hommes de loi et des fonctionnaires, voir Sage Pranchère N., Mettre au monde..., op. cit., p. 236-239.

I20. AD Haute-Marne, i18 T I.

I2I. Baron P. (Dr.), Sages-femmes et maternité à Dijon, op. cit., p. 83.
} 
Exceptionnel par la personnalité remarquable de ses enseignants, le fonctionnement pédagogique de l'Hospice de la Maternité de Paris n'en travaille pas moins profondément tout au long du siècle l'enseignement obstétrical français. Si l'on souhaitait réduire cette influence à l'exemplarité réductrice de quelques noms, l'on pourrait dire que la postérité concrète de Marie-Louise Lachapelle a de loin dépassé au XIX ${ }^{e}$ siècle celle d'Angélique du Coudray. Le modèle scolaire né à l'Office des Accouchées sous l'Ancien Régime et repris par la fondation de l'Hospice de la Maternité de Paris a consacré une figure neuve : la sage-femme hospitalière, subordonnée mais pleinement enseignante. Il y a objectivement, entre Marie Dugès dans les années 1770 et une sage-femme en chef de province en I850, un recul d'autorité. Mais l'évolution de la formation des accoucheuses a multiplié les secondes quand la première était aussi omnipotente que seule dans son genre. Le $\mathrm{XIX}^{e}$ siècle est jusqu'aux années 1870 pour le personnel obstétrical féminin le temps d'une conquête. Les cours publics d'accouchement font aux sages-femmes une place inédite et leur ouvrent les portes de l'hôpital, à part égale avec les congréganistes, mieux placées que les religieuses pour desservir cette invention qu'est l'institution de la maternité. À leurs côtés, les médecinsprofesseurs de province, éloignés pour beaucoup d'entre eux des enjeux de pouvoir hospitalo-universitaires, confortent leur notabilité, dans une duplication tranquille du modèle parisien, sans les concurrences qui déchirent à partir des années 1880 chirurgiens et accoucheurs des hôpitaux ${ }^{122}$.

Monde idyllique alors que celui des cours d'accouchement ? Non sans doute, car traversé des tensions qui pèsent sur la pérennité des institutions, perméable aux débats qui à partir de 1858 clouent au pilori les maternités hospitalières ${ }^{123}$. Monde paisible pourtant, en terre de hiérarchies intériorisées qui disent par contraste la violence des remises en cause personnelles subies par quelques sages-femmes hors rang. Dans le processus de professionnalisation, la sagefemme a perdu le bénéfice d'intertransmission d'un savoir-faire, pour obtenir une part de la transmission d'un savoir. La mue de l'art des accouchements en obstétrique y a joué plus que son rôle.

122. Lefaucheur N., «La création des services de maternité... », art. cit.

123. Beauvalet $\mathrm{S}$., « Faut-il supprimer les maternités ? », art. cit. 

Chapitre 8

\section{Savoirs et méthodes}

De la pratique des accouchements à la fin du XviII ${ }^{\mathrm{e}}$ siècle à l'apprentissage de l'obstétrique, la formation des sages-femmes subit une double évolution, quantitative par la transformation et l'allongement des cours, et qualitative par l'approfondissement et la diversification des savoirs. Il s'agira de considérer la transmutation de l'art des accouchements en obstétrique du point de vue des sages-femmes, comme réceptrices et usagères d'un changement dans la science : on suivra donc les effets de ce changement sur l'enseignement qu' elles reçoivent et on appréciera la manière dont elles s'en saisissent, dont elles l'infléchissent dans leur pratique mais aussi dans leur réflexion sur leur profession. Le discours politico-administratif retient de l'enseignement obstétrical l'organisation d'un sauvetage de masse des enfants à naître; mais le programme en quatre points de cette instruction (art des accouchements, vaccination, saignée, botanique usuelle), précédé d'une nécessaire formation élémentaire, délimite un champ bien plus ambitieux qui place la sage-femme à la croisée des différentes catégories du corps médical : accoucheuse, gynécologue, puéricultrice ou pédiatre, pharmacienne « en herbes »... Passeuse de médecine, gardienne de santé, la sage-femme est autant réceptacle qu'adaptatrice d'un savoir en accroissement constant, de la révolution jennerienne à la révolution pastorienne.

\section{Savoir lire et écrire :}

\section{l'instruction primaire des élèves sages-femmes}

La liste des matières au programme des écoles d'accouchement, diffusée dès I808 par le Mémoire historique et instructif, n'est pas exclusive de la transmission d'autres savoirs, au premier rang desquels, l'instruction primaire. Les exigences en la matière sont toutefois longues à se préciser. La loi du I9 ventôse an XI ne pose aucune obligation pour accéder à la formation obstétricale, et l'examen oral prévu par ce texte puis confirmé par l'arrêté du 20 prairial suivant n'impose 
pas concrètement l'acquisition de ces compétences. Les règlements successifs de l'Hospice de la Maternité de Paris corrèlent pourtant impérativement admission et capacité à lire et écrire. La qualité de l'enseignement dispensé dans cette école explique sans peine cette obligation. La capacité à prendre en notes les leçons du professeur et de la sage-femme en chef, l'aptitude à se reporter à tout instant aux ouvrages de référence sont des qualités indispensables à la future accoucheuse, le seul moyen de s'assurer que le savoir a bien été assimilé. De plus, le règlement de l'Hospice de la Maternité dans sa partie consacrée à l'instruction clinique requiert des élèves qu'elles tiennent « chaque jour une note exacte des accouchements qui se feront dans la salle de pratique ${ }^{1} »$.

Au-delà, les obligations sociales et légales de la sage-femme imposent de savoir signer et témoigner par écrit, c'est d'ailleurs ce que confirme le ministre de l'Instruction publique dans une circulaire du I9 mai 1845 pour rappeler aux préfets les critères de choix des élèves boursières à Port-Royal. La corrélation entre développement de l'enseignement public (loi de 1836 sur l'instruction primaire des filles) et montée des exigences de niveau pour les élèves accoucheuses intervient au bout d'une petite dizaine d'années ${ }^{2}$. En France c'est la précocité de la reconnaissance institutionnelle des sages-femmes par un diplôme qui rend d'autant plus inadmissible le retard pris dans le niveau d'instruction élémentaire des aspirantes. Car ce retard est grand, et les plaintes fusent dans tous les départements.

Le tournant se prend pourtant pour la lecture dans les années 1820 , pour l'écriture dans les années i830, et pour l'orthographe et la grammaire entre les années 1850 et les années 1870 selon les régions ${ }^{3}$. Le retard persistant du midi et des zones très rurales se lit encore jusqu'aux années i880. Le docteur Raymond de Limoges propose en 1880 " [d'] exiger des aspirantes le certificat d'études primaires ${ }^{4} »$, recoupant en cela une préoccupation nationale exprimée par la publication le I $^{\text {er }}$ août 1879 d'un arrêté ministériel instaurant un examen préparatoire pour les aspirantes au titre d'élèves sages-femmes de première classe qui prévoit les épreuves suivantes : lecture, orthographe, problèmes d'arithmétique et notions sur le système métrique ${ }^{5}$. Cet examen correspond au certificat d'études primaires évoqué par le médecin limougeaud : il institutionnalise en

I. AD Corrèze, i X I6I.

2. On retrouve ce décalage dans le Valais suisse. L'obligation scolaire y est décidée en 1844 , tandis que le département de l'Intérieur valaisan ne fait de l'écriture une nécessité qu'en I850, voir Vouilloz-Burnier M.-F., L'accouchement entre tradition et modernité..., op. cit., p. 257.

3. Sur cette progression, voir la mise au point d'A. Chervel, «L'école républicaine et la réforme de l'orthographe (I879-I89I) », Mots, I99I, nº 28, p. 35-37.

4. AD Haute-Vienne, RD CG Haute-Vienne, I880.

5. RLRES 3, p. 270. 
fait une pratique qui émerge dans les années 1830-I840 : le concours d'entrée dans les cours d'accouchement. Ces concours (ou examens) ont à l'origine pour fonction de classer les élèves susceptibles de recevoir une bourse départementale. Au fil du siècle, ils servent de filtre pour écarter les candidates les plus faibles. En 1842, le préfet de l'Hérault publie ainsi un arrêté portant ouverture du concours pour les places d'élèves gratuites à l'école de Montpellier : «Art. 3. L'examen portera sur la lecture, l'écriture, le calcul et sur le degré d'intelligence et d'aptitude spéciale pour la profession de sage-femme ${ }^{6}$. »

Mis à part le dernier point de l'examen, plutôt subjectif, les autres épreuves portent sur des notions censément acquises dans les écoles primaires. Le programme des concours d'entrée, qui concernent majoritairement des futures sages-femmes de seconde classe, est constant sur l'ensemble du territoire jusqu'aux années $1880^{7}$.

La décision de rendre le certificat d'études primaires obligatoire pour tous les enfants scolarisés modifie en I882 les bases du savoir minimal. Les cours d'accouchement ne tardent pas à suivre cette évolution et font entrer, à titre subsidiaire ou facultatif, des questions d'histoire et géographie de la France au nombre des épreuves des concours d'entrée. Grâce à cet ensemble de prescriptions règlementaires et de systèmes d'examens locaux, s'amorce un rattrapage progressif de niveau entre les souhaits du début du siècle et les besoins scolaires et professionnels du métier. Il culmine en I893 lors de la refonte du cursus de formation des sages-femmes :

$9^{\circ}$ Pour le diplôme de sage-femme de $\mathrm{I}^{\text {re }}$ classe, le brevet de capacité élémentaire de l'enseignement primaire ; pour le diplôme de sage-femme de $2^{\mathrm{e}}$ classe, le certificat obtenu à la suite de l'examen prévu par l'arrêté du I ${ }^{\text {er }}$ août $1879 .{ }^{8}$

D'une part, le niveau requis pour accéder aux études de sage-femme de deuxième classe rejoint enfin la réalité de la pratique et de la généralisation de l'examen instauré en août 1879 . D'autre part, les sages-femmes de première classe doivent désormais disposer d'une reconnaissance scolaire qui vaut qualification professionnelle avant de commencer leur formation, puisque le brevet de capacité élémentaire de l'enseignement primaire permet d'exercer les fonctions d'institutrice. Le brevet de capacité mentionné à l'article 9 prend la suite, par le décret du 4 janvier I88I, du brevet « du second ordre » de la loi Falloux 9 .

\footnotetext{
6. AD Hérault, I X 794.

7. S'y ajoute souvent avant cette date une épreuve d'instruction morale et religieuse.

8. RLRES 5, p. 266 : décret relatif aux conditions d'études exigées des aspirantes aux diplômes de sage-femme, 25 juillet 1893 .

9. Gréard $\mathrm{O}$., La législation de l'instruction primaire..., tome V, op. cit., p. 230-23I.
} 
Les aspirantes sages-femmes de première classe justifient donc, à partir de 1893, des mêmes titres que les élèves-maîtresses des écoles normales (loi du i8 janvier I887). Ce critère constitue un brillant point d'arrivée pour la profession qui se débarrasse ainsi des soupçons de lacunes éducatives. Il consacre et réalise de surcroît un vieux souhait de rapprochement des métiers d'institutrice et de sage-femme qui circule dès les années i8Io et dont la mise en œuvre n'est tentée au cours du siècle que dans un nombre restreint de départements (Cher, Corrèze $)^{10}$.

Reste à savoir quelles réponses les établissements de formation obstétricale ont apporté à ces lacunes. La première est celle du renoncement. Le constat de l'analphabétisme débouche parfois sur son acceptation pure et simple. C'est le cas à Bordeaux où sous l'égide de Marguerite Coutanceau un « adjoint » fait aux élèves un «traité de grammaire » pour " leur expliquer tous les mots ${ }^{11}$ ». Ce qui n'empêche pas qu'on lise dans les procès-verbaux des examens des noms d'élèves suivis de la mention «ne sachant pas lire $e^{12} »$. C'est encore le cas dans certains départements qui, conscients du retard de leur population en matière d'alphabétisation, font de cette exigence un élément facultatif : dans l'Aveyron où l'élève désignée saura lire " s'il est possible » (an vi), et dans le Tarn, où celles qui savent lire « seront, à mérite égal, préférées 》 $(\mathrm{I} 823)^{13}$.

Le renoncement n'est toutefois jamais définitif. La méthode retenue de préférence pour remédier aux lacunes primaires est l'inscription des apprentissages dans le cours d'accouchement. La place alors accordée à cette instruction est variable, à l'instar des intervenants qui délivrent ces savoirs : sages-femmes en chef (Aveyron) ; instituteurs ou institutrices laïcs extérieurs à l'établissement (Basses-Pyrénées, Corrèze) ; et enfin religieuses extérieures ou rattachées à l'institution (Aveyron, Ariège).

L'entrée de l'instruction primaire dans les établissements de formation obstétricale a lieu pour compenser une lacune de l'enseignement élémentaire féminin. Elle modifie cependant la physionomie des études de sage-femme en liant indissolublement le savoir spécialisé au savoir primaire. La présence d'institutrices dans les cours d'accouchement élargit le champ des connaissances dispensées dans ces institutions et esquisse entre ce métier et celui d'accoucheuse un rapprochement bénéfique au prestige scientifique et social des sages-femmes à mesure de l'avancée du siècle et de l'accroissement des exigences scolaires.

Io. Voir là-dessus Sage Pranchère N., Mettre au monde..., op. cit., p. 417-424 et dans le cadre colonial pour le $\mathrm{xx}^{\mathrm{e}}$ siècle, Barthélémy P. dans Africaines et diplômées à l'époque coloniale (1918-1957), op. cit.

II. $\mathrm{AN}, \mathrm{F}^{17} / 246 \mathrm{I}$, Gironde.

I2. AD Gironde, 5 M 550.

13. AD Aveyron, 3 X 47 ; AD Haute-Marne, II8 T I. 


\section{Pour la mère, la femme et l'enfant}

\section{La science obstétricale : définitions, manuels et ouvrages de référence}

\section{Une science opératoire}

La formation des sages-femmes comporte dès l'origine une part livresque abordée ici pour ses usages effectifs. Le profil de la production obstétricale française prédispose à cette approche. En 1787 , parmi les questions qui introduisent la première partie de la version augmentée des Principes sur l'art des accouchements, l'une porte sur la définition de l'art des accouchements :

Cet art, pris rigoureusement, n'est que celui d'aider la femme dans l'accouchement même, et d'écarter autant qu'il est possible tout ce qui pourroit alors influer sur ses jours et sur ceux de l'enfant. Considéré dans le sens le plus étendu, non seulement il a pour objet la conservation de la mère et de l'enfant dans le moment de l'accouchement, mais encore le traitement des maladies de l'un et de l'autre, soit pendant la grossesse, soit pendant le temps des couches. ${ }^{14}$

Cinquante-trois ans plus tard, le dictionnaire de médecine d'Adelon est l'un des premiers à inclure une entrée "Obstétrique » qu'il désigne comme «l'une des trois divisions fondamentales ${ }^{15} \gg$ de la médecine.

Pendant la seconde moitié du XVIII ${ }^{\mathrm{e}}$ siècle un savoir-faire auparavant transmis oralement et fondé sur l'expérience sensible reçoit un contenu anatomique et médical. L'appropriation écrite par les chirurgiens du champ d'intervention des sages-femmes au tournant des $\mathrm{XVII}^{\mathrm{e}}$ et $\mathrm{XVIII}^{\mathrm{e}}$ siècles fait basculer un ensemble de connaissances construites dans le ressenti individuel et l'intertransmission féminine vers le cadre conceptuel de ce qui fait science, par l'objectivation d'un savoir. L'érudition, mode universitaire et donc médical d'accès à la connaissance, se complète de la vue pour élaborer un discours concurrent d'une pratique, avant d'intégrer cette dernière au terme de presque un siècle d'exercice chirurgical des accouchements ${ }^{16}$. L'entrée de l'art des accouchements à l'université clôt la première étape de reformulation du savoir-faire en science.

14. Baudelocque J.-L., Principes sur l'art des accouchements [1787], op. cit., p. 4.

15. Adelon, Béclard, Bérard (et al.), Dictionnaire de médecine ou répertoire général des sciences médicales considérées sous le rapport théorique et pratique, $2^{\mathrm{e}}$ édition, $t$. 2I, Paris, Béchet jeune, 1840 , article «Obstétrique ».

I6. Pulz W., « Aux origines de l'obstétrique moderne... », art. cit., p. 595-597; 602. 
Les postes de professeurs extraordinaires de Strasbourg et Göttingen, tout comme la chaire de l'École de médecine de Paris, officialisent ce processus de naturalisation médicale des gestes de l'accoucheuse ${ }^{17}$. Cette naturalisation est sans conteste un détournement de techniques et d'observations ${ }^{18}$. Mais c'est surtout une sécularisation de la naissance, ramenée à un champ d'exploration. Le sacré est évacué au profit de la clinique, jetant les bases d'une obstétrique opératoire à l'efficacité croissante.

S'ouvre alors une nouvelle étape de l'histoire des savoirs sur la naissance. Le discours inaugural de Johann Georg Roederer prononcé en 1752 devant l'université de Göttingen, De artis obstetriciae praestantia, quae omnino eruditum decet, quin imo requirit, constitue une défense et illustration de l'obstétrique autant qu'un programme d'études ${ }^{19}$. L'enjeu est désormais de percer définitivement les secrets de la génération et de comprendre les dynamiques à l'œuvre dans la parturition. C'est cet élargissement de la focale que l'obstétrique française laisse durablement de côté, prise dans la continuité d'un élan pédagogique qui maintient le primat de l'opératoire sur la recherche fondamentale. Cette tendance, durement critiquée par les obstétriciens allemands et déplorée par quelques accoucheurs français, semble s'expliquer par la forme même de l'enseignement de cette spécialité en France. Là où le professeur allemand de l'art des accouchements est toujours professeur d'université et enseigne à de futurs pairs, le professeur français est avant tout un professeur départemental d'accouchement en charge de l'instruction des sages-femmes. La production éditoriale est donc très fortement influencée par cette préoccupation, multipliant les ouvrages dont l'organisation repose sur une démarche d'exposition pédagogique (manuels, traités généraux). La réception d'ouvrages étrangers est faible, à moins que ceux-ci n'adoptent la forme du traité-manuel qui fait ainsi la fortune française des ouvrages de Franz-Carl et Hermann Franz Naegele à partir des années $1850^{20}$.

17. Schlumbohm J., « Comment l'obstétrique... », art. cit., p. I9 ; A. Carol, « Sage-femme ou gynécologue ? », art. cit., p. 237.

I8. Pulz W., «Aux origines de l'obstétrique moderne », art. cit., p. 6II-615.

19. Schlumbohm J., « Comment l'obstétrique... », art. cit., p. I9.

20. Naegele F. C., Manuel d'accouchements à l'usage des élèves sages-femmes, nouvelle traduction de l'allemand par le Dr Schlesinger-Rabier, augmentée et annotée par J. Jacquemier, suivi d'un appendice contenant la saignée, les ventouses et la vaccine et d'un questionnaire complet, Paris, G. Baillière, I853, $3^{\mathrm{e}}$ édition en 1857 , ce manuel est mis au programme des élèves de l'Hospice de la Maternité de Paris, dès sa première traduction française ; Naegele H. F.., Traité pratique de l'art des accouchements, traduit par G. Aubenas sur la sixième et dernière édition allemande, Paris, $1869,2^{\mathrm{e}}$ édition en $\mathrm{I} 880$. 


\section{Quels manuels pour quels usages?}

Les archives des cours ne conservent malheureusement quasiment rien sur les supports et les modalités de l'enseignement. Les bibliothèques sont donc connues par la bande (inventaires de mobilier ou factures de libraire) tandis que les correspondances des enseignants avec l'administration ne les évoquent que de façon allusive.

Le manuel privilégié pendant la première moitié $\mathrm{du} \mathrm{XIX}^{\mathrm{e}}$ siècle par la plupart des établissements est sans conteste le «petit »Baudelocque, dans sa version de 1787 ou dans son édition plus récente de $1806^{21}$. L'Hospice de la Maternité de Paris l'intègre dans les frais que les élèves sages-femmes acquittent à leur admission dans l'école. En I808, s'y adjoint le Mémoire historique et instructif, qui fait simultanément office de règlement intérieur de la maison et de rappel de son histoire. Le deuxième support d'études imposé aux élèves est, à partir de I8I2, le Mémorial de l'art des accouchements de Marie-Anne Boivin sur proposition du préfet de la Seine au ministre de l'Intérieur ${ }^{22}$. Dans les établissements de province en revanche, le professeur limite à un seul le nombre de manuels, pour des raisons financières et de clarté du propos.

Le cours théorique est adossé au manuel qui est choisi en fonction du niveau que l'enseignant suppose aux élèves. Cet ouvrage, remis aux futures sages-femmes au début de leur scolarité, est pour elles une sorte de bible à laquelle se reporter pendant tout le reste de leur carrière. Elles l'obtiennent soit en versant lors de l'admission au cours une somme qui équivaut à l'achat de l'ouvrage, soit grâce à la générosité de la dotation départementale. Dans ce dernier cas, la possibilité de conserver l'ouvrage, à l'issue de la formation, est soumise au bon vouloir de l'administration départementale. En mai 1852 à La Rochelle, le préfet remet en cause l'habitude en usage depuis I8I3 de « faire l'abandon aux élèves, à la sortie du cours »du manuel ${ }^{23}$. Il exige désormais que les élèves sages-femmes diplômées rendent l'ouvrage qui leur a servi de base pour qu'il puisse « servir à celles qui seront appelées à prendre leur place dans le cours ${ }^{24} »$. Une telle décision est lourde de conséquences puisque dès

21. Le succès du manuel de Baudelocque est tel qu'en I825 paraît une adaptation de cet ouvrage par N. Lebeaud, pharmacien militaire, sous le titre Le Baudelocque des campagnes. Guide pratique des sages-femmes, Paris, A. Eymery.

22. Boivin M.-A., Mémorial de l'art des accouchements, ou principes fondés sur la pratique de l'Hospice de la Maternité de Paris et sur celles des plus célèbres praticiens nationaux et étrangers suivi des aphorismes de Mauriceau, Paris, Méquignon l’aîné père, I8I2.

23. AD Charente-Maritime, 3 X 296.

24. Ibid. 
l'époque des cours de démonstration, la diffusion des manuels (Angélique du Coudray, Augier du Fot, Baudelocque ou Icart) est considérée comme un complément indispensable. La faible alphabétisation du public alors concerné n'est pas considérée comme un obstacle puisque la valeur des ouvrages réside dans les planches illustrées. À mesure que le siècle avance, l'amélioration du niveau d'instruction primaire des futures accoucheuses augmente encore l'importance de ces bréviaires.

Le rôle assigné au manuel impose un choix éclairé et capable d'évolution. Les Principes de Baudelocque sont dépassés au cours des années I830 par L'Art des accouchements du même auteur, ouvrage en deux volumes ${ }^{25}$. Certains établissements lui substituent des ouvrages plus récents comme le Cours d'accouchement de Capuron qui fait son apparition sur les tables des élèves tullistes à la fin des années $1830^{26}$. Le souci de ne pas être à la traîne du savoir obstétrical impose ces changements de manuels. Toutefois, il faut parfois un peu de temps pour trouver l'ouvrage adapté à l'évolution de l'obstétrique et aux capacités des élèves. L'adoption à La Rochelle en 1850 du Traité pratique de l'art des accouchements de Chailly-Honoré ne correspond pas au niveau des jeunes femmes ${ }^{27}$ :

Je dois vous faire connaittre, Monsieur le Préfet, qu'il m'a semblé que l'auteur (Chailly), que les élèves suivent depuis deux ans, est, en général, d'une portée scientifique trop élevée pour leur intelligence et leur instruction première. ${ }^{28}$

Ces tâtonnements s'inscrivent dans la réforme du fonctionnement de l'école de la Rochelle. La comparaison du fonds de la bibliothèque connu grâce aux inventaires antérieurs à 1850 et des achats faits par le nouveau professeur dès sa prise de poste révèle le fossé scientifique entre deux générations d'accoucheurs et la profondeur du renouvellement opéré. En I830, les ouvrages cités dans le récapitulatif du mobilier sont au nombre de neuf dont sept ont été publiés aux $\mathrm{XVII}^{\mathrm{e}}$ et $\mathrm{XVIII}{ }^{\mathrm{e}}$ siècles, les plus récents étant le Mémorial de Marie-Anne Boivin et les Nouveaux éléments de la science et de l'art des accouchemens de JacquesPierre Maygrier (I814).

Le décès d'Edme Romieux en 1848 et son remplacement par son fils entraînent un dépoussiérage complet de la bibliothèque. Font leur entrée Chailly-Honoré,

\footnotetext{
25. Baudelocque J.-L., L'Art des accouchements, op. cit. ; Beauvalet-Boutouyrie S., Naître à l'hôpital..., op. cit., p. 120 .

26. Capuron J., Cours théorique et pratique d'accouchement, Paris, Croullebois, I823, voir Sage Pranchère N., Mettre au monde..., op. cit., p. 426.

27. Chailly-Honoré C., Traité pratique de l'art des accouchements, Paris, J.-B. Baillière, I842 ( $2^{\mathrm{e}}$ édition de I845) ; AD Charente-Maritime, 3 X 296.

28. AD Charente-Maritime, 3 X 297.
} 
déjà cité, mais aussi le Traité pratique des accouchements de François-Joseph Moreau (1838-I84I), le manuel de Jean-Baptiste Pigné-Dupuytren, le Traité complet des mancuvres de tous les accouchements d'Adet de Roseville et Mercier (I836 ou I837), la Pratique des accouchements de Marie-Louise Lachapelle (I82I ou 1828), le Manuel des accouchements de Jean-Marie Jacquemier (I846) et le Traité théorique et pratique de l'art des accouchements de Paulin Cazeaux (I840 pour la première édition $)^{29}$. Ce dernier titre est placé dès I84I « au rang des livres classiques destinés aux élèves sages-femmes de la Maternité de Paris » et remplace Baudelocque comme manuel de référence dans nombre d'écoles d'accouchement à partir des années $1850^{30}$. Dans le même temps, le Manuel d'accouchements de Franz Carl Naegele, devenu en Allemagne un classique avec huit éditions successives et déjà adopté dans les écoles suisses, est traduit en français par Jean-Marie Jacquemier. Il est par la suite régulièrement réédité jusqu'aux années 1860 .

La liste des publications pédagogiques à destination des sages-femmes se confond en partie avec celles visant les étudiants en médecine (voir le Précis de Michel Chevreul dans le premier tiers du XIX ${ }^{e}$ siècle). L'arrivée aux affaires d'une nouvelle génération d'accoucheurs, celle qui emporte en 1882 la création du concours d'accoucheur des hôpitaux de Paris, prend le relais des auteurs du milieu du siècle. Stéphane Tarnier, lui-même chirurgien en chef de l'Hospice de la Maternité de Paris, réédite en 1867 avec des ajouts le Traité désormais classique de Paulin Cazeaux. La décennie 1880 est particulièrement féconde en auteurs de ce genre de guides ou manuels : citons de nouveau Tarnier en collaboration avec Chantreuil (I882), Lagarde (I882), Delore et Lutaud (1883), Gallois (I886), Crouzat et Budin (I89I), ou encore Abelin et Pénard qui publient en 1889 la septième édition de leur Guide pratique de l'accoucheur et de la sage-fermme.

La participation des sages-femmes à la production des livres qui fondent leur instruction est beaucoup plus anecdotique, aux exceptions notables du Mémorial de Marie-Anne Boivin et de la Pratique des accouchements de MarieLouise Lachapelle. Ces deux ouvrages sont aussi emblématiques qu'exceptionnels. Leur ancrage très fort dans la pratique et l'observation clinique en fait plus que des manuels, car leur valeur fondée sur les acquis de l'exercice professionnel est moins prompte à se périmer. Le prestige de leurs auteurs et le soutien apporté par l'administration à la diffusion du premier de ces deux livres expliquent leur postérité au-delà des frontières : le Mémorial est traduit

29. AD Charente-Maritime, 3 X 296.

30. Sage Pranchère N., Mettre au monde..., op. cit., p. 426. 
en italien (I822), en allemand (I829), et la Pratique l'est en allemand (1825) ${ }^{31}$. L'ouvrage de Marie-Anne Boivin acquiert même le statut de manuel officiel des élèves sages-femmes de l'école de la maternité de Berlin ${ }^{32}$. Marguerite Coutanceau publie elle aussi mais avec un succès moindre et géographiquement plus limité (Élémens de l'art d'accoucher, en faveur des élèves sages-femmes de la généralité de Guienne en 1784 et Instructions sommaires, théoriques et pratiques sur les accouchemens, à l'usage des élèves de $M^{\text {me }}$ Coutanceau en I800).

Les autres incursions des sages-femmes dans le champ de la littérature pédagogique se limitent à des cas de collaboration entre sages-femmes et médecins (Adet de Roseville et Jeanne Mercier en $1836^{33}$ ), ou à des publications à diffusion locale, comme l'Abrégé de Marie Rose Coutal-Sol (Montpellier, $1877^{34}$ ). Le temps des accoucheuses auteurs de manuels pour leurs consœurs correspond au premier tiers du XIX ${ }^{e}$ siècle. L'ouvrage de Marie-Rose Coutal-Sol est à cet égard un tard-venu, dont le contenu n'a absolument rien de comparable avec les productions de ses devancières ${ }^{35}$. Son principal intérêt est sans doute de concentrer les souvenirs des cours suivis par l'auteure à la maternité de Montpellier quatorze ans plus tôt.

\section{Structures et renvois : la production d'une science normée}

Les publications pédagogiques à destination des sages-femmes reproduisent le déroulement des leçons. C'était déjà le cas des Principes de Baudelocque ${ }^{36}$, ça l'est encore un siècle plus tard ${ }^{37}$.

Le manuel commence toujours par la présentation de l'anatomie féminine en rapport avec la reproduction et l'accouchement, et se poursuit par la description de la grossesse, puis de l'accouchement naturel et de ses suites (délivrance, soins à la femme et au nouveau-né). Il détaille ensuite les situations pathologiques pouvant se déclarer avant, pendant et après l'accouchement et nécessitant l'intervention de la sage-femme ou du médecin. La première moitié

3I. Carol A., « Sage-femme ou gynécologue ?... », art. cit., p. 254.

32. Delacoux A., Biographie des sages-femmes célèbres..., op. cit., p. 42.

33. Adet de Roseville E., Mercier J., Traité complet des mancuvres de tous les accouchements..., op. cit.

34. Coutal M.-R., veuve Sol, Abrégé. Traité pratique d'accouchement, par $M^{m e}$ C. S., sage-femme de $1^{\text {re }}$ classe, Montpellier, impr. de Monnet, 1877 .

35. L'Abrégé de Marie-Rose Coutal-Sol compte seulement I5I pages, et sa deuxième partie est enrichie d'observations personnelles tirées de la pratique de l'auteur.

36. Baudelocque J.-L., Principes sur l'art des accouchements [I806], op. cit., p. XI.

37. Crouzat E., Budin P., La pratique des accouchements..., op. cit., avant-propos. 
du siècle est marquée par une volonté de synthèse et de normalisation des publications antérieures. À partir des années I850, l’obstétrique française s'enrichit de toute une série de découvertes et les intègre progressivement à ses manuels à l'occasion des rééditions (Cazeaux par Tarnier en 1867 où sont mis à l'honneur Depaul et Pajot $\left.{ }^{38}\right)$. Par ailleurs, les traductions d'ouvrages étrangers tendent à les rapprocher des modèles français (Jacquemier pour Naegele, $1853^{39}$ ).

L'attention à l'évolution bibliographique fait des manuels d'accouchements du XIX ${ }^{e}$ siècle les produits d'un réseau serré d'obstétriciens. La dette de reconnaissance envers les auteurs anciens se double d'un équivalent envers les pairs contemporains.

(Cazeaux, 1853) Si ce livre ressemble par la forme à ceux qui ont été publiés en France sur le même sujet, il en differe essentiellement par le fond, car j’ai admis presque complètement les idées des professeurs Naegelé, P. Dubois, Stoltz, qu'on ne retrouve clairement exposées dans aucun de nos livres classiques. J'ai également emprunté au savant traité de M. le professeur Velpeau, dont la vaste érudition a beaucoup facilité les recherches bibliographiques; aux leçons de M. le professeur Moreau, qui fut mon premier maitre ; aux excellents articles de Désormeaux, de Dugès, de M. Guillemot ; aux ouvrages classiques, en Angleterre et en Amérique, de Burns, Campbell, Merriman, Rhamsbotham, Dewees, Meigs, Rigby ; aux traités de Peu, Delamotte, Levret, Smellie, Baudelocque, Gardien, Capuron. J'ai également consulté avec fruit le Manuel récemment publié par mon ami le docteur Jacquemier et les mémoires de MM. Simpson, Tyler-Smith, Depaul, Devilliers, etc. Enfin, on s'apercevra facilement combien j’apprécie les mémoires si éminemment pratiques de madame Lachapelle : en un mot, j’ai pris partout et tout ce qui m'a paru vrai. ${ }^{40}$

L'ouverture vers les auteurs anglais et américains, qui vient compléter les liens déjà évoqués avec les obstétriciens allemands, signale les efforts de l'obstétrique française pour s'insérer dans une dynamique scientifique large, après quelques décennies de repli au tournant des XVIII ${ }^{e}$ et XIX ${ }^{e}$ siècles.

\section{Le cours sans livre}

Il existe cependant une école où les élèves ne reçoivent aucun ouvrage et où le professeur ne transforme jamais son enseignement en livre, c'est l'établissement départemental de Bourg-en-Bresse. Les premiers mois d'existence de l'école sont

38. Cazeaux P., Traité théorique et pratique... [I867], op. cit., p. XI.

39. Naegele F. C., Manuel d'accouchements..., op. cit., p. III.

40. Cazeaux P., Traité théorique et pratique... [1853], op. cit., p. IX-x. 
pour le docteur Pacoud, son fondateur, un temps d'incertitudes et de déceptions : «Aucun ouvrage élémentaire ne remplissait mon but, l'expérience m'avait éclairé sur ce point ${ }^{41}$. $\gg$ Il modifie alors sa méthode, l'appuyant sur des séries de questions dont il puise les réponses chez une multitude d'auteurs (Gardien, Boivin, Maygrier, Stein, Capuron). Ces séries manuscrites (" 450 à 500 pages in $\left.8^{042} 》\right)$ sont recopiées par les élèves dans des cahiers et servent de base aux leçons. Cette habitude s'ancre si profondément dans la pratique pédagogique qu' elle est décrite à l'identique en I880 par une élève boursière de la Drôme.

Le recours à un manuscrit compilant les meilleurs auteurs ne semble pas a priori moins apte à former les élèves sages-femmes qu'un manuel imprimé conçu dans un esprit identique. Toutefois, les voies de circulation de ce manuscrit multiplient les obstacles à son utilité et en font le témoin périmé d'une pratique adaptée aux années 1820 mais incapable de répondre aux exigences de l'enseignement obstétrical des dernières décennies du siècle :

Généralement ces copies manuscrites sont fort mauvaises et comment se pourrait-il qu'il en fût autrement puisque le personnel des sages-femmes ne se recrute que dans des rangs fort peu instruits ? [... C'est indescriptible ! L'orthographe fait absolument défaut ; il s'y rencontre des phrases rédigées en un français impossible; parfois la demande, d'autrefois la réponse n'ont point été traduites ; les expressions techniques surtout y sont tronquées, estropiées, illisibles, incompréhensibles, parce que le ou la copiste ne savaient pas ce qu'ils écrivaient et comment veut-on que l'élève qui aura lu et récité I2O fois au moins le mot par exemple de Ultérus au lieu du mot Utérus, ou bien celui d'Aponirose au lieu d'Aponévrose, ne dise pas toute sa vie Ultérus, Aponirose. ${ }^{43}$

La réponse du docteur Pic, professeur de l'école bressane, à ces critiques, défend le principe du manuscrit par la volonté de ne pas limiter les élèves à un manuel et de les encourager à consulter toutes les références présentes dans la bibliothèque de l'établissement ${ }^{44}$. Le choix des textes spécialisés contre le manuel général se fait dès la fondation de l'école. Il reste toutefois unique et propre à cette institution.

\footnotetext{
4I. $\mathrm{AN}, \mathrm{F}^{17} / 2456$, Ain.

42. AD Drôme, 5 M 20.

43. Ibid.

44. Ibid.
} 


\section{Sage-fermme, gynécologue, puéricultrice et pédiatre?}

La formation des élèves sages-femmes intègre une dimension pathologique qui ouvre vers d'autres domaines médicaux : la gynécologie ainsi que la puériculture et la pédiatrie en cours de constitution. Cette extension du domaine de la sage-femme se fonde sur la nécessité de connaitre pour reconnaître l'accouchement contre-nature ou laborieux et les risques afférents. Elle s'enracine dans l'association traditionnelle entre art des accouchements et maladies des femmes et des enfants. Le rassemblement en un même corps de doctrine de ce qui relève aujourd'hui de trois voire quatre spécialités médicales s'insère dans une compréhension de la physiologie féminine axée sur la fonction génératrice, le nouveau-né venant en prolongement de sa mère.

Cette approche globale connaît néanmoins au cours du XviII ${ }^{e}$ siècle des resserrements sur la pathologie féminine et sur les soins aux enfants, à l'origine de nos actuelles partitions. L'évolution des modes de construction du savoir sur le corps pose les bases d'une réorganisation complète du champ médical. Les savoirs se rapportent désormais à un organe, un âge ou un sexe $e^{45}$, tandis que la réforme des institutions hospitalières aboutit à la création d'espaces spécialisés dans l'accueil de populations particulières (vénériens, fous, enfants, etc. ${ }^{46}$.

Toutes ces évolutions créent les conditions d'un développement accéléré de la gynécologie, à partir des observations menées dans les hospices de maternité et les établissements réservés aux vénériennes (à Paris, Port-Royal et la Salpêtrière). Les résultats confortent les travaux d'un courant d'auteurs qui, dès la seconde moitié du XVIII ${ }^{e}$ siècle, ont orienté leurs écrits sur les femmes et leur statut d'éternelles malades (Traité des maladies des femmes de Jean Astruc réédité en $177 \mathrm{I})^{47}$. Les publications sur la nature féminine et ses affections, en premier lieu l'hystérie, se multiplient en reprenant des théories déjà présentes dans les écrits hippocratiques. Leur influence ultérieure sur la place sociale et politique de la femme n'est pas négligeable ${ }^{48}$. Au début du siècle suivant, Capuron publie un autre Traité des maladies des femmes qui à son tour fait date sur le sujet ${ }^{49}$.

45. Pinell $\mathrm{P}$, "Champ médical et processus de spécialisation 》, Actes de la recherche en sciences sociales, 2005/I, n ${ }^{\circ}$ 156-I57, p. 4-36 et IO-II sur l'individualisation de l'obstétrique comme spécialité.

46. Pinell $\mathrm{P}$., « La genèse du champ médical... », art. cit., p. 322-323.

47. Knibiehler Y., « Les médecins et la "nature féminine"... », art. cit., p. 839.

48. Ibid., p. 839-840.

49. Capuron J., Traité des maladies des femmes depuis la puberté jusqu'à l'âge critique inclusivement, Paris, Croullebois, I8I2. 
L'accès des sages-femmes à ces savoirs passe cependant par une approche traditionnelle et généraliste. L'organisation des manuels fournit aux futures accoucheuses un savoir large sur le corps féminin. Une part importante de la formation porte ainsi sur la reconnaissance des signes de la grossesse et appelle donc l'attention sur toute interruption du cycle menstruel, quelle que soit l'origine qui lui est a posteriori imputée. Dans un autre domaine, l'influence des «vices des parties molles» (tumeur, polype, etc.) sur la grossesse, le terme de l'accouchement et les avortements spontanés impose de déterminer la nature de ces excroissances pour limiter leurs effets. Au-delà du manuel, l'instruction passe par la synthèse, au moment des cours, d'ouvrages plus précis souvent offerts aux élèves sages-femmes comme prix à la fin de leurs études. À l'école d'accouchement de Grenoble dans les années I820, les élèves mettent par écrit l'enseignement à la fin de chaque cours. En I825, l'élève des Hautes-Alpes chargée du chapitre sur les hémorragies utérines mentionne l'accoucheur anglais Edward Rigby (qu'elle écrit « Rigléi ${ }^{0}$ »), auteur d'un Traité sur les hémorragies de l'utérus, traduit par Marie-Anne Boivin en $1818^{51}$, exemple significatif de la diversité des sources employées par les professeurs.

Ces connaissances, acquises pour des usages obstétricaux, n'en sont pas moins adaptables à d'autres accidents ou pathologies. Leur diffusion auprès d'un personnel de sages-femmes en constante augmentation multiplie les circonstances où les femmes sont susceptibles de faire appel à ce savoir. L'accroissement et l'amélioration de l'encadrement obstétrical font que celles-ci sont désormais susceptibles de trouver un recours familier et compétent lorsqu'elles sont confrontées à des affections gynécologiques chroniques ou plus ponctuelles.

De plus, le développement d'un discours sur la fragilité féminine, d'une forme d'éducation privilégiant la clôture, et d'une idéologie bourgeoise plaçant la mère au cour du foyer accroît l'attention des femmes et de leur entourage à tous les symptômes immédiatement interprétés comme des troubles hystériques ou assimilés. Un public émerge donc pour des praticiens, très vite baptisés "médecins des dames », qui se constituent une clientèle spécifiquement féminine dans des milieux sociaux généralement assez aisés ${ }^{52}$. La pudeur féminine reste cependant un obstacle et les patientes demeurent réticentes à confier leur trouble à ces médecins. C'est alors que la sage-femme intervient.

50. AD Hautes-Alpes, 5 M 15 .

5I. Boivin M.-A. (traductrice), Rigby E., Nouveau traité sur les hémorrhagies de l'utérus d'Edouard Rigby et de Stewart Duncan... traduit de l'anglais, accompagné de notes, par Mme Vve Boivin, précédé d'une notice historique sur le traitement des hémorrhagies utérines, et suivi d'une lettre de M. Chaussier sur la structure de l'utérus, Paris, Méquignon l'aîné père, I818.

52. Voir à ce propos Delamotte I., Médecin des dames, Paris, Éditions de la Différence, 2003. 
Sans que l'examen gynécologique lui soit plus aisé (il se pratique quel que soit le soignant à l'aveugle pendant toute la première partie du siècle), la sage-femme est mieux acceptée et peut alors jouer le rôle d'intermédiaire entre le médecin et la patiente $e^{53}$. Le savoir gynécologique des sages-femmes se constitue parallèlement à celui sur l'obstétrique, et le cadre hospitalier et urbain offre un terrain particulièrement riche pour toute sage-femme qui décide d'élargir son activité aux maladies des femmes.

Le second volet non obstétrical recouvre les soins aux enfants. Situé à michemin de la puériculture prônée par Rousseau et d'un intérêt plus précis pour les pathologies du premier âge, l'enseignement reçu par les sages-femmes s'étend de l'évaluation de la santé intra-utérine de l'enfant jusqu'à son sevrage, comme le rappelle en 1850 le docteur Teissier, professeur du cours d'accouchement de Troyes : «Le rôle de la sage-femme est loin d'être terminé par l'accouchement ; elle doit encore [...] suivre le nouveau-né pendant l'allaitement, le sevrage et la dentition ${ }^{54} \gg$.

Les ouvrages pédagogiques comportent tous un ou plusieurs passages consacrés à ces questions. Premiers soins immédiatement consécutifs à la naissance et préalables à la délivrance maternelle, vêture et alimentation de l'enfant sont au cour de ces chapitres. Les gestes correspondants de la ligature et de la coupe du cordon, de l'emmaillotement et de la mise au sein forment la base des savoirs de la sage-femme. Le cortège des interventions sur le corps du nouveau-né - coupe du filet de la langue, modelage du crâne, perforation de l'anus - apanage traditionnel des matrones, est évoqué pour être immédiatement confié aux chirurgiens et aux médecins ${ }^{55}$.

L'emmaillotement perdure mais selon des modalités fortement influencées par les vitupérations de Rousseau contre ce saucissonnage des enfants. L'emmaillotement souple devient cependant rapidement la norme médicale, appuyée dans les cours aux sages-femmes sur des extraits de l'Émile. À Grenoble en I820, une élève retranscrit la leçon suivante : « Rousseau dit : "l'homme nait et meurt dans l'esclavage, à sa naissance on le coud dans une bière". L'auteur parle de la manière de tenir les enfants, qu'il faut tenir ni trop chaud ni trop froid ${ }^{56} »$. Au fil de siècle, les passages consacrés à cette question, tout en maintenant le refus de l'emmaillotement serré, affichent un relativisme croissant, du moment que l'enfant soit mis à l'abri du froid et tenu propre (Maunoury, Salmon, I86I).

53. Carol A., "L'examen gynécologique... », art. cit.

54. AD Aube, $5 \mathrm{M}_{36}$.

55. Baudelocque J.-L., Principes sur l'art des accouchements [1787], op. cit., p. 545-547. Voir Loux F., Le jeune enfant et son corps dans la médecine traditionnelle, Paris, Flammarion, 1978, p. 126-129.

56. AD Hautes-Alpes, $5 \mathrm{M} \mathrm{I5.}$ 
Formées aux différentes méthodes d'habillement des enfants et sensibilisées à l'évolution des modes, les sages-femmes ont pour tâche de diffuser les unes et les autres parmi leur clientèle, avec une certaine fermeté pour imposer l'abandon de l'emmaillotement serré, surtout en milieu rural.

Autre domaine essentiel : l'alimentation. Angélique du Coudray reprend dans son Abrégé les critères de choix d'une bonne nourrice, exigences qu'on retrouve dans l'ensemble des manuels jusqu'à la fin du XIX ${ }^{e}$ siècle. Très rapidement pourtant, l'encouragement en faveur de l'allaitement maternel occupe la première place dans les chapitres concernant l'alimentation de l'enfant, suivi de l'allaitement par une nourrice et de l'allaitement artificiel. Au tournant des années 1850, la place occupée par ce sujet dans les ouvrages pédagogiques s'accroît notablement. Paulin Cazeaux ajoute ainsi à la troisième édition de son Traité théorique et pratique des accouchements une sixième partie sur l'hygiène des enfants ${ }^{57}$. L'allaitement artificiel est sans doute celui qui suscite le plus d'interrogations chez les médecins mais aussi le plus d'initiatives de la part des sages-femmes. Il impose de recourir à une alimentation de substitution, le lait animal (chèvre, ânesse, vache), et à l'usage de récipients divers : gobelet, cuillère, biberon. Ce dernier fait l'objet au XIX ${ }^{\mathrm{e}}$ siècle d'un marché florissant en particulier auprès des nourrices dont le lait se raréfie ${ }^{58}$. En I828, la veuve Breton, sage-femme, publie toute une série d'opuscules pour vanter les mérites du biberon qu'elle vient d'inventer ${ }^{59}$. Paulin Cazeaux définit pourtant ce mode d'allaitement comme «le plus mauvais de tous les modes proposés pour nourrir un enfant $\gg$ et souligne que très peu d'enfants survivent à ce régime ${ }^{60}$. À la fin du siècle, le principal combat des auteurs porte sur la nécessité de garder ces récipients parfaitement propres ${ }^{61}$. L'enseignement prend de plus en compte toutes les difficultés afférentes à l'allaitement et donne aux sages-femmes les moyens de soulager les jeunes mères ou les nourrices. Au-delà, la formation comprend généralement une partie consacrée à l'alimentation de complément (bouillies, panades, etc.) qui permet d'emmener l'enfant vers un sevrage progressif.

Les compétences de la sage-femme s'élargissent aussi en amont de la naissance dans une connaissance de plus en plus fine des étapes d'évolution du foetus. La mise au point des techniques d'auscultation obstétricale à l'aide du

57. Cazeaux P., Traité théorique et pratique... [I853], op. cit., p. XI-XII.

58. Voir Lett D., Morel M.-F., Une histoire de l'allaitement, Paris, Éditions de la Martinière, 2006, p. 13I-I48.

59. Ratier F.-S., Recueil de pièces de $M^{\text {me }}$ veuve Breton, sage-fermme, relatives à l'allaitement artificiel et à l'usage du biberon inventé par elle, Paris, l'auteur, I826-1828.

60. Cazeaux P., Traité théorique et pratique... [1853], op. cit., p. 1055.

6I. Sur le recours aux sages-femmes pour la lutte contre certaines formes de biberon, voir De Luca V., Rollet C., « Nouvelles pratiques de puériculture... », art. cit. 
stéthoscope de Laennec au début des années 1820 par Jacques Alexandre Le Jumeau de Kergaradec bouleverse complètement le suivi ante partum et permet le contrôle de la santé foetale à partir du quatrième mois de la grossesse ${ }^{62}$. Définir la taille de l'enfant à terme pour comparer ses mensurations avec celles du bassin dans ses différents axes reste un enjeu important mais s'insère désormais dans une approche approfondie du déroulement de la grossesse. La description du foetus dans les manuels s'accroît considérablement, intégrant à partir des années 1820-1830 les avancées de l'ovologie, bientôt désignée comme embryogénie, et des chapitres sur les fonctions du foetus (circulation et nutrition ${ }^{63}$. Marie-Anne Boivin développe même dans le Mémorial toute une réflexion sur la faible sensibilité du foetus au toucher et à la douleur ${ }^{64}$.

La sage-femme contracte donc par l'augmentation de son savoir le devoir d'être présente pendant la grossesse : «Le rôle de l'accoucheuse commence en effet bien avant l'accouchement, et toute sage-femme qui attendrait les premières douleurs pour visiter sa malade serait coupable de négligence ${ }^{65} \gg($ I886). Dans l'examen qui est alors pratiqué, la question des mouvements du fœutus, le toucher des parties foetales lorsque la grossesse est suffisamment avancée et l'écoute des bruits utérins (cœur du fotus et souffle placentaire) sont des éléments primordiaux d'information pour la sage-femme, car ils sont des signes certains de la grossesse et déterminent la conduite à tenir au moment du déclenchement de l'accouchement.

Dernière circonstance où sont requises les capacités de la sage-femme : lorsque l'enfant naît en état de mort apparente ${ }^{66}$. Tous les manuels, d'Angélique du Coudray à la fin du XIX ${ }^{e}$ siècle, consacrent de substantiels passages à la description des différentes formes de détresse néonatale (asphyxie bleue ou violette et asphyxie blanche ou syncope ${ }^{67}$ ), dont l'étiologie se précise, permettant l'adaptation des thérapeutiques. Sur le terrain, les sages-femmes, qui ont toutes dans leur trousse un tube laryngien ${ }^{68}$, ne le cèdent en rien aux médecins dans leur mise en œuvre.

62. Lejumeau de Kergaradec J.-A., Mémoire sur l'auscultation appliquée à l'étude de la grossesse, ou Recherches sur deux nouveaux signes propres à faire reconnaître plusieurs circonstances de l'état de gestation, lu à l'Académie royale de médecine, dans sa séance générale du 26 décembre 1821, Paris, Méquignon-Marvis, I822.

63. AD Aisne, RD CG Aisne, 1859.

64. Boivin M.-A., Mémorial... [1836], op. cit., p. I5I.

65. Gallois E., Manuel de la sage-femme..., op. cit., p. 88.

66. Pour plus de détails, voir Sage Pranchère N., « La mort apparente du nouveau-né dans la littérature médicale (France, 1760-I900) », $A D H$, 2012-I, p. I27-I48.

67. Gallois E., Manuel de la sage-femme.., op. cit., p. 254.

68. Stofft H., «La mort apparente du nouveau-né en I78I et I806, l'œuvre de François Chaussier », Histoire des sciences médicales, I997, t. 3I, n 3-4, p. 34I-349. 
L'accumulation des tâches qui reposent sur les épaules des sages-femmes et l'accroissement continu au cours du XIX ${ }^{e}$ siècle de leur champ d'intervention relèvent de l'évolution sans précédent des savoirs obstétricaux, gynécologiques et pédiatriques mais aussi du statut spécifique de l'accoucheuse comme agent médical multifonction, généralement indépendante dans l'exercice de sa profes$\operatorname{sion}^{69}$. Cette indépendance peut toutefois aussi signifier une forme de solitude de la sage-femme, puisque ses qualités d'accoucheuses ne sont qu'une part des attentes de la communauté dont elle doit gagner et conserver la confiance pour vivre de son métier. En l'absence encore fréquente d'un médecin dans la commune, voire le canton, le savoir de la sage-femme en fait souvent la seule interlocutrice médicale, susceptible d'être consultée bien au-delà de ses attributions.

\section{Apprendre et retenir}

\section{La répétition au cœur des apprentissages}

La manière d'enseigner les accoucheuses suscite, dès la mise en place des formations au XvirI ${ }^{\mathrm{e}}$ siècle, au moins autant de discussions que la nécessité de cet enseignement. Les obstacles à une instruction de qualité sont nombreux : brièveté des cours, analphabétisme, non francophonie; et ne sont que très progressivement surmontés par l'allongement de la formation et les progrès de l'instruction primaire. Autant que le contenu, la méthode est donc primordiale pour atteindre les objectifs pédagogiques.

Quelles conclusions tirer de la forme des manuels ? L'Abrégé de l'art des accouchements d'Angélique du Coudray ne se singularise ni par son plan ni par sa présentation des traités d'accouchement contemporains et ses qualités résident principalement dans sa taille restreinte et la simplicité des formulations. La publication en 1775 des Principes de Baudelocque et, quelques mois plus tôt, d'une version plagiée et raccourcie de cet ouvrage par Amable Augier du Fot, marque un tournant dans l'histoire de l'écriture obstétricale pédagogique. Les auteurs reprennent le principe classique du dialogue didactique ${ }^{70}$. Le modèle du dialogue est cependant simplifié à l'extrême dans une alternance non dramatisée de questions et réponses introduites par les lettres $\mathrm{Q}$. et $\mathrm{R}$.

$\mathrm{Au}$ cœur des méthodes de formation des sages-femmes, se trouve donc l'apprentissage par cœur d'un dialogue figé dont la bonne compréhension et

69. Faure O., «Les sages-femmes en France au XIX ${ }^{e}$ siècle... », art. cit., p. I67-I68.

70. Sur la tradition du dialogue didactique, voir Cazanave C., Le dialogue à l'âge classique. Étude de la littérature dialogique en France au XvII siècle, Paris, H. Champion, 2007. 
la mémorisation dépendent de son ordre et de sa complétude. Questions et réponses s'enchaînent et forment la trame serrée d'un savoir qui se construit d'abord à l'échelle de ces binômes, avant de le faire à l'échelle de la section, de l'article, du chapitre puis de la partie. Cette fragmentation des connaissances apparaît plus propre à un public incapable de lire ou relire de longs paragraphes explicatifs. Les élèves sages-femmes s'accrochent alors aux relances régulières de l'interrogateur, au risque de s'enfermer dans cette litanie et de ne pas réussir à l'adapter à la reformulation des questions, ou pire de perdre le lien entre théorie et réalité pratique. C'est d'ailleurs un reproche régulièrement adressé aux futures accoucheuses formées de cette manière.

Le succès des Principes de Baudelocque justifie l'adoption de la méthode à l'Hospice de la Maternité de Paris où l'auteur applique son système à ses élèves. La place de l'exposé magistral est réduite à la moitié du temps d'enseignement, le reste étant consacré aux questions. Marie-Louise Lachapelle applique un rythme similaire à ses propres cours de théorie ${ }^{71}$. Les maîtresses sages-femmes qui lui succèdent accordent aussi une grande importance à cette manière de faire apprendre ; Clémentine Charrier la substitue même entièrement au cours magistral préalable ${ }^{72}$. La part prise dans l'enseignement de l'obstétrique par cette méthode influe tout d'abord sur les fonctions du personnel enseignant (répétitrices) et sur son abondance. Elle se lit ensuite dans la forme de certains manuels : au-delà des sept éditions des Principes de Baudelocque (1775-mi$\mathrm{XIX}^{\mathrm{e}}$ siècle), certains professeurs s'en inspirent pour produire leur propre catéchisme comme le docteur Mespec à Pau en $1837^{73}$. En I853, Jean-Marie Jacquemier publie une nouvelle édition du Manuel d'accouchements à l'usage des sages-femmes de Franz-Carl Naegele, où il restitue en annexe le questionnaire supprimé par le premier traducteur. Quatre ans plus tard, l'ouvrage intègre le programme des élèves sages-femmes de l'Hospice de la Maternité de Paris. L'annexe au Manuel suit strictement l'ordre du texte qui le précède. Elle est composée au total de 647 groupes de questions de taille variable. Le maintien de la méthode catéchétique qu' elle permet, justifie la pérennisation d'une forme d'instruction qui a été entre temps quasiment abandonnée dans l'enseignement primaire : celle de l'enseignement mutuel.

Né en Angleterre à la fin des années I790, cet enseignement repose sur la division des élèves en petits groupes confiés à des moniteurs faiblement

71. Beauvalet-Boutouyrie S., Naître à l'hôpital..., op. cit., p. I62.

72. Ibid., p. I62-I63.

73. Mespec J., Obstétrique ou cours élémentaire d'accouchements sous forme de catéchisme, à l'usage des élèves sages-femmes, Pau, impr. de E. Vignancour, I837. 
rémunérés ou choisis parmi les élèves les plus avancés de l'école ${ }^{74}$ et s'oppose à l'enseignement simultané dispensé à des classes d'âge. L'enthousiasme pour ce principe d'instruction est rapide en France ${ }^{75}$ et les fondations d'établissements se multiplient rapidement pendant la seconde moitié des années I8IO, surtout en milieu urbain.

Ces créations et cette pédagogie rencontrent rapidement les besoins de la formation obstétricale. La taille des promotions d'élèves à l'Hospice de la Maternité de Paris et la coexistence assez rapide de deux niveaux d'instruction, avec la quasi-généralisation du doublement de l'année de cours, réunissent toutes les conditions nécessaires à sa mise en œuvre ${ }^{76}$. Dans les mêmes années, le cours d'accouchement de Bourg-en-Bresse adopte cette pratique, en faisant explicitement référence aux nouvelles écoles ${ }^{77}$. L'accent mis sur l'oralité dans le processus d'apprentissage vise à ancrer profondément les connaissances, de manière à «créer des automatismes ${ }^{78}$ ». C'est aussi, dans les écoles confrontées à l'analphabétisme de leurs élèves, un moyen de contourner, parfois avec succès, les lacunes de l'instruction primaire :

Marie Josèphe Mermet, veuve Maire, âgée de 45 ans, de la commune d'Échallon, douée d'une intelligence très ordinaire, mais pleine de bonne volonté, ne sachant ni lire ni écrire, fut reçue à l'école [...]. Pendant deux mois et demi, elle ne répondait aux questions que je lui adressai, pour m'assurer si elle faisait quelques progrès, que par des larmes et en m'avouant son incapacité [...] ; lorsque j'en vins à l'essai de la méthode dont je viens de rendre compte, un nouveau jour commença à luire pour elle, et à l'examen général, elle a répondu de manière à satisfaire les juges. ${ }^{79}$

Quelle que soit la méthode employée, la formation obstétricale transforme l'enseignement en vaste interrogation, scandée par de multiples examens récapitulatifs. Le principe de contrôle perpétuel du savoir est à l'origine de la documentation sur le contenu des cours, puisque là où les cahiers d'élèves ou les notes des professeurs ne sont la plupart du temps pas conservés, restent les sujets d'examens, régulièrement transmis aux administrations de tutelle.

74. Mayeur F., Histoire générale de l'enseignement et de l'éducation en France..., op. cit., p. 403-404. 75. Ibid., p. 405-408.

76. Beauvalet-Boutouyrie S., Naître à l'hôpital..., op. cit., p. I63.

77. L'école de Bourg se pose par la suite en référence, adressant aux départements alentour copie du programme d'examen qui renferme tous les thèmes abordés dans les cours, AD Saône-et-Loire, M 2088.

78. Beauvalet-Boutouyrie S., Naître à l'hôpital..., op. cit., p. I63.

79. AN, $\mathrm{F}^{17} / 2456$, Ain. 
L'interrogation orale constitue la meilleure préparation au passage devant le jury médical, puis, à partir de 1854 , devant les écoles de médecine. C'est la forme donnée aux examens de fin de scolarité mis en place dans les cours d'accouchement. L'examen de fin d'études constitue à ce titre jusqu'en I854 au moins, plus encore que l'examen officiel, le moment essentiel d'appréciation et de reconnaissance du savoir acquis par les élèves sages-femmes, le sésame vers l'exercice de la profession ${ }^{80}$. Les procès-verbaux rédigés à l'issue de quelquesunes de ces sessions expriment ce primat de l'oral et du questionnaire multiple :

(Brest, 1823) Le jury d'examen [...] a d'abord arrêté une série de 30 questions principales, prises dans les diverses parties du cours complet d'accouchements et offrant le plus d'intérêt sous le rapport de la théorie appliquée à la pratique de l'art. Après avoir inscrit ces questions sur un tableau les élèves ont été appelées, l'une après l'autre, et y ont répondu successivement dans l'ordre désigné par le sort. ${ }^{81}$

L'écrit est souvent absent des examens de fins d'études, tout comme il l'est des examens de réception jusqu'à la réforme de I893. Dans la seconde moitié du siècle, après la dévolution des réceptions aux écoles de médecine, l'examen de fin d'études perd en solennité. Certains règlements de la seconde moitié du siècle ne font plus mention que de la nécessité d'avoir accompli la scolarité complète et de disposer de l'approbation du professeur pour pouvoir se présenter aux examens officiels $(\mathrm{Pau})^{82}$. Cette disparition n'est probablement qu'apparente - les écoles maintiennent des examens de fin d'année; mais elle correspond sans doute à une réévaluation de l'appréciation régulière du progrès des élèves au cours des années de formation qui fait à l'écrit une place nouvelle.

La place tenue par les exercices écrits dans l'enseignement est indissociable du niveau d'instruction primaire des élèves sages-femmes. Les efforts des établissements pour compenser les lacunes initiales des jeunes femmes permettent toutefois une introduction relativement précoce de ce type d'exercices. L'école d'accouchement de l'Isère est sous ce rapport un modèle du genre. Les élèves admises se voient imposer dès les années I82o la rédaction de résumés de cours, de procès-verbaux d'enseignement clinique et de comptes-rendus d'accouchements, qui constituent pour les administrations départementales qui envoient des boursières autant de preuves du sérieux des élèves :

80. Belhoste B., « L'examen, une institution sociale », Histoire de l'éducation, 2002, n 94, p. 5-16.

8I. AD Finistère, $5 \mathrm{M} 22$.

82. AD Haute-Marne, iI8 T I. 
Mardi 27 novembre. - Répétition de la leçon du jour.

La leçon a commencé par une observation que Madame Ciceron nous a donné, où l'enfant est venu mort.

L'on nous a fait l'explication de causes qui peuvent donner lieu à cet accident.

L'on nous a dit que, pour rappeler une enfant à la vie, il fallait lui souffler dans la bouche ou dans les narines.

Marie Michou nous a donné le mécanisme de la quatième espèce par la tête ; elle nous a dit quà la sortie de la vulve, il regardait le coté droit.

L'on lui a fait observer le contraire.

L'on a demandé à Mademoiselle Nougarede combien l'occiput présentait de positions au détroit abdominal ; elle a bien répondu. [... $]$

La leçon s'est terminée. ${ }^{83}$

On rencontre, au fil du siècle, ces répétitions écrites dans les emplois du temps d'autres établissements (deux heures par jour à La Rochelle et Pau) ${ }^{84}$. Elles pallient les lacunes synthétiques de l'enseignement oral et imposent aux futures sages-femmes de se remémorer tous les éléments liés au sujet et de les présenter avec méthode. Certaines institutions, comme l'école de Tulle, organisent des devoirs semestriels où les élèves (de deuxième puis de première année) disposent de six heures pour traiter par écrit une question tirée du programme d'obstétrique ${ }^{85}$. Il en va de même à l'école de Dijon où en 1870 une composition écrite succède aux épreuves orales ${ }^{86}$.

Interrogations orales, interrogations écrites, les questions sont le fil conducteur de l'enseignement. La répétition réduit la timidité et l'émotion qui étreignent les futures accoucheuses au moment de se présenter devant un jury. Au-delà, la défiance continue des enseignants envers les capacités intellectuelles de leurs élèves, l'absence pendant une large première moitié du siècle de toute habitude scolaire antérieure à l'admission au cours expliquent pour une grande part l'insistance sur le contrôle perpétuel des connaissances.

La difficulté à concevoir, tel est l'ennemi du professeur, que seul peut combattre le recours aux autres sens de l'élève sage-femme : la vue et le toucher. À cela deux raisons : un sens de l'abstraction pour partie déficient mais surtout le fait que l'obstétrique opératoire, à l'opposé d'un exercice spéculatif, nécessite d'être appuyée sur une approche concrète des réalités auxquelles elle se rapporte.

\footnotetext{
83. AD Hautes-Alpes, $5 \mathrm{M} 15$.

84. AD Charente-Maritime, 3 X 299 ; AD Haute-Marne, II8 T I.

85. Sage Pranchère N., Mettre au monde..., op. cit., p. 438-440.

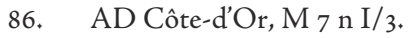




\section{Passer de la théorie à la pratique}

L'acquisition du savoir anatomique, la compréhension des mécanismes de progression de l'accouchement et celle des obstacles qu'il peut rencontrer passent par des supports pédagogiques distincts du manuel. L'approche bidimensionnelle des organes de la génération est un complément de la description orale. Les manuels comportent très souvent un ensemble de figures intercalées dans le texte (Baudelocque, Naegele, Budin) ou de planches annexées au volume (Boivin, Chailly, Maunoury, Bonnet) ${ }^{87}$. Les auteurs y accordent une réelle importance, regrettant parfois à l'instar de Baudelocque d'avoir dû restreindre leur part pour des raisons de coût ${ }^{88}$. Marie-Anne Boivin consacre tout le second volume de son Mémorial à la publication de planches. C'est l'ouvrage de référence qui offre les ressources figurées les plus importantes.

Il existe aussi des recueils spécialisés de planches. Les inventaires de mobilier des cours les mentionnent, comme celui de Rodez en I862 qui évoque un «Atlas de planches coloriées par Moreau ${ }^{89}{ }$. S'ajoutent à cette même catégorie les tableaux pour la démonstration qui reviennent d'inventaire en inventaire ( 15 à Mâcon en I837 ; I2 à La Rochelle en I845; 2 à Troyes en I858 ${ }^{90}$. À la suite d'auteurs comme Charles-Nicolas Jenty ou surtout Jacques-Fabien Gautier d'Agoty $^{91}$, le $\mathrm{xIx}^{\mathrm{e}}$ siècle continue de produire de grands ensembles de planches anatomiques portant sur les organes de la génération, la grossesse et l'accouchement : l'Atlas de l'art des accouchements de Lange et Node en 1835 , ou encore, en I860-1865, l'Atlas complémentaire de tous les traités d'accouchements d'Adolphe Lenoir poursuivi par Stéphane Tarnier et Marc Sée, et réédité sous le titre d'Atlas de l'art des accouchements en $\mathrm{I}^{8} \mathrm{8}^{92}$. Ces publications souvent de grande

87. Pour les figures intercalées dans le texte des manuels: Baudelocque J.-L., Principes sur l'art des accouchements [1787], op. cit. ; Naegele F. C., Manuel d'accouchements... [1853], op. cit. ; Crouzat E., Budin P., La pratique des accouchements..., op. cit. ; et pour les planches annexées à la fin du texte : Boivin M.-A., Mémorial... [1836], op. cit. ; Chailly-Honoré C., Traité pratique..., op. cit. ; Maunoury C.-M.-A., Salmon P.-A., Manuel de l'art des accouchements... [1850], op. cit. ; Bonnet D.-N., Cours d'accouchement..., op. cit.

88. Baudelocque J.-L., Principes sur l'art des accouchements [I787], op. cit., p. X-XII.

89. AD Aveyron, 3 X 5I ; Moreau F.-J., Beau É., Traité pratique des accouchements : atlas, Paris, Germer Baillière, I837, $60 \mathrm{pl}$.

90. AD Saône-et-Loire, M 2085 ; AD Charente-Maritime, 3 X 295 ; AD Aube, 5 M 36.

91. Jenty C.-N., Démonstration de la matrice d'une femme grosse et de son enfant à terme, Paris, Charpentier, 1759 ; Gautier d'Agoty J.-F., L'anatomie des parties de la génération de l'homme et de la femme avec ce qui concerne la grossesse et l'accouchement, jointe à l'angéologie de tout le corps bumain, Paris, Demonville, 1778.

92. Lange A., Node C., Atlas de l'art des accouchements et précis pratique de cette science, Paris, G. Baillière, $\mathrm{I} 835$; Lenoir A., Atlas complémentaire de tous les traités d'accouchements, continué par M. Sée et S. Tarnier, Paris, V. Masson et fils, 1860-1865 ; Tarnier S., Lenoir A., Sée M., Atlas de l'art des accouchements, Paris, G. Masson, I88I. 
taille (l'Atlas de Lange et Node est un in-folio) coûtent assez cher (ill. 7). Elles sont donc acquises en un seul exemplaire et restent généralement en usage pendant plusieurs décennies, au point que les inventaires signalent souvent leur mauvais état.

La représentation à plat est complétée à partir du XVIII ${ }^{\mathrm{e}}$ siècle par les représentations tridimensionnelles. L'enseignement de l'obstétrique n'a, au $\mathrm{XIX}^{\mathrm{e}}$ siècle, que modérément recours à l'étude par la dissection, pour des raisons de sensibilité des élèves ${ }^{93}$, mais aussi pour des raisons plus matérielles d'absence de cadavres sur lesquels la pratiquer. Les occasions de dissection se limitent aux décès de femmes en couches dans les établissements d'enseignement, ce qui n'arrive pas si souvent dans les petites écoles d'accouchement où le taux de mortalité maternelle est très en deçà de ce qu'on peut observer dans les hospices parisiens. De plus, les médecins des hospices rechignent à faciliter la tâche des professeurs d'accouchement sur ce point, comme le montrent en I846 les plaintes du docteur Teissier de Troyes ${ }^{94}$ relayées par le ministre de l'Instruction publique :

[...] le professeur du cours éprouve les plus grandes difficultés à obtenir les cadavres qui lui sont indispensables pour faire les démonstrations qui doivent compléter ses leçons, et les rendre plus intelligibles et plus profitables aux élèves. ${ }^{95}$

Ce courrier du ministre montre les limites de sa circulaire du 6 octobre I837 qui pressait les préfets d'améliorer les possibilités de dissections des écoles secondaires de médecine ${ }^{96}$. Au-delà, le caractère ponctuel de la dissection impose de fonder sur d'autres supports l'étude de l'anatomie. Les cours disposent donc d'os préparés, de bocaux de formol, ou encore de pièces d'anatomie clastique. Les os préparés se retrouvent très fréquemment. Au début des années 1830 une liste de matériel pour l'école de Niort mentionne quatre bassins viciés, un bassin de foetus vicié, un bassin d'adulte désarticulé, deux squelettes de foetus et quatre têtes d'enfants ${ }^{97}$. À Troyes en I859, l'inventaire signale un bassin naturel avec ses diamètres, mais aussi un squelette complet de

93. Gélis J., «La formation des accoucheurs et des sages-femmes... », art. cit., p. I68; et pour une étude diachronique du rapport au corps mort dans l'enseignement médical, voir Godeau E., « "Dans un amphithéâtre..." La fréquentation des morts dans la formation des médecins », Terrain, I993, $\mathrm{n}^{\circ} 20$, p. 82-96.

94. AD Aube, $5 \mathrm{M}_{35}$.

95. AD Aube, $5 \mathrm{M}_{35}$.

96. Circulaire du ministre de l'Instruction publique sur les améliorations à introduire dans les écoles secondaires de médecine, 6 octobre 1837, Gazette médicale de Paris, vol. 5, I4 octobre I837, p. $655-656$.

97. AD Deux-Sèvres, $6 \mathrm{M}$ iob. 
femme ${ }^{98}$. Ces ensembles complets sont presque aussi fréquents que les petites pièces dans les armoires des écoles : à La Rochelle en I845, on trouve « deux squelettes, un grand et un petit », dont l'état est décrit comme mauvais, et « trois bassins humains », deux en bon état et l'autre mauvais ${ }^{99}$. Les préparations en bocal sont moins fréquentes et concernent généralement des fotus à différents stades de la grossesse (II bocaux signalés à La Rochelle en I845) ${ }^{100}$.

Restent les modèles anatomiques en cire ou en papier mâché qui se multiplient sous forme d'anatomies clastiques à partir de la fin du XVIII ${ }^{\mathrm{e}}$ siècle. L'anatomie démontable ou clastique reproduit l'approche de la dissection par l'emboîtement des différentes pièces de l'organe ou du corps figuré. L'utilisation des modèles en cire dans le cadre de l'enseignement obstétrical français à destination des sages-femmes n'est pas documentée à l'inverse de celle des anatomies clastiques en papier mâché produites à partir de la fin des années I820 par le docteur Auzoux ${ }^{101}$. Avec un catalogue riche qui va de la maquette du corps humain entier aux organes isolés très agrandis, le docteur Auzoux fait connaître ses productions dans toute la France. De la fin des années I830 au début des années I850, préfets et médecins reçoivent les opuscules publicitaires qui vantent les mérites des différents modèles :

(Charente, I842) Messieurs, Monsieur le professeur du cours d'accouchement demande les modèles d'anatomie du docteur Auzoux détaillés dans sa lettre ci-jointe pour la démonstration de ce cours. [...] L'administration propose en conséquence au conseil général de voter $:[\ldots] 3^{\circ}$ pour l'acquisition des modèles demandés, I 250 francs. ${ }^{102}$

Les besoins de l'enseignement ne suffisent pourtant pas toujours à convaincre les conseils généraux de voter les sommes nécessaires. C'est le cas à Angoulême où la commission qui étudie la demande en 1842 considère qu'il n'y a pas utilité à faire cet achat. Même refus en I843, cette fois en raison de la situation financière précaire du département ${ }^{103}$. Le prix élevé des modèles obstétricaux (3 200 francs pour le modèle grandeur nature) est un puissant frein, même si

98. AD Aube, $5 \mathrm{M}_{36}$.

99. AD Charente-Maritime, 3 X 295.

Ioo. Ibid.

IoI. Degueurce C., Ruiz G., «Les modèles d'anatomie clastique du docteur Auzoux au musée de l'école vétérinaire d'Alfort », Bulletin de la Société d'histoire de la médecine et des sciences vétérinaires, $2009, n^{\circ} 9, p .35-49$; Une thèse pour le doctorat vétérinaire a été consacrée en 2010 à cette collection du musée d'Alfort par G. Ruiz: Les modèles en papier mâché du docteur Auzoux au Musée de l'École Nationale Vétérinaire d'Alfort (http://theses.vet-alfort.fr/telecharger.php?id=I2II).

I02. $\mathrm{AD}$ Charente, $\mathrm{I} \mathrm{N}_{7}^{*}$.

I03. $\mathrm{AD}$ Charente, $\mathrm{I} \mathrm{N}_{7}$ et i $\mathrm{N}_{32}$. 
certains cours optent pour une acquisition progressive de la collection, ainsi à Dijon au début des années $1850^{104}$.

La pièce maîtresse de l'enseignement reste cependant le mannequin (ill. 8 et 9). Sa centralité dans la formation des sages-femmes n'est jamais questionnée au cours du siècle. Parfait outil de la découverte des mécanismes de l'accouchement, il permet d'appréhender toutes les dystocies qui ne se présentent qu'exceptionnellement dans la formation clinique. Il est enfin le support de la répétition à l'infini des gestes qui forment la base de l'obstétrique pratique. Défendu par les auteurs, Baudelocque en tête, mais aussi par les professeurs départementaux (Romieux, Pacoud), le mannequin est omniprésent dans les inventaires de mobilier, et aucun conseil général n'ose remettre en cause les sommes consacrées à son renouvellement ou à sa réparation. Sa composition précise n'est jamais détaillée dans les récolements des cours (mis à part la présence du foetus), mais les professeurs veillent attentivement à sa qualité. En I8I8, le professeur du cours gersois s'enquiert auprès d'un collègue parisien, le docteur Bagnères, médecin de la garde royale, d'un fabricant pour se procurer un mannequin. Ce dernier lui répond s'être renseigné auprès de l'Hospice de la Maternité et se propose de «surveiller la fabrication avec tout le soin possible $^{105} »$. Il joint à son courrier la note suivante :

Mme Murat, sage-femme, demeurant rue Poupée, fait des phantômes pour des accouchements pour le prix de 150 francs. Il y a aussi un fabricateur nommé Verdier qui en fait de plus beaux et de mieux conditionnés pour le prix de 500 francs, mais les premiers suffisent aux démonstrations qui se font à l'Hospice de la Maternité. $M^{\text {me }}$ Lachapelle n'en employe pas d'autres. ${ }^{106}$

Exactement dans les mêmes intervalles, Marguerite Coutanceau, de passage à Paris, demande au préfet de la Gironde l'autorisation de se procurer un mannequin. Ses vœux la portent justement vers ce même chirurgien Verdier. La lettre que ce dernier lui adresse offre la seule description de mannequin rencontrée dans les sources administratives :

Il sera garni de peau grise en dedans, et couvert, en dessus, en peau noir. Les piqûres faites dans le bassin indiqueront : la forme des os, coccyx pubien, trous sacrés ovales, échancrures ischiatiques, ainsi que les vertèbres lombaires; le coccyx rendu élastique, se déjettera en arrière d'un pouce à un pouce et demi pour augmenter d'autant le diamètre coccy-pubien lors du passage de la tête

I04. AD Côte-d'Or, $\mathrm{M}_{7} \mathrm{n} \mathrm{I} / 3$.

I05. AD Gers, 5 M 6. Le milieu de l'obstétrique et des cours d'accouchement est suffisamment petit pour que le porteur de ce courrier soit le docteur Coutanceau, fils de Marguerite Coutanceau. I06. AD Gers, 5 M 6 . 
de l'enfant. Le périné (sic) de même élastique bombera quand l'occiput cherchera à s'engager sous l'arcade du pubis. Les grandes lèvres aussi élastiques, se distenderont pour laisser passer la tête, et, elles reviendront s'appliquer sur le col de l'enfant, quand l'occiput aura dépassé l'arcade pubienne.

Le tablier est élastique afin que l'opérateur suive avec la main placée sur le ventre artificiel les mouvements imprimés à l'enfant par son autre main, introduite dans l'utérus à dessein d'amener l'enfant dans une position plus convenable pour sa sortie. Mes mannequins sont disposés de manière à se fixer sur une table ordinaire ou un bureau, par un mécanisme très simple.

Le fotus est fait avec le squelette d'un enfant mort-né, et recouvert en peau ; les sutures des différents os de la tête, ainsi que les fontanelles, sont figurées par des coutures, afin de faire reconnaître à la personne qui manœuvre quelle est la présentation de la tête. Un placenta avec son cordon et ses membranes en taffetas gommé. Le prix est de 500 francs $^{107}$.

\section{«Au lit des parturientes »}

L'opposition entre formation pratique sur le mannequin et formation clinique, « au lit des parturientes » constitue pendant la première décennie du XIX ${ }^{\mathrm{e}}$ siècle un outil politique aux mains des ministres de l'Intérieur successifs. Les professeurs pour leur part ont conscience de l'erreur qu'il y a à opposer ces deux aspects de la formation par essence complémentaires. L'enjeu principal de l'instruction des sages-femmes réside dans l'accès des élèves à l'étude clinique, accès qui devient un critère discriminant pour l'organisation ou la reconnaissance des cours d'accouchement dès I806. La fixation progressive d'un nombre minimal de lits (Io à 12) réservés aux femmes enceintes dans l'établissement qui reçoit les élèves aboutit à écarter dans un premier temps nombre de cours du processus d'officialisation des enseignements. Cette manière administrative d'évaluer ne présume ni de l'occupation de ces lits, ni de la durée des séjours ante- et postpartum. Elle ne prend pas non plus en compte les tentatives de diversification des origines du savoir clinique, tentées par les professeurs qui n'ont pas à leur disposition de salle spécifique pour accueillir des accouchées. Dans l'Ariège, le règlement du cours d'accouchement de Pamiers prévoit en 1809 :

Pour multiplier l'instruction, les élèves pourront obtenir l'agrément du professeur pour s'arranger de gré à gré avec les sages-femmes en exercice dans la ville, qu' elles suivront et aideront dans les accouchements. ${ }^{108}$

107. $\mathrm{AD}$ Gironde, $5 \mathrm{M} 552$.

I08. $\mathrm{AN}, \mathrm{F}^{17} / 2457$, Ariège. 
Nonobstant ces initiatives ponctuelles, l'idée d'un seuil de réceptions hospitalières est progressivement reprise par le corps médical, qui tente alors de définir le nombre d'accouchements observés ou réalisés justifiant d'une «bonne » formation, sans jamais réussir à se mettre d'accord au cours du siècle.

Les débats autour de ce nombre s'élèvent surtout à partir des années I840, à un moment où le mouvement de fondation des écoles se ralentit et où les cours les moins bien dotés en matière d'instruction clinique ont déjà disparu (Dax en $\left.1820^{109}\right)$. Les exigences sont variables d'un établissement à l'autre. En 1848, le docteur Naigeon rappelle dans son rapport annuel sur le cours de Dijon les impératifs du règlement : " chaque élève doit avoir fait deux accouchements » et souligne que « chaque élève a fait seule, ou conjointement avec une autre, deux ou trois accouchements ${ }^{110} »$. Ce chiffre correspond au nombre d'accouchements que pratiquent les élèves de l'école de La Rochelle (63 pour l'année I852, soit 3 par élève), ce qui satisfait le professeur et l'administration départementale ${ }^{111}$. Quinze ans plus tard, un tel nombre est néanmoins défini comme « évidemment insuffisant » par le préfet de l'Aveyron ${ }^{112}$. Ce jugement se confirme à mesure qu'on avance dans le siècle, comme le prouve la proposition faite par une commission du conseil général de la Drôme en 1889 d'envoyer désormais les élèves sages-femmes, auparavant boursières dans l'Ain, à l'hospice de la Charité de Lyon :

[... ] attendu qu'elles n'y séjournent que quatre mois par an pendant deux ans, et que, d'après la moyenne de douze années, elles ne peuvent profiter pour leur instruction pratique que de 109 accouchements par an, ce qui fait à peine deux accouchements pour chaque élève ; tandis qu'à la maternité de Lyon les élèves sont astreintes à deux années d'internat et qu'elles assistent à I 200 accouchements $[\ldots]$. ${ }^{113}$

C'est le nombre d'accouchement opérés par les élèves elles-mêmes qui constitue dans ce cas la seule preuve valable de la future capacité des sages-femmes. Le nombre de naissances observées plaide à l'opposé en faveur des petites institutions. En I858, le préfet de l'Aveyron défend auprès du conseil général la réouverture d'un cours à Rodez. Il rappelle alors les conditions dans lesquelles fonctionnait le cours supprimé en I847 : « Le nombre moyen des accouchements

\footnotetext{
I09. $\mathrm{AD}$ Landes, $\mathrm{I}_{\mathrm{N}}{ }^{*}$.

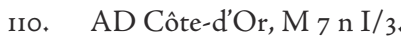

III. AD Charente-Maritime, I N $22^{*}$.

I12. $\mathrm{AD}$ Aveyron, Per 545, RD CG Aveyron, I867.

II3. AD Drôme, $5 \mathrm{M} 20$.
} 
était de 12 à 15 par an ; chaque élève était témoin d'une quarantaine pendant la durée du cours. C'était assez pour compléter son instruction ${ }^{114}{ }$.

Ce primat accordé à l'observation sur l'application directe ne convainc cependant pas les administrations de l'opportunité de conserver le cours lorsque le nombre d'accouchements annuels dans un établissement est inférieur à cinquante. Dans l'Aveyron, le docteur Viallet a beau dénoncer les mesures qui maintiennent la faiblesse du nombre d'admises à la salle d'accouchement (20 en I863-I864; 35 en I864-I865), et faire tout son possible pour augmenter la fréquentation du cours par les femmes enceintes, il ne réussit pas à justifier le maintien de la formation, supprimée en $1867^{115}$.

L'Hospice de la Maternité de Paris a fait une grande part de sa réputation sur l'éventail très large des types d'accouchements qui s'y déroulent. Statistiquement parlant, certains types de naissances laborieuses ne se rencontrent qu'une fois sur plusieurs milliers d'accouchements. Les quelques dizaines d'accouchements annuels des maternités provinciales ne reçoivent donc qu'exceptionnellement ce genre de cas et admettent surtout des parturientes dont l'accouchement se déroule sans encombre. C'est cette constatation qui emporte en I851 la décision de supprimer l'école d'Angoulême ${ }^{116}$.

La qualité de l'enseignement clinique dépend donc du nombre et de la variété. Celle-ci ne se rencontre que dans les très grands établissements, parisien ou lyonnais. Entre les deux accouchements annuels d'une élève dijonnaise de la fin des années i 840 et la centaine pratiquée par les élèves lyonnaises à la fin des années $1860^{117}$, une moyenne acceptable se dessine pourtant, qui inclut les cours où se font entre quatre-vingts et cent accouchements par an. Les élèves $y$ opèrent de douze à quinze naissances, suffisamment pour maîtriser les mécanismes de l'accouchement naturel et pour être confrontées au moins une fois à un accouchement nécessitant une intervention manuelle ou instrumentale.

Au-delà de la maîtrise de la technique obstétricale, l'intérêt de la formation clinique réside dans les obligations qui incombent à l'élève sage-femme dès lors qu'elle se voit confier une patiente. Les articles du règlement de l'Hospice de la Maternité de Paris définissent les devoirs de l'élève envers les femmes en couches :

Art. 19. Les élèves de tour, dans les cas ordinaires, ne pourront quitter la femme qu'elles auront accouchée que deux heures après la délivrance. L'une d'elles restera constamment auprès de cette femme pour veiller à ce qu'il ne

\footnotetext{
II4. AD Aveyron, Per 545, RD CG Aveyron, I858.

I15. AD Aveyron, Per 545, RD CG Aveyron, I864 à I867.

iI6. AD Charente, I N 39*, RD CG Charente, I85I.

II7. AD Aveyron, Per 545, RD CG Aveyron, I868.
} 
survienne pas d'accident, et pour faire appeler à propos la sage-femme en chef, si la circonstance l'exige. L'autre élève sera chargée de donner ses soins à l'enfant.

Art. 20. Les mêmes élèves seront tenues de visiter les femmes qu'elles auront accouchées deux fois le jour, le matin et le soir, afin de bien observer tout ce que présente l'état ordinaire de couche et de prévenir à temps la sage-femme des complications qu' elle pourrait offrir.

Art. 2I. Elles multiplieront leurs visites auprès des femmes qui seront malades ; et, selon la gravité de la maladie, une d'elles sera constamment de garde, pour veiller à ce que le service se fasse ponctuellement, pour observer les variations qui auront lieu dans le cours de la journée et de la nuit et en rendre compte au médecin lors de la visite.

Art. 22. Une seule élève pourra exercer cette surveillance dans plusieurs salles ; elle sera relevée par une autre au bout de quatre heures : toutes feront ce service successivement et à tour de rôle. ${ }^{118}$

Ces instructions sont reprises dans plusieurs règlements de cours départementaux (Marseille, Dijon, etc.) et se combinent avec l'élargissement de l'enseignement clinique en amont et en aval de l'accouchement. Le moment de la grossesse auquel les femmes enceintes peuvent être admises dans les maternités est souvent, pour des raisons d'économie, très proche du terme (dernier mois de la grossesse $)^{119}$. Au-delà, il est plutôt rare en province que les patientes se présentent dans l'établissement avant les premières douleurs de l'enfantement, à moins d'être malades. L'entrée tardive à la maternité limite les possibilités d'étude clinique de l'évolution de la grossesse. Les propositions d'admissions plus précoces (sixième ou septième mois), même formulées par les commissions des assemblées départementales, se heurtent aux réticences des conseils généraux au moment de voter les budgets. Les professeurs tentent alors de compenser ce manque en payant des femmes enceintes pour qu'elles acceptent de se laisser examiner, recourant soit à des indigentes, soit à des femmes appartenant à leur clientèle personnelle ${ }^{120}$. Pour les admises dans les salles de maternité annexées aux cours, la durée du séjour total est variable, d'une dizaine de jours à un ou deux mois. L'allongement concerne plutôt la

II8. RLRES I, p. 88-89.

II9. Beauvalet-Boutouyrie S., Naître à l'hôpital.., op. cit., p. 76.

I20. AD Saône-et-Loire, M 2088, lettre du docteur Pacoud au docteur Carteron, II mai I837 : " Je donne ici de 30 à 40 sols par séance à chaque femme et je n'en ai jamais moins de six. J'en ai toujours une qui n'a pas fait d'enfant, une qui en a fait mais qui n'est pas enceinte, et les quatre autres à diverses époques de la grossesse ». 
période du post-partum comme le décrit le docteur Armand Rey, directeur du cours d'accouchement et de la maternité de Grenoble en I884 :

[... d'après les règlements, ce séjour devrait être au maximum de quarantecinq jours : soit le dernier mois trente jours, et quinze jours de suites de couches. La première période ne se trouve que très exceptionnellement prolongée, et peut être abrégée du tout au tout, quand les parturientes arrivent dans le service au moment du travail ou ayant déjà accouché ; tandis que la seconde période ne devrait être que très exceptionnellement abrégée. Elle est bien plus souvent prolongée, soit par des suites de couches défavorables, soit par des maladies intercurrentes. ${ }^{121}$

Ce prolongement de la présence dans l'école après l'accouchement permet de développer l'apprentissage des soins aux accouchées et aux nouveau-nés. Au-delà des chiffres enfin, de la quantité d'accouchements vus ou faits, du nombre d'accouchées ou d'enfants soignés, la formation clinique offre une confrontation avec le vivant, son caractère imprévisible, sa vulnérabilité ou sa résistance. Elle fait entrer les futures sages-femmes de plein pied dans la réalité de leur profession.

\section{Élargissement du savoir et progrès des soins}

\section{L'ancrage de l'obstétrique dans une approche physiologique élargie}

L'élargissement du programme des cours de l'Hospice de la Maternité de Paris est très précoce mais dans un premier temps, la vaccination, la saignée et les notions de botaniques s'inscrivent dans un prolongement de l'art des accouchements. Très rapidement cependant, la maîtrise de ces savoirs justifie leur application à des contextes sans lien avec la gestation ni la parturition. La concurrence des matrones se fonde très tôt dans le siècle sur leur double fonction d'accoucheuse et de garde-malade. C'est d'ailleurs cette deuxième épithète qui est mise en avant par les magistrats municipaux lorsqu'ils ne souhaitent pas sévir contre ces femmes ${ }^{122}$. La seule réponse possible pour les sages-femmes diplômées réside donc dans l'extension de leurs compétences. Leur capacité à susciter la confiance, et donc à introduire des pratiques prophylactiques telle que la vaccination dans les campagnes et plus généralement dans les milieux sociaux qui n'ont ni l'habitude ni les moyens de recourir au médecin, prépare naturellement le terrain à un exercice minimal mais néanmoins réel de

I2I. AD Drôme, 5 M 20 .

122. Sage Pranchère N., Mettre au monde..., op. cit., p. 504-505. 
la médecine $e^{123}$. Laïques, elles sont l'équivalent officiellement intégré au corps médical des religieuses soignantes étudiées par Jacques Léonard ${ }^{124}$.

La formation de garde-malade combinée à l'instruction obstétricale rapproche fortement la sage-femme de l'officier de santé, au moins pendant la première moitié du $\mathrm{XIX}^{\mathrm{e}}$ siècle. La sage-femme dispose toutefois d'un double avantage : scientifique par sa maitrise de l'art des accouchements et social puisqu'elle doit gratuitement ses soins aux indigents. Cette formation s'ajoute explicitement aux programmes de nombreuses écoles au plus tard dans les années I830. En I835, le programme des examens de l'école de Bourg-en-Bresse consacre ses deux dernières pages aux interrogations sur les devoirs de la gardemalade ${ }^{125}$. Il définit son champ d'intervention (hygiène et soins généraux au malade) comprenant toute une série de médications dont la plupart relèvent de la petite chirurgie, certaines nécessitant en outre des qualifications en herboristerie, voire en pharmacie. Les questions relatives à l'enseignement « accessoire » de la saignée se contentent de développer les différents types de saignées à la lancette (du bras ou du pied) autorisées aux sages-femmes, sans préciser les motifs justifiant d'y avoir recours ${ }^{126}$. Suit un paragraphe consacré à la saignée locale ou capillaire qui décrit la manière d'appliquer sangsues, ventouses, vésicatoires, sinapismes et de faire les pansements.

À la même période, l'école de Grenoble étend elle aussi son enseignement, comme le prouve une commande en 1836 de neuf Art de soigner les malades ou manuel des mères de familles, des garde-malades, des dames de charité, des curés de campagnes, etc., exemple parmi d'autres de la littérature de vulgarisation médicale qui fleurit au cours du siècle ${ }^{127}$. L'année précédente, l'école de Troyes, tout juste recréée, ajoute officiellement la formation des garde-malades à son intitulé. Dans un courrier au préfet, le docteur Teissier, professeur, la désigne comme le « seul établissement de ce genre que possède la France ${ }^{128}$ ». La formule, mensongère dans les faits, renvoie néanmoins à une particularité de l'institution troyenne : la remise d'un diplôme de garde-malade de haut

\footnotetext{
123. Faure O., «Les sages-femmes en France au XIX ${ }^{e}$ siècle... », art. cit., p. 165-I66.

124. Léonard J., «Femmes, religion et médecine... », art. cit., p. 902-904.

125. AD Saône-et-Loire, M 2088.

I26. Voir Léonard J., «À propos de l'histoire de la saignée », dans Médecins, malades et société..., op. cit., p. II9-I23.

127. Lebeaud N., Art de soigner les malades ou manuel des mères de familles, des garde-malades, des dames de charité, des curés de campagnes, etc., Paris, A. Eymery, I825 ; sur la diffusion de cette littérature de vulgarisation médicale, voir Léonard J., "Femmes, religion et médecine... », art. cit, p. 900-90I, et « Les guérisseurs », dans Médecins, malades et société,.., op. cit., p. 77-78.

I28. $\mathrm{AD}$ Aube, $5 \mathrm{M}_{34}$.
} 
niveau des décennies avant la fondation des premières écoles d'infirmières ${ }^{129}$. En I850, le Manuel de Maunoury et Salmon comporte un « exposé sommaire des préparations pharmaceutiques et des opérations de petite chirurgie les plus usitées $^{130}$ ». Après avoir rappelé le monopole des pharmaciens « là où existe une officine de pharmacie », les auteurs détaillent les différents types de médicaments (internes et externes), donnent quelques recettes (tisanes, potions, cérats, suppositoires) et précisent quels produits les sages-femmes peuvent prescrire (pilules d'opium, de fer). L'attention à la maîtrise du savoir de la garde-malade se maintient passé le début des années I880, comme en témoigne cette remarque du docteur Armand Rey de Grenoble: "Toute accoucheuse doit être avant tout une bonne garde-malade ${ }^{131}$ ».

L'association des soins aux malades au savoir obstétrical s'inscrit dans une progression constante de la part accordée à la connaissance de l'anatomie complète et des pathologies communes, lisible dans les manuels. Les ouvrages publiés avant les années I840, et jusqu'au Traité théorique et pratique de Paulin Cazeaux ${ }^{132}$, limitent leur chapitre anatomique à la description des organes de la reproduction. Puis les choix éditoriaux évoluent. Le Manuel de Maunoury et Salmon est précédé d'une « description abrégée des fonctions et des organes du corps humain », tandis que la traduction du Manuel de Franz-Carl Naegele comporte une section entière intitulée « Du corps humain en général et de ses fonctions $s^{133} »$. Ces chapitres introductifs sont révélateurs de la place acquise par une approche anatomique et physiologique globale dans l'instruction des sages-femmes. Leur absence dans certains manuels publiés ultérieurement ne signifie pas un recul mais bien que cette part de la formation est désormais conduite à partir d'ouvrages spécifiques. La consultation de quelques cahiers d'élèves sages-femmes rédigés à la fin du $\mathrm{XIX}^{e}$ siècle souligne l'importance de ce savoir qui fait, à partir de I893, l'objet d'un examen de fin de première année portant sur « l'anatomie, la physiologie et la pathologie élémentaires ${ }^{134} »$.

I29. Sur l'émergence du métier d'infirmière et de leur formation, voir Knibiehler Y., LerouxHugon V., Dupont-Hess O., Tastayre Y., Cornettes et blouses blanches..., op. cit. et Leroux-Hugon V., Des saintes laïques..., op. cit.

I30. Maunoury C.-M.-A., Salmon P.-A., Manuel de l'art des accouchements... [I850], op. cit., p. 393-43I. Ce complément au manuel proprement dit est reproduit à l'identique dans les éditions de I86I et de I874.

I3I. AD Drôme, $5 \mathrm{M} 20$.

132. Cazeaux P., Traité théorique et pratique... [1840], op. cit.

133. Maunoury C.-M.-A., Salmon P.-A., Manuel de l'art des accouchements... [1850], op. cit., p. I-I5 ; Naegele F. C., Manuel d'accouchements... [1853], op. cit., p. I-I9.

134. RLRES 5, op. cit., p. 265 : Décret relatif aux conditions d'études exigées des aspirantes aux diplômes de sage-femme, art. 4 . 
Cet élargissement des compétences correspond au cours de la première moitié du siècle à une translation progressive des fonctions exercées par les chirurgiens d'Ancien Régime aux sages-femmes. Ces dernières occupent donc une part du terrain de la médicalisation dévolue par la loi du I9 ventôse an XI aux officiers de santé, successeurs théoriques des chirurgiens d'avant 1803 .

Se pose alors la question de la réaction du corps médical à ce qu'il pourrait considérer comme un empiétement. Les poursuites contre les accoucheuses pour exercice illégal de la médecine ne semblent pas si fréquentes. Dans le département de la Côte-d'Or, on ne relève que deux exemples parmi l'ensemble des dossiers d'instruction conservés pour le siècle. Le premier, en I847, met en accusation une sage-femme de 24 ans, Jeanne Robert. Celle-ci ne semble pourtant pas sortir de ses attributions puisqu'elle se contente de saigner, d'apposer des sangsues, de prescrire des bains ou des tisanes ${ }^{135}$. Le fonds de l'affaire réside dans la mise en scène qui accompagne la réception des malades (la mère de l'accusée la " magnétise », et celle-ci rend ses diagnostics dans un état hypnotique) et dans l'appel d'air que créent ces consultations dans la clientèle du médecin local. L'année suivante, une autre sage-femme est appelée devant les juges pour avoir pratiqué une césarienne sur les instances du curé de la paroisse qui lui « dit qu'il était de [son] devoir d'ouvrir la mère pour tirer l'enfant de son sein ou au moins de lui donner le baptême », et qui lui promet de justifier son geste auprès du médecin injoignable ${ }^{136}$. L'issue de ces procès n'est pas connue mais il est peu probable qu'elle ait été défavorable aux accoucheuses.

L'exercice de la gynécologie par les sages-femmes suscite en revanche plus de défiance de la part du corps médical, en particulier dans la seconde moitié du siècle alors que la formation des médecins s'améliore dans ce domaine. Ainsi, la dame Fournier, sage-femme à Chinon, fait paraître en 1862 une défense pour justifier sa pratique dans le cadre d'un procès pour exercice illégal de la médecine $^{137}$. Les besoins en personnel médical de la population française et la faiblesse du sentiment hiérarchique dans l'exercice libéral justifient néanmoins la très lente détermination des limites du métier.

135. AD Côte-d'Or, U IX ce 175.

136. AD Côte-d'Or, U IX ce I78.

137. Fournier (Mme), Une sage-femme devant ses juges, défense présentée par Mme Fournier, mầtresse sage-femme devant le tribunal de Chinon, Tours, impr. Ladevèze, I862. 


\section{Quelle formation «continue » bors du cadre scolaire?}

La durée de la formation des sages-femmes fait longtemps l'objet de débats avant de se fixer, dans la seconde moitié du XIX ${ }^{e}$ siècle, entre un et deux ans. La continuité de l'enseignement n'est pas acquise immédiatement et la suppression de l'intervalle entre les deux cours obligatoires impose de nombreuses réorganisations complètes de cours (en particulier pour les cours sans internat et accueillis dans des hospices). La continuité ou quasi continuité des leçons résout le risque d'oubli entre deux sessions, mais laisse pendant ce problème à l'issue de la formation.

La jeunesse des praticiennes diplômées ouvre la voie à plusieurs décennies d'exercice professionnel, pendant lesquelles elles n'ont guère l'occasion de revenir aux sources de leur savoir, ni surtout d'en suivre les évolutions. Les remarques de Jacques Léonard sur l'isolement intellectuel et scientifique des médecins de campagne valent aussi, à plus forte raison, pour les sagesfemmes ${ }^{138}$. Plusieurs éléments sont pourtant susceptibles de préserver un lien avec l'évolution du savoir médical. Leur association précoce à la lutte contre la variole les met en relation avec les comités départementaux de vaccination, en fait des conservatrices du vaccin et, à ce titre, les tient au fait des progrès dans ce domaine. Instruments de la politique de santé publique, elles en suivent de près les objets et les évolutions.

La progression de l'instruction primaire réduit aussi les effets d'une certaine marginalisation. Le manuel devient dans ces conditions un véritable recours et l'accroissement de son contenu en fait un guide efficace pour raffermir les souvenirs des accoucheuses. La maîtrise de la lecture leur permet d'accéder, théoriquement du moins, aux publications nouvelles, même si le coût de ces dernières reste un obstacle important à leur diffusion, à l'exception des périodiques. Or, les journaux spécialisés à destination des sages-femmes n'apparaissent que tardivement. Une première tentative est menée en I867, mais le Journal de la sage-femme, guide pratique des accouchements, des maladies des femmes et des nouveau-nés, bimensuel, ne dépasse pas les dix numéros dont le dernier paraît le 20 mai de la même année. En décembre 1873 naît un nouveau bimensuel, le Journal des sages-femmes, qui compte 8 pages (dont 2 de publicité) et paraît jusqu'en 1914. Le rédacteur en chef de ce journal, Hector Fontan, n'est pas médecin, mais rédige lui-même les chroniques des cliniques des grands professeurs parisiens (Depaul, Budin, Tarnier, etc.). Il sait aussi

138. Léonard J., La vie quotidienne..., op. cit., p. 66 
s'entourer de figures de l'obstétrique et de la pédiatrie de son temps : le docteur Louis Hamon de Fresnay, auteur de multiples écrits sur l'albuminurie ou l'utilisation du forceps asymétrique, le docteur Eugène Bouchut spécialiste des maladies de la petite enfance, etc. ${ }^{139}$. Le coût de l'abonnement n'est pas exorbitant ( 8 francs par an et 5 francs par semestre soit le prix d'un à deux accouchements), mais reste élevé pour des sages-femmes rurales qui peinent parfois à dépasser les 150 à 200 francs de revenu annue ${ }^{140}$. Le public concerné est donc surtout celui des accoucheuses installées en ville, comme le prouvent les quelques réponses aux lectrices (sages-femmes de Bordeaux, Lille, Nantes et Paris) dont rend compte le numéro du i6 juillet i874. C'est le lancement de La Sage-fermme en décembre 1897, lui aussi bimensuel (I2 pages) mais vendu à I5 centimes le numéro et 3 francs l'abonnement annuel, qui met véritablement à la portée des praticiennes la presse professionnelle. Il s'agit de l'organe officiel du syndicat général des sages-femmes de France. À ce titre, le journal ne se contente pas de diffuser des informations scientifiques (articles sur des thèmes spécifiques, comptes-rendus bibliographiques) mais accorde aussi une large place aux intérêts professionnels.

Ces ressources ne reflètent néanmoins que la réalité professionnelle du dernier quart du XIX ${ }^{\mathrm{e}}$ siècle. Avant cette date, il n'existe pour les sages-femmes qu'un seul moyen de rester en contact avec les évolutions de l'art : la correspondance avec l'ancien professeur, qui requiert une maîtrise suffisante de l'écriture. Les archives préfectorales conservent fréquemment des courriers d'accoucheuses sollicitant un secours ou une récompense à la suite d'un accouchement laborieux opéré avec succès, complétés de recommandations du médecin professeur, preuve du maintien de certains liens personnels. Mais le caractère individuel de ces relations ne suffit pas à établir un suivi méthodique des sages-femmes en exercice. Pour pallier ce manque, deux institutions au moins, Bourg-en-Bresse et Troyes, mettent en place un système de formation « continue » pour leurs anciennes élèves en leur imposant d'adresser à la sortie de l'école un compte rendu annuel d'activité au professeur du cours.

L'école départementale d'accouchement de l'Ain est le premier établissement à exiger de ses anciennes élèves qu'elles fassent parvenir tous les ans une statistique des accouchements réalisés, une analyse des accouchements dystociques et une description des techniques mises en œuvre pour contourner ces difficultés. Le système est opérationnel très rapidement après la fondation

139. AD Tarn-et-Garonne, 5 M 613, Journal des sages-femmes, $2^{e}$ année, $n^{\circ}$ I4, 16 juillet 1874 ; AM Bourg-en-Bresse, dossier $n^{\circ} 3$ sur l'école de sages-femmes (I889-1896).

I40. Sur le revenu des sages-femmes, voir Faure O., «Les sages-femmes en France au xix ${ }^{e}$ siècle... », art. cit., p. 169. 
de l'école : en 1824, le préfet de l'Ain envoie au ministre de l'Intérieur une copie du rapport fait par la commission d'examen sur la pratique des élèves sorties du cours de Bourg-en-Bresse ${ }^{141}$. Les sages-femmes en exercice rédigent un compte-rendu clinique sur chaque cas complexe et l'ensemble de ces textes soumis à la commission d'examen aboutit à une distribution de primes d'encouragement ${ }^{142}$. Dans la seconde moitié des années I820, le docteur Pacoud fait connaître cette initiative au-delà du ressort départemental. Il sollicite en janvier I827 l'appui du ministre de l'Intérieur pour un projet de Journal des sages-femmes de la campagne:

Le fonds de ce journal serait fourni par la correspondance et par la clinique de notre école, et alimenté par les immenses matériaux amassés dans le cours de huit ans. Chaque année, nous y ajouterions une table synoptique dans le genre de celle dont nous joignons ici le modèle, et qui pourra par la suite offrir un renseignement aussi sûr que précieux à la science de l'économie politique $\left[. . .{ }^{143}\right.$

Il poursuit en proposant que tous les conseils généraux votent, sur l'invitation du ministre, une somme destinée à l'abonnement de toutes les sagesfemmes enregistrées sur les listes du personnel médical. Le ministre de l'Intérieur confie à l'Académie royale de médecine le soin de rédiger un rapport « qui, selon tout apparence, est encore à faire », comme le signale le docteur Pacoud un an plus tard. L'idée n'est toutefois pas abandonnée et c'est la Société d'émulation, d'agriculture, sciences et arts de Bourg-en-Bresse qui la relève en réservant une partie de son mensuel, le Journal d'Agriculture, Lettres et Arts, à la publication des observations obstétricales. Ce cahier est imprimé séparément et expédié aux frais de la Société d'émulation à toutes les sages-femmes du département. En I828, le docteur Pacoud, pour saluer la première livraison de ce cahier, rédige dans le Journal d'Agriculture, Lettres et Arts un article intitulé «La pratique des élèves de l'école d'accouchement du département de l'Ain » où il détaille l'historique de cette publication. Cet article est alors expédié sous forme de tirés à part dans toutes les préfectures de France, pour encourager les autres départements à profiter de cette ressource en souscrivant pour recevoir un volume annuel. Malheureusement, il ne reste aucune trace d'une quelconque souscription. Les fonds de l'établissement ne conservent aucun exemplaire de la publication projetée, et la décision de la séparer du reste du Journal d'Agriculture empêche d'en suivre l'éventuelle réalisation.

I41. $A N, F^{17} / 2456$, Ain.

142. AD Ille-et-Vilaine, 5 M 30.

143. Ibid. 
La pratique du retour d'observations se maintient néanmoins à Bourg-enBresse et inspire l'Aube lors de la réorganisation du cours d'accouchement de Troyes en 1835. Le règlement consacre un chapitre aux « élèves sorties de l'établissement après avoir complété leurs cours ». Les sept articles reprennent les dispositions en vigueur dans l'Ain, sans prévoir d'utilisation particulière pour les observations rendues par les anciennes élèves qui sont déposées « dans les archives de l'école pour y avoir recours au besoin ${ }^{144} »$. L'Aube est le seul département où le règlement intègre ce suivi de l'exercice professionnel, sans que l'on puisse savoir si les sages-femmes s'y conforment. Dans l'Ain, le rapport du docteur Pacoud au préfet sur ce sujet signale en I 837 que les réponses concernent environ $40 \%$ des accoucheuses sorties de l'école ${ }^{145}$. Pour maintenir l'émulation entre anciennes élèves, le professeur fait publier à la suite des noms des sages-femmes primées pour leurs succès et leur constance à envoyer des informations, ceux de celles qui ont négligé de le faire, tout en se plaignant d'une tentative maladroite des maires d'éviter la taxe sur les paquets d'observations qu'ils sont chargés d'expédier et qui aboutit à les retenir poste restante ${ }^{146}$.

Cette méthode de suivi reste en usage pendant tout le professorat du docteur Pacoud. Il n'est en revanche pas certain qu'elle perdure après sa mort en I848. L'initiative est, quoi qu'il en soit de sa pérennité ultérieure, remarquable. Elle associe un souci pédagogique de complément constant à la formation initiale à un souci médical plus large de surveillance de la pratique obstétricale dans le département. Cette « instruction à domicile » accompagne l'activité des sages-femmes pendant les années critiques où elles ont pour tâche de gagner la confiance d'une clientèle et de justifier la valeur de leur diplôme. La lourdeur pour les sages-femmes et pour le professeur explique sans doute sa faible diffusion hors du département, malgré une politique de communication particulièrement ambitieuse.

\section{La révolution pasteurienne ou l'irruption conjointe du microbe et de l'asepsie}

La fin des années I870 constitue dans l'histoire de la médecine, de l'enseignement médical et de la médicalisation un tournant fondamental. Les recherches sur l'origine de la contamination et de l'infection et sur les moyens de lutte contre ces phénomènes arrivent en quelques années à maturité.

144. $\mathrm{AD}$ Aube, $5 \mathrm{M}_{33}$.

145. AM Bourg-en-Bresse, dossier $n^{\circ} 3$.

146. AM Bourg-en-Bresse, dossier $n^{\circ} 6$ sur l'école d'accouchement de Bourg-en-Bresse. 
En I858, un débat s'élève à l'Académie de médecine à la suite d'une communication du docteur Jules Guérard sur le traitement de la fièvre puerpérale ${ }^{147}$. Il se poursuit pendant six mois, nourri par les opinions contradictoires sur la nature de cette maladie et par la multiplicité des propositions de réforme voire de suppressions des maternités, après que les recherches de Stéphane Tarnier ont montré que la mortalité maternelle est dix-sept fois supérieure à l'Hospice de la Maternité de Paris qu'en ville. Les rapports sur l'estimation de cette mortalité à l'hôpital et en ville se succèdent, pour la France (rapport Malgaigne en I864) et à l'échelle européenne (mémoire de Lefort en I866) ${ }^{148}$. Le 30 juin 1866 parvient aux préfets une circulaire ministérielle transmettant un rapport rédigé par le docteur Devergie et décrivant « les mesures à prendre pour diminuer la mortalité des femmes en couche dans les maternités et les hôpitaux ». Prônant la dispersion des parturientes chez des sages-femmes de ville comme meilleure solution pour les hôpitaux qui n'ont pas de vocation enseignante, le rapport ne retient pas les propositions de Tarnier d'isolement des parturientes malades : «[... $]$ on est en présence d'un mal immédiat de tous les instants et auquel il faut s'empresser de parer ; aussi la Commission ne s'est-elle pas arrêtée à cette proposition ${ }^{149} \gg$.

Des évolutions sont néanmoins en cours depuis les années I840. Parmi les précurseurs, le pharmacien de l'Hospice de la Maternité de Paris, Frigerio, rédige en vain en 1832 un rapport sur les causes de la fièvre puerpérale et propose une série de mesures d'hygiène élémentaires (lavage des mains avant tout examen, etc.) pour limiter les épidémies ${ }^{150}$. La première initiative concrète en ce sens est menée à Vienne par Ignacz Semmelweis. Ce dernier observe en quelques mois l'augmentation brutale de la mortalité maternelle dans la clinique des étudiants en médecine et la chute parallèle de cette mortalité dans celle tenue par les sages-femmes ${ }^{151}$. Faisant le lien entre la pratique des autopsies par les étudiants et la contamination quasi immédiate des accouchées, il impose le lavage des mains au savon et au chlorure de chaux et réussit à faire baisser très significativement la mortalité dans le service. Dans les mêmes années, un chirurgien écossais, Joseph Lister, s'inspirant des travaux de Pasteur

147. Sur ce débat, voir Beauvalet-Boutouyrie S., «Faut-il supprimer les maternités ? », art. cit., p. 65 sq.

148. Bulletin officiel du Ministère de l'Intérieur, Rapport de M. Malgaigne ; Lefort L., Des maternités..., op. cit.

149. AD Savoie, $20 \mathrm{X}_{3}$.

150. Beauvalet-Boutouyrie S., Naître à l'hôpital..., op. cit., p. 249-252.

I5I. Dormandy T., Four Creators of Modern Medicine, Moments of Truth, Chichester, John Wiley and sons, 2003, p. 176-178. 
sur la dissémination des germes, décide de mettre en place des pratiques antiseptiques dans son service de l'hôpital royal de Glasgow. Les résultats sont, à l'instar des expériences de Semmelweis, à la hauteur des espérances, mais l'initiative reste isolée ${ }^{152}$.

Au début des années 1870, la connaissance des méthodes de Lister se diffuse en Europe et plus précisément en Allemagne. En France, Guérin, chirurgien de l'hôpital Saint-Louis à Paris, impressionné par les recherches de Pasteur, suit sans le savoir les traces de son prédécesseur d'outre-Manche, avant que l'antisepsie ne soit progressivement complétée par l'asepsie, le corps médical opérant désormais en milieu stérile ${ }^{153}$. Cet ensemble d'expériences, qui repose aussi sur la multiplication entre I850 et 1875 des « antiputrides » (alcool camphré, glycérine, lotions chlorurées, acide phénique), se conjoint dans la défense des théories pastoriennes des germes pathogènes, qui triomphent définitivement à l'Académie de médecine en $1879^{154}$. La thérapeutique a accompagné dans ce processus les recherches chimiques et biologiques, ce qui explique la diffusion extrêmement rapide des pratiques d'asepsie à partir de la reconnaissance officielle. La généralisation du recours à ces méthodes se fait alors en quelques années, la conversion du corps médical progressant à rythme soutenu, malgré les difficultés qu'occasionnent les techniques d'asepsie ${ }^{155}$.

Les établissements hospitaliers de province adoptent avec enthousiasme le duo antisepsie/asepsie avec des effets immédiats sur les taux de mortalité ${ }^{156}$. Le docteur Monprofit, fait organiser une salle aseptique à la maternité d'Angers en $1889^{157}$. En 1884 , le rapport du docteur Armand Rey sur la maternité de Grenoble souligne lui aussi l'adoption des habitudes désinfectantes tout en pointant leurs limites dans l'état matériel de l'établissement et compte tenu du manque de personnel :

Les pansements, injections et autres soins désinfectants ont pu encore être administrés assez régulièrement pendant le semestre d'hiver, grâce au concours des élèves accoucheuses; mais privés de leurs secours pendant le semestre d'été, pourra-t-il en être de même 158 $^{158}$

\footnotetext{
152. Ibid., p. 256-259.

153. Ibid., p. 264-268.

154. Ibid., p. 262-263 ; Léonard J., « Comment peut-on être pasteurien ? », dans Salomon-Bayet

C., Pasteur et la révolution pastorienne, Paris, Payot, 1986, p. I50-I5I.

155. Ibid., p. I68-I7I.

156. Rollet-Échallier C., La politique à l'égard de la petite enfance..., op. cit., p. I57-I62.

157. Léonard J., « Comment peut-on être pasteurien ? », art. cit., p. 170.

158. AD Drôme, $5 \mathrm{M} 20$.
} 
Les élèves sages-femmes sont donc immédiatement associées à la mise en œuvre des méthodes antiseptiques. Les manuels d'obstétrique des années I880 consacrent tous une place importante à ces questions. Les auteurs détaillent les précautions à prendre avant un accouchement pour éviter toute transmission de germes d'une patiente à une autre. Ils décrivent longuement les gestes de propreté indispensables pour l'accoucheur ou la sage-femme et les produits désinfectants à utiliser, que ce soit en en milieu hospitalier ou dans la pratique privée :

Les mains des accoucheurs et des sages-femmes doivent être l'objet de soins particuliers : toutes les fois qu'elles auront été en contact avec une matière suspecte, putride ou purulente, il faut procéder à un lavage prolongé à l'eau chaude et au savon, se brosser les doigts avec attention, de manière qu'il ne reste aucune particule organique, soit dans l'interstice qui existe entre l'ongle et la pulpe du doigt, soit dans le sillon qui entoure la base et les côtés de l'ongle. Il faut en outre plonger les mains à plusieurs reprises dans un liquide antiseptique, soit dans une solution phéniquée au 40e, soit dans une solution de sublimé corrosif au i oooe (liqueur de Van Swieten). Ces précautions sont habituellement suffisantes $[\ldots] .{ }^{159}$

Le Traité de Tarnier et Chantreuil accorde aussi une place importante à la description de l'application des méthodes antiseptiques dans une maternité, avant, pendant et après les accouchements ${ }^{160}$. Son seul défaut est sans doute d'envisager l'accouchement dans un cadre essentiellement hospitalier, alors que médecins et sages-femmes doivent procéder avec les moyens du bord lorsqu'ils se déplacent chez des patientes. De surcroît, l'autorisation d'employer le sublimé corrosif n'est officiellement accordée qu'en I890 aux accoucheuses ${ }^{161}$. À compter de cette date néanmoins, il devient l'élément indispensable de leurs trousses professionnelles. Jeanne Négrerie, élève sage-femme de l'école de Montpellier en 1895 décrit ainsi son contenu dans son cahier de cours :

Pour se rendre auprès d'une cliente, la sage-femme doit avoir une trousse contenant : une brosse à ongles en chiendent qui doit occuper la première place, des paquets de sublimé colorés de 25 centilitres l'un ; [...] de la gaze iodoformée, un petit pot hermétiquement fermé de vaseline au sublimé [...]. Tous ces instruments doivent être enveloppés dans de la gaze iodoformée et renfermés dans une boîte ; elle devra également emporter une blouse très propre ou tout au moins une camisole, un tablier et des manches blanches. ${ }^{162}$

159. Tarnier S., Chantreuil G., Traité de l'art des accouchements, tome I, Paris, H. Lauwereyns, 1882, p. 703.

160. Ibid., p. 805-807.

I6I. Coulon-Arpin M., La Maternité et les sages-femmes de la Prébistoire au $X x^{e}$ siècle, Paris, R. Dacosta, 198I, t. 2, p. 84-85.

162. AD Corrèze, I J 87/ıo. 
Dans la foulée de l'adaptation des manuels, la décennie I89o confirme les principes de l'antisepsie obstétricale et pose les bases de son application généralisée. Stéphane Tarnier publie, en I894, une synthèse de toutes les recherches et de toutes les expériences accumulées dans ce domaine, sous le titre De l'asepsie et de l'antisepsie en obstétrique ${ }^{163}$. À sa suite, d'autres médecins sont à l'origine de travaux sur l'utilisation des méthodes désinfectantes par le corps médical et les sages-femmes en particulier. Sébastien Rémy, chef de clinique obstétricale à la faculté de Nancy, rédige en 1896 un essai sur l'antisepsie et les sages-femmes, publié dans la Revue médicale de l’Est ${ }^{164}$. Ce texte inspire les « Instructions pour les sages-femmes de Meurthe-et-Moselle », parues dans la même revue en mai $1896^{165}$. La qualité de cette publication justifie sa reprise à peine modifiée par la direction du service départemental des épidémies de la Meurthe-et-Moselle en 1909. La multiplicité de ces initiatives prouve les efforts faits en direction des accoucheuses qui n'ont pu être formées à ces techniques pendant leurs études et à qui il faut désormais inculquer ces gestes comme autant de principes nécessaires et préalables à l'exercice de leur profession.

Le bouleversement provoqué par l'adoption des théories de Pasteur est immédiatement répercuté dans les principes de la formation obstétricale. Les sages-femmes diplômées dès le début des années I880 sont donc des pasteuriennes, chargées d'apporter l'asepsie au lit de leurs patientes comme elles ont été, en d'autres temps, chargées d'imposer la vaccination dans les campagnes. Le contenu de l'instruction des accoucheuses suit ainsi de près, à partir de la seconde moitié $\mathrm{du} \mathrm{XIX}^{\mathrm{e}}$ siècle, les progrès de l'observation clinique et de la thérapeutique. Parfois pessimistes devant les capacités intellectuelles et mnémoniques de leurs élèves, les professeurs d'accouchement n'ont toutefois eu de cesse d'élargir leur savoir. L'augmentation continue de la taille des manuels de référence est révélatrice de cet accroissement objectif des connaissances des praticiennes. Leur champ d'exercice y gagne en profondeur par la maîtrise de toutes les techniques manuelles et instrumentales de l'accouchement et de la petite chirurgie. Il y gagne en largeur, s'étendant aux deux spécialités en cours de constitution que sont la gynécologie et la puériculture. Cette polyvalence place les sages-femmes dans une position privilégiée : elles sont en milieu rural les interlocutrices essentielles et souvent uniques d'une population, à la fois objet et sujet du processus de médicalisation.

163. Tarnier S., De l'asepsie et de l'antisepsie en obstétrique, Paris, G. Steinheil, I894.

164. Hacquin F., Histoire de l'art des accouchements en Lorraine, op. cit., p. 223-224.

165. Lettre de la direction du service départemental des épidémies de la Meurthe-et-Moselle au préfet de la Meurthe-et-Moselle, I5 octobre 1909, citée dans Hacquin F., Histoire de l'art des accouchements en Lorraine, op. cit., p. 234. 
Chapitre 9

\section{La résistance d'une profession}

L'officialisation de la profession de sage-femme consacrée par la loi en I803 n'empêche pas les contestations de tous ordres. La reconnaissance institutionnelle des accoucheuses comme membres à part entière du corps médical sous le Consulat a fait le pari d'une scientificité justifiée par l'émergence d'une formation spécifique. Dépouillée des oripeaux de la matrone, la sage-femme apparaît comme une figure nouvelle, que ses professeurs modèlent selon une logique de contiguïté et de perméabilité des savoirs entourant le processus de transmission de la vie. Rien de ce qui tient à la naissance ne doit lui être étranger, ouvrant son champ d'exercice sur les besoins de la société (vœux des politiques sanitaires et attentes des populations) comme sur les chemins qu'emprunte la science médicale.

Le siècle de formation issu de la loi de ventôse an xi produit, en réponse au laconisme législatif, variété scolaire et polyvalence professionnelle, deux caractéristiques que le monde médical et les autorités administratives s'attachent à réduire pendant la même période. Ce mouvement d'uniformisation et de délimitation touche au but au début des années 1890 alors que s'ouvre une nouvelle ère de réformes qui tire les meilleurs fruits de l'expérience séculaire et fait aboutir pour les sages-femmes la revendication désormais primordiale de l'unification de la profession.

\section{De contestations en concurrence, une place à trouver}

\section{Réformer la loi de ventôse an XI : bilans et projets du milieu du siècle}

La loi du I9 ventôse an XI a fait entrer officiellement la sage-femme dans le corps médical, en organisant sa formation et le contrôle de son savoir. Le pas franchi est immense : la profession possède un cadre national et légal qui consacre 
la nécessité et la valeur des savoirs sur la naissance. Ne peut désormais être sage-femme que celle qui a appris à l'être. Le texte ne va pourtant pas plus loin. L'extension de la pratique autorisée à l'accoucheuse n'est pas définie, à moins de considérer l'article 32 (théorie et pratique des accouchements, accidents qui peuvent les précéder, les accompagner et les suivre, moyens d'y remédier) comme une délimitation suffisante de l'exercice professionnel. L'article 33, seul passage restrictif qui porte sur l'usage des instruments, se contente d'encadrer cet usage par la présence impérative d'un médecin. Il est cependant vite remis en cause par l'exception symbolique de l'Hospice de la Maternité où la sagefemme en chef applique seule les forceps, sans devoir en référer au chirurgien.

S'ensuit une quarantaine d'années pendant lesquelles se mettent en place les structures de la formation. Le niveau des accoucheuses diplômées est variable, à la mesure de la diversité des cours. La sévérité du contrôle opéré par les jurys médicaux est, elle aussi, inégale et les appréciations sur le niveau des accoucheuses varient souvent. La fluctuation des jugements sur les compétences des sages-femmes ne plaide pas en faveur du métier. Dans un contexte où la seconde classe de médecins est de plus en plus décriée et où sa suppression est projetée, médecins et administrateurs s'interrogent aussi sur le sort à réserver aux accoucheuses ${ }^{1}$. L'unanimisme des années 1780 -I800 sur l'incontestable nécessité de former des sages-femmes n'est plus de mise. Au cours de la décennie I840 ressurgit la crainte exprimée trente-cinq ans plus tôt par le ministre de l'Intérieur du danger d'accoucheuses à demi instruites, rendues téméraires par leur savoir incomplet. Si en 1780 on affirme que les sages-femmes « ne savent exactement rien ${ }^{2} \gg$, on déplore avec presque autant d'inquiétude en 1840 qu' elles ne sachent pas assez.

La préparation du congrès médical $\left(\mathrm{I}^{\mathrm{er}}-\mathrm{I} 5\right.$ novembre 1845 à Paris), à l'initiative de la Gazette des hôpitaux, cristallise le malaise des médecins vis-à-vis de la place occupée dans l'exercice de leur science par les autres corps médicaux (officiers de santé et sages-femmes) ${ }^{3}$. Pendant une quinzaine de jours, dans les salons de l'Hôtel-de-Ville, plus de cinq cents praticiens suivent les séances de la section de médecine dont le programme porte sur les réformes à opérer dans l'ordre de l'enseignement, de la police et de l'organisation du corps médical ${ }^{4}$.

\footnotetext{
I. Léonard J., Les médecins de l'Ouest..., op. cit., p. 735 sq.

2. Bib. Acad. de Méd., SRM, cart. 85, voir aussi Sage Pranchère N., «Étude comparée de deux projets de cours d'accouchements... », art. cit.

3. Bourquelot L., «Le congrès médical de France : défense d'une profession libérale sous la Monarchie de Juillet », Annales de Bretagne et des pays de l'Ouest, 1979, vol. 86, nº 2, p. 30I-312.

4. Compte rendu du Congrès médical de Paris, ${ }^{\mathrm{er}}-\mathrm{I} 5$ novembre 1845 , Bulletin général de thérapeutique médicale et chirurgicale, Paris, chez le rédacteur en chef, $1845, \mathrm{n}^{\circ} 29, \mathrm{p} \cdot 322-323$.
} 
Le temps réservé aux sages-femmes dans ces débats est modeste, surtout si on le compare aux heures de discussion sur l'avenir des officiers de santé. Elles font l'objet le I2 novembre d'un des derniers rapports présentés par la commission du congrès. L'institution des sages-femmes n'est pas initialement prévue au programme de la section de médecine. Son ajout montre toutefois l'extension des préoccupations des congressistes. Aux questions de savoir si la sage-femme est suffisamment formée et si sa suppression est possible, la réponse de la commission chargée du rapport est néanmoins sans appel :

Votre commission, messieurs, a été unanime à reconnaitre l'impossibilité de supprimer l'institution des sages-femmes, mais elle a reconnu en même temps qu'on exige d'elles trop peu de garanties, et sous le rapport de la moralité, et sous le rapport de l'instruction première; d'où il résulte que, manquant d'intelligence, elles n'arrivent souvent pas, même avec beaucoup de temps, à apprendre ce qu'elles doivent savoir, et sous le rapport des études obstétriques, surtout pour la pratique. ${ }^{5}$

Les participants au congrès se prononcent à leur tour pour le maintien de la profession. Discuter l'utilité de cette profession et envisager, ne serait-ce que théoriquement, sa suppression est néanmoins révélateur d'un contexte scientifique et social : posséder les rudiments du savoir obstétrical ne suffit plus à satisfaire les attentes de l'État en matière de politique démographique et sanitaire.

En I85I, le docteur Ignace Druhen fait paraittre à Lille un opuscule d'une quarantaine de pages intitulé De l'institution des sages-femmes et de la réforme qu'elle réclame $e^{6}$.' 'auteur est une figure médicale très insérée dans les instances de santé publique : inspecteur du travail des enfants dans les manufactures, membre du comité d'hygiène publique et de salubrité du Doubs, membre correspondant de la Société centrale de médecine du département du Nord. Le médecin déclare apporter sa contribution au travail législatif entamé au lendemain du congrès médical et encore en cours. Conscient de la faible place accordée aux sages-femmes dans les débats de I845, Druhen s'attache à développer dans son texte ce qui n'a pu l'être en choisissant un même point de départ :

La suppression des sages-femmes est-elle possible ? Poser cette question, c'était mettre en doute l'utilité des sages-femmes, c'était du moins avouer implicitement que les services qu'elles rendent, actuellement, à la société ne sont point sans mélange. C'est ce qu'a fait le congrès médical dans le programme qui a servi de base à ses importants travaux.

5. Ibid.

6. Druhen I., De l'institution des sages-femmes et de la réforme qu'elle réclame, Lille, impr. de Lefebvre-Ducrocq, 1851. 
J'ai examiné cette question sous ses différents aspects, et après avoir pesé scrupuleusement les raisons pour ou contre l'institution des sages-femmes, je partage l'avis du congrès, qui me paraît le plus sage, et je pense que cette institution doit être conservée. Toutefois, je l'ai dit, et je crois l'avoir démontré une réforme radicale et complète est urgente et le temps est venu de l'accomplir. ${ }^{7}$

Même interrogation, même conclusion que le congrès, mais aussi mêmes critiques. L'opuscule donne un aperçu vraisemblable des données sur lesquelles se sont appuyés en 1845 les concepteurs du programme et les rapporteurs de la commission : instruction primaire défaillante, moralité peu et mal contrôlée, avec tout ce qui en découle aux yeux de l'auteur (avortements, aide aux abandons, etc. $)^{8}$. Druhen cite le cas de prisonnières suivant les cours d'accouchement pendant leur détention, et celui d'une sage-femme ancienne prostituée. Il poursuit en présentant une longue statistique du revenu annuel moyen des accoucheuses, calculé à partir du nombre de naissances et de l'honoraire demandé par accouchement dans la plupart des grandes villes de France ${ }^{9}$. Des sommes qu'il évoque (dans 5 des 13 villes citées, le revenu moyen est inférieur à 200 francs par an), le médecin déduit l'impossibilité pour les sages-femmes de vivre de leur profession et les tentations d'avoir recours à d'autres ressources.

Les impératifs légaux auxquels doit se soumettre la sage-femme (déclaration de naissance en particulier et refus de prêter assistance à un avortement) font peser sur elle la rigueur d'une société populationniste et moralisante. Le discours du docteur Druhen en est la preuve. À cet égard, le traditionnel rôle d'assistance joué par les accoucheuses auprès des filles-mères, dans tout ce qu' il implique, de l'accueil à la réparation du déshonneur qui passe effectivement par l'abandon de l'enfant illégitime, entre en contradiction flagrante avec les devoirs imposés par l'État.

Les médecins prennent très tôt, en théorie du moins, le contrepied des actions qu'ils reprochent aux sages-femmes. Lorsqu'elles acceptent de taire le nom d'une mère ou d'aider à l'abandon d'un enfant, ce que le discours médicoadministratif condamne comme de l'immoralité et de la cupidité, les sagesfemmes ne font sans doute dans bien des cas qu'exprimer une sollicitude envers les patientes passant avant les obligations légales. Il reste que la tolérance se réduit à mesure que ferment les tours d'abandon et que sont redéfinis les secours

\footnotetext{
7. Ibid., p. 29-30.

8. Ibid., p. II-I2.

9. Ibid., p. I2-13 et I8-23. Citons entre autres Paris ( 39 accouchements ; 585 francs), Lyon ( 43 accouchements, 344 francs), Marseille (66 accouchements, 528 francs), Bordeaux ( 30 accouchements, 240 francs), Nantes (64 accouchements, 512 francs), Strasbourg (22 accouchements, 176 francs).
} 
publics aux enfants trouvés ${ }^{10}$. L'offensive contre la moralité « douteuse » des sages-femmes est contemporaine de la volonté de réduire le nombre d'enfants délaissés qui peuplent les hospices. L'existence de ces attaques ne dédouane pas les premières d'une participation effective à certains trafics (abandon puis reprise en nourrice par la mère), mais explique la virulence des propos qui condamnent leur implication ${ }^{11}$. Modifier le recrutement des sages-femmes et réformer leur formation sont deux voies de renforcement du contrôle exercé sur la profession d'accoucheuse par le corps médical et l'État, et, à travers cette profession, sur l'attitude des «classes dangereuses» (filles-mères, familles indigentes) envers leurs nouveau-nés. Cette nécessité d'une réforme morale du métier s'accentue encore à partir des années I860 lorsqu'une enquête ministérielle révèle l'ampleur de la surmortalité des enfants en nourrice, désignant encore une fois les sages-femmes comme agent des abandons et des mises en nourrice meurtrières ${ }^{12}$.

Le déplacement de la critique sur le terrain social est significatif de l'échec partiel d'un des objectifs de la politique de formation : mettre au service de l'État des surveillantes de la naissance. Il est toutefois remarquable que la seule réponse que propose le corps médical, entre i845 et 185I, passe par le renforcement des exigences du choix et de l'instruction en amont des études, plutôt que par un contrôle de l'exercice professionnel. Les médecins expriment une forte méfiance envers la vocation individuelle des candidates qui réduit la part institutionnelle dans la sélection des élèves. Combinée à la facilité d'accès aux études offerte par le système des bourses, elle entraîne un surpeuplement de la profession avec les effets précédemment évoqués ${ }^{13}$. L'idée d'un trop grand nombre de sages-femmes est d'ailleurs à rapprocher de la dénonciation régulière de « l'encombrement » du corps médical sous la Restauration et la monarchie de Juillet, à cette différence près que les auteurs n'y voient pas seulement le terreau de la gêne pécuniaire mais du crime ${ }^{14}$.

Les voux du congrès médical puis le texte du projet de loi sur l'enseignement et l'exercice de la médecine voté par le Sénat en février I847 expriment officiellement cette aspiration à une amélioration du savoir de base des candidates.

Io. Voir sur le sujet : Enfance abandonnée et société en Europe..., op. cit., et particulièrement l'article de M. Jeorger, «L'évolution des courbes de l'abandon de la Restauration à la première Guerre mondiale (1815-1913) », p. 703-740.

II. Jorland G., Une société à soigner..., op. cit., p. I4I-I47.

12. Ibid., p. 129-I35. Sur l'histoire des nourrices, voir aussi Fay-Sallois F., Les nourrices à Paris au XIX $X^{e}$ siècle, Paris, Payot, 1980.

I3. Druhen I., De l'institution des sages-femmes..., op. cit., p. I5-16.

I4. Léonard J., Les médecins de l'Ouest..., op. cit., p. 530. 
On souhaite en I845 que la future élève « justifie d'une instruction primaire suffisante », et deux ans plus tard, qu' elle sache « lire et écrire correctement». Or, les établissements de formation des sages-femmes n'ont pas attendu ces préconisations pour tenter de pallier les lacunes de leurs élèves, comme le prouve, entre autres, l'examen sur la lecture, l'écriture et l'orthographe pour l'admission à l'Hospice de la Maternité de Paris instauré par une circulaire du I9 mai I845, six mois avant le congrès médical. Les ambitions ne se limitent cependant pas à la maîtrise des savoirs primaires de base. L'opuscule du docteur Druhen prévoit en I85I d'imposer à la première classe des sages-femmes l'obtention du brevet de capacité de l'enseignement primaire et à la seconde, l'examen mis en place en 1845 pour les élèves de Port-Royal, ce qui n'entre en vigueur qu'en $1893^{15}$. Ces propositions sont justifiées par le rappel de l'évolution des titres nécessaires à la préparation du doctorat en médecine et en chirurgie (baccalauréat ès-lettres et ès-sciences physiques depuis 1837) et de la profession de pharmacien (baccalauréat ès-lettres depuis 1844$)^{16}$. Au-delà, il en va pour Druhen de l'autorité sociale des sages-femmes:

«Dans l'état présent de la société française, l'instruction doit être la clé de voute de toutes les institutions médicales » [docteur Serres, président du congrès médical, 1845$]$. Celle des sages-femmes ne doit pas être plus longtemps déshéritée du rang qui lui revient dans les professions médicales, et auquel elle ne peut aspirer que par l'instruction. ${ }^{17}$

Pourtant, à la différence de ce qui est envisagé pour les officiers de santé, ni le congrès médical, ni le projet législatif de i847 n'abordent la question de l'unification du corps des sages-femmes. L'existence des deux classes d'accoucheuses pose pourtant les mêmes problèmes que l'existence de deux classes de médecins ${ }^{18}$. Mais, sans susciter d'argumentaire spécifique, le devenir de la deuxième classe et plus largement la division du corps professionnel des sagesfemmes sont passés sous silence au profit d'un discours plus général sur les nécessités de l'instruction. À l'issue du débat, les vœux se contentent d'appeler à une amélioration générale de la formation (deux ans minimum, examens plus sévères, réception dans les facultés ou les écoles préparatoires $)^{19}$. Ces

\footnotetext{
15. Ibid.

I6. Druhen I., De l'institution des sages-femmes..., op. cit., p. IO-II.

17. Ibid., p. 30-31.

I8. Compte-rendu du Congrès médical de Paris, ${ }^{\mathrm{er}}{ }^{-15}$ novembre $\mathrm{I} 845$, art. cit., p. 457.

I9. Ibid., p. 460.
} 
recommandations sont résumées en 1847 par le projet de loi de Salvandy ${ }^{20}$ qui renvoie cependant encore à un futur règlement d'administration publique. Les propositions concernent l'ensemble des aspirantes au diplôme d'accoucheuse, anticipant peut-être une fusion des classes.

En 185I, Ignace Druhen, dans l'espoir de peser sur les futurs travaux législatifs, se prononce contre toute éventuelle fusion, distinguant pour des raisons pratiques le cas des médecins et des officiers de santé de celui des accoucheuses:

Ces considérations conduisent nécessairement à adopter deux degrés de sages-femmes : l'un, le degré supérieur à qui serait réservé le droit d'exercice dans les villes ; l'autre, le degré élémentaire, qui limiterait ce droit à la pratique rurale. [...] La loi doit, avant tout, se préoccuper des besoins de l'époque à laquelle elle est faite.

Les « besoins de l'époque » résident dans l'encadrement obstétrical encore défaillant des campagnes et dans l'impossibilité, selon Druhen, d'exiger des sages-femmes rurales la même instruction que pour leurs consœurs urbaines. Cette constatation n'empêche pas l'auteur d'envisager une réorganisation complète de la formation, touchant aussi le second degré, et d'appeler à une réduction du nombre de cours départementaux :

La scolarité serait de deux années pour les élèves des deux catégories, et les cours se feraient tous les jours, sans autre interruption que celle des jours de fête et des vacances. Les études seraient surtout pratiques ; elles seraient les mêmes pour les élèves des deux degrés pendant la première année, mais à la seconde, les aspirantes au brevet supérieur suivraient un cours spécial, où la théorie et le mécanisme des accouchements, aussi bien que les nombreuses difficultés de l'art obstétrical, recevraient tous les développements qu'un pareil sujet comporte. [...] Les cours départementaux d'accouchements sont trop nombreux pour offrir les éléments nécessaires à un bon enseignement. [...] Ces cours devraient être réservés aux villes où la maternité pourrait admettre un nombre suffisant de filles ou de femmes enceintes, aux chefs-lieux d'académie par exemple. ${ }^{21}$

Malgré l'ampleur des travaux accumulés depuis les années i830, la réforme de l'enseignement médical n'aboutit ni sous la Deuxième République, ni sous le Second Empire. La seule modification intervient en 1854 lors de la suppression des jurys médicaux. L'instauration de frais d'examen pour les sages-femmes de deuxième classe, si modérés soient-ils ( 25 francs), correspond à une timide

20. Druhen I., De l'institution des sages-femmes..., op. cit., p. 5 .

21. Ibid., p. 32 et 34 . 
tentative de limiter les candidatures et d'amorcer un changement du terreau social du recrutement. C'est aussi une manière de relever le prestige de la profession, à l'instar de ce qui est fait dans des proportions beaucoup plus importantes pour l'officiat de santée ${ }^{22}$. L'évolution des formes et du contenu de l'instruction des sages-femmes est laissée à l'appréciation des établissements, sans que les débats menés sur la limitation de leurs attributions et l'extension de leur savoir n'interferent véritablement avec le fonctionnement des cours.

\section{Le médicament et l'instrument : aux portes de l'obstétrique complexe}

Les décennies centrales du $\mathrm{XIX}^{e}$ siècle ouvrent une période d'interrogations sur le champ d'exercice des sages-femmes. Alors que le discours sur la formation se concentre sur la faiblesse du savoir primaire, celui sur la pratique professionnelle désigne des points d'achoppement durables : le droit de prescription et le recours aux instruments.

Les contestations qui s'élèvent dans les rangs du corps médical s'inscrivent dans un contexte renouvelé depuis les années I830 par l'évolution de la formation obstétricale des médecins. L'inauguration à Paris de l'hôpital des cliniques de la Faculté de médecine le $\mathrm{I}^{\mathrm{er}}$ décembre $\mathrm{I} 334$ a profondément modifié le contenu des apprentissages des futurs médecins. La chaire de clinique obstétricale qui existe théoriquement depuis 1823 prend enfin sens. Les étudiants en médecine, exclus depuis toujours de Port-Royal, peuvent désormais découvrir l'obstétrique au lit des femmes en couches, sous la houlette d'un clinicien expérimenté, Paul Dubois, par ailleurs chirurgien de l'Hospice de la Maternité de Paris. L'introduction d'une dimension pratique dans la formation des futurs médecins compense les lacunes traditionnelles de l'enseignement obstétrical pour ce corps professionnel et leur permet de remplir plus facilement le rôle de recours dans les cas d'accouchements compliqués que leur confie la loi. La gynécologie plus strictement " médicale » prend une place croissante dans l'enseignement dispensé par le détenteur de la chaire d'accouchements à côté des questions purement obstétricales ${ }^{23}$ et permet aux médecins de revendiquer plus légitimement leur compétence dans le traitement des affections féminines et de se plaindre de l'intervention des accoucheuses dans ce domaine.

22. Les frais d'examen pour les officiers de santé s'élèvent en $\mathrm{I} 803$ à 200 francs. Ils sont fortement augmentés en 1854 et passent à 720 francs dans les Écoles préparatoires de médecine et à 840 francs dans les Facultés, Léonard J., Les médecins de l'Ouest..., op. cit., p. 946-947.

23. Carol A., "L'examen gynécologique en France, $\mathrm{XVIII}^{\mathrm{e}}-\mathrm{XIX}^{\mathrm{e}}$ siècle : techniques et usages », dans Bourdelais P., Faure O. (dir.), Les nouvelles pratiques de santé..., op. cit., p. 5I-66. 
Au-delà, la seconde moitié du siècle correspond à une montée en puissance de l'Académie de médecine comme instance de référence des savoirs et des pratiques. C'est à ce titre qu'elle est interpellée à plusieurs reprises au sujet des limites à poser au droit de prescription des sages-femmes et à leur usage des instruments, au premier rang desquels, le forceps.

En avril I845, le préfet du département de la Seine adresse à l'Académie un courrier appelant son attention sur «l'abus que l'on fait du seigle ergoté2 ${ }^{24}$ ». Après avoir rapporté quelques exemples d'avortements provoqués par l'ergot, le préfet pose la question suivante : «Quelle peut être l'influence du seigle ergoté sur la vie des enfants et sur la santé des mères ? ». Il attend de la future réponse des certitudes scientifiques aptes à justifier des mesures de police et émet le vou que l'administration de cette substance soit interdite aux sagesfemmes en l'absence d'un médecin ${ }^{25}$. Ce courrier ouvre un débat en deux temps (I850 et I872), qui, bien plus que l'usage de l'ergot de seigle, interroge la reconnaissance des sages-femmes comme personnel médical capable de prescrire à l'égal des officiers de santé et des médecins.

En octobre 1850, avec cinq ans de retard, Danyau, l'un des commissaires désignés par l'Académie de médecine pour répondre au préfet de la Seine, présente son rapport ${ }^{26}$. Après avoir fait le point des connaissances sur les avantages (lutte contre les hémorragies du post-partum) et les dangers (asphyxie foetale, effet potentiellement abortif) du seigle ergoté en fonction du moment de son utilisation, il déclare, en conclusion, l'impossibilité d'interdire aux sagesfemmes l'utilisation du seigle ergoté. Le droit de prescription des sages-femmes est réaffirmé au nom du devoir médical de secours à une personne en danger et Danyau voit dans l'approfondissement de l'instruction obstétricale la solution la plus simple au mauvais usage d'un produit comme le seigle ergotée ${ }^{27}$.

Velpeau, autre grande figure de l'obstétrique, se montre bien moins confiant que son collègue dans les vertus de la formation et saisit l'occasion de ce débat pour dénoncer l'excessive latitude des sages-femmes dans le traitement des affections du post-partum et gynécologiques : «Il importerait qu'on pût spécifier les accidents qui cessent d'être de leur compétence, et distraire de leur

24. Académie nationale de médecine, Bulletin de l'Académie nationale de médecine, Paris, J.-B. Baillière, Masson, I844-I845, tome IO, séance du 22 avril I845, p. 565. Le seigle ergoté est utilisé pour accélérer les contractions utérines (pour hâter le déroulement de l'accouchement ou à des fins hémostatiques en cas d'hémorragies).

25. Ibid., p. 567 .

26. Académie nationale de médecine, Bulletin de l'Académie nationale de médecine, I850-I85I, tome I6, séance du ${ }^{\text {er }}$ octobre I850, p. 6-30.

27. Ibid., p. I7. 
pratique tout ce qui n'est pas suite immédiate de couches simples ${ }^{28}$. » Mais cette intervention ne suffit pas à remettre en cause les propositions de Danyau et les conclusions du rapport sont votées sans modification à l'issue de la discussion. Les remarques de Velpeau expriment cependant l'inquiétude des médecins quant au statut des sages-femmes. Dans un contexte où les docteurs en médecine travaillent à renforcer leur prestige en se délestant de leur second ordre $^{29}$, une concurrence féminine dans une partie de leur activité apparaît comme un empiétement de moins en moins supportable.

Vingt-deux ans plus tard, à la suite de la plainte d'une sage-femme qui s'est vue refuser la délivrance de seigle ergoté dans un cas d'hémorragie utérine, l'Académie de médecine est de nouveau saisie par le préfet de police de $\mathrm{Paris}^{30}$. Le débat débute par le rapport de Stéphane Tarnier et révèle un désaccord persistant sur l'usage thérapeutique du seigle ergoté et bien plus profond qu'en I850 sur la marge de manœuvre des sages-femmes. Le rapport occupe quatre séances abordant des thèmes divers : avantages et inconvénients de l'ergot, droit de prescription des sages-femmes, rapport entre droit de prescription et droit aux instruments, niveau de qualification des sages-femmes et définition de leurs attributions ${ }^{31}$. La critique la plus régulière est que les sages-femmes ne sauraient pas identifier les circonstances qui nécessitent ou qui interdisent l'usage de l'ergot de seigle.

Connaissances insuffisantes, impatience, incapacité à retenir, routine : le portrait de la sage-femme rappelle de façon troublante celui que dressaient médecins et administrateurs à la veille de la Révolution. Ces arguments ne font toutefois pas l'unanimité, mais ils témoignent une nouvelle fois d'un réel malaise du corps médical vis-à-vis de la profession d'accoucheuse. Il faut dans ce discours faire la part des abus constatés et des critiques proprement misogynes qui dénient indistinctement à ces femmes pourtant diplômées toute capacité d'analyse clinique et de sang-froid. En découlent une opposition entre corps médicaux et une revendication agressive du monopole des médecins sur toute difficulté obstétricale voire sur l'exercice complet de l'art des accouchements.

\footnotetext{
28. Ibid., p. 22.

29. Pinell P., « La genèse du champ médical... », art. cit., p. 327-328 ; Léonard J., Les médecins de l'Ouest..., op. cit., p. 735 sq. ; Guillaume P., Le rôle social du médecin depuis deux siècles (1800-1945), Paris, Comité d'Histoire de la Sécurité Sociale, 1996, p. I25.

30. Académie nationale de médecine, Bulletin de l'Académie nationale de médecine, 1872 , tome I, p. II36-II47 ; II55-II70 ; II85-II 89; I200-I228.

3I. Séances du 26 novembre, 3 , Io et I7 décembre 1872 .
} 
Cette affirmation du pré carré médical sur l'obstétrique passe aussi par la contestation des empiètements, réels ou supposés, des sages-femmes sur l'exercice plus général de la médecine. Le refus aux accoucheuses du moindre droit de prescription est même affirmé au cours du débat :

(M. Poggiale) En effet, l'article 32 de la loi de germinal an XI dispose : « Les pharmaciens ne pourront livrer et débiter des préparations médicinales ou drogues quelconques que d'après la prescription qui en sera faite par des docteurs en médecine ou en chirurgie, ou par des officiers de santé et sur leur signature ». Ainsi, d'après cette loi, les sages-femmes ne sont pas autorisées à prescrire des médicaments quels quilis soient. ${ }^{32}$

L'outrance de cette position heurte néanmoins quelques-uns des médecins présents pour qui le droit de prescription des sages-femmes, s'il mérite d'être redéfini, n'en est pas moins prouvé. Certains, comme Tarnier, le limitent à l'usage de l'ergot de seigle. Le médecin légiste Auguste Ambroise Tardieu, fort d'une connaissance précise des textes législatifs mais aussi de la jurisprudence afférente, développe pour sa part une vision très généreuse des possibilités accordées à la sage-femme :

Je prétends que lorsque la loi autorise le pharmacien à délivrer des médicaments ou des poisons aux seuls médecins, chirurgiens ou officiers de santé, ce dernier terme comprend les sages-femmes. [...] En effet, la jurisprudence de la cour suprême en matière criminelle ayant décidé, dans les termes les plus explicites, que, sous la dénomination de médecins et autres officiers de santé, l'article 317 du Code pénal, dans la généralité de sa disposition, comprenait les sages-femmes, il est juste de poursuivre l'assimilation $[\ldots] .^{33}$

L'assimilation sage-femme/officier de santé recoupe une réalité des enseignements et de la pratique ${ }^{34}$, mais, sensible aux possibles conséquences de son affirmation, Tardieu la retire avant la fin de la discussion. L'élargissement du spectre des produits utilisables par la sage-femme est inacceptable pour la plupart des Académiciens présents, même si Tarnier s'efforce de tempérer les craintes de ses collègues qui imaginent déjà des sages-femmes réclamant de prescrire « d'autres médicaments tels que l'extrait de belladone, l'atropine, le

32. Académie nationale de médecine, Bulletin de l'Académie nationale de médecine... [1872], p. II58-II59.

33. Ibid., p. II64-II65.

34. Voir Hatin J., Petit traité de médecine opératoire ou recueil de formules à l’usage des sages-femmes et des officiers de santé, Paris, Boisjolin et cie, Germer Baillière, I83I. 
laudanum, etc. ${ }^{35} \gg$. Il reste que sur la question du seigle ergoté, les médecins ont bien conscience de l'impossibilité concrète d'empêcher les sages-femmes de s'en procurer « dans les champs ou dans les granges, et par provisions de plusieurs centaines de grammes ${ }^{36} »$.

La conclusion à laquelle aboutissent les quatre séances de débat reflète ce décalage entre droit et pratique, mais gagne en précision par rapport à 1850 . Le rapporteur, Tarnier, a énoncé clairement sa volonté de sortir d'un « modus

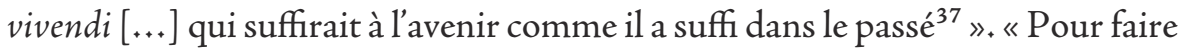
cesser [la] contradiction » entre l'autorisation implicite de prescrire du seigle ergoté présente dans la loi de ventôse an XI et la législation sur la pharmacie, l'Académie de médecine prie « le ministre de l'agriculture et du commerce de prendre les mesures nécessaires pour que les pharmaciens soient autorisés à délivrer du seigle ergoté aux sages-femmes sur la présentation d'une prescription signée et datée par elles ${ }^{38} »$. Le décret du 23 juin 1873 adopte les préconisations de l'Académie.

La discussion sur les risques de l'ergot de seigle en I872, la mise en balance de l'usage de ce produit avec le recours du forceps conduisent à réaffirmer l'interdit sur les instruments, unanimement partagé par les discutants. L'interdiction n'est pourtant pas absolue. Stéphane Tarnier, qui occupe depuis cinq ans le poste de chirurgien en chef de l'Hospice de la Maternité de Paris, est bien placé pour connaître les traditions de cette maison où la sage-femme en chef applique les forceps lorsqu'elle le juge nécessaire ${ }^{39}$. Au-delà, l'article 33 de la loi de ventôse an XI fait pendant très longtemps l'objet dans les écoles d'accouchement d'une interprétation partielle qui retient la possibilité pour la sage-femme d'user des instruments en « oubliant » l'impératif de la présence d'un médecin.

L'apprentissage du maniement du forceps est en fait général dans les cours d'accouchement. Tous les inventaires de mobilier le signalent, avec ses différents modèles (forceps pour le détroit supérieur, à manche quadrillé, brisé, modèle Matthieu, de Moreau, de Dubois, de Flamand), mais on rencontre aussi d'autres objets a priori tout aussi interdits aux sages-femmes : levier de Baudelocque, perce-crâne de Smellie, ergotribe, pince à faux-germe de Levret, céphalotribe,

\footnotetext{
35. Académie nationale de médecine, Bulletin de l'Académie nationale de médecine... [I872], p. II60.

36. Ibid., p. I209-1210.

37. Ibid., p. 1222 .

38. Ibid., p. 1228 .

39. La latitude d'action de la sage-femme en chef se réduit à la fin du XIX ${ }^{e}$ siècle, jusqu'à la mise sous tutelle que constitue la réforme de I895, voir Beauvalet-Boutouyrie S., Naître à l'hôpital..., op. cit., p. 132-133.
} 
perce-membrane de Dubois, ciseaux céphalotomes de Dubois, etc. ${ }^{40}$. L'habitude de voir forceps et levier entre les mains des sages-femmes est telle qu' au moment même où le débat sur l'emploi du seigle ergoté bat son plein et où les intervenants affirment tous l'interdiction des instruments, l'Académie reçoit

[...] une note sur l'emploi du seigle ergoté par les sages-femmes, proposant d'étendre aux sages-femmes le droit d'application du forceps, du levier et des appareils de tamponnement, par M. le docteur Amédée Paris (d'Angoulême). ${ }^{41}$

Ce décalage entre les certitudes de l'Académie de médecine et les pratiques des écoles départementales semble indurer une distinction entre Paris et la province, entre l'abondance du personnel médical de la capitale (qui n'empêche pas les sages-femmes formées à Port-Royal d'user de l'ergot de seigle et des forceps) et les communes où la sage-femme est le seul recours. Il est source d'un certain fatalisme qui vaut pour les instruments comme il vaut pour l'utilisation du seigle ergoté.

\section{L'usure du système napoléonien}

\section{La loi du 30 novembre 1892}

La réforme de la médecine attendue depuis plus d'un demi-siècle, tant de fois initiée, aboutit finalement en 1892. Elle a été confrontée, depuis les débuts de la Troisième République, à une multiplicité de questions qui ont encore ralenti le travail législatif : liberté de l'enseignement médical, création de nouvelles facultés, etc. Les commissions se succèdent et l'instabilité ministérielle de la seconde moitié des années 1880 n'aide pas à l'avancée de la réforme. En mars et avril I892 encore, le texte provoque de très longues discussions au Sénat, avant de subir trois navettes entre les deux chambres, pour finalement être promulgué le 30 novembre suivant ${ }^{42}$. La loi est relativement courte ( 36 articles). Elle comporte six titres qui règlementent les conditions d'exercice des professions médicales (médecin, chirurgien-dentiste et sage-femme) (titres I à IV), la défnition et la répression de l'exercice illégal (titre $\mathrm{V}$ ) et les dispositions transitoires nécessaires à l'application de la loi (titre VI) ${ }^{43}$.

40. AD Charente-Maritime, 3 X 295 ; AD Aube, 5 M 36 ; AD Aveyron, 3 X 51 .

4I. Académie nationale de médecine, Bulletin de l'Académie nationale de médecine... [I872], p. II73.

42. Léonard J., Les Médecins de l'Ouest..., op. cit., p. I094-IIII.

43. RLRES 5, p. 233-240. 
Le texte du 30 novembre 1892 prend acte de quatre-vingt-dix ans d'évolution de la médecine et de son exercice. Il rejette une organisation du personnel médical héritée des lendemains de la Révolution. En I803, la loi de ventôse initie, avec le duo docteur en médecine/officier de santé, la simplification d'un corps médical foisonnant, formé sous l'Ancien Régime et toujours en exercice pendant les premières décennies du XIX ${ }^{e}$ siècle $^{44}$. La loi de I892 marque une seconde étape de cette simplification avec la suppression de l'officiat de santé (art. I) et avec celle du doctorat en chirurgie (art. 8) ${ }^{45}$. Elle renonce cependant à l'unification des deux classes de sages-femmes (art. 3) : « Les sages-femmes de première et de deuxième classe continueront à exercer leur profession dans les conditions antérieures ${ }^{46} »$.

À la différence de ce qui s'est passé pour les officiers de santé, il n'y a pas eu de véritable campagne pour la suppression de la deuxième classe de sagesfemmes. Quelques voix ont bien sûr dénoncé le manque de connaissances de ces praticiennes mais les critiques ne font pas toujours la distinction entre les deux ordres. L'unification de la profession vient néanmoins en débat pendant les échanges entre la Chambre des Députés et le Sénat :

La question s'est agitée de savoir, s'il n'y avait pas lieu, pour les sages-femmes, comme pour les médecins, d'établir l'unité de grade. La commission de la chambre des députés avait supprimé les sages-femmes de deuxième classe (rapport Chevandier, p. 349) ; mais leur maintien fut voté par la chambre et par le sénat. Il fut reconnu en effet, que les sages-femmes de deuxième classe étaient beaucoup plus nombreuses que les sages-femmes de première classe, et qu'elles se fixaient de préférence dans les petites villes et les campagnes. Elles répondent ainsi au but pour lequel elles ont été créés. ${ }^{47}$

C'est donc la limitation géographique du champ d'exercice des sages-femmes de deuxième classe qui emporte la décision. L'attachement à l'ancrage départemental, même si l'obligation de résidence pour les boursières est finalement rejetée par le Sénat comme « contraire à la liberté individuelle ${ }^{48}$ », reflète le poids des administrations départementales dans la formation des sages-femmes. Le département est l'échelon majeur de l'enseignement obstétrical, et supprimer

44. Voir Léonard J., Les Médecins de l'Ouest..., op. cit., p. I24 sq. ; Rabier C., «Une révolution médicale ?... », art. cit., p. I4I-I48.

45. RLRES 5, p. 233 et 235 .

46. RLRES 5, p. 234.

47. Société de législation comparée, Annuaire de législation française, Paris, A. Cotillon, I893, notice de M. Edouard Delalande, docteur en droit, substitut du procureur de la République au Havre, sur la loi du 30 novembre I892, p. 197-198.

48. Ibid., p. I97. 
les sages-femmes de deuxième classe signifie supprimer les établissements qui les forment, c'est-à-dire tout le réseau des écoles départementales d'accouchement, fierté des conseils généraux qui les financent. Or, les voix des conseillers généraux comptent dans ce processus législatif et ils se sont montrés soucieux de conserver tant leurs sages-femmes de bourgs et de campagne que leurs cours d'accouchement. La loi reste d'ailleurs évasive au sujet des établissements de formation et renvoie cette partie de la réforme à un arrêté « pris après avis du conseil supérieur de l'Instruction publique ${ }^{49} »$.

Mais l'enjeu n'est pas qu'institutionnel. Maintenir des accoucheuses en milieu rural répond au souci de ne pas affaiblir ni déséquilibrer l'encadrement obstétrical du territoire. La crainte d'un afflux des sages-femmes vers les grandes villes ou vers les départements les plus riches est un frein puissant à l'unification de la profession et rejoint l'argumentation ancienne selon laquelle une sage-femme de première classe est toujours tentée de choisir la résidence qui lui apportera la meilleure clientèle tandis qu'une sage-femme de deuxième classe reste dans le département pour lequel elle a été reçue, surtout depuis l'instauration de frais d'examen en 1854.

Or, la défaite de 1870 a réveillé les hantises de la dépopulation. L'État veut compenser la perte des territoires alsaciens-lorrains annexés et voit dans le recul des naissances (pratiques contraceptives et abortives) et le maintien d'une mortinatalité et mortalité infantile élevées, un danger vis-à-vis du voisin allemand.

Pendant les deux premières décennies de la Troisième République, les accoucheuses sont en première ligne des dénonciations d'avortement, tandis que procès et comparutions de sages-femmes se multiplient ${ }^{50}$. L'évolution des méthodes abortives n'est pas pour rien dans cette implication apparemment accrue des accoucheuses dans la pratique des avortements. Munies d'une trousse contenant seringue, canule et speculum, elles ont à leur disposition tout le matériel nécessaire pour provoquer un avortement. Formées en botanique, les sages-femmes connaissent les effets de certaines plantes. Elles savent et peuvent prescrire officiellement depuis 1873 l'ergot de seigle dont l'utilisation à cette fin est régulière.

Revoir les limites légales de la profession de sage-femme constitue donc une réponse positive au déchaînement des accusations dont ce métier fait l'objet.

\footnotetext{
49. RLRES 5, p. 234.

50. Sohn A.-M., Chrysalides : femmes dans la vie privée (XIX ${ }^{e}-X^{e}$ siècles), Paris, Publications de la Sorbonne, 1996, p. 866-869 ; Le Naour J.-Y., Valenti C., Histoire de l'avortement, XIX $X^{e}-X X^{e}$ siècles, Paris, Seuil, 2003, p. I29-I3I ; Cahen F., Gouverner les mours. La lutte contre l'avortement en France, 1890-1950, Paris, INED Éditions, 2016, p. 35-37, 44-45.
} 
L'article 4 de la loi du 30 novembre 1892 décrit les bornes désormais posées à l'activité des accoucheuses :

Il est interdit aux sages-femmes d'employer des instruments. Dans les cas d'accouchements laborieux, elles feront appeler un docteur en médecine ou un officier de santé. Il leur est également interdit de prescrire des médicaments, sauf le cas prévu par le décret du 23 juin 1873 et par les décrets qui pourraient être rendus dans les mêmes conditions, après avis de l'Académie de médecine. Les sages-femmes sont autorisées à pratiquer les vaccinations et les revaccinations antivarioliques. ${ }^{51}$

La question des instruments est tranchée par la négative. La méconnaissance de leur usage par les médecins, l'insuffisance numérique et la mauvaise répartition du personnel médical qui justifient depuis 1803 une certaine tolérance sur cette question ne sont plus considérées comme des motifs valables. La volonté de dissocier clairement intervention manuelle et recours aux instruments pour en faire deux espaces de compétences distincts est en revanche bien présente.

La définition du droit de prescription s'inscrit dans une même logique. La loi dénie ce droit aux sages-femmes, mais confirme les exceptions concernant l'ergot de seigle et implicitement le sublimé corrosif à usage antiseptique. L'objectif est de faire entrer dans le champ de l'exceptionnel tout ce qui ne relève pas de l'obstétrique physiologique, de manière à mettre sous le contrôle de l'Académie de médecine tout élargissement futur des attributions de la sage-femme. La précision sur l'autorisation de pratiquer la vaccination antivariolique, qui fait pourtant partie intégrante de la mission sanitaire des sages-femmes depuis le début du siècle, confirme bien cette démarche. N'est plus permis à compter de la loi de 1892 que ce qui est clairement exprimé.

Le corollaire à cette délimitation des compétences de l'accoucheuse est la mise en place d'un vaste arsenal répressif contre l'exercice illégal de la médecine. La lutte contre le charlatanisme, contre les empiétements constants par les religieuses ou par d'autres membres du corps médical sur les attributions des docteurs en médecine ou des pharmaciens est l'un des buts les plus importants de la loi du 30 novembre $1892^{52}$. Cette lutte passe par la surveillance stricte du personnel médical et de son mouvement. L'article 9 impose aux médecins, chirurgiens-dentistes et sages-femmes de se faire enregistrer dans le département où

\section{I. RLRES 5, p. 234.}

52. Sur la multiplicité des formes et des acteurs de la médecine illégale, voir Léonard J., « Les guérisseurs en France au XIx ${ }^{e}$ siècle », RHMC, 1980, p. 50I-516 ; sur la répression de l'exercice illégal dans la loi de 1892, voir Léonard J., Les Médecins de l'Ouest..., op. cit., p. III7-II2O. 
ils s'installent ; l'obligation est réitérée en cas de changement de résidence ou en cas de cessation de l'exercice professionnel supérieure à deux ans. Associée à la constitution annuelle de listes départementales du personnel médical ( $\mathrm{art} . \mathrm{IO})$, cette préconisation assure une connaissance plus fine des soignants en exercice dans les communes, en particulier à la campagne. Elle permet de réduire dans ces zones le nombre de guérisseurs se vantant d'être diplômés; en ville où la population médicale est, à l'image de la population urbaine, plus nombreuse et plus mobile, son impact est moins fort ${ }^{53}$.

Le titre $\mathrm{V}$, le plus long de la loi (I2 articles), est consacré à la répression de l'exercice illégal. Nouveauté complète, les sages-femmes sont désignées comme la catégorie du personnel médical la plus susceptible d'outrepasser ses fonctions. Le législateur définit ensuite les moyens de réprimer des pratiques qui ne donnaient auparavant que très rarement lieu à inculpation. L'article i7 attribue ainsi les cas aux juridictions correctionnelles et accorde aux membres du corps médical (individuellement ou collectivement) la possibilité d'en appeler directement à la justice dans les cas de non-respect des termes de la loi ${ }^{54}$. Les articles suivants (I8, I9 et 22) fixent les peines prévues dans les différents cas d'exercice illégal ou de transgression des règles édictées par les titres précédents (usurpation de titre, non enregistrement de diplôme) :

Art. I8: [...] L'exercice illégal de l'art des accouchements est puni d'une amende de 50 à 100 francs et, en cas de récidive, d'une amende de 100 à 500 francs et d'un emprisonnement de six jours à un mois, ou de l'une de ces deux peines seulement.

Art. 19. [...] L'usurpation du titre de sage-femme sera punie d'une amende de Ioo à 500 francs et, en cas de récidive, d'une amende de 500 à I 000 francs et d'un emprisonnement de un à deux mois, ou de l'une de ces deux peines seulement. [...]

Art. 22. Quiconque exerce la médecine, l'art dentaire ou l'art des accouchements sans avoir fait enregistrer son diplôme dans les délais et conditions fixés à l'article 9 de la présente loi, est puni d'une amende de 25 à Ioo francs. ${ }^{55}$

La loi de I892 sépare clairement le délit d'exercice illégal du délit d'usurpation de titre et punit le second plus durement que le premier. Si les sagesfemmes risquent désormais à empiéter sur l'espace des médecins de lourdes amendes voire un emprisonnement, le texte du 30 novembre 1892 accorde à

53. Léonard J., Les Médecins de l'Ouest..., op. cit., p. III8.

54. RLRES 5, p. 237.

55. Ibid., p. 237-238. 
leur profession une réelle protection législative. En I803, l'exercice illégal de l'art des accouchements était seul réprimé, théoriquement par une amende de Ioo francs, dans les faits par des sommes très largement inférieures (art. 36). De plus, à la différence des médecins et des officiers de santé, la sage-femme était le seul membre du personnel médical pour qui l'usurpation de titre ne constituait pas explicitement un délit. Quatre-vingt-dix ans plus tard, l'amende pour exercice illégal de l'art des accouchements ne peut être inférieure à 50 francs en première condamnation et la récidive peut justifier une peine de prison. L'usurpation du titre de sage-femme est punie des mêmes types de peines que celle du titre de médecin et de chirurgien-dentiste. La sévérité de ces articles par rapport au régime en vigueur depuis le début du siècle est révélatrice de la place désormais occupée par les accoucheuses diplômées dans l'encadrement obstétrical du pays. Les matrones existent toujours, difficiles à quantifier car leur activité n'est plus aussi visible ni aussi fréquente que pendant les premières décennies $\mathrm{du} \mathrm{XIX}^{\mathrm{e}}$ siècle, mais incapables dorénavant de concurrencer pleinement les sages-femmes en titre ${ }^{56}$. Cette sévérité témoigne aussi d'une volonté politique et médicale de sauvegarder le métier de sage-femme. La loi de 1892 confirme sa légitimité en le comptant au nombre des trois professions médicales, et en lui confiant, à l'égal des médecins, une mission de surveillance épidémique $(\operatorname{art} .15)^{57}$. Elle le protège des accoucheuses illégales en sanctuarisant sa pratique et son appellation. Elle lui accorde un moyen de défense professionnelle en lui reconnaissant le droit de se syndiquer (art. 13) ${ }^{58}$. Elle le spécialise enfin en réduisant son champ d'exercice mais en prévoyant le renforcement des études qui y conduisent.

\section{Les décrets d'application et la mise en cuvre de la réforme}

Après le vote de novembre 1892 , plusieurs décrets suivis de circulaires ministérielles développent la lettre de la loi entre 1893 et I896. Ils portent sur le régime des études en fonction de la classe à laquelle aspire l'élève sage-femme, sur les prérequis imposés pour l'accès à ces études (diplômes, âge), les possibilités de passage entre la première et la deuxième classe ainsi que les évolutions institutionnelles générées par la modification des cursus obligatoires.

56. Sage Pranchère N., « Bébés sans diplôme... », art. cit.

57. RLRES 5, p. 236. Voir aussi Faure O., Histoire sociale de la médecine..., op. cit., p. I89.

58. RLRES 5, p. 236. 


\begin{tabular}{|c|c|}
\hline Date & Intitulé \\
\hline I893, 25 juillet & $\begin{array}{l}\text { Décret relatif aux conditions d'études exigées } \\
\text { des aspirantes aux diplômes de sage-femme. }\end{array}$ \\
\hline I893, 3I décembre & $\begin{array}{c}\text { Décret relatif aux aspirantes aux diplômes } \\
\text { de sage-femme de } \mathrm{I}^{\text {re }} \text { classe et de pharmacien de } 2^{\mathrm{e}} \text { classe. }\end{array}$ \\
\hline I893, 3I décembre & $\begin{array}{l}\text { Décret relatif aux aspirantes au diplôme de sage-femme } \\
\text { de } \mathrm{I}^{\text {re }} \text { classe élèves des maternités de Lyon et de Nancy. }\end{array}$ \\
\hline I894, I4 février & $\begin{array}{l}\text { Décret relatif aux conditions d'âge et aux droits à percevoir } \\
\text { des aspirantes aux diplômes de sage-femme. }\end{array}$ \\
\hline I894, Io juillet & $\begin{array}{l}\text { Circulaire relative aux élèves sages-femmes } \\
\text { [organisation des examens et dispositions temporaires]. }\end{array}$ \\
\hline I894, I5 novembre & $\begin{array}{l}\text { Circulaire relative à la limite d'âge imposée } \\
\text { aux aspirantes élèves sages-femmes. }\end{array}$ \\
\hline 1895,2 mars & $\begin{array}{l}\text { Circulaire concernant les sages-femmes de } 2^{\mathrm{e}} \text { classe } \\
\text { aspirant au diplôme de } \mathrm{I}^{\mathrm{re}} \text { classe (régime de } 1895 \text { ). }\end{array}$ \\
\hline I896, I8 janvier & $\begin{array}{l}\text { Décret relatif à l'inspection de l'enseignement } \\
\text { donné dans les maternités. }\end{array}$ \\
\hline I896, Io juillet & $\begin{array}{l}\text { Circulaire relative aux brevet et certificats que doivent produire } \\
\text { les aspirantes aux diplômes de sage-femme. }\end{array}$ \\
\hline I896, 25 juillet & $\begin{array}{l}\text { Décret relatif aux élèves sages-femmes qui font leurs études } \\
\text { dans la Maternité de Bordeaux. }\end{array}$ \\
\hline I896, II novembre & $\begin{array}{l}\text { Circulaire concernant les aspirantes au diplôme } \\
\text { de sage-femme de } \mathrm{I}^{\text {re }} \text { classe. }\end{array}$ \\
\hline
\end{tabular}

Tableau 5. Récapitulatif des textes règlementaires et des circulaires explicatives sur le régime des études de sage-femme, 1893-1896.

En juillet I893, le docteur Louis Lortet présente au Conseil supérieur de l'Instruction publique un projet de décret sur les études des aspirantes sagesfemmes qui a déjà reçu l'aval de la commission préparatoire. Le principe adopté par Lortet puis par le Conseil supérieur de l'Instruction publique est celui d'une uniformisation des études. La durée, le lieu et le mode de contrôle de la formation sont définis pour l'ensemble de la France et de manière homogène pour chacune des classes de sages-femmes. Le programme de l'enseignement découle de celui des examens prévus au cours de la scolarité. Les articles i à 5 alignent l'instruction réformée des sages-femmes sur les cursus les plus exigeants : deux 
années d'études théoriques et pratiques, sanctionnées par un examen à chaque fin d'année (anatomie, physiologie et pathologie élémentaires ; théorie et pratique des accouchements). La préparation du diplôme de $2^{e}$ classe peut se faire dans une faculté, une école de médecine (préparatoire ou de plein exercice) ou une maternité ; celle du diplôme de $\mathrm{I}^{\text {re }}$ classe impose que la deuxième année soit effectuée dans une faculté ou une école de médecine de plein exercice. Les examens se passent devant ces deux types d'établissements pour la $\mathrm{I}^{\text {re }}$ classe ainsi que devant les écoles préparatoires de médecine pour la $2^{\text {e59. }}$.

Le décret met sur le même plan de durée les deux classes de sages-femmes, puisque seul change l'établissement dans lequel elles sont formées. Le maintien de la deuxième classe, avec sa restriction géographique, ne justifie pas, aux yeux $\mathrm{du}$ rapporteur, que son instruction soit négligée ${ }^{60}$. Le but est, par cet alignement des cursus, de préparer à moyen ou long terme l'unification du corps.

On retrouve sous la plume de Lortet une préoccupation déjà présente en I854 : accroître la somme des droits de réception pour établir une barrière minimale à l'entrée de la profession. Le décret du I4 février 1894 répond à ce $v{ }^{61}{ }^{61}$. Les droits de réception des sages-femmes de première classe restent fixés à leur niveau de 1854, I30 francs, tandis que ceux des sages-femmes de deuxième connaissent une hausse considérable : de 25 à 80 francs. Cet augmentation est une tentative de modifier le terreau social du recrutement et de combler en partie l'écart entre les deux classes, en reconnaissance du rapprochement des cursus.

Les attentes en matière d'instruction primaire à l'admission sont revues et augmentées : brevet de capacité de l'enseignement primaire pour les aspirantes à la première classe, certificat de l'examen établi par décret du I $\mathrm{I}^{\text {er }}$ août $\mathrm{I} 879$ pour les aspirantes à la deuxième classe $(\operatorname{art} .7)^{62}$. Prenant acte du développement de l'enseignement secondaire féminin, le décret du 3I décembre I893 accepte que les élèves admises à la préparation du diplôme de première classe présentent le certificat d'études secondaires instauré par le décret du I4 janvier I882 au même titre que le brevet de capacité de l'enseignement primaire ${ }^{63}$. La nécessaire élévation du niveau scolaire des futures sages-femmes explique la mise en

\footnotetext{
59. RLRES 5, p. 265-266.

6o. Ibid., p. 265 .

6I. Ibid., p. 38I-382.

62. Ibid., p. 266.

63. RLRES 5, p. 377. Le certificat d'études secondaires peut être obtenu à l'issue des trois premières années de l'enseignement secondaire féminin institué en I880, voir Prost A., "Inférieur ou novateur ? L'enseignement secondaire des jeunes filles (1880-1887) », Histoire de l'éducation, 2007, no II5-II6, p. 157 .
} 
place de dispositions transitoires. Les aspirantes à la deuxième classe ont dès la rentrée I893 l'obligation de présenter le certificat lié à l'examen de i879. Une période transitoire est fixée pour les jeunes femmes qui préparent le diplôme de première classe et qui ne disposeraient pas d'ores et déjà du brevet de capacité de l'enseignement primaire. Celui-ci ne devient impératif qu'à partir de la rentrée I896 et le certificat de l'examen d'août I879 peut y suppléer entre temps (art. 9) ${ }^{64}$. Cette même tolérance s'applique aux sages-femmes de deuxième classe qui souhaitent passer le diplôme de première classe, à condition qu'elles aient subi l'examen de fin de première année d'études et qu'elles aient suivi la deuxième année propre à la formation de première classe, ainsi que le précise la circulaire du io juillet $1894^{65}$. En rapport avec l'élévation du niveau d'instruction primaire et/ou secondaire des postulantes et pour faire coïncider l'obtention du diplôme avec la majorité, l'âge minimal d'admission est fixé par le décret du I4 février I894 à I9 ans ${ }^{66}$.

Le passage de la deuxième vers la première classe est donc non seulement possible mais de plus en plus fréquemment souhaité par les meilleures élèves des établissements formant à la deuxième classe. Avant I893, il suffisait pour prétendre à la première classe de se présenter aux examens devant un jury de Faculté et de payer les frais exigés ${ }^{67}$. Après cette date, les conditions nouvelles de passage d'une classe à l'autre, qui imposent la poursuite d'une scolarité pour les femmes déjà diplômées ou sa reprise pour les sages-femmes en exercice, soulignent la priorité accordée à l'instruction universitaire sur l'expérience professionnelle et l'auto-formation. Elles reflètent aussi la nouvelle orientation institutionnelle donnée à l'organisation des études, qui place beaucoup plus clairement les établissements d'enseignement supérieur au cœur du système. Car la réforme de I893 est aussi, voire surtout, une réforme des lieux d'enseignement. Le tissu de l'enseignement supérieur médical s'est considérablement enrichi depuis 1803 et compte en plus des trois facultés de médecine (Paris, Montpellier, Nancy depuis 1872), quatre facultés mixtes de médecine et de pharmacie sur le territoire métropolitain (Bordeaux, Lille, Lyon et Toulouse), deux écoles de médecine et de pharmacie de plein exercice (Marseille et Nantes), et treize

64. RLRES 5, p. 266. La fin de la période de tolérance est rappelée par une circulaire en date du Io juillet $1896, R L R E S$ 5, p. 605.

65. Ibid., p. 392.

66. RLRES 5, p. 38I. Le I5 novembre I894, une circulaire précise que toute dispense d'âge sera dorénavant refusée et que les élèves boursières des départements qui entreraient dans les écoles d'accouchement avant l'âge de I9 ans, ne verraient leur scolarité débuter officiellement qu'en atteignant cet âge, voir RLRES 5, p. 419.

67. $\mathrm{AD}$ Corrèze, RD CG Corrèze, $\mathrm{I} 887$. 
écoles préparatoires de médecine et de pharmacie ${ }^{68}$. Le décret du 25 juillet I 893 répartit la formation entre ces différents niveaux d'établissements. Les sagesfemmes de deuxième classe peuvent être instruites indistinctement dans une faculté, une école de plein exercice, une école préparatoire ou une maternité. Il en est de même pour les sages-femmes de première classe pendant leur première année d'études, mais ces dernières doivent impérativement rejoindre une Faculté ou une école de plein exercice pour la seconde année.

Le vocable de maternité désigne les cours départementaux et municipaux d'accouchement, ravalés du même coup au dernier rang des établissements d'enseignement, et seulement justifiés par la formation pratique qu'ils permettent d'acquérir. Très critiquées à cause du caractère inégal de l'instruction qui y est dispensée et de la taille parfois très réduite des maternités, les écoles départementales sont cependant maintenues. Le décret les place dans une position subalterne et multiplie en théorie les institutions concurrentes, alors qu'il n'existait auparavant qu'assez peu de formations à destination des sagesfemmes dans les écoles préparatoires de médecine (Caen, Lille à partir de I853).

Pourtant, ces établissements résistent bien et il subsiste près de 36 écoles d'accouchement rattachées à des maternités en 1900 en France (carte 8$)^{69}$. Cette persistance des cours d'accouchement s'explique par plusieurs facteurs. Dans les villes où un cours coexiste avec une école de médecine (préparatoire ou de plein exercice), le professeur du cours est en général le titulaire de la chaire d'obstétrique de l'école. Supprimer le cours pour le rattacher directement à l'école de médecine reviendrait à se priver des avantages de l'internat et à éloigner les élèves des lieux de leur formation pratique. De plus, nombre de ces établissements repose sur un principe de subvention départementale (pour les élèves ou le fonctionnement complet de l'école), principe qui soulage d'autant les finances de l'État et permet le maintien d'une politique sociale d'aide aux études obstétricales. Le décret du 25 juillet 1893 n'aboutit donc qu'exceptionnellement à la fermeture d'un de ces établissements, la politique du ministère de l'Instruction publique associant contrôle rigoureux de l'adéquation des maternités aux nécessités de l'enseignement et encouragements à la mise aux normes des établissements mal équipés.

68. La cinquième faculté mixte est à Alger. Les écoles préparatoires sont : Amiens, Angers, Besançon, Caen, Clermont-Ferrand, Dijon, Toulouse, Grenoble, Limoges, Poitiers, Reims, Rennes, Rouen, Tours.

69. Il s'agit des écoles de Bourg-en-Bresse, Laon, Pamiers, Marseille, Caen, Dijon, Besançon, Chartres, Brest, Nîmes, Bordeaux, Montpellier, Rennes, Tours, Grenoble, Blois, Nantes, Orléans, Angers, Reims, Chaumont, Nancy, Lorient, Clermont-Ferrand, Pau, Perpignan, Lyon, Mâcon, Chambéry, Rouen, Albi, Toulon, Draguignan, Avignon, Poitiers et Limoges. 
Les inspections commencent dès le printemps et l'été I895 et sont effectuées par les professeurs d'obstétrique exerçant dans la faculté la plus proche : le docteur Morache de la faculté de Bordeaux à Tulle, le docteur Crouzat de Toulouse à Pamiers, etc. ${ }^{70}$. Le décret du I 8 janvier 1896 fixe a posteriori le cadre de ces visites.

Les conclusions présentées par les professeurs-inspecteurs s'attardent surtout sur les lacunes des établissements et insistent souvent sur le mauvais état matériel des bâtiments :

Des réparations urgentes s'imposent à la maternité de Pamiers. Il y aurait lieu de remplacer le pavé au premier étage ; de refaire les waterclosets, de changer les lits qui sont en bois de tous les styles et de toutes les époques, de supprimer les paillasses des lits des accouchées en y substituant des sommiers.

L'enseignement pratique est insuffisant ; le nombre des accouchements n'est que de dix en I894 et il paraît difficile de maintenir une école d'accouchements auprès d'un établissement où les entrées sont si peu fréquentes.

Matériel insuffisant. Pas de bibliothèque. ${ }^{71}$

Le maintien ou la fermeture de ces institutions reposent donc sur la capacité des établissements à pallier rapidement les manques signalés lors des inspections. Le ministère de l'Instruction se réserve en dernier ressort de décider de l'avenir des écoles.

Le caractère souverain du choix ministériel ne doit pas faire perdre de vue qu'il est toujours le résultat d'une négociation : entre le ministère et les conseils généraux, mais aussi dans bien des villes entre les conseils généraux et les commissions des hospices. La position de principe du ministère vise d'ailleurs à conserver autant que possible les institutions en place. C'est le cas en Corrèze où l'avenir de l'école est discuté lors de la session d'août 1895 du conseil général. À la suite de l'inspection officielle, une commission départementale a été nommée pour juger de la possibilité d'adapter l'institution aux nouvelles exigences de la formation. Ses conclusions sont peu favorables : les sommes à débourser pour moderniser l'établissement (réparations et modifications dans la maison, achat de matériel, etc.) sont très importantes ; s'y ajoutent la nécessité de revoir l'organisation des cours qui duraient jusque-là trois ans, l'habitude des élèves corréziennes de postuler avec succès au diplôme de première classe et la perspective du déséquilibre produit dans le service de la maternité par leur départ à l'issue de la première (ou deuxième) année d'études. Ces différentes raisons

70. AD Corrèze, I X 176 ; RD CG Ariège, 1897.

71. RD CG Ariège, I897. 
convainquent l'assemblée départementale de supprimer l'école et de persister dans cette décision malgré les interventions réitérées du ministre de l'Intérieur pour obtenir le maintien de l'établissement ${ }^{72}$.

L'exemple corrézien est cependant loin d'être représentatif. Les cours qui réussissent à perdurer jusqu'aux années I880-I890 passent en général sans difficulté le cap de la réforme de I893, et l'attachement à la structure locale justifie la plupart du temps de multiplier les efforts pour la conserver. À Pamiers dans l'Ariège, le préfet ne se saisit sérieusement de la question qu'en I897 pour la soumettre au conseil général. La date limite du $\mathrm{I}^{\mathrm{er}}$ novembre 1896 imposée par le ministre de l'Instruction publique pour avoir effectué tous les changements demandés à l'issue de l'inspection, déjà largement dépassée, justifie cette interpellation. Au cours des mois précédents, le préfet a œuvré pour maintenir le cours. Il a convaincu la commission des hospices de procéder à une amélioration des locaux, promise en décembre 1896 mais encore non réalisée. Les lacunes dans le matériel d'enseignement ont été inopinément comblées par le décès du professeur et le legs de sa bibliothèque et de ses instruments au cours. Le ministre donne son aval le 24 février 1897 sous réserve de « l'exécution des travaux de réparation projetés ${ }^{73} »$.

Comme en Corrèze, une commission est nommée par le conseil général pour examiner le sort à réserver au cours d'accouchement. Son rapport, confirmé par le vote de l'assemblée départementale, « conclut au maintien du cours à Pamiers ${ }^{74}$ ». Deux années sont encore néanmoins nécessaires pour que les hospices entament enfin les travaux demandés, et que la maternité soit en mai 1899 officiellement « autorisée par M. le ministre de l'Instruction publique à bénéficier des prérogatives concédées à ces établissements par le décret du 25 juillet $1893^{75} \gg$. Dans l'intervalle, les cours n'ont pourtant jamais cessé de fonctionner.

Dans de nombreux départements, lorsque les inspections ne signalent pas trop de défauts à corriger, l'adaptation à la loi se fait sans soulever le moindre débat. À Mâcon en 1894 , le préfet présente aux conseillers généraux pendant la session du mois d'août son projet d'augmentation du budget de l'école d'accouchement en le fondant sur les observations et les propositions du directeur, le docteur Jacquelot :

72. Sage Pranchère N., Mettre au monde..., op. cit., p. 657-658.

73. RD CG Ariège, I897.

74. Ibid.

75. RD CG Ariège, I899. 
Il en résulte que nos élèves qui, sous l'empire de l'ancienne législation, ne restaient que cinq mois au cours chaque année, seront obligées d'accomplir la durée normale de l'année scolaire soit, en déduisant les vacances du premier de l'an et de Pâques, environ huit mois. De là, en comptant huit élèves, car deux restaient antérieurement pour l'infirmerie, un minimum de 720 journées pour trois mois, soit [...] une augmentation de dépense de I 152 francs. D'autre part, le personnel enseignant composé du directeur et de deux maîtresses sages-femmes sont astreints à augmenter leurs cours suivant les nouveaux programmes et à en étendre la durée de 5 à 8 mois. J'ai pensé qu'il convenait de tenir compte de ce surcroît de travail, [...] soit de ce chef une augmentation de I Ioo francs. ${ }^{76}$

Le conseil général vote ce budget sans discussion ${ }^{77}$. Le bilan de la mise en place du décret de juillet 1893 confirme bien cette déclaration du rapporteur ariégeois en 1897 : « il importe de remarquer que le gouvernement, s'inspirant des intentions du législateur, n'a pas l'intention de supprimer les maternités ». Le but du ministère de l'Instruction est en effet de s'appuyer sur le réseau d'institutions d'enseignement existantes, de l'uniformiser et de renforcer ses liens avec les établissements d'enseignement médical, en le soumettant au besoin à une possible concurrence. Ce souci repose sur la volonté affirmée et désormais mise en pratique d'élargir et d'approfondir le contenu de la formation des sages-femmes.

La décision de placer la seconde année d'études des aspirantes à la première classe dans le cadre universitaire relève du même projet. Elle fait des facultés de médecine et des écoles de plein exercice le sommet du système de formation des sages-femmes dans la continuité de la loi de ventôse an XI. Des trois écoles de médecine de 1803 , seule celle de Paris organise réellement un enseignement pour ses sages-femmes, Strasbourg et Montpellier se contentant d'examiner les élèves formées dans des maternités qui ne dépendent pas directement des deux facultés. Dans la seconde moitié du XIX ${ }^{e}$ siècle, la fondation de facultés mixtes de médecine et de pharmacie à Lille, Bordeaux ou Lyon entraîne la mise en place de cours spécifiquement destinés aux accoucheuses dans ces établissements. En 1882, deux arrêtés mettent successivement en place à la faculté de Bordeaux (22 mai) et à celle de Lyon ( $\mathrm{I}^{\text {er }}$ août) un enseignement spécial pour les élèves sages-femmes ${ }^{78}$. Ils préfigurent le décret du 25 juillet 1893 : la durée de l'enseignement est fixée à deux ans. Les élèves doivent présenter au moment de leur inscription le certificat obtenu à la suite de l'examen instauré par l'arrêté

76. RD CG Saône-et-Loire, I894.

77. Ibid.

78. RLRES 3, p. 618-619 et 669-670. 
du I ${ }^{\text {er }}$ août 1879. La formation conduit aux deux classes de sages-femmes mais les élèves qui ont choisi de ne préparer que la deuxième classe doivent suivre une année de cours supplémentaire pour passer les examens de première classe, à l'instar des sages-femmes déjà diplômées de deuxième classe qui aspirent au diplôme supérieur.

L'émergence de ces enseignements universitaires repose cependant sur une demande locale et sur la personnalité des professeurs d'obstétrique. Leur présence à Bordeaux et à Lyon, deux villes à forte tradition de formation en maternité, relève d'une stratégie d'affirmation de la Faculté vis-à-vis des structures plus anciennes d'enseignement obstétrical. Car si les plus petites institutions de ce type sont suspendues au bon vouloir de leurs autorités de tutelle et du ministre de l'Instruction publique, les plus importantes en termes numériques et d'ancienneté (Paris, Nancy, Lyon, Bordeaux) se retrouvent rapidement en position, non pas d'être concurrencées, mais de concurrencer les facultés qui les jouxtent.

L'Hospice de la Maternité obtient dès la rédaction du décret de I893 un statut exceptionnel qui lui conserve sa capacité à former en deux ans des sagesfemmes de première classe $(\operatorname{art} .9)^{79}$. Le règlement est toutefois réformé à cette occasion par l'arrêté du 20 juillet 1895. L'examen d'entrée se rapproche des attentes du brevet élémentaire ${ }^{80}$ et le programme des études est complété de notions de chimie " portant principalement sur les antiseptiques utilisés en accouchement » mais aussi de physique et d'urologie pour permettre le dépistage de l'albuminurie en cas de suspicion d'éclampsie ${ }^{81}$. Aucun examen de fin de première année n'est toutefois mis en place, seules les élèves « les plus mal notées [étant] soumises à un examen dit de passage, au seuil de la deuxième année ${ }^{82}$ ».

Dès le mois de décembre suivant, un décret étend l'exception parisienne aux maternités de Nancy et de Lyon en reconnaissance de la qualité de l'instruction qui y est délivrée ${ }^{83}$. Le dernier établissement à bénéficier de cette prérogative est la maternité de Bordeaux, mais l'exception est ici le résultat de mois de négociations menées entre le conseil général de la Gironde et le ministère par l'intermédiaire du préfet. En I895, les risques inhérents à la réforme pour l'école départementale d'accouchement qui forme essentiellement des sages-femmes de première classe sont évoqués en session du conseil général. Le débat tourne

79. RLRES 5, p. 266.

80. Administration générale de l'Assistance publique à Paris, L'Assistance publique en 1900, Paris, 1900, p. 122 .

8I. Ibid., p. II9 ; Tucat D., Les sages-femmes parisiennes..., op. cit., p. I36.

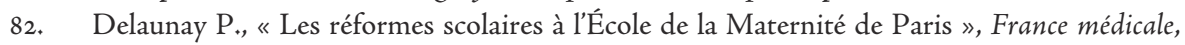
I9IO, p. 64 .

83. RLRES 5, p. 377, décret du 3I décembre i893. 
rapidement à l'aigre entre le président de la commission de surveillance de l'école et la commission d'administration théoriquement en charge de l'étude du dossier. Il s'avère, par-delà les inimitiés personnelles qui traversent le conseil général, que l'affaire est à cette date plutôt mal engagée selon les informations rapportées par le préfet : «[... à la date du 30 juin, M. le ministre m'a fait connaitre que les conditions dans lesquelles l'enseignement était donné à l'école ne permettraient pas de la faire bénéficier du régime de faveur sollicitée ${ }^{84}$ ».

Le débat qui s'ensuit fait ressortir la rivalité entre l'école d'accouchement et la faculté de médecine. Certains conseillers se plaignent du comportement des jurys de la faculté qui ont écarté les élèves sages-femmes de l'école-maternité en leur attribuant une note éliminatoire sur un programme qu'elles n'avaient pas eu l'occasion d'étudier. D'autres dénoncent plus directement encore une volonté de détournement des élèves de la maternité vers l'université :

(M. Clouzet) [...] Nous sommes en présence d'une prétention des professeurs de la Faculté qui veulent la suppression de notre école d'accouchement pour avoir nos élèves. Le département doit tenir avec la plus grande énergie au maintien de cette école. [...] Ce que nous devons faire, c'est défendre notre œuvre qui remonte à un grand nombre d'années, qui a rendu des services considérables, dans tous les départements du sud-ouest. Il serait véritablement déplorable que, pour un caprice de messieurs de la Faculté, notre école dût être supprimée par une mesure arbitraire du ministre. ${ }^{85}$

La discussion se termine sur une délibération un brin grandiloquente :

Invoquant son passé que des succès éclatants ont marqué, et se réclamant de la supériorité constante de ses élèves sur les étudiantes libres de la Faculté, l'école départementale d'accouchement de la Gironde semble pouvoir prétendre que son enseignement est aussi complet que possible et le conseil général paraît à votre commission d'administration devoir s'associer à $M$. le préfet pour réclamer énergiquement que l'administration supérieure accorde à la maternité de Pellegrin le traitement de faveur dont bénéficient déjà les maternités de Paris, Lyon et Nancy. ${ }^{86}$

Le plaidoyer du conseil général et les négociations serrées menées par le préfet touchent finalement au but et permettent à la maternité de Bordeaux de continuer à former elle-même ses élèves sages-femmes aspirant à la première classe. L'exception est confirmée par un décret ministériel en date du 25 juillet

84. AD Gironde, I $\mathrm{N}$ iII ${ }^{*}$.

85. AD Gironde, I $\mathrm{N} \mathrm{III}^{*}$.

86. Ibid. 
I896, après un rapport du docteur Albert Pitres, pourtant doyen à cette date de la faculté de médecine de Bordeaux ${ }^{87}$.

\section{Le désir permanent de réforme}

Le 22 juillet $\mathrm{I} 897$, F. de Ribier consacre à la condition des sages-femmes la thèse pour le doctorat en médecine qu'il présente devant la Faculté de médecine de Paris sous le titre, Les sages-femmes en France, ce qu'elles ont été, ce qu'elles sont, ce qu'elles pourraient être : essai bistorique et critique. Cette étude pose le bilan cumulé d'un siècle de formation et d'exercice de la profession, mêlant l'approche historique à la constatation des manques contemporains. Elle affirme l'insuffisance de la loi du 30 novembre $1892^{88}$ et lui propose une réponse partagée par l'ensemble du monde médical, des sages-femmes elles-mêmes aux obstétriciens :

Le remède, le voici : élever plus haut, très haut le niveau des études des sagesfemmes, non pas seulement le niveau des études techniques, mais encore celui des études premières. [... Q Que l'on exige le brevet supérieur ou le baccalauréat de l'enseignement moderne, et l'on verra bien vite quel avantage en résultera. [...] Que ne porte-t-on à trois ans, la durée des études au lieu de deux années ? Les élèves sages-femmes seraient alors astreintes à des études plus approfondies de l'anatomie de la femme et de l'obstétrique, en même temps que de la pathologie de la grossesse. ${ }^{89}$

Les propositions de F. de Ribier expriment une attente nouvelle qu'ont permise le vote de la loi de I892 et la publication de ses décrets d'application. Quelques mois plus tard, la «ligue de protection des accoucheuses de France» dépose d'ailleurs au parlement une pétition concernant le droit à l'utilisation $\mathrm{du}$ forceps dont le second point demande « l'augmentation de durée des études professionnelles qui seraient portées de deux à trois ans, dans le but d'élever le niveau scientifique de la corporation ${ }^{90} »$.

Le signal d'une rénovation des études obstétricales est lancé et la faculté de Paris est l'une des premières à revoir l'organisation en 1898 de son cursus destiné aux sages-femmes. Avant cette date, l'enseignement était calqué sur celui des étudiants en médecine et se déroulait pendant le semestre d'été avec un stage de 43 jours et nuits à la clinique d'accouchement de la Faculté, rue

87. RLRES 5, p. 616.

88. Ribier F. (de), Les Sages-femmes en France..., op. cit., p. 37.

89. Ibid., p. 45-46.

90. La Presse médicale, $\mathrm{I}^{\text {er }}$ décembre $\mathrm{i} 897, \mathrm{n}^{\circ}$ Ioo, p. CLXXVIII. 
d'Assas. Le nombre réduit de naissances dans cet établissement (6oo par an) et la restriction aux gardes de nuit de l'accès des élèves sages-femmes aux parturientes sont autant d'obstacles à une formation clinique suffisante ${ }^{91}$. Après I893, le doyen de la Faculté demande à l'Assistance publique l'ouverture d'une clinique obstétricale propre aux sages-femmes qui lui est accordée en I898. Celle-ci prend alors place à l'hôpital Beaujon dans le service du professeur Ribemont-Dessaignes ${ }^{92}$, déjà titulaire du cours théorique. Cet enseignement est officiellement transformé en « chaire obstétricale en faveur des élèves sagesfemmes » en 1908.

La proposition d'allonger la scolarité des sages-femmes est reprise en 1906 par Félicité Henry, ancienne sage-femme en chef de l'Hospice de la Maternité de Paris : «La troisième année serait consacrée à l'étude théorique et clinique du diagnostic des maladies syphilitiques et tuberculeuses chez la mère et l'enfant et de la prophylaxie de ces deux maladies. De plus, les élèves suivraient des cours théoriques et cliniques sur le forceps ${ }^{93}$. $\gg$ Le souci que les élèves soient instruites du maniement du forceps est toujours présent, tandis que le premier argument, moins polémique, vise avant tout à répondre à l'obligation de veille épidémique établie par l'article 15 de la loi de 1892 et confirmée par la loi relative à la protection de la santé publique du is février 1902.

$\mathrm{Au}$ cours des années suivantes, les voix continuent de s'élever, réclamant a minima l'application stricte de la règlementation des années I 890 et plus généralement la refonte de l'enseignement en vue d'une unification des deux classes de sages-femmes par le haut. En 1908, le statut dérogatoire de l'Hospice de la Maternité de Paris est aboli par le décret présidentiel du 23 décembre, sans que cela n'occasionne de grands bouleversements puisque les modalités d'admission avaient déjà été réformées en 1895 (examen pour les candidates n'ayant pas le brevet élémentaire $)^{94}$. Les élèves sont désormais soumises à l'examen en fin de première année. Cet aménagement mineur se double cependant d'une réflexion sur le contenu des enseignements confiée au Comité de perfectionnement de la Maternité et mise en œuvre à la rentrée igıo. Un cours spécifique d'anatomie et de physiologie est créé pour les élèves de première année ainsi qu'un cours de clinique obstétricale et de puériculture pour les deux années ; l'enseignement d'hygiène privée, publique et sociale est réparti entre le cours du

91. Tucat D., Les sages-femmes parisiennes..., op. cit., p. 27.

92. Ibid., p. I35.

93. «Mme Henry », article paru dans Berthod P. (dir.), La Médecine sociale et professionnelle, Paris, I905, repris dans La Sage-Femme, 5 septembre 1906, n²02, p. I30-I3I.

94. JORF, Lois et décrets, 27 décembre I908, p. 9047. 
médecin et celui du pharmacien ; les conférences des internes sont consacrées à la pathologie élémentaire, la petite chirurgie et aux répétitions d'anatomie tandis que le cours à l'amphithéâtre d'anatomie de Clamart est supprimé tout comme celui du chef de laboratoire qui redistribue ses interventions dans les cours d'anatomie, de pathologie et d'hygiène ${ }^{95}$. Les évolutions respectives des deux phares de l'enseignement obstétrical français (Hospice de la Maternité et Faculté de médecine de Paris) ouvrent la voie au chantier majeur de la décennie I9IO : l'unification de la profession par la suppression de la deuxième classe.

\section{Le bilan d'un siècle de formation obstétricale}

\section{Combien de sages-femmes?}

Compter les sages-femmes formées au cours $d u \mathrm{XIX}^{\mathrm{e}}$ siècle est un exercice périlleux ${ }^{96}$. Les sources statistiques existent mais elles sont très variées et diffèrent entre la première et la seconde moitié du siècle. De plus, l'existence de deux catégories d'accoucheuses brouille un peu plus les calculs du nombre total de sages-femmes instruites au XIX ${ }^{\mathrm{e}}$ siècle. Les années I800-I875 sont marquées par un éparpillement extrême des sources, avant que la série des Annuaires statistiques de la France récapitule pour la période i875-1900 les données annuelles du personnel médical diplômé.

Les sages-femmes de première classe sont les plus aisément comptabilisables, car elles sont reçues dans des établissements dont le fonctionnement est sous la tutelle directe du ministère de l'Intérieur puis de l'Instruction publique. Les bureaux de ce dernier ministère publient en I864, à partir des archives des trois facultés de médecine, l'État numérique des docteurs en médecine, docteurs en chirurgie, officiers de santé, sages-femmes de $1^{r e}$ classe, sages-femmes de $2^{e}$ classe, etc. reçus entre 1794 et 1863 , compilé à partir des archives des facultés ${ }^{97}$. Ce tableau donne annuellement, établissement par établissement (facultés de Paris, Strasbourg, Montpellier et Hospice de la Maternité de Paris), les effectifs des accoucheuses diplômées, à partir de I8OI. Il aboutit à un total de 5555 sagesfemmes de première classe pour la période. Les années I864-1874 sont en revanche mal documentées. Il faut alors se contenter d'une estimation fondée sur le maintien pendant ces onze années d'une moyenne annuelle constante

95. La Sage-Femme, avril ı9ıо, nº 245, p. 54-56.

96. O. Faure évalue leur nombre à 30000 entre 1800 et 1850 , Les Français et leur médecine..., op. cit., p. 25.

97. AD Maine-et-Loire, 392 T 193. 
pour les quatre établissements formateurs : une cinquantaine d'élèves par an pour l'Hospice de la Maternité, une quarantaine pour la faculté de médecine de Paris, entre 25 et 30 pour celle de Montpellier et entre 3 et 5 pour celle de Strasbourg, soit au total I 300 à I 350 sages-femmes de première classe. Le dernier quart du siècle, a priori le mieux renseigné, pose toutefois d'importants problèmes de concordance des données fournies par l'Annuaire statistique de la France ${ }^{98}$. Entre 1875 et I898, on comptabilise donc entre 6063 (chiffre plancher) et 6587 (chiffre plafond) réceptions de ce type.

Entre 13 ooo et 13500 sages-femmes obtiennent donc un diplôme de première classe pendant le siècle. Le chiffre est tout à fait remarquable, surtout si l'on considère qu'il est pendant les trois premiers quarts du siècle essentiellement le produit des formations parisienne et montpelliéraine, Strasbourg ne délivrant qu'un nombre extrêmement réduit de diplômes. Il reste néanmoins que la rareté des établissements qui dispensent cette instruction et le coût de la réception pour la première classe la rendent inaccessible à la majeure partie des élèves sages-femmes ${ }^{99}$. Même parmi les jeunes femmes qui ont la possibilité de se former à Paris, Montpellier ou Strasbourg et donc de passer leurs examens devant les facultés, certaines se contentent, faute de moyens, d'être reçues sages-femmes de deuxième classe.

L'État numérique de I864 recense 4390 d'accoucheuses de deuxième classe diplômées de faculté réparties de manière inégale (Paris, I 854 ; Strasbourg, I 444 ; Montpellier, I 092). Ces chiffres sont très inférieurs à la réalité de la formation des sages-femmes de deuxième classe, puisqu'ils laissent de côté les réceptions devant les jurys médicaux puis celles devant les écoles de médecine à partir de 1855 . Comme pour la première classe, il faut attendre la publication de l'Annuaire statistique de la France pour avoir des données synthétiques nationales. Les manques restent toutefois importants et une estimation globale de l'effectif des sages-femmes de deuxième classe ne peut donc résulter que d'une extrapolation de données particulières.

Les écoles qui forment plus de dix élèves par an sont rares et se situent en général dans de très grandes villes. Le jury médical du Rhône reçoit pendant ses cinq décennies d'existence 915 sages-femmes, soit une moyenne de 17,5 par an $^{100}$. Entre I862 et 1903, 469 élèves achèvent leur scolarité à l'hospice de la Charité,

98. L'écart entre les données détaillées et les données synthétiques est parfois considérable.

99. Les droits de réception d'une sage-femme de première classe (droits d'examen et de visa) s'élèvent à 120 francs avant 1854 et à 130 francs après cette date.

Ioo. Faure O., Les Français et leur médecine..., op. cit., p. 25. 
soit environ II par an ${ }^{101}$. Autre exemple d'école à forte recrutement : Bourg-enBresse. Cette école, fondée en I819, accueille 870 élèves entre I82I et I893, soit une moyenne de I2 par an ${ }^{102}$. Cest cependant une exception parmi les gros bataillons de la formation obstétricale au XIX ${ }^{e}$ siècle et les établissements installés dans les départements ruraux admettent en général un nombre limité d'élèves.

Derrière les quelques établissements forts pourvoyeurs de sages-femmes, un grand nombre d'écoles produit une moyenne de 7 à 9 élèves annuellement (Chaumont, Angers ou Laon). Les effectifs ne sont cependant pas forcément stables sur le siècle et on observe une baisse des réceptions à mettre en relation avec la stabilité des financements départementaux et l'allongement des cursus.

Ces estimations aboutissent au chiffre considérable de près de 45000 accoucheuses de deuxième classe diplômées au cours du XIX ${ }^{e}$ siècle.

Ces résultats cumulés ( 13 ooo sages-femmes de $\mathrm{I}^{\text {re }}$ classe et 45000 de $2^{\mathrm{e}}$ ) viennent confirmer l'intuition d'Olivier Faure d'un " recrutement massif et complexe $^{103} »$. La politique d'instruction des accoucheuses impulsée par le gouvernement et par les départements est objectivement un succès. Elle permet d'accroître au fil du siècle la présence des praticiennes dans les campagnes.

Dans les années I880-I890, le ratio sage-femme/habitants oscille entre I pour 2770 et I pour 2950 . Les sages-femmes égalent quasiment le nombre cumulé des médecins et des officiers de santé (I4 343 sages-femmes en I89I pour I4 919 médecins et officiers de santé). La confirmation du statut de la profession d'accoucheuse qu'entérine la loi du 30 novembre 1892 se fonde sur un personnel omniprésent qui complète voire supplée l'action des médecins sur l'ensemble du territoire français et plus particulièrement dans les zones rurales. L'objectif d'une sage-femme par canton est atteint dès la moitié du siècle dans la plupart des départements, et lorsque ce n'est pas le cas, ces absences constituent un motif d'inquiétude et justifient une modification de la politique locale de formation. En 1858, dans l'Aveyron, le préfet déclare que seize cantons sur quarante-deux sont dépourvus d'accoucheuses ${ }^{104}$. Ce manque est très rapidement corrélé à l'insuffisance des envois d'élèves sages-femmes à Montpellier qui ne comblent pas les besoins départementaux ; il entraîne à court terme la réouverture du cours d'accouchement de Rodez. En Vendée, le recensement de I85I permet d'identifier 130 sages-femmes, réparties dans 99 communes, soit une

\footnotetext{
IOI. AM Lyon, archives de l'hospice de la Charité, I K 2.

I02. AD Ain, liste alphabétique des élèves sages-femmes de l'école d'accouchement de l'Ain, I82II893, par M. Gauge (Recherche et études généalogiques de l'Ain).

103. Faure O., «Les sages-femmes en France... », art. cit., p. 158.

I04. AD Aveyron, Per 545.
} 
sage-femme pour trois communes et une sage-femme pour 2928 habitants ${ }^{105}$. Seules 46 résident dans des chefs-lieux de canton, signe de leur ancrage profond dans le territoire. Dans le Doubs, les listes du personnel médical pour les années I877, I888 et I894 montrent le maillage du département par les sagesfemmes qui sont deux fois plus nombreuses (entre I73 et 23I) que médecins et officiers de santé réunis (entre 9r et I04) ${ }^{106}$.

Toutefois, dans les départements où est privilégiée la formation de sagesfemmes de deuxième classe, c'est souvent dans les villes qu'elles sont proportionnellement les moins nombreuses. La-Roche-sur-Yon n'en compte aucune en I85I. L'installation dans les villes et particulièrement dans les préfectures est davantage le fait des sages-femmes de première classe, beaucoup moins nombreuses que leurs consœurs de deuxième classe, à l'exception des départements qui choisissent de former leurs accoucheuses exclusivement à Paris (Dordogne jusqu'en 1873, Tarn-et-Garonne, Nièvre, Orne, etc.). Mais la différence entre les deux catégories, évidente en termes d'effectifs cumulés, évolue cependant au cours du siècle.

\section{Première et deuxième classes : vers l'unification du corps}

$20 \%$ des accoucheuses formées au cours du XIX ${ }^{\mathrm{e}}$ siècle obtiennent un diplôme de première classe et les $80 \%$ restantes sont limitées dans leur exercice professionnel au cadre départemental. La part respective des deux catégories n'est cependant pas constante au fil du siècle. Entre I875 et I898, il est reçu autant de sages-femmes de première classe que de sages-femmes de deuxième classe. Au-delà, à l'échelle du siècle, ces vingt-cinq dernières années sont celles pendant lesquelles sont formées entre 47 et $49 \%$ des accoucheuses de première classe.

Les sages-femmes autorisées à exercer dans l'ensemble du pays augmentent donc en part absolue et en part relative à partir de 1875 . Cette croissance relève de facteurs institutionnels, scientifiques et sociaux. Elle reflète en premier lieu la multiplication des institutions de délivrance du diplôme de première classe avant 1893 et de formation spécialisée pour ce diplôme après cette date. Les facultés se rapprochent des élèves à une période où les moyens de transport s'améliorent et se diversifient, réduisant le coût et la pénibilité de la distance. En second lieu, la réforme des études médicales fait l'unanimité et accélère la prise de conscience dans tous les établissements de formation obstétricale de la nécessité d'exiger plus des élèves sages-femmes, tant sur le plan de l'instruction

105. AD Vendée, sous-série $6 \mathrm{M}$.

I06. AD Doubs, M I5I4. 
primaire que sur celui de l'instruction scientifique. L'élévation du niveau scientifique de l'enseignement rencontre l'intérêt croissant des élèves qui n'hésitent plus, poussées par leurs professeurs et souvent défrayées de leurs frais de voyage par les assemblées départementales, à briguer, après leur diplôme de deuxième classe, celui de première classe. À partir de la fin des années 1870 et jusqu'aux années I890, les promotions du cours d'accouchement de Laon comptent au moins moitié d'élèves présentant le diplôme de première classe, après avoir obtenu celui de deuxième classe. Il est donc probable que l'augmentation du nombre de réceptions de première classe soit en partie liée à ce phénomène de double diplôme qui peut concerner jusqu'à 30 voire $50 \%$ des effectifs de certaines écoles départementales. La contrepartie de cette tendance est de réduire de quelques centaines le nombre réel de sages-femmes de deuxième classe puisqu'une partie de celles-ci s'échappent presque immédiatement vers l'exercice national, et de réduire d'autant l'estimation du nombre total d'accoucheuses formées au cours de cette période.

Le rapprochement des deux corps est révélateur du rapprochement des formations. Si avant 1893 des élèves issues des cours départementaux, réussissent avec les honneurs les examens de sage-femme de première classe, c'est que leur instruction est au diapason des exigences manifestées par les jurys. Après cette date, l'homogénéisation de la durée des cours et des programmes accentue encore la proximité entre les deux catégories. Au-delà, les scolarités communes, dans leur intégralité avant la réforme de juillet I893, ou pour une année seulement après cette date, jouent un rôle important dans la constitution d'une conscience professionnelle qui transcende en partie les différences entre sages-femmes de deuxième classe et sages-femmes de première classe.

L'essor des premières associations mutuelles d'accoucheuses à partir des années I880 marque l'intégration des deux catégories dans un seul système de solidarité sociale ${ }^{107}$. Tardif mais unitaire, le mouvement mutualiste des sages-femmes se différencie des médecins qui refusent aux officiers de santé l'accès à leur société centrale de secours mutuels, l'Association générale de prévoyance et de secours mutuels des médecins de France (AGMF) ${ }^{108}$. L'associationnisme des sagesfemmes s'inscrit dans une chronologie plus lente et, dans sa dimension syndicale,

I07. Sur l'histoire de la mutualité, voir Gibaud B., Mutualité, assurances, 1850-1914. Les enjeux, Paris, Economica, 1998 ; Dreyfus M., Les Femmes et la mutualité, de la Révolution française à nos jours, Paris, Éditions Pascal, 2006.

I08. Léonard J., Les Médecins de l'Ouest..., op. cit., p. 1004-1007. 
ne devance en aucune façon les prescriptions législatives ${ }^{109}$. Il se construit d'ailleurs probablement en réponse à l'essor du syndicalisme médical dès le début des années $1880^{110}$ pour préserver l'espace professionnel des accoucheuses.

En juin 1896 , l'Association mutuelle des sages-femmes de la Seine donne naissance au premier syndicat de sages-femmes en application de l'article 13 de la loi du 30 novembre I892 : le Syndicat des sages-femmes de la Seine. La transformation, lors d'une réunion générale du 20 mai I897, de ce syndicat en Syndicat général des sages-femmes de France crée la première organisation nationale de défense professionnelle des accoucheuses, indépendamment du type de diplôme dont elles disposent (art. 3$)^{111}$.

La devise du syndicat reproduite dans la manchette du journal La Sage-femme, fondé en décembre I897 pour être l'organe officiel du syndicat, est : « Science, Solidarité, Dévouement ». L'article 2 des statuts souligne d'ailleurs le premier objectif qui est « d'apprendre aux sages-femmes à se connaître, à se protéger et à resserrer entre elles les liens de confraternité et de bonne harmonie ${ }^{112} » . \mathrm{Si}$ les premières revendications (fixation d'honoraires minimaux, droit au forceps, accès des sages-femmes aux postes féminins de l'Assistance publique, caisse de retraite) ne portent pas sur l'unification des diplômes, ce sujet surgit dès novembre 1902 dans une chronique de Marie Bocquillet, directrice du journal La Sage-femme et présidente du syndicat. La demande est entourée de précautions sur la nécessité d'uniformiser complètement les enseignements délivrés aux sages-femmes et de les approfondir plus encore et insiste sur la légitimité d'exiger des futures praticiennes la possession du brevet élémentaire voire d'un diplôme supérieur. Plutôt confiante dans le succès de cette revendication, déposée sous forme de pétition auprès du ministère de l'Instruction publique ${ }^{113}$, Marie Bocquillet demande néanmoins, avant toute réforme, l'extension du droit d'exercice des sages-femmes de deuxième classe à l'ensemble de la France ${ }^{114}$.

I09. Sage Pranchère N., « "Sciences, solidarité, dévouement". Les débuts de la syndicalisation des sages-femmes en France (1896-I9I4) », à paraître dans Bugnon F., Carribon C., Dussert-Galinat D., Lachaise B., Picco D. (dir.), Femmes et réseaux dans les sociétés modernes et contemporaines, Bordeaux, Presses Universitaires de Bordeaux, 2017.

Iı. Léonard J., Les Médecins de l'Ouest..., op. cit., p. 1055-1060 ; Vergez-Chaignon B., « Le syndicalisme médical français de sa naissance à sa refondation : intérêts et morale au pays de l'individualisme (1892-1945) », RHMC, 1996, 43-3, p. 709-710.

III. "Statuts du Syndicat général des sages-femmes de France », La Sage-femme, 20 décembre I $897, \mathrm{n}^{\circ} \mathrm{I}, \mathrm{p} .6$.

II2. Ibid.

II3. «Bulletin officiel du syndicat général des sages-femmes de France. Procès-verbal de la réunion du 7 novembre $1902 »$, La Sage-femme, 5 décembre 1902, p. 353.

II4. "Sages-femmes de première et de deuxième classe », La Sage-femme, 20 novembre I902, $\mathrm{n}^{\mathrm{o}} \mathrm{II7}, \mathrm{p} \cdot 306$. 
La revendication de l'unification n'est pas propre aux accoucheuses, et sa légitimité est reconnue par le corps médical et les parlementaires. Au cours de l'année I9IO, Marie Bocquillet est conviée, avec d'autres sages-femmes, à participer aux travaux de la commission de réforme des études médicales. Cette commission émet le vœu unanime de supprimer la deuxième classe, Paul Strauss relaie ce souhait lors d'un débat au Sénat en février I9I3 pour une loi visant à lutter contre la dépopulation ${ }^{115}$. Le 3 février 1914, le député Louis Marin dépose devant la chambre une proposition de loi en ce sens ${ }^{116}$. Le rapporteur, Gilbert Laurent, conclut à son adoption en soulignant qu'il faut « uniformiser le titre, le niveler, non en l'abaissant, mais en le relevant ${ }^{117}{ }$, alors que les pétitions syndicales affluent à la Chambre pour soutenir la proposition ${ }^{118}$. Celle-ci est votée le 2 avril suivant par les députés, puis au Sénat le 29 juillet sur le rapport de Paul Strauss ${ }^{119}$. La déclaration de guerre interrompt le processus législatif et ce n'est qu'en juin 1916 qu'un nouveau rapport est présenté devant le Sénat par le même Paul Strauss en vue d'un nouveau vote qui a lieu en urgence le 28 juillet ${ }^{120}$. Le 5 août, la publication de la loi consacre enfin l'unification des deux classes :

Article unique. Désormais, il ne sera plus délivré qu'un seul diplôme de sagefemme et qu'un seul diplôme d'herboriste, correspondant l'un et l'autre pour chacune de ces deux professions au diplôme de première classe existant lors de la promulgation de la présente loi. La présente loi, délibérée et adoptée par le sénat et la chambre des députés, sera exécutée comme loi de l'État. ${ }^{121}$

L'avènement d'une seule catégorie de sages-femmes débouche immédiatement sur une réforme complémentaire des études (décret présidentiel du 9 janvier 1917) destinée à aligner l'enseignement sur les exigences de l'ancienne première classe. L'arrêté du II janvier I9I7 vient préciser le programme des examens : notions élémentaires d'anatomie, de physiologie et de pathologie pour la première année ; examens théorique (anatomie spécialisée, obstétrique, puériculture avant et après la naissance, prophylaxie, obligations légales) et clinique (examen d'une femme enceinte) pour la deuxième année. L'évolution législative double ses conséquences scientifiques de conséquences institutionnelles :

\footnotetext{
II5. JORF, débats parlementaires, sénat, 6 février 1913, p. 4I.

II6. JORF, débats parlementaires, chambre des députés, 3 février I9I4, p. 446.

II7. La Presse médicale, 4 juin I917, E. Bonnaire, «La suppression des sages-femmes de deuxième classe », p. 324.

II8. La Sage-femme, mai 1914, p. 52.

II9. La Presse médicale, 4 juin I917, art. cit.

I20. JORF, débats parlementaires, sénat, 28 juillet I916, p. 764.

I2I. "Unification des diplômes », dans La Sage-femme, octobre I916, n 300, p. I.
} 
preuve de leur résistance et de leur qualité, les maternités retrouvent leur pleine légitimité dans le dispositif pédagogique. Mises à l'écart avant 1917 du cursus de première classe à quelques exceptions près, elles obtiennent à l'issue d'une inspection ministérielle l'autorisation d'accueillir la deuxième année (art. 2 et 3). Le 24 juillet 1917, un arrêté fixe la liste des 29 établissements autorisés dont 27 fonctionnaient déjà en 1900 (carte 8), montrant la grande stabilité du réseau des maternités-écoles (carte 9) ${ }^{122}$. Dans l'intervalle, neuf établissements ont disparu (Laon, Pamiers, Grenoble, Angers, Reims, Pau, Perpignan, Albi, Draguignan), dont trois dans des villes sièges d'écoles préparatoires de médecine (Grenoble, Angers, Reims), tandis que Rodez regagne son droit d'enseignement. Le bilan est sans appel : c'est bien l'école-maternité départementale qui reste l'institution prédominante d'instruction des accoucheuses en France, plus d'un siècle après que la loi de 1803 l'a définie comme brique essentielle de la politique de formation obstétricale française.

Le régime médical instauré par la loi de 1803 s'achève donc en deux temps : par la loi du 30 novembre I892 qui permet la réforme des études organisée par le décret du 25 juillet 1893, puis, beaucoup plus tardivement, par la loi du 5 août I9I6 et les règlements de I9I7 qui effacent les dernières traces de la dichotomie sur laquelle a reposé pendant un siècle l'exercice de la médecine. Le véritable tournant se prend néanmoins dans les années 1890 à une période où se conjoignent trois dynamiques. La première dynamique est législative et s'inscrit dans l'histoire longue de la réforme des études médicales en France. Elle s'appuie intelligemment sur les acquis d'un siècle d'inventivité pédagogique pour poser les bases d'une formation nationale homogène, adaptant sans les supprimer les institutions qui ont porté jusqu'à cette date l'instruction des sages-femmes françaises. La seconde dynamique est démographique. Les sages-femmes ne sont jamais aussi nombreuses au cours du siècle que pendant sa dernière décennie. Au moment où disparaît le corps intermédiaire des officiers de santé, elles sont alors la seule profession médicale à pouvoir rivaliser en termes numériques avec les médecins. De ce nombre et de la reconnaissance officielle que renouvelle la loi de 1892 à ce corps de métier, naît une troisième et dernière dynamique : celle des intérêts communs de la profession et de ses praticiennes. L'unification de 1916, aboutissement nécessaire du texte précédent,

122. Il s'agit des maternités de Bourg-en-Bresse, Rodez, Marseille, Caen, Dijon, Besançon, Chartres, Brest, Nîmes, Bordeaux (école départementale et maternité annexée aux hospices civils), Montpellier, Rennes, Tours, Blois, Nantes, Orléans, Chaumont, Nancy, Lorient, ClermontFerrand, Lyon, Mâcon, Chambéry, Rouen, Toulon, Avignon, Poitiers, Limoges. 
couronne aussi une évolution interne à la profession qui a su se saisir des outils politiques (pétitions, journaux, syndicats) pour obtenir sa réunion dans un même corps. À la différence du couple clairement dissymétrique docteurs en médecine/officiers de santé, les sages-femmes de première et deuxième classes manifestent dans le dernier quart du XIx ${ }^{e}$ siècle leur conscience d'appartenir à un seul et même corps professionnel. Première ou deuxième classe, c'est parce qu'elles sont formées sur les mêmes bases et souvent aux mêmes écoles, tout comme critiquées à même enseigne, que les sages-femmes réclament leur unification, non pour amputer un membre malade de la profession mais pour faire reconnaître l'équivalence de leur savoir et de leurs compétences. 


\section{Conclusion}

\section{Une conscience professionnelle}

Je m'interrogeais au début de ce travail sur le rôle que la sage-femme avait été capable de jouer dans la définition et la promotion de sa profession. La question se pose encore aujourd'hui et la tenue en $2013 \mathrm{du}$ premier colloque de l'association «Je suis la sage-femme », intitulé « Qui est la sage-femme? » souligne, parmi d'autres initiatives, l'intensité de la réflexion à l'œuvre au sein de la profession. Les sages-femmes s'interrogent, et pionnières d'une fertile pluridisciplinarité, elles vont sans hésitation à la rencontre des sciences humaines et sociales pour penser leur fonction auprès des femmes, des nouveau-nés et de la société en préservant l'originalité de leur identité médicale.

Pour le $\mathrm{XIX}^{\mathrm{e}}$ siècle, la réponse à cette question de l'auto-définition des sagesfemmes pourrait tenir dans les quelques mots de Marie Roger-Bocquillet, secrétaire du Syndicat général des sages-femmes de France, en ouverture du journal La Sage-femme du 20 mai I9or :

Le titre de Sage-Femme est notre titre LÉGAL ; en outre, il nous a été donné depuis que l'Art des Accouchements existe, et bien avant que cet art fût classé parmi les professions libérales. Quoi que l'on dise ou que l'on écrive, c'est enlever une partie de sa dignité à notre corporation que de vouloir lui substituer celui d'Accoucheuse qui, pour certaines personnes, serait plus MODERNSTYLE. [...] Le titre Sage-Femme doit nous être conservé tant qu'il n'aura pas été changé par une loi ou un décret quelconque. Ce titre est inscrit sur nos diplômes ; et c'est par lui que nous entrons dans la profession. ${ }^{1}$

I. «Sages-Femmes ou Accoucheuses », dans La Sage-Femme, 20 mai I90I, p. I45-I46. 
La décision politique prise à la fin du XVIII ${ }^{\mathrm{e}}$ siècle de faire de la sage-femme l'instrument d'encadrement de la naissance n'a pas été le deus ex machina qui aurait arbitrairement fait dévier la voie d'une société prête à se remettre toute entière entre les mains des accoucheurs. Elle a rencontré l'attachement de la population à ses sages-femmes et la volonté bien ancrée d'une partie d'entre elles de ne pas abandonner la place et de sauver leur titre de la réprobation médicoadministrative qui s'attache à la même époque aux auxiliaires féminines de la naissance. Lorsqu'Angélique du Coudray reçoit un brevet royal pour enseigner l'art des accouchements à ses consœurs, lorsqu'elle-même distribue certificats et brevets à la fin de ses cours, elle pose les bases d'un corps professionnel qui se distingue par son savoir de la pratique traditionnelle d'assistance interféminine. Lorsque Marie Roger-Bocquillet refuse la dénomination d'accoucheuse, elle affirme à son tour la spécificité de son métier et des femmes qui le pratiquent. La science remplit l'espace qui sépare l'accoucheuse de la sage-femme.

Dès lors que l'État reconnaît les sages-femmes en les investissant d'une mission sociale et en garantissant (tant bien que mal) leur monopole, cellesci travaillent en retour à conférer une valeur morale et matérielle au diplôme qui les distingue. Elles sont de ce point de vue le fer de lance de la répression contre l'exercice illégal de l'obstétrique, ne tolérant aucun empiètement sur leur champ d'activité. Trahison de genre ? Substitution d'une mentalité commerciale à l'antique solidarité des femmes en travail d'enfant? L'affirmer serait leur dénier le droit légitime à une juste rémunération et, au-delà, méconnaître la haute opinion que les sages-femmes se font de leur profession et de leur devoir vis-à-vis des femmes et des femmes en couches. La clé de cette attitude réside dans l'identification profonde et irrévocable de la sage-femme à sa formation. Sa légitimité au lit des femmes en couches ne lui vient d'ailleurs pas tant dans un premier temps de ce qu'elle a appris que du fait de l'avoir appris et d'avoir pour cela été admise à exercer. En découlent la certitude du bien-faire dans les accouchements et celle d'agir pour le salut des futures mères en dénonçant sans relâche les matrones. La profession se construit et se perpétue sur ce parcours commun de la scolarité obstétricale ainsi que sur l'interreconnaissance immédiate que créent le diplôme et l'inscription sur les listes du personnel médical.

L'enracinement de cette conscience professionnelle, que ne semble pas entamer la division en deux catégories du corps des sages-femmes, est indissolublement lié au statut désormais officiel et national du métier. Dans la mesure où elles forment une profession libérale mais placée par la loi sous le strict contrôle des autorités, les sages-femmes retirent de cette mise sous tutelle partielle l'avantage de la protection que l'État s'engage à leur accorder. Cette interdépendance entre le personnel médical et le pouvoir politique, matérialisée par la loi, 
est sans doute une des raisons de la survie des sages-femmes françaises comme profession médicale. Les États-Unis offrent le parfait contre-exemple. Là-bas, la reproduction de structures d'enseignement obstétrical à l'européenne se révèle insuffisante pour justifier le maintien de l'activité des sages-femmes puisque ces dernières n'obtiennent des autorités à l'issue de leur formation aucune reconnaissance officielle susceptible de les différencier d'accoucheuses improvisées ${ }^{2}$.

\section{Une action médicale}

La sage-femme française traverse le $\mathrm{XIX}^{\mathrm{e}}$ siècle sans encombre car sa formation lui permet de ne plus être réduite à la seule fonction d'accompagnatrice de la parturition. Le processus de professionnalisation des sages-femmes poursuit donc le processus de scientifisation et de médicalisation de la naissance amorcé lors de l'entrée (en scène) du chirurgien accoucheur. Représentante incontournable et souvent unique du personnel médical dans la quasi-totalité des cantons français, la sage-femme diplômée parachève, par sa simple présence, cette évolution médicale de la naissance. Elle permet en outre la diffusion progressive des protocoles prophylactiques qui se définissent au fil du siècle : vaccination des enfants en bas âge, prévention des hémorragies du post-partum par l'administration d'ergot de seigle, techniques d'antisepsie et d'asepsie tout au long de l'accouchement.

L'action sanitaire de la sage-femme s'intègre donc, à part entière, au faisceau de facteurs qui déterminent l'importante baisse des mortalités maternelle et infantile tout au long du $\mathrm{XIX}^{\mathrm{e}}$ siècle ${ }^{3}$. Avant même la révolution pastorienne, l'intervention de la sage-femme réduit la mortalité maternelle pendant et immédiatement après l'accouchement. Le perfectionnement continu de la réanimation néonatale augmente les chances de survie des enfants nés en état de détresse respiratoire. Après I880, le recul de la fièvre puerpérale grâce à l'application minutieuse des principes de lutte contre les germes infectieux est aussi,

2. Voir Charlotte G. Borst, Catching babies..., op. cit. ; cette interprétation est confirmée par les recherches d'Irvine Loudon dans son article « Midwives and the Quality of Maternal Care » dans Hilary Marland, Anne Marie Rafferty (dir.), Midwives, Society and Childbirth..., op. cit., p. 189.

3. Un calcul réalisé à partir de la base Vendée qui recense à partir de l'état civil et des listes nominatives de recensement de population l'ensemble des habitants du département dont le nom commence par « V » aboutit ainsi à une division par plus de deux du taux de mortalité maternelle, qui passe de 5,86\%o entre I 800 et I 849 à 2,I8 \%o entre 1850 et 1905. Je remercie Jean-Pierre Bardet de m'avoir donné accès à ces données et d'avoir mis ces résultats à ma disposition. Pour mesurer parfaitement la baisse de la mortalité maternelle, il faudrait pouvoir calculer le risque de mortalité par femme et par accouchement. Sur ce point, voir Jean-Pierre Bardet et alii, « La mortalité maternelle autrefois : une étude comparée de la France de l'Ouest à l'Utah », dans $A D H$, 198I, p. 3I-48. 
en milieu hospitalier ou à domicile, à mettre en grande partie au compte des sages-femmes. En France, comme dans le reste des pays occidentaux ${ }^{4}$, l'évolution positive des taux de mortalité maternelle au cours des années I800-I950 est corrélée à la formation des sages-femmes ${ }^{5}$, et au-delà de cette formation, à l'association du savoir et de la reconnaissance politique de leur corps professionnel qui soutient l'efficacité mesurable de leur intervention ${ }^{6}$.

Les modalités de la formation des sages-femmes françaises au XIx ${ }^{e}$ siècle répondent en tous points à ces critères. La protection des autorités est d'emblée acquise puisque l'État est à l'origine de l'institutionnalisation de la formation. Le rôle social et sanitaire des sages-femmes est donc reconnu et même élargi d'un commun accord entre l'administration et les médecins. Toutes les mesures sanitaires prises avant la révolution pastorienne pour réduire la mortalité maternelle reposent sur le constat de l'hécatombe puerpérale en milieu hospitalier et sur l'éloge consécutif de l'accouchement pratiqué à domicile par les sages-femmes ${ }^{7}$. Encouragé en ville pour pallier les lacunes des institutions hospitalières, l'exercice libéral de la profession est organisé en milieu rural par le processus départemental de recrutement des élèves et la formation de sages-femmes de deuxième classe. À la différence de ce qui se produit pour les médecins, la rhétorique d'un encombrement du métier par l'excès numérique des praticiennes ne réussit jamais au XIX $X^{e}$ siècle à s'imposer face au discours sur la nécessité continue et irréfutable de la présence des sages-femmes auprès des femmes en couches.

\section{Un cadre d'activité : entre exercice libéral et cadre hospitalier}

Faire en sorte que chaque canton, voire chaque commune aient une sagefemme est le but inlassablement répété des administrations centrales et

4. Loudon I., Death in Childbirth: an International Study of Maternal Care and Maternal Mortality, 1800-1950, Oxford, Clarendon Press, 1992.

5. Après avoir consacré les deux premières parties de son ouvrage à la mesure et à l'étiologie de la mortalité maternelle, l'auteur examine les effets de l'encadrement obstétrical sur son évolution. Pour une présentation particulière de ces résultats, voir Loudon I., « Midwives and the Quality of Maternal Care », art. cit., p. I80-200.

6. Ibid., p. 196-197 : «Between I850 and World War II, the lowest rates of maternal mortality were found in those countries, regions or areas in which maternity services were based largely or wholly on trained midwives. I found no exceptions, but it was also clear that the success of midwives was dependent not only on effective training, but also on being accepted and respected as professional by the communities they served, and preferably by the medical profession as well $»$.

7. Beauvalet-Boutouyrie S., Naître à l'hôpital..., op. cit., p. 313 sq. 
départementales. C'est là, dans les campagnes toujours très peuplées et aux abords des villes en pleine expansion, que se concentrent les accouchements avant le grand déménagement vers les hôpitaux de la seconde moitié du $\mathrm{xx}^{\mathrm{e}}$ siècle ${ }^{8}$. Pour des raisons sociales et morales, le cadre familier de l'accouchement reste encore très majoritairement le domicile de la parturiente, les hôpitaux accueillant quasi exclusivement les mères illégitimes et indigentes? Les dernières décennies du $\mathrm{XIX}^{\mathrm{e}}$ siècle correspondent toutefois à l'amorce d'un changement. Accoucher à l'hôpital est toujours socialement signifiant, mais deux tendances ouvrent progressivement les portes des établissements hospitaliers à un autre public. Les écoles d'accouchement ont, pour des raisons pédagogiques, provoqué la multiplication des possibilités d'accueil des futures mères. Ầ cette première évolution structurelle, il faut ajouter à partir de I880 l'évolution des techniques médicales qui encouragent des patientes mariées à franchir les portes de l'hôpital à la recherche d'un accouchement plus sûr. L'augmentation des accouchements hospitaliers a pour les sages-femmes deux conséquences professionnelles majeures et contradictoires : l'amenuisement (relatif) des clientèles urbaines et l'ouverture d'un nouvel horizon professionnel, celui de l'exercice en milieu hospitalier.

La question se pose alors du rapport des sages-femmes à cet espace, qui ne peut se réduire à une mise sous tutelle des praticiennes par le corps médical ${ }^{10}$. La formation obstétricale fait du service d'accouchement à l'hôpital ou de la maternité départementale (son équivalent autonome et spécialisé) le lieu impératif de formation et le premier milieu de pratique des élèves sages-femmes. Destinées aux campagnes ou à l'exercice privé en ville, celles-ci n'en sont pas moins professionnalisées dans ce contexte atypique et minoritaire de l'accouchement institutionnel. Les formes et les impératifs de l'espace hospitalier leur sont familiers et la population particulière qui le fréquente (filles-mères, mères indigentes) est aussi celle que l'assistance médicale gratuite leur confie dans les campagnes. En termes de modèle, la référence scientifique, pédagogique, morale et humaine qui leur est présentée à l'hôpital est féminine : c'est celle de la sage-femme en chef qui les forme et les encadre. Après I 880 et la mise en place des protocoles anti-infectieux, les services d'accouchements fournissent

8. En 1952, le nombre d'accouchements dans les maternités publiques et les cliniques dépasse (de peu) celui des accouchements à domicile : $532 \%$. Dix ans plus tard, ce sont $855 \%$ parturientes qui accouchent à l'hôpital.

9. Beauvalet-Boutouyrie S., Naître à l'hôpital..., op. cit., p. I42-156 ; Thébaud F., Quand nos grands-mères donnaient la vie..., op. cit., p. 62-65.

Io. Ibid., p. I63. 
un second modèle, tant symbolique que pratique : l'innocuité aseptique de la salle de travail. Les techniques d'antisepsie et d'asepsie constituent alors pour les sages-femmes une contrainte professionnelle concrète (désinfecter demande du temps et de la rigueur), mais une contrainte acceptée qu'elles transposent dans leur exercice quotidien au domicile des patientes. Plus proches des populations que les médecins, les sages-femmes transmettent au tournant des XIX ${ }^{e}$ et $\mathrm{xx}^{\mathrm{e}}$ siècles l'hygiène pastorienne et les pratiques nouvelles de puériculture élaborées dans les services des accoucheurs parisiens, comme elles ont transmis la vaccination antivariolique à des générations d'enfants, dans la continuité de leur rôle d'« institutrices du système de santé ${ }^{11} »$.

Pour toutes ces raisons, l'espace hospitalier n'est pas perçu à la fin du $\mathrm{XIX}^{\mathrm{e}}$ siècle par les sages-femmes comme le champ d'une aliénation professionnelle. Le statut quasi fonctionnarial des sages-femmes en chef des cours d'accouchement leur apporte prestige social et sécurité matérielle, second aspect que l'exercice libéral peine à garantir aux praticiennes de bien des départements. L'essor d'autres professions féminines (surveillantes des dispensaires, dames visiteuses, dames déléguées pour l'Assistance publique) dans le sillage $\mathrm{du}$ système hospitalier offre par ailleurs aux sages-femmes, dans les grandes villes du moins, un nouveau champ d'application de leur savoir et de leurs compétences ${ }^{12}$. L'ouverture aux femmes des fonctions ressortissant à l'Assistance publique à Paris est réclamée en 1898 par le Syndicat général des sages-femmes de France comme une avancée pour les femmes, les nouveau-nés et pour la profession ${ }^{13}$. Il faut toutefois attendre 1975 pour que soient créés des postes de sages-femmes dans les services de Protection maternelle et infantile.

Savoir et appartenance au corps médical, telles sont les raisons quavancent les sages-femmes pour justifier de se placer à la jonction de l'institution et de la société. Elles se proposent d'être l'avant-garde de l'hôpital dans la ville, c'està-dire l'avant-garde de la médecine et de l'assistance mais au sein des foyers, manière de concilier les politiques sanitaires avec le lien humain tissé dans le canevas de leur pratique professionnelle. Cette proposition est sans doute une première défense. Les sages-femmes réagissent au développement de l'accouchement hospitalier des femmes aisées qu'elles ne cessent de dénoncer en ce début de $\mathrm{xx}^{\mathrm{e}}$ siècle. Elles prennent acte aussi de la reconfiguration des

II. Faure O., «Les sages-femmes en France au XIX ${ }^{e}$ siècle... », art. cit, p. 157.

I2. Dans le cadre de l'Assistance Publique parisienne, il s'agit des surveillantes des dispensaires, des dames visiteuses, des dames déléguées et des employées.

13. "Assistance Publique, Féminisme et Sages-Femmes », dans La Sage-Femme, 5 avril I898, p. IO9-III. 
hiérarchies dans les salles d'accouchements. La mise en place en 1882 d'un corps de cadres médecins spécialistes, les accoucheurs de l'Assistance Publique, contemporaine de la révolution pastorienne et de la maîtrise technique de l'opération césarienne, creuse l'écart entre l'accouchement physiologique et les techniques de l'obstétrique opératoire et, par conséquent, entre les sagesfemmes et les médecins.

La ligne assumée dès cette période par les associations puis les syndicats de sages-femmes est donc celle d'une appropriation complète de l'accouchement eutocique, tout en attirant l'attention des autorités sur la nécessité de leur conserver une marge de manœuvre dans les cas d'urgence (pour le recours aux instruments). Les attentes de la profession ne sont pas cependant comblées, et l'augmentation continue de la part des accouchements hospitaliers impose un bouleversement profond du métier ${ }^{14}$. L'évolution du métier au cours du $\mathrm{xx}^{\mathrm{e}}$ siècle accentue la tension entre la vocation physiologique des sages-femmes et leur rôle toujours accru d'accompagnement de la pathologie. S'y ajoutent un manque de reconnaissance sociale à la hauteur de leur responsabilité médicale et une inquiétude de plus en plus marquée pour les conditions d'exercice : «Métier formidable, conditions fort minables » lisait-on dans les manifestations de l'automne 2013.

Tout au long des crises auxquelles sont confrontées les sages-femmes au cours de ce siècle, une constante s'affirme toutefois : le discours sur l'accompagnement des mères et des enfants dans la naissance. À travers le XIX ${ }^{\mathrm{e}}$ siècle de la formation obstétricale et grâce à lui, la solidarité de celle qui accouche et de celle qui aide à accoucher ne s'est donc pas rompue ; elle s'est même renforcée. La fonction, ou plutôt le service rendu entre femmes, n'a jamais cessé d'irriguer la profession.

14. Thébaud F., Quand nos grands-mères donnaient la vie..., op. cit., p. 163-178 ; Knibiehler Y., Accoucher. Femmes, sages-femmes et médecins..., op. cit., p. 31-50 et 133-150. 



\section{Sources}

Présenter les sources de cette étude dans le cadre d'une publication impose d'opter pour un choix distinct de celui qui avait été opéré dans la version originale de cette recherche. Les sources manuscrites ne seront donc point ici développées sous forme d'un état reprenant cote par cote l'ensemble des dossiers dépouillés au cours des années de doctorat, mais je m'attacherai à éclairer dans le cadre d'une présentation synthétique les modalités de collecte de ces sources, les caractéristiques de cette masse documentaire et leurs conséquences sur l'orientation de cette recherche.

\section{L'odyssée des archives}

À l'origine de l'étude nationale sur la formation des sages-femmes se trouvait l'étude départementale d'une école spécifique, celle de Tulle en Corrèze. Cette première recherche avait posé une méthode, celle du recours premier aux sources locales et plus précisément départementales pour l'élucidation du processus d'établissement de la formation obstétricale ainsi que pour la pesée des choix politiques en la matière. La monographie locale avait mis en lumière les lacunes et la modestie des sources nationales, conservées aux Archives du même nom, faiblesses qui se confirmèrent lors des dépouillements ultérieurs. Le passage de l'échelon local à l'échelle nationale ne pouvait donc s'appuyer sur les seules ressources centrales et impliqua de retrouver le chemin des archives départementales à travers leurs multiples incarnations. 
65 dépôts (les Archives nationales, 63 archives départementales et deux archives municipales ${ }^{1}$ ) ont ouvert leurs portes à cette étude, quelques-uns indirectement grâce à la bienveillance de proches que ne rebutaient pas les heures passées entre mauvais papier $\mathrm{XIX}^{\mathrm{e}}$ siècle et cartons Cauchard, pour l'essentiel arpentés à la faveur des vacances universitaires. Cette thèse est en ce sens le fruit de la qualité des réseaux routier et ferré français, de la générosité des quotas de consultation des archives départementales et de la révolution technologique que constitue pour l'historien du $\mathrm{XXI}^{\mathrm{e}}$ siècle l'appareil photo numérique. Elle est née aussi de la bienveillance des conservateurs et des équipes de ces dépôts d'archives qui ont su accompagner de leur connaissance fine des fonds et de leur compréhension face aux impératifs matériels et calendaires tous ces séjours de recherche.

L'exploration en profondeur du territoire archivistique national est sans doute le meilleur observatoire qui soit pour apprécier la richesse et la précision des inventaires produits par les générations successives d'archivistes, culminant dans l'édition parfois in extenso des délibérations d'assemblées révolutionnaires au sein des inventaires de série L (Administration et tribunaux de l'époque révolutionnaire). Au-delà, on ne dira jamais assez les bienfaits des cadres de classement nationaux (archives départementales, communales et hospitalières) qui sont au chercheur autant de bornes familières et immanquablement retrouvées dans la progression de ses dépouillements, même si certaines séries ne comblent que progressivement leur retard de classement (série X, Assistance et prévoyance sociale en particulier), tandis que d'autres sont parfois sujettes à des reclassements (série $M$, Administration générale et économie du département). Le choix de la période, I786-1917, est cependant favorable à la recherche car il s'inscrit dans le cadre des séries anciennes (avant 1790) et modernes (de I790 à 1940) en général parfaitement circonscrites et inventoriées.

Le chemin a toutefois ses difficultés, le temps a pu manquer et des aléas matériels ont pu faire obstacle : fermeture annuelle des dépôts mal anticipée (Ariège, Vosges), mauvaise conservation des archives du XIX ${ }^{\mathrm{e}}$ siècle. Les destructions des deux guerres mondiales ont ainsi justifié de renoncer à certaines visites faute de matière à collecter (Ardennes, Manche). L'objectif premier de mon étude était d'obtenir un panorama complet des politiques de formation des sages-femmes département par département, indépendamment du type de sources mobilisées dès lors qu'elles permettaient de restituer une évolution séculaire. L'exemple corrézien avait permis d'identifier très précocement les trois politiques possibles :

I. Les archives municipales de Bourg-en-Bresse étaient temporairement déposées aux archives départementales de l'Ain à l'époque de mes recherches. 
la formation sur place, l'envoi à l'extérieur, et l'alternance ou la coexistence de ces deux pratiques. La formation sur place étant susceptible de produire beaucoup plus d'archives locales que l'envoi à l'extérieur, jai donc privilégié pour mes visites les départements où une école avait fonctionné au cours du XIX ${ }^{\mathrm{e}}$ siècle. Les départements de la couronne parisienne (Seine-et-Oise et Seine-et-Marne) n'ont par exemple pas fait l'objet d'un séjour en raison de leur proximité à la capitale et de la dépendance de ces départements à l'Hospice de la Maternité pour la formation de leurs accoucheuses. Des sources complémentaires ont été mobilisées pour pallier ces manques (annuaires départementaux, publications locales, revues d'histoire régionale, etc.), et parmi elles, la collection des rapports de préfet et procès-verbaux des délibérations de conseils généraux de la Bibliothèque nationale de France a tenu une place essentielle. La numérisation de cette collection et sa mise en ligne progressive sur Gallica ont coïncidé avec le temps de mes dépouillements et ont parfois permis de limiter les consultations en archives aux seuls registres manuscrits de la série $\mathrm{N}$ (Conseil général) pour le premier tiers du XIX ${ }^{e}$ siècle, les procès-verbaux imprimés et numérisés prenant la suite à partir des années 1835-1840.

\section{Les sources manuscrites}

\section{Traits principaux (producteurs, répartition, variété)}

Les sources nationales sont pauvres, en comparaison des sources locales d'une part, et intrinsèquement d'autre part. Elles offrent un tour d'horizon complet de la situation de l'enseignement obstétrical à destination des sages-femmes à travers des dossiers départementaux mais les documents qui composent ces liasses ne dépassent pas le milieu du XIX ${ }^{\mathrm{e}}$ siècle. Au-delà, aucun carton ne fournit de récapitulatif des textes législatifs, règlementaires qui encadrent la formation et l'exercice professionnel des sages-femmes ou n'aborde les débats qui se sont élevés au cours du siècle. Il a fallu les chercher dans d'autres sources : recueils législatifs, périodiques médicaux, etc. L'information des liasses de la sous-série $\mathrm{F}_{7} 7$ des Archives nationales est répétitive et dispersée au sein de chaque sous-dossier départemental. Cette dispersion est néanmoins significative de l'échelle à laquelle tout se joue : le niveau déconcentré du département qui a formé la cellule de base de cette étude, dans la mesure où il forme la cellule de base de la formation des sages-femmes pendant cette période.

À l'échelle départementale, les sources varient peu et il s'agit pour leur immense majorité d'archives d'origine publique. Les fonds d'Ancien Régime, la série C (Administrations provinciales) en particulier, ont été sollicités pour 
établir le lien entre cette période et la Révolution et saisir les continuités de ces décennies dans les formes et le personnel de l'enseignement obstétrical. La série $\mathrm{L}$ (Administration et tribunaux de l'époque révolutionnaire) s'est révélée typologiquement riche et a permis de saisir les passages entre les décisions (procès-verbaux des assemblées départementales) et leur mise en application (dossiers d'administration départementale) à tous les niveaux des nouvelles circonscriptions (districts, cantons).

Pour le $\mathrm{XIX}^{\mathrm{e}}$ siècle, les séries $\mathrm{M}$ (Administration générale et économique du département) et $\mathrm{X}$ (Assistance et prévoyance sociale) ont quasi systématiquement été complétées par les informations des séries $\mathrm{N}$ (Conseil général), éclairant là aussi les contrastes entre fonctionnement permanent et rythme politique des assemblées départementales. Les dynamiques d'émulation et de complémentarité entre les conseils généraux et les administrations préfectorales ont ainsi été au cour de cette étude dans un permanent effet de miroir entre les sources. S'y ajoutent aussi, bien que moins fréquemment, les fonds des séries $T$ (Enseignement, Culture) et $Z$ (Sous-préfectures) qui apportent un éclairage administratif partiellement différent des sources précédentes : académie ou administration des établissements d'enseignement médical dans un cas, circonscription plus réduite dans l'autre.

Viennent enfin les sources communales (EDEP) ou hospitalières (H-Dép) qu'elles soient déposées dans les institutions départementales (AM de Bourgen-Bresse) ou qu'elles aient conservé une indépendance de gestion (AM de Lyon). Ces dernières n'apportent cependant que des compléments mineurs au tableau que dessine l'administration préfectorale de l'action en faveur de la formation des accoucheuses. La seule exception véritable réside dans l'exemple lyonnais où les hospices civils de la ville ont la haute main sur l'instruction médicale, prédominance qu'ils conservent pour l'instruction des sages-femmes au détriment de la faculté de médecine au-delà même des réformes nationales de la fin du XIX ${ }^{e}$ siècle.

\section{Les limites de la documentation}

L'abondance de la documentation ne met évidemment pas à l'abri des pièges de l'effet de source. Les sources qui m'ont renseignée sur les modalités et l'évolution de la formation des sages-femmes sont des sources publiques, administratives et départementales. Elles portent un discours et une politique : celle de la déconcentration plutôt réussie d'une des branches de l'enseignement médical au XIX ${ }^{e}$ siècle, contre le modèle centripète de l'école ou de la faculté de médecine. Leur omniprésence présente un risque : celui de réduire sans nuance la 
transmission du savoir obstétrical à la voie scolaire, la pauvreté et la rareté de fonds d'origine privée ne pouvant que renforcer cette interprétation (à quelques exceptions comme des manuscrits de Joseph-Alexis Stoltz dans le fonds I50 J aux $\mathrm{AD}$ du Bas-Rhin). La consultation des sources judiciaires apporte à cette tendance un contrepoint précieux en offrant de nombreux exemples de femmes accusées d'exercice illégal de l'art des accouchements. Le fossé qui se creuse à la lecture de ces dossiers d'instruction ou de procédure entre la figure de la matrone, émanation d'une certaine forme de solidarité populaire, et la sage-femme formée et diplômée souligne par contraste la domination en voie de devenir exclusive dès la seconde moitié du siècle d'un modèle institutionnel d'acquisition du savoir sur la naissance. Les archives de la formation des sages-femmes au $\mathrm{XIX}^{\mathrm{e}}$ siècle sont publiques car telle est la dimension donnée par la loi à cette profession et à sa formation. Elles sont administratives par voie de conséquence et départementales par choix réfléchi d'un cadre géo-administratif (le département) adapté à une conception nouvelle de l'encadrement de la naissance.

\section{Dépôts d'archives visités}

Archives nationales.

Archives départementales: Aisne, Alpes-de-Haute-Provence, Hautes-Alpes, Alpes-Maritimes, Ardèche, Aube, Aude, Aveyron, Bouches-du-Rhône, Calvados, Cantal, Charente, Charente-Maritime, Cher, Corrèze, Corse du Sud, Côte-d'Or, Côtes-d'Armor, Creuse, Dordogne, Doubs, Drôme, Eure-etLoir, Finistère, Gard, Haute-Garonne, Gers, Gironde, Hérault, Ille-et-Vilaine, Indre, Indre-et-Loire, Isère, Landes, Haute-Loire, Loire-Atlantique, Lot, Lotet-Garonne, Lozère, Maine-et-Loire, Marne, Haute-Marne, Morbihan, Puyde-Dôme, Pyrénées-Atlantiques, Hautes-Pyrénées, Pyrénées-Orientales, BasRhin, Haut-Rhin, Rhône, Saône-et-Loire, Sarthe, Savoie, Seine-Maritime, Deux-Sèvres, Tarn, Tarn-et-Garonne, Var, Vaucluse, Vendée, Vienne, Haute-Vienne, Yonne.

Archives communales : Bourg-en-Bresse (conservées aux archives départementales de l'Ain), Lyon. 


\section{Les sources imprimées}

\section{Des publications institutionnelles...}

Si les sources manuscrites ont permis de restituer le fonctionnement de la formation obstétricale, ses processus de décision et ses évolutions, les sources imprimées ont permis de les ancrer dans l'histoire politique, institutionnelle et législative, des cahiers de doléances, édités dans la Collection des documents inédits pour l'bistoire économique de la Révolution française ou dans les premiers volumes des Archives parlementaires de 1787 à 1860, aux débats des premières assemblées révolutionnaires (Archives parlementaires, recueil complet des débats législatifs et politiques des chambres françaises, première série, I787 à 1799). Aux procès-verbaux des travaux des chambres, il faut ajouter ceux des commissions thématiques créées dans les années 1790 : comité de salubrité (Vues générales sur la restauration de l'art de guérir, lues à la séance publique de la Société de médecine, le 31 août 1790, et présentées au Comité de salubrité de l'Assemblée nationale, le 6 octobre; suivies d'un Plan d'hospices ruraux pour le soulagement des campagnes de Jean-Gabriel Gallot) et comité d'instruction publique de la Convention nationale (édités par James Guillaume).

Les recueils de projets de loi et de textes effectivement votés ont été particulièrement précieux pour saisir la chronologie des intérêts politiques en matière d'instruction publique (La législation de l'instruction primaire en France depuis 1789 jusqu'à nos jours. Recueil des lois, décrets, ordonnances, arrêtés, règlements, éditée par Octave Gréard) et d'enseignement supérieur ; et la capacité d'adaptation aux terrains locaux dont ils témoignent. Le XIX ${ }^{\mathrm{e}}$ siècle est éclairé sur ces questions par les considérables travaux d'Arthur Marais de Beauchamp, qu'il s'agisse des Enquêtes et documents relatifs à l'enseignement supérieur, XXVIII, Médecine et pharmacie, 1789-1803 ou des cinq volumes du Recueil des lois et règlements sur l'enseignement supérieur : comprenant les décisions de la jurisprudence et les avis des conseils de l'Instruction publique et du Conseil d'État. Moins systématiquement collecté, le champ de la législation sanitaire n'est toutefois pas en reste et la fin du XIX ${ }^{e}$ siècle a donné lieu à de multiples publications locales ou nationales sur les évolutions en matière d'assistance médicale comme le Petit manuel de l'assistance publique, des hospices, hôpitaux, bureaux de bienfaisance et des bureaux d'assistance médicale (exécution de la loi du 15 juillet 1893): textes législatifs et réglementaires, instructions détaillées, commentaires et rapports officiels, statistiques générales, formules et modèles à adopter de Victor Turquan en I894. 


\section{... à la bibliographie médicale et obstétricale}

L'approche institutionnelle et sociale de cette recherche ne pouvait laisser de côté la dimension scientifique propre à l'essor de la formation obstétricale entre les années 1780 et le début du $\mathrm{xx}^{\mathrm{e}}$ siècle. Les sources ont été variées : des périodiques médicaux qui se multiplient au cours du XIX ${ }^{e}$ siècle (Bulletin général de thérapeutique médicale et chirurgicale, Bulletin de l'Académie de médecine, Gazette obstétricale, etc.), aux dictionnaires spécialisées et encyclopédies (Encyclopédie méthodique. Médecine, 1787-1830 ; Dictionnaire de médecine, de chirurgie, de pharmacie, des sciences accessoires et de l'art vétérinaire dirigé par Pierre-Hubert Nysten en 1833 et souvent réédité ; Dictionnaire encyclopédique des sciences médicales dirigé par Amédée Dechambre de I874 à I889, entre autres), en passant par la masse des manuels d'obstétrique, et plus originaux, les récits biographiques qui mettent à l'honneur les grandes figures du siècle en obstétrique (Accoucheurs et sages-femmes célèbres, esquisses biographiques de Gustave Witkowski en I89I qui clôt le XIX ${ }^{\mathrm{e}}$ siècle ouvert par la Notice sur la vie et les écrits de $M^{\text {me }}$ Lachapelle de François Chaussier en I823). Constitué en troisième branche de la médecine aux côtés de la chirurgie dès la fin du XviII ${ }^{\mathrm{e}}$ siècle, l'art des accouchements y gagne ses historiens dès le siècle suivant avec l'Essai sur l'histoire de l'obstétricie d'Eduard Caspar Jacob von Siebold (I839-I845) et les Lettres obstétricales du même, présentées en français en 1866 par Joseph-Alexis Stoltz, qui, confrontées à la grande enquête sur les maternités européennes menée la même année par Léon Lefort (Des Maternités, étude sur les maternités et les principales institutions charitables d'accouchement à domicile dans les principaux pays états de l'Europe), ouvrent sur l'évolution de la formation obstétricale à l'échelle européenne.

Cette recherche a enfin été l'occasion de recenser aussi exhaustivement que possible les publications émanées des sages-femmes françaises tout au long du $\mathrm{XIX}^{\mathrm{e}}$ siècle. Cet inventaire fait l'objet de l'annexe 2 de cet ouvrage (voir infra p. 433). 



\section{Bibliographie}

Plutôt qu'une reprise organisée des travaux cités en notes de bas de page dans le corps de l'ouvrage, il s'agit ici de proposer un état des lieux de la bibliographie française et internationale sur l'histoire des sages-femmes aux XVIII ${ }^{e}$, XIX $^{e}$ et $\mathrm{xx}^{\mathrm{e}}$ siècle (surtout pour sa première moitié). Le classement retenu sépare la bibliographie portant sur la France et celle sur les autres pays.

\section{France}

«L'Heureux Événement » : une histoire de l'accouchement, catalogue d'exposition, Musée de l'Assistance publique-Hôpitaux de Paris, 1995.

Les Sages-femmes d'bier à aujourd'bui. Pour quel avenir? (Actes du colloque de Nantes, 2004), Société d'Histoire de la Naissance, 2005 (dactylographié).

La "machine » de Madame Du Coudray ou l'Art des accouchements au XVIII siècle, Rouen, édition point de vues, musée Flaubert et d'histoire de la médecine, 2004.

Naissance, enfance et éducation dans la France méridionale $d u x v I^{e}$ au $X X^{e}$ siècle. Hommage à Mireille Laget, Montpellier, Université Paul Valéry-Montpellier III, 1999.

Arnaud-Lesot, Sylvie, "Pudeur et pratique obstétricale au Xix ${ }^{e}$ siècle », Histoire des sciences médicales, 2009, t. 43, n ${ }^{\circ}$ I, p. 39-48.

Aschauer, Lucia, «Histoire(s) de la naissance. L'observation obstétricale au Xviri siècle. », Dix-buitième siècle, I/2015, nº 47, p. I49-163.

Baron, Paul, Sages-femmes et maternité à Dijon, Dijon, Librairie Rebourseau, 1933.

Beauvalet, Scarlett, Renard, Jacques, « Des sages-femmes qui sauvent les mères? », HES, 1994, vol. 13, nº 2, p. 269-290. 
406 - L'ÉCOLE DES SAGES-FEMMES. NAISSANCE D'UN CORPS PROFESSIONNEL

Ead., «Perdre la vie en la donnant : la mortalité maternelle à Port-Royal, I815I826 », ADH, 1994, p. 237-260.

Ead., Naître à l'hôpital au XIX $X^{e}$ siècle, Paris, Belin, I999.

Bénézet, Jean Pierre, Bénézet, Marie-Claude, Naître en Rouergue, de l'ostal à l'hôpital: des sages-femmes et matrones à la médicalisation de la naissance, XVIII ${ }^{e}-X X^{e}$ siècles, Millau, Impr. Maury, 20I3.

Berthiaud, Emmanuelle, «Attendre un enfant » : vécu et représentations de la grossesse aux XVIII et XIX ${ }^{e}$ siècles (France), thèse pour le doctorat en histoire moderne et contemporaine, Université de Picardie-Jules-Verne, 20II.

Ead., Enceinte. Une histoire de la grossesse entre art et société, Paris, éditions de La Martinière, 2013.

Bonnel, Marie-Charlotte, Les Sages-femmes dans le Nord de la France au XVIII ${ }^{e}$ siècle, mémoire de master I soutenu à l'université d'Artois, 2010.

Caer, Gaëlle, Les Sages-femmes et l'accouchement en Bretagne (1750-1850), mémoire de maîtrise soutenu à l'université Rennes 2, 2002.

Carol, Anne, "Sage-femme ou gynécologue ? M.-A. Boivin (I773-I84I) », Clio. Histoire, Femmes et Sociétés, 201I, nº 33, p. 237-260.

Coulon-Arpin, Madeleine, La Maternité et les sages-femmes de la Prébistoire au $X X^{e}$ siècle, Paris, R. Dacosta, $198 \mathrm{I}, 2$ vol.

Couvreur, Isabelle, Delcroix, Michel, François, Martine, La Sage-femme à travers les 100 ans d'histoire d'une école, École de sages-femmes, Faculté libre de Lille, 1883-1983, Lille, 1983.

Delaunay, Paul, « Les chirurgiens-accoucheurs en chef de la Maternité de Paris, titulaires et prétendants », BSFHM, 1906, $\mathrm{n}^{\circ}$ 5, p. 327-344.

Id., La Maternité de Paris. Port-Royal de Paris. Port-Libre. L'hospice de la Maternité. L'École des sages-femmes et ses origines (1625-1907), Paris, Librairie Jules Rousset, 1909.

Id., L'Obstétrique dans le Maine aux XvIII et au XIX $X^{e}$ siècle, Le Mans, A. de Saint-Denis, I9II.

Delmas, Paul, Sept siècles d’obstétrique à la faculté de médecine de Montpellier, Montpellier, Coulet-Dubois et Poulain, 1927.

Dereudre-Fermaut, Catherine, De matrone à sage-femme. L'bistoire des sages-femmes à Lille sous l'Ancien Régime, DEA d'histoire du droit, université Lille 2, 1998.

Dubesset, Mathilde, Zancarini-Fournel, Michelle, Parcours de femmes, réalités et représentations, Saint-Étienne 1880-1950, Lyon, Presses universitaires de Lyon, 1993. 
Dubesset, Mathilde, «Paroles de sages-femmes sur les mutations de leur profession. Saint-Etienne dans les années 1920-I950 », Les Sages-femmes d'bier à aujourd'bui. Pour quel avenir ? op. cit., p. 29-35.

Dubreuil-Chambardel, Louis, L'Enseignement des sages-femmes en Touraine, Paris, Honoré Champion, I9II.

Faure, Olivier, "Les sages-femmes en France au XIX ${ }^{e}$ siècle : médiatrices de la nouveauté », Patrice Bourdelais, Olivier Faure (dir.), Les Nouvelles

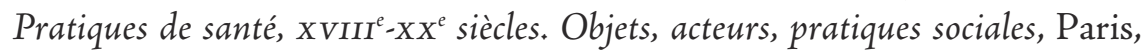
Belin, 2005, p. 157-I74.

Faure, Olivier, «Introduction », Bulletin du Centre Pierre-Léon d'bistoire économique et sociale, $1995, \mathrm{n}^{\circ} 2-3$, «Les femmes soignantes », p. 3-5.

Feutrel, Sophie, Les Sages-femmes et la quête d'une identité professionnelle dans le Nord de la France, pendant l'entre-deux-guerres, mémoire de master I soutenu à l'université de Valenciennes et du Hainaut-Cambrésis, 20II.

FlotT Es, Laetitia, Enquête de l'an XIV : prémices d'une formation organisée pour les sages-femmes, mémoire pour le diplôme d'État de sage-femme, École de sages-femmes Baudelocque, 2014.

Fosseyeux, Marcel, "Sages-femmes et nourrices à Paris au XviII ${ }^{e}$ siècle », La Revue de Paris, I921, septembre-octobre, p. 535-554.

Gelbart, Nina Rattner, The King's Midwife. A History and Mystery of Madame du Coudray, Berkeley, University of California Press, 1998.

GéLIs, Jacques, « L'accoucheuse rurale au XVIII ${ }^{\mathrm{e}}$ siècle : transformation du rôle d'un intermédiaire entre culture rurale et culture urbaine », Les Intermédiaires culturels. Actes du colloque du centre méridional d'Histoire sociale, des mentalités et des cultures, 1978, Aix-en-Provence, Publications de l'Université de Provence, 198I, p. 127-137.

Id., « La pratique obstétricale dans la France moderne : les carnets du chirurgien-accoucheur Pierre Robin (1770-1797) », Annales de Bretagne et des pays de l'Ouest, 1979, vol. 86, n' 2, p. 191-210.

$I d$., "L'enquête de I786 sur les sages-femmes du royaume », $A D H$, I980, p. 299-343.

Id., «La formation des accoucheurs et des sages-femmes aux XVII ${ }^{\mathrm{e}}$ et $\mathrm{XVIII}^{\mathrm{e}}$ siècles. Évolution d'un matériel et d'une pédagogie », $A D H$, 1977, p. 153-180.

Id., "Sages-femmes et accoucheurs : l'obstétrique populaire aux XVII ${ }^{\mathrm{e}}$ et XVIII ${ }^{\mathrm{e}}$ siècles », Annales. Histoire, Sciences Sociales, I977, 32-5, p. 927-957.

Id., L'Arbre et le fruit. La naissance dans l'Occident moderne (XVI $I^{e}$-XIX ${ }^{e}$ siècles), Paris, Fayard, 1984.

Id., La Sage-femme ou le médecin, une nouvelle conception de la vie, Paris, Fayard, 1988. 
408 - L'ÉCOLE DES SAGES-FEMMES. NAISSANCE D'UN CORPS PROFESSIONNEL

Id., Laget, Mireille, Morel, Marie-France, Entrer dans la vie. Naissances et enfances dans la France traditionnelle, Paris, Gallimard, Julliard, 1978.

George, Jocelyne, Caron-Leulliez, Marianne, «La sage-femme après 1950 : une profession féminine dans une société en évolution ", Les sages-femmes d'bier à aujourd'bui. Pour quel avenir ? op. cit., p. 36-42.

Gutton, Jean-Pierre, « Matrones, chirurgiens et sages-femmes en Lyonnais aux XVII ${ }^{e}$ et $\mathrm{XVIII}^{\mathrm{e}}$ siècles », Isabelle Robin, Jean-Pierre Poussou (dir.), Histoire des familles, de la démographie et des comportements, en hommage à Jean-Pierre Bardet, Paris, PUPS, 2007, p. 105-II9.

Hacquin, François, Histoire de l'art des accouchements en Lorraine, des temps anciens au $X X^{e}$ siècle, Nancy, Librairie lorraine, 1979.

Hélie, Anissa, «Les sages-femmes marseillaises : vers un nouveau statut (1826-1945) », Provence Historique, 1989, vol. 39, n' ${ }^{\circ}$ 157, p. 437-457.

Jean, Véronique, L'École des sages-femmes de l'Ain au XIX ${ }^{e}$ siècle, maîtrise d'histoire, Lyon III, 1996.

Jusseaume, Anne, «Soigner des femmes en couches : un interdit levé pour évangéliser ? », Chrétiens et Sociétés, 2012, n ${ }^{\circ}$ 19, p. I17-153.

Knibienler, Yvonne, Accoucher. Femmes, sages-femmes et médecins depuis le milieu du $x x^{e}$ siècle, Rennes, Éditions de l'ENSP, 2007.

Laget, Mireille, Naissances, l'accouchement avant l'âge de la clinique, Paris, Seuil, 1982.

Lefaucheur, Nadine, Les accoucheurs des hôpitaux de l'Assistance publique à Paris: de l'art des accouchements à la protection maternelle et infantile. Rapport final mars 1989, Paris, IRESCO-CNRS, 1992.

McTavish, Lianne, Childbirth and the Display of Authority in Early Modern France, Aldershot, Ashgate, 2005.

Ead., "Practices of Looking and the Medical Humanities: Imagining the Unborn in France, 1550-1800", The Journal of Medical Humanities, 2010, vol. 3I-I, p. II-26.

Monroziès, Maurice, Au service des femmes. Les services de gynécologie et d'obstétrique de l'Hôpital de la Grave à Toulouse. 250 ans d'bistoire, 1729-1979, Toulouse, Privat, 1980.

Morel, Marie-France, "Sages-femmes et accoucheurs. Perspectives historiques », Jacques Battin (dir.), Naître aujourd'bui, Paris, Glyphe, 2015, p. 239-255.

Papin, Stéphanie, Étude sur la formation des sages-femmes du Châtelleraudais (1750-1792), mémoire de maîtrise soutenu à l'université de Poitiers, 1998.

Penot, Charlotte, L'École d'accouchement de Bordeaux au XIX siècle, maîtrise d'histoire, Bordeaux III, 2003. 
Sage Pranchère, Nathalie, Mettre au monde. Sages-femmes et accouchées en Corrèze au XIX siècle, Tulle, Archives départementales de la Corrèze, 2007. Ead., "Grossesse, naissance et obstétrique, quelle place dans la langue occitane ? », Jean-Loup Lemaître et Françoise Vielliard (dir.), L'Occitan, une langue $d u$ travail et de la vie quotidienne $d u X X^{e}$ au XXI siècle, actes $d u$ colloque de Limoges, Ussel, Musée du Pays d'Ussel/Centre Trobar, Paris, Diffusion de Boccard, 2009, p. 173-203.

Ead., "Étude comparée de deux projets de cours d'accouchement à la fin du xviII ${ }^{e}$ siècle », HES, 2009-2, p. 37-58.

Ead., "Bébés sans diplôme. Les matrones, le droit et les légitimités locales en France, 1780-1900 », Constantin Barbulescu, Alin Ciupala (dir.), Medicine, Hygienism and Society in XVIIIth-XXth centuries, Cluj-Napoca, Editura Mega, 2012, p. 25-54.

Ead., «L'appel à la sage-femme. La construction d'un agent de santé publique (France, xIx ${ }^{e}$ siècle) », $A D H, 2014 / \mathrm{I}, \mathrm{p} \cdot \mathrm{I} 8 \mathrm{I}-209$.

Ead,, "Sages-femmes et sœurs en France au XIX ${ }^{e}$ siècle. La voie à part de la sororité professionnelle », Fabrice Boudjaaba, Christine Doucet-Seiden, Sylvie Mouysset (dir.), Frères et sœurs du Moyen Âge à nos jours, Peter Lang, 2016, p. 403-423.

Ead., "Au cœur des familles. Les matrones auprès des mères en France au XIX ${ }^{e}$ siècle », Marie-France Morel (dir.), Naître à la maison d'bier à aujourd'bui, Toulouse, Erès, 2016, p. 79-IOI.

Ead., "Sciences, solidarité, dévouement". Les débuts de la syndicalisation des sages-femmes en France (I896-1914) », Fanny Bugnon, Carole Carribon, Delphine Dussert-Galinat, Bernard Lachaise, Dominique Picco (dir.), Femmes et réseaux dans les sociétés modernes et contemporaines, Bordeaux, Presses Universitaires de Bordeaux, 2016, à paraître.

Théв Aud, Françoise, Quand nos grands-mères donnaient la vie. La maternité en France dans l'entre-deux-guerres, Lyon, Presses universitaires de Lyon, 1986.

Tissier, Agathe, Les Sages-femmes à Amiens aux XVIII et XIX ${ }^{e}$ siècles, mémoire de master I, université d'Amiens, 2007.

Tucat, Danielle, Les Sages-femmes parisiennes, 1871-1914, thèse de troisième cycle, Paris VII, 1983, sous la direction de Michelle Perrot.

Ead., "Les sages-femmes à Paris de I87I à I9I4 », Les Sages-femmes d’hier à aujourd'bui. Pour quel avenir?, op. cit., p. 23-27.

Verdier, Yvonne, Façons de faire, façons de dire, Paris, Gallimard, I979.

Wijland, Jérôme Van, «Enluminer les accouchements, éclairer l'enseignement. Les planches de l'Abbrégé de l'Art des Accouchemens de Madame du Coudray », Histoire des sciences médicales, 20I2, vol. 46, n 44, p. 403-4I4. 


\section{International}

Loudon, Irvine, Death in Childbirth. An International Study of Maternal Care and Maternal Mortality, 1800-1950, Oxford, Clarendon Press, 1992.

Michaels, Paula A., Lamaze. An International History, New York, Oxford University Press, 20I4.

Van Teijlingen, Edwin R., Lowis, George W., McCaffery, Peter Gabriel, Porter, Maureen, (eds.), Midwifery and the medicalization of childbirth: comparative perspectives, Commack, NJ, Nova Science Publishers, I999.

\section{Europe}

Marland, Hilary, (dir.), The Art of Midwifery: Early Modern Midwives in Europe, London, New York, Wellcome institute series in the history of medicine, Routledge, 1993.

Ead., Rafferty, Anne-Marie (dir.), Midwives, Society and Childbirth: Debates and Controversies in the Modern Period, Londres, Routledge, 1997.

Schlumboнm, Jürgen, Duden, Barbara, Gélis, Jacques, Veit, Patrice (dir.), Rituale der Geburt. Eine Kulturgeschichte, C. H. Beck, 1998.

\section{Allemagne}

Benedict, Susan, Shields, Linda (ed.), Nurses and Midwives in Nazi Germany. The "Euthanasia Programs", London, Routledge, 2014.

FlüGGE, Sibylla, Hebammen und heilkundige Frauen. Recht und Rechtswirklichkeit im 15. und 16. Jahrbundert, Francfort/Bâle, Stroemfeld Verlag, 1998.

Gross, D., „Deprofessionalisierung ' oder ,Paraprofessionalisierung“? : Die berufliche Entwicklung der Hebammen und ihr Stellenwert in der Geburtshilfe des 19. Jahrhunderts", Sudhoffs Archiv, 1998, vol. 82, n² 2, p. 219-238.

Hampe, Henrike, Zwischen Tradition und Instruktion. Hebammen im 18. und 19. Jahrbundert in der Universitätstadt Göttingen, Göttingen, 1998.

Hilpert, Claudia, Wehemütter. Amtshebammen, Accoucheure und die Akademisierung der Geburtshilfe im kurfürstlichen Mainz, 1550-1800, Frankfurt/M, Berlin, Peter Lang, 2000.

Labouvie, Eva, Beistand in Kindsnöten. Hebammen und weibliche Kultur auf dem Land, 1550-1910, Frankfurt/New York, Campus Verl., 1999. 
Loytved, Christine, Hebammen und ihre Lehrer. Wendepunkte in Ausbildung und Amt Lübecker Hebammen (1730-1850), Osnabrück, Universitätsverlag Rasch, 2002.

Ead,, „Lehrtochter oder Hebammenschülerin? : Zur Verschulung der Hebammenausbildung an Beispielen aus Lübeck, Altona, Flensburg und Kiel im ausgehenden I8, und Anfang des I9. Jahrhunderts“, NTM, 2006, vol. I4, n' 2, p. 93-106.

Nava, Patrizia, Hebammen, Accoucheure und Man-midwives. Ein deutschamerikanischer Vergleich (1750-1850), Herbolzeim, Centaurus Verlag, 2003. Pulz, Waltraud, "Nicht Alles Nach Der Gelahrten Sinn Geschrieben“: Das Hebammenanleitungsbuch von Justina Siegemund. Zur Rekonstruktion Geburtshilfichen Überlieferungswissens Frühneuzeitlicher Hebammen und seiner Bedeutung bei der Herausbildung der Modernen Geburtshilfe, Münchner Beiträge zur Volkskunde, Munich, Munchner Vereinigung fur Volkskunde, I994.

Ead., "Aux origines de l'obstétrique moderne en Allemagne ( $\mathrm{xVI}^{\mathrm{e}}$-xVIII ${ }^{\mathrm{e}}$ siècle): accoucheurs contre matrones ? ", RHMC, I996, t. 43, n 4, p. 593-617.

Robilliard, Gabrielle, Midwives in Early Modern Germany, 1650-1810, University of Warwick, 2010.

Schlumbонм, Jürgen, “The pregnant women are here for the sake of the teaching institution': The Lying-in Hospital of Göttingen University, I75I to c. I830", Social History of Medicine, 200I, vol. I4, n' I p. 59-78.

Id., "Comment l'obstétrique est devenue une science », ARSS, 2002, vol. I43, $\mathrm{n}^{\mathrm{o}} \mathrm{I}, \mathrm{p}+\mathrm{I} 8-3 \mathrm{O}$.

$I d$, « Les limites du savoir : médecin et femmes enceintes à la maternité de l'université de Göttingen aux alentours de I800 », RHMC, 2005, 52-I, p. 64-94. Id., "The Practice of Practical Education: Male Students and Female Apprentices in the Lying-in Hospital of Göttingen University, 1792-1815 », Medical History, 2007, 51, p. 3-36.

Id., Lebendige Phantome: Ein Entbindungshospital und seine Patientinnen 17511830. Göttingen, Wallstein 2012.

\section{Danemark}

Løкке, Anne, "Did Midwives Matter? 1787-1845”, Pathwaye of the Past. Essays in Honour of Sølvi Sogner, Oslo, Novus forlag, 2002, p. 59-72.

Ead., "The Antibiotic Transformation of Danish Obstetrics. The Hidden Links between the Decline in Perinatal Mortality and Maternal Mortality in the Mid-Twentieth Century", $A D H, 2012-1$, p. 205-224. 


\section{Espagne}

Gonzalez Canalejo, Carmen, « Cuidados y bienestar: el trabajo sanitario femenino en respuesta a la 'cuestión social' (1857-1936) », Dynamis, 2007, vol. 27, p. I2-I3, 2II-235.

Ruiz-Berdún, Dolores, Gomis, Alberto, «La depuración de las matronas de Madrid tras la Guerra Civil », Dynamis, 2012, vol. 32-2, p. 439-465.

Ead., «La primera enseñanza reglada de las matronas en España: el Real Colegio de Cirurgía de San Carlos de Madrid », Llull: Revista de la Sociedad Espanola de Historia de las Ciencias y de las Tecnicas, vol. 36, $\mathrm{n}^{\circ} 78,2013$, p. 387-410.

Ead., " La enseñanza de la obstetricia en el Real Colegio de Cirugía de San Carlos: La cátedra de partos », Medicina e Historia, Revista de Estudios Históricos de las Ciencias de la Salud, 2014-I, p+ 22-35.

\section{Grèce}

Bournova, Eugenia, Garden, Maurice, "Naitre à Athènes dans la première moitié du $\mathrm{xx}^{\mathrm{e}}$ siècle. Démographie et institutions », $A D H, 2014 / \mathrm{I}$, p. 209-234.

Italie

Berti Logan, Gabriella, "Women and the Practice and Teaching of Medecine in Bologna in the Eighteenth and Early Nineteenth Centuries », Bulletin of the History of Medicine, vol. 77, $\mathrm{n}^{\circ}$ 3, automne 2003, p. 506-535.

Filippini, Nadia Maria, La Naissance extraordinaire. La mère, l'enfant, le prêtre, le médecin face à l'opération césarienne (Italie, $X V I I I^{e}-X^{e}$ siècle), thèse pour le doctorat en histoire, EHESS, 1993.

Ead., "Sous le voile : les parturientes et le recours aux hospices de maternité à Turin, au milieu du XIX ${ }^{\mathrm{e}}$ siècle », RHMC, t. 49, n ${ }^{\circ} \mathrm{I}$, janv.-mars 2002, p. 173-194.

Gissi, Alessandra, Le Segrete manovre delle donne. Levatrici in Italia dall'unità al fascismo, Roma, Biblink, 2006.

Pancino, Claudia, Il Bambino e l'acqua sporca. Storia dell'assistenza al parto dalle mammane alle ostetriche (secoli XVI-XIX), Milan, Franco Angeli, «Storia », 1984. $E a d$., «Comari, levatrici, ostetriche: alcune tappe della storia di un'antica professione femminile », Saveria Chemotti (dir.), Donne al lavoro: ieri, oggi, domani, Padova, il Poligrafo, 2009, p. II5-I28. 
Spina, Elena, Ostetriche e Midwives. Spazi di autonomia e identità corporativa, Milano, Francoangeli, 2009.

Vannozi, Francesca (dir.), Figure femminili (e non) intorno alla nascita: la storia in Siena dell'assistenza alla partoriente e al nascituro, XVIII-XX secolo, Sienna, Protagon ed., 2005.

Pays-Bas

Lieburg, M. J. van, Marland, Hilary, "Midwife Regulation, Education, and Practice in the Netherlands during the Nineteenth Century", Medical History, 1989, vol. 33, n 3, p. 296-317.

Marland, Hilary, "Mother and Child were saved". The Memoirs (1693-1740) of the Frisian Midwife Catharina Schrader, Amsterdam, Editions Rodopi, 1987.

Ead., "The Guardians of Normal Birth: the Debate on the Standard and Status of the Midwife in the Netherlands around 1900", Eva AbrahamVan der Mark (ed.), Successful Home Birth and Midwifery: the Dutch Model, Westport, Conn., London, Bergin \& Garvey, 1993, p. 2I-44.

Ead., "Questions of Competence: the Midwife Debate in The Netherlands in the Early Twentieth Century", Medical History, 1995, vol. 39, n 3, p. 317-337. Ead., "A Broad and Pleasing Field of Activity'? The Payments, Posts and Practices of Dutch Midwives in the Early Twentieth Century", John Woodward, Robert Jütte (eds), Coping With Sickness. Historical Aspects of Health Care in a European Perspective, Sheffield, European Association for the History of Medicine and Health Publications, 1995, p. 67-9I.

Ead., "Stately and Dignified, Kindly and God-fearing': Midwives, Age and Status in the Netherlands in the Eighteenth-Century", Hilary Marland, Margaret Pelling (eds.), The Task of Healing: Medicine, Religion, and Gender in England and the Netherlands, 1450-1800, Rotterdam, Erasmus, 1996, p. 27I-305.

Ead., "Smooth, speedy, painless and still Midwife delivered? The Dutch Midwife and Childbirth Technology in the Early Twentieth Century", Lawrence Conrad, Anne Hardy (eds.), Women and modern medicine, Clio medica, Wellcome series in the history of medicine, $\mathrm{n}^{\circ}$ 6I, Amsterdam, Rodopi, 200I, p. 173-I94.

Ead., "Midwives, Missions and Reform: Colonizing Dutch Childbirth Services at Home and Abroad ca. 1900", Mary P. Sutphen, Bridie Andrews (eds.), Medicine and colonial identity, Routledge studies in the social history of medicine, $\mathrm{n}^{\circ}$ 17, London, Routledge, 2003, p. 6I-78. 
Ead., "Catholic girls, there is work!' Dutch midwives, childbirth reform and Catholicism in the early twentieth century", Anne Hilde van Baal, Catharina Th. Bakker, Gemma Blok, Amanda Kluveld (eds.), Genezen: opstellen bij het afscheid van Marijke Gijswijt-Hofstra, Amsterdam, Pallas Publications, Amsterdam University Press, 2005, p. 40-53.

VAn der Borg, E., "Dutch Midwives: Image and Occupation. Developments in Midwifery in Leiden, Arnhem, 's-Hertogenbosch and Leeuwarden, $1650-$ I865", Histoire des Sciences Médicales, I994, vol. 28, nº I, p. 57-62.

\section{Roumanie}

Trăuşan-Matu, Lidia, "The Doctor and the Midwife. A Study of Two Medical Professions in the Romanian Society of the igth Century (I83II874)", Constantin Barbulescu, Alin Ciupala (dir.), Medicine, Hygienism and Society in XVIIIth-XXth centuries, op. cit., p. 8I-IOO.

Royaume-Uni, Irlande

Allotey, Janette C., "Writing Midwives' History: Problems and Pitfalls", Midwifery, vol. 27, n², p. I3I-I37.

Ead., "English Midwvives' Responses to the Medicalisation of Childbirth (1671-1795)", Midwifery, 201I, vol. 27, n 4, p. 532-538.

Aveling, J. H., English Midwives: their History and Prospects, London, Hugh K. Elliot, 1967 .

Borelli, Sara Elisabetta, "What is a Good Midwife? Some Historical Considerations", Evidence Based Midwifery, January 2013, II(2), p. 5I-59.

Borsay, Anne, Hunter, Billie, Nursing and midwifery in Britain, Basingstoke, Palgrave Macmillan, 20I2.

Donnison, Jean, Midwives and Medical Men. A History of the Struggle for the Control of Childbirth, Londres, Heinemann Educational, 1977.

Evenden, Doreen, The Midwives of Seventeenth-Century London, Cambridge, Cambridge University Press, 2000 (réédition en 2006).

Fealy (G. M.), Care to Remember. Nursing and Midwifery in Ireland, Cork, Mercier Press, 2005.

Garcia, J., Kilpatrick, R., Richards, M., The Politics of Maternity Care: Services for Childbearing Women in Twentieth-Century Britain, Oxford, Clarendon, 1990.

Grundy, I., "Sarah Stone: enlightenment midwife”, Clio Medica, 1995, vol. 29, p. I28-I44. 
Hannam, June, "Rosalind Paget. The Midwife, the Women's Movement and Reform before I9I4", H. Marland, A.-M. Rafferty (eds), Midwives, Society and Childbirth, op. cit., p. 8I-IOI.

Harley, David, "Ignorant midwives - a persistent stereotype", The Society for the Social History of Medicine Bulletin, 198I, nº 28, p. 6-9.

Id., "Historians as Demonologists: The Myth of the Midwife-witch", Social History of Medicine, $1990, \mathrm{n}^{\circ} 3, \mathrm{p}, \mathrm{I}-26$.

Heagerty, Brooke Victoria, Class, Gender and Professionalization: The Struggle for British Midwifery, 1900-1936, PhD diss., Michigan State University, 1990. Ead., "Reassessing the Guilty: The Midwives Act and the Control of English Midwives in the Early 2oth Century", Mavis Kirkham (ed.), Supervision of Midwives, Hale, Cheshire, England, Books for Midwives, 1996, p. 13-27. Hunter, Billie, "Midwifery, I920-2000: The Reshaping of a Profession", A. Borsay, B. Hunter (eds), Nursing and midwifery in Britain, op. cit, chapitre 7. KING, Helen, "Midwifery, I700-I800: The man-midwife as competitor", A. Borsay, B. Hunter (eds), Nursing and midwifery in Britain, op * cit, chapitre 5. Kirkнам, Mavis (ed.), Supervision of Midwives, Hale, Cheshire, England, Books for Midwives, I996.

Leap, Nicky, Hunter, Billie, The Midwife's Tale: An Oral History from Handywoman to Professional Midwife, London, Scarlet Press, I993.

Lieske, Pam (ed.), Eighteenth-Century Midwifery, Londres, Pickering \& Chatto, 2007-2009, I2 volumes.

Lloyd, Josephine M., Lella, Joseph W., Teigen, Philip M., Nation, Earl, Bliss, Michael, "The Languid Child and the Eighteenth-Century Man-midwife", Bulletin of the History of Medicine, 200I, vol. 75, n 4, p. 64I-679. McIntosh, Tania, "Profession, Skill, or Domestic Duty? Midwifery in Sheffield, I88I-I936", Social History of Medicine, II, jan. I998, p. 403-420.

Nightingale, Florence, Introductory notes on lying-in institutions together with a proposal for organizing an institution for training midwives and midwifery nurses, London, Longmans, I87I.

Pantin, C. G., "A Study of Maternal Mortality and Midwifery on the Isle of Man, I882 to I96I", Medical History, I996, vol. 40, n² 2, p. I4I-I72.

Reid, Alice, "Mrs Killer and Dr Crook: Birth Attendants and Birth Outcomes in Early Twentieth-century Derbyshire", Medical History, 2012, vol. 56, $\mathrm{n}^{\circ} 4, \mathrm{p}+5 \mathrm{II}-530$.

Robinson, Sarah, "Maintaining the Independence of the Midwifery Profession: A Continuing Struggle", J. Garcia et al. (eds),, The Politics of Maternity Care: Services for Childbearing Women in Twentieth-Century Britain, op. cit., p. 6I-9I. 
416 - L'ÉCOLE DES SAGES-FEMMES. NAISSANCE D'UN CORPS PROFESSIONNEL

St anley, Heather, "Sairey Gamps, Feminine Nurses and Greedy Monopolists: Discourses of Gender and Professional Identity in the Lancet and the British Medical Journal, 1886-1902", Canadian Bulletin of Medical History, 2012, vol. 29, n' I, p. 49-68.

Thомаs, F.D., Mayes' handbook for midwives and maternity nurses, Bailliere, Tindall and Cox, 1959.

Towler, J., Bramall, J., Midwives in History and Society, Beckenham, Croom Helm, 1986.

Tomkins, Alannah, "Demography and the Midwives: Deliveries and their Denouements in North Shropshire, I78I-1803", Continuity E Change, 20I0, vol. 25, n' 2, p. 199-232.

VASSET, Sophie, "La querelle des accoucheurs et des sages-femmes en Grande-Bretagne : l'exemple d'Elizabeth Nihell », Littératures classiques, 2013/2, p. 243-255.

Wilson, Adrian, The Making of Man-Midwifery: Childbirth in England 16601770, London, UCL Press, 1995.

Woods, Robert, "Lying-in and Laying-out: Fetal Health and the Contribution of Midwifery", Bulletin of the History of Medicine, 2007, vol. 8I, n ${ }^{\circ} 4$, p. 730-759.

Worboys, Michael, "Unsexing Gonorrhoea: Bacteriologists, Gynaecologists, and Suffragists in Britain, 1860-1920", Social History of Medicine, 2004, vol. I7, ${ }^{\circ}$ I, p. 4I-59.

Suisse

Bettoli, Lorenza, « 1850-I930 : cinquante ans d'histoire des sages-femmes en Suisse ", Les Sages-femmes d'bier à aujourd'bui. Pour quel avenir ?, op. cit., p. 60-65.

Favre, Adeline, Moi Adeline, accoucheuse, Sierre, Éditions Monographic, 1982. Vouilloz-Burnier, Marie-France, L'Accouchement entre tradition et modernité, naître au XIX ${ }^{e}$ siècle, Sierre, Monographic, 1995.

Vuille, Marilène, Les Sages-femmes vaudoises face à l'accouchement sans douleur (ASD) (1950-1989), Rapport final de recherche, Réseau d'Études Appliquées des Pratiques de Santé, de Réadaptation et de Ré/insertion (RéSaR), Haute école spécialisée de Suisse occidentale (HES-SO). Lausanne, Haute école de la santé La Source, 2009, 84 p. [https://doc,rero.ch/record/I7284] 


\section{Amérique}

Canada

Jasen, P., "Race, Culture, and the Colonization of Childbirth in Northern Canada", Social History of Medicine, 1997, vol. Io, n' ${ }^{\circ}$ 3, p. 383-400.

LAFORCE, Hélène, Histoire de la sage-femme dans la région de Québec. Québec, Institut québécois de la recherche sur la culture, 1985.

Mitchinson, Wendy, Giving Birth in Canada, 1900-1950. Toronto/Buffalo/ London, University of Toronto Press, 2002.

Rivard, Andrée, Histoire de l'accouchement dans un Québec moderne, Montréal, Éditions du Remue-Ménage, 2014.

Rousseau, Nicole, Daigle, Johanne, Infirmières de colonie : Soins et médicalisation dans les régions du Québec, 1932-1972, Québec, Presses de l'Université Laval, 2013.

Young, Judith, "Nineteenth-Century Nurses and Midwives in Three Canadian Cities, I86I-I89I", Canadian Bulletin of Medical History, 2013, vol. $30, n^{\circ}$ I, p. 189-208.

\section{États-Unis}

Berman, P., "The practice of obstetrics in rural America, I800-1860", Journal of the History of Medicine and Allied Sciences, 1995, vol. 50, n 2, p. 175-193.

Borst, Charlotte G., Catching Babies. The Professionalization of Childbirth, 1870-1920, Harvard University Press, Cambridge (Massachussetts), Londres, 1995.

Clark, Katherine, Motherwit: An Alabama Midwife's Story, New York, Dutton, 1989.

Craven, Christa, Glatzel, Mara, "Historical Accounts of African American Midwives and Contemporary Struggles for Midwifery", Feminist Studies, 2010, vol. 36, no 2, p. 330-358.

Donegan, Jane B., Women and Men Midwives: Medicine, Morality and Misogyny in Early America, Westport, Greenwood Press, 1978.

Ehrenreich, Barbara, English, Deirdre, Witches, Midwives and Nurses: A History of Women Healers, Oyster Bay, New York, Glass Mountain Pamphlets, 1973 [traduction française : Sorcières, sages-femmes et infirmières: une histoire des femmes soignantes, Paris, Cambourakis, 2014]. 
418 - L'ÉCOLE DES SAGES-FEMMES. NAISSANCE D'UN CORPS PROFESSIONNEL

Ettinger, Laura, Nurse-Midwifery: the Birth of a New American Profession, Ohio State University Press, 2006.

Ead., "Midwives on Horseback: Saddlebags and Science", American History Home, Smithsonian, 2015 [en ligne], http://americanhistory.si.edu/blog/ midwives-horseback-saddlebags-and-science.

Feldhusen, Adrian E., "The History of Midwifery and Childbirth in America:

A Timeline", Midwifery Today, 2000, [en ligne], http://www.midwiferytoday.com/articles/timeline.asp.

Gaskin, Ina May, Spiritual Midwifery, Summertown, Book Publishing Company, 1975.

Leavitt, Judith Walzer, Brought to Bed. Childbearing in America, 1750-1950, New York, Oxford University Press, 1986.

Litoff, Judy Barrett, American Midwives, 1860 to the Present, Westport, Conn., Greenwood Press, 1978.

Ead., "Midwives and history", Rima D. Apple, Women, Health and Medicine in America. A Historical Handbook, New York, London, Garland Publishing inc., 1990, p. 443-458.

McGregor, Deborah Kuhn, From Midwives to Medicine. The Birth of American Gynecology, New Brunswick/New Jersey/London, Rutgers University Press, 1998.

Morel, Marie-France, «Les sages-femmes peuvent-elles disparaître ? Le cas des États-Unis ( $\mathrm{XVII}^{\mathrm{e}}-\mathrm{XX}^{\mathrm{e}}$ siècles)», Les Sages-femmes d'bier à aujourd'bui. Pour quel avenir ?, op. cit., p. 43-53.

Morgen, Sandra, Into Our Own Hands: The Women's Health Movement in the United States, 1969-1990, New Brunswick, NJ, Rutgers University Press, 2002 .

Rooks, Judith Pence, Midwifery and Childbirth in America, Philadelphia, Temple University Press, 1997.

Scrivener, Laurie, Barnes, J. Suzanne, A Biographical Dictionary of Women Healers: Midwives, Nurses and Physicians, Westport, Oryx Press, 2002.

Ulrich, Laurel Thatcher, A Midwife's Tale. The Life of Martha Ballard, Based on her Diary, 1785-1812, New York, Alfred A. Knopf, Inc., I990.

Ead., „Ihre Arbeit - seine Arbeit. Geburtberichte in Tagebüchern aus NeuEngland im I8. Jahrhundert", Sснцимвонм, Jürgen, et al. (dir.) Rituale der Geburt. Eine Kulturgeschichte, op. cit., p. 30-49.

Wertz, Richard and Dorothy C., Lying-In: A History of Childbirth in America, New Haven, Yale University Press, 1989. 
Brésil

Brenes, Anayansi Correa, "Las parteras Francesas de Rio de Janeiro en el siglo XIX: entre la filantropia y la practica liberal a bajo costo (I826-I890) », Chantal Cramaussel, Delia González (dir.), Viajeros y Migrantes franceses en la America española y portuguesa durante el siglo XIX, Michoacan, El colegio de Michoacan, 2007, vol. 2, p. 427-447.

Ead., "Un regard brésilien sur le cas de Paris : le mouvement des accoucheuses instruites à Rio de Janeiro. Entre la philanthropie et la pratique libérale à bas prix (1844-1895) », Fatou Sow (dir ${ }_{*}$, Recherche féministe francophone. Langages, identités et enjeux, Paris, Karthala, 2009, p. 497-512.

Мотт, Maria Lúcia, «Une sage-femme franco-brésilienne à Rio de Janeiro au $\mathrm{xIx}^{\mathrm{e}}$ siècle », Clio. Femmes, Genre, Histoire [En ligne], I9|2004, mis en ligne le 23 août 20I3, consulté le I6 février 20I6. URL: http://clio.revues.org/658.

\section{Mexique}

Diaz Robles, Laura Catalina, Oropoza Sandoval, Luciano, « Las parteras de Guadalajara (México) en el siglo xıx: el despojo de su arte », Dynamis, 2007, vol. 27, p. I3, 237-26I.

\section{Pérou}

Quiroz-PÉrez, Lissell, « De la comadrona a la obstetriz. Nacimiento y apogeo de la profesión de partera titulada en el Perú del siglo xix », Dynamis, 2012, vol. 32-2, p. 270, 415-437.

Ead., "Benoîte Cadeau-Fessel et la naissance de la profession de sage-femme », Clio. Femmes, Genre, Histoire, no 4, 2014, p. 225-247.

Ead,, «Des femmes dans la cité : les sages-femmes péruviennes du XIx ${ }^{\mathrm{e}}$ siècle », Nuevo Mundo Mundos Nuevos [En ligne], Colloques, mis en ligne le 8 avril 20I4, consulté le I6 février 20I6. URL : httpः// nuevomundo.revues.org/666I3. Ead., "Isidora Martínez, une femme en quête de liberté dans le Pérou du $\mathrm{xIx}^{\mathrm{e}}$ siècle », Arenal, Revista de Historia de Las Mujeres, 2015, vol. 22, $\mathrm{n}^{\circ} 2$, p. 23I-246. 


\section{Afrique}

\section{Afrique Occidentale française (AOF)}

Barthélémy, Pascale, "Sages-femmes africaines diplômées en AOF des années 1920 aux années I960. Une redéfinition des rapports sociaux de sexe en contexte colonial », Anne Hugon (dir.), Histoire des femmes en situation coloniale. Afrique et Asie, $\mathrm{XX}^{e}$ siècle, Paris, Karthala, 2004, p. II9-I44.

Ead., Africaines et diplômées à l'époque coloniale (1918-1857), Rennes, PUR, 2010.

\section{Afrique du Sud}

Deacon, Harriet, "Midwives and Medical Men in the Cape Colony before I860", Journal of African History, 1998, vol. 39, n 2, p. 27I-292.

\section{Algérie}

Fredj, Claire, «Encadrer la naissance dans l'Algérie coloniale. Personnels de santé et assistance à la mère et à l'enfant « indigènes » ( $\mathrm{XIX}^{\mathrm{e}}$-début du $\mathrm{xx}^{\mathrm{e}}$ siècle) 》, $A D H, 201 \mathrm{I}-2$, p. 169-203.

\section{Égypte}

Faнmy, Khaled, "Women, Medicine, and Power in igth-century Egypt", Lila Abu-Lughod (ed.), Remaking Women: Feminism and Modernity in the Middle East, Princeton, Princeton University Press, 1998, p. 35-72.

\section{Ghana}

Hugon, Anne, « La redéfinition de la maternité en Gold Coast, des années 1920 aux années 1950 : projet colonial et réalités locales », Anne Hugon (dir.), Histoire des femmes en situation coloniale..., op. cit., p. I45-I72.

Ead., « Les sages-femmes africaines en contexte colonial : auxiliaires de l'accouchement ou agents de la médicalisation ? Le cas du Ghana, des années 1930 aux années 1950 », Patrice Bourdelais, Olivier Faure (dir.), Les Nouvelles Pratiques de santé,.., op. cit., p. 175-193.

Ead., "L L'internat de l'école de sages-femmes d'Accra à l'époque coloniale : lieu de sociabilité et formation d'une identité professionnelle (années I9301950) », Laurent Fourchard, Odile Goerg, Muriel Gomez-Perez (dir.), Lieux de sociabilité urbaine en Afrique, Paris, L'Harmattan, 2009, p. 135-150. 
Ead., « Mémoire de (sages)-femmes à l'époque coloniale (Ghana, I920-1960): sources orales, émergence d'un nouveau groupe socio-professionnel et histoire de la maternité », Geneviève Dermenjian, Françoise Thébaud, (dir.), Quand les femmes témoignent. Histoire orale, Histoire des femmes, Mémoire des fermmes, Paris, Publisud, 2009.

\section{Soudan}

Bell, Heather, "Midwifery Training and Female Circumcision in the InterWar Anglo-Egyptian Sudan", Journal of African History, 1998, 39 (2), p. 293-312.

Cruikshank, Alexandre, "The Golden Age of Tropical Medicine and its Impact on the Modernization of the Sudan", M. W. Daly (ed.), Modernization in the Sudan, Essays in Honor of Richard Hill, New York, Lilian Barber Press, 1985, p. 85-100.

\section{Orient, Asie}

\section{Inde}

LAL, Maneesha, « Politiques médicales et politiques du genre dans l'Inde coloniale : le Fonds de la comtesse de Dufferin, I885-1888 », Cabiers du Genre, I/2005, p. 87-I26.

LANG, Sean, "Drop the demon Dai: Maternal mortality and the state in Colonial Madras, I840-1875", Social History of Medicine, 2005, vol. I8, n 3 p. 357-378.

Japon

Homer, Aya, "Birth Attendants in Meiji Japan: The Rise of a Medical Birth Model and the New Division of Labour", Social History of Medicine, 2006, vol. 19, $\mathrm{n}^{\circ} 3, \mathrm{p} .407-424$.

\section{Palestine (ottomane)}

Shehory-Rubin, Zipora, "Jewish Midwives in Eretz Israel During the Late Ottoman Period, I850-1918”, Social History of Medicine, 2011, vol. 24, n² 2, p. 299-315. 
422 - L'ÉCOLE DES SAGES-FEMMES. NAISSANCE D'UN CORPS PROFESSIONNEL

\section{Turquie (ottomane)}

Balsoy, Gülhan, The Politics of Reproduction in Ottoman Society, 1838-1900, London, Pickering \& Chatto, 2013.

Ülman, Yeşim Işil, « Besim Ömer Alkalin (I862-1940) : ange gardien des femmes et des enfants », Méropi Anastassiadou-Dumont (dir.), Médecins et ingénieurs ottomans à l'âge des nationalismes, Paris, Istanbul, Maisonneuve et Larose, Institut d'Études anatoliennes, 2003, p. IOI-I23.

\section{Vietnam (Indochine)}

Nguren, Thuy Linh, "French-Educated Midwives and the Medicalization of Childbirth in Colonial Vietnam", Journal of Vietnamese Studies, 2010, vol. 5, $\mathrm{n}^{\circ} 2, \mathrm{p}+\mathrm{I} 33-\mathrm{I} 82$. 


\section{Annexes}

\section{Annexe I - Tableau récapitulatif des modalités de formation obstétricale par département (I790-I9I7)}

\begin{tabular}{|c|c|}
\hline Département & Récapitulatif des modalités de la formation \\
\hline Ain & $\begin{array}{l}\text { Cours fondé par arrêté du } 7 \text { ventôse an XII, en fonctionnement jusqu'à à } \\
\text { l'an XIII. Envois à Paris, puis recréation en I8I8 d'un cours ouvert à } \\
\text { Bourg-en-Bresse en I8Ig. Cours maintenu en I9I7. } \\
\text { Cours hospitalier (hospice de Bourg-en-Bresse, puis bâtiment indé- } \\
\text { pendant), avec un internat. }\end{array}$ \\
\hline Aisne & $\begin{array}{l}\text { Cours existant au début de la Révolution (I790-179I). Projet sans suite } \\
\text { en l'an IV-an v. Envois à Paris, puis ouverture d'un cours à l'hospice } \\
\text { civil en I } 832 \text {. Cours maintenu en I917. } \\
\text { Cours hospitalier (Hospice civil de Laon) avec un internat. }\end{array}$ \\
\hline Allier & $\begin{array}{l}\text { Cours à Moulins sous la Révolution, interrompu à une date indéterminée. } \\
\text { Demandes de rétablissement du cours entre l'an XII et l'an XIV. Envois à } \\
\text { Paris, puis rétablissement d'un cours à Moulins entre I8Ig et I82I. Envois } \\
\text { d'élèves à Clermont-Ferrand dans la deuxième moitié du siècle. }\end{array}$ \\
\hline Basses-Alpes & $\begin{array}{l}\text { Création d'un cours à Digne en I } 835 \text { mais fermeture de l'école en I } 838 \text {, } \\
\text { après refus du jury médical de recevoir plus longtemps des jeunes } \\
\text { femmes sans formation pratique. À partir de I } 865 \text {, création de bourses } \\
\text { d'élèves sages-femmes à l'école d'accouchement de Marseille. }\end{array}$ \\
\hline Hautes-Alpes & $\begin{array}{l}\text { Cours ouvert à Gap par arrêté du } 4 \text { frimaire an XI (fermé entre I806 } \\
\text { et I809). Entretien parallèle de deux élèves par an à l'Hospice de la } \\
\text { Maternité de Paris. Envois à Grenoble à partir de I82I. }\end{array}$ \\
\hline $\begin{array}{l}\text { Alpes- } \\
\text { Maritimes }\end{array}$ & $\begin{array}{l}\text { Cours professé à Sospel en l'an XII-an XIII. Aucun cours n'est mis en } \\
\text { place après la réunion du département en I } 860 \text {, aucune élève boursière } \\
\text { n'est envoyée hors du département. }\end{array}$ \\
\hline
\end{tabular}




\begin{tabular}{|c|c|}
\hline Ardèche & $\begin{array}{l}\text { Arrêté du I2 septembre } \mathrm{I} 807 \text { fondant un cours censé ouvrir à Aubenas } \\
\text { le } \mathrm{I}^{\text {er }} \text { septembre } \mathrm{I} 808 \text { (non tenu). Envoi des élèves à Paris jusqu'en } \mathrm{I} 8 \mathrm{I} 8 \text {, } \\
\text { puis Bourges jusqu'en } \mathrm{I} 837 \text {, puis Paris. }\end{array}$ \\
\hline Ardennes & Envois d'élèves à Paris à partir de l'an XII. \\
\hline Ariège & $\begin{array}{l}\text { Cours à Pamiers sous l'Ancien Régime, non maintenu sous la } \\
\text { Révolution. Création à l'hospice de Pamiers en I809 (règlement du } \\
\mathrm{I}^{\text {er }} \text { septembre I809). Réorganisation du cours (arrêté préfectoral du } \\
\text { I7 janvier I838). Suppression en I9I6. } \\
\text { Cours hospitalier (Hospice de Pamiers) avec un internat (I878). }\end{array}$ \\
\hline Aube & $\begin{array}{l}\text { Cours à Troyes sous l'Ancien Régime, interrompu à la Révolution. } \\
\text { Envois (irréguliers) à Paris à partir de I807, réguliers de I8I6 à I } 835 \text {. } \\
\text { Cours semi-officiel entre l'an Ix et I8I4, repris en I8I6, officialisé en } \\
\text { I835. Suppression en I859. Reprise des envois à Paris. } \\
\text { Cours hospitalier (Hôtel-Dieu-le-Comte à Troyes) avec internat. }\end{array}$ \\
\hline Aude & $\begin{array}{l}\text { Cours à Carcassonne sous l'Ancien Régime, interrompu dans les } \\
\text { années I790. Envois d'élèves à Paris, puis à Montpellier (à partir de } \\
\text { I8I9 jusqu'à la fin du siècle). }\end{array}$ \\
\hline Aveyron & $\begin{array}{l}\text { Cours en I792, puis interruption. Cours fondé à Rodez par l'arrêté du } \\
7 \text { pluviôse an VI, maintenu de façon semi-officielle jusqu'à la réorga- } \\
\text { nisation de I8I3. Suppression en } 1847 \text {. Envois d'élèves à Montpellier. } \\
\text { Rétablissement du cours le } \mathrm{I}^{\text {er }} \text { novembre I859. Suppression en I867. } \\
\text { Envois à Lyon à partir de cette date. Recréation d'une école en I9I7. } \\
\text { Établissement indépendant sans internat au XIX }{ }^{\mathrm{e}} \text { siècle. }\end{array}$ \\
\hline $\begin{array}{l}\text { Bouches-du- } \\
\text { Rhône }\end{array}$ & $\begin{array}{l}\text { Cours sous l'Ancien Régime. Pendant la décennie I8Io, envois à Paris } \\
\text { (de la part des hospices). Arrêté réglementaire pour la création d'un } \\
\text { cours à Marseille approuvé le } 27 \text { juillet I8I3 par le ministre de l'Inté- } \\
\text { rieur, revu en I8I8 et de nouveau approuvé par le ministre le } 3 \text { juillet } \\
\text { I8I8 (Hôtel-Dieu, section de la maternité). Faute de fonds, l'établisse- } \\
\text { ment n'ouvre qu'en I822. Cours maintenu en I9I7. } \\
\text { Cours hospitalier (Hospice de la maternité de Marseille) avec internat. }\end{array}$ \\
\hline Calvados & $\begin{array}{l}\text { Cours à Caen sous l'Ancien Régime, maintenu de façon semi-officielle } \\
\text { sous la Révolution, puis réorganisé par l'arrêté du } 29 \text { novembre I } 809 \text {, } \\
\text { approuvé par le ministre de l'Intérieur. En parallèle, envoi d'une élève } \\
\text { par an à Paris à partir de } 1807 \text {, puis de deux, à partir des années I } 820 \\
\text { jusqu'en I } 852 \text {. Cours maintenu en } 1917 \text {. } \\
\text { Cours hospitalier (Hospice des malades de Caen) avec internat pour } \\
\text { les élèves boursières. }\end{array}$ \\
\hline Cantal & $\begin{array}{l}\text { Envois à Paris à partir de l'an XII jusqu'en I8I2, reprise en I8I8 et à } \\
\text { partir de I834, envoi d'élèves à Tulle. Maintien par ailleurs d'un envoi } \\
\text { à Paris, comme année de perfectionnement pour la meilleure élève } \\
\text { sortant de Tulle (jusqu'en I846). À partir de I845, envois à Clermont- } \\
\text { Ferrand (sauf quelques cas exceptionnels à Paris et Montpellier). }\end{array}$ \\
\hline
\end{tabular}




\begin{tabular}{|c|c|}
\hline Charente & $\begin{array}{l}\text { Cours à Angoulême de l'an viI (arrêté du I2 ventôse) à l'an XI (au } \\
\text { moins). Après une interruption pendant laquelle des élèves sont } \\
\text { envoyées à Paris, cours recréé par l'arrêté du } 23 \text { février I8I3 (approuvé } \\
\text { par le ministre). Suppression en I } 852 \text { puis envois d'élève à Toulouse } \\
\text { (jusqu'en I859) puis à Bordeaux. } \\
\text { Cours hospitalier (hospice général d'Angoulême) avec internat pour } \\
\text { les élèves boursières. }\end{array}$ \\
\hline $\begin{array}{l}\text { Charente- } \\
\text { Maritime }\end{array}$ & $\begin{array}{l}\text { Cours fondé à La Rochelle en } \mathrm{I} 806 \text {, régularisé en } \mathrm{I} 8 \mathrm{1} 3 \text {. Suppression du } \\
\text { cours en } \mathrm{I} 888 \text {. Les élèves du département vont à Bordeaux par la suite } \\
\text { (mais sans bourse). } \\
\text { Établissement indépendant avec internat (pour les boursières à partir } \\
\text { de } 1840 \text { et les internes payantes à partir de } 1850 \text { ). }\end{array}$ \\
\hline Cher & $\begin{array}{l}\text { Cours créé à Bourges en I818. L'établissement rayonne sur plusieurs } \\
\text { départements : Corrèze (1818 à I820); Creuse (1823-1828) ; Ardèche } \\
\text { (I818-1836); Indre (I818-1836). Suppression en I836. Envoi des élèves } \\
\text { à Paris. } \\
\text { Établissement indépendant avec internat. }\end{array}$ \\
\hline Corrèze & $\begin{array}{l}\text { Cours sous l'Ancien Régime, interrompu puis cours en l'an X. Envois à } \\
\text { Paris à partir de l'an XI et, en plus, à Bourges de I8I8 à I820. Créations } \\
\text { de cours d'arrondissement: Tulle (I827), Meymac (I828), Brive (I829). } \\
\text { Fondation de l'école départementale en I834. Suppression en I895. } \\
\text { Envois d'élèves à Bordeaux à partir de cette date. } \\
\text { Établissement indépendant avec internat (I834). }\end{array}$ \\
\hline Corse & $\begin{array}{l}\text { Médecin chirurgien désigné pour faire un cours par arrêté du } 24 \text { ven- } \\
\text { démiaire an XIV (sans suite). Cours théorique existant dans les années } \\
\text { I8Io (sans précision) et interrompu avant I8I9. Cours fondé à Bastia en } \\
\text { I852. Suppression en I860. Aucun envoi hors du département. } \\
\text { Cours hospitalier. }\end{array}$ \\
\hline Côte-d'Or & $\begin{array}{l}\text { Continuité parfaite du cours à Dijon avec l'Ancien Régime hormis une } \\
\text { brève interruption (an IV-an v). Reprise en l'an VI (arrêté du I } 8 \text { ven- } \\
\text { tôse) jusqu'en I809. Interruption faute de fonds avant réouverture en } \\
\text { I8I2. Le cours est réorganisé en I82I (création d'une maternité). Cours } \\
\text { maintenu en I9I7. } \\
\text { Cours hospitalier (bâtiment particulier à partir de I845) avec internat } \\
\text { partiel (I845). }\end{array}$ \\
\hline $\begin{array}{l}\text { Côtes-du- } \\
\text { Nord }\end{array}$ & $\begin{array}{l}\text { Cours à Saint-Brieuc sous l'Ancien Régime, brièvement interrompu } \\
\text { en I79I puis repris (sous forme fixe ou itinérante) jusqu'en l'an v. } \\
\text { Envois d'élèves à Paris à partir de } 1807 \text {. }\end{array}$ \\
\hline Creuse & $\begin{array}{l}\text { Envois à Paris à partir de l'an XII, puis à Bourges de I823 à I828. Reprise } \\
\text { des envois à Paris puis envois à Montpellier à partir de } 1876 .\end{array}$ \\
\hline Dordogne & $\begin{array}{l}\text { Cours à Périgueux de I792 à l'an v. Envois à Paris dès l'an x jusqu'en } \\
\text { I } 873 \text { puis à Bordeaux. }\end{array}$ \\
\hline
\end{tabular}




\begin{tabular}{|c|c|}
\hline Doubs & $\begin{array}{l}\text { Cours à Besançon jusqu'en I790, puis brève reprise entre l'an viI et } \\
\text { l'an Ix. Un nouveau cours, voté en I809, approuvé par le ministre en } \\
\text { I8I2, n'est finalement organisé qu'en I8I9 avec adjonction d'une salle de } \\
\text { maternité. Cours maintenu en I9I7. } \\
\text { Établissement indépendant (maison de refuge de Bellevaux) avec internat. }\end{array}$ \\
\hline Drôme & $\begin{array}{l}\text { Envois réguliers d'élèves à Paris dès l'an x, transférés à Bourg-en- } \\
\text { Bresse à partir de I } 836 \text { jusqu'en I894, puis envois à Lyon. Quelques } \\
\text { envois ponctuels à Grenoble dans les années I840-1850. }\end{array}$ \\
\hline Eure & $\begin{array}{l}\text { Annonce d'un cours à Évreux à partir du I }{ }^{\text {er }} \text { juin } 1807 \text { (sans suite } \\
\text { pérenne apparente). Envois à Paris. }\end{array}$ \\
\hline Eure-et-Loir & $\begin{array}{l}\text { Création d'un cours à Chartres le } 27 \text { brumaire an } \mathrm{x} \text {, supprimé en I8I4, } \\
\text { puis rétabli en I } 820 \text {. Cours maintenu en I9I7. } \\
\text { Cours hospitalier (hospice de Chartres) sans internat. }\end{array}$ \\
\hline Finistère & $\begin{array}{l}\text { Projet d'établissement d'un cours à Brest en l'an XIII (sans suite). } \\
\text { Nouvelle création en I816. Suppression en I827. Envois à Paris puis, } \\
\text { à partir de I839, à Lorient. Rétablissement d'un cours à Brest en I854. } \\
\text { Cours maintenu en 917. } \\
\text { Cours hospitalier (hospice civil de Brest) avec internat (I854). }\end{array}$ \\
\hline Gard & $\begin{array}{l}\text { Cours semi-officiel à Nîmes à partir de l'an VII, officialisé en l'an IX et } \\
\text { poursuivi jusqu'en I806. Quelques envois à Paris à partir de l'an XIII. } \\
\text { Nouvelle création en I827, suppression officielle en I850, concrète en } \\
\text { I868. Rétablissement en I883. Cours maintenu en I9I7. } \\
\text { Cours hospitalier (hospice d'humanité) sans internat. }\end{array}$ \\
\hline $\begin{array}{l}\text { Haute- } \\
\text { Garonne }\end{array}$ & $\begin{array}{l}\text { Existence d'un cours à Toulouse en I792, interrompu à une date incon- } \\
\text { nue. Nouveau cours à partir de l'an XI, réorganisé en I808. Suppression } \\
\text { de l'internat des élèves en I893. Cours non maintenu en I9I7 (peut-être } \\
\text { supprimé dès la décennie I890). } \\
\text { Cours hospitalier (hospice Saint-Jacques puis hôpital de la Grave) } \\
\text { avec internat (I809). }\end{array}$ \\
\hline Gers & $\begin{array}{l}\text { Cours à Auch sous l'Ancien Régime et jusqu'au début des années } \\
\text { I790. Cours privé à partir de l'an XI, semi-officiel à partir de I } 807 \text { mais } \\
\text { ne bénéficiant jamais d'une organisation approuvée par le ministre. } \\
\text { Suppression en I839. Envois à Toulouse. } \\
\text { Cours indépendant (maison départementale de secours), sans internat. }\end{array}$ \\
\hline Gironde & $\begin{array}{l}\text { Continuité entre l'Ancien Régime et la période suivante. } \\
\text { L'administration du département renouvelle en I79I sa mission à } \\
\text { Marguerite Coutanceau (cours semi-itinérant et bordelais jusqu'en } \\
\text { l'an viII). Réorganisation en I8I6, I8I7 au sein de l'école d'accouche- } \\
\text { ment. Réforme en I } 849 \text { qui lie plus étroitement école d'accouchement } \\
\text { et hospice de la maternité jusqu'à la réunion en I854 de tous les ensei- } \\
\text { gnements à l'hospice de la maternité. Lors de la réforme de I893, l'école } \\
\text { de Bordeaux obtient le droit de faire exception par décret ministériel } \\
\text { du } 25 \text { juillet I895. Cours maintenu en I9I7. } \\
\text { Établissement indépendant puis hospitalier (annexé aux hospices } \\
\text { civils de Bordeaux; Maternité Pellegrin) avec internat ouvert (I8I7) } \\
\text { puis fermé (I854). }\end{array}$ \\
\hline
\end{tabular}




\begin{tabular}{|c|c|}
\hline Hérault & $\begin{array}{l}\text { Cours à Montpellier sous l'Ancien Régime, interrompu au début } \\
\text { de la Révolution jusqu'en l'an v. Rétablissement auprès de l'école de } \\
\text { santé, puis à partir de l'an XI, cours surtout théorique à l'hospice de } \\
\text { Montpellier. Réorganisation en } 1807 \text { puis en I8I3. Cours à statut déro- } \\
\text { gatoire attaché à la faculté de médecine (formation de sages-femmes } \\
\text { de ière classe). Cours maintenu en I9I7. } \\
\text { Cours hospitalier (hôpital Saint-Éloi) puis établissement semi-hospita- } \\
\text { lier indépendant (dépôt de mendicitéà partir de I8I3) avec internat (I824). }\end{array}$ \\
\hline Ille-et-Vilaine & $\begin{array}{l}\text { Cours à Rennes sous l'Ancien Régime, interrompu entre I793 et } \\
\text { l'an IV. Rétablissement jusqu'en l'an XI. Envois à Paris de l'an XIII à } \\
\text { I8I6. Création d'un cours à Rennes, financé par le conseil général à } \\
\text { partir de I820. Réorganisation en I847. Cours maintenu en I9I7. } \\
\text { Cours extra-hospitalier (dépôt de mendicité jusqu'en I824 puis au } \\
\text { domicile du professeur), puis hospitalier (Hôtel-Dieu en I847 puis } \\
\text { hôpital Napoléon III en I867). "Internat » chez une sage-femme. }\end{array}$ \\
\hline Indre & $\begin{array}{l}\text { Envois à Paris avec quelques interruptions à partir de l'an XI, puis à } \\
\text { Bourges de I8I8 à I836. À la fermeture de l'école de Bourges, les envois } \\
\text { à Paris reprennent. }\end{array}$ \\
\hline $\begin{array}{l}\text { Indre-et- } \\
\text { Loire }\end{array}$ & $\begin{array}{l}\text { Cours à Tours sous l'Ancien Régime. Réorganisation (ou rétablisse- } \\
\text { ment) du cours d'accouchement à Tours par arrêté du } 29 \text { ventôse an X, } \\
\text { jusqu'en I } 808 \text {. Envois à Paris jusqu'en I8I } 8 \text { et la recréation d'un cours à } \\
\text { l'hospice de Tours. Cours maintenu en I9I7. } \\
\text { Cours hospitalier (hospice Saint-Clément pour la théorie, hospice } \\
\text { Saint-Jacques pour la pratique; puis maternité de l'hospice général) } \\
\text { sans internat. }\end{array}$ \\
\hline Isère & $\begin{array}{l}\text { Cours à Grenoble depuis l'Ancien Régime, sans solution de continuité } \\
\text { pendant la période révolutionnaire. Cours de district au début des } \\
\text { années } 1790 \text { : Vienne, Saint-Marcellin et Crémieu. Réorganisation du } \\
\text { cours en I8I6. Cours maintenu en I9I7. } \\
\text { Cours extra-hospitalier (maternité du dépôt de mendicité puis en I8I3 } \\
\text { maison de correction et de refuge de Saint-Robert) puis hospitalier } \\
\text { (hospice civil de Grenoble en I846) avec internat. }\end{array}$ \\
\hline Jura & $\begin{array}{l}\text { Sans doute existence d'un cours sous l'Ancien Régime. Période révo- } \\
\text { lutionnaire : cours à Arbois (I790-I793), à Saint-Claude (I790-an IV) } \\
\text { et à Salins (I789-I794). Envois à Paris à partir de l'an XI, puis à Lyon } \\
\text { à partir de } 1820 \text { (quelques envois à Paris en I822-I823). Changement } \\
\text { pour Bourg-en-Bresse à partir de I859 (au plus tard) et Besançon à } \\
\text { partir de } 1876 \text {. }\end{array}$ \\
\hline Landes & $\begin{array}{l}\text { Existence d'un cours au moins à partir de l'an x, organisé par le préfet } \\
\text { en } 1809 . \text { La reconnaissance officielle par le ministre intervient en I8I8. } \\
\text { Suppression en I820. Envois à Paris à partir de cette date. } \\
\text { Cours hospitalier (hospice de Dax) avec internat (I8I8). }\end{array}$ \\
\hline Loir-et-Cher & $\begin{array}{l}\text { Cours à Blois sous l'Ancien Régime puis sous la Révolution (pas de } \\
\text { dates précises). Après une interruption, le cours est recréé en I8Io, } \\
\text { signalé supprimé en I8I4 et rétabli en I829. Cours maintenu en I9I7. } \\
\text { Cours hospitalier (Hôtel-Dieu de Blois) sans internat. }\end{array}$ \\
\hline
\end{tabular}




\begin{tabular}{|c|c|}
\hline Loire & $\begin{array}{l}\text { Envois à l'école de Bourg-en-Bresse des années I830 à I } 888 \text {. Création } \\
\text { d'un cours à Saint-Etienne en I } 889 \text { sur une base d'admission biannuelle } \\
\text { qui perdure au moins jusqu'en I9I3. Le cours n'existe plus en I9I7. } \\
\text { Cours hospitalier (Hôtel-Dieu). }\end{array}$ \\
\hline Haute-Loire & $\begin{array}{l}\text { Envois à Paris jusqu'en I833. En I845 et } 1856 \text { (peut-être I854), envois } \\
\text { de boursières à Lyon jusqu'en I894. }\end{array}$ \\
\hline $\begin{array}{l}\text { Loire- } \\
\text { Inférieure }\end{array}$ & $\begin{array}{l}\text { Existence d'un cours à Nantes sous la Révolution (an IV), interrompu } \\
\text { puis rétabli en l'an viı de façon pérenne. Organisation officielle en } \\
\text { I808. Cours maintenu en I9I7. } \\
\text { Cours hospitalier (Hospice des orphelins puis maternité de l'Hôtel- } \\
\text { Dieu, I873) avec internat. }\end{array}$ \\
\hline Loiret & $\begin{array}{l}\text { Cours à Orléans sous l'Ancien Régime, interrompu puis recréé en } \\
\text { l'an viI. Réorganisation du cours par l'arrêté du 2I brumaire an x qui } \\
\text { fonctionne jusqu'en l'an XII. Envois à Paris, puis rétablissement d'un } \\
\text { cours en } 1808 \text {. Cours maintenu en I9I7. } \\
\text { Cours hospitalier (maison de la Croix) avec internat. }\end{array}$ \\
\hline Lot & $\begin{array}{l}\text { Cours sous l'Ancien Régime, interrompu sous la Révolution. Envois à } \\
\text { Paris, puis création d'un cours à Cahors en I8I8. Suppression en I823, } \\
\text { puis retour à la pratique d'envois à Paris. } \\
\text { Cours hospitalier sans internat. }\end{array}$ \\
\hline $\begin{array}{l}\text { Lot-et- } \\
\text { Garonne }\end{array}$ & $\begin{array}{l}\text { Cours à Agen sous la Révolution (I79I à l'an x), interrompu. Recréation } \\
\text { d'un cours dans les années I830, officialisé en I836. Suppression en } \\
\text { I840. Envois à Paris à partir de cette date. } \\
\text { Cours extra-hospitalier sans internat. }\end{array}$ \\
\hline Lozère & $\begin{array}{l}\text { Cours sous l'Ancien Régime, interrompu à la Révolution. Envois à } \\
\text { Paris à partir de } 1820 \text {, puis à Montpellier à partir de } 1844 \text {. }\end{array}$ \\
\hline $\begin{array}{l}\text { Maine-et- } \\
\text { Loire }\end{array}$ & $\begin{array}{l}\text { Cours à Angers dès le début de la période révolutionnaire. } \\
\text { Réorganisation du cours en } 1808 \text {. Cours maintenu en I9I7. } \\
\text { Cours hospitalier (hospice des enfants naturels de la patrie puis Hôtel- } \\
\text { Dieu) avec internat (I808). }\end{array}$ \\
\hline Manche & $\begin{array}{l}\text { À partir de I848, subvention aux élèves sages-femmes, qui vont soit à } \\
\text { Paris, soit à Caen. }\end{array}$ \\
\hline Marne & $\begin{array}{l}\text { Cours (dans différentes villes) sous l'Ancien Régime, qui se pour- } \\
\text { suivent jusqu'en l'an Iv (Reims, Châlons-en-Champagne, Vitry-le- } \\
\text { François, Sainte-Menehould, Sézanne). Reprise d'un cours en l'an viII } \\
\text { à l'Hôtel-Dieu de Reims. Cours maintenu en I917. } \\
\text { Cours hospitalier (Hôtel-Dieu) avec internat (I809). }\end{array}$ \\
\hline Haute-Marne & $\begin{array}{l}\text { Cours sous la Révolution (an IV), interrompu puis repris à Chaumont } \\
\text { à partir de l'an viII. Fondation d'une école en I834. Cours maintenu en } \\
\mathrm{I} 9 \mathrm{I} 7 . \text { En I8I2-I8I3 se tient aussi un cours à Langres. } \\
\text { Cours (hospitalier ?) puis établissement indépendant avec internat } \\
(\mathrm{I} 834) \text {. }\end{array}$ \\
\hline
\end{tabular}




\begin{tabular}{|c|c|}
\hline Mayenne & $\begin{array}{l}\text { Cours sous l'Ancien Régime et pendant une partie de la Révolution. } \\
\text { Interruption puis reprise d'un cours à Laval en I809. Réorganisation } \\
\text { du cours en I8I3 et création de cours parallèles à Mayenne et Château- } \\
\text { Gontier (encore en fonctionnement dans les années I830). Suppression } \\
\text { en I876 du cours de Laval, puis envois à Angers. } \\
\text { Cours hospitaliers puis établissement indépendant (hospice de la } \\
\text { maternité de Laval) sans internat. }\end{array}$ \\
\hline $\begin{array}{l}\text { Meurthe puis } \\
\text { Meurthe-et- } \\
\text { Moselle }\end{array}$ & $\begin{array}{l}\text { Cours sous l'Ancien Régime et jusqu'en I792. Reprise en l'an VI } \\
\text { jusqu'en l'an x. Interruption puis reprise du cours à Nancy en I805, } \\
\text { officialisé en I } 808 \text {. En I } 893 \text {, le cours bénéficie d'une exception pour } \\
\text { former au diplôme de ière classe. Cours maintenu en I9I7. } \\
\text { Cours extra-hospitalier (maison de secours de Nancy) avecinternat(I808). }\end{array}$ \\
\hline Meuse & $\begin{array}{l}\text { Cours à Bar et à Verdun par arrêté préfectoral en l'an viII mais sup- } \\
\text { primés en l'an XII. Envois à Paris. Fondation d'une école à Bar en I82I, } \\
\text { en fonctionnement au moins jusqu'aux années I } 880 \text { (suppression dans } \\
\text { la décennie suivante). } \\
\text { Cours hospitaliers (Hospice de Bar-le-Duc) avec internat (I82I). }\end{array}$ \\
\hline Morb & $\begin{array}{l}\text { Cours fait bénévolement à Lorient par un médecin à partir de l'an IX. } \\
\text { Le cours est officialisé en I8I3 et transformé en école d'accouchement } \\
\text { en I820. Cours maintenu en I9I7. } \\
\text { Établissement indépendant avec internat (I820). }\end{array}$ \\
\hline Moselle & $\begin{array}{l}\text { Cours fondé à Metz par arrêté du I5 germinal an x. En I804, le } \\
\text { professeur du cours, le docteur Morlanne, crée la future congréga- } \\
\text { tion des Sœurs de la Charité maternelle (religieuses sages-femmes). } \\
\text { Réorganisation des cours en I808 et création d'une école en I83I. } \\
\text { Suppression en I850 et envois à Paris et Strasbourg (selon que les } \\
\text { élèves sont ou non francophones). } \\
\text { Établissement indépendant avec internat (I843). }\end{array}$ \\
\hline Nièvre & $\begin{array}{l}\text { Peut-être existence d'un cours début XIX }{ }^{e} \text { siècle (mais sans précision). } \\
\text { Envois à Paris à partir de l'an XIV. }\end{array}$ \\
\hline Nord & $\begin{array}{l}\text { Cours à Lille sous l'Ancien Régime qui perdure sous la Révolution } \\
\text { au moins jusqu'en I809 (enseignement purement théorique). Envois à } \\
\text { Paris dès l'an x. Mise en place dans les années I } 830 \text { d'un cours complet } \\
\text { à l'Hôtel-Dieu puis à hospice Saint-Sauveur qui dépend de l'école pré- } \\
\text { paratoire de médecine de Lille. Le cours théorique se fait à la faculté de } \\
\text { médecine à partir de années i86o. } \\
\text { Cours hospitalier et universitaire sans internat. }\end{array}$ \\
\hline Oise & $\begin{array}{l}\text { Cours à Beauvais sous l'Ancien Régime, interrompu sous la Révolution. } \\
\text { Recréation d'un cours le 3i janvier i } 806 \text { qui fonctionne pendant deux } \\
\text { ans. Envois à Paris jusqu'à la fin du siècle. }\end{array}$ \\
\hline Orne & $\begin{array}{l}\text { Cours à Alençon sous l'Ancien Régime et la Révolution (au moins jusqu'en } \\
\text { I792). Interruption et envois irréguliers à Paris pendant le XIX siècle. }\end{array}$ \\
\hline
\end{tabular}




\begin{tabular}{|c|c|}
\hline Pas-de-Calais & $\begin{array}{l}\text { École sous l'Ancien Régime à Arras, conservée en I790. Cours à Boulogne } \\
\text { de I790 à I795. Interruption à Arras, cours refondé en I809 puis re-sup- } \\
\text { primé après I8I4. Recréation en I } 826 \text {. L'école est transférée à Rouen pen- } \\
\text { dant la Première Guerre mondiale. Cours maintenu après I9I7. } \\
\text { Établissement indépendant (maternité d'Arras) avec internat (I838). }\end{array}$ \\
\hline $\begin{array}{l}\text { Puy-de- } \\
\text { Dôme }\end{array}$ & $\begin{array}{l}\text { Cours au début de la Révolution (jusqu'en I790) puis à partir de l'an IV } \\
\text { et jusqu'en l'an XII. Envois à Paris à partir de l'an XIII mais parallèle- } \\
\text { ment à partir de I807 existence d'un cours à l'école de médecine de } \\
\text { Clermont-Ferrand. Création d'une école officielle en I8I6, réorganisée } \\
\text { en I82I. Cours maintenu en I9I7. } \\
\text { Cours hospitalier (Hôtel-Dieu de Clermont-Ferrand) puis établisse- } \\
\text { ment indépendant et école liée à la maternité (I896). }\end{array}$ \\
\hline $\begin{array}{l}\text { Basses- } \\
\text { Pyrénées }\end{array}$ & $\begin{array}{l}\text { Cours sous l'Ancien Régime (depuis } 1784 \text { ), interrompu en I789 et } \\
\text { repris en I79I mais sans doute rapidement interrompu. Cours semi- } \\
\text { officiel sous la Restauration. Envois à Paris jusqu'à la création d'un } \\
\text { cours à Pau en I833. Cours maintenu en } 1917 . \\
\text { Établissement indépendant avec internat (I883). }\end{array}$ \\
\hline $\begin{array}{l}\text { Hautes- } \\
\text { Pyrénées }\end{array}$ & $\begin{array}{l}\text { Cours sous l'Ancien Régime et jusqu'en l'an iv (au moins). Cours } \\
\text { refondé en I8I6, ouvert en I8I8 à Bagnères-de-Bigorre. Suppression en } \\
\text { I892 (transfert de la maternité à l'hospice de Tarbes). } \\
\text { Cours hospitalier (hôpital de Bagnères-de-Bigorre) avec internat. }\end{array}$ \\
\hline $\begin{array}{l}\text { Pyrénées- } \\
\text { Orientales }\end{array}$ & $\begin{array}{l}\text { Cours organisé à partir de l'an viı à Perpignan (professeurs rattachés } \\
\text { d'abord à l'école centrale puis bénévoles). Officialisation du cours I8I4. } \\
\text { Cours maintenu en I9I7. } \\
\text { Cours hospitalier (hôpital civil de Perpignan) sans internat. }\end{array}$ \\
\hline Bas- & $\begin{array}{l}\text { École d'accouchement fondée à Strasbourg au XVIII siècle (I728 puis } \\
\text { I737), continuité complète avec la période contemporaine. À partir de } \\
\text { messidor an XIII, l'école de médecine institue un cours régulier à des- } \\
\text { tination des sages-femmes. En I8I4, une école départementale d'accou- } \\
\text { chement est créée. Elle subsiste par-delà la période prussienne et existe } \\
\text { encore lors de la réintégration du Bas-Rhin à la France après I9I8. } \\
\text { Cours hospitalier (hospices civils de Strasbourg) puis établissement } \\
\text { indépendant avec internat (I838). }\end{array}$ \\
\hline Haut-Rhin & $\begin{array}{l}\text { Création d'un cours à Colmar par l'arrêté préfectoral du I I frimaire an XII, } \\
\text { officialisé en } 1807 \text {. Réorganisation du cours sous forme d'école départe- } \\
\text { mentale en I } 843 \text { et I } 846 \text {. L'école subsiste par-delà la période prussienne et } \\
\text { existe encore lors de la réintégration du Bas-Rhin à la France après I9I8. } \\
\text { Cours hospitalier puis établissement indépendant (hospice de la } \\
\text { maternité) avec internat. }\end{array}$ \\
\hline Rhône & $\begin{array}{l}\text { Cours sous l'Ancien Régime à Lyon et maintenu sous la Révolution. } \\
\text { Le cours n'est jamais interrompu. Lors de la réforme de I893, le cours } \\
\text { obtient un statut dérogatoire pour former des sages-femmes de } \\
\text { I }^{\text {re }} \text { classe. Cours maintenu en I9I7. } \\
\text { Cours hospitalier (hospice de la Charité de Lyon) avec internat (date } \\
\text { indéterminée). }\end{array}$ \\
\hline
\end{tabular}




\begin{tabular}{|c|c|}
\hline Haute-Saône & $\begin{array}{l}\text { Cours à Vesoul sous l'Ancien Régime et au début de la Révolution puis } \\
\text { interruption. Envois d'élèves à Paris et parallèlement à Besançon à par- } \\
\text { tir de i } 846 \text {. La double destination se maintient jusqu'à la fin du siècle. }\end{array}$ \\
\hline $\begin{array}{l}\text { Saône-et- } \\
\text { Loire }\end{array}$ & $\begin{array}{l}\text { Cours à Mâcon de I782 à l'an III, interrompu puis repris en l'an viII et } \\
\text { officialisé en I8I3. Cours maintenu en I9I7. } \\
\text { Établissement indépendant puis hospitalier (hospice de la Providence) } \\
\text { avec internat. }\end{array}$ \\
\hline Sarthe & $\begin{array}{l}\text { Cours au Mans sous l'Ancien Régime, interrompu au début de la } \\
\text { Révolution et rétabli en l'an vir. Le cours est officialisé en I808, sus- } \\
\text { pendu en I } 82 \text { I, rétabli en I } 826 \text { et supprimé définitivement en I } 854 \text {. } \\
\text { Envois à Angers par la suite. } \\
\text { Cours hospitalier avec internat. }\end{array}$ \\
\hline Savoie & $\begin{array}{l}\text { Création d'un cours à Chambéry en I } 808 \text { (après plusieurs propositions } \\
\text { en l'an XII et XIV) maintenu au moins jusqu'en I8I5. Création en I858 } \\
\text { pendant la période piémontaise de l'Institut Pillet-Will pour les sages- } \\
\text { femmes, devenu école départementale à partir de I860 à destination } \\
\text { des deux Savoies. Cours maintenu en I9I7. } \\
\text { Cours hospitalier (hospice de Chambéry) puis établissement indépen- } \\
\text { dant avec internat. }\end{array}$ \\
\hline Haute-Savoie & Envois d'élèves à l'Institut Pillet-Will à partir de 1858 . \\
\hline Seine & $\begin{array}{l}\text { L'école d'accouchement de l'Hospice de la Maternité de Paris prend en } \\
\text { l'an x le relais de l'office des Accouchées de l'Hôtel-Dieu. } \\
\text { Établissement indépendant avec internat. }\end{array}$ \\
\hline $\begin{array}{l}\text { Seine- } \\
\text { Inférieure }\end{array}$ & $\begin{array}{l}\text { Cours à Rouen sous l'Ancien Régime supprimé en l'an X. Demandes } \\
\text { de rétablissement de l'an XI à I8I3. Pas de date précise de recréation } \\
\text { du cours (circa I8I5), réorganisé en I820. Suppression officielle en I } 830 \\
\text { au profit d'envois à Paris (jusque dans les années I } 860 \text { avec une inter- } \\
\text { ruption dans les années I850); mais le cours continue en réalité de } \\
\text { fonctionner. Cours maintenu en I9I7. } \\
\text { Cours hospitalier (Hôtel-Dieu puis hospice général de Rouen) avec } \\
\text { internat (I820). }\end{array}$ \\
\hline $\begin{array}{l}\text { Seine-et- } \\
\text { Marne }\end{array}$ & Envois \\
\hline Seine-et-Oise & Envois à Paris. \\
\hline Deux-Sèvres & $\begin{array}{l}\text { Création d'une école à Niort en I824, réorganisé en I832 et supprimée } \\
\text { en } 1834 \text {. Après cette date envois à Poitiers et à Paris. } \\
\text { Cours hospitalier (hospice de Niort) avec internat. }\end{array}$ \\
\hline Somme & $\begin{array}{l}\text { Cours à Amiens sous l'Ancien Régime, maintenu au début de la } \\
\text { Révolution, interrompu puis rétabli en l'an viII. Cours officialisé en } \\
\text { I8Io et maintenu au moins jusque dans les années I } 840 \text {. } \\
\text { Cours hospitalier (Hôtel-Dieu d'Amiens) sans internat. }\end{array}$ \\
\hline Tarn & $\begin{array}{l}\text { Cours à Albi et Castres sous l'Ancien Régime, interrompus à la } \\
\text { Révolution. Envois à Paris puis à Toulouse. Création d'un cours à } \\
\text { Albi en } 1825 . \text { Suppression en } 1907 \text {. } \\
\text { Cours hospitalier (hospice civil d'Albi) avec internat. }\end{array}$ \\
\hline
\end{tabular}




\begin{tabular}{|c|c|}
\hline $\begin{array}{l}\text { Tarn-et- } \\
\text { Garonne }\end{array}$ & Envois à Paris à partir de $\mathrm{I} 8 \mathrm{IO}$. \\
\hline Var & $\begin{array}{l}\text { Envois à Paris en I8I4 et I8I5 ; puis à Marseille entre I826 et I83I. } \\
\text { Créations de cours à Toulon et Draguignan en I83I. Fonctionnement } \\
\text { parallèle des deux cours jusqu'en I9I7 où le cours de Draguignan est } \\
\text { supprimé. } \\
\text { Cours hospitaliers (hospice du Saint-Esprit à Toulon) avec internat. }\end{array}$ \\
\hline Vaucluse & $\begin{array}{l}\text { Cours à Avignon de l'an xi à l'an XIv, supprimé. Recréation d'un cours } \\
\text { en I830. Cours maintenu jusqu'en I9I7. } \\
\text { Cours hospitalier (hôpital d'Avignon) sans internat. }\end{array}$ \\
\hline Vendée & $\begin{array}{l}\text { Cours à Fontenay sous l'Ancien Régime, interrompu sous la } \\
\text { Révolution. Envois à Paris, puis à La Rochelle (I822-I824), puis Paris, } \\
\text { puis Niort (I825-I834), puis Angers (jusqu'en I873) et enfin Nantes } \\
\text { jusqu'à la fin du siècle. }\end{array}$ \\
\hline Vienne & $\begin{array}{l}\text { Cours à Poitiers sous l'Ancien Régime et jusqu'en l'an II. Reprise en } \\
\text { I806 mais envois d'élèves à Paris en parallèle. Officialisation en I8I3, } \\
\text { transformation en école en I } 842 \text {. Cours maintenu en I9I7. } \\
\text { Cours hospitalier (grand hospice de Poitiers) puis établissement indé- } \\
\text { pendant avec internat (I842). }\end{array}$ \\
\hline $\begin{array}{l}\text { Haute- } \\
\text { Vienne }\end{array}$ & $\begin{array}{l}\text { Cours sous l'Ancien Régime à Limoges, interrompu en I790. Fondation } \\
\text { d'un cours en I8I8 qui est supprimé en I829. Rétablissement en I836, } \\
\text { officialisation en I840. Cours maintenu en I9I7. } \\
\text { Cours extra-hospitalier puis établissement indépendant avec internat } \\
\text { (I876). }\end{array}$ \\
\hline Vosges & $\begin{array}{l}\text { Cours à Epinal sous l'Ancien Régime et jusqu'en I79I. Création d'un } \\
\text { nouveau cours en I802, réorganisé en école départementale en I84I } \\
\text { puis à la fin des années } 1840 \text {. Suppression en I88I puis envois à Nancy. } \\
\text { Établissement indépendant avec internat. }\end{array}$ \\
\hline Yonne & $\begin{array}{l}\text { Création d'un cours à Auxerre en date du } 22 \text { août I8I8 mais suppres- } \\
\text { sion par manque de fonds dès I8I9. Envois à Paris jusqu'en I850, puis à } \\
\text { Troyes jusqu'en I } 859 \text { et à nouveau à Paris jusquà la fin du siècle. } \\
\text { Cours extra-hospitalier (dépôt de mendicité) sans internat. }\end{array}$ \\
\hline Belfort & Envois à Besançon et à Nancy (à partir de I872). \\
\hline
\end{tabular}




\section{Annexe 2 - Publications de sages-femmes au XIX ${ }^{e}$ siècle}

Andrieu (Mlle), Du rôle de la sage-femme dans la société, Paris, impr. de AlcanLévy, I889.

Borvin (Marie-Anne), Mémorial de l'art des accouchements ou principes fondés sur la pratique de l'Hospice de la Maternité de Paris et sur celles des plus célèbres praticiens nationaux et étrangers suivi des aphorismes de Mauriceau, Paris, Méquignon l'aîné père, I8I2, consulté aussi dans ses trois éditions suivantes, corrigées et augmentées (1817, I824 et I836), traduit en italien [Dell'arte di assistere ai parti ; opera classica della signora Boivin, Milano, Giovanni Silvestri, 1822] et en allemand [Handbuch der Geburtshülfe, nach den Grundsätzen der Entbindungs-Anstalt zu Paris und denen der berübmtesten in- und ausländischen Geburtshelfer, nach der 3ten Ausg. d. Originals übersetzt von Ferdinand Robert, durchgesehen u. mit e. Vorrede begleitet von Dietr. Wilhelm Heinr. Busch, Cassel, Krieger, I829].

Ead., Mémoire sur les hémorragies internes de l'utérus, qui a obtenu le prix d'émulation au concours ouvert (en 1818) par la Société de médecine de Paris, suivi des Aphorismes d'Andrew Blake sur les hémorragies utérines, Paris, Gabon, I819.

Ead., Nouvelles recherches sur l'origine, la nature et le traitement de la môle vésiculaire, ou grossesse bydatique, Paris, Méquignon l'ainé père, I827, traduit en allemand [Neue Nachforschungen über die Entstebung, das Wesen und die Behandlung der Blasenmola oder Hydatidenschwangerschaft, Weimar, Landes-Industriecomptoir, 1828].

Ead., Recherches sur une des causes les plus fréquentes et la moins connue de l'avortement, suivies d'un mémoire sur l'intro-pelvimètre ou mensurateur interne du bassin, couronné par la Société royale de médecine de Bordeaux, Paris, J.-B. Baillière, I828, traduit en allemand [Ueber eine sebr gewöbnliche und noch wenig gekannte Ursache des Abortus, nebst einer Denkschrift über den IntroPelvimeter oder innern Beckenmesser, Leipzig, s. n., 1829].

Ead., Observations et réflexions sur les cas d'absorption du placenta, Paris, impr. de $\mathrm{M}^{\text {me }}$ Huzard, 1829.

Ead., Dugìs Antoine, Traité pratique des maladies de l'utérus et des annexes... accompagné d'un atlas de 41 planches in-fol., gravées et coloriées, représentant les principales altérations morbides des organes génitaux de la femme, Paris, J.-B. Baillière, I833, 2 vol. in- $8^{\circ}$, et atlas in-fol., traduit en anglais [A practical treatise on the diseases of the uterus and its appendages, London, Sherwood, Gibert and Piper, 1834].

Ead., Dugès Antoine, Anatomie pathologie de l'utérus et de ses annexes, Paris, J.-B. Baillière, I866, I vol., atlas de $45 \mathrm{pl}$. in-fol., gravées et coloriées. 
Borvin Marie-Anne, traductrice, Rigby (Edward), Nouveau traité sur les bémorrhagies de l'utérus d'Edouard Rigby et de Stewart Duncan... traduit de l'anglais, accompagné de notes, par $M^{\text {me }} V$ ve Boivin,... précédé d'une notice bistorique sur le traitement des hémorrhagies utérines, et suivi d'une lettre de M. Chaussier sur la structure de l'utérus, Paris, Méquignon l'aîné père, I818, traduit en italien d'après la traduction de Marie-Anne Boivin en I829-I830.

Borvin Marie-Anne, traductrice, BARon John, Recherches, observations et expériences sur le développement naturel et artificiel des maladies tuberculeuses, Paris, Vve Desray, I825.

Bouffier Prosper, Dr, Bouffier Mme, Maladies des femmes, métrite chronique, Paris, J.-B. Baillière et fils, I862.

Bourgeois Louise, Récit véritable de la naissance de Messeigneurs et Dames les enfans de France; Fidelle relation de l'accouchement, maladie et ouverture du corps de feu Madame; Instruction à ma fille, suivie du Rapport de l'ouverture du corps de feu Madame. Remontrance à Madame Bourcier, touchant son apologie, textes établis et annotés par François Rouget et Colette H. Winn, Genève, Droz, 2000.

Bretonville $\mathrm{M}^{\mathrm{me}}$, Confidence aux femmes, Paris, au cabinet de consultation de l'auteur, 1843.

Carrier Henriette, Origines de la maternité de Paris. Les maîtresses sagesfemmes et l'office des accouchées de l'ancien Hôtel-Dieu (1378-1796), par H. C., ancienne élève de la maternité, sage-femme de l'hôpital Lariboisière, Paris, Georges Steinheil, I888.

Charpentier $\mathrm{M}^{\mathrm{me}}$, Invitation, adressée aux sages-femmes par le Comité de la Société des sages-femmes unies, à prendre part à la souscription ouverte pour "offrir au Gouvernement provisoire une offrande patriotique ». Signé : Mmes Voilquin, Charpentier, Hugonen, Lavanture, Paris, impr. de Galban, I848.

Coillot J., Des Principaux empoisonnements et de leur mode de traitement, Besançon, impr. de J. Jacquin, I846.

Constant $\mathrm{M}^{\mathrm{me}}$, Avis d'une grand-mère aux mères de famille sur l'éducation physique des petits enfants et sur les premiers soins à leur donner, lorsqu'ils sont malades, Paris, au Comptoir des imprimeurs unis, I843.

Coquillard $\mathrm{M}^{\mathrm{me}}$, Mémoire sur les hémorragies utérines, Belleville, impr. de Galban, I844.

Coudray Marguerite-Angélique Le Boursier du, Abrégé de l'art des accouchements, Paris, Veuve Delaguette, 1759.

Coutal Marie Rose, veuve Sol, Abrégé. Traité pratique d'accouchement, par $M^{m e}$ C. S., sage-femme de $1^{\text {ère }}$ classe, Montpellier, impr. de Monnet, 1877. 
Coutanceau Marguerite Guillomance, épouse, Instructions théoriques et pratiques sur les accouchements à l'usage des élèves de $M^{\text {me }}$ Coutanceau, Bordeaux, A. Levieux, an viII.

Fournier $M^{\text {me }}$, Une sage-femme devant ses juges, défense présentée par $M^{m e}$ Fournier, maitresse sage-femme devant le tribunal de Chinon, Tours, impr. Ladevèze, I862.

Holleville Marguerite-Caroline, Discours funèbre, déposé sur la tombe du Dr Chaussier, au Père-Lachaise, le 21 juin 1828, Paris, impr. de H. Fournier, s. d. Holleville Marguerite-Caroline, Projet de cabinets de lecture populaire, dits "omnibus », spécialement destinés aux ouvriers et hommes de journée, conçu par Mlle Holleville, Paris, impr. de Everat, 1829.

Lachapelle Marie-Louise, Pratique des accouchements ou mémoires et observations choisies sur les points les plus importants de l'art, publiées par Antoine Dugès, son neveu, docteur en médecine, Paris, J. B. Baillière, libraire, I82I, consulté dans sa $2^{\mathrm{e}}$ édition augmentée (1825) et traduit en allemand [Practische Entbindungskunst; oder, Abhandlungen und auserlesene Beobachtungen über die wichtigsten Puncte der Geburtshülfe, Weimar, Landes-IndustrieComptoir, 1825].

Menne-Vaulot $\mathrm{M}^{\mathrm{me}}$, Mesdames enceintes, malades ou infécondes, Paris, chez l'auteur, I869.

Mercier J., Traité complet des manoeuvres de tous les accouchements, avec 180 aphorismes sur les soins que réclament la mère et l'enfant... par E. Adet de Roseville,... et $M^{m e}$ J. Mercier, Paris, Deville Cavellin, I836. ( $2^{e}$ édition en I837).

Messager Virginie, Traité pratique des fleurs blanches et des ulcérations de la matrice, Paris, chez l'auteur, I85I, réédité augmenté la même année sous le titre Traité pratique des maladies des femmes.

Ead., Manuel de la jeune mère, ou Conseils aux jeunes fermmes sur les soins que demandent leur santé et celle de leurs enfants en bas âge, suivi d'une instruction sur les soins de la toilette, Paris, chez l'auteur, I852, consulté dans sa $3^{\mathrm{e} e ́ d i t i o n}$ (1857).

Ead., Guide pratique de l'âge critique, ou Conseils aux femmes sur les maladies qui peuvent les attaquer à cette époque de leur vie, suivis de réflexions et d’observations sur les maladies laiteuses, Paris, chez l'auteur, I859.

Missart $\mathrm{M}^{\text {me }}$, Conseils à une mère sur l'allaitement et l'emmaillotement des nouveaux-nés, Epinal, impr. de E. Busy, I882.

$\mathrm{PAU}_{\mathrm{AU}} \mathrm{M}^{\mathrm{me}}$ veuve, Aux asthmatiques. Guérison radicale de l'asthme et du catarrhe par le traitement de $M^{\text {me }}$ Vve Pau, Paris, chez l'auteur, i867. (L'ouvrage connaît au moins huit éditions, chez plusieurs éditeurs différents entre 1867 et I879). 
Pinel Mme, Adresse à Messieurs du comité de salubrité, à l'Assemblée nationale, pour $M^{m e}$ Pinel, sage-femme, au sujet d'un instrument inventé par elle pour remédier aux abaissements de l'utérus, s. l, 1792.

Ratier Félix-Séverin, Dr, Recueil de pièces de $M^{\text {me }}$ veuve Breton, sage-femme, relatives à l'allaitement artificiel et à l'usage $d u$ biberon inventé par elle, Paris, l'auteur, I826-I828.

Renard M., Paris, villa d'accouchements et maison de santé pour dames. $1^{\text {er }}$ novembre 1857, Paris, impr. de Dubuisson, 1857.

Rondet Marie-Louise Chéon, épouse, Mémoire sur le prolapsus, ou chute de la matrice, et tous les autres déplacements des organes génito-urinaires de la femme, suivi de plusieurs observations et de deux rapports faits à l'Académie royale de médecine de Paris et à la société de médecine pratique, Mémoire envoyé à l'Institut (Académie des sciences) pour le concours aux prix de Monthyon, année I833, Paris, chez l'auteur, I833, réédité la même année.

Ead., Mémoire sur le cystocèle vaginal, ou hernie de la vessie par le vagin, et sur les meilleurs moyens d'y remédier, suivi de quelques observations relatives à divers autres déplacements des organes génitaux de la femme, Mémoire présenté à l'Académie des sciences, Paris, chez l'auteur, I835, traduit en allemand [Abhandlung über die Vesico-Vaginal-Hernie oder über den Bruch der Blase durch die Vagina und über die besten Mittel, demselben abzuhelfen, Quedlinburg, Leipzig, Basse, I839].

Ead., Guide des sages-femmes dans l'art de traiter le prolapsus ou chute de la matrice et autres déplacements des organes génito-urinaires de la femme, suivi d'observations authentiques, Mémoire présenté à l'Académie royale de médecine, Paris, chez l'auteur, 1836.

Tridon A., Mémoire sur le régime et les soins qui conviennent aux femmes après l'accouchement, Paris, chez l'auteur, impr. de Brun, s. d. (avant 1838).

Vion M.-H., Maladies de la matrice, ou Exposé succinct des signes qui font reconnaître les diverses affections qui attaquent cet organe, Paris, chez l'auteur, I837.

Wion-Pigalle Mme, Le conseiller secret des femmes, ou Conseils sur les moyens de se préserver des maladies qui atteignent spécialement les femmes, Paris, chez l'auteur, I858, réédité en $186 \mathrm{I}$.

Ead., De la Peur du choléra et de l'influence pernicieuse que ce sentiment exerce sur la santé, Paris, chez l'auteur, 1865. 


\section{Index}

A

Abelin, Germain, médecin, 317

Académie de médecine, 26I, 345,

$347-348,359-363,366$

Adet de Roseville, Ernest, médecin, 317-318

Afrique Occidentale française, 25

Agen, Lot-et-Garonne, préf., 214, 272, 428

Ain, dép., I48, 168, 173-174, 184, 190, I93, 196, 20I, 218, 247-248, 274, 279-28I, 284, 292, 299-300, 303, $336,344-346,432$

Aisne, dép., 190, 271, 284-285, 305, 423 Aix-en-Provence, Bouches-du-Rhône, ch.-l. d'arr., 200 Albi, dép. Tarn, préf., 70, 163, 29I, 387, 43I

Alençon, Orne, préf., 429

Alfort, voir Maisons-Alfort

Algérie, 25, 167, 272

Alhoy, membre de la commission des hospices de Paris, 147
Allemagne, 25, II5, 317, 348, 365

Allier, dép., 7I, 192, 423

Alpes (Basses-), voir

Alpes-de-Haute-Provence

Alpes (Hautes-), dép., 53, 62, 74, 88,

93, I04, I06, I45, I67, I70, 204, 322, 423

Alpes-de-Haute-Provence, dép., I67, 423

Alpes-Maritimes, dép., I6I, 193, 423

Alsace, 88, I48, 365

Amérique, voir États-Unis

Amiel, médecin, professeur

d'accouchement (Rodez), 185

Amiens, baillage de, voir Somme

Amiens, Somme, préf., 43I

Amsterdam, Pays-Bas, cap., I42, 166

Anaba, anc. Bône, Algérie, 272

André, Antoine Balthazar Joachim

(d'), député, 82

Angers, Maine-et-Loire, préf., 88, 90, 96, I00, I85, I9I, 200, 210, 237, 244, 25I, 272, 295, 348, 382, 387, 428429, 43I-432 
Angleterre, voir Royaume-Uni, Angoulême, Charente, préf., 4I, 163,

I77, 251, 278-279, 333, 337, 363, 425 Angoumois, voir Maine-et-Loire Angoulême, Marie-Thérèse de

France, duchesse (d'), 287

Annonay, Ardèche, ch.-l. cant., I79I80, 272

Aquitaine, 88-9I, IOI

Arbois, Jura, ch.-l. cant., 427

Ardèche, dép., 147, 165, 168, 218, 267,

$272,274,424-425$

Ardennes, dép., 165, 199, 398, 424

Ariège, dép., 49, 102-103, 162, 190, 25I, 279, 312, 335, 374, 398, 424

Arnezan, médecin, 294

Arno, anc. dép. français, auj. Italie, I37-I38, I44

Arques, auj. Arques-la-Bataille, SeineMaritime, cant. Dieppe, 37 Arras, Pas-de-Calais, préf., 95, 430 Astruc, Jean, chirurgien, 32I Aube, dép., 96, 171, 175, 177, 208, 226, 240, 273, 280-28I, 304, 346, 424 Aubenas, Ardèche, ch.-l. cant., 424 Auch, Gers, préf., 95, I73, 178, 426 Aude, dép., 51, 90, 92, 150, 165, 167, I92-I93, 204, 260, 424

Augier du Fot, Amable, chirurgien, démonstrateur d'accouchement (Soissons), 316, 326 Aups, Var, ch.-l.cant., 37, 44 Aurillac, Cantal, préf., 55, 72 Auvergne, 72, 218, 303-304 Auxerre, Yonne, préf., I63, 432 Auzoux, Louis Thomas, médecin, 333 Aveyron, dép., 40, 91, 132, I64, I90, I92, 20I, 204, 207, 235, 245, 249, 274, 279, 293, 312, 336-337, 382, 424 Avignon, Vaucluse, préf., 294, 432
B

Bagnères, médecin, 334

Bagnères-de-Bigorre, Hautes-Pyrénées, ch.-l. arr., I60, I64, I85, I88, 29I, 293, 430

Bailly, Oise, cant. Thourotte, 35

Ballainvilliers, Siméon-CharlesSébastien Bernard (de), intendant, 34

Baraillon, Jean-François, député, 44, 75, 78, 83-85

Barbier-Neuville, chef de division

(ministère de l'Intérieur), I33

Bar-le-Duc, Meuse, préf., 279-280, 429

Bar-sur-Seine, Aube, ch.-l. cant., 226

Basse-Auvergne, voir Cantal

Bastia, Haute-Corse, préf., 294, 425

Bastin, Mme, sage-femme en chef (Limoges), 284

Bâtie-Neuve (La), Hautes-Alpes, ch.-l. cant., 63

Baudelocque, Jean-Louis, chirurgien en chef de l'Hospice de la Maternité de Paris, 79, II2-II3, I2OI22, I3I, I5I, I53, I79, 276-277, 294, 315-319, 326-327, 33I, 334, 362

Bazas, Gironde, cant. Le Sud-Gironde, 214

Bazin, Jenny, sage-femme en chef (Montpellier), 283

Beauce, 9I

Beauvais, Oise, préf., 429

Belfort, terr. (de), dép., I65, 180, 432

Berlin, Allemagne, cap., I16, 318

Besançon, Doubs, préf., 96, 165, 169,

I80, 25I, 426-427, 43I-432

Bézille, Amélie, sage-femme en chef (La Rochelle), 230 
Bigeschi, Giovanni, chirurgien, professeur d'accouchement (Florence), I38, I44 Bigorre, voir Hautes-Pyrénées, Blois, Loir-et-Cher, préf., 427 Bocquillet, Marie, épouse Roger, secrétaire du Syndicat général des sages-femmes de France, 385-386, 389-390

Boerhaave, Herman, botaniste et médecin, 45

Bois-le-Duc, Bouches-du-Rhin, préf., auj. Pays-Bas, 142

Boivin, Marie-Anne-Victoire, sagefemme, docteure, 21, 288, 298, 315$318,320,322,325,331$

Bologne, Italie, I43-I44

Bonafos, médecin, professeur d'accouchement (Perpignan), I78

Bonaparte, Jérôme, roi de Westphalie, 137

Bonaparte, Napoléon, empereur, 93, I4I, I44

Bône, voir Anaba

Bonfils, François, médecin, professeur d'accouchement (Nancy), I76-177, 234, 240-244 Bonnet, Delphin-Napoléon, médecin, professeur d'accouchement (Poitiers), 33I

Bonnet, chirurgien, démonstrateur d'accouchement (Narbonne), 49, 51

Bonnieu, chirurgien, démonstrateur d'accouchement (Saint-Brieuc), 74, 89-90, 97, 99, 105-106

Bordeaux, Gironde, préf., I66, 20I, 208, 213-2I4, 219, 227, 237-239, 287, $344,371,373,375-376,378,426$
École départementale d'accouchement, 30, 167, I87, I9I, 237, 247, 251, 286-288, 296-297, $301,312,426$

Hospice de la maternité, 88, I66, I9I, 286, 288, 426

Maternité et école d'accouchement, I9I, 25I, 27I, 289, 298, 301, 304-305, 376-377, 425-426

Bouches-de-l'Elbe, anc. dép. français, auj. Allemagne, 139

Bouches-de-la-Meuse, anc. dép. français, auj. Pays-Bas, 138-139 Bouches-du-Rhin, anc. dép. français, auj. Pays-Bas, 139

Bouches-du-Rhône, dép., 167, 190, 197, 424

Bouches-du-Weser, anc. dép. français, auj. Allemagne, 52, 137, 139

Bouchut, Eugène, médecin, 344 Bouot, Honorine, épouse Gerbaine, sage-femme en chef (Dijon), 282 Bouquier, Gabriel, député, 83 Bourbonnais, voir Allier, 7I Bourbon-Vendée, voir La Roche-sur-Yon

Bouresches, Aisne, cant. ChâteauThierry, 35

Bourg-en-Bresse, Ain, préf., IOI, I62I63, I68-I69, I73-I74, I84, I87, I96, 248, 291, 297, 299-300, 302-303, $319,328,340,344-346,382,400$, 423, 426-428

Bourgeois, Louise, sage-femme, I8, 47,220

Bourgeois de Jessaint, Claude, préfet, 93

Bourges, Cher, préf., I68-169, 272, 279, 282, 299, 301, 424-425, 427 
Bourgogne, 88, 91

Brême, Bouches-du-Weser, préf., auj. Allemagne, 139, 142

Brest, Finistère, ch.-l. arr., 160, 18I, 25I, 299, 329, 426

Bretagne, 7I, 74, 88, 90, 96, I04, I48

Breteuil, Achille Le Tonnelier (de), préfet, 287

Breton, Mme, sage-femme, 324

Bretonville, Mme, sage-femme, I8I

Brione, chirurgien, démonstrateur d'accouchement (Rennes), 96

Brive-la-Gaillarde Corrèze, ch.-l. arr., I59, 209-210, 425

Bruges, Belgique, I4I

Brunswick, Allemagne, II6

Budin, Pierre, médecin, 317, 331, 343

Buellet, Julie, sage-femme en chef (Mâcon), 299

C

Cabanis, Jean-Georges, médecin, député, 83

Caen, Calvados, préf., 88, 100, 162, I9I, 25I, 293, 372, 424, 428

Cahors, Lot, préf., 428

Calès, Jean-Marie, médecin, député, 83-85

Calvados, dép., 73, 162, 190, 195, 207, 235, 279, 304, 424

Camus du Martroy, Emmanuel, préfet, I73

Cantal, dép., 55, 57, 72, 88, 90, I68, 272,424

Capuron, Joseph, médecin, 316, 3I9-32I

Carcassonne, Aude, ch.-l.arr., I82, 424
Carteron, Jean-Baptiste, médecin, professeur d'accouchement (Mâcon), 174, 299

Cassel, Allemagne, in6

Castres, Tarn, ch.-l. arr., 48, 88, 43I

Catherine II, impératrice de Russie, II8

Cazeaux, Paulin, médecin, 317, 319, 324, 34I

Celle, Allemagne, 137

Chailly-Honoré, Charles, médecin, 316,331

Chalmy, administrateur départemental (Haut-Rhin), 61, 62

Châlons-en-Champagne, Marne, préf., 70, 89, 96-97, 102, 428

Chambéry, Savoie, préf., I6I, I7I-I72, 251, 279, 431

Champagne, 70, 77, 88, 90, 293

Champagny, Jean-Baptiste Nompère de, ministre de l'Intérieur, 133-135, I4I, I49, I57, I78-I79

Champmol, Emmanuel Crétet, comte de, ministre de l'intérieur, I4O

Chantreuil, Georges, médecin, 317, 349

Chaptal, Antoine, ministre de l'Intérieur, 93, I13-II4, I18-I20, I25, I3I-I33, I45, I48, I5O

Charente, dép., 65, 74, I48, I66, I90, 193-194, 235, 300, 333, 425

Charente-Inférieure, voir Charente-Maritime

Charente-Maritime, dép., I54-I55, 192-I93, I96, 201, 219, 224, 230, 280, 294, 425

Charrier, Clémentine, sagefemme en chef de l'Hospice de la Maternité de Paris, 327 
Chartres, Eure-et-Loir, préf., I63, I85, I89, 278-279, 295, 426

Château-Gontier, Mayenne, ch.-l. arr., I60, 429

Chaumont, Haute-Marne, préf., I7I, 210, 212-213, 247, 293-294, 382, 428

Chaussier, François, médecin, 90, I24, 403

Cher, dép., 40, 75, 77, 9I-92, I68, I93, I99, 28I, 293, 304, 312, 425

Chevandier, Antoine-Daniel, médecin, sénateur, 364

Chevreul, Michel, médecin, professeur d'accouchement (Angers), 88, 96, 295, 317

Chicotot, Bénigne, sage-femme en chef (Dijon), 282

Chinon, Indre-et-Loire, ch.-l. arr., 342 Cisalpine, République, auj. Italie, I36 Clément (père) médecin, professeur d'accouchement (Avignon), 293

Clément (fils), médecin professeur d'accouchement (Avignon), 293

Clermont-Ferrand, Puy-de-Dôme, préf., I62, I73, 294, 299-300, 303304, 423-424, 430

Colmar, préf. du dép. du Haut-Rhin, I80-I8I, 296-297, 430

Cologne, Allemagne, I40, 142

Coninck, Patrice (de), préfet, 139

Corbière, Jacques-Joseph, ministre de l'Intérieur, 26I

Corrèze, dép., 66, 91, I46, I59, I62, I68, I87-I88, I9O, 2OI, 208-2I2, 2I52I8, 22I-23I, 236-238, 248, 25I, 269, $274,285,289,297,300,304,312$, $373-374,397,425$

Corse, dép., 162, 167, 294, 425
Côte-d'Or, dép., 39, 6I, 65, 86, 90-9I, 95, I34, I46, I62, I74, 20I, 245, 25I, 272, 279, 293-294, 342, 425

Cotentin, bailliage, auj. Manche, 25, 36 Côtes-d'Armor, dép., 7I, 86, 90, 95, 97, 99, 105-106, 165, 208-210, 219, 238,425

Côtes-du-Nord, voir Côtes d'Armor Coudray, Marguerite-Angélique Le Boursier (du), sage-femme, I9, 59, 60, IOI, I27, I67, 22I, 240-24I, $275,286,307,316,324-326,390$ Coupé, Marie, épouse Altenbach, sage-femme en chef (Dijon), 282

Coutal-Sol, Marie-Rose, sagefemme, 318

Coutanceau, chirurgien, IOI, I66, 286

Coutanceau, Marguerite, sage-femme, professeure d'accouchement (Bordeaux), 88, IOI, I66-I67, 247, 25I, 275-276, 286288, 290, 3I2, 3I8, 334, 426

Crémieu, Isère, ch.-l. cant., I02, 427

Creuse, dép., 37, 44, 75, 91, 165, 168, 425

Crouzat, Eugène, médecin, professeur de clinique des accouchements, 317, 373

Cuvier, Georges, anatomiste, 26I Cuxac-Cabardès, Aude, cant. Saissac, I5O

\section{D}

Dalle Donne, Maria, sage-femme, docteure en médecine, professeure d'accouchement (Bologne), I43-I44

Damilaville, Étienne François, encyclopédiste, 5I 
Danemark, 235

Danyau, Antoine, médecin, 359

Darantière, médecin, professeur d'accouchement (Chaumont), 247, 293-294

Daubenton, Louis, naturaliste, 34

Daunou, Pierre, député, 83, 85

Dauphiné, 104, I70

Dax, Landes, ch.-l. arr., I60, I73, I79, 299, 336, 427

Delzeuzes, Jean-François, officier de santé, professeur d'accouchement (Évreux), I76

Delore, Xavier, médecin, 317

Depaul, Jean, médecin, 319, 343

Derchigny, Seine-Maritime, cant.

Dieppe-est, 37, 50

Desfarges, Joseph, chirurgien, 53, 204

Désormeaux, Antonin Jean, médecin, 319

Deux-Nèthes, anc. dép. français, auj. Pays-Bas, 143

Devergie, Alphonse, médecin, 347

Diderot, Denis, encyclopédiste, 34

Digne, Alpes-de-Haute-Provence, préf., 423

Dijon, Côte-d'Or, préf., 96, I35-136, I62, I74, I89, 244, 25I, 278, 282$284,305-306,330,334,336,338$, 425

Dinan, Côtes-d'Armor, ch.-l. arr., 39

Dordogne, dép., 165-166, 271, 383, 425

Doubs, dép., 95, 190, 234, 353, 383, 426

Draguignan, sénéchaussée de, voir Var

Draguignan, Var, ch.-l. arr., 160, 387, 432

Drôme, dép., I3I, 169-170, 199, 213, $302-303,320,336,426$
Druhen, Ignace, médecin, 353-354, 356-357

Dubois, Antoine, chirurgien en chef de l'Hospice de la Maternité de Paris, 4I, 277, 362-363

Dubois, Jacques, chirurgien, démonstrateur d'accouchement (Bretagne), 53, 73, 105

Dubois, Paul-Antoine, chirurgien en chef de l'Hospice de la Maternité de Paris, 319, 358

Duclos, Jean-Marc, chirurgien, démonstrateur d'accouchement (Toulouse), I76

Dugès, Antoine, médecin, 319

Dugès, Marie, sage-femme en chef de l'Office des Accouchées de l'Hôtel-Dieu, III, 307

Dupéché, Caroline, épouse Duboscq, sage-femme, professeure d'accouchement (Bordeaux), 288-289

Dupouy, Jean-Cézaire, chirurgien en chef de l'hospice de la maternité de Bordeaux, 287-289

Durozier, chirurgien, professeur d'accouchement (Dax), I77, I79

E

Échallon, Ain, cant. Nantua, 328 Élisabeth Petrovna, régnant comme Élisabeth $\mathrm{I}^{\mathrm{re}}$ de Russie, impératrice, II 8

Empire romain germanique, II5-II6, I37 Ems Oriental, anc. dép. français, auj. Allemagne, I4I

Ems supérieur, anc. dép. français, auj. Allemagne, I37 
Énaux, Joseph, chirurgien, professeur d'accouchement

(Dijon), 90, 96

Engel, médecin, professeur-adjoint d'accouchement (Colmar), 295

Épernay, Marne, ch.-l. arr., 89, 102

Épinal, Vosges, préf., I62, I71, 432

Escaut, anc. dép. français, auj.

Belgique, 143

Espagne, 235

Espalion, Aveyron, ch.-l. cant., 40

États-Unis, 24, 206, 391

Eure, dép., 149, 154, 426

Eure-et-Loir, dép., 162, 190, 193, 278, 426

Europe, 90, IOI, II7-II8, I36, I44, 220, 235

Évreux, Eure, préf., I54, 176, 426

Eyméoud, Pierre, chirurgien, démonstrateur d'accouchement (Gap), 53, 62-63, 104, 203-204

F

Fauchet, Jean Antoine Joseph, préfet, I38, 144

Faure, Marie, sage-femme en chef

(Montpellier), 283

Ferdinand III, grand-duc de

Toscane, 144

Finistère, dép., I05, 160, 181, 193-194, 235, 426

Flaubert, Achille Cléophas, médecin, professeur d'accouchement (Rouen), 26I, 295

Florence, Arno, préf., auj. Italie, 137, I42, I44

Fontan, Hector, journaliste, 343

Fontenay-le-Comte, Vendée, ch.-l. arr.,
Forêts, anc. dép. français, auj.

Luxembourg, I43

Fortoul, Hippolyte Nicolas, ministre de l'Instruction publique, 262

Fourcroy, Antoine-François, médecin, député, 83, I26-I27, I29I30, I45

Fournial, Jeanne, épouse Bondet, sage-femme, professeure d'accouchement (Tulle), 236, 289, 297

Fournier, Mme, sage-femme, 342

Frasne, Doubs, cant. Levier, 64

Fried, Jean-Jacques, médecin, professeur d'accouchement (Strasbourg), II5-II6

Frigerio, Jacques, pharmacien de l'Hospice de la Maternité de Paris, 347

G

Gallois, Ernest, médecin, 317

Gallot, Jean-Gabriel, médecin, député, 79

Gap, Hautes-Alpes, préf., 93, 423

Gard, dép., 90, 158, 177, 190, 291, 426

Gardien, Émile, médecin, 319-320

Garonne (Haute-), dép., 91, 93, I62, 193, 197, 279-280, 293, 426

Gautier d'Agoty, Jacques-Fabien, graveur, 33I

Gautrelet, Paul, médecin, professeur d'accouchement (Dijon), 282

Genève, anc. dép. français Léman, préf., auj. Suisse, I4I-I42

Gers, dép., 91, 95, I66, I78-I79, I97, $207,280,285,289,334,426$

Ghana, 25 
Girault, employé de l'Hospice de la Maternité de Paris, 120

Gironde, dép., 30, 88, 91, 161, 166-167, 2OI, 204, 227, 25I, 285-287, 290, $334,376-377,426$

Glasgow, Écosse, 348

Gorcum, Pays-Bas, 138

Göttingen, Allemagne, II6-II7, 139, 314

Gramberg, chirurgien, professeur d'accouchement (Oldenbourg), I39 Grenoble, Isère, préf., 88, 102, I04, I69-170, 295, 322-323, 339-34I, 348, $387,423,426-427$

Guéniard, Jean-Baptiste, médecin, professeur d'accouchement (Dijon), 282

Guérard, Jules, médecin, 347 Guérin, Alphonse, médecinchirurgien, 348

Guillotin, Joseph-Ignace, médecin, député, 79, 8I-82, 98, 267

Guizot, Pierre, ministre de l'Instruction publique, 26I Guyenne (Haute-), 94

$\mathrm{H}$

Halem (von), médecin, professeur d'accouchement (Aurich), I4I

Hambourg, Allemagne, I39

Hamon de Fresnay, Louis, médecin, 344

Hanovre, Allemagne, II7, 137

Haye (La), Pays-Bas, 138-139

Henry, Félicité, sage-femme en chef de l'Hospice de la Maternité de Paris, 379

Hérault, dép., 91, 159, 162, 167, 284, 3II, 427
Hoin, François-Jacques, chirurgien, professeur d'accouchement (Dijon), 90

Hollande, royaume de, voir Pays-Bas Hucherard, agent de surveillance de l'Hospice de la Maternité de Paris, I2O

\section{I-J-K}

Icart, Jean-François, chirurgien, professeur d'accouchement (Castres), 48-49, 52, 70, 316

Ille-et-Vilaine, dép., 90, 94-96, 99, 427

Indre, dép., 91-92, 168, I77, 425, 427

Indre-et-Loire, dép., 7I, 91, 427

Innocenti, Ospedale degli, Florence, Italie, 138,144

Isère, dép., 46, 73, 95, I02, I6I, I70, 2OI, 218, 295, 329, 427

Italie, 24-25, II5, I36, I43-I44 Jacquelot, Laurent, médecin, professeur d'accouchement (Mâcon), 374

Jacquemier, Jean-Marie, médecin, $317,319,327$

Jacquier, Nicolas, médecin, professeur d'accouchement (Troyes), 175, 177

Jallet, médecin., professeur d'accouchement (Poitiers), 249 Jard-Panvilliers, Louis-Alexandre, médecin, député, 126 Jaucourt, Louis (de), encyclopédiste, 34

Jemmapes, anc. dép. français, auj.

Belgique, I40, I43 Jenner, Edward, médecin, I23 
Jenty, Charles-Nicolas, graveur, 331 Jura, dép., I65, I69, 427

Jurine, Louis, médecin, professeur d'accouchement (Genève), I4I Klinglin, François-Joseph, prêteur royal (Strasbourg), II5

$\mathrm{L}$

La Mettrie, Julien Jean Offray (de), médecin et philosophe, 45

Lachapelle, Marie-Louise, née Dugès, sage-femme en chef de l'Hospice de la Maternité de Paris, 2I, III, II5, I22, I25, I3O, I77, 277, $307,317,319,327,334$

Ladoucette, Charles-François (de), préfet, 93

Laennec, René Hyacinthe, médecin, 325

Lagarde, Ernest, médecin, 317

Lakanal, Joseph, député, 85

Lamballe, Côtes-d'Armor, ch.-l. cant., 299

Landes, dép., 9I, 160, 166, I73, I77, 280,427

Lange, A., anatomiste, 331-332

Langres, Haute-Marne, ch.-l. arr., 206

Languedoc, 34, 91

Laon, Aisne, préf., I84-187, 27I, 285, $382,384,387,423$

Larrey Dominique, chirurgien, 158

Larrey, François, chirurgien, professeur d'accouchement (Nîmes), 158, 177

Laurent, Gilbert, député, 386

Lauw, Haut-Rhin, cant. Masevaux, 180

Laval, Mayenne, préf., I60, 170, 429

Lavaur, Tarn, ch.-l. cant., 49
Le Chapelier, Isaac, député, 82

Le Jumeau de Kergaradec, Jacques Alexandre, médecin, 325

Lebrun, Charles François, député, 76 Lefort, Léon, médecin, 347, 403

Léman, anc. dép. français, auj. Suisse, I4I

Lenoir, Adolphe, médecin, 33I

Leroy, Alphonse, médecin, II2-II3

Levret, André, chirurgien accoucheur, 138, 319, 362

Leyde, Pays-Bas, I38-139

Ligurienne, République, auj. Italie, 136 Lille, Nord, préf., 88, 163, 195, 197, $252,257,266,344,353,371-372$, 375,429

Limoges, généralité, voir Limousin Limoges, Haute-Vienne, préf., 34, 204, 251, 269, 310, 432

Limousin, 35, 37

Lister, Joseph, chirurgien, 347

Loire (Haute-), dép., 213, 218-219, 428

Loire, dép., I63, 169, 193, 218, 245, 428

Loire-Atlantique, dép., 162, 195, 291, 428

Loire-Inférieure, voir Loire-Atlantique

Loiret, dép., 36, 145, I63, 283, 428

Loir-et-Cher, dép., 7I, 427

Lorges, Mlle, sage-femme en chef (Dijon), 282

Lorient, Morbihan, ch.-l. arr., 160, $236,426,429$

Lorraine, 36, 88, 9I, 365

Lortet, Louis, médecin, 369-370

Lot, dép., 428

Lot-et-Garonne, dép., 9I, 177, 245, 428

Loudéac, Côtes-d'Armor, ch.-l. cant., I05

Loudun, Vienne, ch.-l. cant., 200 
Louis XVI, roi de France, 286

Louis, Antoine, médecin, 34, 79

Louviers, Eure, ch.-l. cant., 149

Lozère, dép., 91, I65, 428

Lübeck, Allemagne, 139

Lutaud, Auguste, médecin, 317

Lyon, Rhône, préf., 37, 80, 88, 162, I64, I69, I85, I97, 200-20I, 208, 2102I3, 2I5, 2I8-219, 22I-223, 227-23I, 236-239, 25I, 299, 336-337, 37I, 375$377,381,400,424,426-428,430$

\section{M}

Mâcon, Saône-et-Loire, préf., 95, 169, I74, 185, 234, 240, 250, 33I, 374, 43I Mahé, Jean-François, chirurgien, démonstrateur d'accouchement (Ille-et-Vilaine), 51, 90, 97, 99-IOI

Maine-et-Loire, dép., 36-37, 7I, 88, 93, I6I, 208, 2II, 245, 428

Maisons-Alfort, Val-de-marne, ch.-l. cant., II2, 200

Malgaigne, Joseph-François, médecin, 347

Malthus, Thomas, économiste, 5I Manche, dép., 165, 398, 428

Mangin, chirurgien, démonstrateur d'accouchement (Châlons-enChampagne), 96, 98

Mans (Le), Sarthe, préf., I62, I64, I69, 29I, 43I

Manzac, auj. Manzat, dép. Puy-deDôme, arr. Riom, ch.-l. cant., 64 Marche, province de la, voir Creuse Marche, Marguerite (de la), sagefemme, 18

Marennes, Charente-Maritime, ch.-l. cant., 230
Maria Feodorovna, née SophieDorothéa de Wurtemberg, impératrice de Russie, II8

Marie de Médicis, reine de France, 47,220

Marin, Louis, député, 386

Marne (Haute-), dép., 162, I71-172, I87, 20I, 208, 2II-213, 235, 247, 293, 428

Marne, dép., 77, 89, 93, 97-98, 102, I62, 280, 283, 428

Marseille, Bouches-du-Rhône, préf., 88 , 185, 197, 279, 283, 338, 371, 423-424, 432

Masevaux, Haut-Rhin, ch.-l. cant., I80 Masseret, Corrèze, ch.-l. cant., 227

Mattéi, Antoine, médecin, professeur d'accouchement (Corse), 294

Maunoury, Charles-MichelAlphonse, médecin, professeur d'accouchement (Chartres), 295, 323, 33I, 34I

Mauriac, Cantal, ch.-l. arr., Mayence, Allemagne, 140, 142, 259 Mayenne, dép., 7I, 159, 170, 429 Mayenne, Mayenne, ch.-l. arr., I60, 429

Maygrier, Jacques-Pierre, médecin, 316,320

Menne-Vaulot, Mme, sage-femme, I8I

Mercier, Jeanne, sage-femme, 317-318

Mérilhon, chirurgien, professeur d'accouchement (Angoulême), 4I, 177

Mespec, Jean, médecin, professeur d'accouchement (Pau), 327 
Messager, Virginie, sage-femme, I8I Metz, Moselle, préf., I63, I84, I86, 253-258, 429

Meurthe, anc. dép., I46, I62, I74, I76178, 199, 234, 240, 429

Meurthe-et-Moselle, dép., 350, 429

Meuse, dép., 192, 199, 279, 299, 429

Meymac, Corrèze, ch.-l. cant., I59, 204, 210, 425

Milan, Italie, 143

Mirabeau, Honoré Gabriel Riquetti, comte (de), député, 80-8I

Mirande, Gers, ch.-l. arr., 95

Molinier, médecin, 182

Monprofit, Jacques-Ambroise, médecin, professeur d'accouchement (Angers), 348

Mons, Belgique, 140

Montalivet, Jean-Pierre Bachasson, comte de, ministre de l'Intérieur, I38-I39, I44, I5I, I54-I55, I6I, I64 Montbard, Côte-d'Or, ch.-l. arr., 273 Mont-Blanc, anc. dép. français, auj. Savoie, 143, I6I

Montchrétien, Antoine (de), économiste, 5 I

Mont-de-Marsan, Landes, préf., 160

Montesquieu, Charles de Secondat, baron de la Brède (et de), philosophe, $5 \mathrm{I}$

Montpellier, Hérault, préf., 83, I09, I59, I64, I67, I82, I86, I90, 259-260, 262, 279, 283, 285, 291, 3II, 318, 349, 37I, 375, 380-382, 424-425, 427-428 Montpensier, Marie (de), princesse, 47

Mont-Tonnerre, anc. dép. français, auj. Allemagne, 140
Morache, Georges Auguste, médecin, 373

Morbihan, dép., 160, 234-235, 268, 429

Moreau, François-Joseph, médecin, 317, 319, 331, 362

Morel, Gabriel, médecin, professeur d'accouchement (Colmar), 294, 296

Morlanne, Pierre Étienne, médecin, professeur d'accouchement (Metz), 254, 256

Moscou, Russie, II8

Moselle, dép., 86, 20I, 253, 255-256, 429

Moulins, Allier, préf., I63, 423

Moyne, Numa, médecin, professeur d'accouchement (Dijon), 282-283

$\mathrm{N}$

Naegele, Franz-Carl, médecin, 314, 317, 319, 327, 331, 34I

Naegele, Hermann Franz, médecin, 314

Naigeon, Alfred Jules, médecin, professeur d'accouchement (Dijon), 336

Nancy, Meurthe-et-Moselle, préf., 37, 135, I62, I65, I7I, 176, 240, 25I, 299, 350, 371, 376-377, 429, 432

Nantes, Loire-Atlantique, préf., 73, 25I, 29I, 344, 37I, 428, 432 Napoléon I ${ }^{\text {er }}$, voir Bonaparte, Napoléon

Narbonne, Aude, ch.-l. arr., 34, 49

Nedey, Anatole-François, chirurgien, démonstrateur d'accouchement (Besançon), 96 
Nièvre, dép., 193, 383, 429

Nìmes, Gard, préf., 158, 163, 177, 189, 291, 296, 426

Niort, Deux-Sèvres, préf., 169, 236, 332, 43I-432

Node, C., anatomiste, 33I-332

Nogent-sur-Seine, Aube, ch.-l. arr., 273

Nord, dép., 88, 146, 162, 193, 195, 252,

$257,266,353,429$

Normandie, 88, 90

Normandie (Haute-), voir

Seine-Maritime

\section{$\mathrm{O}$}

Oise, dép., 199, 429

Oldenbourg, Allemagne, I39

Orfila, Mathieu, doyen de la faculté de médecine de Paris, 26I

Orléans, bailliage, voir Loiret

Orléans, Loiret, préf., 132, 162, 25I, 279, 428

Orne, dép., 383, 429

Osiander, Friedrich Benjamin, médecin, professeur d'obstétrique (Göttingen), II6-II8

Ourthe, anc. dép. français, auj. Belgique, I43

\section{$\mathbf{P}$}

Pacoud, Denis-François, médecin, professeur d'accouchement (Bourg-en-Bresse), I68, 173I74, I84, 248, 297, 299, 320, 334, 345-346

Page, Mme, sage-femme en chef (Bourg-en-Bresse), 284 Pajot, Charles, médecin, 317
Pamard, Alfred (fils), médecin, professeur d'accouchement (Avignon), 294

Pamard, Paul (père), médecin, professeur d'accouchement (Avignon), 294

Pamiers, Ariège, ch.ll. arr., 102-103, I85, 25I, 283, 335, 373-374, 387, 424

Paris, France, cap., 82, 88, 90, 100, IO9-IIO, II2-II3, II8-II9, I23, I3I, I37, I42, I45-I46, I48, I52, I62, I77, I8I, 245, 252, 264, 266-267, 294-295, $321,334,344,347-348,352,360$, 394

Conseil général des hospices, I46, 265

École de santé, puis de médecine, 40, 65, 66, 83, 96, IO9, III-II3, I3I, I33, I35, I51, 314, 375

Faculté de médecine, II2, I52, I90, 259, 26I-262, 358, 37I, 376, 378-38I Hospice de la Maternité, 2I, 30, 87, IO7, I09, III, II3-II5, II 8-I27, I29-I36, I38-I4O, I42-I55, I57-I59, I62-I66, I68-I74, I77-I79, I83, I95, 200, 208210, 216, 224-226, 229, 234, 236-238, 244-246, 249-253, 256, 262-263, 270-27I, 273-274, 276-279, 285$286,289,297,300,307,310,315$, $317,321,327-328,334,337,339,347$, $352,356,358,362-363,376-377,379-$ 38I, 423-432

Hospice des Enfants trouvés, III Office des Accouchées de l'HôtelDieu, I8, 2I, 80, 87, 95-96, IIO-III, II4-II5, II8, I52, 250, 276, 278, 307, 43I

Paris, Amédée, médecin, 363

Pas-de-Calais, dép., 174, 430 
Pasteur, Louis, chimiste, 24, 347348,350

Pau, Pyrénées-Atlantiques, préf., 25I, 29I-292, 305-306, 327, 329-330, 387, 430

Pays-Bas, I37-I39, I42-I43

Pénard, Lucien, médecin, 317

Périgueux, Dordogne, préf., 425

Perpignan, Pyrénées-Orientales, préf., I58, 208, 387, 430

Pic, Adrien, médecin, professeur d'accouchement (Bourg-en-

Bresse), 320

Picardie, 36

Piémontaise, République, voir Piémont-Sardaigne

Piémont-Sardaigne, royaume (de), auj. Italie, I4I-I42, I43, I6I

Pigeotte, Jean-Baptiste, médecin, professeur d'accouchement (Troyes), I77

Pigné-Dupuytren, Jean-Baptiste, médecin, 317

Pilhès, François, médecin, professeur d'accouchement (Pamiers), 49, 94, IO2-IO3

Pillet-Will, institut, I6I, 17I-I72, 195, 43I

Pillet-Will, Frédéric Michel, comte, I6I, I72

Pitres, Albert, doyen de la faculté de médecine de Bordeaux, 378

Pleindoux, Augustin, médecin, professeur d'accouchement (Nîmes), 29I

Poggiale, Antoine-Baudouin, médecin, $36 \mathrm{I}$

Poitiers, Vienne, préf., 75, 162, 249, 29I, 43I-432
Pomarel, Céleste, épouse Uminski, sage-femme, professeure d'accouchement (Tulle), 229, 289, 297

Pontarlier, Doubs, ch.-l. arr., 39, 64

Porte, Mme, sage-femme, professeure d'accouchement (Tulle), 290

Port-Brieuc, voir Saint-Brieuc

Port-Malo, voir Saint-Malo

Port-Royal, voir Paris, Hospice de la Maternité

Prieur, médecin, professeur d'accouchement (Auch), 178

Puejac, Agnès, sage-femme en chef (Montpellier), 283

Puy-de-Dôme, dép., 64, 95, 162, I72I74, I86, 20I, 218, 269, 294, 300, 430 Pyrénées (Basses-), voir Pyrénées-Atlantiques

Pyrénées (Hautes-), dép., 73, 88, 90, 145, 160, I62, 197, 291, 430 Pyrénées-Atlantiques, dép., 166, 291, 312, 430

Pyrénées-Orientales, dép., I58, 162, 178, 193, 208, 224, 430

Q

Quintin, Côtes d'Armor, ch.-l.cant., 77, 99

$\mathrm{R}$

Raguet, Virginie, sage-femme (Laon), 284-285

Raillard, officier de santé, 40, 75

Raymond, médecin, professeur d'accouchement (Limoges), 269, 310 
Reims, Marne, ch.-l. arr., 89, 96, I02, I62, I85, 244, 25I, 387, 428

Rémy, Sébastien, médecin, chef de clinique obstétricale (Nancy), 350

Rennes, Ille-et-Vilaine, préf., 71, 73, 77, 92-93, 100, 427

Révolat, Charles, médecin, 294

Rey, Armand, médecin, professeur d'accouchement (Grenoble), 339, 34I, 348

Rey, chevalier, fondateur de cours d'accouchement (Savoie), I6I

Rhin (Bas-), dép., 86, 92, 161-162, 274, 40I, 430

Rhin (Haut-), dép., 6I, 62, 165, I80, 20I, 267, 294, 430

Rhin-et-Moselle, anc. dép. français, auj. Allemagne, 142

Rhône, dép., 65, 86, 16I, 193, 197, 2102II, 2I8-219, 228, 38I, 430

Ribemont-Dessaignes, Alban, médecin, 379

Ribier, F. (de), médecin, 378

Rigby, Edward, médecin, 319, 322

Rignac, Aveyron, cant. Enne et Alzou, 26I

Riviera, Tarzisio, médecin, professeur d'accouchement (Bologne), I43

Robin, Pierre, chirurgien, démonstrateur d'accouchement (Reims), 89, 96

Rochelle ( $\mathrm{La}$ ), Charente-Maritime, préf., I5I, 155, 164, 179, 25I, 28I, 305, 315-316, 330-33I, 333, 336, 425, 432 Roche-sur-Yon (La), Vendée, préf., I74, 383

Rodez, Aveyron, préf., 40, 164, I85, I87, 249, 251, 274, 305, 331, 336, 382, 387,424
Roederer, Johann Georg, médecin, professeur d'obstétrique (Göttingen), II6, 314

Roer, anc. dép. français, auj. Allemagne, I40

Romain, médecin, professeur d'accouchement (Bagnères-deBigorre), 293

Rome, Amable, médecin, professeur d'accouchement (Grenoble), 295

Romieux, Edme (fils), médecin, professeur d'accouchement (La Rochelle), 316

Romieux, Edme (père), médecin, professeur d'accouchement (La Rochelle), I5I-155, 242-243, 316, 334 Romme, Charles Gilbert, député, 83 Rostrenen, Côtes-d'Armor, ch.-l. cant., I05

Rotterdam, Pays-Bas, 138-139

Rouen, préf. du dép. de Seine-

Maritime, 80, 87, 162, 19I, 252, 26I, 295, 430-43I

Rouergue, 164

Rousseau, Jean-Jacques, 323

Royaume-Uni, 24-25, 327

Russie, II8, I42

S

Sacombe, Jean-François, médecin, professeur d'accouchement, iIo Saint-Affrique, Aveyron, ch.-l. cant., 40

Saint-Bonnet-en-Champsaur, HautesAlpes, ch.-l. cant., I04

Saint-Brieuc, Côtes-d'Armor, préf., 39, 65, 90, 99, 105-106, 425

Saint-Chamond, Loire, ch.-l. cant., 256 
Saint-Claude, Jura, préf., 427

Sainte-Menehould, Marne, ch.-l. arr.,

$89,102,428$

Saint-Étienne, 24, 163, 169, 428

Saint-Flour, Cantal, ch.-l. arr., 55-56, 58-59, 6I, 74, 77

Saint-Malo, Ille-et-Vilaine, ch.-l. arr., 99

Saint-Marcellin, Isère, ch.-l. cant., Io2, 427

Saint-Pétersbourg, Russie, II 8

Salins, auj. Salins-les-Bains, Jura, cant. Arbois, 427

Salmon, Pierre-Alphonse, médecin, professeur d'accouchement (Chartres), 295, 323, 331, 34I

Salvandy, Narcisse-Achille, ministre de l'Instruction publique, 357

Sambre-et-Meuse, anc. dép. français, auj. Belgique, I43

Santa Caterina alla Ruota, Ospedale di, Milan, Italie, I43

Santa Maria Nuova, ospedale di, Florence, Italie, 137-I38

Saône (Haute-), dép., 431

Saône-et-Loire, dép., 162, I85, 201, 218, 299, 304, 43I

Sardaigne, Royaume de, voir PiémontSardaigne, Royaume de

Sarre, anc. dép. français, auj. Allemagne, 140

Sarthe, dép., 39, 7I, 95, 193, 43I

Sausseret, employé de l'Hospice de la Maternité de Paris, I2O

Sauxemesnil, Manche, cant. Valogne, 36 Savoie, province, I43, I7I, 195, 43I

Savoie (Haute-), dép., I6I, I72, 43I

Savoie, dép., I6I, I72, 43I

Sée, Marc, médecin, 33I
Seine, dép., 161, 199, 238, 265, 315, 359, 385,431

Seine-Inférieure, voir Seine-Maritime

Seine-et-Marne, dép., 165, 399, 431

Seine-et-Oise, anc. dép., 165, 199, 399, 431

Seine-Maritime, dép., 65, 73, 162, 195, $43 \mathrm{I}$

Semmelweis, Ignace, médecin, 347-348

Serres, Étienne, médecin, 356

Sèvres (Deux-), dép., 43I

Sézanne, Marne, ch.-l. cant., 89, I02, 428

Siebold, Eduard Caspar Jacob (von), médecin, professeur d'obstétrique (Göttingen), I8I, 403

Siegemund, Justina, sage-femme

(Berlin), I8

Simplon, anc. dép. français, auj. Suisse, I4I

Sion, Suisse, I4I-I42

Smellie, William, chirurgien, 319, 362

Société royale de médecine, 35 , 39-40, 48, 60, 79, 82, 84, 95

Soissons, Aisne, ch.-l. arr., 35

Soissons, généralité, voir Aisne

Somme, dép., 37, 199, 431

Sospel, Alpes-Maritimes, ch.-l. cant., I6I, 423

Stassart, Goswin (de), préfet, 138

Stein, Georges Guillaume, médecin, professeur d'obstétrique (Cassel), 320

Stoltz, Joseph-Alexis, médecin, professeur d'obstétrique (Strasbourg puis Nancy), 319, 40I, 403

Stone, Sarah, sage-femme, I8 
Strasbourg, Bas-Rhin, préf., 83, 88, IO9, II5-II7, I80-I8I, I90-I9I, 25I, 256, 259, 262, 274, 291, 314, 375, 380-38I, 429-430

Strauss, Paul, sénateur, 386

Stura, anc. dép. français, auj. Italie, I43

Subalpine, République, voir

Piémontaise, République

Suisse, 317

$\mathrm{T}$

Talleyrand, Charles-Maurice de

Périgord, prélat, député, 80-8I, 84-85

Tarascon-sur-Ariège, Ariège, cant.

Sabarthès, 180

Tarbes, Hautes-Pyrénées, préf., I60, I88, 430

Tardieu, Auguste Ambroise, médecin, 36I

Tarin, Pierre, anatomiste, 34

Tarn, dép., 48, 70, 163, 169, 197, 235, 292, 312, 431

Tarn-et-Garonne, dép., 165, 383, 432

Tarnier, Stéphane, chirurgien en chef de l'Hospice de la Maternité de Paris, 317, 319, 331, 341, 347, 349350, 360-362

Tenon, Jacques René, médecin, député, 79, IIO

Teissier, médecin, professeur d'accouchement (Troyes), 240-24I, $243,323,332,340$

Thaller, François, médecin accoucheur, $\mathrm{I} 8 \mathrm{O}$

Thivet, médecin, professeur adjoint d'accouchement (Chaumont), 294 Toscane, Italie, 144
Toulon, Var, préf., I60, 236, 299, 305, 432

Toulouse, Haute-Garonne, préf., I63, I69, I76, 197, 200, 25I, 26I, 37I, 373, 425-426, 431

Tour du Pin (La), Isère, ch.-l. arr., 6I

Touraine, voir Indre-et-Loire

Tournon-Simiane, Camille (de), préfet, 287

Tours, Indre-et-Loire, préf., 71, I63, 427

Tréméreuc, Côtes-d'Armor, cant. Ploubalay, 39

Trèves, Allemagne, I40, 142

Troyes, Aube, préf., 35, 88, 164, 175, 226, 240, 273, 278, 282, 292, 323, $33 \mathrm{I}-332,340,344,346,424,432$

Troyes, élection, voir Aube

Tulle, préf. du dép. de Corrèze, 159 , I62, I68, 2I0-2II, 224-225, 227, 229, 23I-232, 236-237, 244, 25I, 272, 289290, 297, 299-300, 303, 305, 316, $330,373,397,424-425$

Turgot, Anne Robert Jacques, intendant, 34

Turin, Italie, II5, I4I

$\mathrm{U}$

Ussel, Corrèze, ch.-l. arr., 209, 218, 225

V

Valli, Francesco, médecin, professeur d'accouchement (Florence), I38

Vallois, Henri-Victor, médecin, professeur d'accouchement (Montpellier), 283 
Var, dép., 36-37, 44, 159-160, 167, 432

Vaucluse, dép., 162, 167, 293, 432

Velpeau Alfred, médecin, 319, 359-360

Vendée, dép., 91, 165, 174, 382, 432

Verdier, chirurgien, 334

Verdun, Meuse, ch.-l. arr., 429

Vernon, Eure, ch.-l. cant., 149

Verrier, Eugène, médecin, 264, 267

Vesoul, Haute-Saône, préf., 43I

Vespa, Giuseppe, médecin, professeur d'accouchement (Florence), 138

Viallet, Louis, médecin, professeur d'accouchement (Rodez), 337

Vicq d'Azyr, Félix, médecin, 40, 79

Vienne (Haute-), dép., 91, 284, 432

Vienne, Autriche, 144, 347

Vienne, dép., 7I, 91, 162, 432

Vienne, Isère, ch.-l. arr., IO2, 427

Villefranche-de-Rouergue, Aveyron, ch.-l. arr., 40

Villefranche-sur-Saône, Rhône, ch.-l. arr., 256

Villeneuve, François Pons Louis, marquis (de), préfet, 168

Vincent, Jean-Marie, chirurgien démonstrateur d'accouchement (Saint-Brieuc), 97, 99

Vitry-le-François, Marne, ch.-l. arr., 89,428

Voreppe, Isère, cant. Voiron, 295

Vosges, dép., I7I, 398, 432

\section{W-Y-Z}

Wallonie, Belgique, I43

Westphalie, royame (de), auj. Allemagne, 137
Witkowski, Gustave, médecin et historien, 403

Yonne, dép., 273, 432

Zuydersée, anc. dép. français, auj.

Pays-Bas, 142 



\section{- Table des matières}

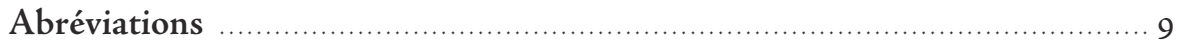

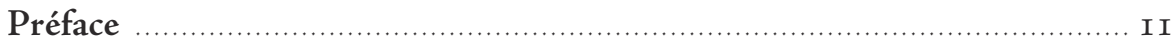

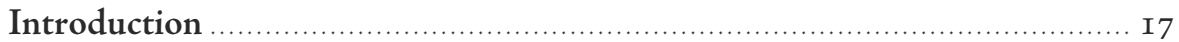

Chapitre I

«Il se croit dispensé d'entrer dans aucun détail

sur la nécessité d'un cours d'accouchement » ............................................ 33

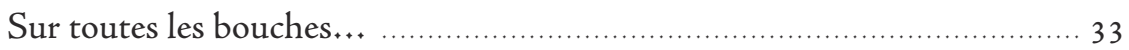

Trame, fil et navette : le tissage d'un discours ........................................ 4I

"C'est d'elles que dépendent souvent la santé et la vie

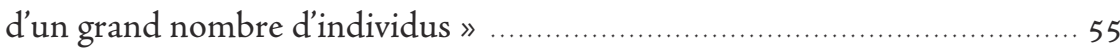

Chapitre 2

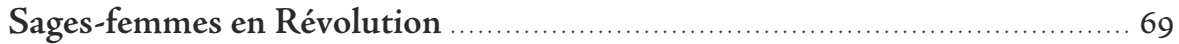

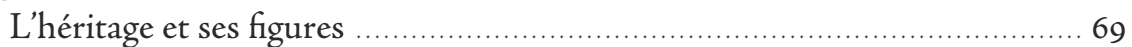

Les cours d'accouchement avant la loi de l'an XI :

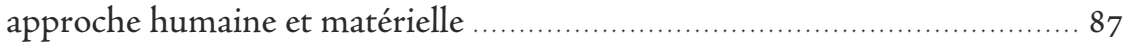

Chapitre 3

De l'institution à la loi : naissance de la sage-femme française ................... Io9

École exceptionnelle, école unique :

l'Hospice de la Maternité de Paris ………………............................. I09

Des ambitions à la pratique …………………………….................... I25

La légitimité départementale :

résistances locales et appropriation de la loi de ventôse .......................... I 44

Chapitre 4

Mailler la France d'écoles ................................................................... I57

Les cours d'accouchement français au XIX ${ }^{e}$ siècle …………………....... I57

Le fonctionnement des cours : formes et financement …….................. I 75 


\section{Chapitre 5}

L'élève sage-femme : un portrait social ................................................ 203

«Cet état si méprisable » (Pierre Eyméoud, 179I) .................................. 203

"Tirer les élèves de la classe des pauvres » ............................................ 208

Filles et sœurs d'accoucheuses, sages-femmes « par famille »? .................. 220

\section{Chapitre 6}

L'éclosion de l'agent de santé publique …………................................. 233

Façonner une nouvelle sage-femme ………………............................ 233

De l'État au département, la sage-femme,

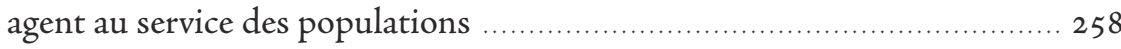

\section{Chapitre 7}

Le personnel des écoles d'accouchement …………............................... 275

Professer l'art des accouchements : un titre, deux postes ......................... 275

Compléter le savoir des élèves et tenir la maison ………….................... 296

\section{Chapitre 8}

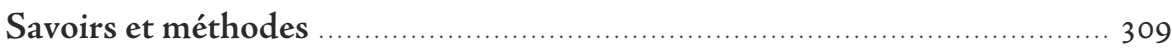

Savoir lire et écrire :

l'instruction primaire des élèves sages-femmes …………..................... 309

Pour la mère, la femme et l'enfant ..................................................... $3 \mathrm{I} 3$

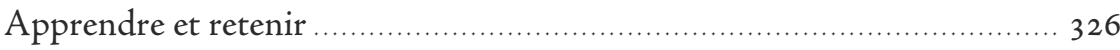

Élargissement du savoir et progrès des soins ……………..................... 339

\section{Chapitre 9}

La résistance d'une profession ............................................................... $35 \mathrm{I}$

De contestations en concurrence, une place à trouver ……………….... $35 \mathrm{I}$

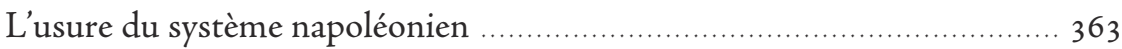

Le bilan d'un siècle de formation obstétricale ………............................ 380

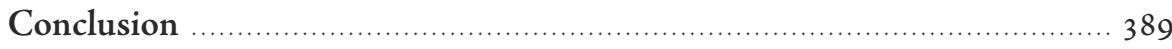

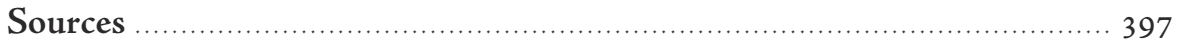

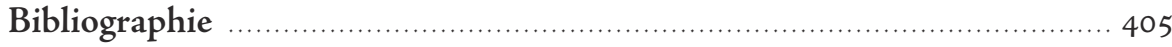

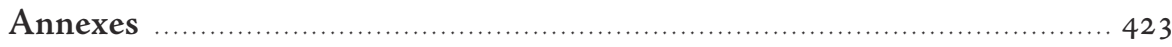

Tableau récapitulatif des modalités de formation obstétricale

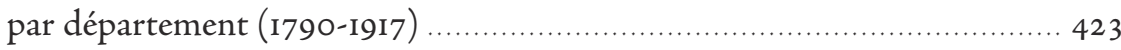

Publications de sages-femmes au $\mathrm{xIX}^{\mathrm{e}}$ siècle ………............................ 433

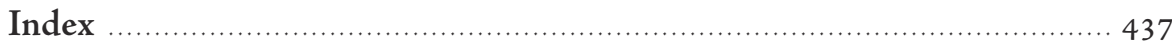




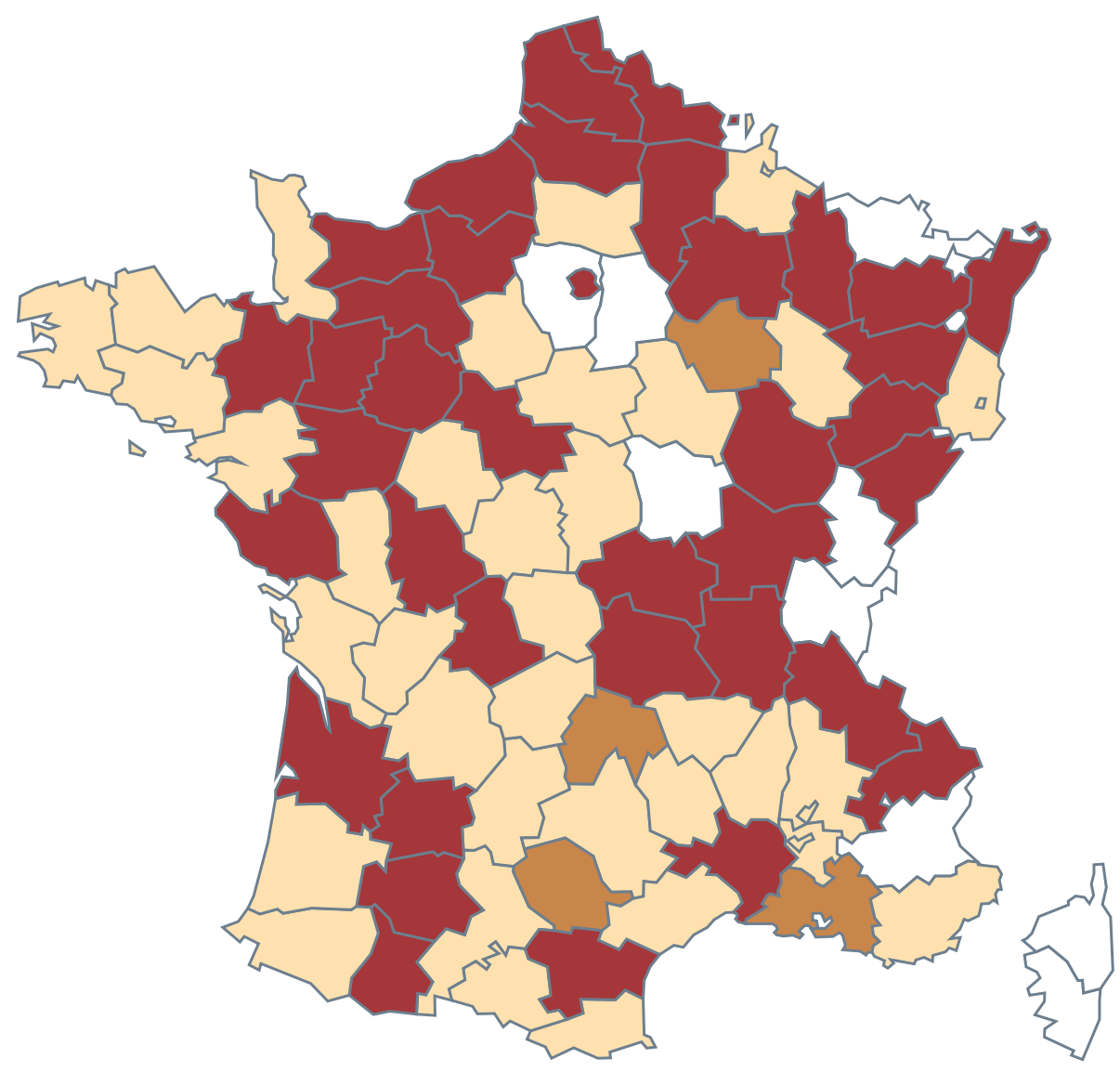

Formation obstétricale (1790-1791)

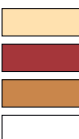

$0 \mathrm{~N}=35$

Cours $\mathrm{N}=37$

Projet $\mathrm{N}=4$

Absence d'information

Les hauteurs des rectangles du diagramme à bâtons

sont proportionnelles au nombre d'unites spatiales

pour chaque modalité de la variable

'Formation obstétricale (1790-1791)'

maximum $=37$ pour la modalité 'Cours'

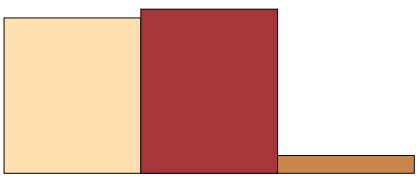

Carte 1. Formation obstétricale à destination des sages-femmes (1790-1791).

[Nathalie Sage Pranchère. Fait avec Philcarto * 28/04/2016 14:15:19 * http://philcarto.free.fr] 


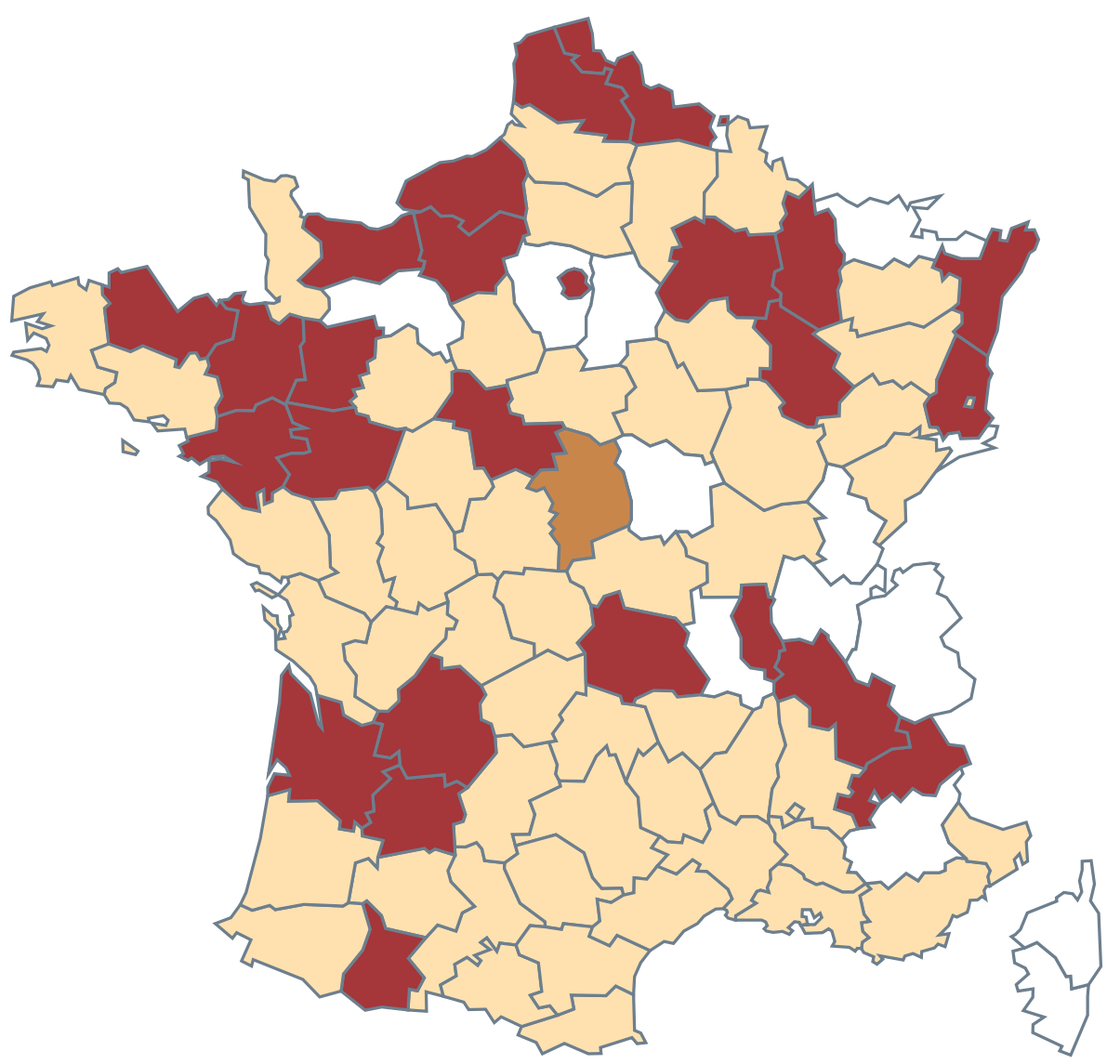

Formation obstétricale (an IV)

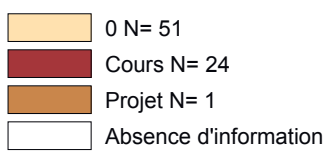

Les hauteurs des rectangles du diagramme à bâtons sont proportionnelles au nombre d'unites spatiales pour chaque modalité de la variable :

'Formation obstétricale (an IV)'

maximum $=51$ pour la modalité ' 0 '

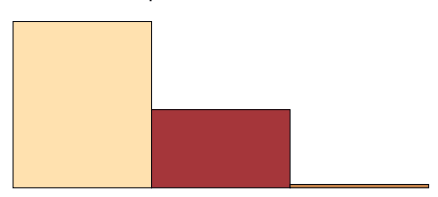

Carte 2. Formation obstétricale à destination des sages-femmes (an IV).

[Nathalie Sage Pranchère. Fait avec Philcarto * 28/04/2016 14:19:38 * http://philcarto.free.fr] 


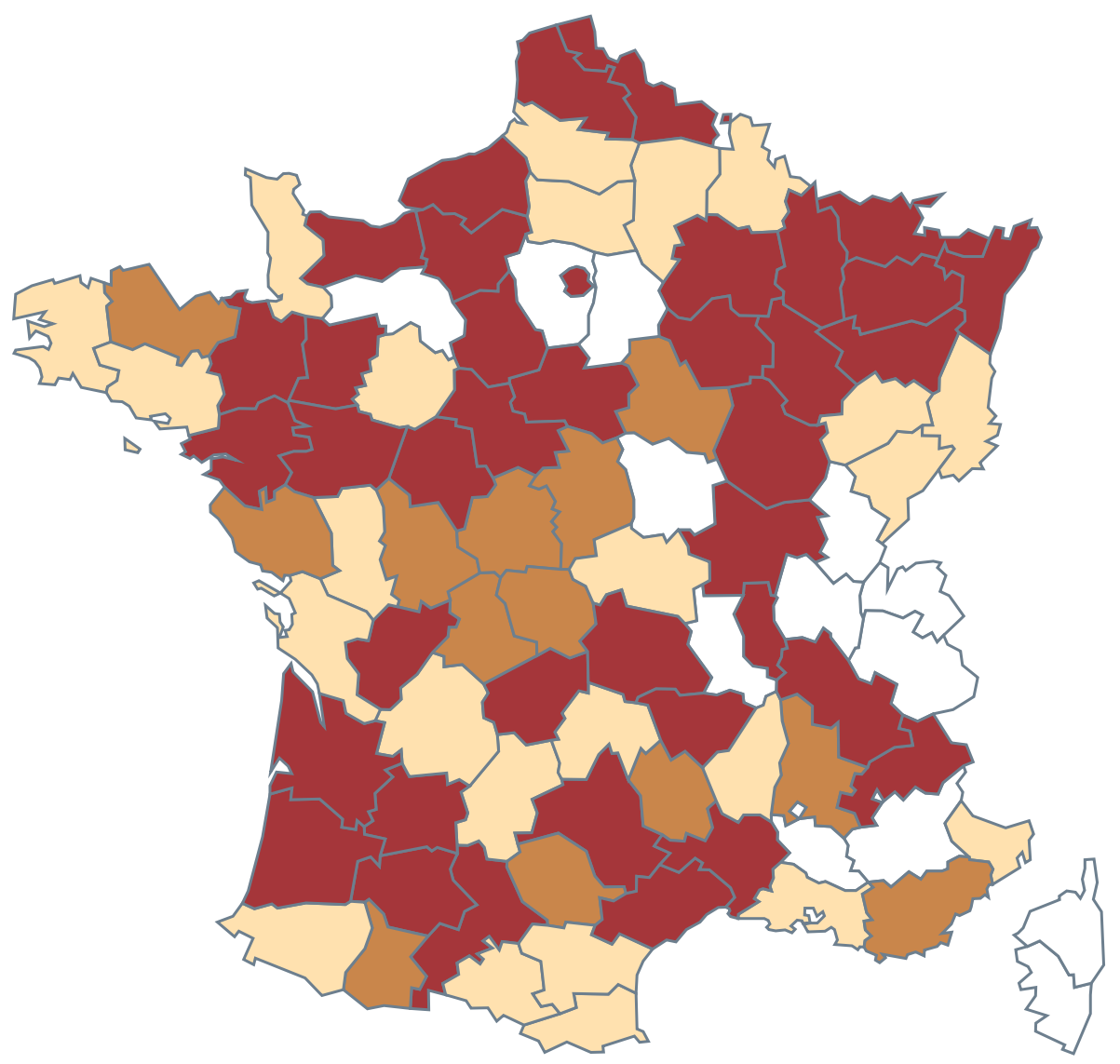

Formation obstétricale (1802-1803)

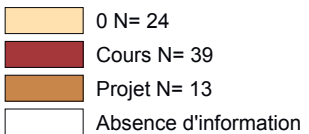

Les hauteurs des rectangles du diagramme à bâtons sont proportionnelles au nombre d'unites spatiales pour chaque modalité de la variable :

'Formation obstétricale (1802-1803)'

maximum $=39$ pour la modalité 'Cours'

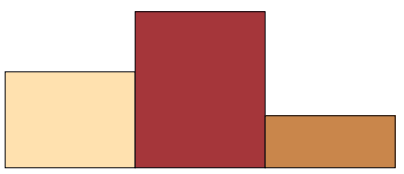

Carte 3. Formation obstétricale à destination des sages-femmes (1802-1803).

[Nathalie Sage Pranchère. Fait avec Philcarto * 28/04/2016 14:27:55 *

http://philcarto.free.fr] 


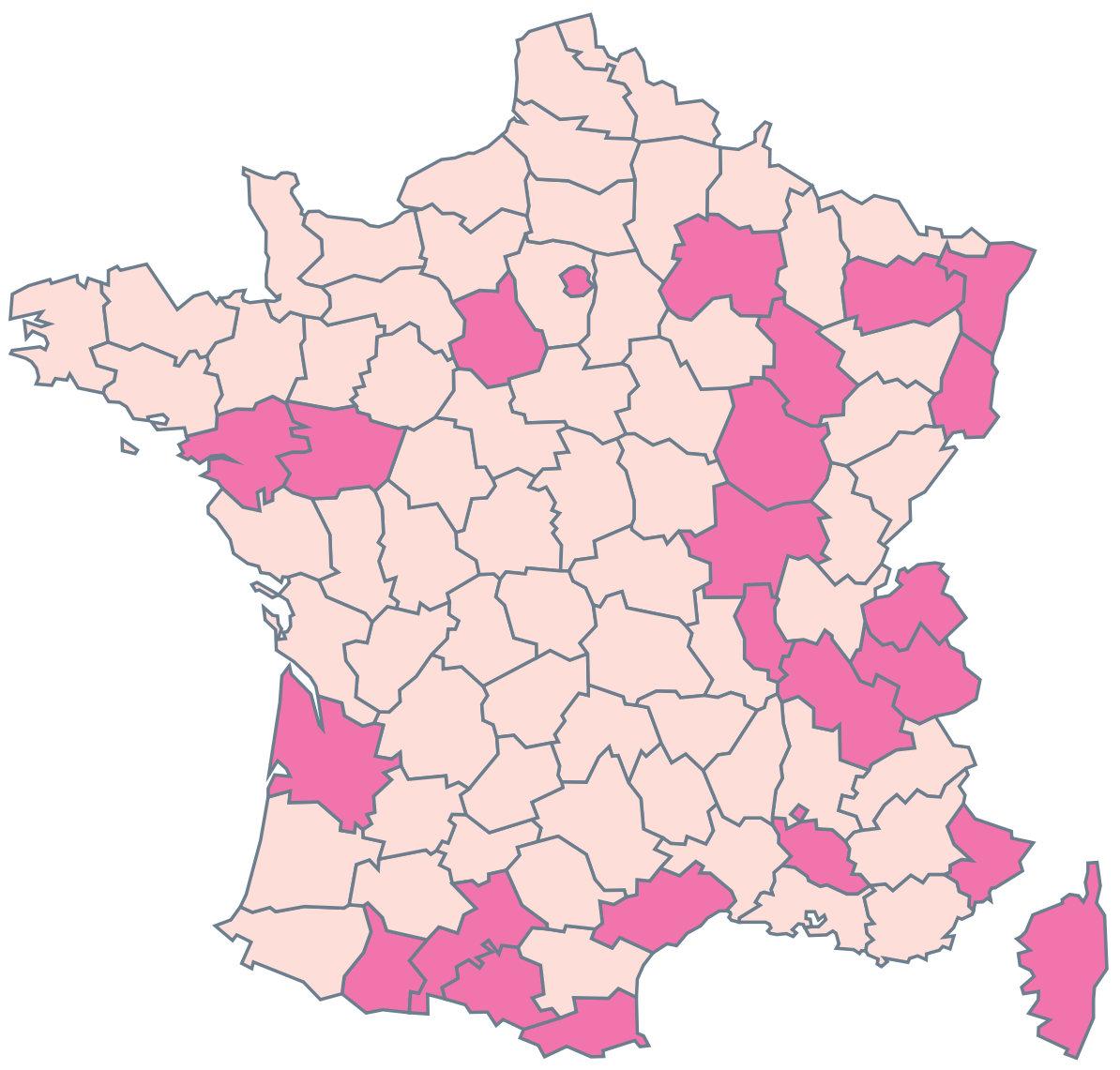

Tradition purement locale de formation obstétricale

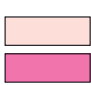

$0 \mathrm{~N}=65$

Cours locaux $\mathrm{N}=24$

Les hauteurs des rectangles du diagramme à bâtons sont proportionnelles au nombre d'unites spatiales pour chaque modalité de la variable :

'Tradition purement locale de formation obstétricale' maximum $=65$ pour la modalité ' 0 '

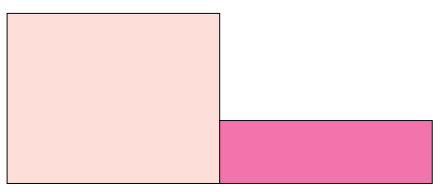

Carte 4. Tradition de formation strictement locale (Groupe A). [Nathalie Sage Pranchère. Fait avec Philcarto * 28/04/2016 15:10:24 * http://philcarto.free.fr] 


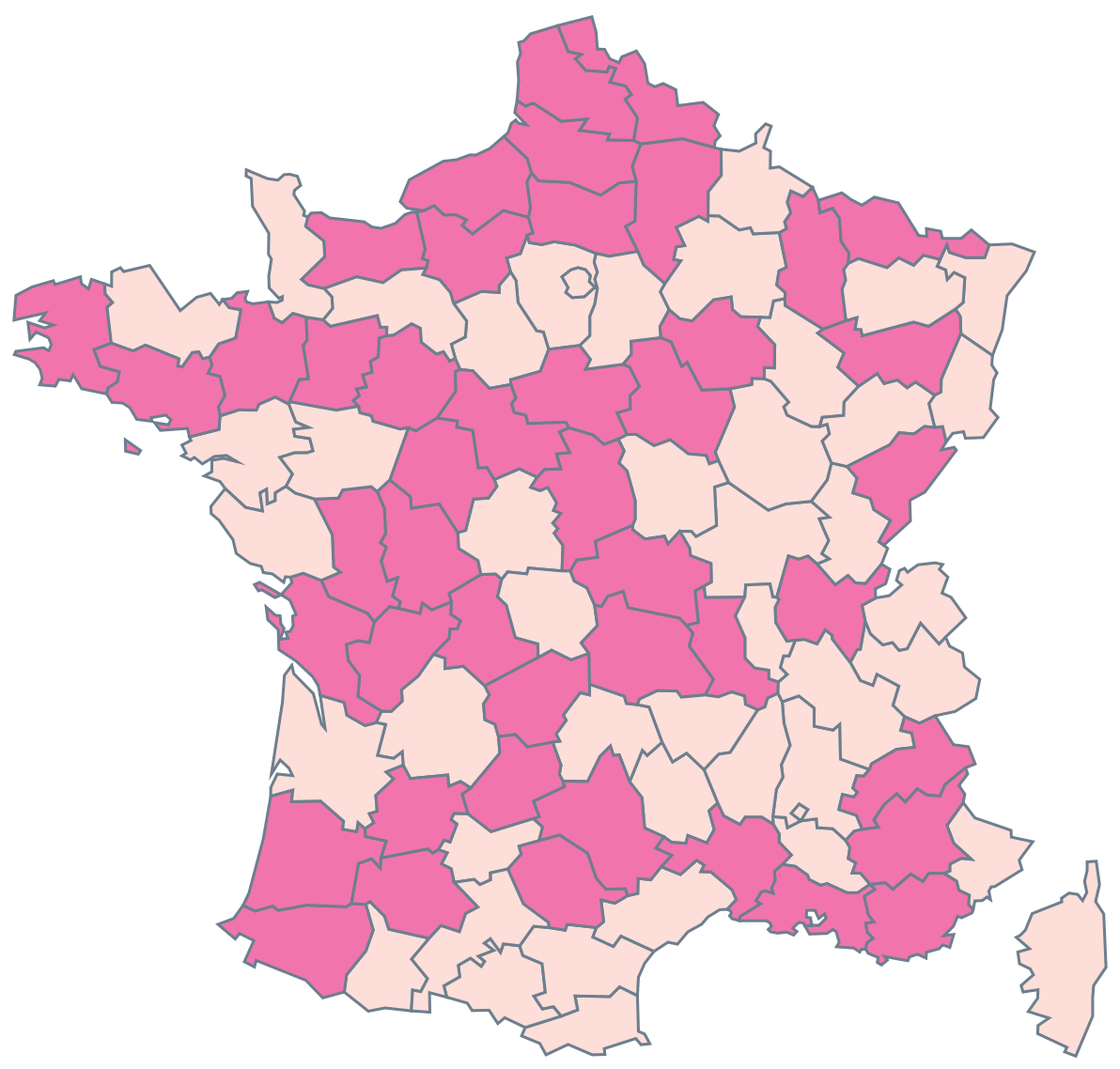

Politiques alternées

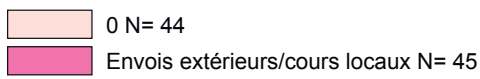

Les hauteurs des rectangles du diagramme à bâtons sont proportionnelles au nombre d'unites spatiales pour chaque modalité de la variable :

'Politiques alternées'

maximum $=45$ pour la modalité 'Envois extérieurs/cours locaux'

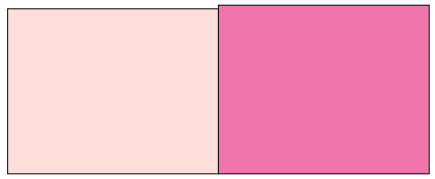

Carte 5. Alternance de formation locale et d'envois à l'extérieur (Groupe B). [Nathalie Sage Pranchère. Fait avec Philcarto * 28/04/2016 15:14:10 * http://philcarto.free.fr] 


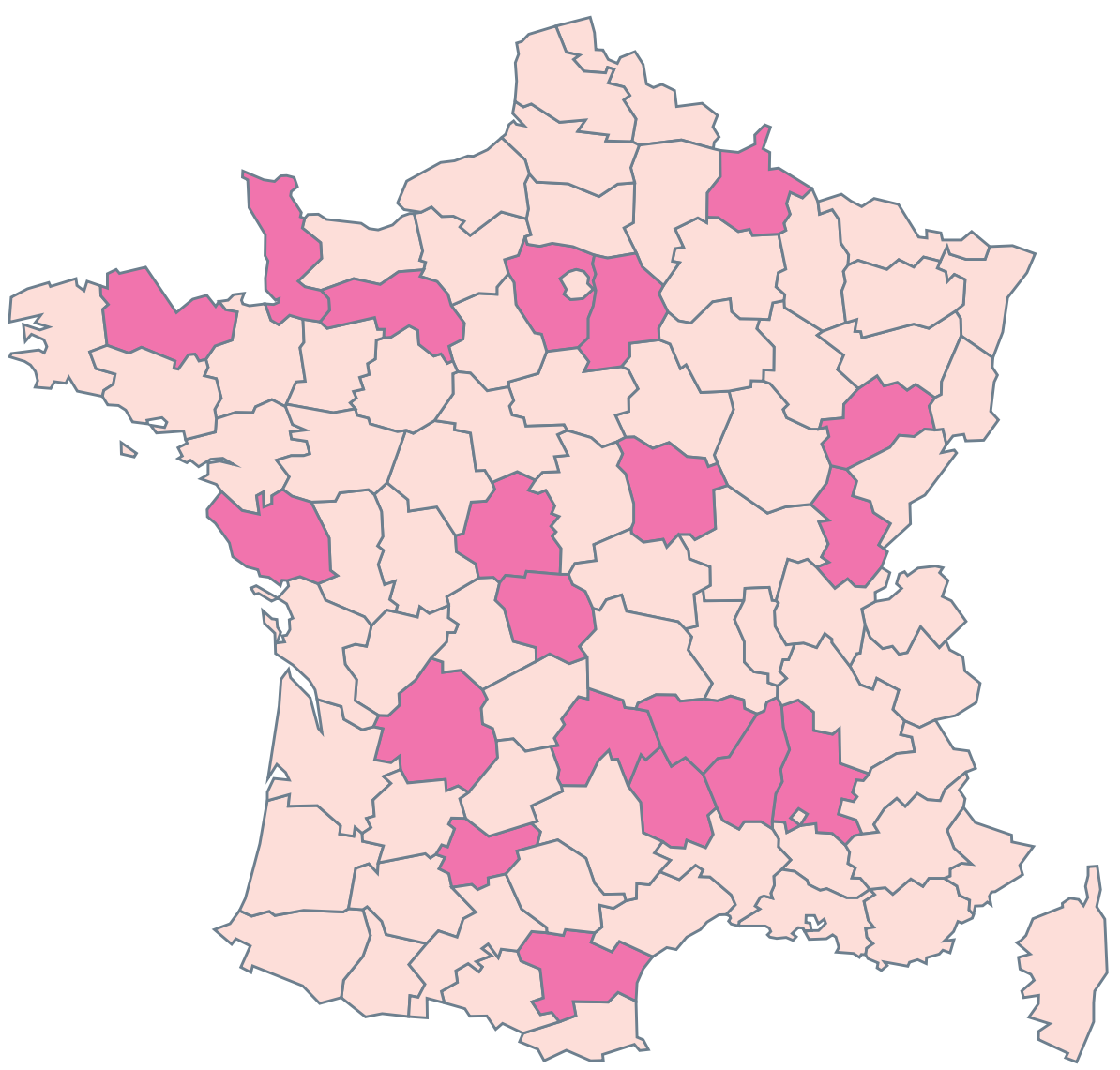

Envois des élèves sages-femmes hors du département

$0 \mathrm{~N}=69$

Envois à l'extérieur $\mathrm{N}=20$

Les hauteurs des rectangles du diagramme à bâtons sont proportionnelles au nombre d'unites spatiales pour chaque modalité de la variable:

'Envois des élèves sages-femmes hors du département' maximum $=69$ pour la modalité ' 0 '

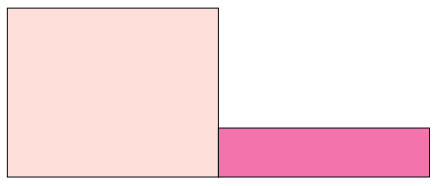

Carte 6. Envois d'élèves hors du département (Groupe C).

[Nathalie Sage Pranchère. Fait avec Philcarto * 28/04/2016 15:16:30 * http://philcarto.free.fr] 


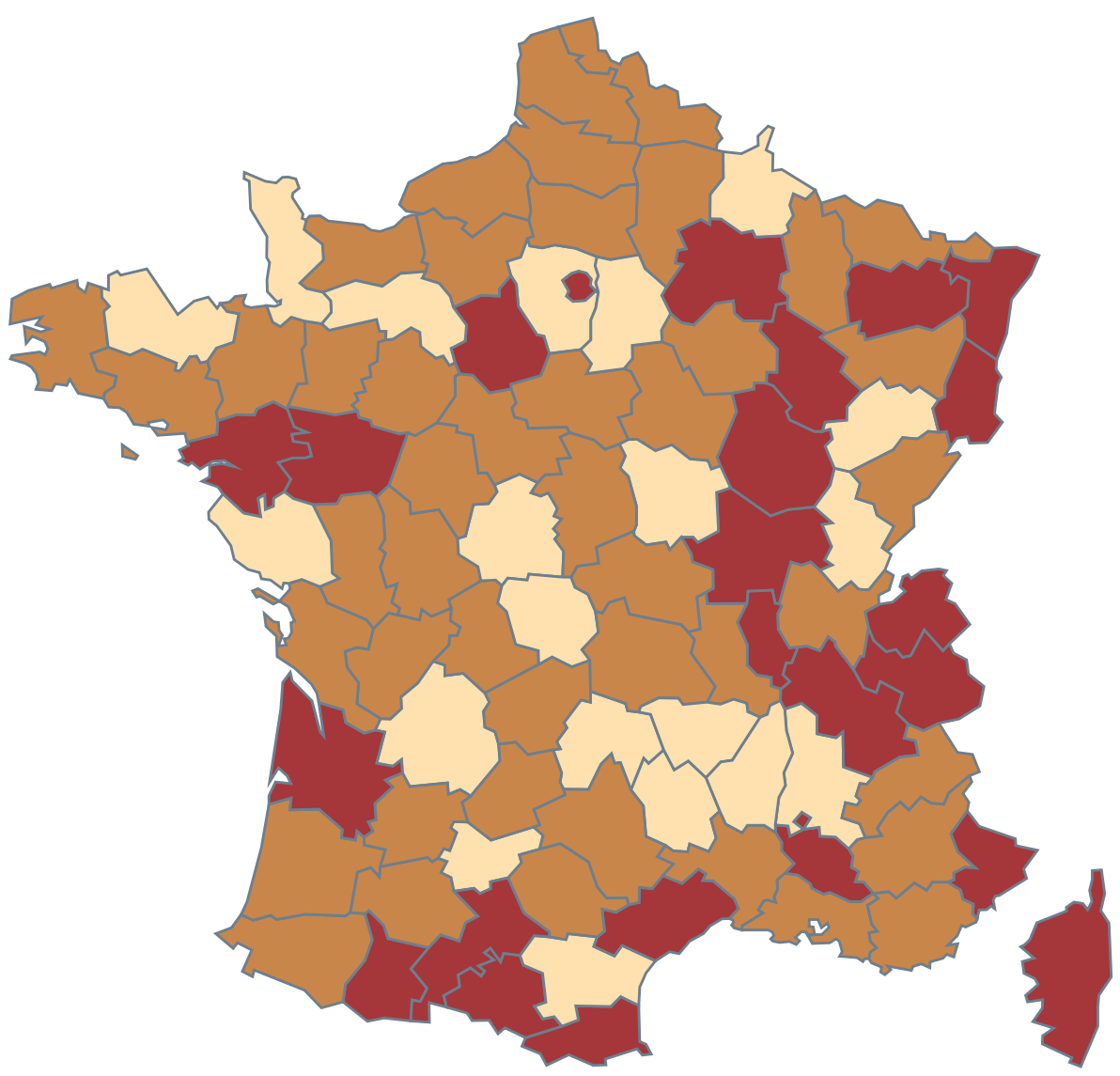

Types de politique de formation obstétricale

Cours locaux $\mathrm{N}=24$

Envois à l'extérieur $\mathrm{N}=20$

Envois extérieurs/cours locaux $\mathrm{N}=45$

Les hauteurs des rectangles du diagramme à bâtons sont proportionnelles au nombre d'unites spatiales pour chaque modalité de la variable :

'Types de politique de formation obstétricale'

maximum $=45$ pour la modalité 'Envois extérieurs/cours locaux'

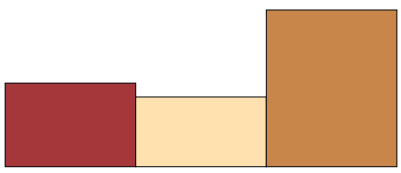

Carte 7. Récapitulatif des politiques de formation obstétricale. [Nathalie Sage Pranchère. Fait avec Philcarto * 28/04/2016 15:56:40 * http://philcarto.free.fr] 


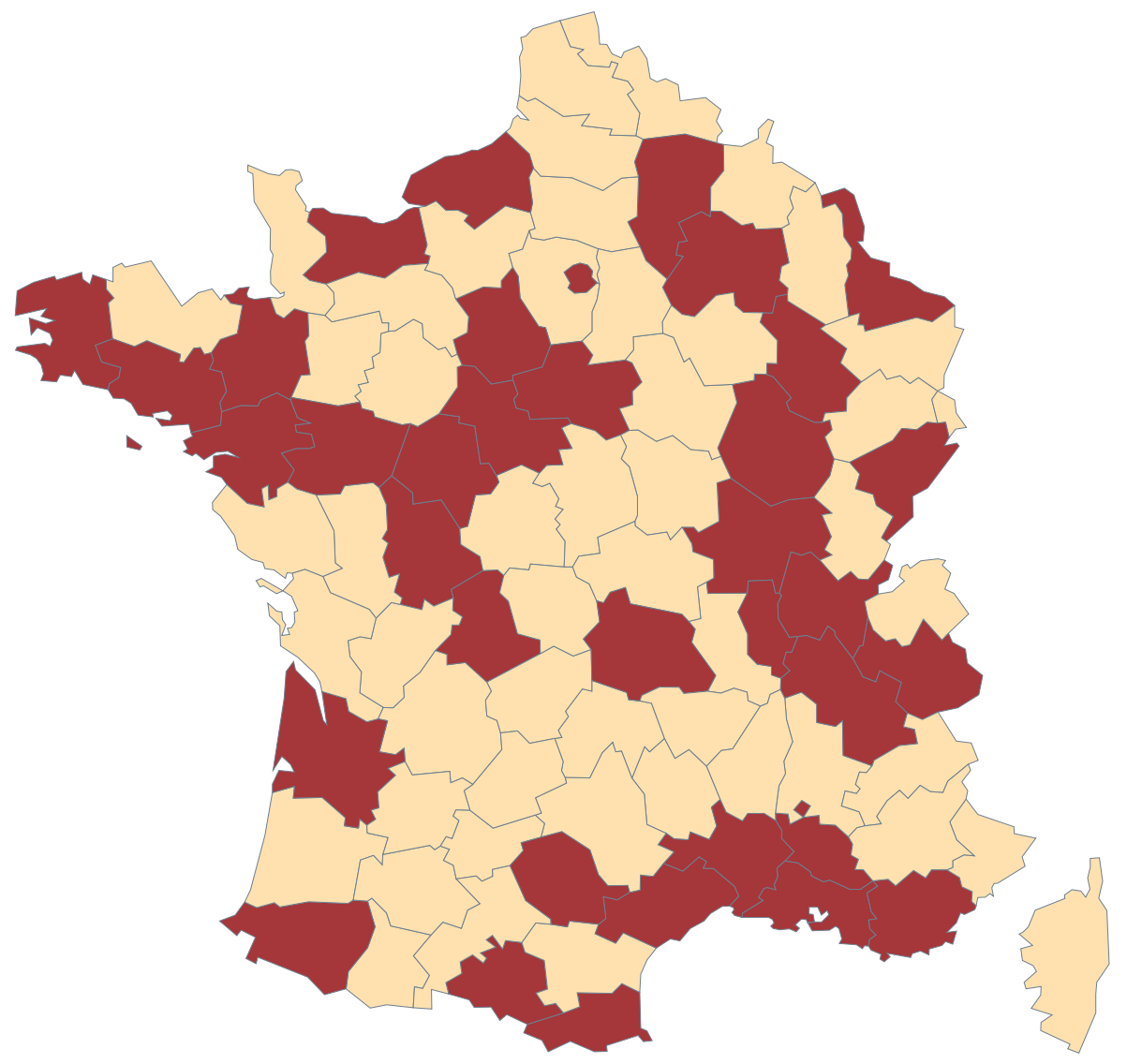

Maternités-écoles en fonctionnement

$0 \mathrm{~N}=51$

Cours $\mathrm{N}=36$

Les hauteurs des rectangles du diagramme à bâton: sont proportionnelles au nombre d'unites spatiales pour chaque modalité de la variable:

'Maternités-écoles en fonctionnement' maximum $=51$ pour la modalité ' 0 '

\section{Carte 8. Maternité-écoles (1900).}

[Nathalie Sage Pranchère. Fait avec Philcarto * 28/04/2016 15:49:29 * http://philcarto.free.fr] 


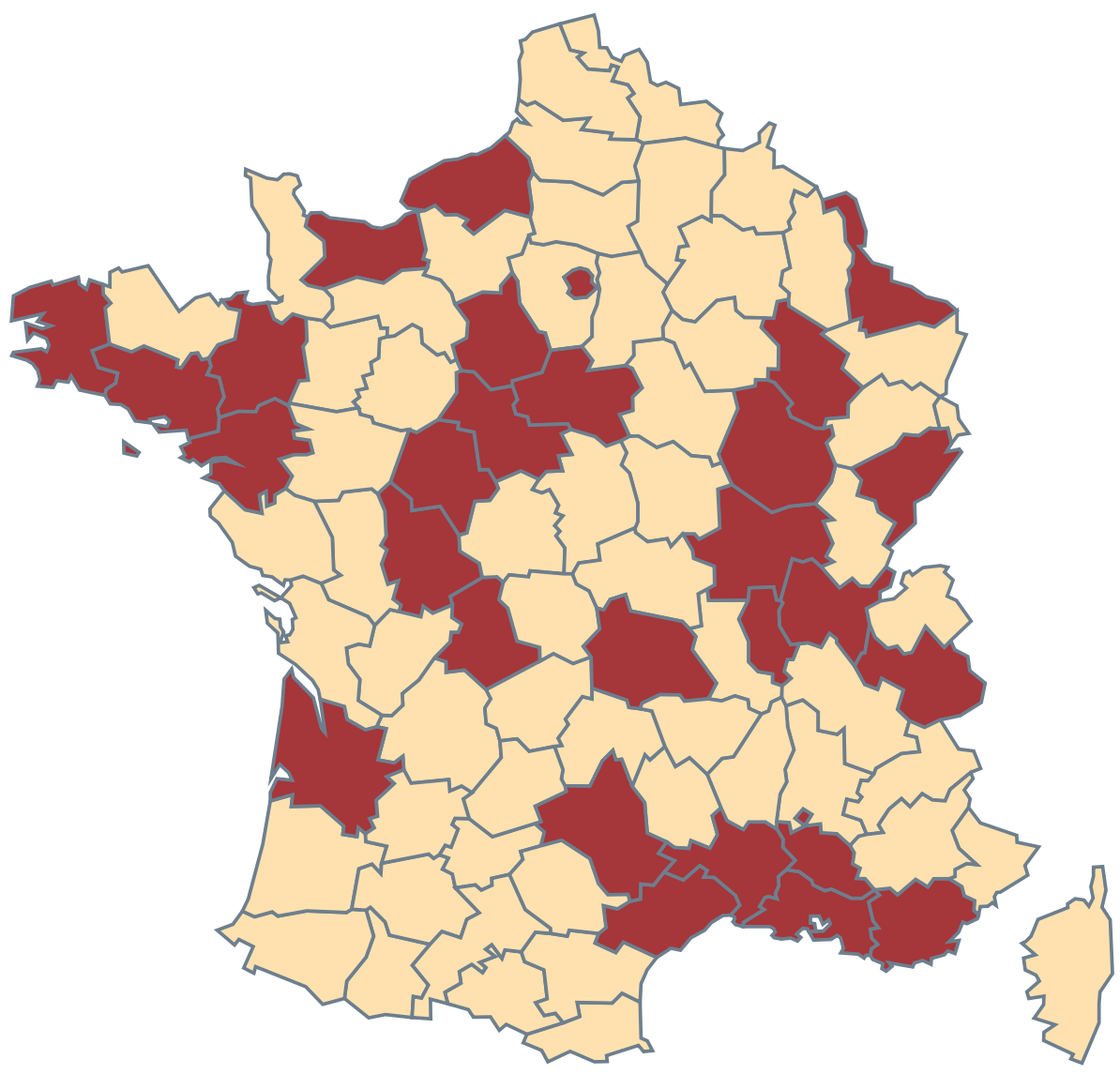

Maternités-écoles en fonctionnement

$0 \mathrm{~N}=58$

Cours $\mathrm{N}=29$

Les hauteurs des rectangles du diagramme à bâtons sont proportionnelles au nombre d'unites spatiales pour chaque modalité de la variable :

'Maternités-écoles en fonctionnement'

maximum $=58$ pour la modalité ' 0 '

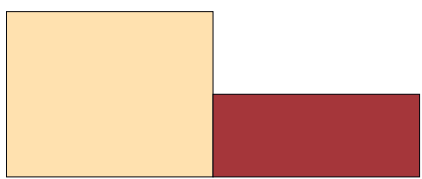

Carte 9. Maternité-écoles maintenues en 1917.

[Nathalie Sage Pranchère. Fait avec Philcarto * 28/04/2016 15:51:16 * http://philcarto.free.fr] 


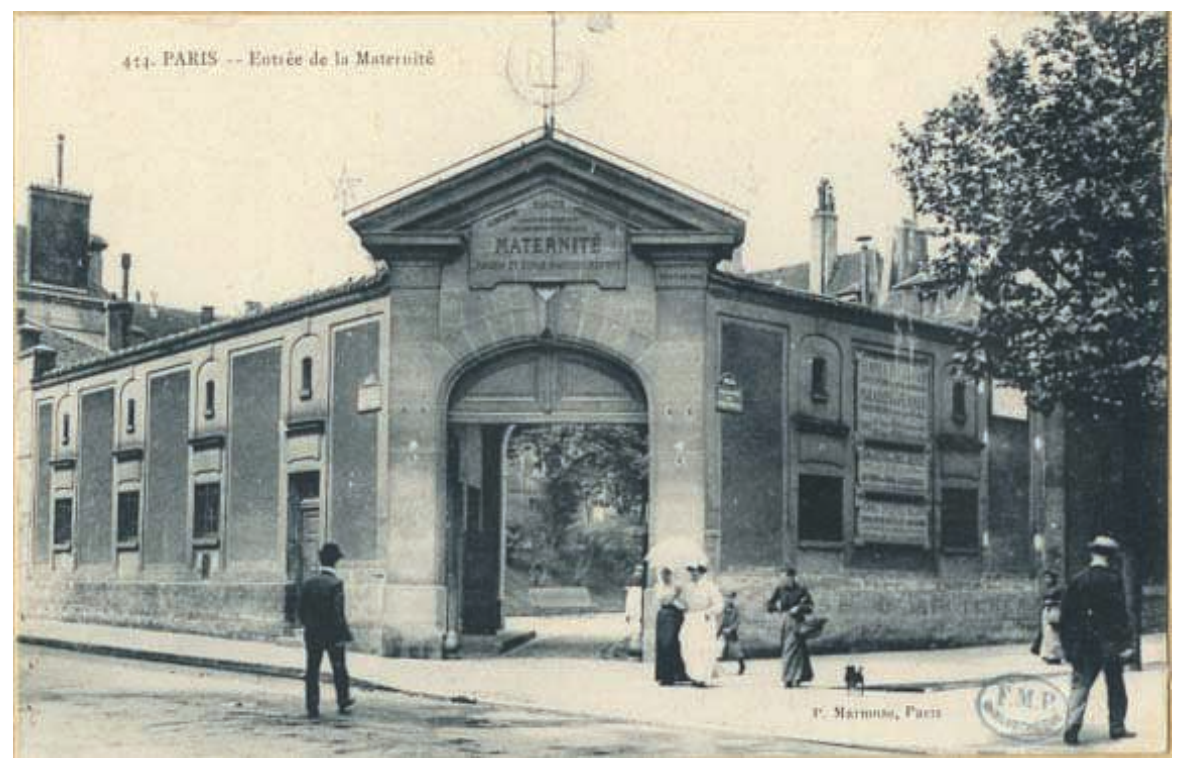

IIl. 1. Entrée de l'Hospice de la Maternité de Paris. [Collections BIU Santé, P. Marmuse à Paris, s. d.] 


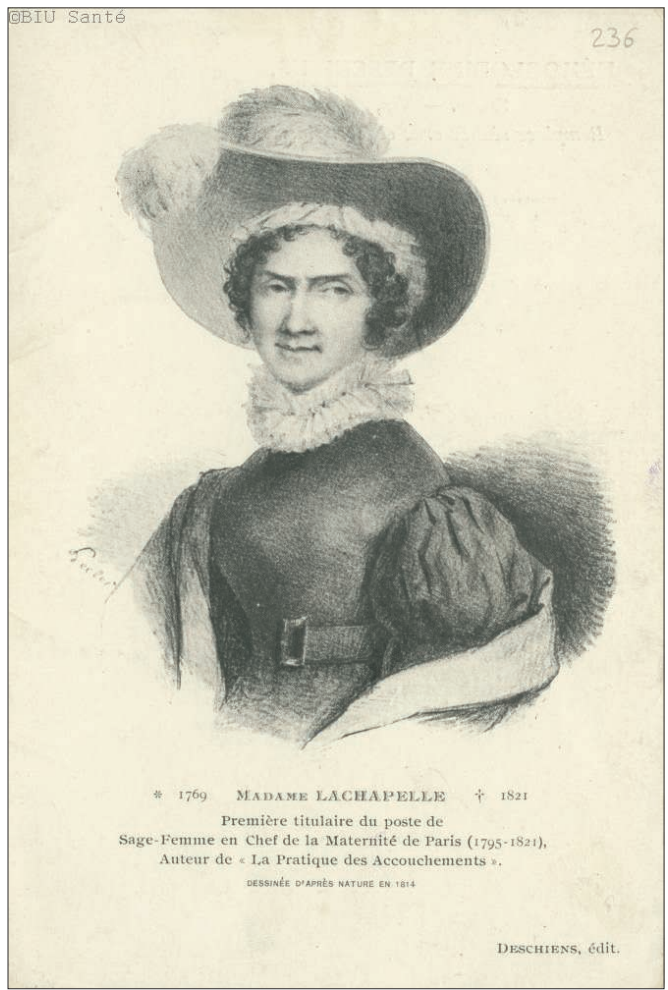

IIl. 2. Portrait de Marie-Louise Lachapelle, sage-femme en chef de l'Hospice de la Maternité de Paris. [Collection de portraits, BIU Santé.]

IIl. 3. Portrait de Jean-Louis Baudelocque, accoucheur, chirurgien en chef de l'Hospice de la Maternité de Paris.

[Medic@, extrait d'A. Corlieu, Centenaire de la Faculté de médecine de Paris (1794-1894), Paris, 1896.]

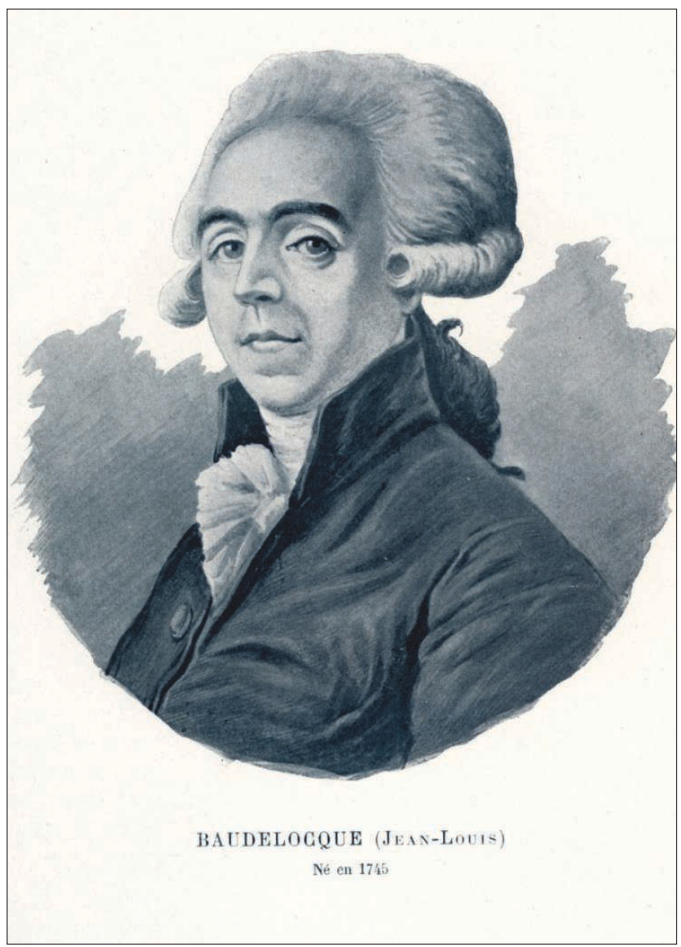




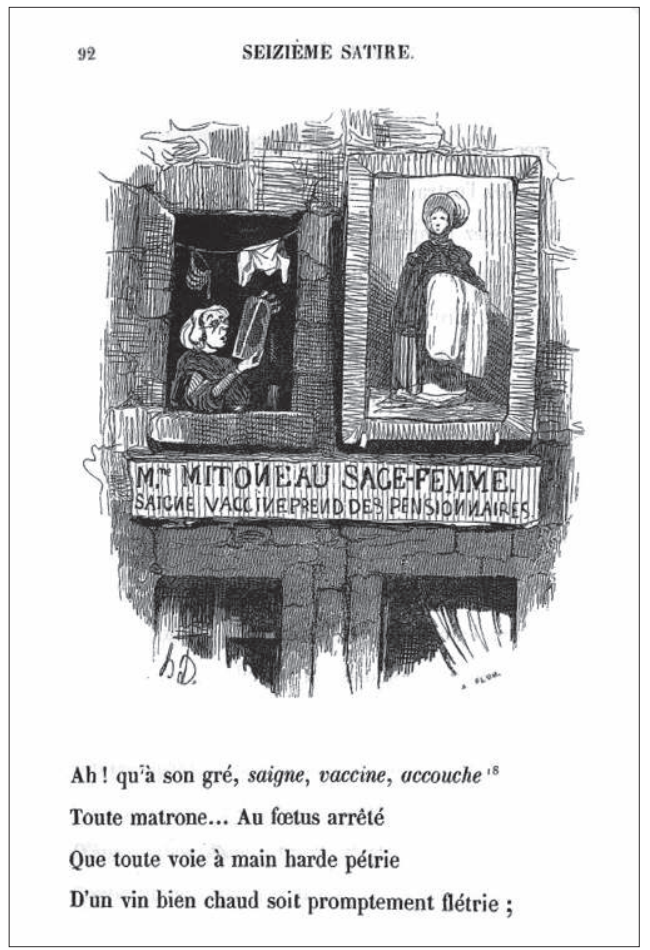

IIl. 4. Gravure d'après un dessin d'H. Daumier, extraite de F. Fabre, Némésis médicale illustrée, t. 2, Paris, 1840, p. 92. [Medic@.]

L'enseigne reprend les différentes compétences des sages-femmes et illustre la variété de leurs activités (obstétrique, saignée, vaccination, maison d'accouchements).
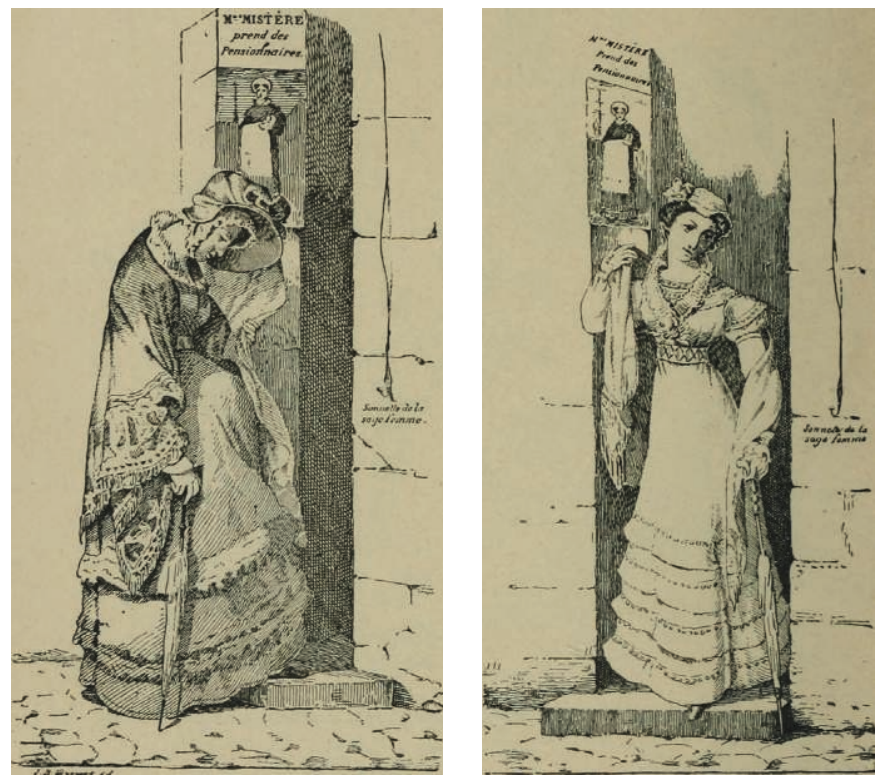

IIl. 5. Lithographies d'E. Wattier, extraites d'Un an dans la vie d'une jeune fille, Paris, 1824 et reproduites dans G.-J. Witkowski, Les Accouchements dans les beaux-arts, dans la littérature et au théâtre, Paris, 1894, p. 66.

La scène reprend les planches XIV («Elle y entre ») et XV («Elle en sort ») montrant la jeune fille se rendant chez la sage-femme pour accoucher et en sortant sans son enfant. Elle illustre la complicité des sages-femmes dans l'abandon d'enfants. 


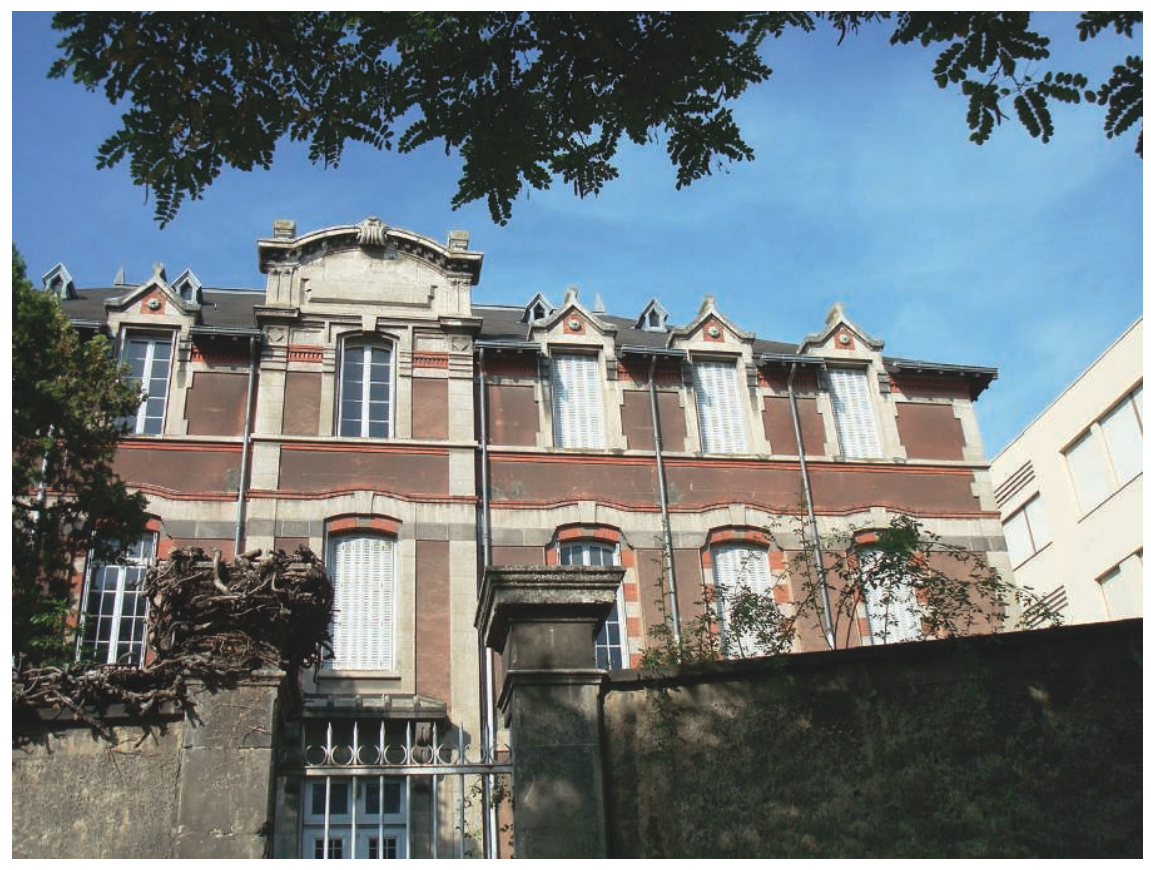

IIl. 6. École de sages-femmes de Clermont-Ferrand, construite en 1891-1892 par l'architecte Jean Teillard. L'école est installée dans le bâtiment quelques années avant sa laïcisation en 1896.

[C Rilba - Own work, CC BY-SA 3.0,

https://commons. wikimedia.org/w/index. php?curid=16704048.]

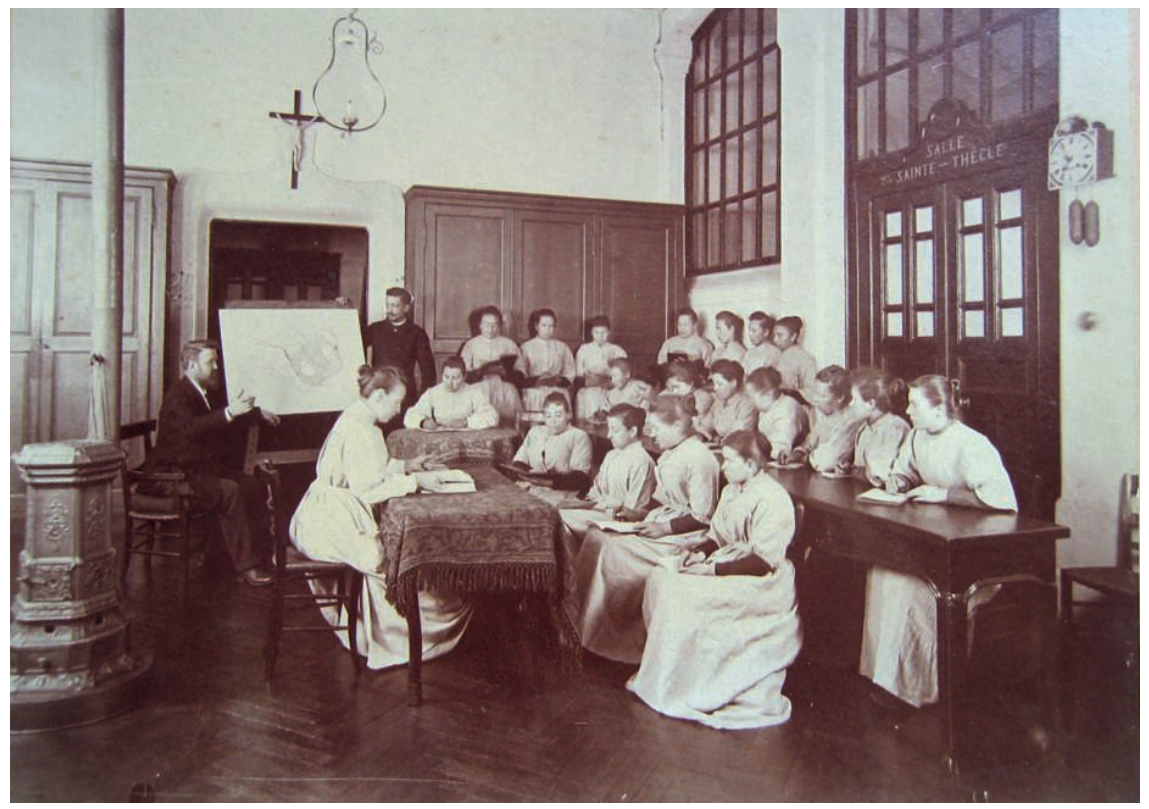

IIl. 7. Une classe d'élèves sages-femmes, Angers, fin xixe siècle.

[@ AD Maine-et-Loire, 392 T 196.] 


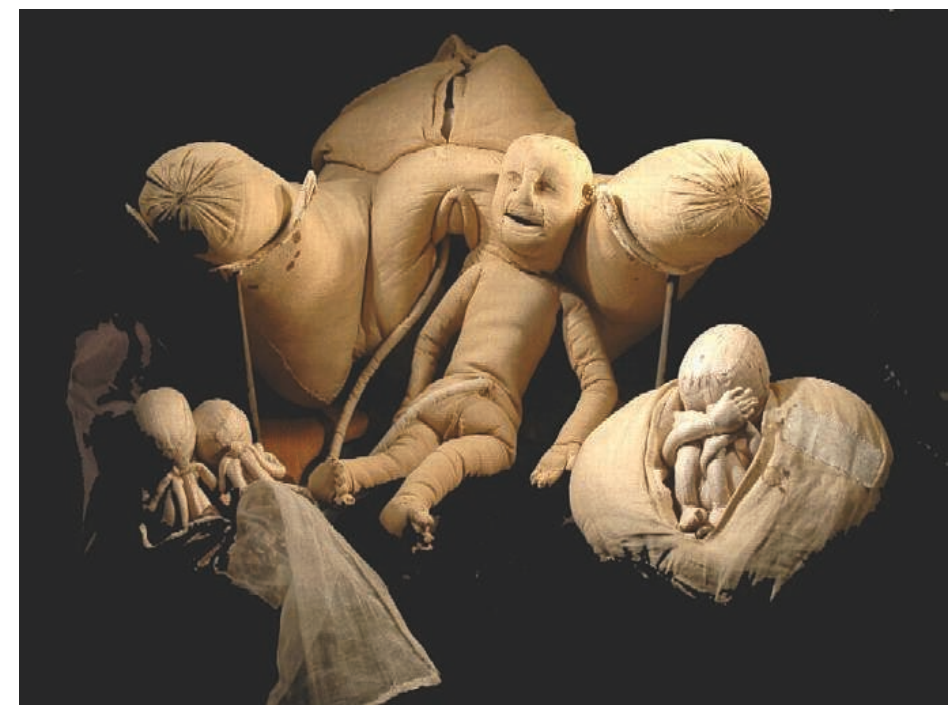

IIl. 8. Mannequin obstétrical d'Angélique du Coudray, xvIII siècle.

[@ Jacques Petitcolas, (c) CHU Rouen.]

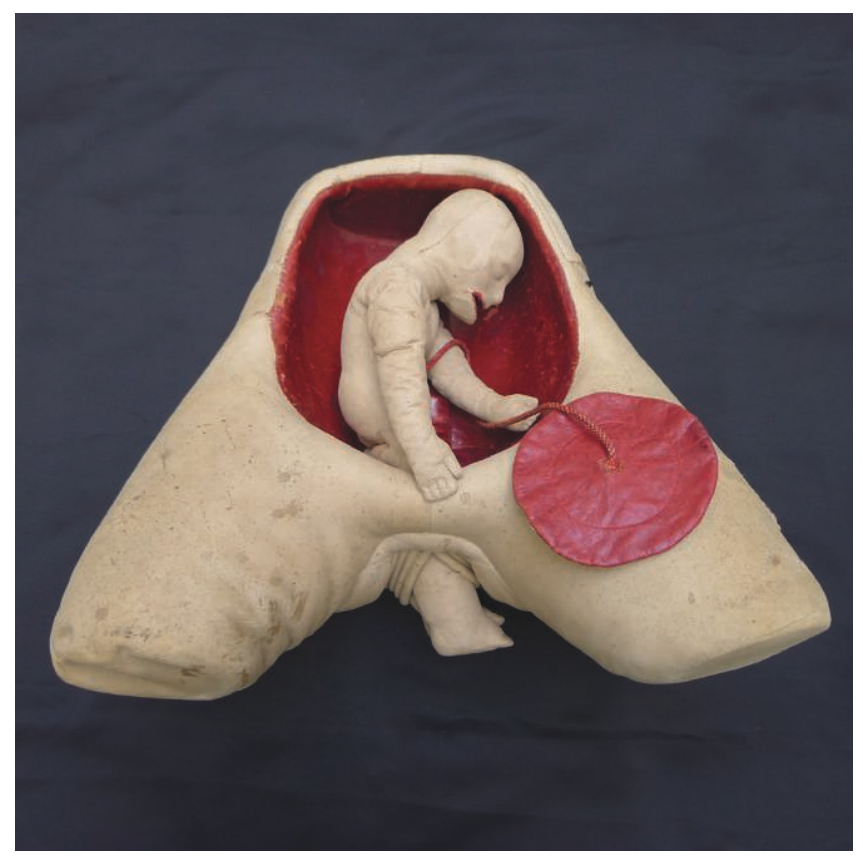

III. 9. Mannequin obstétricale de fabrication artisanale, sans doute $\mathrm{xIX}^{\mathrm{e}}$ siècle. [Collection particulière ; (c) NSP.] 